\title{
Improving the Fire Resistance of Concrete Masonry Walls
}

\author{
by \\ Hamish Pope, B.Sc. \\ A thesis submitted to the \\ Faculty of Graduate and Postdoctoral Affairs \\ in partial fulfillment of the requirements for the degree of \\ PhD \\ Department of Civil and Environmental Engineering \\ Carleton University \\ Ottawa, Ontario \\ September, 2021 \\ (C)Copyright \\ Hamish Pope, 2021
}




\section{Abstract}

The purpose of this research was to understand the fire resistance of existing masonry construction and to identify ways to improve upon masonry's fire resistance. First, a literature review was conducted to determine the known effects fire had on concrete, and how this could change with different mix designs and temperature ranges. These included common mixes (such as normal-weight and lightweight concrete) as well as novel mixes (such as fly ash, recycled aggregate, or glass aggregate concrete). As masonry units have different geometries, research was also conducted to determine the effects different geometries have on the fire resistance of materials. Once this baseline was established, research was conducted on insulation materials, to determine which materials might be suitable and compatible with concrete masonry. Full scale experimental data was collected to determine how standard masonry units and building techniques reacted to the standard fire. Then new geometries and mix designs were tested to evaluate how the fire resistance was affected by these changes. After experimental data had been collected, thermal models were created to identify which masonry units could be tested in the future. Finally, novel concrete mixes were modeled and compared to determine their possible effect on the fire resistance of concrete masonry walls. The results showed that compartmentalisation of masonry blocks and walls improved the overall fire resistance, as heat flow through the hollow cells is the leading cause of insulation failure. Increasing the faceshell thickness or including insulation materials within the hollow cells improved the overall fire resistance. The data indicated that mortar joint types did not appear to have an impact on the insulation failure of masonry walls. Lightweight concrete mixes showed improved fire resistance when compared to normal weight concrete. Modeling results demonstrated that there are several new mix designs that can improve the thermal performance of masonry; however, with an increase in thermal performance there is usually a decrease in mechanical performance. The results of this research have helped establish a baseline for existing and novel masonry construction and provide recommendations 
for future study into improving the fire resistance of concrete masonry. 


\section{Acknowledgments}

There are many individuals and organizations that helped me complete my thesis. I would like to thank my family and friends for their continued support both professional and emotional. I would like to extend my gratitude towards my supervisor Ehab Zalok for his guidance through my program without whom I would not have embarked on my professional journey.

I would like to thank the Canada Masonry Design Centre (CMDC) and the Canadian Masonry Producers Association (CCMPA) for their financial and in-kind support. I would especially like to extend my gratitude to Bennett Banting and David Stubbs for their personal involvement during my research. I would like to extend my gratitude to the Ottawa Fire Services OFS, especially Peter McBride and Sean Tracey, for their help with providing a location and support to continue my testing but more importantly their personal support and encouragment. I would like to thank the National Science and Engineering Research of Canada (NSERC), for their funding support. I would also like to thank Brendan Knapman from Rockwool for his time and donated supplies. Finally, I would like to give my appreciation to all those faculty, students, and support staff who helped me at Carleton University.

Without the support of so many people, my research would not have been possible. 


\section{Table of Contents}

Abstract $\quad$ iii

Acknowledgments $\quad$ v

Table of Contents $\quad$ vi

List of Tables $\quad$ viii

List of Figures $\quad$ ix

Nomenclature $\quad$ xii

0.1 Variables ....................... . xii

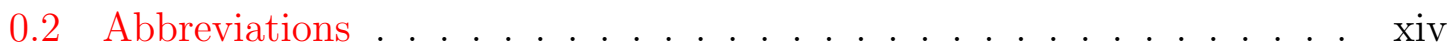

1 Introduction 3

1.1 Background .......................... 3

1.2 Research Objectives . . . . . . . . . . . . . . . . . 4

1.3 Layout of the Thesis . . . . . . . . . . . . . . 5 5

2 Literature Review $\quad 6$

2.1 Masonry Construction . . . . . . . . . . . . . . 6

2.2 Thermal Properties of Masonry . . . . . . . . . . . . . . . . 9

2.2.1 Specific Heat Capacity . . . . . . . . . . . . . . . . . . . 9

2.2.2 Thermal Expansion . . . . . . . . . . . . . . . . . . 10

2.2.3 Free Water Content . . . . . . . . . . . . . . . . . 11

2.2.4 Thermal Conductivity . . . . . . . . . . . . . . 12

2.3 Concrete Strength at Different Temperatures . . . . . . . . . . . 15

2.3.1 Effect of Aggregates on Concrete Strength . . . . . . . . . . . 20 
2.3.2 Effect of Supplementary Cementitious Materials . . . . . . . . 25

2.4 Heat Transfer . . . . . . . . . . . . . . . . . . . . . . . . 32

2.5 Fire Resistance Testing . . . . . . . . . . . . . . . . . . . . 34

2.5.1 Issues with Fire Testing . . . . . . . . . . . . . . . . 37

2.6 Methods of Improving Fire Resistance: Mix design . . . . . . . . . 38

2.7 Methods of Improving Fire Resistance: Geometry . . . . . . . . . . . 39

2.7.1 Equivalent Thickness . . . . . . . . . . . . . . . . . 39

2.7 .2 Other Geometries . . . . . . . . . . . . . . . . . 42

2.8 Methods of Improving Fire Resistance: Insulation . . . . . . . . . . . 42

2.8.1 Mineral Wool . . . . . . . . . . . . . . . . . . . . . 42

2.8.2 Gypsum ...................... 46

2.8.3 Epoxy Insulation . . . . . . . . . . . . . . . . . . . 47

2.8.4 Intumescent Paint . . . . . . . . . . . . . . . . . . 48

2.9 Issues with Heated Masonry Walls . . . . . . . . . . . . . . . . 49

2.9.1 Thermal Bowing ................. 49

2.9 .2 Spalling ........................... 52

2.9.3 Summary of Issues . . . . . . . . . . . . . . . . . . 56

3 Experimental Procedure $\quad 57$

3.1 Introduction to the Experiment . . . . . . . . . . . . 57

3.2 Thermocouples ....................... 57

3.2.1 Thermocouple Placement . . . . . . . . . . . . . . . 57

3.2.2 Thermocouple Readings and Accuracy . . . . . . . . . . . . . 59

3.3 Furnace Temperature . . . . . . . . . . . . . . . . . . . 60

3.4 Supplemental Monitoring, Thermal Imaging . . . . . . . . . . . . . . 60

3.5 Test Structure Almonte Lab . . . . . . . . . . . . . . . . . . . 61

3.6 Test Structure Barnsdale Lab . . . . . . . . . . . . . . . . . . 63

3.7 During the test and after the test . . . . . . . . . . . . 64

3.8 Test Matrix . . . . . . . . . . . . . . . . . 65

3.9 Almonte Test $1 \mathrm{~A}$ and $1 \mathrm{~B} \ldots \ldots \ldots \ldots$. . . . . . . . . 67

3.9.1 Almonte Test 1, Walls tested . . . . . . . . . . . . 67

3.9.2 Almonte Test 1, Issues and Improvements . . . . . . . . . . . 69

3.10 Almonte Test $2 \mathrm{~A} \ldots \ldots \ldots$. . . . . . . . . . . . . . . 71

3.10 .1 Tested Walls Almonte $2 \mathrm{~A}$. . . . . . . . . . . . . . 71

3.11 Barnsdale Test $1 \mathrm{~A}$ and $1 \mathrm{~B} \ldots \ldots . \ldots . \ldots . \ldots 73$ 
3.11.1 Tested Walls Barnsdale Test 1A and 1B . . . . . . . . . . 73

3.11 .2 Barnsdale Test 1, Issues and Improvements . . . . . . . . . . . 76

3.12 Barnsdale Test $2 \ldots \ldots$. . . . . . . . . . . . . . . . 77

3.12.1 Tested Walls Barnsdale Test 2 . . . . . . . . . . . . . . . 77

3.13 Barnsdale Test 3 . . . . . . . . . . . . . . . . . . . . . . . 79

3.13.1 Tested Walls Barnsdale Test 3 . . . . . . . . . . . . 79

4 Experimental Results $\quad 83$

4.1 Almonte Test $1 \mathrm{~A}$ results . . . . . . . . . . . . . . . . . . . 83

4.1.1 Almonte Test 1A Furnace temperature . . . . . . . . . . . . 83

4.1.2 Almonte Test 1A Average Exposed and Unexposed Surface temperatures of the walls . . . . . . . . . . . 83

4.1.3 Comparing temperatures at specific points on the walls . . . 85

4.2 Almonte Test 1B results . . . . . . . . . . . . . . . . 87

4.2.1 Almonte Test 1B Average Exposed and Unexposed Surface temperatures of the walls . . . . . . . . . . . . 87

4.2.2 Almonte Test 1B Comparing temperatures at specific points on the walls................... . . 87

4.2.3 Almonte Test 1 Wall cracking and thermal imaging . . . . . . 88

4.3 Almonte Test2 results . . . . . . . . . . . . . . . . . . . . . . 92

4.3.1 Almonte Test2 Wall Failure Times . . . . . . . . . . . . . . . 92

4.3.2 Almonte Test2 The Effect of Thermocouple Placement . . . . 93

4.3.3 Almonte Test2 The Effect of the Hollow Cell . . . . . . . . . . 95

4.3.4 Almonte Test2 The Effect of the Mortar . . . . . . . . . . . . 95

4.3.5 Almonte Test2 The Effect of the Bond Beam . . . . . . . . . . 96

4.3.6 Almonte Test2 The Effect of the Reduced Webs . . . . . . . . 98

4.3.7 Almonte Test2 Thermal Imaging Results . . . . . . . . . . . . 100

4.3.8 Almonte Test2 Results of Thermal Bowing . . . . . . . . . . . 101

4.3.9 Almonte Test2 Results of Spalling . . . . . . . . . . . . . . 103

4.3.10 Almonte Test2 Experimental Conclusions . . . . . . . . . . . . 104

4.4 Barnsdale Test 1A results . . . . . . . . . . . . . . . 106

4.4.1 Barnsdale Test 1A Furnace temperature during all heating attempts .................... 106

4.4.2 Barnsdale Test 1A Final test Furnace temperature . . . . . . . 106 
4.4.3 Barnsdale Test 1A Average Unexposed temperaures of the four walls . . . . . . . . . . . . . . . . . . . . 108

4.4.4 Barnsdale Test 1A Internal Temperatures Within a Block . . . 109

4.4.5 Barnsdale Test 1A Unexposed surface cooling rate of the different thermocouple locations . . . . . . . . . . . . . 111

4.4.6 Barnsdale Test 1A The difference between exposed, internal, and unexposed temperatures in the hollow cell . . . . . . . . 111

4.4.7 Barnsdale Test 1A Effect of the bond beam . . . . . . . . . 113

4.4.8 Barnsdale Test 1A Effect of the mortar . . . . . . . . . . . 116

4.4.9 Barnsdale Test 1A Thermal Imaging . . . . . . . . . . . . 117

4.5 Barnsdale Test 1B results . . . . . . . . . . . . . . . . . . 122

4.5.1 Barnsdale Test 1B Furnace temperature . . . . . . . . . . 122

4.5.2 Barnsdale Test 1B Failures . . . . . . . . . . . . . . . . 122

4.5.3 Barnsdale Test 1B Heating Period . . . . . . . . . . . . 128

4.5.4 Barnsdale Test 1B Cooling Phase . . . . . . . . . . . . 135

4.5.5 Barnsdale Test 1B Thermal Imaging . . . . . . . . . . . 138

4.6 Comparing Almonte Tests and Barnsdale Tests 1A and 1B . . . . . 148

4.6.1 Comparing Barnsdale Tests 1A and 1B . . . . . . . . . 148

4.6.2 Comparing Almonte to Barnsdale Tests . . . . . . . . . . . 150

4.7 Barnsdale Test 2 results . . . . . . . . . . . . . . . . . . . 153

4.7 .1 Furnace temperature . . . . . . . . . . . . . . . . . . 153

4.7.2 Integrity failure, thermal bowing, spalling . . . . . . . 153

4.7.3 Insulation Failure Times . . . . . . . . . . . . . . . . . 162

4.7.4 Barnsdale Test2 Heating Period . . . . . . . . . . . . . . . 163

4.7 .5 Cooling Period . . . . . . . . . . . . . . . . . . . . . 169

4.7 .6 Thermal Imaging . . . . . . . . . . . . . . . . . . 170

4.7.7 Comments on the different blocks . . . . . . . . . . . 177

4.8 Barnsdale Test 3 results . . . . . . . . . . . . . . . . . . . . . . . . . 179

4.8 .1 Furnace temperature . . . . . . . . . . . . . . . . . . . 179

4.8.2 Integrity failure, thermal bowing, spalling . . . . . . 180

4.8.3 Insulation Failure Times . . . . . . . . . . . . . . . . 185

4.8.4 Average Wall Temperatures . . . . . . . . . . . . . . 186

4.8.5 Comparing Block Surface Locations . . . . . . . . . . . . 187

4.8.6 Comparing the Rockwool Insulated Walls . . . . . . . . . . 190 
4.8.7 Thermal imaging . . . . . . . . . . . . . . . . . . . 191

4.8.8 Barnsdale Test 3 comments on the different types of blocks . . 198

5 Model Creation 200

5.1 Introduction . . . . . . . . . . . . . . 200

5.2 Numerical Simulation Technique . . . . . . . . . . . . . . . . . . 201

5.2 .1 Material thermal properties . . . . . . . . . . . . . . 201

5.2 .2 Meshing . . . . . . . . . . . . . . . . . . 205

5.2 .3 Interaction Properties . . . . . . . . . . . . . . . . 208

5.2.4 Loads and boundary conditions . . . . . . . . . . . . . . 213

5.3 Created Models . . . . . . . . . . . . . . . . . . . . . . 213

5.3.1 Model For 20CM standard unit . . . . . . . . . . . . . . . 213

5.3.2 Modeling the other tested wall geometries . . . . . . . . . 214

5.3 .3 Model Accuracy . . . . . . . . . . . . . . . . . . . . . . . . 222

5.3.4 Summary of Creating a model . . . . . . . . . . . . . 223

5.4 Modeling Results . . . . . . . . . . . . . . . . . . . . . 225

5.4.1 The Effect of Aggregate types . . . . . . . . . . . . . 225

5.4.2 The Effect of faceshell Thickness _ . . . . . . . . . . . 228

5.4.3 The Different Block Sizes . . . . . . . . . . . . . . . . . 230

5.4.4 The Effect of an Asymetrical Block . . . . . . . . . . . . 232

5.4.5 The Effect of an extra faceshell . . . . . . . . . . . . . . 233

5.4.6 Effect of Block Facing and Ribs . . . . . . . . . . . . 235

5.4.7 The Effect of Insulation Material . . . . . . . . . . . . . . 237

6 Modeling Different Mix Designs $\quad 242$

6.1 Methodology . . . . . . . . . . . . . . . . . . . . . . . 242

6.1.1 Thermal properties collation . . . . . . . . . . . . . . . . 242

6.1 .2 Model creation . . . . . . . . . . . . . . . . . . . . . . 242

6.2 Aggregate Type Results . . . . . . . . . . . . . . . . . . . . . 243

6.2.1 Effect of changing different thermal properties . . . . . . . . 243

6.2.2 Normal weight concrete . . . . . . . . . . . . . . . . . 244

$6.2 .3 \mathrm{RCA} \ldots \ldots \ldots \ldots \ldots \ldots \ldots \ldots \ldots \ldots$

6.2 .4 Common LWA Mixes . . . . . . . . . . . . . . . . . . . . . 249

6.2.5 Comparing NWC, RCA, LWC, and novel LWC . . . . . . . 251

6.3 Aggregate Type Conclusion _. . . . . . . . . . . . . . . 255 
6.4 Novel Aggregate Results . . . . . . . . . . . . . . . . . . . 257

6.4.1 Vermiculite and Expanded Polystyrene coarse aggregate . . . 257

6.4 .2 Polyurethane . . . . . . . . . . . . . . . . 258

6.4 .3 Perilte aggregate . . . . . . . . . . . . . . . . 259

6.4.4 Expanded Perlite . . . . . . . . . . . . . . . . . . 261

6.4.5 High impact polystyrene . . . . . . . . . . . . . . . 262

6.4.6 Cement-based lightweight composites . . . . . . . . . . . 263

6.4.7 Lightweight Concrete with Furnace bottom ash replacement . 264

6.4.8 NSC and HSC with LWA replacement . . . . . . . . . . 265

6.4 .9 Novel Aggregate Conclusion . . . . . . . . . . . . . . 267

6.5 Cement, Pozzolans, and Addatives Results . . . . . . . . . . . . 269

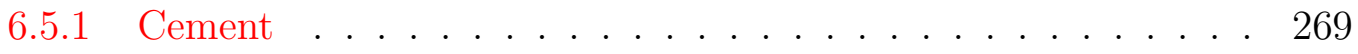

6.5 .2 POZZOLANS . . . . . . . . . . . . . . 270

6.5.3 RELATIVE HUMIDITY . . . . . . . . . . . . . . . 273

6.5 .4 SILANE AND SF . . . . . . . . . . . . . . . . . 275

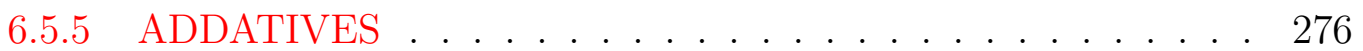

6.5.6 FOAMED/AERATED CONCRETE . . . . . . . . . . . 279

6.6 Cement, Pozzolans, and Addatives Conclusion . . . . . . . . . . . . 282

6.7 Cenosphere Results . . . . . . . . . . . . . . . . . . . . . . 283

6.7.1 Glazed Hollow Beads . . . . . . . . . . . . . . . . . . . 283

6.7 .2 Glass bubble . . . . . . . . . . . . . . . . . . . 285

6.7.3 Fly Ash Cenospheres sizes and hole filling . . . . . . . . . 285

6.7.4 Fly Ash Ccenospoheres replaced by Iron Ore Tailings . . . . . 288

6.7.5 Effect of Exlite and QK300 _. . . . . . . . . . . . 290

6.7 .6 Use of lightweight fillers . . . . . . . . . . . . . . . . . . 291

6.8 Cenospheres Conclusion _. . . . . . . . . . . . . . . . . . 297

6.9 Novel Materials Results . . . . . . . . . . . . . . . . . . . . . . . . 298

6.9 .1 FIBERS . . . . . . . . . . . . . . . . . . . 298

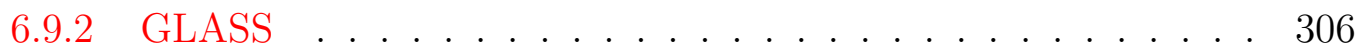

6.9 .3 Hemp Concrete . . . . . . . . . . . . . . . . . . . . 310

6.9.4 PHASE CHANGE MATERIALS . . . . . . . . . . . . . 312

6.10 Novel Materials Conclusion . . . . . . . . . . . . . . . . . . . . 314 
7 Summary, Conclusions, Limitations, Recommendations

7.1 Research Summary . . . . . . . . . . . . . . . . . . . . 316

7.2 Conclusions . . . . . . . . . . . . . . . . . . . . 317

7.3 Limitations . . . . . . . . . . . . . . . . . . . . . . . 318

7.4 Recommendations for Future Studies . . . . . . . . . . . . 318

$\begin{array}{ll}\text { List of References } & 319\end{array}$ 


\section{List of Tables}

2.1 Thermal Conductivities without moisture . . . . . . . . . . . 13

2.2 Thermal Conductivities with moisture . . . . . . . . . . . . 13

2.3 Changes in OPC Paste with Temperature . . . . . . . . . . . . 16

2.4 Changes in natural aggregates . . . . . . . . . . . . . . . 20

2.5 The percentage of heat flux through a $20 \mathrm{~cm}$ masonry block at ambient and fire temperatures . . . . . . . . . . . . . . 34

3.1 Test Matrix . . . . . . . . . . . . . . . . . 66

4.1 Failure Times . . . . . . . . . . . . . . . . . . . . . 92

4.2 Barnsdale Test 1B Failure Times . . . . . . . . . . . . . . . . 127

4.3 Barnsdale Test 1B Failure Times corrected . . . . . . . . . . . . . . . 127

4.4 Barnsdale Test2 Predicted Failure Times . . . . . . . . . . . . . . . . 162

4.5 Barnsdale Test2 Failure Times . . . . . . . . . . . . . . . . . . 163

4.6 Barnsdale Test2 Corrected Failure Times . . . . . . . . . . . . . . . . 163

4.7 Barnsdale Test3 Temperatures at the end of the test . . . . . . . . 185

5.1 Thermal Properties of Normal Weight Concrete . . . . . . . . . . . . 201

5.2 Thermal Properties of Mortar . . . . . . . . . . . . . . . . . . 202

5.3 Mesh Refinement Error . . . . . . . . . . . . . . . . . . . . . 208

5.4 Heat Transfer Coefficient Values . . . . . . . . . . . . . . . . . . . . . 212

5.5 Thermal Properties for Lightweight Concrete . . . . . . . . . . . . . 220

5.6 Error Between Experimental and Numerical Fire Resistance . . . . . 224

5.7 Extra Faceshell Block Dimensions . . . . . . . . . . . . . . . . . . 234

5.8 Insulation Thermal Properties . . . . . . . . . . . . . . . . . . . . 240

6.1 Mounanga et al 2008 Mix designs . . . . . . . . . . . . . . . 259

6.2 Zhou et al 2019 Mix designs . . . . . . . . . . . . . . . . . 266

6.3 Huang et al 2013 Mix Designs . . . . . . . . . . . . . . . . . . . . . 289

6.4 Wu et al 2015 Mix Designs . . . . . . . . . . . . . . . . . . . . . . . . 291

6.5 Brookes et al 2018 Mix Designs . . . . . . . . . . . . . . . . . 293 
6.6 Zhou et al 2019 Mix Designs . . . . . . . . . . . . . . . . . . . . 304

6.7 Al-Sibahy 2012 Mix Designs . . . . . . . . . . . . . . . . . 306 


\section{List of Figures}

2.1 Hollow $20 \mathrm{~cm}$ concrete block. (1) Faceshell (2) Web (3) Cell . . . . . 7

2.2 a)Failure Parallel to bed joint b) Failure Perpendicular to Bed Joint. Where (1) Is a Bed Joint and (2) is a Head Joint . . . . . . . . . . 7

2.3 Different Mortar Joints . . . . . . . . . . . . . . . . . . . . 8

2.4 The Specific heat of concrete . . . . . . . . . . . . . . . . . . 10

2.5 The Specific heat of concrete . . . . . . . . . . . . . . . . . 12

2.6 Thermal conductivity of concrete with respect to temperature . . . . 14

2.7 Ultrasonic pulse velocity decrease with temperature . . . . . . . . 16

2.8 (a) Composition of concrete after 8 hours exposure and (b) Effect of heating duration on concrete composition . . . . . . . . . . . . . 17

2.9 Residual compressive strength of different concrete tests at various temperatures . . . . . . . . . . . . . . . . . . . . 19

2.10 Concrete with waste glass samples after failure . . . . . . . . . . . 24

2.11 Ternary diagram of cementitious materials . . . . . . . . . . . 25

2.12 Residual Strengths of Various Cement Pastes . . . . . . . . . . . . . . 28

2.13 Unloaded and Cooled FA Cement Paste Specimens . . . . . . . . . . 29

2.14 CAN ULC S101 standard fire . . . . . . . . . . . . . . . . 36

2.15 Stability (Left) Integrity (Centre) Insulation (Right) . . . . . . . . . 36

2.16 The problem with equivalent thickness . . . . . . . . . . . . . 40

2.17 The effect of different partions on the fire resistance . . . . . . . . . 41

2.18 (a) Mineral wool sample) (b) Mineral wool fibers . . . . . . . . . . 43

2.19 Specific heat of Type X gypsum board as a function of temperature . 47

2.20 Intumescing process . . . . . . . . . . . . . . . . . . 49

2.21 Thermal Bowing a) Loaded b) Unloaded . . . . . . . . . . . . . . . 50

2.22 (a) Masonry Spalling (Exposed Surface) (b) Close Up of Masonry Spalling 53

2.23 Thermal Gradient Induced Stresses . . . . . . . . . . . . . . . . 55 
3.1 Thermocouple locations. (M) Mortar, (S) Solid Web, (H) Hollow Cell. The fire exposed side is the side with H1, S1 and M1 . . . . . . . . 59

3.2 Barnsdale Burner . . . . . . . . . . . . . . . . . . . 61

3.3 Almonte Test Structure . . . . . . . . . . . . . . . . . . . . 62

3.4 Barnsdale Test Structure (a) Uninstrumented (b) Instrumented . . . 64

$3.510 \mathrm{~cm}$ block shape . . . . . . . . . . . . . . . 67

$3.615 \mathrm{~cm}$ block shape . . . . . . . . . . . . . . . 68

3.7 (a) Bond Beam and (b) Reduced Web . . . . . . . . . . . . . 72

3.8 (a) Raked Joints and (b) Concave Joints . . . . . . . . . . . . . . 73

$3.915 \mathrm{~cm}$ block shape . . . . . . . . . . . . . . . . . 74

$3.1015 \mathrm{~cm}$ block shape . . . . . . . . . . . . . . . . . . 75

3.11 Jointing types a) struck joint b) concave joint . . . . . . . . . . 75

$3.1215 \mathrm{~cm}$ Splitter Block . . . . . . . . . . . . . . . 76

3.13 a) LW15cm b) Semi Solid $15 \mathrm{~cm}$. . . . . . . . . . . . . . . . 78

3.14 a) Carbon Cured $20 \mathrm{~cm} \mathrm{b)} \mathrm{Split-Face} \mathrm{Carbon} \mathrm{Cured} 20 \mathrm{~cm}$. . . . . . 79

3.1520 cm Two Hour Fire Block . . . . . . . . . . . . . . . . . . . . 80

3.16 a) Block With Full Rockwool Insualtion b) Block With 1inch Rockwool Insulation . . . . . . . . . . . . . . . . . 81

3.17 a) Vermiculite Sample b) Vermiculite Filled block . . . . . . . . . . . 82

4.1 Almonte Test1A Comparing the furnace temperature to the standard fire temperature . . . . . . . . . . . . . . . .

4.2 Almonte Test1A a) Average exposed wall temperature b) Average unexposed wall temperature . . . . . . . . . . . . . . .

4.3 Almonte Test1A Comparing the temperatures at various locations on the unexposed side of the walls. a) comparing the three thermocouple locations on the LW15 wall. b) Comparing the temperatures on the unexposed surface in line with the hollow cell. c) Comparing the temperatures on the unexposed surface in line with the solid web cell. d) Comparing the temperatures on the unexposed surface in line with the

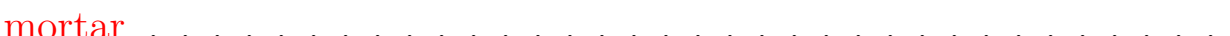

4.4 AlmonteTest1B a) Average exposed wall temperature b) Average unexposed wall temperature . . . . . . . . . . . . .

4.5 Almonte Test1B Comparing the three thermocouple locations on the NW15 wall . . . . . . . . . . . . . . . . . . . . 
4.6 AlmonteTest1B NW10 a) Crack formation b) Thermal Image . . . . . 89

4.7 AlmonteTest1B LW10 a) Crack formation b) Thermal Image . . . . . 90

4.8 AlmonteTest1B NW15 a) Crack formation b) Thermal Image . . . . . 90

4.9 AlmonteTest1B LW15 a) Crack formation b) Thermal Image . . . . . 91

4.10 Time Temperature Curves for the Unexposed Side of the Four Walls . 93

4.11 The effect of different thermocouple locations . . . . . . . . . . . 94

4.12 Effect of the Hollow Cell . . . . . . . . . . . . . . . . . . . 95

4.13 Comparing mortar temperatures between the control wall and the raked joint wall . . . . . . . . . . . . . . . . . . . . 96

4.14 The effect of the bond beam . . . . . . . . . . . . . . . . 97

4.15 The effect of the bond beam . . . . . . . . . . . . . . . . . . 98

4.16 The effect of the different wall geometries . . . . . . . . . . . . . . . 99

4.17 (a) Control Wall (b) Raked Wall (c) Bond Beam Wall and (d) Reduced Web Wall . . . . . . . . . . . . . . . . . . . . . . 100

4.18 Thermal Bowing a) Loaded b) Unloaded . . . . . . . . . . . . . . . . 102

4.19 (a) Concave Wall Cracks and (b) Raked Wall Cracks . . . . . . . . . 103

4.20 (a) Reduced Web Wall Spalling and (b) Close up of Spalling . . . . . 104

4.21 Barnsdale Test 1A, The furnace temperature throughout the test. . . 107

4.22 Barnsdale Test 1A, The furnace temperature compared to the average exposed wall temperatures. . . . . . . . . . . . . . . . . . 107

4.23 Barnsdale Test 1A, Average unexposed wall temperatures . . . . . . . 109

4.24 Barnsdale Test 1A, The effect of thermocouples locations on the temperatures halfway through the wall . . . . . . . . . . . . . . . . . 110

4.25 Barnsdale Test 1A, The effect of thermocouples locations on the temperatures on the unexposed side of the wall . . . . . . . . . . . . . . . 112

4.26 Barnsdale Test 1A, Temperatures within the hollow cell. H1 being the exposed side of the wall, and H5 being the unexposed side. H2-H4 are intermediate points within the hollow cell. . . . . . . . . . . . . 113

4.27 Barnsdale Test 1A, The locations of the extra thermocouples on the Lintel Wall . . . . . . . . . . . . . . . . . . . . . . . . . 114

4.28 Barnsdale Test 1A, Comparing the unexposed temperatures above and below the bond beam a) left side of the wall b) right side of the wall .

4.29 Barnsdale Test 1A, Comparing the cell temperatures between the Lintel Wall and the Struck Joint Wall . . . . . . . . . . . . . . . . . 116 
4.30 Barnsdale Test 1A, Comparison of mortar temperatures for the four different walls. . . . . . . . . . . . . . . . . . . . . . . . 117

4.31 Barnsdale Test 1A, Thermal images before the start of the test. a) Control Wall b) Lintel Wall c) Splitter Wall d) Struck Joint Wall. . . 118

4.32 Barnsdale Test 1A, a) Temperature profile early on in the test b) Temperature later in the test . . . . . . . . . . . . . . . . . . . 119

4.33 Barnsdale Test 1A, Thermal images of the different walls during the test. a) Control wall b) lintel wall c) Splitter Wall d) struck joint wall

4.34 Barnsdale Test 1A, Comapring the temperatures on the Lintel Wall to the Control Wall . . . . . . . . . . . . . . . . . . . . 121

4.35 Barnsdale Test 1B, Standard Fire Temperature Compared to the Furnace temperature . . . . . . . . . . . . . . . . . 123

4.36 Barnsdale Test 1B, Different crack formation in the four walls a) Control Wall b) Lintel Wall c) Splitter Wall d) Struck Joint Wall . . . . . 125

4.37 Barnsdale Test 1B, Spalling of the concrete pad . . . . . . . . . . . 126

4.38 Barnsdale Test 1B, Time Temperature Curve of the average temperature of the unexposed side of the four walls. . . . . . . . . . . . . . . 129

4.39 Barnsdale Test 1B, Comparing the internal thermocouple temperatures. 130

4.40 Barnsdale Test 1B, The unexposed temperature difference above and below the bond beam. The 1st bond beam is the lowest, and the 3rd bond beam is the highest. . . . . . . . . . . . . . . . . . . . 131

4.41 Barnsdale Test 1B, Comparing the cell temperatures within the Lintel Wall to the cell temperatures within the Struck Joint wall. . . . . . . 132

4.42 Barnsdale Test 1B, Effect of the wall type on the unexposed mortar temperature. . . . . . . . . . . . . . . . .

4.43 Barnsdale Test 1B, Average unexposed temperature of the four walls during the cooling period . . . . . . . . . . . . . . . 135

4.44 Barnsdale Test 1B, The effect of cooling on different parts of the masonry.

4.45 Barnsdale Test 1B, Temperatures within the hollow cell. H1 being the exposed side of the wall, and H5 being the unexposed side. H2-H4 are intermediate points within the hollow cell. a) Heating period b) cooling period. . . . . . . . . . . . . . . 137 
4.46 Barnsdale Test 1B, Thermal imaging during the heating period. a) $\mathrm{T}=5 \mathrm{mins}$, The thermal profile of the struck joint wall a few minutes after the test started b) $\mathrm{T}=15 \mathrm{mins}$, The thermal profile of the struck joint wall in the middle of the heating period c) $\mathrm{T}=17 \mathrm{mins}$, Thermal profile of the Lintel Wall at the early heating period d) $\mathrm{T}=30 \mathrm{mins}$, Thermal profile of the Lintel Wall in the middle of the heating period e) $\mathrm{T}=0 \mathrm{mins}$, Initial temperature profile of the splitter wall before the test $\mathrm{f}$ ) $\mathrm{T}=28 \mathrm{mins}$, Thermal profile of the splitter wall partway through the heating period. . . . . . . . . . . . . . .

4.47 Barnsdale Test 1B, Thermal profile of the four walls after 1 hour (the point when the furnace was turned off). a) Control wall b) Lintel Wall c) Splitter Wall d) Struck Joint Wall . . . . . . . . . . . . . . . . . . 142

4.48 Barnsdale Test 1B, Thermal profile of the four walls after 2 hours (When the unexposed surface temperatures were the maximum) a) Control wall b) Lintel Wall c) Splitter Wall d) Struck Joint Wall . . .

4.49 Barnsdale Test 1B, Thermal profile of the four walls during the cooling phase (3 hours after the test) a) Control wall b) Lintel Wall c) Splitter Wall d) Struck Joint Wall . . . . . . . . . . . . . . . . . . . . 146

4.50 Barnsdale Test 1B, Cooling of the mortar on different walls . . . . . 147

4.51 Barnsdale Test 1B Thermal Data a) Hollow Cell b) Soild Web . . . . 147

4.52 Barnsdale Test 2, Furnace Temperature during the heating period . . 153

4.53 Barnsdale Test 2, Crack Patterns a) Carbon Cured Wall b) LW15cm Wall c) Semi Solid Wall d) Split-Face Wall . . . . . . . . . . . . . . . 155

4.54 Barnsdale Test 2, Fire exposed side of the walls 24 hours after the test a) Carbon Cured Wall b) LW15cm Wall c) Semi Solid Wall d) Split-Face Wall . . . . . . . . . . . . . . . . . . . 157

4.55 Barnsdale Test 2, Fire exposed side of the walls one week after the test a) Carbon Cured Wall b) LW15cm Wall c) Semi Solid Wall d) Split-Face Wall . . . . . . . . . . . . . . . . . . . . . 158

4.56 Barnsdale Test 2, Fire exposed side of the walls one week after the test (closeup) a) Carbon Cured Wall b) LW15cm Wall c) Semi Solid Wall d) Split-Face Wall . . . . . . . . . . . . . . . . . . . . . . . . . 159

4.57 Barnsdale Test 2, Spalling Residue . . . . . . . . . . . . . 160 
4.58 Barnsdale Test 2, Single block spalling after removal from the wall a) Carbon Cured Wall b) Semi Solid Wall c) Split-Face Wall . . . . . . . 161

4.59 Barnsdale Test 2, Average Wall Temperatures during the heating period 164

4.60 Barnsdale Test 2, Free water evaporating at the start of the test a) Carbon Cured Wall b) Split-Face Wall . . . . . . . . . . . . . . 165

4.61 Barnsdale Test 2, Free water evaporating at the start of the test a) LW15cm Wall b) Split-Face Wall . . . . . . . . . . . . . . . . 165

4.62 Barnsdale Test 2, Unexposed Surface Temperature of the Carbon Cured Wall at various locations during the heating period . . . . . . 166

4.63 Barnsdale Test 2, The temperature profile at $\mathrm{H} 2$ for each of the four walls during the heating period . . . . . . . . . . . . . . 167

4.64 Barnsdale Test 2, The temperature profile of the cells for each of the four walls during the heating period . . . . . . . . . . . . . . . . . 168

4.65 Barnsdale Test 2, The temperature profile of the furnace after the burner was turned off . . . . . . . . . . . . . . . . . . . . . . 169

4.66 Barnsdale Test 2, Average Wall Temperatures during the cooling period170

4.67 Barnsdale Test 2, Temperature at H2 for each of the walls during the cooling period . . . . . . . . . . . . . . . . . . . . . . 171

4.68 Barnsdale Test 2, Initial Thermal Images a) Carbon Cured Wall b) LW15cm Wall c) Semi Solid Wall d) Split-Face Wall . . . . . . . . . . 172

4.69 Barnsdale Test 2, Thermal Images at 15 minutes a) Carbon Cured Wall b) LW15cm Wall c) Semi Solid Wall d) Split-Face Wall . . . . . . . . 173

4.70 Barnsdale Test 2, Thermal Images at 1 hour a) Carbon Cured Wall b) LW15cm Wall c) Semi Solid Wall d) Split-Face Wall . . . . . . . . . . 174

4.71 Barnsdale Test 2, Thermal Images the end of the test (140 minutes) a) Carbon Cured Wall b) LW15cm Wall c) Semi Solid Wall d) Split-Face Wall ............................. 175

4.72 Barnsdale Test 2, Thermal Images after 3.5 hours a) Carbon Cured Wall b) LW15cm Wall c) Semi Solid Wall d) Split-Face Wall . . . . . 176

4.73 Barnsdale Test 3, Furnace Temperature during the test . . . . . . . . 179

4.74 Barnsdale Test 3, Crack Patterns a) Two Hour Fire Wall b) Rockwool 1inch Wall c) Vermiculite Wall d) Rockwool Full Wall . . . . . . . . . 181 
4.75 Barnsdale Test 3, Fire exposed side of the walls 4 days after the test a) Two Hour Fire Wall b) Rockwool 1inch Wall c) Vermiculite Wall d) Rockwool Full Wall . . . . . . . . . . . . . . . . . . . . . . . . 183

4.76 Barnsdale Test 3 Spalling of the Two Hour Fire wall a) Faceshell bowing b) Close up of the cracks at the centre of the wall . . . . . . . . . 184

4.77 Barnsdale Test 3, Average Wall Temperatures . . . . . . . . . . . . . 187

4.78 Barnsdale Test 3, Unexposed Surface Temperature of the hollow cell for each wall . . . . . . . . . . . . . . . . . . . . . 188

4.79 Barnsdale Test 3, Unexposed Surface Temperature of the solid webs for each wall . . . . . . . . . . . . . . . . . . . . . . . . . . . 189

4.80 Barnsdale Test 3, Unexposed Surface Temperature of the mortar for each wall . . . . . . . . . . . . . . . . . . . . . . . 190

4.81 Barnsdale Test 3, Surface Temperatures at different block locations for the a) Rockwool 1inch Wall b) Rockwool Full Wall . . . . . . . . . . 191

4.82 Barnsdale Test 3, Temperatures through the hollow cell on the Rockwool walls . . . . . . . . . . . . . . . . . . . . . . 192

4.83 Barnsdale Test 3, Thermal Images at 15 minutes a) Two Hour Fire Wall b) Rockwool 1inch Wall c) Vermiculite Wall d) Rockwool Full Wall193

4.84 Barnsdale Test 3, Thermal Images at 25 minutes a) Two Hour Fire Wall b) Rockwool 1inch Wall c) Vermiculite Wall d) Rockwool Full Wall194

4.85 Barnsdale Test 3, Thermal Images at 1 hour a) Two Hour Fire Wall b) Rockwool 1inch Wall c) Vermiculite Wall d) Rockwool Full Wall .

4.86 Barnsdale Test 3, Thermal Images at 90 minutes a) Two Hour Fire Wall b) Rockwool 1inch Wall c) Vermiculite Wall d) Rockwool Full Wall196

4.87 Barnsdale Test 3, Thermal Images at 3h a) Two Hour Fire Wall b) Rockwool 1inch Wall c) Vermiculite Wall d) Rockwool Full Wall . . . 197

5.1 Solid Concrete Block Model . . . . . . . . . . . . . . . . . . . . . . 202

5.2 Effect of concrete properties on failure time a) Thermal conductivity b) Specific Heat c) Density . . . . . . . . . . . . . . . . . . 204

5.3 Comparing the NW15cm block experiment data with the model, with free water in the model a) Hollow Cell b) Solid Web and without free water in the model c) Hollow Cell d) Solid Web . . . . . . . . . . . . 205

5.4 Difference between mesh sizes a)Very Coarse Mesh40 b)Very Fine Mesh5206

5.5 Difference between mesh sizes a) and c)Hollow Cell b) and d)Solid Web 207 
5.6 Modelled Masonry Blocks a) $15 \mathrm{~cm}$ block b) 20cm block . . . . . . . . 209

5.7 Effects of different Emmisivity values . . . . . . . . . . . . . . 210

5.8 Difference between Heat Transfer coeficient (units $\mathrm{W} / \mathrm{m}^{2} \mathrm{k}$ ) a)Hollow Cell b)Solid Web . . . . . . . . . . . . . . . . . . . 210

5.9 Properties of air at different temperatures . . . . . . . . . . . . 211

$5.1020 \mathrm{~cm}$ standard unit experimental and numerical average unexposed time temperature curve comparison . . . . . . . . . . . . . . . . . . . 214

5.11 a) Reduced Web Block Model b) Comparing the Reduced Web Block experimental and modeling data . . . . . . . . . . . . . . . 215

5.12 a) Lintel Block Model b) Comparing Lintel Block experimental and modeling data . . . . . . . . . . . . . . . . 216

5.13 a) Comparing Raked Joint Wall experimental and modeling data b) Comparing Numerical Raked Joints to Numerical Concave Joints . 217

5.14 a) $15 \mathrm{~cm}$ Normal Weight Model b) Comparing the experimental and modeling data of the $15 \mathrm{~cm}$ normal weight block . . . . . . . . . . 217

5.15 Carbon Cured 20cm standard unit experimental and numerical average unexposed time temperature curve comparison . . . . . . . . . . . . . 218

$5.16 \mathrm{LW} 15 \mathrm{~cm}$ unit experimental and numerical average unexposed time temperature curve comparison . . . . . . . . . . . . . . . . . . . . 219

5.17 a) $15 \mathrm{~cm}$ Normal Weight Model b) Comparing the experimental and modeling data of the $15 \mathrm{~cm}$ normal weight block . . . . . . . . . . . . 221

5.18 a) $15 \mathrm{~cm}$ Normal Weight Model b) Comparing the experimental and modeling data of the $15 \mathrm{~cm}$ normal weight block . . . . . . . . . . . 221

5.19 Two Hour Fire Block experimental and numerical average unexposed time temperature curve comparison . . . . . . . . . . . . . . . 222

5.20 Rockwool Full unit experimental and numerical average unexposed time temperature curve comparison . . . . . . . . . . . . . . . . . 223

5.21 Rockwool linch unit experimental and numerical average unexposed time temperature curve comparison . . . . . . . . . . . . . . . . 223

5.22 Finite Element Model of a Masonry Block . . . . . . . . . . . . . . . 225

5.23 The change in failure times based on material . . . . . . . . . . . . . 227

5.24 No-fines pumice fire resistance vs density . . . . . . . . . . . . . . . 228

5.25 The difference between the web and the cell . . . . . . . . . . 229 
5.26 The effect of the faceshell thickness on the a) Failure Time b) Temper-

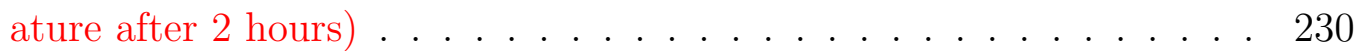

5.27 faceshell Model . . . . . . . . . . . . . . . . . . . . . 231

5.28 a) $25 \mathrm{~cm}$ Hollow Block b) 25cm Semi-Solid Block . . . . . . . . . . . . 232

5.29 Effect of Different Hollow Block Sizes . . . . . . . . . . . . . . . . . 233

5.30 Effect of Different Semi-Solid Block Sizes . . . . . . . . . . . . . . 234

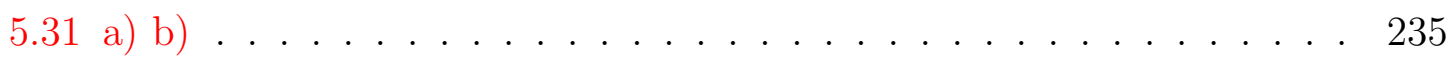

5.32 a) EFS1 b) EFS2 c) EFS3 d) EFS4 . . . . . . . . . . . . . . 236

5.33 Effect of the different faceshell tests . . . . . . . . . . . . . . . 237

5.34 a) $15 \mathrm{~cm}$ Split Face Block b) $15 \mathrm{~cm}$ Split Face with two ribs c) $15 \mathrm{~cm}$ Split Facae with three ribs . . . . . . . . . . . . . . . . 238

5.35 The effect of Ribs on the time temperature curves of the Hollow Cells with various block sizes. . . . . . . . . . . . . . . . . 239

5.36 The effect of Ribs on the time temperature curves of the Solid Web with various block sizes . . . . . . . . . . . . . . . . . . . 239

5.37 Block With Insulation Model . . . . . . . . . . . . . . . . . . 240

5.38 Block With Insulation Model . . . . . . . . . . . . . . . . . . . 241

6.1 Thermal Modeling Block . . . . . . . . . . . . . . . . . . 243

6.2 The effect of changing different thermal properties (a) Thermal Conductivity (b) Specific Heat (c) Density . . . . . . . . . . . . . . . 245

6.3 Modeling time temperature curves of normal weight concrete mixes. . 246

6.4 The effect of RCA replacement (a) Zhao 2018 (b) Guo et al 2020 (c) Tosic et al 2015 . . . . . . . . . . . . . . . . . . . . . . . . . 248

6.5 RCA concrete with different w/c ratios (a) Marinkovic et al 2020 and (b) Damdelen et al 2014 . . . . . . . . . . . . . . . . . . . . . . . . . 249

6.6 The effect of pumice replacemnt on fire resistance (a) Turkman et al 2017 (b) Uysal et al 2004 . . . . . . . . . . . . . . . . . . . . . . 250

6.7 Different LWA replacement (a) Shale and Pumice (b) 4/10 Clay and 4/8 Clay (c) All four aggregates with 100\% fine aggregate replacement 252

6.8 The effect of different aggregate types Real et al 2016 . . . . . . . . . 253

6.9 Comparing the effect of the different aggregate types Stephan et al 2020256

6.10 Time temperature curves of EPS and Vermiculite concrete . . . . . . 258

6.11 Effect of concrete mixes with different amounts of PUR (a) Mix1 (b) Mix2 ...................... . . 260 
6.12 The effect of diffrent perlite aggregate mixes with different densities . 260

6.13 Comparing the effect of different EP replacement . . . . . . . . . . . 262

6.14 Comparing the effect of the different HIPS replacement . . . . . . . 263

6.15 Comparing the effect of the different CLC mixes . . . . . . . . . . . . 264

6.16 Comparing the effect of the different aggregate FBA replacement . . 265

6.17 Comparing the effect of the different NSC and HSC mixes . . . . . . 268

6.18 Time temperature curves of Concrete and Cement . . . . . . . . . 269

6.19 Time temperature curves of concrete mixes with various amounts of cement $(\mathrm{Kg} / \mathrm{m} 3)$. . . . . . . . . . . . . . . . . . . . 270

6.20 Effect of NA and RCA concrete mixes with different Pozzolans (a) Higher w/c ratio (b) Lower w/c ratio . . . . . . . . . . . . . . . . . 271

6.21 Time temperature curves of concrete with FA and GGBFS replacement 272

6.22 Time temperature curve of concrete with pozzolans . . . . . . . . . 273

6.23 The effect of hummidity (from 20-100\%) on the fire resistance of NC and FA concrete . . . . . . . . . . . . . . . . . 274

6.24 Comparing the effect of different amounts of silane . . . . . . . . 275

6.25 Comparing the effect of SF within cement paste and mortar . . . . . 276

6.26 Comparing the effect of SRA . . . . . . . . . . . . . . 277

6.27 Comparing the effect of VMA . . . . . . . . . . . . . . 278

6.28 Comparing the effect of different amounts of AE . . . . . . . . . . . . 279

6.29 Comparing the effect of the different foamed concrete densities . . . . 280

6.30 Comparing the effect of foamed concrete with different amounts of ceramic fine aggregate . . . . . . . . . . . . . . . . 281

6.31 Comparing the effect of the different aerated concrete densities and thermal conductivities . . . . . . . . . . . . . . . . . . . . . 282

6.32 TIC mix with 30\% RCA and varying amounts of GHB . . . . . . . . 284

6.33 Effect of glass bubbles with different aggregates a) Stalite (t) (b)

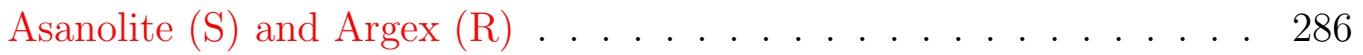

6.34 FAC with percentage of the holes that were not filled . . . . . . . . . 287

6.35 Performance of FAC with only a dingle diameter . . . . . . . . . . . . 288

6.36 Performance of FAC with bimodal mixes . . . . . . . . . . . . . . . 289

6.37 Comparing the effect of different mix designs . . . . . . . . . . . . . . 290

6.38 Comparing the effect cenosphere type and w/b ratio . . . . . . . . . . 292

6.39 Brooks et al 2018 Control specimen time temperature curve comparison 294 
6.40 Brooks et al 2018 EPS beads time temperature curve comparison . . 295

6.41 Brooks et al 2018 TPMS time temperature curve comparison . . . . . 296

6.42 Brooks et al 2018 HGM 28\% replacement time temperature curve comparison . . . . . . . . . . . . . . . . . . 297

6.43 Brooks et al 2018 Fly Ash 28\% replacement time temperature curve comparison . . . . . . . . . . . . . . . . . . 298

6.44 Brooks et al 2018 All LWF 28\% replacement failure times comparison 299

6.45 Effect of Fibers in concrete . . . . . . . . . . . . . . . . . . . . 300

6.46 The effect of different fiber types (a) Hooked Steel (b) Wavey Steel (c) $\mathrm{PP} \ldots \ldots \ldots \ldots . \ldots \ldots 2$

6.47 Concrete with Fibers and Silane . . . . . . . . . . . . . . . 303

6.48 Effect of fibers on HSC (a) HSC without Fibers (b) HSC with Fibers 305

6.49 RCA with PP fibers . . . . . . . . . . . . . . . . . 305

6.50 Effect of waste glass and $\mathrm{MK}$. . . . . . . . . . . . . . 307

6.51 Comparing glass mixes between $15 \mathrm{~cm}$ and $10 \mathrm{~cm}$ blocks . . . . . . . . 308

6.52 Effect of RG and RP . . . . . . . . . . . . . . . . . . . 309

6.53 Effect of different hemp concrete mixes . . . . . . . . . . . . . . . . . 311

6.54 Effect of different thermal conductivity measurment techniques . . . . 312

6.55 The effect of PCM . . . . . . . . . . . . . . . . . . . . 313

6.56 The effect of different MPCM . . . . . . . . . . . . . . . . . . . 314 


\section{Nomenclature}

\section{$0.1 \quad$ Variables}

$$
\begin{array}{ll}
t & =\text { time (minutes) } \\
r & =\text { the correlation } \\
\delta \mathrm{y} / \mathrm{y} \theta & =\text { the amount of C-S-H decomposition relative to its original amount. } \\
\dot{q}^{\prime \prime} & =\text { heat flow per unit area }\left(\mathrm{W} / \mathrm{m}^{2}\right) \\
\mathrm{k} & =\text { thermal conductivity }(\mathrm{W} / \mathrm{mK}) \\
\mathrm{X} & =\text { the distance in the direction of the heat flow }(\mathrm{m}) \\
\mathrm{h} & =\text { convective heat transfer coefficient }\left(\mathrm{W} / \mathrm{m}^{2} \mathrm{~K}\right) \\
\phi & =\text { configuration factor } \\
\varepsilon_{e} & =\text { emissivity of the emitting surface } \\
\sigma & =\text { Stefan-Boltzmann constant }\left(5.67 x 10^{-8} \mathrm{~W} / \mathrm{m}^{2} \mathrm{~K}^{4}\right) \\
\mathrm{T} & =\text { temperature }\left({ }^{\circ} \mathrm{C} \text { or } \mathrm{K}\right) \\
T_{e} & =\text { absolute temperature of the emitting surface }(\mathrm{K}) \\
\mathrm{T}\{g\} & =\text { furnace temp }\left({ }^{\circ} \mathrm{C}\right) \\
\mathrm{T}\{0\} & =\text { ambient temp. }\left({ }^{\circ} \mathrm{C}\right) \\
\mathrm{T}_{w} & =\text { the concrete surface temperature }\left({ }^{\circ} \mathrm{C}\right) \\
\Delta_{m} & =\text { displacement at midspan } \\
\alpha & =\text { thermal expansion coefficient } \\
L & =\text { height of the wall } \\
d & =\text { thickness of the wall }
\end{array}
$$




$$
\begin{aligned}
& \mathrm{C}=\text { corrected fire endurance period }(\mathrm{h}) \\
& \mathrm{I}=\text { fire endurance period obtained before correction (h) } \\
& \mathrm{A}=\text { area under the curve }\left({ }^{\circ} \mathrm{C}^{*} \mathrm{~h}\right) \\
& \text { As }=\text { area under the standard curve for the same part of the period, }\left({ }^{\circ} \mathrm{C}^{*} \mathrm{~h}\right) \\
& \mathrm{L}=\text { lag correction (in the same units as } \mathrm{A} \text { and } \mathrm{As}),\left(30^{\circ} \mathrm{C}^{*} \mathrm{~h}\right) \\
& R_{e}=\text { the Reynolds number } \\
& \rho \quad=\text { density } \\
& \rho_{0} \quad=\text { original density }\left(\mathrm{kg} / \mathrm{m}^{3}\right) \\
& u=\text { flow speed } \\
& L=\text { characteristic linear dimension } \\
& \mu \quad=\text { viscocity of the fluid } \\
& N u=\text { the Nusselt number } \\
& \operatorname{Pr}=\text { the Prandtl number } \\
& \theta=\text { temperature }\left({ }^{\circ} \mathrm{C}\right) \\
& C_{p}=\text { specific heat }(\mathrm{J} / \mathrm{kgK}) \\
& C_{p, 0}=\text { original specific heat }(\mathrm{J} / \mathrm{kgK}) \\
& C_{p, u}=\text { moisture content factor }(\mathrm{J} / \mathrm{kgK}) \\
& \lambda=\text { thermal conductivity }(\mathrm{W} / \mathrm{mK}) \\
& \lambda_{0}=\text { original thermal conductivity }(\mathrm{W} / \mathrm{mK})
\end{aligned}
$$




\subsection{Abbreviations}

\begin{tabular}{|c|c|c|}
\hline $\mathrm{AE}$ & $=$ & Air entraining \\
\hline $\mathrm{APP}$ & $=$ & Ammonium polyphosphate \\
\hline ASR & $=$ & Alkali-silicate Reaction \\
\hline BFS & $=$ & Blast Furnace Slag \\
\hline CLC & $=$ & Cement-based Lightweight Composites \\
\hline $\mathrm{EP}$ & $=$ & Expanded Perlite \\
\hline EPS & $=$ & Expanded polystyrene \\
\hline ETM & $=$ & Expanded thermoplastic microspheres \\
\hline FA & $=$ & Fly Ash \\
\hline FAC & $=$ & Fly Ash Cenospheres \\
\hline FBA & $=$ & Furnace Bottom Ash \\
\hline GGBFS & $=$ & Ground granulated blast furnace slag \\
\hline GHB & $=$ & Glazed Hollow Beads \\
\hline GHP & $=$ & Guarded hot plate \\
\hline GLECC & $=$ & Green lightweight engineered cementitious composites \\
\hline $\mathrm{HGB}$ & $=$ & Hollow glass beads \\
\hline HGM & $=$ & Hollow glass microspheres \\
\hline HIPS & $=$ & High Impact Polystyrene \\
\hline HRWRA & $=$ & High range water reducing admixture \\
\hline $\mathrm{HSC}$ & $=$ & High Strength Concrete \\
\hline IOT & $=$ & Iron ore tailings \\
\hline
\end{tabular}




$$
\begin{aligned}
& \text { LFC }=\text { Lightweight Foamed Concrete } \\
& \text { LW }=\text { Lightweight } \\
& \text { LWC }=\text { Lightweight Concrete } \\
& \text { LWF }=\text { Lightweight fillers } \\
& \text { MIP }=\text { Mercury Intrusion porosimetry } \\
& \text { MK }=\text { Metakaolin } \\
& \text { MPCM = Microencapsulated phase change materials } \\
& \mathrm{NA} \quad=\text { Natural Aggregate } \\
& \mathrm{NC}=\text { Normal Concrete } \\
& \text { NCSL }=\text { Nano-crystalline surface layer } \\
& \text { NS } \quad=\text { Normal Strength } \\
& \mathrm{NW}=\text { Normal weight } \\
& \text { NWC }=\text { Normal weight Concrete } \\
& \mathrm{OPC}=\text { Ordinary Portland Cement } \\
& \mathrm{PA}=\text { Pumice aggregate } \\
& \mathrm{PCM}=\text { Phase change materials } \\
& \text { PFA }=\text { Pulverized fly ash } \\
& \mathrm{PP} \quad=\text { Polypropylene } \\
& \mathrm{PPF} \quad=\text { Polypropylene fibers } \\
& \text { PUR = Polyurethane } \\
& \text { PVA }=\text { Polyvinyl alcohol } \\
& \text { RATIC }=\text { Recycled Aggregate Thermal Insulation Concrete } \\
& \mathrm{RCA}=\text { Recycled Concrete Aggregate }
\end{aligned}
$$




$\begin{array}{ll}\mathrm{RG} & =\text { Recycled glass } \\ \mathrm{RP} & =\text { Recycled polystyrene } \\ \mathrm{RPC} & =\text { Self-compacting cement-based lightweight composites } \\ \mathrm{SCLC} & =\text { Supplementary cementitious material } \\ \mathrm{SCM} & =\text { Silica fume } \\ \mathrm{SF} & =\text { Therss transition temperature } \\ \mathrm{Tg} & =\text { Peak crystallization temperature } \\ \mathrm{TIC} & =\text { Transient plane source } \\ \mathrm{Tp} & =\text { Ultrasonic Pulse Velocity } \\ \mathrm{TPS} & =\text { Vibrated cement-based lightweight composite } \\ \mathrm{UPV} & =\text { Water to Cement or Water to Binder } \\ \mathrm{VCLC} & \end{array}$




\section{Chapter 1}

\section{Introduction}

This section will provide background information on the topic of masonry and fire resistance, outline the research objectives, and explain the layout of this thesis.

\subsection{Background}

Masonry is good at passive fire protection as it has excellent fire resistance. It is noncombustible, which means that it does not add fuel to the fire. Furthermore, when exposed to fire, masonry does not produce smoke or any other toxic gases which are harmful to occupants trying to escape a burning building [1]. Unreinforced masonry is usually used in low-rise and medium-rise buildings where there is low or negligible seismic activity [2], or acting as non-loadbearing partition walls. As with most brittle materials, masonry itself has higher compressive strength compared to its tensile strength. Masonry provides good aesthetics, sound insulation, thermal insulation, fire protection, and low life cycle costs. Loadbearing masonry walls are known to maintain their loadbearing capacity to support a building under fire situations. Nonloadbearing walls are able to remain in place and serve as a fire barrier to prevent smoke and heat transfer from the fire side of the wall to the other side. Masonry walls can also be used to protect other structural elements that may not be as resistant to flame and heat [2].

There has been limited testing conducted on full scale masonry walls. A large portion of the research into concrete mix designs is conducted using small concrete cubes which are not always applicable to masonry blocks or masonry walls, and do not account for the effects of the mortar [3] [4] [5]. When research is conducted to investigate the effects of fire on masonry, the tests are normally conducted on small 
scale masonry walls (usually masonry prisms a few blocks high) [6] [7]. These smallscale tests are not as accurate at predicting the temperatures within the hollow cells, as the smaller scale reduces the negative effect of hot gasses travelling up through the cells. They also limit the failure mechanisms as the effects of thermal bowing are minimized in small scale walls. More research into the fire resistance of existing full scale masonry walls was necessary to get a better understanding of how masonry behaves in fire scenarios, and how its fire resistance can be improved.

When full scale fire testing is conducted on masonry materials, it is normally for a standard fire test. The CAN-ULC-S101 standard outlines the exact procedure that needs to be followed to complete these tests. Unfortunately these standard fire tests only give the fire resistance of the wall, and do not include important results such as failure mechanisms or temperature profile.

Research into different concrete mixes is usually conducted to improve the mechanical or ambient thermal properties or to reduce the impact of the concrete on the environment [8] [9]. With each of those new mixes, their effect on the fire resistance is not usually the focus of the research. Knowledge of how the novel mix designs affect the fire resistance would be beneficial for determining their applicability as new masonry materials. Modeling of those novel materials is a cost-effective way of achieving this goal.

\section{$1.2 \quad$ Research Objectives}

This research was devoted to investigate the effects of different concrete masonry materials on the fire resistance of concrete masonry walls. The research objectives are detailed as follows:

1. An experimental programme was needed to investigate the fire resistance of existing full scale masonry materials. This was mainly focused on different existing masonry wall geometries and mix designs, as well as different styles of mortar joints. More novel wall geometries and the use of insulation materials were also researched to improve the fire resistance.

2. A finite element model was developed from the experimental results. The finite element model was used to predict the fire resistance of novel concrete mixes 
to determine their use for improving masonry's fire resistance. The fire resistance of different aggregate types, cement types, pozzolans, addatives, cenospheres, novel materials, and more were expolored.

\subsection{Layout of the Thesis}

-Chapter one is based on the introduction, objectives of the research, and a general description of the thesis by chapters.

-Chapter two presents a general literature review covering the behavior of concrete masonry materials at elevated temperatures.

-Chapter three outlines a general description of the experimental program including an overview of the test setup, as well as a description of individual masonry walls tested.

-Chapter four is focused on studying and analysing the results obtained from the experimental testing, focusing on the factors affecting the insulation failure of the tested walls.

-Chapter five outlines the development of Finite Element Models to simulate the thermal performance of different tested masonry blocks, as well as blocks to be tested in the future.

-Chapter six presents further modeling into novel mix designs and their effects on masonry fire resistance.

-Chapter seven presents the main conclusions of the research. The limitations of this research are discussed and suggestions for future studies based on the findings reported in this thesis are proposed. 


\section{Chapter 2}

\section{Literature Review}

\subsection{Masonry Construction}

Masonry walls are walls made up of blocks and mortar. The blocks are usually made of concrete, clay, or stone, with each different block type having its own advantages and limitations. To connect the different blocks together a mixture of cement paste and fine aggregates called mortar is used. There are several types of concrete blocks, with numerous options for matching mortars. Each of the different options has their own benefits and restrictions and are chosen to best meet the construction requirements.

Concrete masonry blocks can come in varied sizes, but the common dimensions in Canada are $190 \mathrm{~mm}$ high by $390 \mathrm{~mm}$ wide. The dimension that is varied is the thickness of the block. The blocks can also be hollow, semi-solid or solid. An example of a $190 \mathrm{~mm}$ thick hollow block can be seen in Figure 2.1. Each part of the hollow block has its own name. The solid part of the block on either end is called the faceshell, and this is where most of the strength of the masonry comes from. The three solid parts that connect the two faceshells are called webs. In Canada, the webs have no mortar on them, and so they cannot carry any of the load on their own [2]. This is because the masonry units in Canada are not designed in a way that the webs line up perfectly from one course to another. Finally, the hollow parts of the block are called cells. Reinforcing steel can be placed in the cells to improve the strength of the masonry. For the reinforcing steel to be used the cells need to be filled with a flowing cementitious material called grout.

When the blocks are connected in a wall, each row of blocks (referred to as a course) are usually overlapped in a running bond as seen in Figure 2.2 [2]. The most 


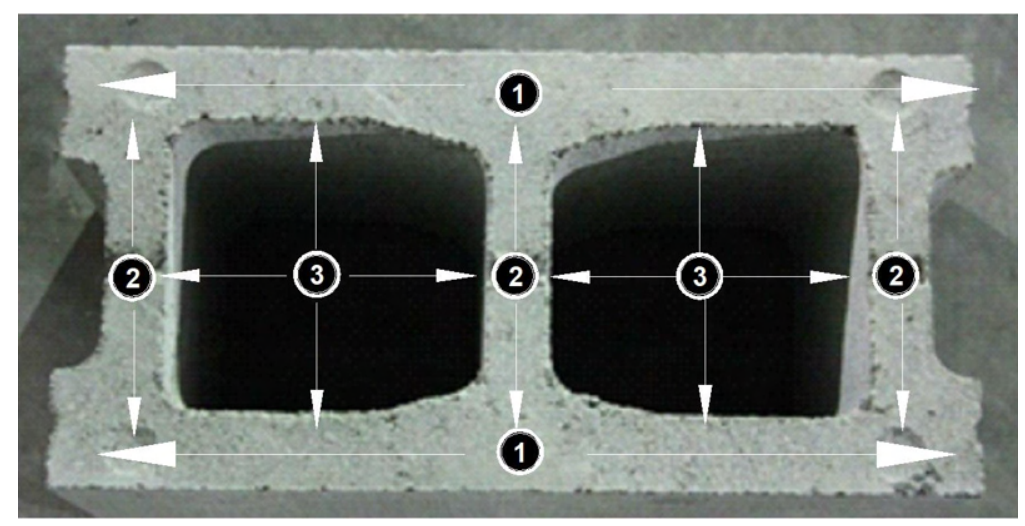

Figure 2.1: Hollow $20 \mathrm{~cm}$ concrete block. (1) Faceshell (2) Web (3) Cell

common overlap is a half bond, but others can be used as well. The overlapping helps to increase the structural integrity as well as its flexural strength [2]. The horizontal mortar joints are called bed joints, and the vertical mortar joints are called head joints. Because the masonry wall is not homogeneous, it has different properties depending on the direction on the load. If the wall is loaded parallel to the bed joint it will be weaker than if it is loaded perpendicular to the bed joint. This is because for the wall to fail perpendicular to the bed joint, the mortar joint must fail either around the blocks, or through the blocks. When the wall fails parallel to the bed joint it can fail straight along the bed joint. This is demonstrated in Figure 2.2.
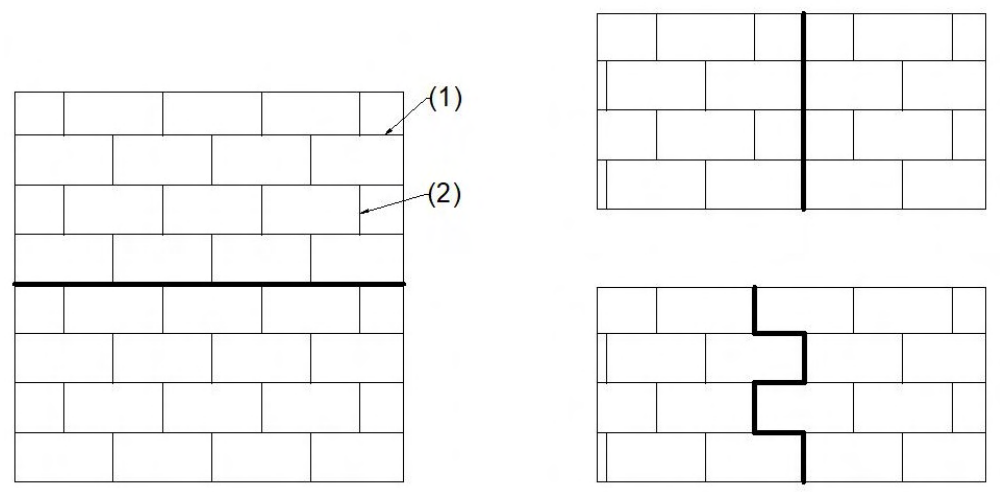

Figure 2.2: a)Failure Parallel to bed joint b) Failure Perpendicular to Bed Joint. Where (1) Is a Bed Joint and (2) is a Head Joint

The thickness of the mortar is usually $10 \mathrm{~mm}$, but its exact dimensions can depend on the specific design and the experience of the mason [2]. There are several different 
methods for finishing up the joints which are outlined in Figure 2.3. The most common joint type is the concave joint, as it has good structural performance due to the bond between block and mortar, and it has good durability because the shape does not allow water to remain in the mortar and cause degradation. [2]. The other mortar finishes are usually used for aesthetic purposes, to save the masons' time, or are the result of durability related degradation [2].

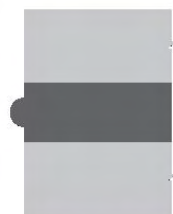

Beaded Concave

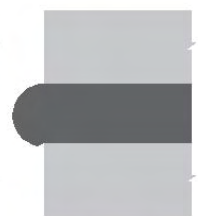

Extruded

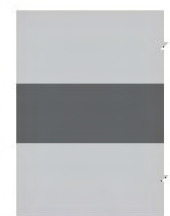

Flush

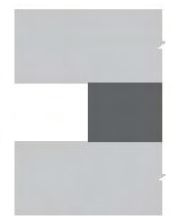

Raked

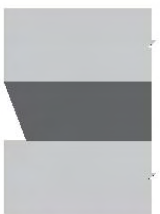

Struck

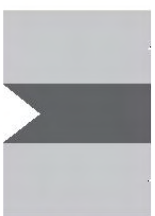

Vee

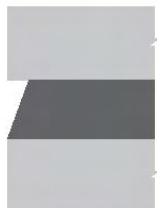

Weathered

Figure 2.3: Different Mortar Joints

There are three different mixes for the blocks, the mortar, and the grout. Each part can have a different strength, free water content, special additives, etc. The concrete blocks are premade and cured for at least a month before being used [2]. The blocks are the most uniform part of the masonry wall, as the mix cannot be changed after they are manufactured. The mortar is made on the date of construction and depending on the mason's preference for workability, as well as the amount of time it is left out to dry while the structure is constructed, the mortar may not be as uniform. A workable mortar needs to be able to hold the blocks together during construction so it is required to be strong enough to support the weight of the blocks. A mason also needs a workable mortar to stick to the trowel and allow for efficient placement on the blocks. When block and mortar are joined, the mortar loses some of its moisture as the block absorbs it, this creates a bond that helps to increase the strength of the wall [2]. When grout is used, it needs to flow enough to get into all the small cells in the blocks, and so there is a limit on the aggregate size and minimum water content [2]. There are still problems with grout reaching every part of the block, and so strength reduction factors are used in design of masonry walls [2].

The mortar that holds masonry blocks together is usually made with sand and cement, and it is an important part of the structure [10]. Mortar takes up between $5-7 \%$ of the surface area of masonry walls [6]. The smaller the brick size the higher the percentage of mortar. However, mortar has a higher thermal conductivity and as such 
it is not as good for thermal insulation at low temperatures [11]. After fire exposure, it was determined that concrete strength is reduced, while the mortar strength is increased slightly due to evaporation of free water. The mortar getting stronger helps to compensate for the reduction in block strength [11].

The connections between the walls and roof, floor and other walls are important for reaching the correct performance of the wall. The connection of the wall to the floor and roof system is designed in a way that the roof failure does not lead to the collapse of the wall. If the wall is meant to be a loadbearing wall, the wall and the roof act as diaphragms and will distribute lateral loads to the walls [2]. If the wall is non-loadbearing, then the connections must be made in a way that the load transfer is minimized [2].

\subsection{Thermal Properties of Masonry}

The thermal properties of masonry affect the heat flow through the concrete, as well as the integrity and stability of the member. Notable properties include specific heat capacity, thermal expansion, free water content, and thermal conductivity.

\subsubsection{Specific Heat Capacity}

Specific heat is the amount of energy that is required to raise the temperature of a certain mass by one degree Kelvin $(\mathrm{J} / \mathrm{kgK})$. Materials with low specific heat values require little energy to raise their temperature, whereas materials with high specific heat require more energy and will heat up slowly. In terms of thermal insulation, having a high specific heat is preferred. Both the concrete itself and the water in its voids have a large specific heat. Water's specific heat is $4,185.5 \mathrm{~J} / \mathrm{kgK}$ and concrete's specific heat is around $800-1,000 \mathrm{~J} / \mathrm{kgK}$, which means that it takes more energy to heat up water than concrete for a given mass and temperature difference [12]. The concrete aggregates can have a substantial impact on the specific heat of the concrete masonry. As the temperature increases, the specific heat of normal weight aggregates (siliceous and calcareous) will also increase; whereas the specific heat of the lightweight aggregate remains constant. This means that normal weight concrete requires more energy to heat at higher temperatures.

Water is incorporated into cementitious materials in several different forms. There is chemically bound water that is used to hydrate the cement. There is free water 
that is either trapped in the voids during mixing or that enters the voids later due to weather or humidity. The free water within concrete materials increases the specific heat of the concrete as the water requires more energy to vaporise (dotted spike in Figure 2.4). Since mortar usually has more free water than concrete, it takes more energy to increase the mortar temperature above $100{ }^{\circ} \mathrm{C}$ than it does for the concrete block.

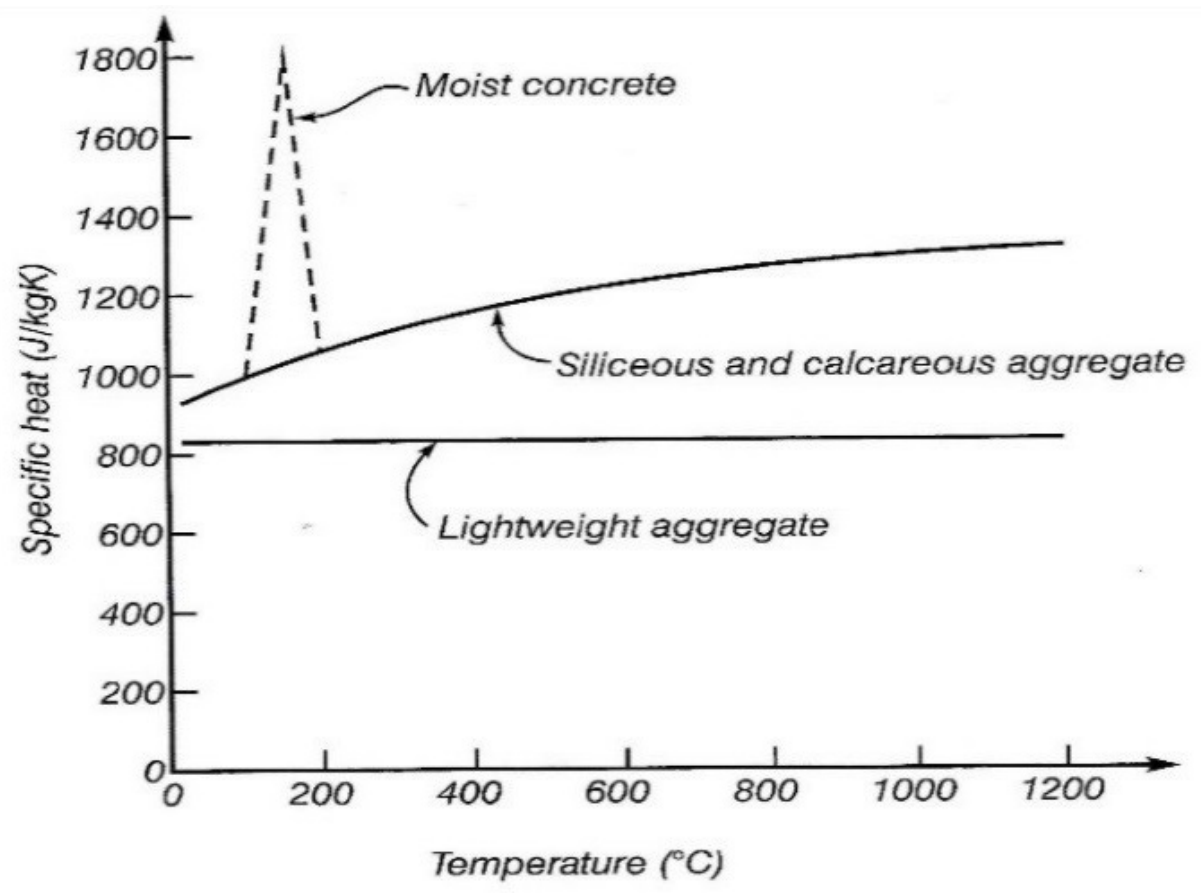

Figure 2.4: The Specific heat of concrete

\subsubsection{Thermal Expansion}

Thermal expansion is the change in material size and/or shape with respect to temperature (units $1 / \mathrm{K})$. A material with a high coefficient of thermal expansion is one that increases its size significantly with an increase in temperature, a material with a low coefficient is one that increases in size minimally with an increase in temperature. A material with a negative thermal expansion is one that decreases in size with an increase in temperature. The coefficient of thermal expansion changes based on the material, as well as with different temperature ranges.

Thermal expansion for most aggregates increases linearly with temperature [13]. 
After $570{ }^{\circ} \mathrm{C}$ the thermal expansion suddenly increases due to the transformation of quarts (which swells) [13]. Siliceous aggregates like flint have higher thermal expansion than other aggregates (around twice as much), which causes cracking to occur around the aggregates due to the mismatch in thermal expansions of the aggregate and the cement [13]. After cooling residual thermal strains are much higher for siliceous aggregates compared to other normal weight aggregates.

The main problems with thermal expansion are the induced thermal stresses, as well as unequal thermal expansion. Because masonry expands when heated, it exerts a force on the frame surrounding it. If the frame is ridged enough to withstand this force, the wall is put into compression [14]. Concrete is strong in compression, so if the forces are even, there is usually no concern. However, masonry is made up of different materials that all have different values of thermal expansion. The mortar does not expand as much as the blocks it holds together. This, coupled with shrinkage from loss of water, can cause cracks to form at the mortar to block interface. These cracks reduce the bonding between blocks and can greatly reduce the strength of the wall, allowing heat, smoke, and flames to pass through. This can be mitigated by choosing a block that will expand enough to fill the gaps resulting from shrinking mortar, but not so much that it begins to increase the stresses on the wall and the surrounding frame. Another problem involves the aggregates inside of the concrete. If the aggregates expand at a rate different from that of cement, micro cracks can form and reduce the strength of the concrete. Choosing an aggregate with a similar thermal expansion to the cement paste (like calcarious aggregates) is one way to reduce micro cracking.

\subsubsection{Free Water Content}

Water exists in masonry in two forms, free water in the voids, and chemically bound water. These can have a large effect on the temperature profile of the wall, as energy is required to vaporise the water. Each part of the wall has a different amount of free water in it, and so the temperature on the unexposed side of the wall varies at different points on the masonry unit. Once the mortar reaches $100{ }^{\circ} \mathrm{C}$ the temperature rise slows drastically due to an endothermic peak. Whenever a part of the wall reaches $100{ }^{\circ} \mathrm{C}$, that part of the wall stops increasing in tepmerature, which is caused by the free water in the block and mortar being heated and driven out in a steam form, Figure 2.5. This free water is beneficial since they increase the specific heat of the 
unit while the water is evaporating [15]. The more free water available to evaporate, the longer the member takes to heat up.

The evaporatoin of free water in the mortar increases its strength, but it also shrinks the mortar. This could cause problems with the mortar to block bonding. The vaporised water also helps reduce the radiation in the cavities because the water migrates to the cavity space and creates an opaque barrier which reduces the radiation [15]. Since the mortar has more free water, the mortar goes from being the hottest part of the wall to the coolest part. Once a point on the wall runs out of free water the temperature starts to increase again, indicating that the free water content of the materials is one of the key factors for fire resistance as it affects the fire rating of the assembly. It also has a large impact on spalling, which will be discussed in a later section.

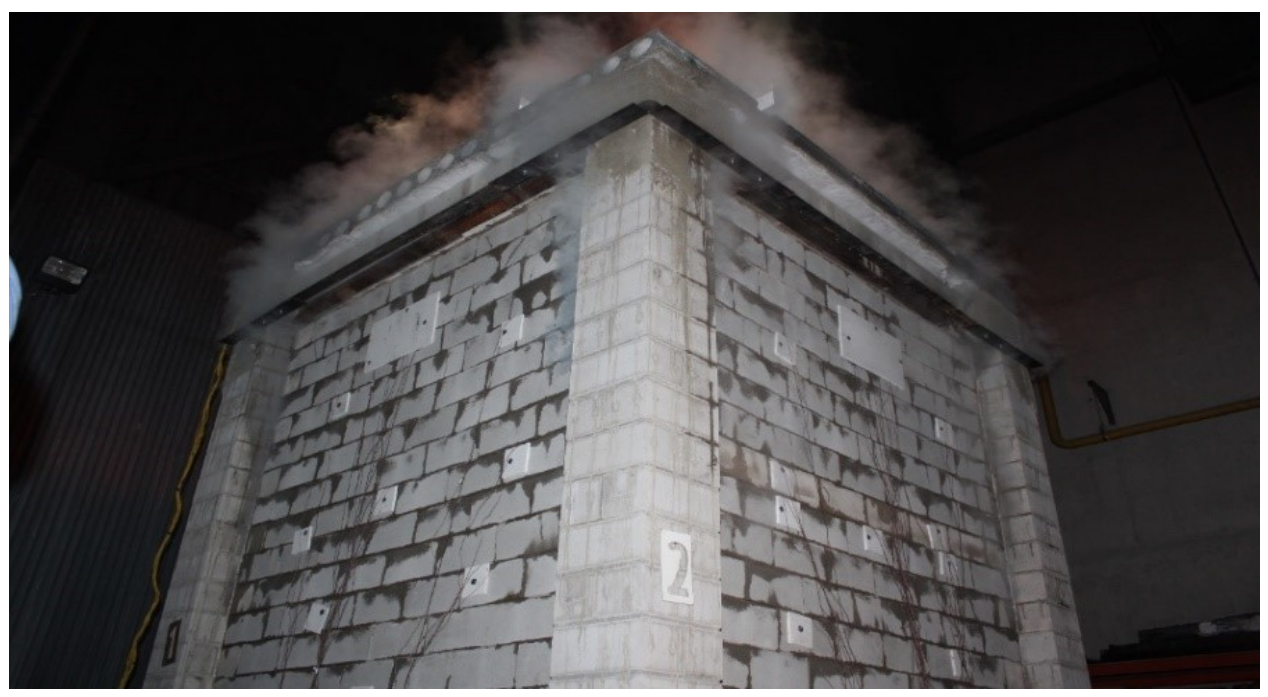

Figure 2.5: The Specific heat of concrete

\subsubsection{Thermal Conductivity}

Thermal conductivity is a material property that determines how well a material conducts heat $(\mathrm{W} / \mathrm{mK})$. To reduce the heat flow by conduction, a material with a lower thermal conductivity should be chosen. The thermal conductivity of concrete is normally within the range of $0.05-1.75 \mathrm{~W} / \mathrm{mK}$, which means that concrete is good at insulating [12]. The thermal conductivity of concrete is temperature dependent, and its value depends on the type of aggregate, the porosity of the material, and the 
free water content. The aggregates with lower density generally have a lower thermal conductivity, so lightweight aggregates have lower thermal conductivity than normal weight aggregates. The pores in lightweight aggregates are also very small, and so the effects of convection/conduction are minimized. Similar to porous aggregates, porous concretes have lower thermal conductivities as well. Table 2.1 and 2.2 demonstrate the effect of different aggregates on the thermal conductivity. The tables show an increase in thermal conductivity with an increase in density, and a decrease in thermal conductivity for lightweight aggregates.

Table 2.1: Thermal Conductivities without moisture [16]

\begin{tabular}{|l|r|r|r|r|r|r|r|r|r|r|}
\hline \multirow{2}{*}{\multicolumn{1}{c|}{ Material Type }} & \multicolumn{9}{|c|}{ Density (Kg/m3) } \\
\cline { 2 - 10 } & $\mathbf{4 8 1}$ & $\mathbf{6 4 1}$ & $\mathbf{8 0 1}$ & $\mathbf{9 6 1}$ & $\mathbf{1 1 2 1}$ & $\mathbf{1 2 8 1}$ & $\mathbf{1 4 4 2}$ & $\mathbf{1 6 0 2}$ & $\mathbf{1 7 6 2}$ & $\mathbf{1 9 2 2}$ \\
\hline Natural pumice & 0.11 & $\mathbf{0 . 1 5}$ & 0.20 & $\mathbf{0 . 2 5}$ & 0.32 & 0.39 & 0.48 & 0.58 & & \\
\hline Sintered fly ash and coal cinders & & & & 0.25 & 0.30 & 0.37 & 0.44 & 0.53 & 0.62 & \\
\hline Volcanic slag and scoria & & & & 0.25 & 0.30 & 0.36 & 0.43 & 0.51 & & \\
\hline Expanded slag & & & & 0.22 & 0.27 & 0.32 & 0.38 & 0.45 & 0.52 & 0.60 \\
\hline Expaned and sintered clay, shale, and slate & 0.13 & 0.17 & 0.22 & 0.27 & 0.34 & 0.41 & 0.49 & 0.58 & 0.69 & \\
\hline Sanded expaned clay, shale, and slate & & & 0.25 & 0.32 & 0.41 & 0.51 & 0.62 & 0.76 & 0.92 & 1.10 \\
\hline No-fines pumice, expaneded & & & & & & & & & & \\
and sintered clay, shale, and slate & 0.14 & 0.18 & 0.23 & 0.29 & 0.35 & 0.42 & 0.49 & & & \\
\hline Limestone & & & & & 0.37 & 0.46 & 0.57 & 0.69 & 0.83 & 0.99 \\
\hline Cement-sand mortar and foam concrete & & & & 0.34 & 0.43 & 0.54 & 0.66 & 0.81 & 0.97 & 1.16 \\
\hline
\end{tabular}

Table 2.2: Thermal Conductivities with moisture [16]

\begin{tabular}{|c|c|c|c|c|c|c|c|c|c|c|}
\hline \multirow[b]{2}{*}{ Material Type } & \multicolumn{10}{|c|}{ Density (Kg/m3) } \\
\hline & 481 & 641 & 801 & 961 & 1121 & 1281 & 1442 & 1602 & 1762 & 1922 \\
\hline Natural pumice & 0.14 & 0.19 & 0.25 & 0.32 & 0.41 & 0.51 & 0.62 & 0.76 & & \\
\hline Sintered fly ash and coal cinders & & & & 0.32 & 0.40 & 0.48 & 0.57 & 0.68 & 0.80 & \\
\hline Volcanic slag and scoria & & & & 0.32 & 0.39 & 0.47 & 0.56 & 0.67 & & \\
\hline Expanded slag & & & & 0.28 & 0.35 & 0.41 & 0.49 & 0.58 & 0.68 & 0.79 \\
\hline Expaned and sintered clay, shale, and slate & 0.15 & 0.20 & 0.26 & 0.33 & 0.41 & 0.50 & 0.60 & 0.71 & 0.84 & \\
\hline Sanded expaned clay, shale, and slate & & & 0.31 & 0.40 & 0.51 & 0.63 & 0.78 & 0.95 & 1.15 & 1.37 \\
\hline No-fines pumice, expaneded & \multirow{2}{*}{0.17} & \multirow{2}{*}{0.22} & \multirow{2}{*}{0.28} & \multirow{2}{*}{0.35} & \multirow{2}{*}{0.42} & \multirow{2}{*}{0.51} & \multirow{2}{*}{0.60} & & & \\
\hline and sintered clay, shale, and slate & & & & & & & & & & \\
\hline Limestone & & & & & 0.45 & 0.56 & 0.69 & 0.84 & 1.01 & 1.21 \\
\hline Cement-sand mortar and foam concrete & & & & 0.41 & 0.52 & 0.66 & 0.81 & 0.98 & 1.18 & 1.42 \\
\hline
\end{tabular}


Higher free water contents mean that voids are filled with more water instead of air. Water has a higher thermal conductivity than air $(0.58 \mathrm{~W} / \mathrm{mK}$ for water and $0.024 \mathrm{~W} / \mathrm{mK}$ for air), and as such concrete mixes with higher free water content will have a higher thermal conductivity until the free water has been evaporated [12]. In general the thermal conductivity of the block is lower than that of the mortar, based on mortar's different mix designs and the higher free water content of the mortar. The most optimal mix to reduce the thermal conductivity would be lightweight aggregates with porous concrete with a low free water content.

The thermal conductivity of concrete changes with respect to temperature. As the temperature increases the thermal conductivity decreases, which means that it improves with temperature. This is due to the loss of free water, chemical changes in the cement paste, and the breakdown of the aggregates. For this reason the total improvement depends mainly on the aggregate type. After $800{ }^{\circ} \mathrm{C}$ the thermal conductivity stops decreasing and remains constant, as can be seen in Figure 2.6 [17].

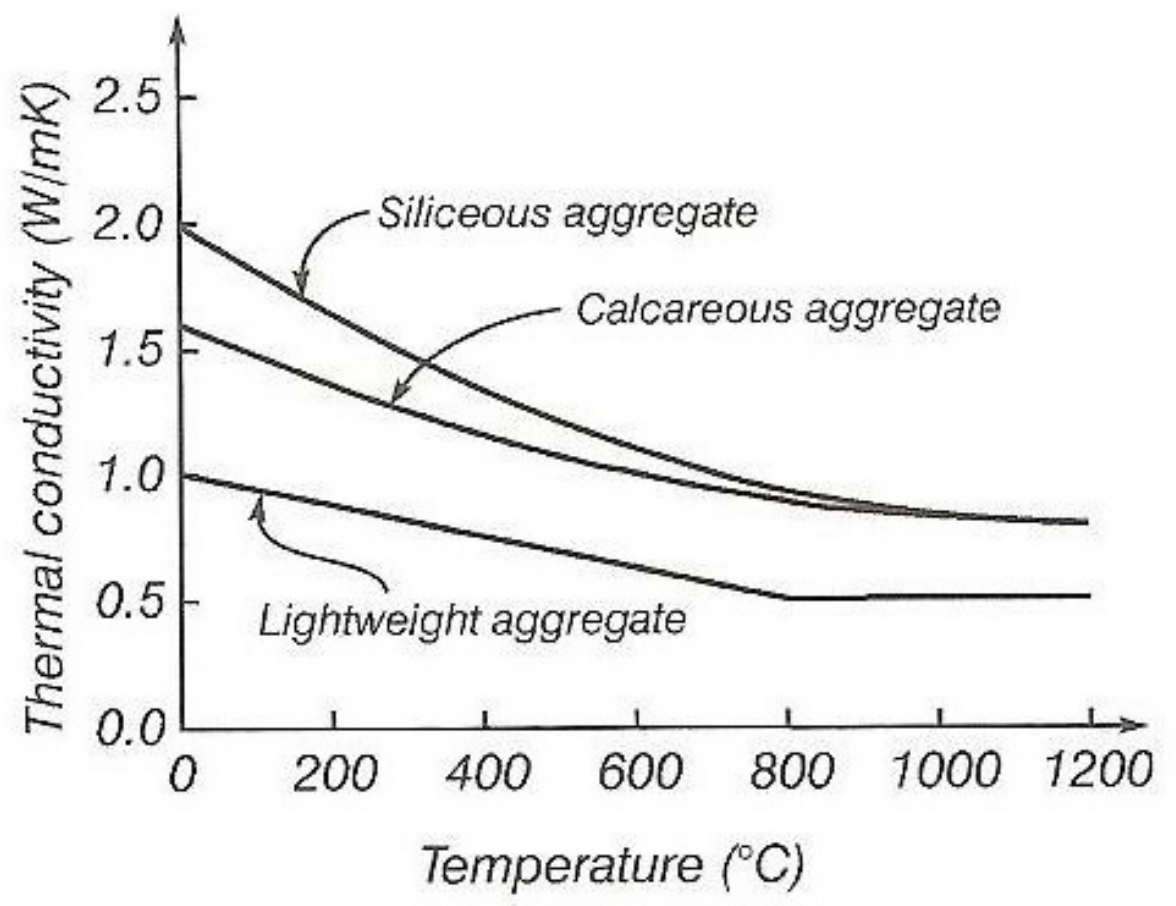

Figure 2.6: Thermal conductivity of concrete with respect to temperature [17] 


\subsection{Concrete Strength at Different Temperatures}

Up to $400{ }^{\circ} \mathrm{C}$ any changes to the compressive strength in concrete are usually assumed to be negligible [18] [19]. Below $400{ }^{\circ} \mathrm{C}$ drying occurs which "relieves pressure and creates greater Van der Waals forces" which results in "a closer configuration of capillary pores and a strength gain" [20] [19]. Another reason for the strength gain up to $300{ }^{\circ} \mathrm{C}$ is due to the improved hydration of the unhydrated cement grains "due to an internal autoclaving condition" which is caused by the elevated temperature and the evaporation of free water [21]. This strength gain is more prevalent in high strength concrete due to the low permeability which resists the flow of water. So the Van der Waals forces and the autocalving action are two reasons for why the compressive strength of concrete remains constant or increases when it is heated. This strength gain is then lost again as the temperature continues to increase. After $400{ }^{\circ} \mathrm{C}$ the strength decreases because of the loss of chemically bound water. This loss results in a reduction of Calcium-silicate-hydrate $(\mathrm{C}-\mathrm{H}-\mathrm{S})$ content and the formation of microcracks [18]. A detailed outline of changes in the Ordainary Portland Cement (OPC) paste strength with temperature can be found in Table 2.3.

Several methods have been used to determine concrete's loss of quality as temperature increases. One method is the ultrasonic pulse velocity test (UPV) which is used to determine how intact a concrete specimen is. Higher velocities indicate good continuity of the material, whereas lower velocities indicate that the concrete has many cracks and voids [18]. It can be seen in Figure 2.7 that as the temperature increases, the quality of the concrete decreases, and the concrete has a significant amount of cracks and voids above $700{ }^{\circ} \mathrm{C}$. 
Table 2.3: Changes in OPC Paste with Temperature [21]

\begin{tabular}{|l|l|}
\hline Temperature & Changes in OPC paste \\
\hline $70-90{ }^{\circ} \mathrm{C}$ & Ettringite dehydrates and decomposes \\
\hline $70-90{ }^{\circ} \mathrm{C}$ & The OPC paste expands up to $93^{\circ} \mathrm{C}$ and contracts up to $491{ }^{\circ} \mathrm{C}$ \\
\hline $100-110{ }^{\circ} \mathrm{C}$ & Removal of evaporable water, increased porosity and micro-cracking \\
\hline $120{ }^{\circ} \mathrm{C}$ & $\begin{array}{l}\text { Evaporable water in the cement paste and CSH gel is completely } \\
\text { removed from concrete }\end{array}$ \\
\hline $110-170{ }^{\circ} \mathrm{C}$ & Gypsum decomposes \\
\hline $100-300{ }^{\circ} \mathrm{C}$ & $\begin{array}{l}\text { Removal of non-evaporable water } \\
\text { Internal autoclaving hydrates non-hydrated cement particles. }\end{array}$ \\
\hline $200-700{ }^{\circ} \mathrm{C}$ & $\mathrm{CSH}$ gel is not affected up to $300{ }^{\circ} \mathrm{C}$ \\
\hline $350-550{ }^{\circ} \mathrm{C}$ & $\mathrm{CH}$ decomposes into lime and water \\
\hline $\begin{array}{l}\text { Cooling to } \\
20{ }^{\circ} \mathrm{C}\end{array}$ & $\begin{array}{l}\text { Volume expansion and deterioration of concrete due to micro and } \\
\text { macro cracks }\end{array}$ \\
\hline
\end{tabular}

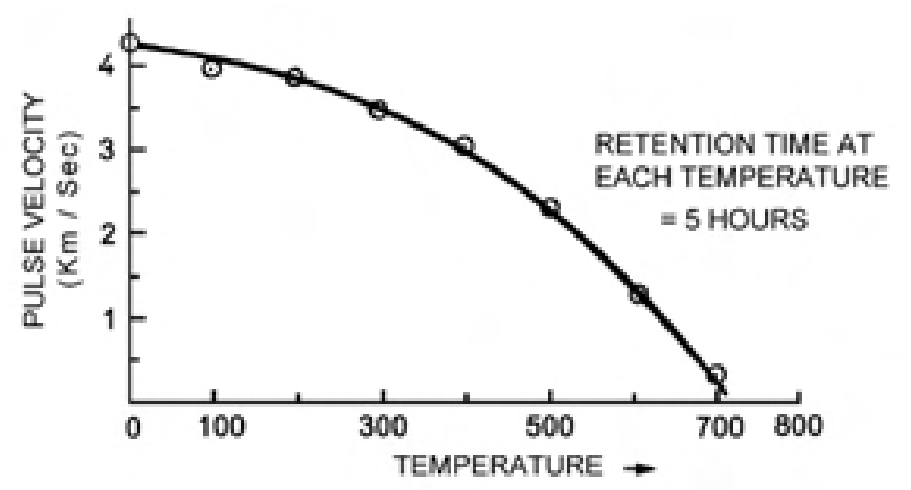

Figure 2.7: Ultrasonic pulse velocity decrease with temperature [18]

Another method for determining the quality of concrete is the use of x-ray diffraction to determine the change in chemical composition. Figure 2.8a shows the composition of concrete exposed to various temperatures for 8 hours [22]. It can be seen that most elements remained constant up to $400{ }^{\circ} \mathrm{C}$, and the C-S-H and portlandite even increase due to the further hydration of the cement [22]. At $500{ }^{\circ} \mathrm{C}$ portlandite and 


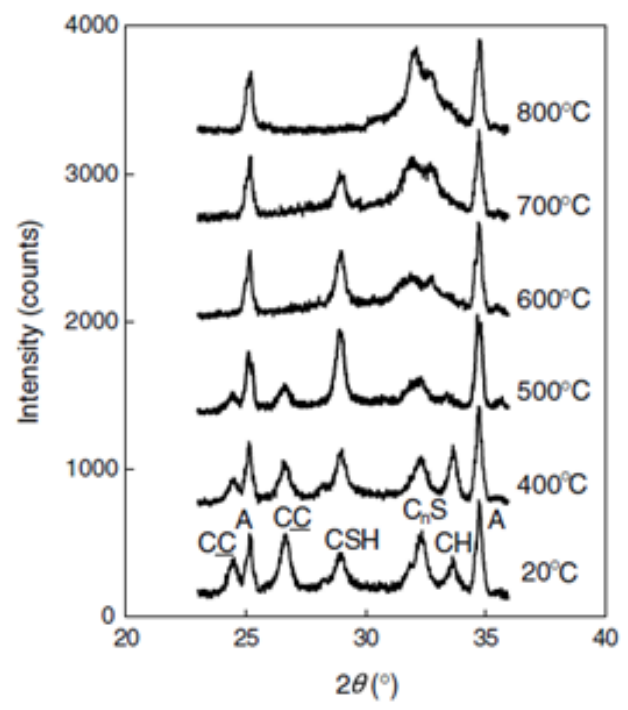

(a)

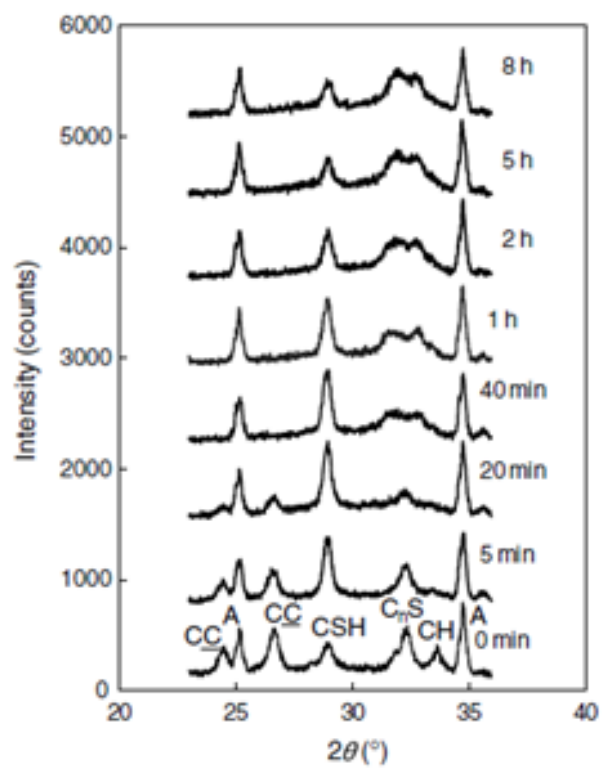

(b)

Figure 2.8: (a) Composition of concrete after 8 hours exposure and (b) Effect of heating duration on concrete composition

$\mathrm{CaCO} 3$ begin to decompose, and after $600{ }^{\circ} \mathrm{C}$ C-S-H also begins to decompose [22].

When experiments were conducted to test the effect of duration at each maximum temperature, it was found that it took 20 minutes for portlandite to decompose at $500{ }^{\circ} \mathrm{C}[22]$. Further tests found that the decomposition of portlandite, CaCO3, and C-S-H occur at temperatures of $430{ }^{\circ} \mathrm{C}, 530{ }^{\circ} \mathrm{C}$, and $560{ }^{\circ} \mathrm{C}$ respectively [22]. Equations for the amount of C-S-H lost at elevated temperatures can be found in Equation 2.1 [23]. Since C-S-H is related to the strength of concrete, it can be useful for qualitative determination of strength loss [22]. Since C-S-H loss does not start until $560{ }^{\circ} \mathrm{C}$, the main reason for strength loss at lower temperatures is caused by micro cracks and loss of C-H-S [22]. 
For $600^{\circ} \mathrm{C}$,

$$
\begin{aligned}
& \Delta y / y_{0}=-1.0 X 10^{-6} t^{3}+0.0013 t^{2}-0.36 t+97.72, \\
& r=0.990
\end{aligned}
$$

For $700^{\circ} \mathrm{C}$,

$$
\begin{aligned}
& \Delta y / y_{0}=-2.0 X 10^{-6} t^{3}+0.002 t^{2}-0.67 t+100.61, \\
& r=0.999
\end{aligned}
$$

For $800^{\circ} \mathrm{C}$,

$$
\begin{aligned}
& \Delta y / y_{0}=-2.0 X 10^{-8} t^{5}+8.0 X 10^{-6} t^{4}-0.0015 t^{3}+0.13 t^{2}-5.47 t+99.82, \\
& r=0.998
\end{aligned}
$$

Where $t=$ the time in minutes, $r=$ the correlation, and $\Delta \mathrm{y} / \mathrm{y}_{0}=$ the amount of C-S-H decomposition relative to its original amount.

It is also important to note that for each maximum temperature there were changes in the chemical composition of the concrete for up to a two hour exposure, but the chemical composition did not significantly change between the two hour exposure and the eight hour exposure, Figure 2.8b [22] [19]. This means that eight hour exposures are somewhat excessive, and that tests that expose concrete to a certain temperature for under two hours may not be as reliably compared to one another.

At ambient conditions there are portlandite, C-S-H and calcium aluminate [18]. Up to $200{ }^{\circ} \mathrm{C}$ there is no significant change in morphology and at $300{ }^{\circ} \mathrm{C}$ the components begin to deform and some of the portlandite transforms into $\mathrm{CaCO} 3$ [18]. At $500{ }^{\circ} \mathrm{C}$ micro cracks form due to the distortion of the components [18]. From 600$800{ }^{\circ} \mathrm{C}$ there are significant microcracks and voids formed due to the deformation of crystals, and the C-S-H phase boundaries are disrupted [18]. The microcracks and deformations reduce the strength of the concrete [18]. While the portlandite is not the major factor affecting the strength of the concrete, the amount of portlandite left in the concrete can help to determine what temperature the concrete reached, the amount of microcracking that occurred, and how deformed the other components in 
the concrete are [18].

Residual compressive strength is highly variable due to differences in concrete mixes and fire resting procedures (Figure 2.9). Even with the variability, there are certain factors that are known to improve the residual compressive strength. A lower water to cement $(\mathrm{w} / \mathrm{c})$ ratio will have an improved residual compressive strength and modulus of elasticity, however lower w/c ratios have a higher chance of spalling [21] [19].

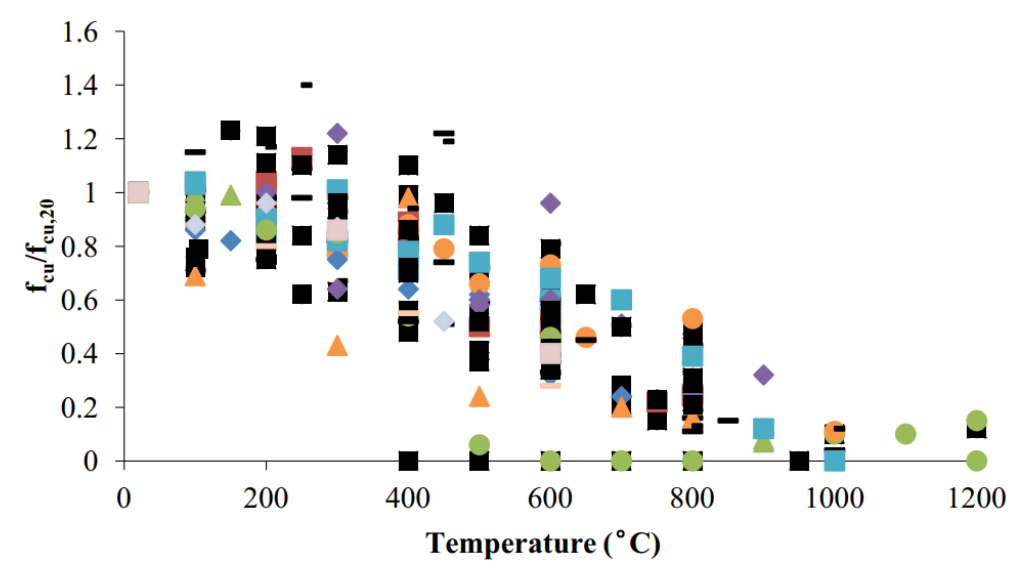

Figure 2.9: Residual compressive strength of different concrete tests at various temperatures [21]

It is also important to know if the residual strength is being measured during the heating or after the concrete has cooled. When the concrete is heated below $400{ }^{\circ} \mathrm{C}$, the compressive strength of hot concrete is lower than the cooled concrete [21] [19]. This is due to the high vapor pressure in the hot concrete being increased due to the compressive forces which damages the concrete more. However, when concrete is heated above $400{ }^{\circ} \mathrm{C}$ the hot concrete is higher than the cooled concrete [21]. This is because the cracking of the concrete becomes the dominant reason for strength loss and during cooling the aggregates shrink, which causes more cracks to form around the transition zone between aggregate and cement [21]. There are also problems with rehydration after the concrete cools, which can lead to further cracking.

Concrete specimens can also be stressed or unstressed during loading. It was found that applying up to $40 \%$ of the design compressive load to the concrete specimens improved the strength and modulus of elasticity of the concrete [21]. This is because the pre-loading is able to restrain part of the thermal expansion, which limits the 
thermal cracking. The load also makes the pore structure more dense which increases the strength, but may also increase the chance of spalling [21].

Concrete loses weight as it is heated due to the release of water. When bound water is released from the cement paste, more air voids are formed in the concrete. This deteriorates the structural integrity of the concrete. The weight loss based on temperature was $4 \%$ at $400{ }^{\circ} \mathrm{C}, 6 \%$ at $600{ }^{\circ} \mathrm{C}$, and $8 \%$ at $800{ }^{\circ} \mathrm{C}$ [24]. A way to reduce the mass loss and keep the integrity is to add pozzolans. Pozzolans are materials that are either siliceous or siliceous and aluminous materials which can react chemically with water and either calcium hydroxide or portlandite to form compounds (such as C-S-H gel) possessing cementitious properties [24]. These compounds can add to the compressive strength of the material. This reaction process is known as the pozzolanic action. For this reason, adding aggregates and mixtures which have silica contents (such as fly ash) will provide a good pozzolanic action and improve the strength of the concrete. It was found that the mixtures with pozzolans had higher compressive strengths at $400{ }^{\circ} \mathrm{C}$ because of this pozzolanic action changed the $\mathrm{Ca}(\mathrm{OH}) 2$ into the C-S-H gel filled the pores [24].

\subsubsection{Effect of Aggregates on Concrete Strength}

Concrete aggregates can have a large impact on the fire resistance of concrete. Lightweight concrete (LWC) aggregates are known to behave better than normal weight aggregates at elevated temperatures. There are also several other aggregates that can be used in concrete mixes, each with their own advantages and disadvantages. Table 2.4 outlines the changes in normal weight aggregates with the increase in temperature.

Table 2.4: Changes in natural aggregates with temperature (modified from [21])

\begin{tabular}{|l|l|}
\hline Temperature & Changes in natural aggregates \\
\hline$<100{ }^{\circ} \mathrm{C}$ & Free water evaporates in aggregates \\
\hline $300-500{ }^{\circ} \mathrm{C}$ & Common aggregates remain stable \\
\hline $570{ }^{\circ} \mathrm{C}$ & Quartz expands by approximately $5.7 \%$ in volume \\
\hline $600-800{ }^{\circ} \mathrm{C}$ & Carbonate aggregate undergo a de-carbonation reaction \\
\hline $800-1200{ }^{\circ} \mathrm{C}$ & Carbonate aggregate complete disintegration \\
\hline
\end{tabular}


Benefits of LWC are that it provides reduced dead load, higher thermal insulating, and enhances the fire resistance of the element. The thermal conductivity of concrete is based on its density. The lower the density the better the resistance. LWC can be made with different aggregates such as natural, processed, and unprocessed materials. LWC for insulation usually has a density less than $1450 \mathrm{~kg} / \mathrm{m}^{3}$ and strength as low as $0.5 \mathrm{MPa}$ [6]. LWC aggregate contains numerous voids inside which lower its thermal conductivity and make it lighter and better at insulating. The trade-off is that it is not as strong as regular concrete (so it is well suited for partition walls). LWC has a higher thermal resistance than normal concrete. The increase in thermal resistance between lightweight and regular concrete can be as high as 99.5\% [25].

Calcareous aggregates generally have better fire resistance than siliceous aggregates. Calcareous rocks contain a high proportion of calcium carbonate (CaCO3). Some common calcareous rocks include limestone, dolomite, and chalk. Siliceous rocks contain silica $(\mathrm{SiO} 2)$. The reason calcareous aggregate has a better fire resistance is due in part to an endothermic calcination process that occurs at elevated temperatures which absorbs heat [26]. The lower density of the calcined material means that the material is better able to insulate [26]. At around $700{ }^{\circ} \mathrm{C}$ the calcium carbonate begins to decompose into lime $(\mathrm{CaO})$ and carbon dioxide $\left(\mathrm{CO}_{2}\right)$, which reduces the strength of the aggregate. Siliceous aggregates have inferior fire resistance because the quartz in the siliceous aggregate undergoes physical changes at elevated temperatures which causes the aggregate and the concrete itself to weaken 2.4 [26]. Lightweight aggregates such as pumice and expanded clay are formed at high temperatures, and so have lower thermal conductivity and improved fire resistance. Lightweight aggregates are able to maintain fire properties superior to most normal weight aggregates at all temperatures, and lightweight aggregates are also able to retain mechanical properties at temperatures where normal aggregates have lost all strength.

Netinger et al [26] have studied the effect of using different aggregate materials on fire resistance. Specifically, clay brick and tile waste, slag, diabase, and dolomite were compared to siliceous natural river aggregate. Samples of concrete with each type of aggregate were heated up to various temperatures between ambient and 1000 ${ }^{\circ} \mathrm{C}$. All mixes had the same cement content and the same water/cement ratio of 0.50. At ambient conditions it was found that the concrete with river aggregate had higher compressive and flexural strengths than the other mixes. The concretes with diabase 
and dolomite aggregates had only slightly lower values of flexural and compressive strengths at ambient conditions. The reason diabase was chosen was because it is commonly used in concrete and it has good fire resistance since it is an eruptive rock. Dolomite was chosen to show that calcareous aggregates have superior fire resistance to siliceous river gravel. The steel slag and crushed brick/tile both had lower mechanical properties. Slag was chosen was because it is formed at very high temperatures (possibly up to $1650^{\circ} \mathrm{C}$ ) which means that it is thermally stable. Similar to the diabase, the steel slag lends improved thermal stability to the concrete [27]. Two different steel slags were used, with one having lower mechanical properties than the other. The reason for this reduction in mechanical properties is due to the steel slag being of low quality. The replacement of coarse aggregate with steel slag can improve the post-fire behaviour of concrete; however, if the slag is of poor quality, the effect on the fire performance can be detrimental [27]. Weathering the slag can eliminate the possible traces of free lime $(\mathrm{CaO})$ and/or free magnesium oxide $(\mathrm{MgO})$, which, if present, can lead to expansion and cracking of the concrete [27]. Hence, it is important to ensure high quality steel slag in order to ensure adequate mechanical properties at ambient conditions. The reason crushed brick/tile had lower mechanical properties was because of the lower grain hardness compared to the siliceous river aggregate.

It was found that the concrete with calcareous dolomite had a better fire resistance than the mixes with siliceous river gravel. The dolomite samples began to lose their strength at furnace temperatures between $800{ }^{\circ} \mathrm{C}$ and $1000{ }^{\circ} \mathrm{C}$ due to the decomposition of calcium carbonate. The crushed brick/tile had a lower rate of mechanical property decline compared to the reference river gravel. This is due to the lower thermal conductivity of the crushed brick/tile. The diabase aggregate mixes had higher flexural strength than the river gravel up to $400{ }^{\circ} \mathrm{C}$, and higher compressive strength over the whole temperature range. This is due to its high melting point of $1227^{\circ} \mathrm{C}$. It is important to note that at elevated temperatures the diabase did not have as high a fire resistance as the calcareous dolomite aggregate. The slag samples were found to have improved mechanical properties over the whole temperature range. The slag was found to be stable at temperatures between $800{ }^{\circ} \mathrm{C}$ and $1000{ }^{\circ} \mathrm{C}$, which is better than even the dolomite mixtures.

In a subsequent study, Netinger et al [28] tested the performance of slag aggregate and thermally treated slag aggregate by comparing it to dolomite aggregate. The 
thermally treated slag aggregates were heated to $1000{ }^{\circ} \mathrm{C}$, held at that temperature for 1 hour, and allowed to cool prior to mixing. This was done because the ferrous oxide (also know as wüstite) in the slag transforms into magnetite $\left(\mathrm{Fe}_{3} \mathrm{O}_{4}\right)$ at temperatures in excess of $800{ }^{\circ} \mathrm{C}$. This transformation causes irreversible volumetric expansion, which means that thermally treated slag aggregate will not undergo this expansion when included in the concrete [28]. It was found that the residual compressive strength of the slag aggregate concrete was $30 \%$ at $800{ }^{\circ} \mathrm{C}$, whereas the residual compressive strength of the dolomite concrete was $45 \%$ of the initial at $800{ }^{\circ} \mathrm{C}$. However, the slag aggregate performed better at $400{ }^{\circ} \mathrm{C}$. In fact, the thermally treated slag aggregate concrete showed an increase in strength at $400{ }^{\circ} \mathrm{C}$. The crack formation of concretes with slag aggregates was found to be less for the thermally treated slag, however all slag aggregates had more cracking than the reference dolomite concrete. While thermally treated slag had better fire properties, it is more expensive to produce which may prohibit its widespread use.

While slag may be a good aggregate for fire resistance, it can have some negative results when used with Portland cement due to micro cracking. Micro cracks normally occur because the aggregate expands when heated, but the cement paste shrinks at elevated temperatures. Slag aggregate expands more than regular aggregate due to its high coefficient of thermal expansion, which causes more micro cracking to occur [20]. These cracks in turn weaken the concrete itself, most notably the flexural strength. The addition of polypropylene fibers and fly ash can help to improve the fire resistance when using slag because they both reduce microcracks in concrete. When tests were done with slag aggregate, mixtures with fly ash and fibers had higher residual strengths.

\section{Waste Glass}

Waste glass can be added to concrete as fine or coarse aggregate replacement [27]. When crushed waste glass is used as fine aggregate in conjunction with coarse slag aggregate, fire behaviour of the concrete is improved. This is because the glass melts at elevated temperature, which relieves thermal stresses. This can be seen in Figure 2.10, where the concrete with steel slag and waste glass failed in a much more ductile mode and spalled to a much lesser degree than the normal and lightweight concretes.

Additionally, the concrete that contained waste glass as partial fine aggregate in 

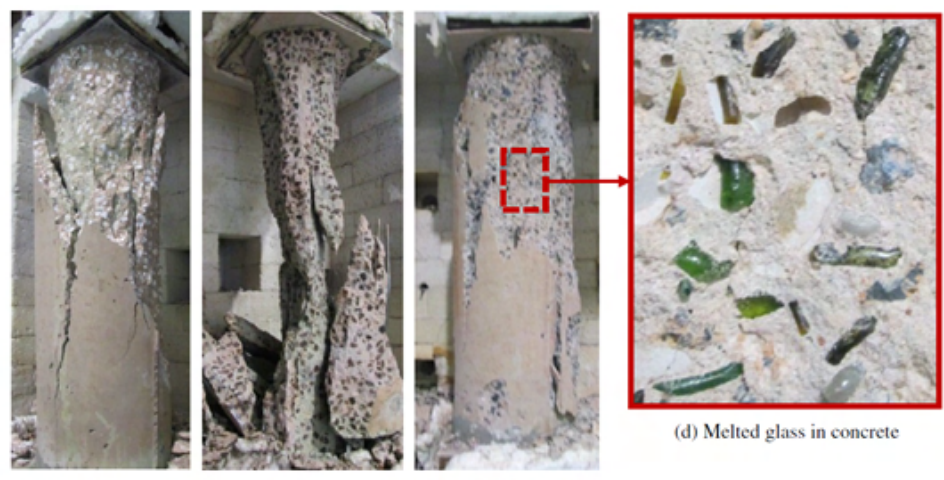

(d) Melted glass in concrete

Figure 2.10: Concrete with waste glass samples after failure [27]

addition to steel slag as coarse aggregate performed better than the steel slag concrete with $100 \%$ natural sand as fine aggregate. However, care must be taken in replacing the fine aggregate with waste glass, as this can cause alkali-silicate reaction (ASR). ASR is an expansive reaction that causes cracking throughout the concrete structure. Reducing the particle size of the glass aggregate can be effective in preventing the cracking [23]. Additionally, the ASR can be reduced by ensuring that the cement is low in alkali metals, or by using cement with pozzolanic materials. The waste glass itself can be used as a pozzolan if ground finer than $38 \mu \mathrm{m}[23,24]$.

Another test compared four different types of mixtures to determine the effect of glass. The four mixes were used: control mix (natural aggregates), fine crushed glass, coarse crushed glass, and a combination of fine and coarse crushed glass. These specimens had glass percentages equal to $0 \%, 25 \%, 50 \%$, and $100 \%$ in order to check for variance of fire resistance [29]. For this test, a muffle furnace was used to heat the specimens [29].

At ambient temperatures the control mix had a slightly higher strength then the mixtures with glass. However, once the samples were heated the samples with $10 \%$ glass aggregates performed better than the control mix, up to $700{ }^{\circ} \mathrm{C}$ [29]. This strength improvement is due in part to the fact that glass does not absorb water, so concrete mixes with glass are more compact after being exposed to fire due to the evaporation of free water [29]. With higher glass replacement the concrete strength decreases, due to the loss of initial strength. The reason for this lower strength is the loss of cohesion between the different aggregate grades, as well as the cement matrix.

The main issue was the large difference in the coefficient of thermal expansion 
which created internal stresses causing cracks to form at the interface between the glass aggregates and cement paste [29]. Since the coarse aggregate has a less homogeneous distribution compared to fine aggregates, the thermal stresses are more pronounced with coarse aggregate. The use of crushed glass aggregates can lead to sustainable construction because glass is easily attainable from recycling [29].

\subsubsection{Effect of Supplementary Cementitious Materials}

Supplementary cementitious materials (SCMs) can be used as a replacement for a portion of cement, saving money and reducing carbon dioxide emissions. SCMs often originate as by-products of other manufacturing industries, which means that they reduce the amount of waste material produced while reducing the carbon dioxide emissions. SCMs have a lower calcium content than cementitious material like Portland cement, Figure 2.11. One of the main differences between mixes with SCMs are the reduction in portlandite and the increase in the C-S-H formed. The C-S-H also has a lower $\mathrm{Ca} / \mathrm{Si}$ ratio. SCMs have been known to improve the durability of concrete at ambient conditions, as well as provide other specialized advantages like sulfate resistance and reduced permeability.

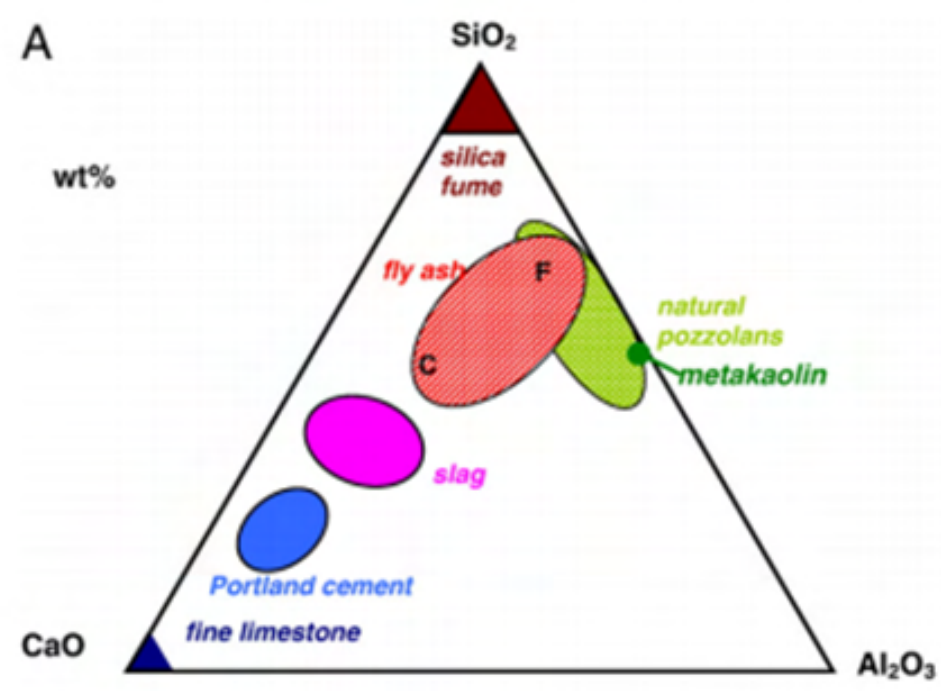

Figure 2.11: Ternary diagram of cementitious materials [31]

SCMs may also improve the fire performance of concrete. One of the reasons SCMs (specifically fly ash and blast furnace slag) are so effective at improving the 
residual compressive strength at temperatures below $600{ }^{\circ} \mathrm{C}$ is due to the formation of tobermorite [30]. Tobermorite is formed by reactions between unhydrated pulverized fuel ash or ground-granulated blast furnace slag particles and lime at high temperatures. Tobermorite is two to three times stronger than C-S-H gel [30]. A few of the different types of SCM's and their behaviours under elevated temperatures are briefly described below.

Silica fume (SF) is a by-product from the production of silicon metal and it tends to have a small particle size [32]. Since it has a small particle size, it is commonly used in HSC to increase the strength and durability. SF also lowers the permeability of the concrete, which can lead to explosive spalling when exposed to elevated temperatures. The explosive spalling was found to occur even when the heating rate was as low as $1{ }^{\circ} \mathrm{C} / \mathrm{min}$ [32]. When $\mathrm{SF}$ is used in concrete at elevated temperatures the residual strength is not significantly improved, and in most cases it is worse than regular concrete [30]. Studies have shown that $10 \% \mathrm{SF}$ is the maximum amount that can be added in order to still have good fire properties [32].

Fly ash (FA) comes from coal combustion, and it is usually small round particles [31]. Fly ash can be added in order to improve the workability and the sulfate resistance, and lower the heat of hydration. It can also increase the compression strength and the rate of strength development [32]. When concrete with FA is exposed to fire it can improve the residual compressive strength, as well as the surface cracking. When OPC re-hydrates after fire exposure the $\mathrm{CH}$ inside expands and cracks the concrete. When $10 \% \mathrm{FA}$ is used it reduces or eliminates the surface cracking because the FA reduces the amount of $\mathrm{CH}$ left in the concrete [32]. Cement pastes with FA were found to have improved strength up to $600{ }^{\circ} \mathrm{C}$ when pumice or granite aggregates were used [32]. However experiments with limestone aggregates and 30-40\% FA gave results that suggest concretes with limestone aggregate and FA are more sensitive to elevated temperatures than conventional concrete [32]. Instead of improving the residual compressive strength, when FA is added with limestone aggregates the residual strength decreased more than OPC. These results suggest that FA can be beneficial to fire resistance; however, it is sensitive to aggregate types.

Blast furnace slag (BFS) is a SCM that is produced as a waste material from steel manufacturing. When BFS is used as an SCM it is normally ground as a fine powder, with smaller particles than OPC. The benefit of BFS is that it reduces the permeability of the concrete which can improve the durability. BFS also has positive results at 
elevated temperatures. At $300{ }^{\circ} \mathrm{C}$ Ordinary Portland cement (OPC) paste performed marginally better than BFS. At temperatures above $400{ }^{\circ} \mathrm{C}$ BFS outperformed the OPC paste in residual strength and had less surface cracking. Depending on concrete type, aggregate type, and the amount of BFS added the residual strength of BFS concrete can remain at $100 \%$ up to $600{ }^{\circ} \mathrm{C}$. With BFS mixes the cracking normally occurs between $300-400{ }^{\circ} \mathrm{C}$, and the concrete normally spalls around $400{ }^{\circ} \mathrm{C}$.

The cooling method can have a large impact on the residual compressive strength of concrete. Air cooling usually results in higher residual compressive strengths than water cooling. [32]

The type of aggregate can have a significant impact on the effectiveness of SCMs. When pumice aggregate is used, SCMs tend to perform better than the OPC. [32]

\section{Cement Paste Specimens}

A study by Sullivan and Sarshar tested the effects on concrete's performance at elevated temperatures when part of the cement is replaced with FA (30\%), BFS (65\%), and SF (10\%) [33]. They tested 63x63mm cylinder specimens at temperatures ranging from $50{ }^{\circ} \mathrm{C}$ to $600{ }^{\circ} \mathrm{C}$ and the specimens were then held at their respective temperatures for 9 to 22 hours before cooling naturally in the furnace. The $\mathrm{w} / \mathrm{b}$ ratio was 0.34 and a heating rate of $1{ }^{\circ} \mathrm{C} /$ minute was used. The effect of the different mixtures on the residual compressive strength can be found in Figure 2.12. The SF mixture had lower residual strength than the OPC for most temperatures, and so it did not improve the concrete. The fly ash specimen (noted as PFA) performed above the level of the OPC paste after $300{ }^{\circ} \mathrm{C}$. The BFS (noted as slag paste) performed better than all of the mixes at every temperature. The ground, granulated blast furnace slag had no significant reduction in strength up until $600{ }^{\circ} \mathrm{C}$. Hence, under the conditions stated above, it can be concluded that using BFS as the SCM results in the pastes' optimum performance at all temperatures tested.

Dias et al. tested the mechanical properties of hardened cement pastes that were heated in the furnace for 4 months [34]. While this long period of exposure may not be applicable to most structural applications of concrete, the results again confirmed that adding FA to cement paste increased its residual compressive strength. The specimens had similar conditions as the specimens tested by Sullivan and Sarshar: a heating rate of $1{ }^{\circ} \mathrm{C}$ per minute, a w/b of 0.3 , a $20-600{ }^{\circ} \mathrm{C}$ temperature range, 


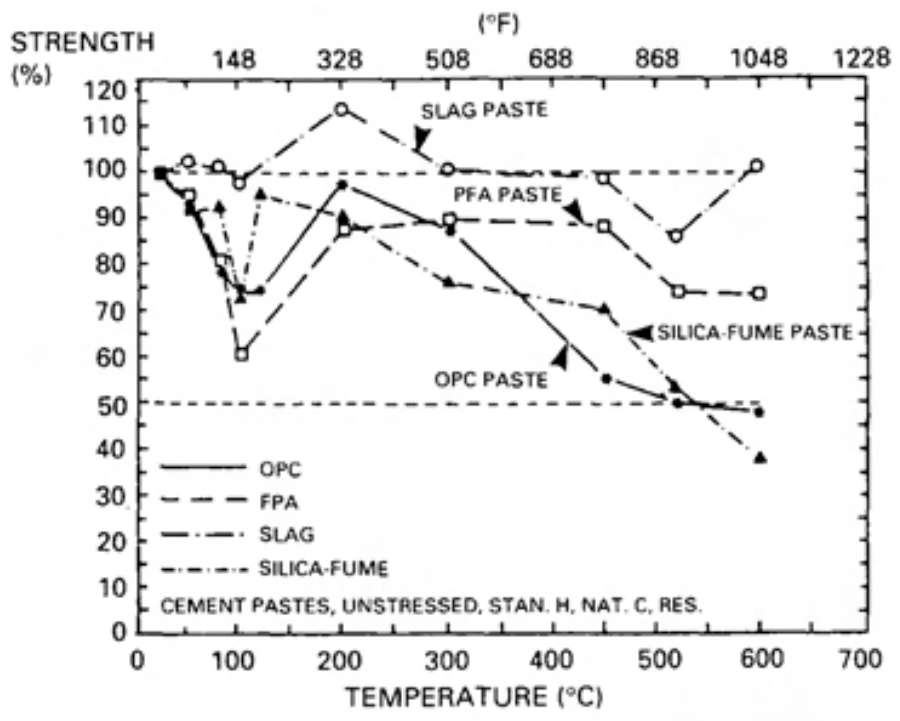

Figure 2.12: Residual Strengths of Various Cement Pastes [33]

and furnace cooling. However, the specimens were cast into $187.5 \times 62.5 \mathrm{~mm}$ cylinders. This 3:1 ratio was used to ensure uniaxial stress conditions in the middle of the specimens. The specimens had FA contents of 10\%, 25\%, and $40 \%$ with retained residual strengths of $27 \%, 36 \%$, and $40 \%$, respectively. In these tests, increasing the FA content increased the residual strength. The authors explained that this trend occurs because the FA causes pozzolanic reactions which reduce the amount of calcium hydroxide, or portlandite, present in the paste. Less calcium hydroxide in the paste prior to heating means that once the specimens are cooled and exposed to atmospheric moisture there will be less expansive rehydration of dissociated calcium hydroxide. This explanation can be seen visually in Figure 2.13. These unloaded cylinders were heated to $400{ }^{\circ} \mathrm{C}$ or above and cooled while exposed to air. Note that when initially removed from the furnace, the OPC specimen was not cracked. Adding $10 \%$ fly ash or greater eliminated the surface cracks present in the OPC specimen due to the lesser amount of expansive rehydration from dissociated calcium hydroxide.

Mendes et al. found that, like FA specimens, including BFS reduced surface cracks because there was less calcium hydroxide in the hydrated paste and therefore less disruption from the re-formation of calcium hydroxide [34]. Specimens were cast into $50 \times 100 \mathrm{~mm}$ cylinders, heated at a rate of $6.25{ }^{\circ} \mathrm{C} / \mathrm{min}$ within a range of $20-800$ ${ }^{\circ} \mathrm{C}$, and held at their respective temperatures for 1 hour. The w/b ratio was 0.5 and they were furnace cooled. Above $400{ }^{\circ} \mathrm{C}$, the $\mathrm{OPC}$ specimens crumbled and had no 

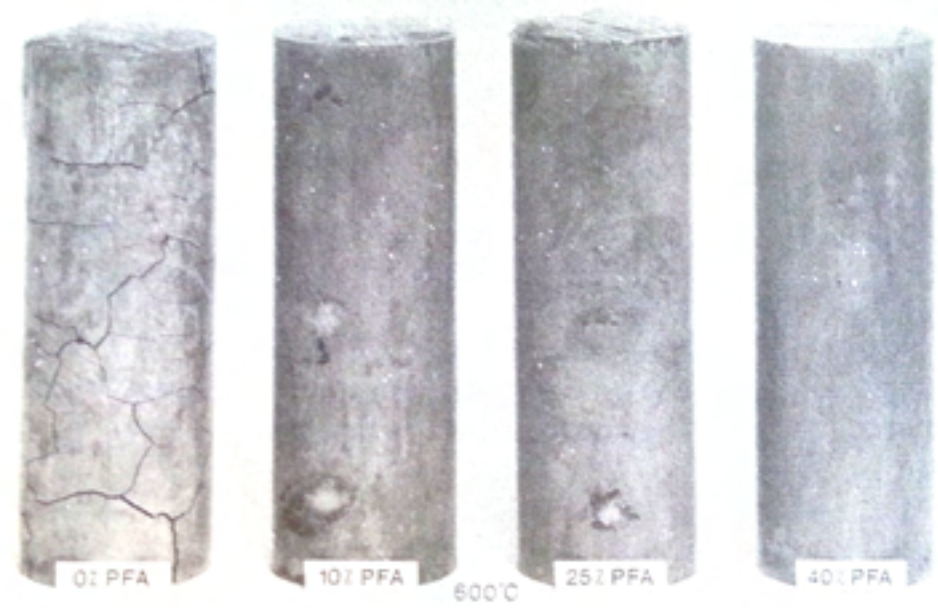

Figure 2.13: Unloaded and Cooled FA Cement Paste Specimens [34]

strength. At $600{ }^{\circ} \mathrm{C}$, the BFS specimens decreased in strength by $43-54 \%$, a marked improvement over the OPC results. BFS contents of $35 \%, 50 \%$, and $65 \%$ were used, however, no trends were evident to indicate the optimum content of BFS. The lack of trends could be a result of testing only one specimen at each temperature for each mix. However the results by Mendes et al. do show that adding BFS has benefit, especially over $400{ }^{\circ} \mathrm{C}$.

A series of experiments by Wang implemented 10\%, 20\%, 50\%, 80\%, and $100 \%$ BFS into 20x40mm cylinder cement paste specimens [35]. W/b ratios of $0.23,0.47$, and 0.71 were used for a total of 588 test specimens. They were heated at a rate of $0.67{ }^{\circ} \mathrm{C} /$ min over a range of $25-1050{ }^{\circ} \mathrm{C}$ for between 2 to 4 hours and were cooled naturally. It was found that with a w/b ratio of 0.23 , the optimum BFS content for fire resistance is between $50-80 \%$. However, there were no clear trends for the two higher $\mathrm{w} / \mathrm{b}$ ratios. This may be because of outliers and a lack of repeated tests as only one specimen at each $\mathrm{w} / \mathrm{b}$ ratio was tested at each temperature. At a w/b ratio of 0.71 , the addition of BFS does not significantly improve the specimens' residual compressive strength. The reason BFS is not useful at high $\mathrm{w} / \mathrm{b}$ ratios is that the ambient strength is greatly reduced (at 50\% replacement with BFS the ambient compressive strength was less than one third of the OPC specimen). So it is important to balance the fire performance with the potential reduction in strength at ambient conditions. 


\section{Concrete Specimens}

$\mathrm{Xu}$ et al. incorporated low calcium FA, equivalent to ASTM Class F, into concrete with fine river sand and coarse granite aggregates at 25\% and 55\% [36]. Two different w/b ratios were used: 0.30 and 0.50 . A superplasticiser was used to achieve 0.30. $100 \mathrm{~mm}$ cubic specimens were heated at a rate of $1{ }^{\circ} \mathrm{C} / \mathrm{min}$ and held at temperatures up to $800{ }^{\circ} \mathrm{C}$ for 1 hour. When both w/b ratios were compared to the OPC concrete, the residual compressive strength at $450{ }^{\circ} \mathrm{C}$ decreased by $4-15 \%$ whereas the OPC decreased by about $20 \%$. The $55 \% \mathrm{FA}$ specimens and the $0.3 \mathrm{w} / \mathrm{b}$ ratio specimens experienced less loss compared to their $25 \%$ and 0.5 counterparts. This lower w/b ratio has a greater risk of spalling; however, spalling was not reported. The benefits of $55 \%$ FA were still significant at $650{ }^{\circ} \mathrm{C}$ but they diminished at $800{ }^{\circ} \mathrm{C}$. In the interest of comparison, note that the relative strength of OPC is very low at $800^{\circ} \mathrm{C}$. Sharp drops in FA specimen strengths were observed above $650{ }^{\circ} \mathrm{C}$ because after this temperature decomposition of C-S-H becomes inevitable. The microstructure becomes coarser and binder properties are lost. To summarize, $55 \% \mathrm{FA}$ is better than $25 \% \mathrm{FA}$ at improving the fire resistance of concrete with granite coarse aggregate up to $650{ }^{\circ} \mathrm{C}$, and there is very little strength loss up to $450{ }^{\circ} \mathrm{C}$.

Poon et al. conducted a series of tests on normal strength concrete with $30 \%$ FA, $40 \% \mathrm{FA}, 30 \% \mathrm{BFS}$, or $40 \%$ BFS [37]. The specimens were $100 \mathrm{~mm}$ cubes and they were heated at a rate of $2.5{ }^{\circ} \mathrm{C} / \mathrm{min}$ at temperatures up to $800{ }^{\circ} \mathrm{C}$. They were held at their respective temperatures for 1 hour and allowed to cool naturally. Local natural river sand and crushed granite were used as the fine and coarse aggregates, respectively. A w/b ratio of 0.30 was used. Based on their residual compressive strengths, the benefits of adding SCM's were more pronounced at temperatures at and below $600{ }^{\circ} \mathrm{C}$; because at $800^{\circ} \mathrm{C}$ all of the specimens showed severe deterioration due to the decomposition of C-S-H gel. All the tests with SCM's had a higher residual compressive strength compared to the OPC control specimen. From these tests, the authors concluded that the optimum replacement level was $40 \%$ BFS. No spalling or cracking was observed except for hairline cracks. Rapid chloride diffusion tests were used to obtain a measure of the concrete's permeability at $600{ }^{\circ} \mathrm{C}$ and 800 ${ }^{\circ} \mathrm{C}$. The BFS specimens gave the least loss of impermeability, demonstrating that more permeable specimens show a more pronounced loss of compressive strength. Likewise, mercury intrusion porosimetry (MIP) tests, which examine the porosity and pore size distribution, found that increasing temperatures cause increases in 
porosity and average pore diameter. As these increases are responsible for strength and impermeability losses, the results are further validated. In addition, porosity and average pore diameter were less for specimens with SCM's in comparison to OPC. As mentioned by other researchers, the better performance of concrete with SCM's is due to the reaction of the SCM's and free lime whereby the content of free lime is reduced.

\section{Summary of Concrete Strength}

The strength of concrete is usually unchanged below $400{ }^{\circ} \mathrm{C}$. Above $400{ }^{\circ} \mathrm{C}$ the strength starts to decrease due to a combination of water loss, micro cracks, chemical decomposition, and thermal stresses. Lightweight aggregates have improved fire properties over normal weight aggregates, as they are normally created at high temperatures. For normal weight aggregates, calcareous aggregates are better than siliceous aggregates. The addition of small amounts of glass aggregates (under 10\%) can improve the fire properties of the concrete.

In general, adding either FA or BFS as a replacement for cement improves the fire resistance of cement paste or concrete specimens above $400{ }^{\circ} \mathrm{C}$. Research suggests that FA or BFS improves the fire resistance because they create pozzolanic reactions which reduce the amount of calcium hydroxide, or portlandite, present in the material. The cause of the detrimental cracking in OPC is the rehydration, and hence expansion, of the dissociated calcium hydroxide [36]. Thus, by reducing the amount of dissociated calcium hydroxide, the SCM's are improving the quality of the cementitious materials. The reduction of surface cracking was directly seen in Figure 2.13 for FA, and discussed by Mendes et al. for BFS.

From the results of Sullivan and Sarshar regarding cement paste, $65 \%$ BFS was determined to be optimum in comparison to $30 \% \mathrm{FA}$. Cement paste experiments by Wang at w/b of 0.47 demonstrated better residual compression than OPC, but no optimum content could be established. However, he did find that adding BFS at a $0.71 \mathrm{w} / \mathrm{b}$ ratio was not effective. Mendes et al. tested $35 \%, 50 \%$, and $65 \%$ contents of BFS in cement pastes but was unable to determine an optimum value. For normal strength concrete, Poon et. al determined that $40 \%$ BFS was optimum.

Based on the literature review, further testing with the aggregates is recommended with $40 \%$ BFS. A BFS content of $40 \%$ is suggested because out of the experiments 
listed, Poon et al. [37] were the sole authors who were able to determine an optimum content. Comparing specific tests from one researcher to the next on a strictly quantitative basis is not conducted because there are many variables influencing their results, as discussed throughout. However, a $40 \%$ content falls within the range of contents gathered by multiple researchers found to improve the fire resistance.

\subsection{Heat Transfer}

Heat transfer methods such as conduction, convection and radiation can have a large impact on the fire resistance of the wall $[1,12,17,38,39]$. In the case of masonry, conduction can pass through the solid concrete in the webs or the faceshell, as well as the mortar. Conductive heat transfer happens due to the interactions involving free electrons. This means that materials that are good conductors of electricity (e.g. metals) are also good conductors of heat. Since concrete is a poor conductor it is difficult for heat to transfer through it. Technically air also has a value for conduction, but it is so low $(0.02 \mathrm{~W} / \mathrm{mK})$ that it is usually ignored [12]. Heat transfer through pure conduction can be calculated using Equation 2.2 [17].

$$
\dot{q}^{\prime \prime}=k d T / d X
$$

Where, $\dot{q}^{\prime \prime}=$ heat flow per unit area $\left(W / m^{2}\right), k=$ thermal conductivity $(\mathrm{W} / \mathrm{mK})$, $T=$ temperature $\left({ }^{\circ} \mathrm{C}\right.$ or $\left.\mathrm{K}\right), X=$ the distance in the direction of the heat flow $(\mathrm{m})$.

Convection is the heat transfer by the movement of fluids, either gases or liquids. In masonry, the fluids are the air in the cells of the blocks, the hot air on the fire side of the wall, and the ambient air on the unexposed side. The value of heat transferred depends on the geometry of the surface, the direction of the flow, and the thickness of the boundary layer. For research purposes the convection through the cells is of interest because it is the one area that can be changed by changing the geometry of the block. Heat transfer through pure convection can be calculated using Equation $2.3[17]$.

$$
\dot{q}^{\prime \prime}=h \Delta T
$$

Where, $\dot{q}^{\prime \prime}=$ heat flow per unit area $\left(\mathrm{W} / \mathrm{m}^{2}\right), h=$ convective heat transfer coefficient $\left(W / m^{2} K\right), \Delta T=$ temp difference between the surface of the solid and the fluid $(\mathrm{K})$. 
Radiation is the transfer of energy by electromagnetic waves that can travel through a vacuum, transparent solid or liquid. This is one of the main mechanism for heat transfer from flames to the masonry wall. Radiation also occurs inside the cells of the blocks, as well as from the unexposed side to ambient. The effects of radiation are dependent on the configuration factor (ability for one object to see the other based on size and distance) as well as the emissivity of the materials [1]. Concrete has an emissivity of around 0.94 [12]. Heat transfer through pure radiation can be calculated using Equation 2.4 [17].

$$
\dot{q}^{\prime \prime}=\phi \varepsilon_{e} \sigma T_{e}^{4}
$$

Where $\dot{q}^{\prime \prime}=$ heat flow per unit area $\left(W / m^{2}\right), \phi=$ configuration factor, $\varepsilon_{e}=$ emissivity of the emitting surface, $\sigma=$ Stefan-Boltzmann constant $\left(5.67 \times 10^{-8} \mathrm{~W} / \mathrm{m}^{2} \mathrm{~K}^{4}\right), T_{e}=$ absolute temperature of the emitting surface $(\mathrm{K})$.

The heat flow through the masonry can be decreased by several methods. Two simplest methods are to increase the thickness of the wall or to use insulating materials or additives. By increasing the thickness, it will take the wall longer to heat up with conduction and it will reduce the radiation in the cells. More complex methods involve changing the material of the blocks and mortar to materials with lower thermal conductivities, thereby reducing the effect of conduction in the blocks. Another method of reducing the heat flow in the blocks is by changing the geometry of the blocks or wall assemblage. Some research has been done to determine the optimal block geometries to limit heat flow at ambient temperatures, but very limited research has been done to determine how this relates at higher temperatures.

The reason that heat flow through the block is different at elevated temperatures is because the governing method of heat transfer changes with increase in temperature, Table 2.5. At low temperatures conduction is usually the governing factor. Since most building owners want to save money on heating and cooling costs in ambient conditions, the amount of conduction in the blocks is limited to reduce the heat flow [2]. This is done through the creation of very large hollow cells in the blocks. However, during fire situations the temperature goes well above ambient, and the governing method of heat transfer changes. Since radiation is related to temperature to the $4^{\text {th }}$ power, its effect becomes more dominant than conduction. The effect of convection also becomes more important as the temperature difference between one side of the cell and the other increases. This means that large hollows are not 
recommended, and several smaller hollows would be more beneficial.

Table 2.5: The percentage of heat flux through a $20 \mathrm{~cm}$ masonry block at ambient and fire temperatures

\begin{tabular}{|l|l|l|}
\hline & Ambient & Fire \\
\hline Radiation & 16.70 & $\mathbf{7 2 . 8 2}$ \\
\hline Convection & 26.83 & 17.41 \\
\hline Conduction & $\mathbf{5 6 . 4 7}$ & 9.77 \\
\hline
\end{tabular}

\subsection{Fire Resistance Testing}

In Canada the CAN/ULC-S101 Fire Endurance Tests of Building Construction and Materials test (herein referred to as CAN/ULC-S101 Standard Time-Temperature Curve or standard time-temperature curve), is used to give structural members or assemblages a fire resistance rating [38]. The National Building Code of Canada defines fire resistance rating as "the time in minutes or hours that a material or assembly of materials will withstand the passage of flame and the transmission of heat when exposed to fire under specified conditions of test and performance criteria". This fire resistance rating is used to qualitatively compare members to one another. For example, if a material had a fire resistance of two hours, it would be better than another material with a one-hour fire rating. There are several different standards around the world, each with their own specifications. The differences between the standards are usually minimal (within $4 \%$ ), and so for research purposes it is possible to compare members tested with different standards in a qualitative manner. The equations for each of the standards can be found in Equations 2.5, 2.6, 2.7.

CAN/ULC-S101-14:

$$
T_{g}=T_{0}+750(1-\exp (-0.49 \sqrt{t}))+22.0 \sqrt{t}
$$

ISO 834:

$$
T_{g}=345 \log _{1} 0(8 t+1)+T_{0}
$$


ASTM 119:

$$
T=750\left[1-e^{(-3.79553 \sqrt{t / 60})}\right]+170.41 \sqrt{t / 60}+T_{0}
$$

Where, $T_{g}=$ furnace temp $\left({ }^{\circ} \mathrm{C}\right), t=$ time $(\min ), T_{0}=\operatorname{ambient}$ temp. $\left({ }^{\circ} \mathrm{C}\right)$

These equations each depict a different standard time-temperature curve (e.g. CAN/ULC-S101 curve in Figure 2.14). The curve describes the furnace temperature required to ensure that the results will be consistent and comparable. It can be seen in Figure 2.14 that the temperature rises quickly at the start of the test and then continues to increase more gradually. When the tests are preformed, the three failure criteria are stability, integrity, and insulation (Figure 2.15). The test is stopped once the member has failed any one of the failure criteria. The specimen fails stability if the structural element is no longer able to carry the applied load. The specimen fails integrity if any cracks or fissures form which allow smoke or hot gasses to pass through. The specimen fails insulation if the unexposed side exceeds an average increase of 140 ${ }^{\circ} \mathrm{C}$ or a maximum increase of $180{ }^{\circ} \mathrm{C}$ at a single point [38]. Once the member fails the standard test, the failure time is recorded and rounded down to give the member its fire resistance rating. These ratings are a way of qualitatively comparing different materials. Building codes require members to have minimum fire resistance ratings, so having a higher fire resistance rating is best.

To test a wall in the standard fire test the applied load on the wall must be determined. If the wall is meant to be a partition wall (non-loadbearing) then the stability aspect of the test can usually be ignored because the only load on the wall is its own self weight. Although cracks can form at elevated temperatures, the frame around the walls during the standard time-temperature curve tests generally stop the walls from being able to separate [14]. This means that unless large cracks or holes form in the wall, integrity will usually not be the cause of failure. This suggests that governing failure criterion is usually insulation for partition walls.

The standard time-temperature curves are simply based on standardized laboratory fire tests and as such are not representative of all fire conditions. This is problematic in the sense that these standardized tests do not simulate an actual fire. Despite this issue, these standardized fire tests can be used as a means to create a standard for material testing under controlled laboratory conditions to determine the 


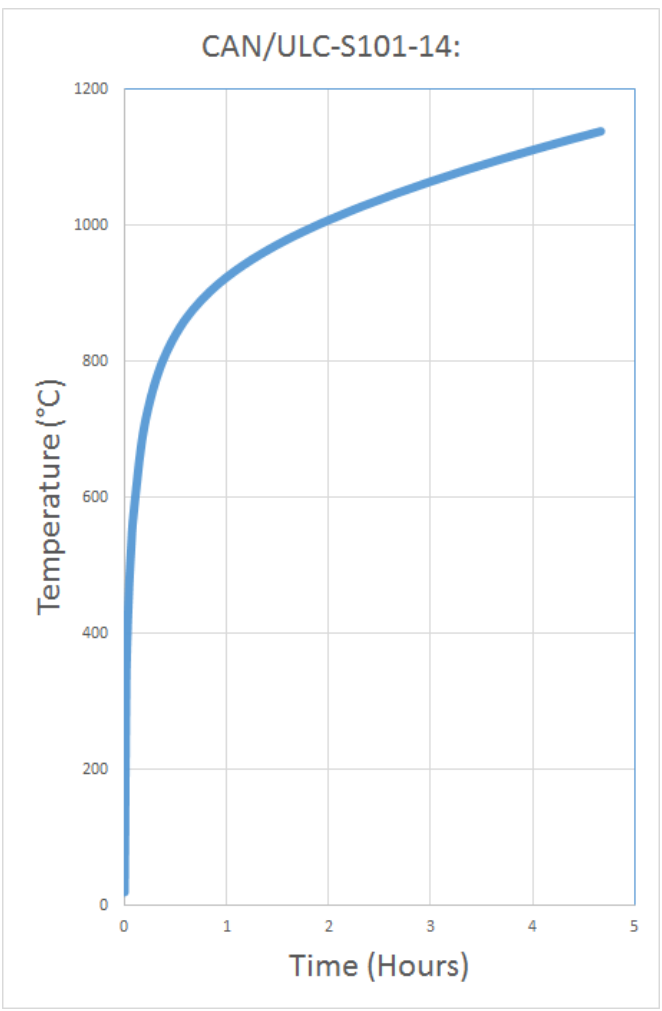

Figure 2.14: CAN ULC S101 standard fire [38]
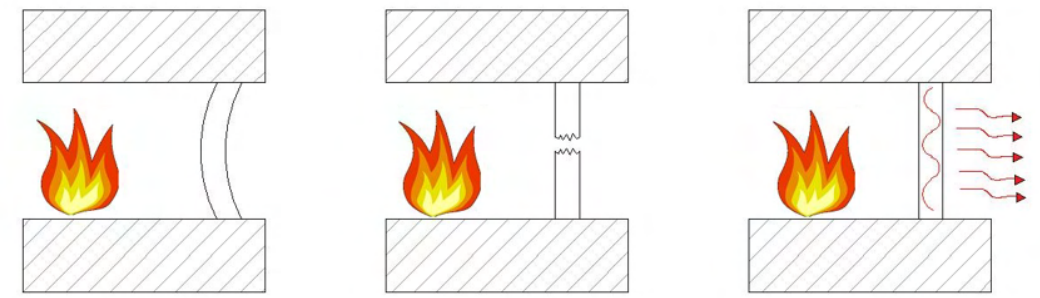

Figure 2.15: Stability (Left) Integrity (Centre) Insulation (Right) response of a test specimen and its failure. 


\subsubsection{Issues with Fire Testing}

Most test procedures used for determining the behavior of concrete at elevated temperatures do not involve a full-scale member or a standard furnace temperature. Instead most fire tests use small specimens (usually a concrete cylinder cured for at least 28 days) which are heated to a maximum temperature at a specified heating rate. Once the desired temperature is reached, the temperature remains constant for a specified duration. After this duration, the specimen can be cooled in a variety of ways. The simplest way is to allow the specimen to naturally cool to ambient conditions. When a cooling regime is specified the specimen is left in the furnace, and the furnace temperature is decreased by a specified cooling rate. Finally, some specimens are cooled with the use of water.

While almost all researchers follow a specific test procedure for each of their specimens, the test procedures can vary significantly between researchers. For example, heating rates can range between $0.1{ }^{\circ} \mathrm{C} / \mathrm{min}$ and $500{ }^{\circ} \mathrm{C} / \mathrm{min}$ or more. The maximum temperatures can range from ambient to over $1200{ }^{\circ} \mathrm{C}$. In addition, the cooling regimes can range from $1{ }^{\circ} \mathrm{C} / \mathrm{min}$ to almost instantaneous cooling (when specimens are removed from the furnace or water cooled). While testing can help to gain new knowledge on the behavior of concrete masonry material in fire situations, it is important to think critically when comparing the results of different fire tests together.

Furthermore, when new materials are added to a concrete mix to determine their effects at elevated temperatures it is important to note that mixes used by researchers can be significantly different, despite the use of similar terminology. For example, two researchers may replace $30 \%$ of the fine aggregate with fly ash, but without knowing factors such as the w/c ratio, aggregate type, and additives used, it will be difficult to quantitatively compare results. A similar problem occurs when comparing control specimens with new mix designs. Most researchers include a control specimen made of regular concrete without the addition of the new material or additives when comparing the effects of one or more changes to the mix design. If the control sample is too different from the new mix, then the comparison is less useful. This problem usually occurs when the addition of a new material requires the change of several factors (such as w/c ratio, amount of course and light aggregates, and additives) in the mix design [40].

It is important to note that unlike steel, concrete does not conduct heat quickly through the material. Therefore, the outer layers of concrete are hotter than the 
inner layers. One method for determining the temperature of the concrete is to use Wikstroms method [41]. Equation 2.8 determines the surface temperature of the concrete given the fire temperature and duration of exposure. Equations 2.9-2.11 are used to determine the temperature at a given point within the concrete for one dimensional heat flow and two-dimensional heat flow respectively [41]. Because the standard fire goes well above $1000{ }^{\circ} \mathrm{C}$, it is important to know what happens to concrete as it is heated from ambient to this elevated temperature. When cylinders are used for testing they are normally exposed from all sides, so they are able to heat up to the desired temperature relatively quickly. After being exposed to the same temperature for a long enough time, the temperature of the entire cylinder becomes uniform. Tests with short durations or larger specimens are not as accurate due to the lack of temperature uniformity in the cylinders. If majority of the concrete is unaffected by the elevated temperature, then the results are not indicative of its fire resistance properties.

$$
\begin{gathered}
T_{w}=\left(1-0.0616 t_{h}^{(-0.88)}\right) T_{f} \\
n_{x}=0.18 \ln \left(t_{h} / x^{2}\right)-0.81 \\
T_{c}=n_{x} T_{w} \\
T_{c}=\left[n_{w}\left(n_{x}+n_{y}-2 n_{x} n_{y}\right)+n_{x} n_{y}\right] T_{f}
\end{gathered}
$$

Where $T_{w}=$ the surface temperature $\left({ }^{\circ} \mathrm{C}\right), T_{f}=$ the fire temperature $\left({ }^{\circ} \mathrm{C}\right), t_{h}=$ the fire duration ( $\mathrm{min})$, and $x=$ the distance into the concrete $(\mathrm{m})$.

\subsection{Methods of Improving Fire Resistance: Mix design}

The mix design is one of the major factors affecting the fire resistance of masonry. Since the heat transfer is affected by thermal conductivity, specific heat, and density, it is important to find mixes that have beneficial thermal properties [12]. For example, using materials with lower thermal conductivity such as lightweight aggregates can 
greatly improve the fire resistance [25]. Choosing materials that increase the specific heat is another way to improve the fire resistance. Free water has a large effect at temperatures around its boiling point, due to the increase in specific heat. Other additives which increase the specific heat of concrete would also be beneficial. Since the downside to free water is the risk of spalling, having concretes with increased porosity would help to improve the fire resistance.

The main issues with changing the mix design is that there are usually other factors that need to be considered. For example, lightweight concrete is more fire resistant, but it is also structurally weaker. Additives to increase the specific heat of concrete improve the fire resistance, but also increase the cost. While there are definite benefits to changing the mix design, there are other methods that could be considered.

\subsection{Methods of Improving Fire Resistance: Geom- etry}

\subsubsection{Equivalent Thickness}

A simple method of estimating the fire resistance of different masonry block mixes and geometries is to use the equivalent thickness method [42]. The first step is to determine the volume of physical material in the masonry block, ignoring the hollow cells. Then the equivalent thickness is found by dividing the volume by the height and width (which are usually same for most blocks). Once this thickness is found it can be used to interpolate from tables to determine the estimated fire resistance. The tables are sorted by concrete type, and the fire resistance increase as the effective thickness increases [38]. This method is useful in quickly giving rough estimates on the fire resistance rating, but the ratings are not always reliable because of different block geometry effects.

Harmathy had several rules that explained how the fire resistance would change depending on the geometry of materials and assemblies [1,11,43].

1. The added fire resistance of two entities tested separately is less than their fire resistance when tested together.

2. Having an air gap within the material increases the fire resistance.

3. Having a larger air gap has a limited change in the fire resistance. 
4. Having a material with lower thermal conductivity on the fire side, and higher thermal conductivity on the unexposed side is better than the inverse.

5. For an unsymmetrical material, there is a difference in fire resistance depending upon the side that is exposed to the fire.

In particular, for masonry the thickness of the faceshells is more important than the thickness of the webs, as thicker faceshells will have less radiation within the cores [14] [42]. This is because there is more material to absorb heat before it can reach the cores. Some examples that outline the problem with the equivalent thickness method are shown in Figure 2.16 [15]. Configurations (1), (2), and (3) have very different geometries, and should have different fire ratings $(t)$. Since (3) has more air gaps, it would have the best fire resistance and (1) would have the worst fire resistance due to the lack of air gaps. However, as they have the same amount of material $\left(L_{e q}\right)$, they all have the same fire resistance rating with the equivalent thickness method. Similarly, configurations (4) and (5) have the same fire resistance, even though (5) has a greater faceshell thickness, which should lead to a better fire resistance. The fact that equivalent thickness does not account for geometry is the major reason why using the equivalent thickness method may not be the best option for determining the fire resistance of masonry.

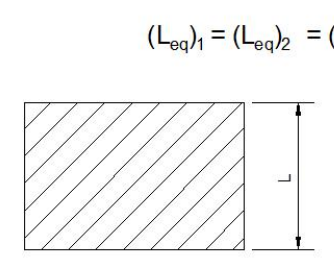

(1)

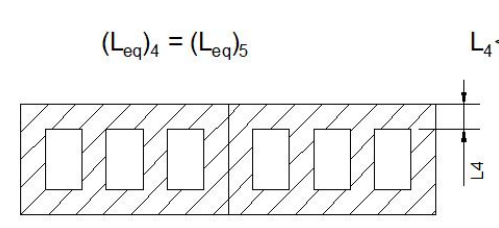

(4)

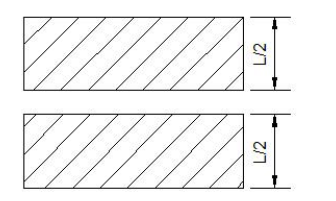

(2)

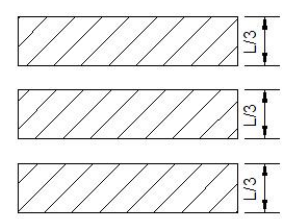

(3)

Figure 2.16: The problem with equivalent thickness (modified from [44])

The fire resistance of hollow blocks is dependent on the amount of material (equivalent thickness) and the geometry of the block [42]. Most masonry blocks have two 
large hollow cells within the block. To improve the thermal resistance of the block several smaller cells can be used to reduce the convection and radiation through the larger cells. The smaller the cells the better the thermal resistance of the block. Blocks with staggered air cells are even more thermally resistant as the heat flow does not have a direct path to travel through [44]. Other important geometric concerns are the thickness of the faceshell relative to the thickness of the webs. The amount of material on the faceshells has a greater impact on the fire resistance than the amount of material on the webs [1].

Alhazmy et al. conducted a test with small folded inclined partitions placed in the hollows of the blocks (Figure 2.17) [39]. The purpose of the partitions was to break up the hollow and affect the horizontal convection through the blocks. It was found that the heat transferred was lessened as the number of partitions increased (up to a certain amount which would depend on the size of the hollow) [39]. Therefore, when the convection through the hollows is reduced, it has a significant effect on the overall thermal resistance of the block.
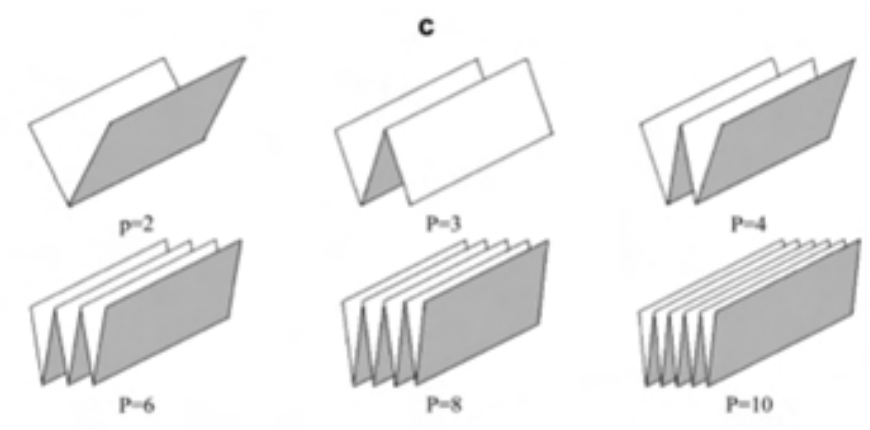

Figure 2.17: The effect of different partions on the fire resistance [39]

While some research has been done on improving the block geometry to reduce the horizontal heat flow through the wall, there has been very little research to determine the effect of vertical heat flow. Just as the geometry of the block can change the horizontal heat flow, the geometry of the wall can affect the vertical heat flow. Putting a horizontal partition should reduce the vertical heat transfer, just as a vertical partition reduces horizontal heat flow [42]. 


\subsubsection{Other Geometries}

Masonry walls can have different geometries to improve the thermal performance of the wall. A common method for increasing the thermal performance is to build a cavity wall. Cavity walls are simply two walls constructed with an air gap in between, and they are an effective way to increase the fire resistance of masonry walls. A special type of cavity walls are double skin walls, which have insulating material such as gypsum board in the place of the air gap. The problem with cavity and double skin walls are that they are more expensive and time consuming to create. A simpler method of increasing the thermal resistance at low temperatures is the use of hollow blocks, as they are easier to create than cavity walls.

The fire resistance of hollow blocks is dependent on the amount of material (equivalent thickness) and the geometry of the block. Most masonry blocks have two large hollow cells within the block. To improve the thermal resistance of the block several smaller cells can be used in order to reduce the convection and radiation through the larger cells. The smaller the cells the better the thermal resistance of the block. Blocks with staggered air cells are even more thermally resistant as the heat flow does not have a direct path to travel through [6]. Other important geometric concerns are the thickness of the faceshell relative to the thickness of the webs. The amount of material on the faceshells has a greater impact on the fire resistance than the amount of material on the webs [43]. The thickness of the faceshells is more important than the thickness of the webs because if the faceshells are thicker there will be less radiation within the cells [15]. This is because there is more material to absorb heat before it can reach the cells.

\subsection{Methods of Improving Fire Resistance: Insu- lation}

\subsubsection{Mineral Wool}

Mineral wool is classified as an inorganic fibrous material. This means that air is trapped between the mineral fibers. As air has a very low thermal conductivity $(0.024 \mathrm{~W} / \mathrm{mK})$ this makes mineral wool a good thermal insulator [45]. Mineral wool is an incombustible and cost effective insulator which allows it to be used in a wide variety of applications. Because of this, mineral wool is widely used. [45]. 
Mineral wool is mainly composed of amphibolite and the rest of it is comprised of additives (usually limestone and calcium oxides) and Fe2+ [45]. The components are all put into a blast furnace and the temperature is increased to around $1500{ }^{\circ} \mathrm{C}$ so that everything melts [45]. It is then put into a rotating tank and the mixture escapes through microscopic holes which creates molten fibres [45]. The mixture then cools and solidifies the fibers. Special resins are used to hold to fibers together as the mineral wool is compressed into different shapes [45]. The resins increase the fibers' cohesion and the material stiffness. The newly shaped material is put into a furnace and heated to $170{ }^{\circ} \mathrm{C}$ and the resin combines with the fibers [45]. Then the material is heated to $250{ }^{\circ} \mathrm{C}$ to create a hard plate, Figure 2.18 [45].

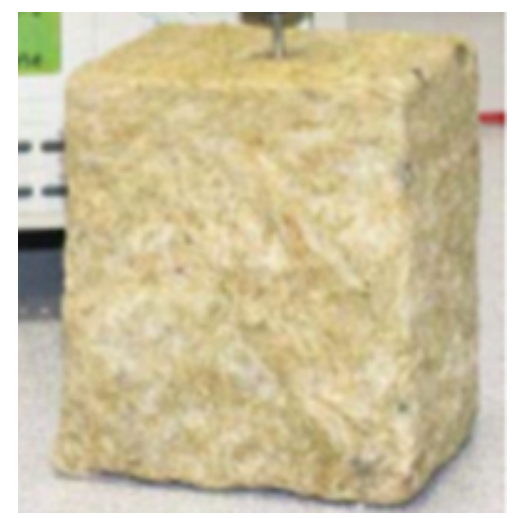

(a)

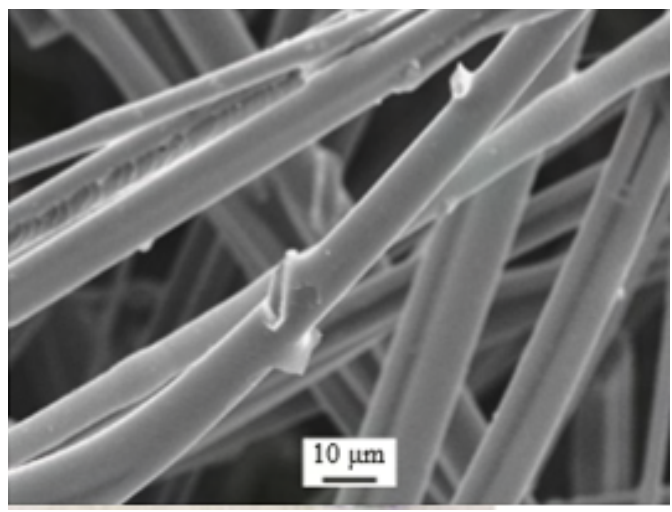

(b)

Figure 2.18: (a) Mineral wool sample) (b) Mineral wool fibers [45]

Moisture inside the mineral wool is usually undesirable, so some mineral wool includes hydrophobic additives in order to help the material repel water [46]. Sometimes hydrophilic additives are used in special circumstances such as the "desalination of masonries and green roofs" [46]. Therefore, the thermal properties of both hydrophilic and hydrophobic mineral wool are of interest.

As mineral wool is heated it goes through several different phases. The first phases occurs at $100{ }^{\circ} \mathrm{C}$, as a small loss of mass occurs due to removal of free water and causes a "weak endothermic effect" [47]. At "200 ${ }^{\circ} \mathrm{C}$ the binder resin decomposes, and changes the properties of the [mineral] wool" [45]. At $680{ }^{\circ} \mathrm{C}$, the material reaches its glass transition temperature $(\mathrm{Tg})$ and the material beings to oxidize. Once the material reaches above $800{ }^{\circ} \mathrm{C}$ (the crystallisation temperature Tc) the material beings to crystalize until a peak crystallisation temperature $(\mathrm{Tp})$ is reached [47]. At 
this point an exothermic effect is observed which is caused by the final crystallization of the mineral wool fiber [47]. When Tp is reached the specific heat drops due to an exothermic reaction while the material crystallises. After the exothermic reaction is completed the specific heat increases again, but it is lower than before [48].

Mineral wool used in working temperatures higher than $240-250{ }^{\circ} \mathrm{C}$ run the risk of the organic binders in the mineral wool decomposing [47]. This in turn would cause the mineral wool to fall apart and no longer provide thermal insulation. Therefore, mineral wool should not be used in furnace applications where the temperature is expected to regularly go above $250{ }^{\circ} \mathrm{C}$. The mineral wool still has favorable thermal insulation properties at high temperatures, which makes it good for passive fire protection. However, if the mineral wool is exposed to a fire and reaches a temperature of above $250{ }^{\circ} \mathrm{C}$ it may need to be replaced due to the loss of organic binders and the physical property changes during the crystallisation process.

\section{Moisture}

Moisture in the mineral wool takes the place of air and because water has a higher thermal conductivity than air, the thermal conductivity of the mineral wool is increased [45]. However, when the water evaporates out again the material goes back to its original thermal conductivity because the moisture "only displaces the air and does not affect the material's fibers" [45]. "Many mineral wool products are provided with hydrophobic substances" to help reduce the moisture content and improve the thermal insulation properties [49]. During the test it was found that materials that were more hydrophobic had higher thermal conductivities at higher moisture contents compared to more hydrophilic materials.

It was found that moisture had a negative effect on the thermal conductivity of the material; however, once the water evaporated the thermal conductivity returned to normal [45]. This means that if the mineral wool is being used at low temperatures, special care should be taken to ensure that no moisture is allowed to contaminate it. However, if the material is being used at high temperatures, the moisture content is not as large a concern. The other finding about moisture content was that hydrophilic materials had lower thermal conductivities than hydrophobic materials as the moisture content is increased.

The reason why hydrophobic materials are still used is that they can reduce the amount of moisture that is able to enter the material, whereas a hydrophilic materials 
increase the amount of moisture. Because of this hydrophobic materials have lower moisture content than their hydrophilic counterparts under the same conditions. As can be seen from the data, a lower moisture content was more important to the thermal conductivity than the type of additive used. However, if it is known that the moisture content will be high regardless of the type of additive used, hydrophilic additives would be the better choice, as they have better thermal conductivities at high moisture contents [46].

\section{Oxygen}

When $\mathrm{Fe}_{2}+$ becomes oxidised it becomes $\mathrm{Fe}_{3}+$, which adds to the mass of the material. This normally occurs at around $760{ }^{\circ} \mathrm{C}$ (between the glass transition temperature and the temperature of crystallisation) [48]. The oxidation of Fe2+ causes a nanocrystalline surface layer (NCSL) to be formed on the mineral wool. This oxidation and NCSL do not form in argon due to the lack of oxygen [48].

When the amount of $\mathrm{Fe} 2+$ is low, there is little mass increase and little change in $\mathrm{Tp}$ when heated in air or argon due to the limited oxidation that occurs in air [48]. The NCSL lowers the activation energy for crystallisation and protects the material from sintering [48]. This means that the material was able to hold itself together better and avoid breaking apart into powder. The materials that had less Fe2+ were unable to form much of a NCSL, and so they were found to have a worse high temperature stability. Also, as materials that had pre-oxidised the $\mathrm{Fe} 2+$ were also unable to form very much of a NCSL, and so they were also found to have a worse high temperature stability. Also, as the creation of the NCSL requires oxygen, it was found that materials heated in argon did not perform as well as those in air. For these reasons a material with higher $\mathrm{Fe} 2+$ is a better choice for use in high temperatures when there is oxygen available. Materials that have been pre-oxidised or that were created with low $\mathrm{Fe} 2+$ should be avoided as they will fall apart at high temperatures and lose a significant amount of their thermal insulating ability.

Mineral wool is well suited for repeatedly being heated to temperatures under $250{ }^{\circ} \mathrm{C}[47]$. At the lower temperature range it is important that the material have a low moisture content to improve the thermal conductivity. At high temperatures, moisture is of little significance and the focus shifts towards the amount of $\mathrm{Fe} 2+$ that is mixed into the material. A higher concentration of $\mathrm{Fe} 2+$ is preferred for its oxidation properties. Due to its superior thermal properties at all temperatures, 
mineral wool is well suited as a passive fire protection material.

\subsubsection{Gypsum}

Gypsum is a common material used in the protection of major structural components of a building. For example concrete structures, steel structures, and wood structures have to be protected from deterioration resulting from fire conditions. It is common in practice to protect structural components using gypsum wallboards due to its relatively cheap economic value and effective properties under fire conditions. Even though gypsum has been proven to be excellent under fire conditions, experiments have shown that it can be improved by the introduction of diverse fillers made from industrial by products or pure substances.

Gypsum is a sedimentary rock found in nature and mostly embedded in the ground. The rock is mined from different parts of the world and is easily extracted. Gypsum consists of $32.6 \%$ lime, $46.5 \%$ sulphuric anhydrite, and $20.9 \%$ water and has a $\mathrm{PH}$ of 8.5-10 [50]. Gypsum board is a construction material that consists of a layer of gypsum plaster compressed between two pieces of paper to create a solid panel $[50,51]$. The primary material of gypsum board is the porous solid gypsum plaster which is composed mostly of calcium sulfate dihydrate, CaSO42H2 [50, 51]. When heat is applied to gypsum board, two chemical reactions known as calcination (Equation 2.12 and 2.13), allow water to be liberated as vapour and the gypsum plaster to become dehydrated calcium sulfate $[50,51]$.

$$
\begin{gathered}
\mathrm{CaSO}_{4} 2 \mathrm{H}_{2} \mathrm{O}+\mathrm{Q} \leftrightarrow \mathrm{CaSO}_{4} \frac{1}{2} \mathrm{H}_{2} \mathrm{O}+\frac{3}{2} \mathrm{H}_{2} \mathrm{O} \\
\mathrm{CaSO}_{4} \frac{1}{2} \mathrm{H}_{2} \mathrm{O}+\mathrm{Q} \leftrightarrow \mathrm{CaSO}_{4}+\frac{1}{2} \mathrm{H}_{2} \mathrm{O}
\end{gathered}
$$

During a fire, this endothermic dehydration reaction delays the transfer of heat until the water is removed from the gypsum board and therefore increases the fire resistance of gypsum board 2.19 [51]. For improved fire resistance, several gypsum boards (such as Type X) are available which have their mixtures modified in order to make it more fire resistant than typical gypsum board [50]. 


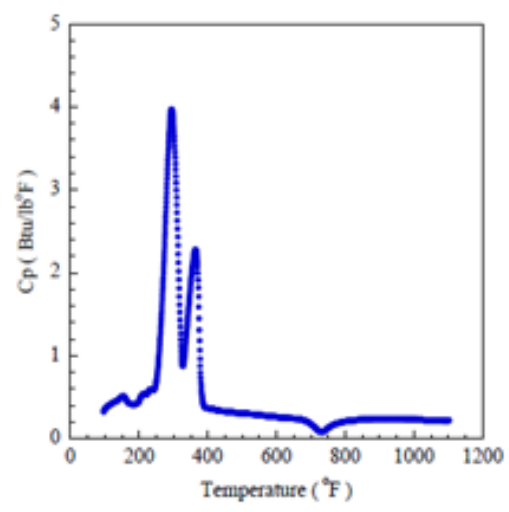

Figure 2.19: Specific heat of Type X gypsum board as a function of temperature [51]

As a function of temperature, thermal conductivity was found to originally decrease at around $100{ }^{\circ} \mathrm{C}$, and then steadily increase as temperature increased further [51]. This original decrease in thermal conductivity represents dehydration of the gypsum board. The specific heat increase dramatically between $121^{\circ} \mathrm{C}\left(250^{\circ} \mathrm{F}\right)$ and $204^{\circ} \mathrm{C}\left(400^{\circ} \mathrm{F}\right)$ which is caused by the dehydration of the gypsum board, Fig $\mathrm{x}$. The first spike represents the first calcination reaction, which is often completed by the time a specimen reaches $125^{\circ} \mathrm{C}\left(257^{\circ} \mathrm{F}\right)$. The second spike represents the second calcination reaction. The slight drop in specific heat at around $385{ }^{\circ} \mathrm{C}\left(725^{\circ} \mathrm{F}\right)$ is indicative of an exothermic reaction in which the crystalline calcium sulfate restructures itself from a soluble to insoluble energy state $[51,52]$.

\subsubsection{Epoxy Insulation}

Epoxy resins have been found to have "superior properties in adhesion, heat resistance, corrosion resistance, and low shrinkage on cure" [53]. Because of these properties it is widely used for a number of different applications. Epoxy materials also have to maintain a high thermal and flame resistance. Some ways to improve the thermal resistance of epoxy resins are by the addition of flame retardants [53]. Some additives such as "bromine-containing aromatic compounds in conjunction with antimony oxide and inorganic materials such as metal hydroxides and metal oxide are widely used" [53]. The problem with theses additives is that during the combustion process they create toxic fumes [53]. Because of this, "non-halogenated flame retardants" are preferred [53].

Jeng et al tested phosphorus-containing epoxy polymers to determine their flame 
retardant properties [53]. The results of these epoxy polymers was an improvement in the fire resistant properties, but with a minor reduction in the thermal stability during early part of the fire [53]. The best phosphorus content was $6.19 \%$, as shown by the "high char yield of nearly $30 \%$ at $850{ }^{\circ} \mathrm{C} "$ [53].

\subsubsection{Intumescent Paint}

Intumescent coatings are a thin paint-like substance usually placed on a member (usually steel) to increase its fire resistance. The coating takes up little space, is aesthetically pleasing, and is not difficult to install [54]. Because of this, intumescent coatings are now a prominent passive fire protection materials used in steel buildings [55]. The intumescent coatings are composed of a three parts: an acid source, a carbon source and a blowing agent [55] [54]. These ingredients are bound together by a polymer matrix [55]. When exposed to flame or radiation, "the acid source breaks down to yield a mineral acid, then it takes part in the dehydration of the carbonization source to yield the carbon char and finally, the blowing agent decomposes to yield gaseous products. The latter cause the char to swell and produce the insulating multi-cellular protective layer" [54]. The char layer has low reactivity and provides a barrier with high thermal resistance which slows the temperature rise of the protected steel [55].

At the start of heating, the coating increases its temperature rapidly [55]. When the temperature of the intumescent coating reaches its critical temperature (around $100-250^{\circ} \mathrm{C}$ ), the polymer matrix starts to melt and forms a viscous fluid [55]. When the temperature of the coating reaches $280-350{ }^{\circ} \mathrm{C}$, "the blowing agent within the coating decomposes to release a large amounts of gas of which some fraction is trapped within the fluid coating" [55]. Finally, the coating changes from a fluid to a form of char [55]. Figure 2.20 demonstrates the process. The structure of coatings is divided a layer of virgin coating, a swelling layer, and a layer of char [55].

The intumescing process is quite complex, and so determine the thermal conductivity of an intumescent coating is not done directly, but instead by using an effective thermal conductivity [55]. Han et al found that at thicknesses of intumescent coating greater than $0.8 \mathrm{~mm}$ the effectiveness did not increase at a large rate [56]. Therefore, the common use of $1 \mathrm{~mm}$ thickness of coating is adequate [56].

Two common additives are ammonium polyphosphate (APP) and boric acid [54]. 


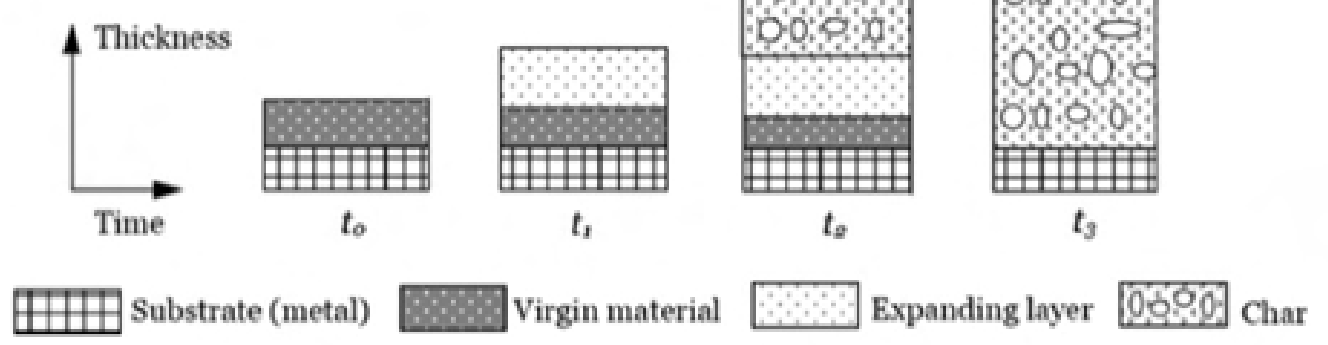

Figure 2.20: Intumescing process [55]

Both of these are used as fire retardant additives and increase the time to failure of the protected steel. If the melted intumescent coating has a low viscosity, easy diffusion of gases takes place and the gases will not be trapped but rather escape to feed the flame [54]. So it is important not to have low viscocity during the blowing phase of the process. Boric acid helps to stop the fall of viscosity in the intumescent paint by dehydration into boron oxide, which is like a hard glass [54]. When APP is added it can be used both as blowing agent and acid source. The problem is APP is that the char created is too light and exhibits poor mechanical resistance [54]. It was found that adding boric acid is better than adding APP, but adding both together is better still [54].

\subsection{Issues with Heated Masonry Walls}

\subsubsection{Thermal Bowing}

Thermal bowing is caused when one side of a wall is exposed to fire and heated while the other side is unexposed [57]. The temperature difference causes an uneven expansion inside the wall, due to the fire exposed side expanding more than the unexposed side [57]. This causes the wall to bend out towards the fire, with the maximum curvature being at the wall's centre, Figure 2.21 [57]. Data on thermal bowing is limited since standard testing does not require the measurement of samples' displacements during testing. This is an important phenomenon since it can lead to premature failure due to the curvature of the wall. The curvature occurs rapidly at the start of the fire and then recovers during the fire. This rapid change happens 
due to the increase in the temperature difference between the exposed and unexposed side. The reason the wall recovers is that the unexposed part eventually heats up as well and reduces the temperature difference between the two sides [58] [57]. Another reason the wall recovers is that the Young's modulus decreases at high temperatures [58] [57]. Thermal bowing causes eccentric loads, which adds stress to the wall. If the deflections are large enough they may cause the wall to fail earlier. Large deflections from thermal bowing usually occur in unrestrained brick walls and concrete floors, and the deflections are increased when the element is subjected to a faster heating rate [59] [57].

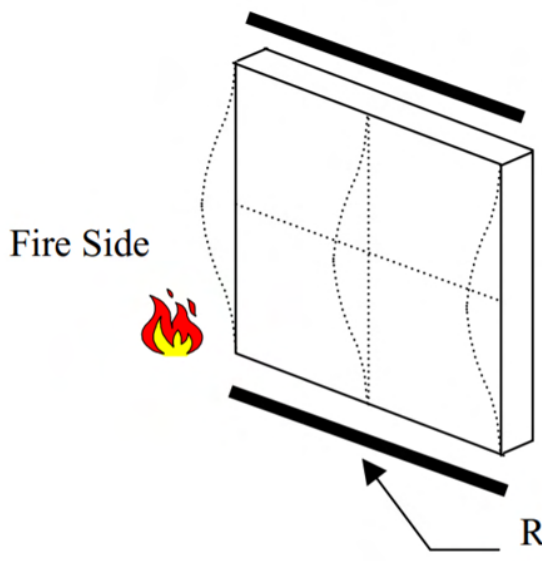

(a)

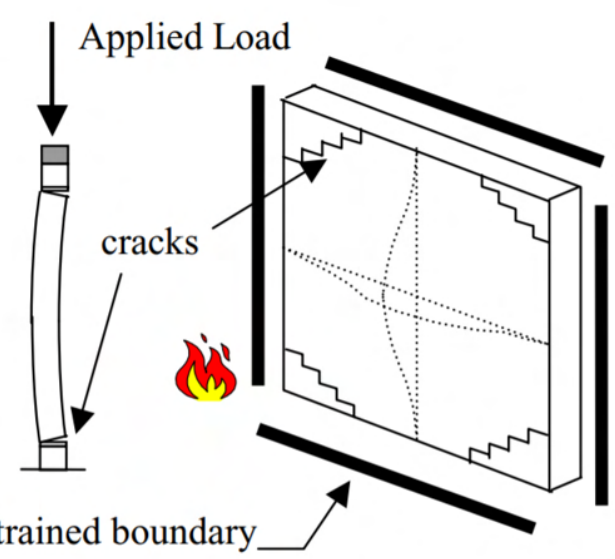

(b)

Figure 2.21: Thermal Bowing a) Loaded b) Unloaded [60]

When masonry walls are heated and undergo thermal bowing, they go through three phases. The length of each phase depends on the loading and the slenderness ratio. Phase 1 is a rapid increase in deflection, which is caused by thermal bowing. Phase 2 has no increase in deflection which is caused by the applied loads counteracting thermal bowing. This phase is lengthened if the applied load is higher. Phase 3 is a further increase in deflection, which is caused by the eccentricity of the applied load. This phase is shorter if the applied loads are higher [61] [57]. In general, the higher the slenderness ratio the faster the walls collapse. Lightly loaded walls with high slenderness ratios take longer to fail, whereas walls with a low slenderness ratio and with an applied load of approximately $50 \%$ of the permissible design load fail the fastest. Walls with low slenderness ratio and with the applied load above or below 
the $50 \%$ load also take longer to fail [61] [57].

Masonry materials with a low coefficient of thermal expansion can help to reduce thermal bowing, but if the values are too low it may cause the wall to fail prematurely due to integrity failure (when a member allows that passage of smoke or flames). When walls were tested with scoria aggregate (an aggregate with low thermal expansion), several walls failed in integrity [14] [57]. The reason for this is that the mortar undergoes shrinkage when heated, and if the blocks do not expand, to some degree, cracks will form where the mortar and block meet and the wall will have integrity failure. In non-load bearing tests, the specimens are built to fit tightly into a semi-rigid rectangular frame and the resistance provided by the frame makes it unlikely for any cracks to open up [14] [57]. This means that, in testing of non-load bearing walls integrity failure is less likely to occur. When non-load bearing walls are tested, the restraint from the frame causes the wall to curve in a spherical shape with cracks across the four corners.

Load bearing walls exposed to high temperatures do not usually undergo crushing failure because of thermal bowing [11] [57]. Instead, instability failure occurs due to the horizontal displacement in the wall [11]. It has been found that failure is most likely to occur when the displacement at midspan reaches 0.8 times the thickness of the wall [11]. Equations to calculate the midspan deflection with respect to temperature have been created for simply supported and cantilever walls, Equations 2.14 and 2.15 respectively [11]. It can be seen that the deflection for a cantilever wall is four times that of a simply supported wall. The supports help to reduce thermal bowing by resisting movement and providing confinement forces, with fixed supports being the most effective. While loading can mitigate the effect of thermal expansion, the mechanical decay induced by high temperatures on the exposed side can force the compressive stress to migrate towards the unexposed side [11]. If the load is high enough, reverse bowing can occur. Reverse bowing occurs when the structural response is dominated by the decay of mechanical properties.

$$
\begin{aligned}
& \Delta_{m}=\left(\alpha L^{2} \Delta T\right) / 8 d \\
& \Delta_{m}=\left(\alpha L^{2} \Delta T\right) / 2 d
\end{aligned}
$$

$\Delta_{m}=$ displacement at midspan, $\alpha=$ thermal expansion coefficient, $L=$ height of 
the wall, $\Delta T=$ change in temperature, and $d=$ thickness of the wall [11].

Thermal bowing is mostly controlled by the coefficient of thermal expansion and geometry of the wall. Therefore as long as the aggregate or additive do not significantly change the coefficient of thermal expansion it should not have a large impact on the thermal bowing that occurs. The cement mix has minimal effect on the coefficient of thermal expansion, and so SEMs added to the cement mix should not have a large impact on the thermal bowing. Aggregates can have a much higher impact on the coefficient of thermal bowing. However, lightweight aggregates usually have lower values for the coefficient of thermal expansion, so the risk of failure due to thermal bowing would be minimized.

\subsubsection{Spalling}

Spalling can result in a significant loss of concrete during fire [57]. This exposes the deeper layers of the concrete to the fire, which in turn increases the heat transmission to the inner layers. This can cause members to fail sooner than anticipated. It is a special concern for masonry walls that are ungrouted since the inner cavity can heat up very quickly once the faceshell spalls off. This heated inner cavity can cause part of the wall to spall and fail due to integrity, or even cause the unexposed side to reach the critical failure temperature much sooner than anticipated.

There are two different types of spalling. Explosive spalling occurs earlier on, and involves chunks of concrete exploding from the concrete member. Slower spalling (sloughing off) occurs later as cracks form parallel to the fire-exposed surfaces, which causes the separation of the concrete layers and part of the concrete falls off [62] [57]. An example of the slower spalling can be seen in Figure 2.22a [57]. Cracks formed in between the web and the faceshell of the masonry units and after some time the faceshells began to slowly fall off. In Figure 2.22b it can be seen that the remaining faceshell has had some loss of material, either from explosive spalling during heating, or slower spalling after cooling.

When concrete is heated to $105{ }^{\circ} \mathrm{C}-160{ }^{\circ} \mathrm{C}$ the free water vaporises and causes a rise in pore pressure [63]. Another rise in pore pressure occurs between $160{ }^{\circ} \mathrm{C}$ $180{ }^{\circ} \mathrm{C}$ and is caused by the release of the chemically bound water [63]. After 180 ${ }^{\circ} \mathrm{C}$ the pore pressure continues to rise slowly until the concrete reaches $220{ }^{\circ} \mathrm{C}-245$ ${ }^{\circ} \mathrm{C}$ where it reaches the maximum pore pressure [63]. Once the maximum pressure 


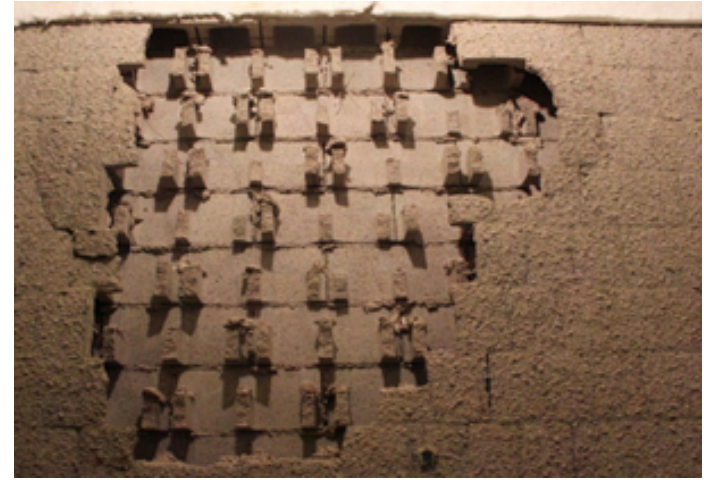

(a)

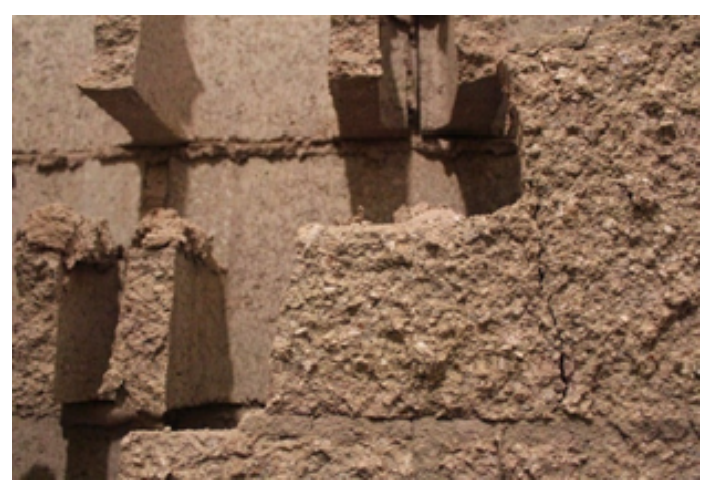

(b)

Figure 2.22: (a) Masonry Spalling (Exposed Surface) (b) Close Up of Masonry Spalling

is reached cracks form and the concrete either explodes because of the pore pressure, or the pressure is allowed to escape through the cracks and the system reaches an equilibrium [63]. Even when there are some paths for moisture to escape, spalling may still occur due to the phenomena of moisture clog [64]. Moisture clog occurs when the moisture in the concrete closest to the fire exposed surface evaporates and results in the significant increase in the pore pressure. This pore pressure increase causes part of the vapor to migrate to the surface, and the remainder migrates deeper into the concrete [64]. The vapor deep within the concrete condensates and results in the saturation on the concrete and can significantly increase the pore pressure of the concrete [64].

While it is difficult to predict exactly when and where spalling will occur, factors that increases the likelihood of spalling are known. The higher the strength of the concrete, the higher the chance of spalling. This is because higher strength concrete has lower porosity, which means that the vapour pressure cannot escape due to the higher density [65]. The probability of spalling occurring is also increased when the moisture content is higher because it causes a higher vapour pressure under fire conditions [63]. It is important to note that larger specimens have a greater chance of spalling, so if smaller specimens are used in testing it can lead to incorrect results.

Another method of reducing the occurrence of spalling is to change the type of aggregate used. Carbonate aggregate has better fire resistance and better spalling resistance than siliceous aggregate. This is due to the fact that carbonate aggregate has a higher specific heat, better strength, ductility, thermal expansion, and thermal 
stability [65]. However siliceous aggregate like flint may reduce spalling by forming micro cracks when they expand, [13]. These micro cracks can increase the permeability of the concrete and allow the vapours to escape, however they also decrease the strength of the concrete [13].

Since spalling is directly related the porosity of the concrete, lightweight concrete has less chance of spalling than high strength concrete. The voids in the porous lightweight aggregates help to reduce moisture clog and allow moisture paths to escape. The dense structure of the high strength concrete has the opposite effect, and so other methods are required to reduce the spalling. Fibre reinforcement is traditionally used to help minimize spalling, especially in high strength concrete. Adding polypropylene or steel fibres into the concrete helps to minimize the spalling. The polypropylene fibres (PPF) melt at lower temperatures and allow the vapour pressure to escape, whereas the steel fibers increase the strength and ductility of the concrete and reduce crack widths, which makes the concrete less likely to fall apart [65]. The addition of the PPF causes a significant decrease in pore pressure, which stops the concrete from spalling when it otherwise might have [63]. The reason for the decrease in pore pressure is that PPF increases the gas permeability. For concretes with PPF the permeability increases in the range of $120-250{ }^{\circ} \mathrm{C}$ (around the melting point of the PPF) [13]. When PPF melts at around $170{ }^{\circ} \mathrm{C}$ they first expand (forming cracks) and then shrink [13]. After shrinking, a void is created in the concrete which increases the permeability to around seven times higher than at ambient conditions [13]. If the cracks formed during the expansion connect together, they can create passageways for moisture to escape. For concretes without PPF, the gas permeability only begins to increase during the range of $250-400{ }^{\circ} \mathrm{C}$ [13].

Also, the heating rate can be beneficial or detrimental, depending on the temperature increase used. Some researchers have found that higher thermal gradients can be beneficial since it can create micro cracks in the concrete which allows pore pressure to escape $[13,63]$. When samples were tested with a $5{ }^{\circ} \mathrm{C} /$ min heating rate vs a 25 ${ }^{\circ} \mathrm{C} / \mathrm{min}$ it was found that the higher heating had consistently lower pore pressure due to the increased number of micro cracks [63]. However, other researchers found that when heating rates are too high (over $150{ }^{\circ} \mathrm{C} / \mathrm{min}$ ) they can cause an increase in spalling of concrete [65-67]. This means that there is a point where the heating rate goes from creating beneficial micro cracks, to increasing the likelihood of harmful spalling. 
Spalling may be caused not only from the pore pressure, there is also potential for spalling due to the high thermal gradients that occur due to high heating rates $[66,67]$. These thermal gradients cause thermal stresses in the concrete and can cause cracking or spalling. The thermal stresses are formed because the temperature increases faster at the surface of the concrete, so compressive stresses are formed parallel to the heated concrete surface, while tensile stresses are generated in the inner concrete in a perpendicular direction. When the compressive stress exceeds the tensile stress, spalling of concrete occurs", as seen in Figure 2.23 [21]. It has been found that when concrete was heated to $500{ }^{\circ} \mathrm{C}$ after three minutes, the cracks in un-spalled concrete were mainly formed by the thermal stresses from the large temperature gradient [66]. To put this into perspective, the standard fire is $487^{\circ} \mathrm{C}$ after three minutes [38]. It can be inferred from these results that when concrete is heated quickly the temperature gradient might be a more important factor than the pore pressure. Researchers are still debating the exact ${ }^{\circ}$ umstances that determine whether the pore pressure or thermal stresses are the dominant cause of spalling.
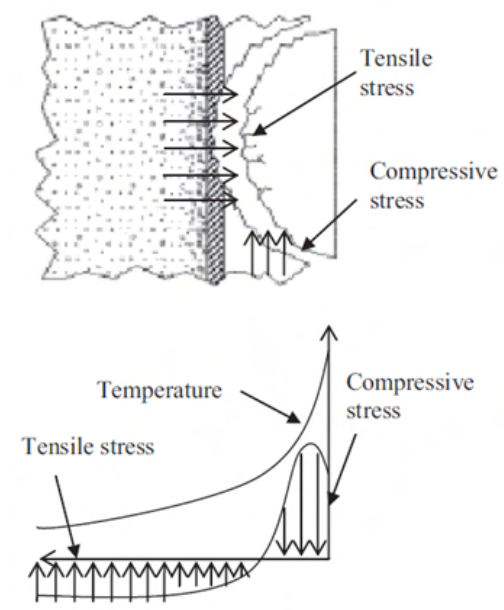

Figure 2.23: Thermal Gradient Induced Stresses [21]

Tests have been done with low heating rates $\left(0.1^{\circ} \mathrm{C} / \mathrm{min}\right)$ to determine if spalling will occur [67]. The low heating rate did not produce any spalling, partially because there were very minimal stresses from thermal gradients, and partially because the pore pressure had much more time to attenuate. Tests have also been done with no free moisture by baking the sample to $80{ }^{\circ} \mathrm{C}$ in order to evaporate all the free moisture [13]. When the sample was put in several different heating rates and no 
spalling occurred. These tests proved that high thermal gradients and pore pressure are both required in order for spalling to occur, however it is still unclear the exact role each plays.

\subsubsection{Summary of Issues}

The choice of aggregates can have a large impact on the thermal and mechanical properties of masonry. Lightweight aggregates retain their strength at high temperatures for longer period than normal weight aggregates. However, the specific heat of normal weight aggregates improves more than lightweight aggregates as temperature increases. The aggregates and cement need to have similar thermal expansions in order to reduce cracking during heating. It is also important for the mortar and the blocks to have complementary thermal expansions in order to minimize the cracking that can occur at the interfaces. In general, more moisture present in the masonry member improves its fire resistance by increasing the specific heat (as long as it does not lead to spalling).

To mitigate thermal bowing a material with a low coefficient of thermal expansion should be chosen. Thermal bowing can also be reduced by increasing the distance between the exposed and unexposed surfaces, or decreasing the slenderness ratio. Also, the use of fixed supports as opposed to pin, roller, or cantilever supports greatly reduces the thermal bowing because even at large deflections the specimens are stable due to the confinement forces from the frame. While the applied loads on a masonry wall can reduce the effects of thermal bowing, high loading can cause reverse bowing and structural failure.

Moisture can have a large impact on the fire resistance of concrete masonry member, but it can also cause harmful spalling at lower heating rates. It is important to choose the proper aggregates and mix designs in order to ensure a higher porosity in order to reduce the likelihood of spalling. High heating rates can either reduce spalling by creating micro cracks to relieve pore pressure, or increase spalling because of the high temperature gradients depending on the heating rate used. Spalling caused by high heating rates is usually caused more by thermal gradient-induced stress instead of the increased pore pressure, but there is some debate over how much each factor contributes to spalling. 


\section{Chapter 3}

\section{Experimental Procedure}

\subsection{Introduction to the Experiment}

The purposed of this experimental program was to investigate the fire resistance of existing full scale masonry materials. Different existing masonry wall geometries and mix designs, as well as different styles of mortar joints were investigated. More novel wall geometries and the use of insulation materials were also researched. To accomplish this feat a test structure was built to instrument and test four full scale masonry walls at once. A propane burner was used to ensure the specimens were exposed to the standard fire. With each test a new set of four full scale masonry walls were built, instrumented, tested, then demolished to make room for the next set of specimens. Details on the exact experimental procedure can be found in the following sections.

\subsection{Thermocouples}

\subsubsection{Thermocouple Placement}

The CAN/ULC-S101-14 states that a minimum of nine type K thermocouples are required to measure the temperature on the unexposed side of a partition wall [38]. Five of the thermocouples are required to be placed in specific locations. One must be placed at the centre of the test specimen, and four other must be placed at the center of its quarter sections. The remaining four thermocouples can be located at the discretion of the testing authority. Further restrictions are that none of the thermocouples can be located within the greater of 1.5 times the thickness of the wall 
or $300 \mathrm{~mm}$. The only time when a thermocouple should be placed on the outside edge is when there is some element of the construction not otherwise represented with the other thermocouples.

In order to comply with the standard and get the best coverage of the wall, the thermocouples were placed in a diamond shape. This is because vertical heat flow within the masonry wall is of particular concern for ungrouted masonry, and has limited data. The diamond shape allows for a thermocouple to be placed at the lower limit of the masonry wall, as well as the upper limit, thereby achieving the best coverage to determine the effects of vertical heat flow. Another reason for the diamond shape is that each column of cells can heat up differently due to cracks in the masonry. If a crack occurs at the bottom of the wall the heat will flow up through the hollow cells and heat up the top of the wall. This will also heat up any thermocouples within the same column of cells. By placing the remaining two thermocouples in the left and right extremities of the wall, they have their own distinct columns of cells.

For modelling purposes, another nine thermocouples were placed in the same locations on the exposed side of the walls. This is to allow monitoring of heat transfer between the unexposed side and the exposed sides.

There are four unique locations on the blocks that a thermocouple could be placed $[6,7,68,69]$. This is because masonry walls are not homogeneous, and so depending on where the thermocouple is placed on the block, a different temperature will be measured. The four different thermocouple locations were in line with the corner of the block in the mortar $(\mathrm{C})$, the middle of the block in the mortar $(\mathrm{M})$, the solid webs $(\mathrm{S})$, and the hollow cells of the block (H), Figure 3.1. The nine thermocouples were split between these four different locations.

The top block of each wall (the $9^{\text {th }}$ thermocouple position) was made into a highly instrumented block (HIB) with four times the number of thermocouples on the surface to measure the temperature. The thermocouples in the HIB served a dual purpose: a) aid in future modeling and b) to allow for localized comparison of various aspects of the block. The top block was the location for the HIB because the top of the wall would heat up faster due to the heat rising, and it would therefore be the most critical location.

Thermocouples were placed on the exposed side (S1), on the middle of the block (S2), and on the unexposed side of the block (S3). For the thermocouples through the cells, two extra thermocouples were used on each inner face of the cell. An outline 


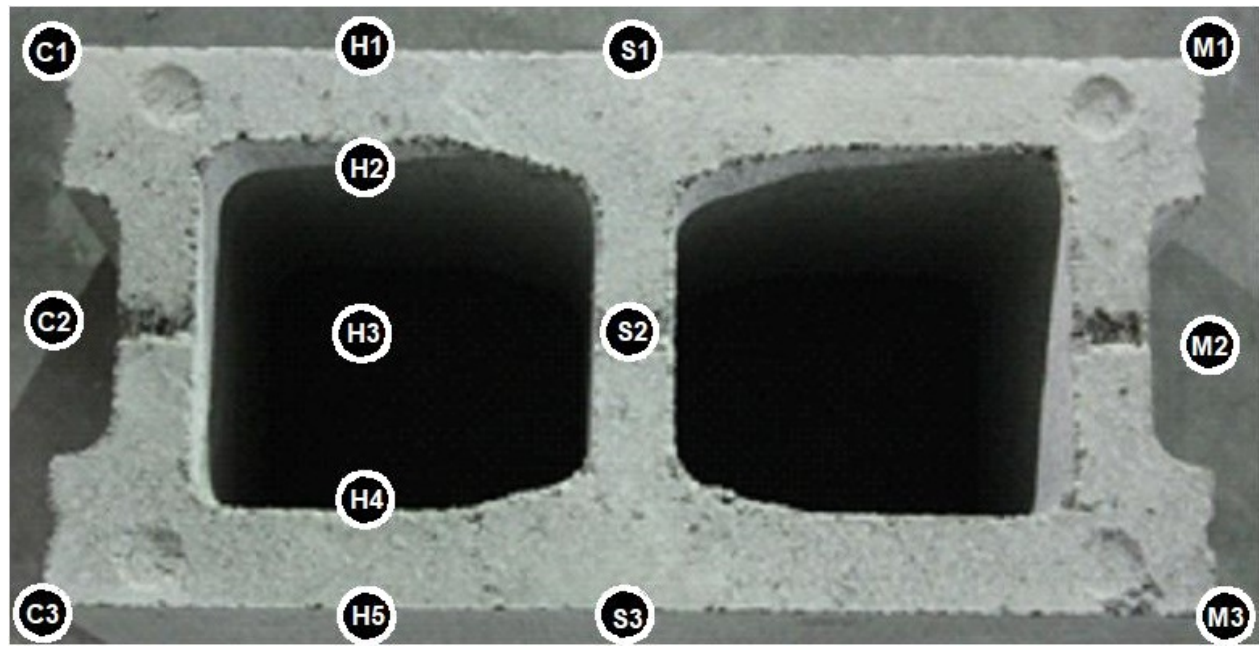

Figure 3.1: Thermocouple locations. (M) Mortar, (S) Solid Web, (H) Hollow Cell. The fire exposed side is the side with H1, S1 and M1

of the different placements throughout the block can be seen in Figure 3.1.

The thermocouples that were used were type K thermocouples. The thermocouples tree measuring the furnace temperature was constructed of shielded thermocouples due to their reusability. The thermocouples that were exposed or placed inside the wall were not shielded. The thermocouples on the unexposed side of the wall were also unshielded, but they were covered with special insulating pads as per the CAN/ULC-S101 requirements [38]. The thermocouples were placed in the centre of a $150 \mathrm{~mm}$ by $150 \mathrm{~mm}$ fibrefrax insulating boards and the boards were secured firmly to wall to ensure that the wire would remain covered. The purpose of the pads was to ensure that the temperature readings will not be affected by the convection or radiation to or from the ambient conditions.

\subsubsection{Thermocouple Readings and Accuracy}

The standard requires that the temperatures shall be read at intervals of at least 1 minute throughout the test. In the case of this experiment, the thermocouples readings were taken once every five seconds in order to allow for better modeling of the data, as well as to reduce the effect of short term equipment errors. Measurements were taken with a National Instruments NI cDAQ-9188 data acquisition unit, and Labivew software was used to organize and export the data.

The accuracy of Type $\mathrm{K}$ thermocouples is $2.2{ }^{\circ} \mathrm{C}$ or $0.75 \%$ of the temperature, 
whichever is higher [70]. While thermocouples are accurate, there is a time delay between the temperature reaching a certain point, and the thermocouple registering that temperature. The reason for this is that the thermocouple itself needs to heat up in order to measure the temperature. The CAN-ULC-S101 code requires the use of a lag correction for measuring the furnace temperature in order to compensate for the thermal lag in the thermocouples. Some of the thermocouple temperatures at the beginning of the test may not reflect the exact temperature at that point, due to this thermal lag.

\subsection{Furnace Temperature}

The ULC standard calls for the furnace temperature to follow the ULC standard fire curve, as seen in Equation 3.1. CAN/ULC-S101-14:

$$
T_{g}=T_{0}+750(1-\exp (-0.49 \sqrt{t}))+22.0 \sqrt{t}
$$

Where, $T_{g}=$ furnace temp $\left({ }^{\circ} \mathrm{C}\right), t=$ time $(\min ), T_{0}=$ ambient temp. $\left({ }^{\circ} \mathrm{C}\right)$

Propane burners were built to produce up to a $7 \mathrm{MW}$ fire which distributes the heat evenly between all walls tested Figure 3.2. The heat produced by the burners was controlled manually to ensure that the temperature followed the standard fire curve. The furnace had an additional eight thermocouples that were used to measure the temperature at several different heights along the furnace, and the average value was used to ensure the standard fire curve was being followed. After testing, the equivalent area concept was used to equate the furnace time temperature curve to the standard fire curve [38].

\subsection{Supplemental Monitoring, Thermal Imaging}

Thermocouples are used for a variety of different purposes. They are used to evaluate temperature gradients, heat propagation, and in-plane temperature homogeneity. They can also be used to figure out if spalling happens; however, the area where spalling occurs must be where the thermocouples are located. The drawback to using thermocouples is that they only give the temperature at distinct points on the wall.

As part of the testing procedure, thermal imaging was used to constantly monitor 


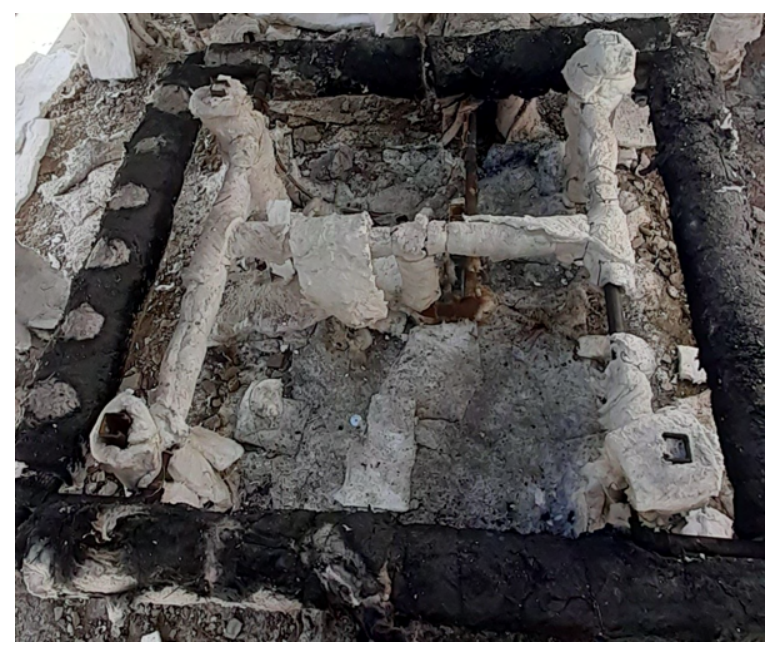

Figure 3.2: Barnsdale Burner

the test walls. The camera used was a high-resolution science grade LWIR CAMERAFLIR A655sc. Data from thermal imaging was used to draw contours of the non-uniform temperature profile on the unexposed surface of the walls, which allowed for the determination of the critical points on the surface both during and after the test. Unlike thermocouples, thermal imaging allows for monitoring the whole wall surface, which was useful if the critical points happen to be somewhere where there were no thermocouples. The thermal imaging was also used to determine locations of cracks and other defects in the wall, which helped to explain localized temperature increases in some thermocouples. Temperatures from the camera were also used to validate the thermocouple readings to ensure their accuracy when hot spots arose in the wall.

The thermal imaging camera was calibrated by inputting the emissivity of concrete (0.94), the relative humidity on the day of the test, the distance from the camera to the walls and the ambient temperature.

\subsection{Test Structure Almonte Lab}

The test structure built inside the Carleton Lab at Almonte, Figure 3.3. It was comprised of a base slab, with three course of grouted and reinforced masonry placed on top to create a base beam. From there, four fully grouted reinforced masonry columns extend upwards for 16 courses $(3.2 \mathrm{~m})$. Above the $16^{\text {th }}$ course there are another two courses of fully grouted reinforced masonry in order to create a masonry 
beam. Finally, precast concrete slab was placed above this beam in order to form the roof. A hole was cut into the roof slab in order to allow for ventilation during the test.

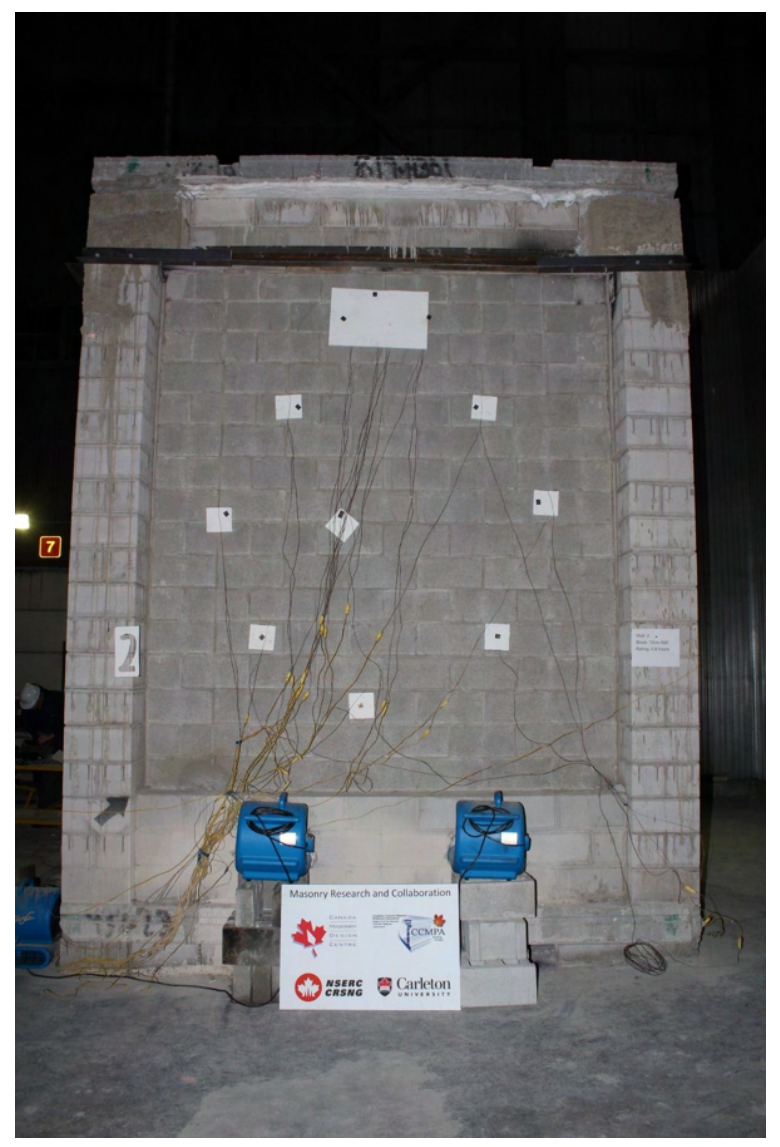

Figure 3.3: Almonte Test Structure

Each of the test walls were built in between the columns and the top and bottom beams. After each test the walls can be demolished and the next set of walls rebuilt in their place. The walls were all $2.8 \mathrm{~m}$ wide and $3.2 \mathrm{~m}$ tall ( 7 blocks wide, 16 courses high).

In order to protect the test structure itself from the effects of high temperature, permanent Ceramic Fiber insulation was used on all permanent parts of the structure. Ceramic fiber boards were placed on the columns and on the base of the beam in order to ensure that the insulation would provide enough strength to resist the forces exerted by the walls as they expanded. After the walls were built another set of fiber board was placed at all edges of the walls to ensure that if cracks form, the test structure 
would not be effected. This means that the outer $20 \mathrm{~cm}$ of the walls were insulated (not directly exposed to heat). For this reason the outer $20 \mathrm{~cm}$ of the wall was not considered part of the walls being tested, and no thermocouples were placed in this area.

Ventilation was provided by eight blowers (two under each of the four walls). These blowers provided oxygen to the burner and ensured that the hot gasses within the structure were mixed evenly.

\subsection{Test Structure Barnsdale Lab}

The test structure was built outdoors in the Carleton Lab at Barnsadale, Figure 3.4. The main test structure was built of prefabricated steel members. The test structure was bolted to a solid concrete pad with the eight support columns (four long columns on every corner, and four smaller support columns at the midway points along the perimeter). The structure formed four square wall sections of $2.4 \mathrm{~m}$ by $2.4 \mathrm{~m}$ where the masonry walls were built. This mean that the masonry walls were each 12 courses high, and six blocks wide. The roof of the test structure was solid steel, with a square hole in the centre to allow for ventilation during the test. Any steel sections surrounding the walls were insulated with ceramic fiber insulation to protect the structure from the elevated temperatures. After the walls were built flexible ceramic fiber insulation was placed at each of the four corners in order to protect the test structure from the intense heat. As such, the outer $20 \mathrm{~cm}$ of the walls were not considered part of the walls being tested, and no thermocouples were placed in this area.

Ventilation was provided from air entrained under the test structure itself. In order to protect the thermocouple wires, insulated cement boards were placed around the perimeter of the test structure. These boards also helped to stop any flames from impinging from below the test structure and heating up the exterior of the wall. Since the test structure was build outdoors, plywood barriers were erected to reduce the effects of wind during the test. 


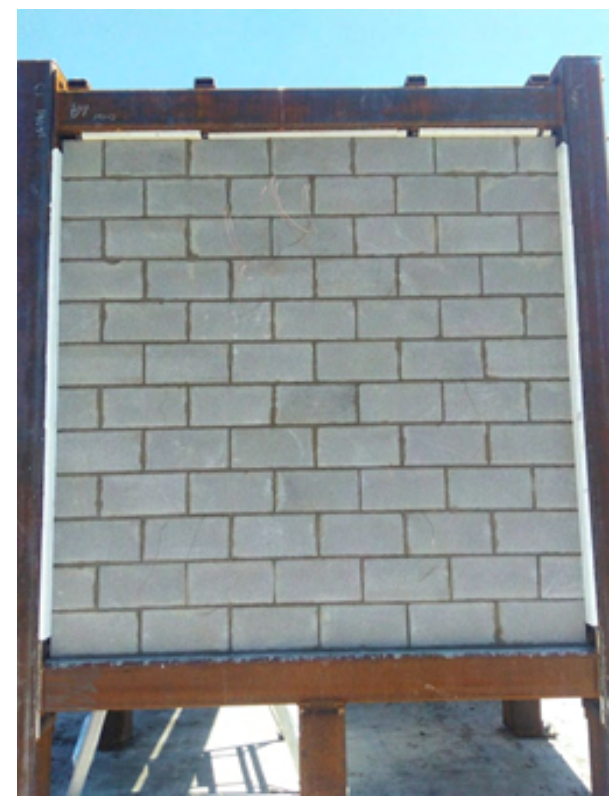

(a)

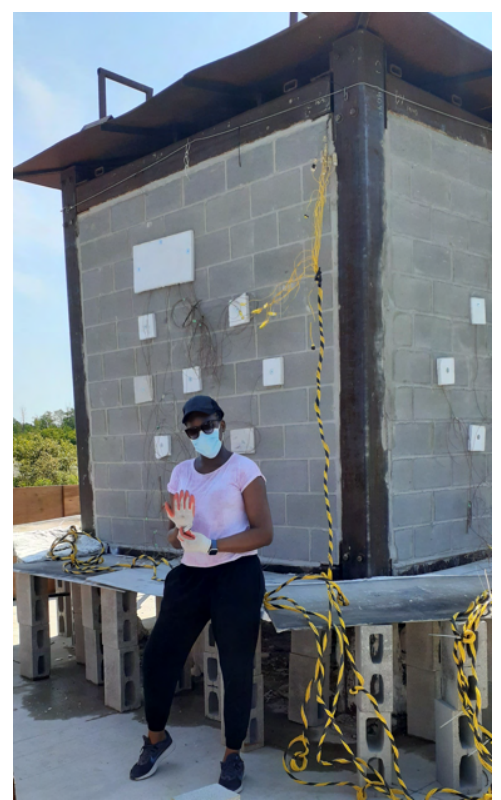

(b)

Figure 3.4: Barnsdale Test Structure (a) Uninstrumented (b) Instrumented

\subsection{During the test and after the test}

During the test the Labview software was used to monitor both the thermocouples on the walls, as well as the furnace thermocouples. The average furnace temperature (taken from eight furnace thermocouples) was controlled manually to ensure that the fire remained close to the standard fire temperature. The average wall temperatures were used to determine when all of the walls had failed. After the test is complete the thermocouples continue to take readings as the furnace cools and the walls begin to attenuate and then cool.

While the thermocouple readings are being logged, the thermal imaging camera is moved from wall to wall, taking thermal imaging pictures. This is done throughout the test to get as many temperature profiles as possible. After the test the thermal camera continues to take thermal imaging pictures, however this is done less frequently due to the length of the cooldown period.

After the walls have cooled the cracks are outlined and photographed in order to get a sense of the failure pattern. The amount of deflection after cooling is also measured and compared between all tested walls. Any other areas of failure or spalling are also photographed. 


\subsection{Test Matrix}

The test matrix can be found in Table 3.1. As the walls were tested four at a time, and so the test matrix is organized in groups of four walls for each test. The blocks sizes ranged from 10, 15, or $20 \mathrm{~cm}$ blocks. The concrete mixes included were either Normal Weight (NW), Lightweight (LW) or Carbon Cured (CC). The predicted fire resistance values calculated from the equivalent thickness of the blocks is provided. The naming convention for each wall that is used in the rest of the document is also provided.

It is important to note that Almonte Test $1 \mathrm{~A}$ and Almonte Test $1 \mathrm{~B}$ were conducted to ensure the test structure in the Almonte lab was capable of undergoing a standard fire test. As such the tests are incomplete. Likewise, Barnsdale Test 1A and Barnsdale Test 1B were conducted to ensure that the test structure in the Barnsdale lab was capable of undergoing a standard fire test. The reason for the change in the lab site was due to the closure of the Almonte lab. While these four tests cannot be used to determine the fire resistance of the respective walls, they are still useful for qualitative comparison of the different wall types.

Further information on the different tests and wall types can be found in the following sections. 
Table 3.1: Test Matrix

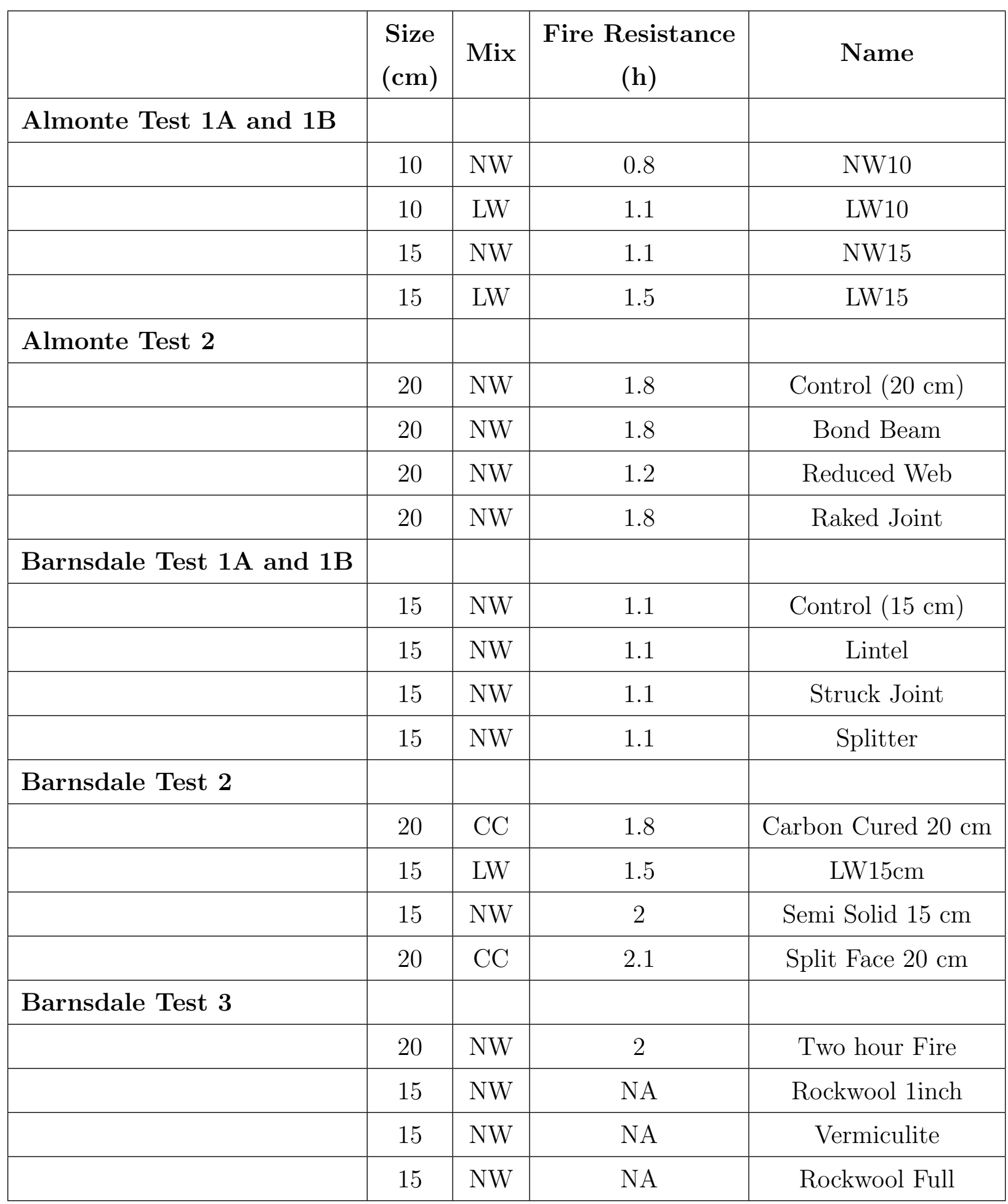




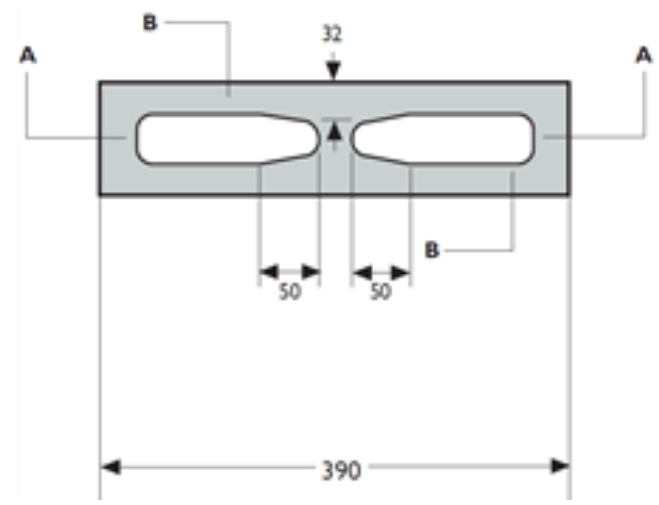

(a)

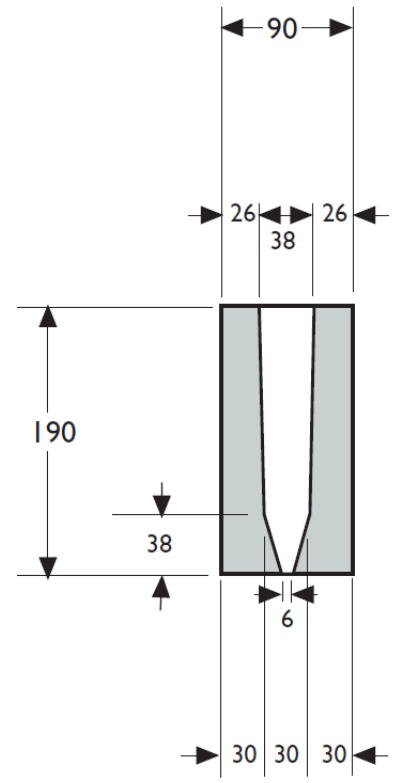

(b)

Figure 3.5: $10 \mathrm{~cm}$ block shape

\subsection{Almonte Test $1 \mathrm{~A}$ and $1 \mathrm{~B}$}

\subsubsection{Almonte Test 1, Walls tested}

The walls that were tested came in two mix designs and two sizes. The blocks were either lightweight (LW) or normal weight (NW) concrete and were either $15 \mathrm{~cm}$ or 10 cm thick. The four walls were NW10, LW10, NW15, and LW15. The smaller blocks were expected to have lower fire resistance, and the lightweight blocks were expected to have higher fire resistance. It is important to note that while the LW15 wall was expected to have the highest fire resistance, and the NW10 was expected to have the lowest fire resistance, the other two walls had the same fire resistance rating. BLock size, concrete type, fire rating, and wall for the four walls of Almonte Test 1 can be found in Table ??. Pictures and dimension can be found in 3.5 and 3.6. 


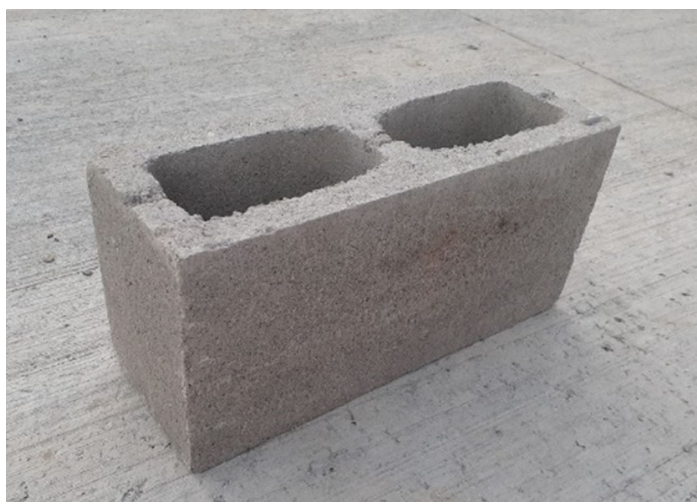

(a)

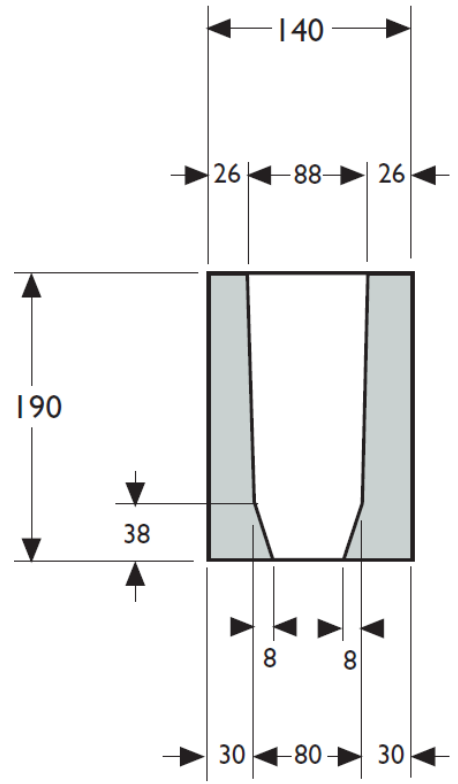

(b)

Figure 3.6: $15 \mathrm{~cm}$ block shape 


\subsubsection{Almonte Test 1, Issues and Improvements}

While it is important to use standards and tests done by others to help shape the test procedure, it is also important to improve the test procedure with each subsequent test. The first two tests done on this project were not run to completion, and were instead used to update the test structure and help determine which block types to use or avoid.

During this test there were several issues that arose. The first set of issues had to do with the structural aspects of the test structure. The columns on either side of NW15 began to bend outward due to the heat. This bending caused integrity failure of NW10, as a crack formed where the wall and column met. This allowed flame and smoke to escape the inside and may have skewed some of the thermocouple results near that side. In order to reduce the movement of the columns, exterior steel plates were placed on all of the columns, and connected together with even more steel in order to prevent the movement of the columns. Another issue caused by the beams bending was that the top beams cracked at the corners. While this did not have a significant effect on the current test, it had to be fixed for future tests in order to prevent permanent damage that would require a new beam. The final structural issue was the spalling of the roof. The temperature on top of the roof was hotter than expected, and so spalling occurred where the roof was unprotected. During the first test the roof had no insulation on it, and this was fixed for future tests by covering top of the structure with fiber insulation.

Another issue with the test was a result of the ventilation. For the first test there were only two blowers used to provide the furnace with oxygen. The blowers were placed on either end of the structure, offset from each other in order to induce air movement and improve the temperature homogeneity of the furnace. The first issue with this was that the two blowers were not sufficient to produce the necessary amount of oxygen for complete combustion of the propane. This meant that the fire temperature could not reach the proper standard temperature. It also meant that there was incomplete combustion on the inside of the room, causing a lot of soot to be produced. Also, a lot of the combustion was forced outside of the test structure, which had negative consequences on the roof. Another issue with the two blowers was that air inside the room was not as equally distributed as was hoped, which led to some of the walls being hotter than others. This negatively affected the results because only one furnace temperature is used to determine the equivalent standard 
fire time for all walls. To fix this four more blowers were added to the structure in order to ensure enough oxygen and equal distribution of heat.

As the test was ended early due to the structural issues, another test was completed in order to determine if the new test structure was functional. The one difference between the first test and the re-test is that the walls have been pre-burned, so there would be less free water inside. Also, since the NW10 wall had undergone integrity failure during the first test, the second test could not be run to completion without risk of structural failure.

The purpose of this second test was mainly to ensure that the test structure was operational. The issues with columns bending, integrity failure, and spalling were fixed. The other issues involving the air flow was also solved, as there was good combustion no soot inside the room, and little soot seen in the exhaust. The furnace temperature had the capability to follow the standard fire curve. In this test six blowers were used, with two blowers on Wall LW15, Wall NW10, and Wall NW15. This meant that there were no blowers on Wall LW10. This meant that the air inside of the room was not equally distributed. It was found that the fire exposed side of Wall LW15 and Wall NW10 were hotter than the other two walls. This was due to the lack of equal airflow inside the room because Wall LW10 had no blowers. To fix this two more blowers were added on the Wall LW10 side.

Another issue that arose in this test was that the NW10 and LW15 had a large different in projected failure times, with the LW15 have a fire resistance of almost double the NW10. This meant that there was a large difference in temperature between the four walls. Because of this issue the NW10 wall began to weaken and undergo thermal bowing when the LW15 wall was still structurally sound. This meant that the test could not continue due to safety concerns (both for the researchers and the test structure). In the future blocks were required to be chosen so that their failure times were as closely related as possible to ensure that all four of the walls are allowed to reach their failure time without risking collapse of the test structure. 


\subsection{Almonte Test 2A}

\subsubsection{Tested Walls Almonte 2A}

Each of the masonry walls were made of $20 \mathrm{~cm}$ thick, ungrouted, concrete masonry units. The walls were $3.2 \mathrm{~m}$ high by $2.8 \mathrm{~m}$ wide (16 courses high, 7 blocks wide). A concave mortar joint of type $\mathrm{S}$ premixed mortar was used for all walls. The walls were all connected to the ridged test assembly via mortar on the perimeter. The walls were allowed to cure for a month before testing. The concrete mix was $9.01 \%$ Cement Type GU (10), 10.72\% Stone 7.0mm, 29.42\% Fine Aggregates (sand), and $50.85 \%$ Stone Screenings.

\section{Control Wall}

A control wall was constructed of normal weight $20 \mathrm{~cm}$ units without a bond beam and with full webs.

\section{Bond Beam Wall}

Lintel units are normally used at the bottom of a bond beam to allow grouting to be done. The lack of hollow air cells stops the grout from passing through and allows it to fill the beam. The purpose of the bond beam in this test was to determine the effect of the vertical heat transfer in the walls. Similar to how the bond beam stops grout from falling through, the heat would not be able to transfer from one side of the bond beam to the other. This would stop the heat from the bottom of the wall from reaching the top of the wall like it does in the vertical hollows. As the hollow part of the wall usually heats up faster than solid part and the mortar, stopping this heat flow may decrease the temperature at the top of the wall, and increase the thermal resistance of the wall assembly. As the test fails when the average temperature increases by 140 ${ }^{\circ} \mathrm{C}$ average or $180{ }^{\circ} \mathrm{C}$ at a critical point, this would help to reduce the likelihood of any parts at the top of the wall from reaching that $180{ }^{\circ} \mathrm{C}$ mark.

The bond beam was made out of $20 \mathrm{~cm}$ normal weight lintel units. Unlike the regular blocks, these units do not have the hollow cells or webs, and has slightly different thicknesses (Figure 3.7b). In the test the bond beam was left un-grouted. The bond beam was located at the 8th course from the bottom. The rest of the wall was built with $20 \mathrm{~cm}$ normal weight hollow units. 


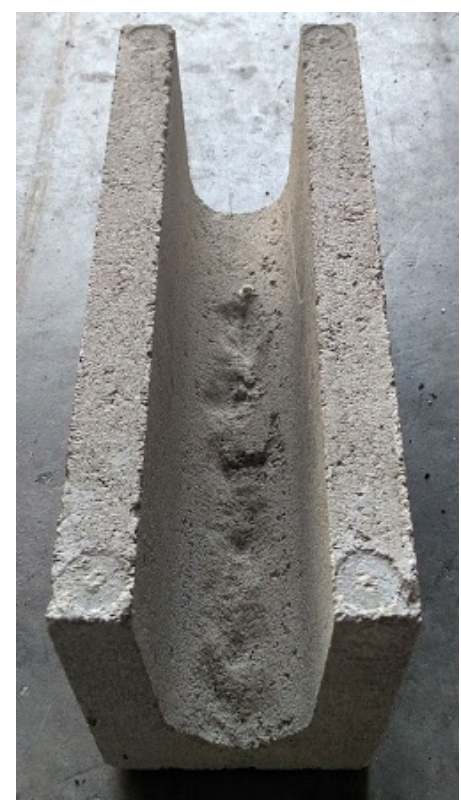

(a)

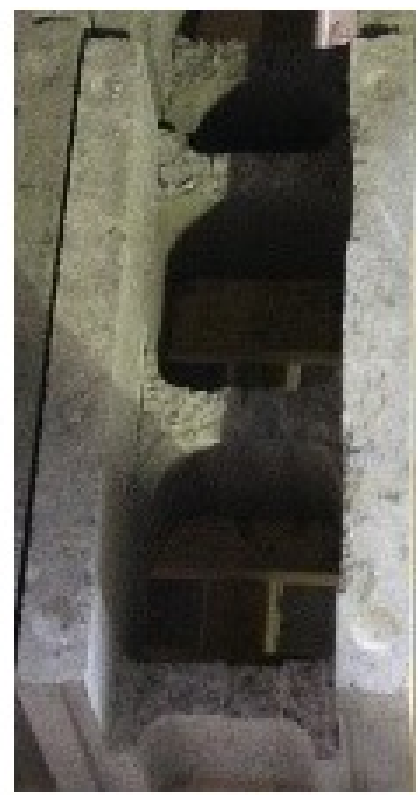

(b)

Figure 3.7: (a) Bond Beam and (b) Reduced Web

\section{Reduced Web Wall}

Reduced web blocks (Figure $3.7 \mathrm{~b}$ ) are used to allow for horizontal reinforcing steel to be placed in the walls, as well as to increase the efficiency of the grout. In this case the walls were left un-grouted and unreinforced, and so the major reason for testing reduced webs was because they are lighter units. With less web height, the units are lighter than the regular $20 \mathrm{~cm}$ units, and could be used to decrease the dead load in a building.

\section{Raked Joint Wall}

Raked joints are usually an artistic choice that involves the removal of some of the mortar in the mortar joints. In the current ULC standard the fire endurance of the masonry walls is based on full mortar in the joints. This means that if the joints are not full of mortar due to the raked joints or due to the masons not jointing after placing the blocks, the wall is considered not to meet its fire rating. To test the effect of raked joints, a wall using joints raked to $5 \mathrm{~mm}$ was constructed and compared to the concave joints (Figure 3.8). The rationale for this test was to see if there was any effect on the fire resistance of the wall. Results with no negative effect would give 
good indication that both raked joints and poorly jointed walls may deserve a higher fire resistance rating than they currently have.

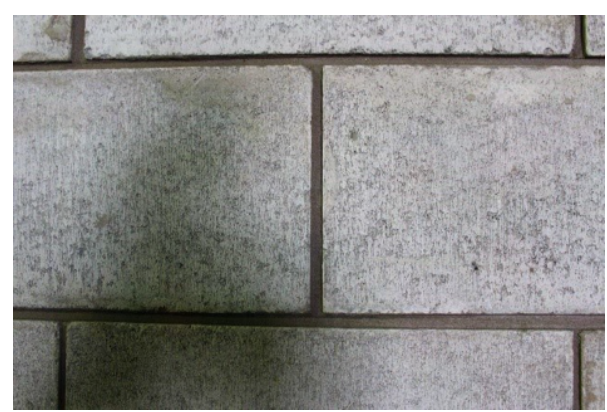

(a)

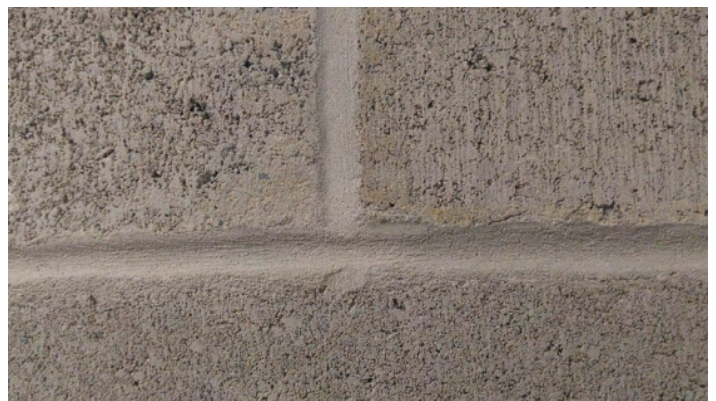

(b)

Figure 3.8: (a) Raked Joints and (b) Concave Joints

\subsection{Barnsdale Test 1A and 1B}

\subsubsection{Tested Walls Barnsdale Test 1A and 1B}

Each of the masonry walls were made of $15 \mathrm{~cm}$ thick, ungrouted, normal weight concrete masonry units. The walls were $2.4 \mathrm{~m}$ high by $2.4 \mathrm{~m}$ wide $(12$ courses high, 6 blocks wide). A concave mortar joint of type $\mathrm{S}$ premixed mortar was used for all of the walls but the raked joint wall. The walls were allowed to cure for over 28 days before testing.

\section{NW15cm Conrol Wall}

A control wall (Figure 3.9)was constructed of normal weight $15 \mathrm{~cm}$ units without a bond beam and with concave mortar joints.

\section{Lintel/Bond Beam Wall}

Similar to the Almonte test, lintel units were included in this test in order to determine their benefit. While the earlier results did seem to indicate that the bond beam improved the fire resistance, a crack in the wall caused it to fail prematurely. In order to continue the research, a new wall was constructed with three bond beams in order 


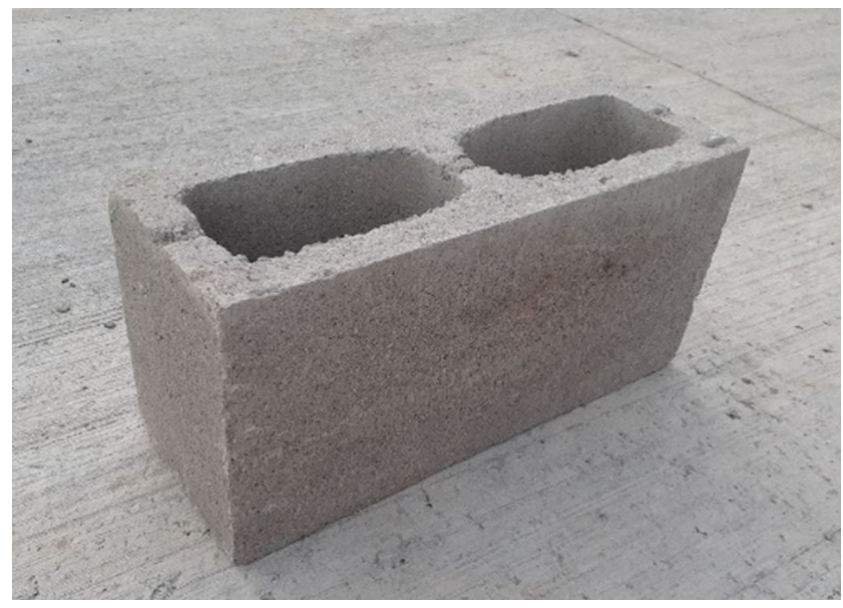

(a)

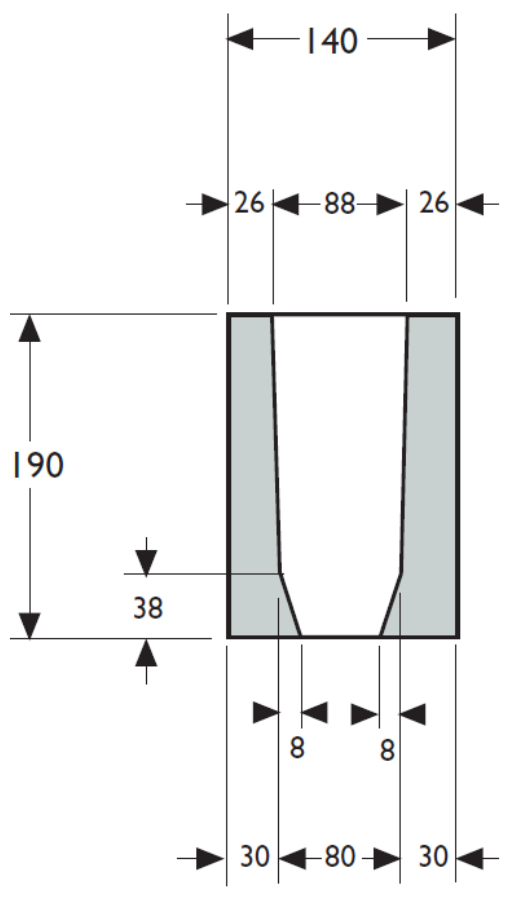

(b)

Figure 3.9: $15 \mathrm{~cm}$ block shape

to determine the effects of the reduced vertical heat transfer. The bond beams were constructed out of $15 \mathrm{~cm}$ normal weight lintel units. Unlike the standard blocks, lintel units do not have hollow cells or webs, and have slightly different faceshell thicknesses (Figure 3.10). In the test the bond beams were left un-grouted. The bond beams were located at courses four, seven, and ten (starting from the bottom). The rest of the wall was built with $15 \mathrm{~cm}$ normal weight hollow units (Figure 3.9).

\section{Struck Joint Wall}

There are many different types of masonry joints. The difference in jointing is due to reasons such as aesthetics, degradation, time saving, or mason error. Some of the joints like raked and concave take time to be done properly, while extruded is a joint type that comes mainly from not scraping off the excess mortar. Struck joints or flush joints take less time to finish than concave or raked joints, but there is some uncertainty about the quality of these joints.

The earlier Almonte test found that raking a joint, which involves removing a 


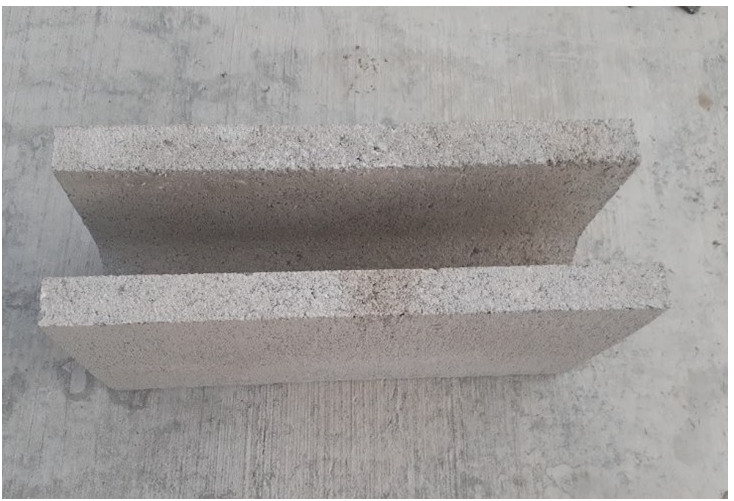

(a)

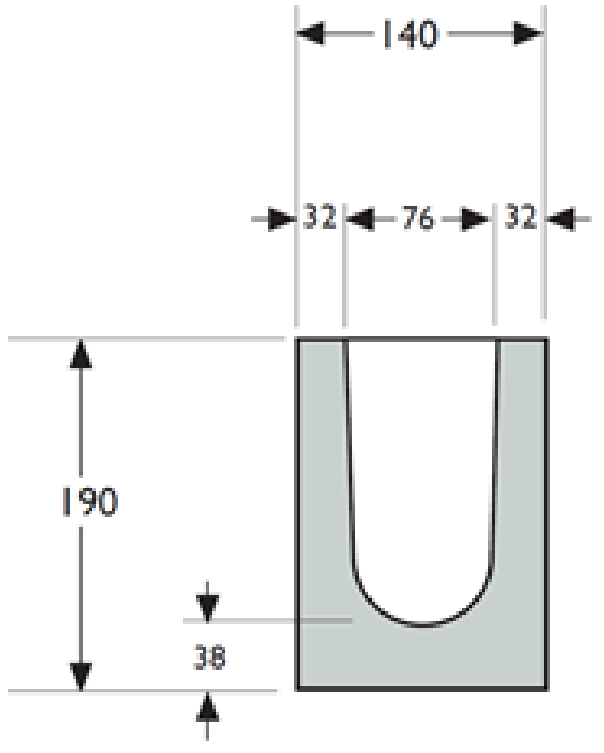

(b)

Figure 3.10: $15 \mathrm{~cm}$ block shape

significant portion of the mortar, did not have a large impact on the fire resistance of the masonry wall. In order to continue to experiment with masonry joint types, a struck joint wall was created. The masons did not joint the wall with a concave joint, but instead limited their jointing to striking off the excess mortar (Figure 3.11). Without concave joints, the wall has a higher chance of integirty failure due to cracks opening up at the joints.

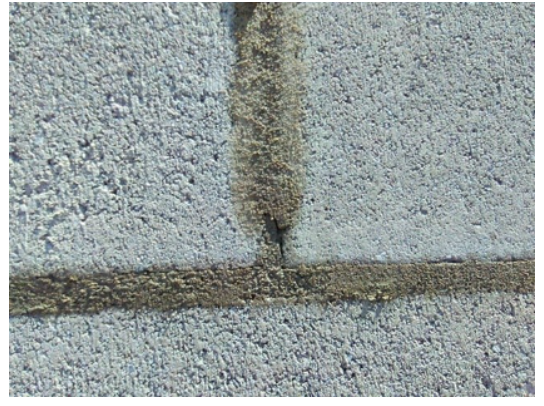

(a)

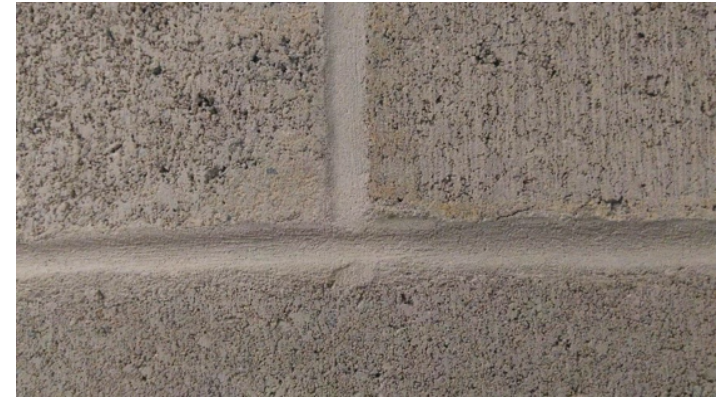

(b)

Figure 3.11: Jointing types a) struck joint b) concave joint 


\section{Splitter Wall}

Concrete walls are often built with a running bond, where the joints of the course above is horizontally offset. This offset requires the use of half masonry blocks. In order to expedite the process of splitting a masonry block in half, splitter blocks are created. These blocks are similar in shape to the standard blocks, except for minor changes in the cells and central web in order to allow for a thin central gap. This central gap is where the block can be easily split in two (Figure 3.12). Splitter blocks have the same equivalent thickness as standard blocks, and so can be used interchangeably, even though they have slight variations in cell configuration. One wall was constructed entirely of splitter blocks in order to determine the effect of the different block configuration.

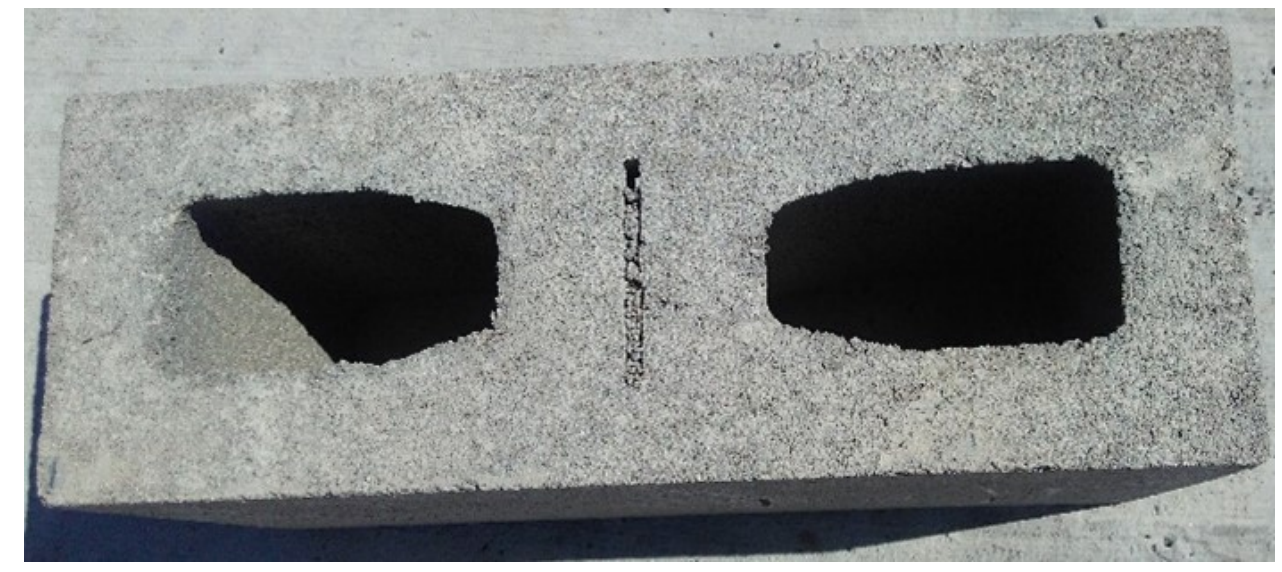

Figure 3.12: $15 \mathrm{~cm}$ Splitter Block

\subsubsection{Barnsdale Test 1, Issues and Improvements}

The main issue that arose with the Barnsdale Test 1B was related to excessive thermal bowing. This excessive bowing occurred because the walls were not fixed to the steel frame due to the ceramic fiber boards placed at the interface between the walls and the steel. In the subsequent tests, this issue was resolved by removing the boards and instead using a full mortar joint to affix the blocks to the steel. To protect the top steel beam from the hot gasses traveling through the cells, lintel beams were placed upside down on the top course to protect the steel and allow for a full mortar joint between the blocks and the steel. This top course was not part of the tested walls, 
and so no thermocouples were placed on this course.

\subsection{Barnsdale Test 2}

\subsubsection{Tested Walls Barnsdale Test 2}

This test included four walls that all had prescribed failure times around 1.5-2h. These included a mixture of $15 \mathrm{~cm}$ and $20 \mathrm{~cm}$ ungrouted masonry units. The walls were $2.4 \mathrm{~m}$ high by $2.4 \mathrm{~m}$ wide (12 courses high, 6 blocks wide). A concave mortar joint of type $\mathrm{S}$ mortar was used for all of the walls. The walls were allowed to cure for 1 month before testing.

\section{Lightweight $15 \mathrm{~cm}$ Wall $(\mathrm{LW} 15 \mathrm{~cm})$}

Normal weight $15 \mathrm{~cm}$ units have an equivalent thickness of $81.2 \mathrm{~mm}$, and a fire resistance of 1.1h. Lightweight concrete has a higher fire resistance due to the change in mix design to include porous lightweight aggregates, and so the Lightweight $15 \mathrm{~cm}$ $(\mathrm{LW} 15 \mathrm{~cm})$ block has a fire resistance rating of $1.5 \mathrm{~h}$. The geometry of the LW15cm block is the same as a normal weight $15 \mathrm{~cm}$ (NW15cm) (Figure 3.13a). Lightweight blocks are more expensive than normal weight blocks, but the improved fire resistance, faster construction, and reduced dead load can make them a good choice for masonry design. The purpose of testing these blocks is to determine exactly how the lightweight concrete behaves compared to the normal weight concrete.

\section{Semi Solid Normal Weight $15 \mathrm{~cm}$ Wall (Semi Solid)}

A semi solid block is one that has more material than a hollow block. In this case a hollow $15 \mathrm{~cm}$ block is $58 \%$ solid, and a semi solid block is $80 \%$ solid (equivalent thickness $112 \mathrm{~mm}$ ). This means that the face shells and webs have been made thicker on the semi solid block (Figure 3.13). With the semi solid blocks, most of the material goes towards making the face shells thicker, which helps to improve the fire resistance of the block. The fire resistance of the $15 \mathrm{~cm}$ semi solid ( $80 \%$ solid) block is $2 \mathrm{~h}$, which is almost double the fire resistance of the hollow block. As $20 \mathrm{~cm}$ blocks have a fire resistance of $1.8 \mathrm{~h}$, the $15 \mathrm{~cm}$ block can reduce the amount of space taken by walls 


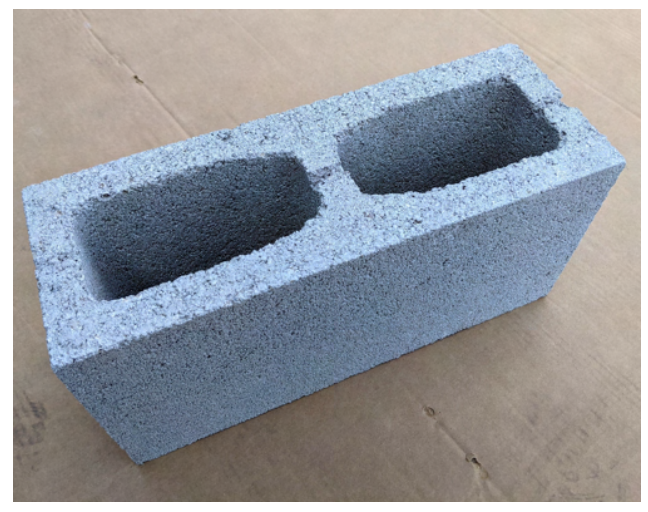

(a)

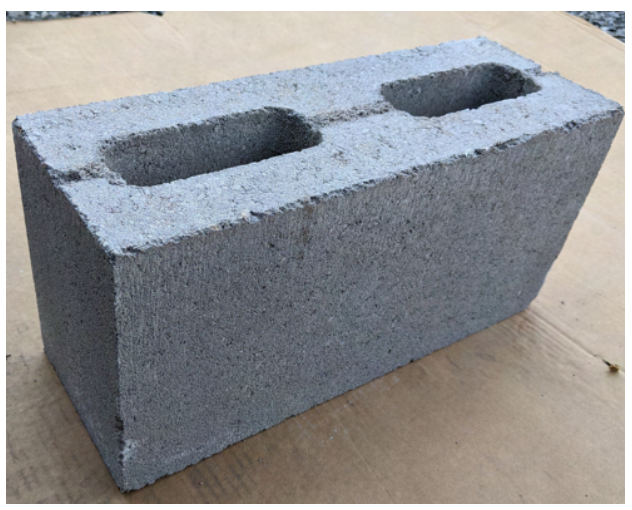

(b)

Figure 3.13: a) LW15cm b) Semi Solid $15 \mathrm{~cm}$

while also improving the fire resistance. The $15 \mathrm{~cm}$ blocks are also easier to handle than the $20 \mathrm{~cm}$ blocks, which improves the efficiency of the masons.

\section{Carbon Cured NW20cm (Carbon Cured)}

Masonry blocks are precast members, which means that they come premade and already cured. The curing process can be done through autoclaving, which is when pressurized steam is used to cure the block. In the case of Carboclave blocks, $\mathrm{CO}_{2}$ is added to the block during this process in order to increase the strength of the block, as well as trap $\mathrm{CO}_{2}$ for environmental reasons. This block has a slightly different mix design (such as the inclusion of some slag) when compared to regular $20 \mathrm{~cm}$ units, however the main difference is the curing process. Even with the differences in mix design and curing process, it has the same $99 \mathrm{~mm}$ equivalent thickness of a NW20cm block and has a 1.8 hour fire resistance (Figure 3.14).

\section{Split-Face Carbon Cured NW20cm (Split-Face)}

Split face blocks are used for aesthetics, as having a rough exposed surface can be visually appealing (Figure 3.14). The block is treated the same as NW20cm block for fire resistance and structural purposes. The difference with the Splitface lies in the geometry of the block. The cells are smaller than a regular $20 \mathrm{~cm}$ unit and it is unsymmetrical, with a thicker face shell on the side with the rough face. This added material and smaller cells should improve the fire resistance above the 1.8 hour rating. Based on equivalent thickness of $117 \mathrm{~mm}$ it should have a fire resistance of $2.1 \mathrm{~h}$. As 
the block is not symmetrical, the thicker side was chosen to be exposed to the fire, as it was expected to produce improved fire resistance.

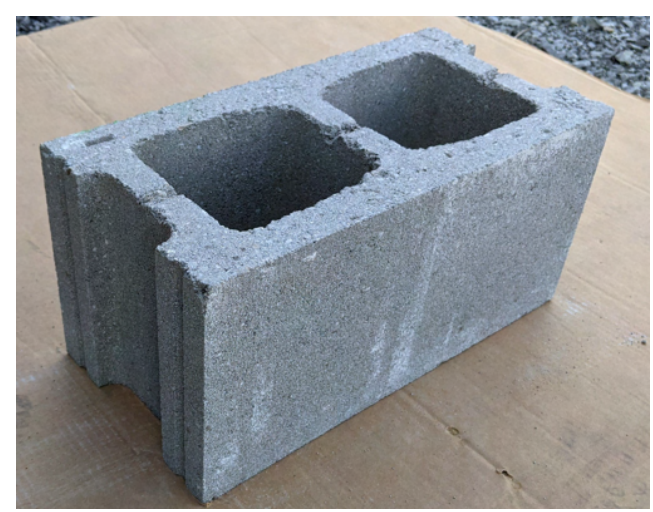

(a)

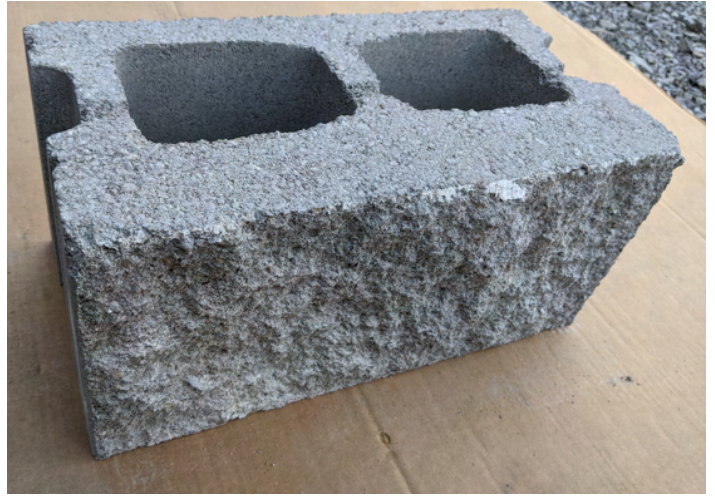

(b)

Figure 3.14: a) Carbon Cured $20 \mathrm{~cm}$ b) Split-Face Carbon Cured $20 \mathrm{~cm}$

\subsection{Barnsdale Test 3}

\subsubsection{Tested Walls Barnsdale Test 3}

This test was done to determine the effects of insulation on the fire resistance of the masonry walls. This test included insulated NW15cm blocks and a 2-hour fire rated NW20cm block. The walls were $2.4 \mathrm{~m}$ high by $2.4 \mathrm{~m}$ wide (12 courses high, 6 blocks wide). A concave mortar joint of type $\mathrm{S}$ mortar was used for all of the walls. The walls were allowed to cure for 6 days before testing.

The purpose of the test is to determine whether or not the insulation could allow $15 \mathrm{~cm}$ blocks to surpass a $2 \mathrm{~h}$ fire resistance rating. A common method of surpassing a $2 \mathrm{~h}$ fire resistance rating is grouting the wall. This has increased material and labour costs and can be difficult to implement in some cases. Having a prefabricated alternative can be useful if it can meet the fire resistance requirements.

\section{NW20cm Two Hour Fire rated block (Two Hour Fire)}

While most $20 \mathrm{~cm}$ units are rated for 1.8 hours, it is possible to get a unit that has a 2-hour fire resistance rating by adding more material to the unit (Figure 3.15). The 
mix design is the same as regular $20 \mathrm{~cm}$ units, however the $2 \mathrm{~h}$ rated block has a higher equivalent thickness (114mm) when compared to regular $20 \mathrm{~cm}$ units (99mm). The increased equivalent thickness is what accounts for the increased fire resistance. As this wall has a $2 \mathrm{~h}$ rating, it can be used as a control wall for comparison with the insulation walls. If the other walls fail after the Two Hour Fire block, then they will have exceeded the 2 hour fire resistance.

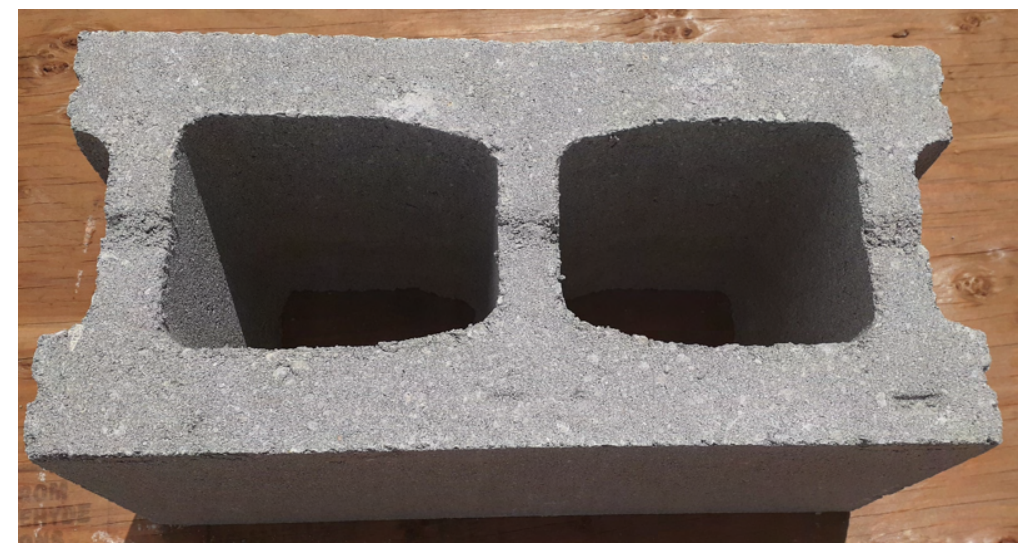

Figure 3.15: $20 \mathrm{~cm}$ Two Hour Fire Block

\section{NW15cm with full rockwool cavity insulation blocks (Rockwool Full)}

Rockwool AFB batt insulation was placed within a NW15cm unit such that the cavity was filled completely (Figure 3.16). Full cavity insulation would reduce the horizontal heat transfer through the cells, as well as the vertical heat transfer of hot gasses. There are some issues with the full cavity insulation. The simplest issue is that these blocks would have increased materials cost and dead weight due to the extra insulation. However, the main concern is with the workability of the blocks. Masons grip the webs and the faceshells in order to place and adjust the blocks on the mortar. With full cavity insulation the blocks become more difficult to lay, which could increase the labour costs.

When the masons were building with the blocks the workability issues were minor, but the insulation was depressed slightly at the top of the blocks to allow for the blocks to be handled by the masons. While the rockwool would slightly expand back after being laid, this would still leave a thin air gap at the top of the cells. 


\section{NW15cm with 1inch rockwool cavity insulation blocks (Rockwool 1inch)}

Rockwool AFB batt insulation was placed within a NW15cm unit such that the fire side of the cavity had 1inch of rockwool insulation (Figure 3.16). While full cavity insulation would provide better fire resistance, the linch was an alternative that might reduce cost and improve the workability for the masons. When the Rockwool 1inch blocks were being laid the masons had no issues handling the blocks and commented that the soft insulation was comfortable to grip. A purpose made mould could be created during the manufacturing process to ensure that the insulation material was secure and separate if a more hazardous insulation material was used.

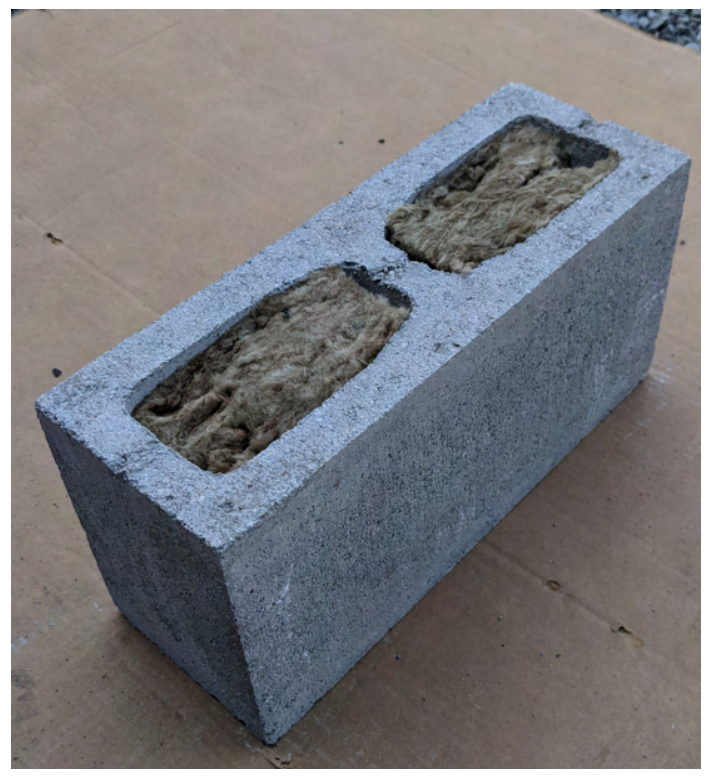

(a)

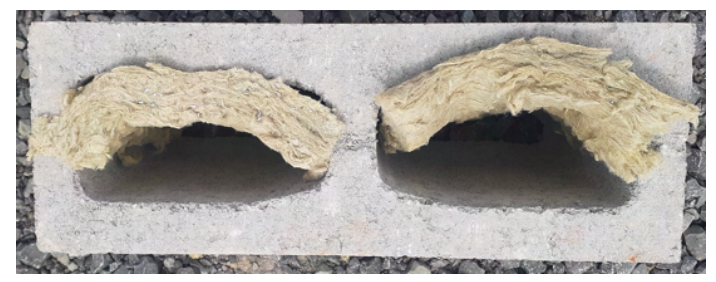

(b)

Figure 3.16: a) Block With Full Rockwool Insualtion b) Block With 1inch Rockwool Insulation

\section{NW15cm with full vermiculite cavity insulation blocks (Vermiculite)}

Vermiculite is an inorganic loose fill insulation material that can be used to fill masonry cells. As the walls are being built, vermiculite is poured into the hollow cells until they are filled up completely (Figure 3.17). Pouring the insulation takes time and means that the masons have to stop while the vermiculite is poured. This wall is useful to compare an existing cavity insulation with the other two more novel 
insulation options.

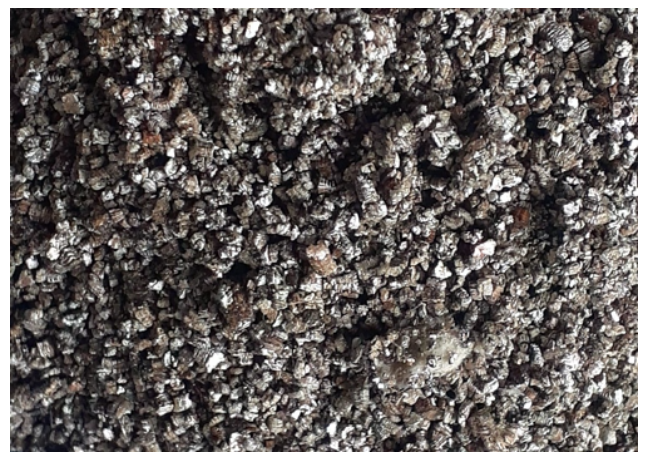

(a)

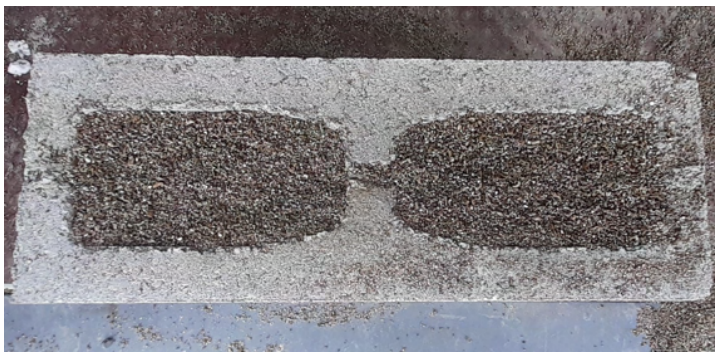

(b)

Figure 3.17: a) Vermiculite Sample b) Vermiculite Filled block

\section{Wall construction General Note}

As with the previous test, the top course used in all four walls was made with inverted lintel units to protect the steel beam. In the case the Two Hour Fire wall the lintels were left empty. In the case of the other three walls, the cells were filled with Rockwool insulation. This was done even for the vermiculite wall, as an inverted lintel unit cannot hold the loose fill vermiculite insulation. 


\section{Chapter 4}

\section{Experimental Results}

\subsection{Almonte Test $1 \mathrm{~A}$ results}

The test had to be stopped due to issues with the test structure. The furnace was unable to get hot enough to match the standard fire and the flames coming from the ceiling vent caused spalling of the roof slab. Also, one of the concrete columns began to deflect, which caused integrity failure in one of the walls. For these reasons the test was stopped in order to make modifications to the test structure.

\subsubsection{Almonte Test 1A Furnace temperature}

During the 18 minutes of burning, the furnace was able to follow the shape of the curve relatively well, but it remained cooler throughout the test (Figure 4.1). The interior of the test structure after the burn was covered in soot, which indicated that there was not enough ventilation to provide the fire with enough combustion oxygen. Since there was not enough oxygen there was also a large amount of flames coming out of the ceiling vent, which caused spalling to occur on the precast concrete roof. This roof was subsequently protected with insulation to reduce the chance of further spalling.

\subsubsection{Almonte Test 1A Average Exposed and Unexposed Surface temperatures of the walls}

One of the issues with the test structure was that the ventilation was limited. The other issue was that the ventilation was not even due to an unsymmetrical number 


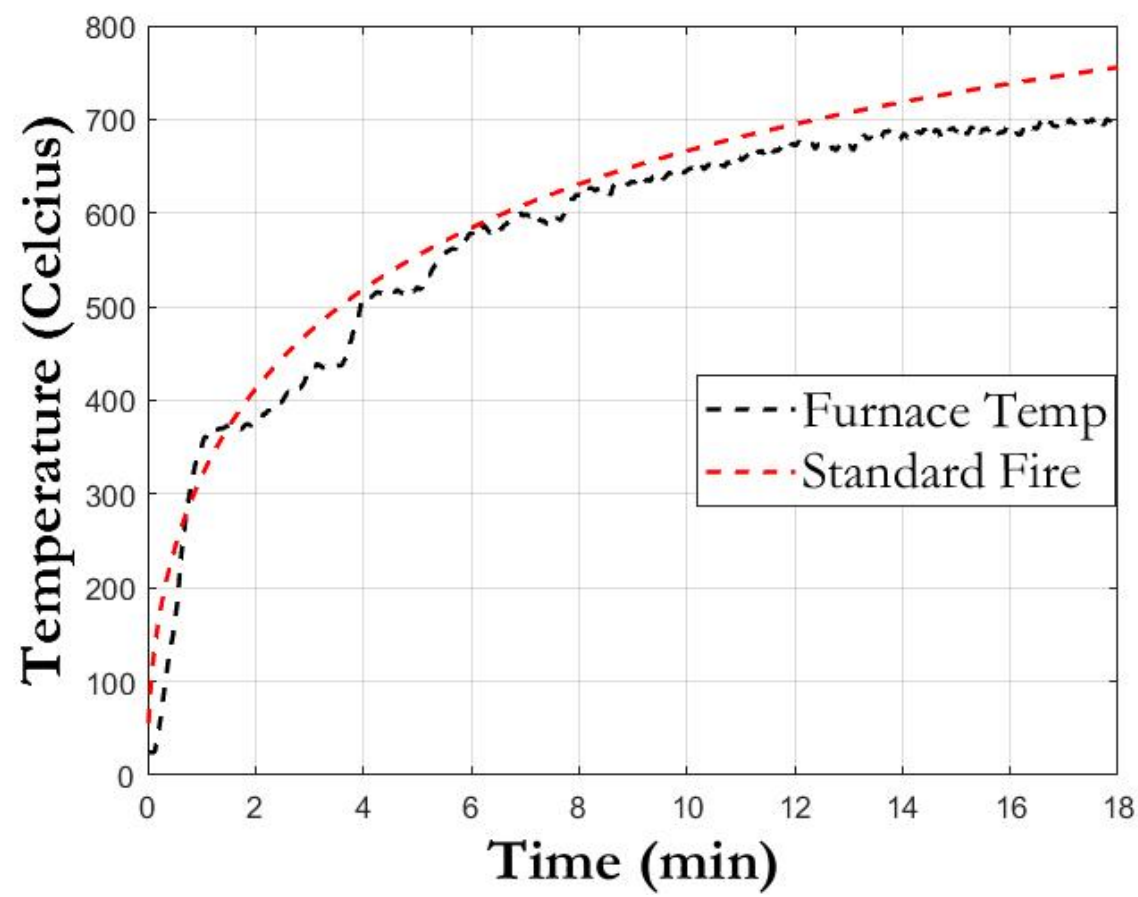

Figure 4.1: Almonte Test1A Comparing the furnace temperature to the standard fire temperature

of blowers. This meant that some of the walls heated up faster than others, which would cause the unexposed side to heat up faster. In the case of the test more of the heat was blown onto the exposed surface of the NW15 wall, and less heat was on the LW15 wall. The difference in unexposed wall temperatures can be seen in Figure 4.2a. Once the furnace was shut off, the exposed surface temperatures all began to drop. Since the blowers were shut off along with the furnace, the exposed sides of the walls all cooled to the same temperatures and the difference between the NW15 and LW15 surface temperatures became minimal. For the unexposed side of the wall each wall took around 10 minutes to begin to heat up (Figure 4.2b). It can be seen that the walls began to heat in the order that was expected. With the NW10 being the hottest and the LW15 being the coldest. Surprisingly, even with the hotter exposed surface temperature, the NW15 wall remained cooler than the LW10 wall. 


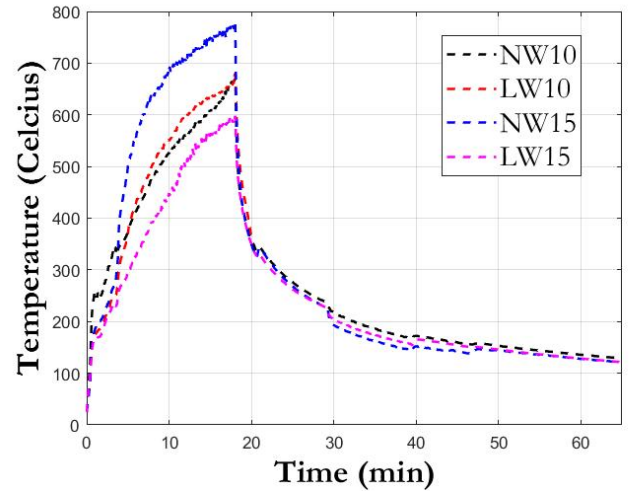

(a)

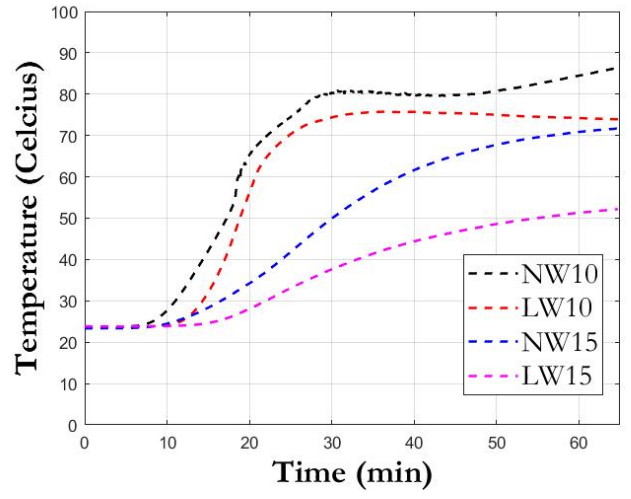

(b)

Figure 4.2: Almonte Test1A a) Average exposed wall temperature b) Average unexposed wall temperature

\subsubsection{Comparing temperatures at specific points on the walls}

Each of the walls had different thermocouple locations. From Figure 4.3a It can be seen that the hollow cell began to heat up first. A few minutes later the solid web also began to heat up, and soon after the mortar followed. As the furnace stopped heating at 18 minutes, this was just when the mortar and the solid web were starting to heat up. The mortar remained cooler throughout test.

When comparing these specific thermocouple locations between the four walls, it becomes clear that the LW15 wall is superior in all locations (Figure 4.3). The NW10 wall began to heat up first in all locations. The mortar had interesting results. The rate of temperature increase in the mortar was the same for all walls other than the LW15. The NW10 wall began to heat up at around 8 minutes, and the LW10 and NW15 walls began to heat up two minutes later at almost identical rates. This is because the mortar was the same for all wall types. So while their may be some difference due to conduction from the surrounding blocks, and the difference in cavity size between the $10 \mathrm{~cm}$ and $15 \mathrm{~cm}$ blocks, the thermal properties of the mortar are the same for all walls. 


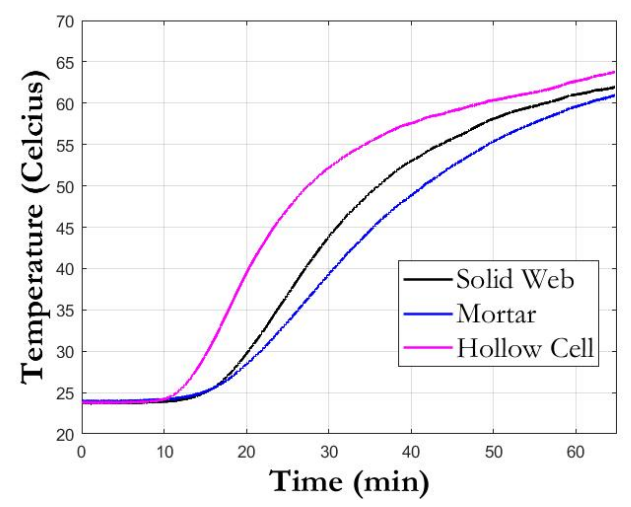

(a)

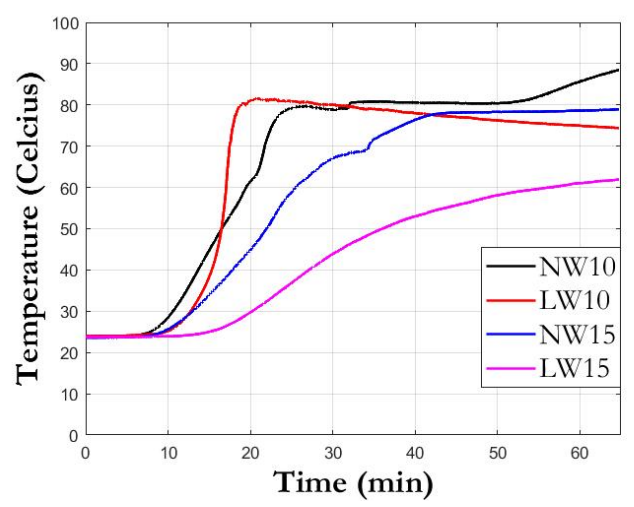

(c)

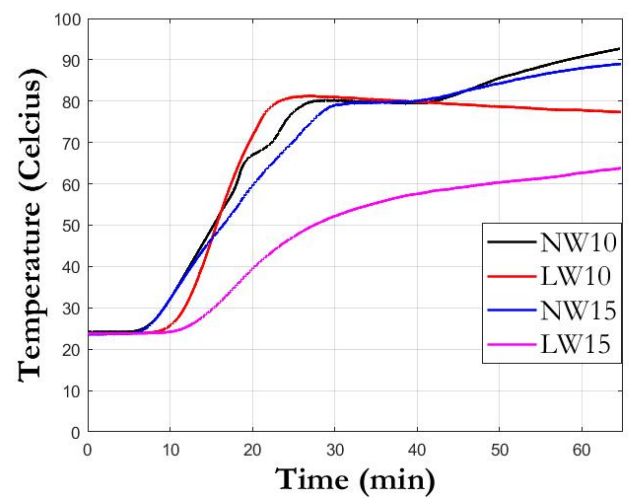

(b)

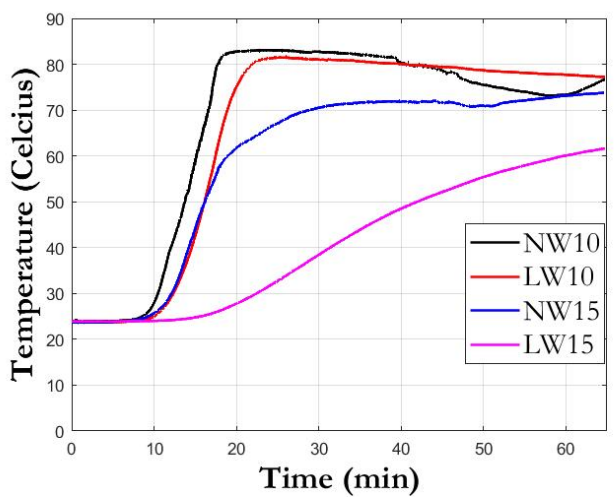

(d)

Figure 4.3: Almonte Test1A Comparing the temperatures at various locations on the unexposed side of the walls. a) comparing the three thermocouple locations on the LW15 wall. b) Comparing the temperatures on the unexposed surface in line with the hollow cell. c) Comparing the temperatures on the unexposed surface in line with the solid web cell. d) Comparing the temperatures on the unexposed surface in line with the mortar 


\subsection{Almonte Test $1 \mathrm{~B}$ results}

The test was repeated to ensure that the changes to the test structure had been sufficient. New blowers had been added to increase the amount of airflow within the structure. Steel had been added to the top of the columns to reduce the effects of thermal expansion and buckling. Finally, insulation had been placed on the ceiling to ensure that the roof slab would not undergo spalling.

\subsubsection{Almonte Test 1B Average Exposed and Unexposed Surface temperatures of the walls}

Unlike during the first test, the repeated test had a more uniform unexposed wall temperature (Figure 4.4) except for the LW10 wall. This was because more blowers were used to provide combustion oxygen, but no blowers were placed on the side of the LW10wall. After this test two blowers were placed on the LW10wall side, in order to ensure even wall temperatures. Even though the surface temperatures were not all the same, the furnace temperature was able to follow the standard fire curve better, and there was no soot inside the furnace. This means that the extra two blowers were not needed to provide oxygen, but to provide symmetry in the furnace.

During the first test it took over ten minutes for the walls to start to heat up. In the repeat test the walls began to heat up after eight minutes. This was due in part because the free water within the walls was evaporated during the first test. Since the repeat test used the same walls, the loss of free water is most likely the reason the walls began to heat up sooner. The four walls heated up in the expected order, similar to the first test (Figure 4.4b).

\subsubsection{Almonte Test 1B Comparing temperatures at specific points on the walls}

The relative speed at which different wall locations heated did not change between tests 1A and 1B (4.5). The hollow cell still heated up faster. Even with the reduced free water, the mortar still took longer to start to heat up than the solid web. The temperature difference between the three points was very similar to those obtained in the first test. 


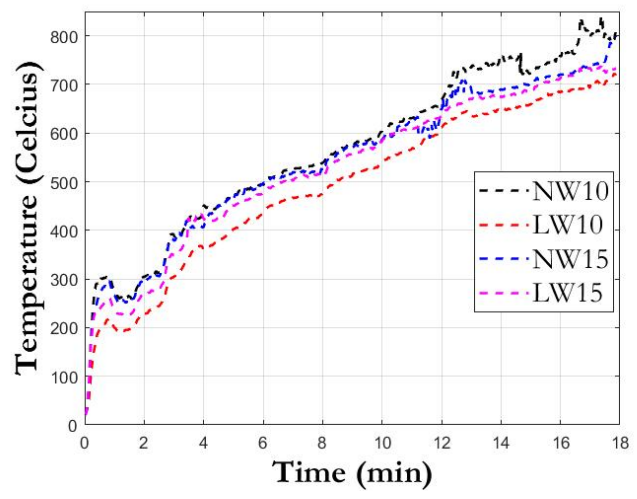

(a)

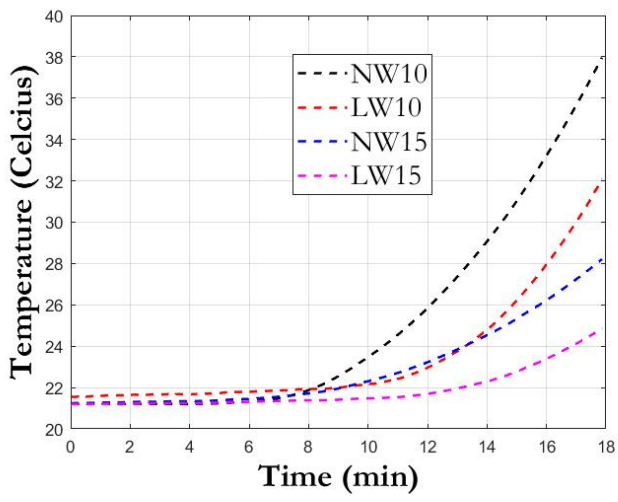

(b)

Figure 4.4: AlmonteTest1B a) Average exposed wall temperature b) Average unexposed wall temperature

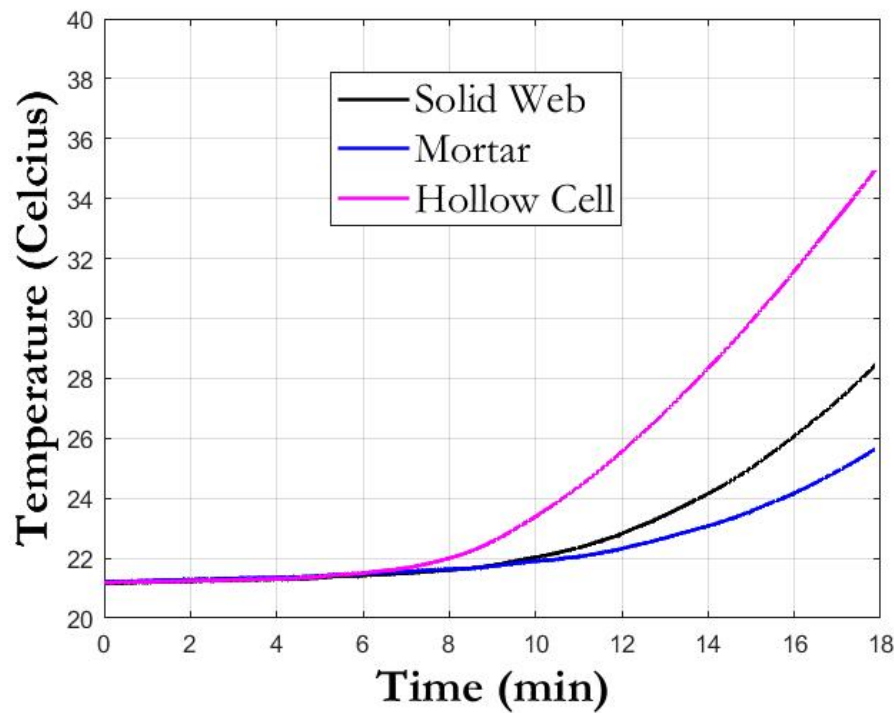

Figure 4.5: Almonte Test1B Comparing the three thermocouple locations on the NW15 wall

\subsubsection{Almonte Test 1 Wall cracking and thermal imaging}

During the test thermal imaging pictures were taken to get a thermal profile of the walls, as well as to determine the locations of any cracks (Figures 4.6, 4.7, 4.8, and 4.9). The images showed that the hollow cells began to heat up first, forming a checkerboard pattern (Figure 4.9). As the walls continued to heat up, that the hot air travelled vertically up the wall and collected at the highest point. These columns of 
hot air began to warm up the horizontal mortar joints, thus resulting in a checkerboard pattern instead of forming columns of heat (Figure 4.8). The images also showed when and where cracks formed during the test.

The walls all developed cracks during the test. Thermal bowing was the major cause of cracking the normal weight walls, and the NW10 wall underwent significant thermal bowing induced deflection. The larger cracks were focused mainly on the corners of the walls. The lightweight concrete walls developed less cracking than the two normal weight concrete walls, and the cracking was from long vertical lines through the centre of the walls (Figure 4.7, and 4.9). The reason the lightweight masonry walls did not undergo as much cracking was most likely due to their lower coefficient of thermal expansion, which would have reduced the impact of thermal bowing.

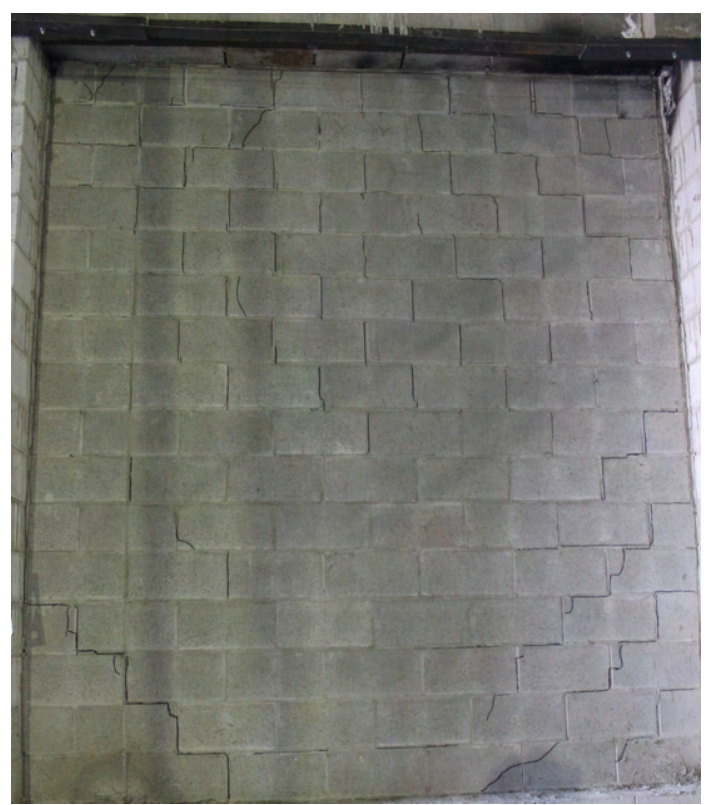

(a)

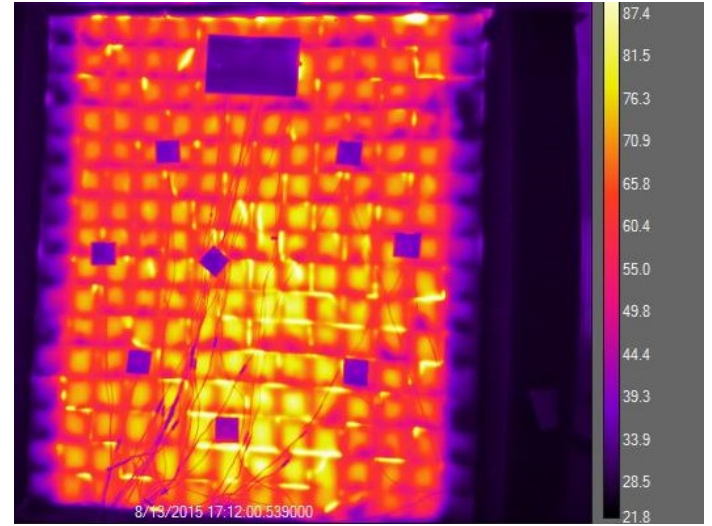

(b)

Figure 4.6: AlmonteTest1B NW10 a) Crack formation b) Thermal Image 


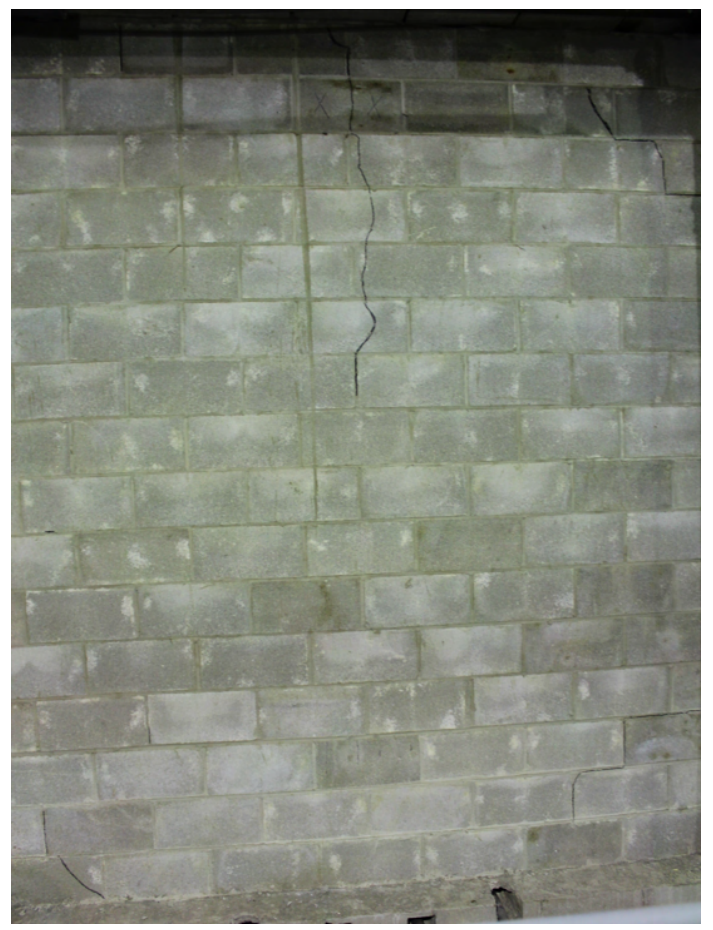

(a)

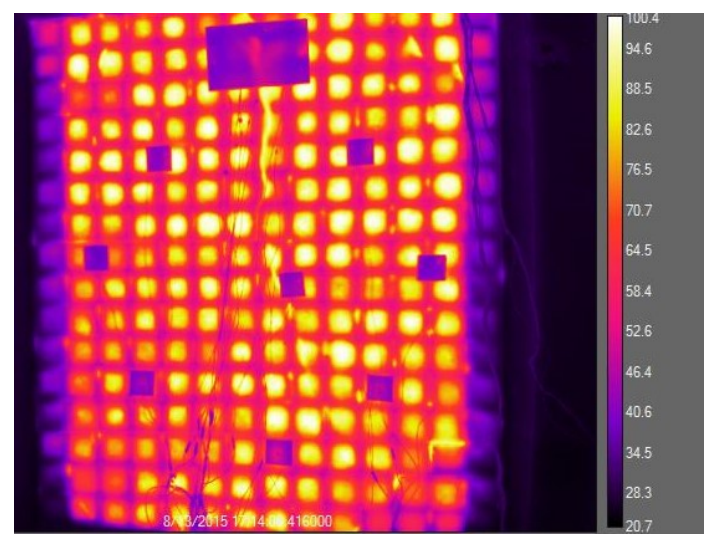

(b)

Figure 4.7: AlmonteTest1B LW10 a) Crack formation b) Thermal Image

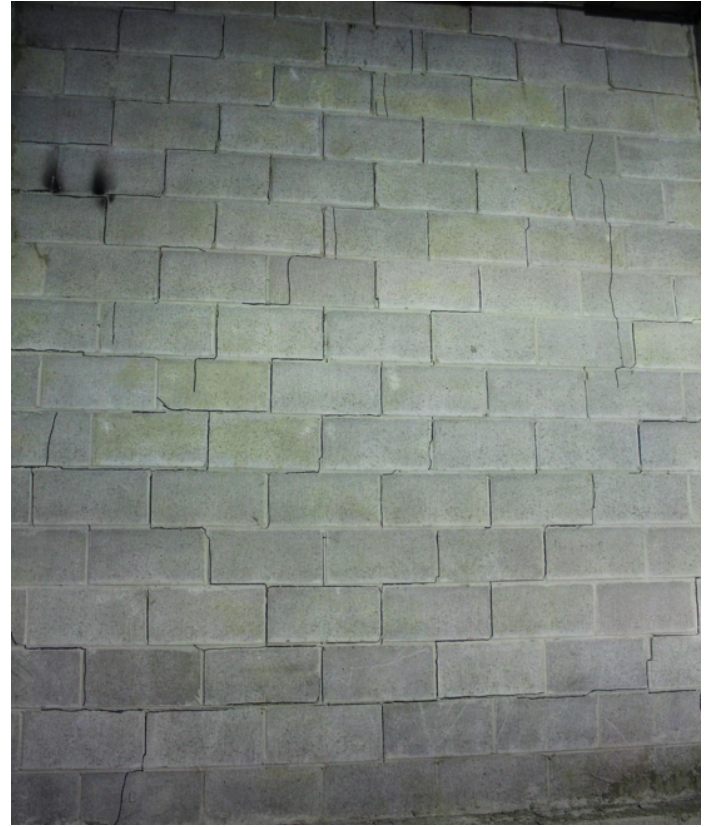

(a)

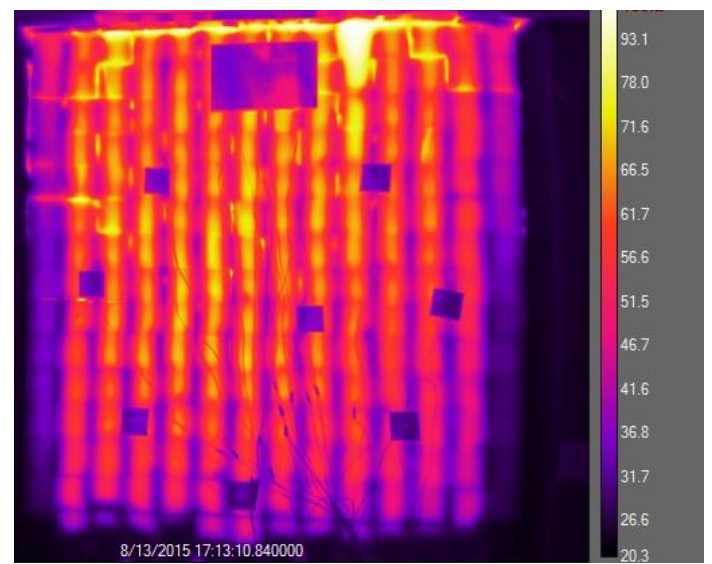

(b)

Figure 4.8: AlmonteTest1B NW15 a) Crack formation b) Thermal Image 


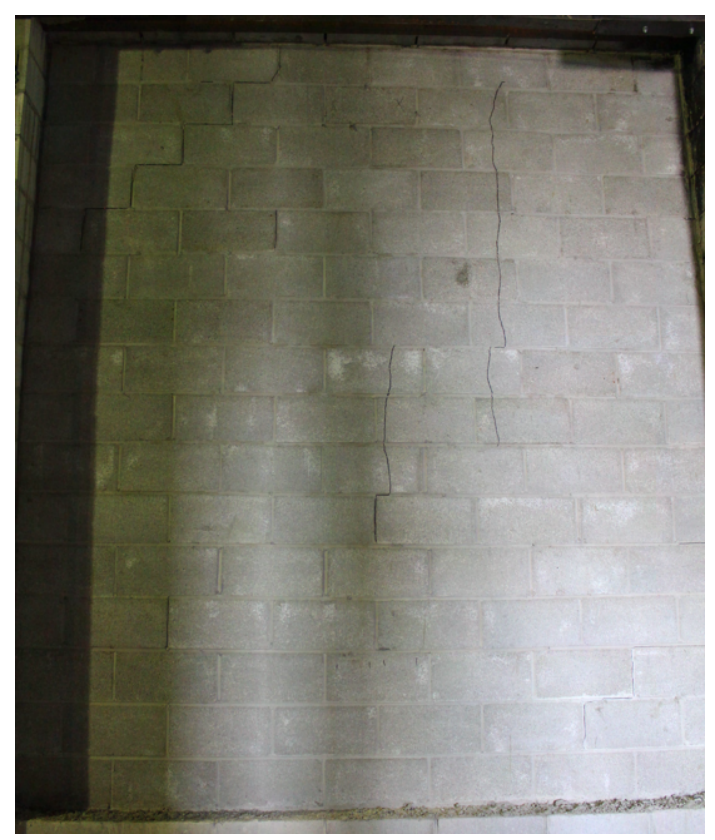

(a)

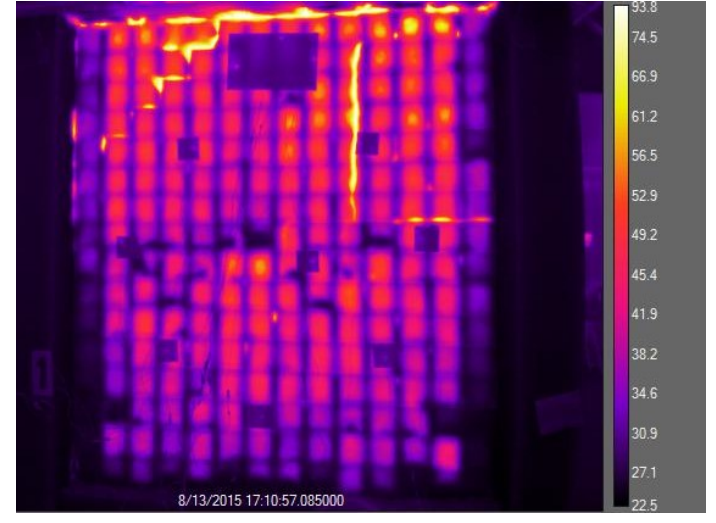

(b)

Figure 4.9: AlmonteTest1B LW15 a) Crack formation b) Thermal Image 


\subsection{Almonte Test2 results}

\subsubsection{Almonte Test2 Wall Failure Times}

Before the test the failure times of the walls were estimated using the equivalent thickness method. This test used the ULC standards to get a more accurate time for failure of the walls assemblies. For the ULC standards, the wall is said to have failed once the average temperature on the unexposed side of the wall increases by $140{ }^{\circ} \mathrm{C}$, or when a single point on the unexposed side increases by $180{ }^{\circ} \mathrm{C}$. These temperature increases are based on the furnace perfectly following the standard fire curve. In the case of this experiment the furnace temperature was increased or decreased to follow the standard fire curve as closely as possible; however, the test furnace could not perfectly follow the standard fire. For this reason, a corrected time is required. The corrected time is calculated using Equation 4.1. The corrected results of each of the walls can be seen in Table 4.1 .

$$
C=I+\frac{2 I *(A-A s)}{3(A s+L)}
$$

Where: $\mathrm{C}=$ corrected fire endurance period (h) I = fire endurance period obtained before correction (h) $\mathrm{A}=$ area under the curve of indicated average furnace temperature for the first three quarters of the uncorrected fire endurance period obtained from the test, $\left({ }^{\circ} \mathrm{C}^{*} \mathrm{~h}\right) \mathrm{As}=$ area under the standard curve for the same part of the period, $\left({ }^{\circ} \mathrm{C}^{*} \mathrm{~h}\right) \mathrm{L}=$ lag correction (in the same units as $\mathrm{A}$ and $\left.\mathrm{As}\right),\left(30{ }^{\circ} \mathrm{C}^{*} \mathrm{~h}\right.$ )

Table 4.1: Failure Times

\begin{tabular}{|l|l|l|l|}
\hline Wall Type & $\begin{array}{c}\text { Equivalent } \\
\text { Thickness } \\
\text { (hours) }\end{array}$ & $\begin{array}{l}\text { Experimental failure } \\
\text { Average } 140{ }^{\circ} \mathbf{C} \text { (hours) }\end{array}$ & $\begin{array}{c}\text { Experimental failure } \\
\text { Single point } \\
\mathbf{1 8 0}{ }^{\circ} \mathrm{C} \text { (hours) }\end{array}$ \\
\hline Raked Joint & 1.8 & 2.05 & $\mathbf{2 . 0 0}$ \\
\hline Bond Beam & 1.8 & 1.95 & $\mathbf{1 . 9 0}$ \\
\hline Reduced Web & 1.2 & 1.62 & $\mathbf{1 . 5 5}$ \\
\hline Control & 1.8 & 2.08 & $\mathbf{2 . 0 6}$ \\
\hline
\end{tabular}

The results from Table 4.1 show that the control wall had the best fire resistance, 
followed by the raked joint wall, then the bond beam wall. The Reduced Web wall had a much lower fire resistance than the other three. Figure 4.10 demonstrates that all of the wall had very similar average unexposed temperatures except for the Reduced Web wall, which had a higher unexposed temperature than the rest throughout the test. This was caused in part by the significant amount of cracking that occurred. The other reason why wall heated faster was that it had a lower fire resistance than the other three walls. Another item that Figure 4.10 demonstrates is that all of the unexposed temperatures follow a trend where it is a steep temperature increase at the start, a mild increase when the temperature is close to $100{ }^{\circ} \mathrm{C}$, and then it returns to the steep temperature increase again afterwards. This reduction in the temperature increase occurs due to the evaporation of water inside of the blocks and mortar. The reason that this part of the graph is not a plateau is due to the fact that these graphs are average temperatures.

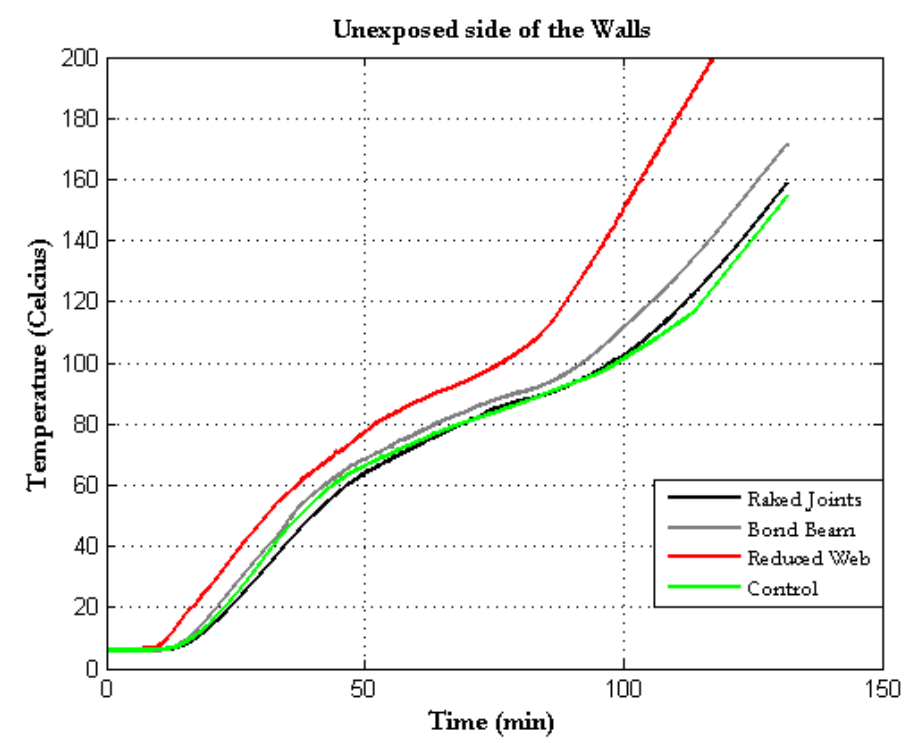

Figure 4.10: Time Temperature Curves for the Unexposed Side of the Four Walls

\subsubsection{Almonte Test2 The Effect of Thermocouple Placement}

The temperature on the unexposed side of the wall varied, depending on where the thermocouple was placed (Figure 4.11). At the beginning of the test the thermocouple on the unexposed side of the hollow cell heated up faster than the mortar or the solid part. At around $50{ }^{\circ} \mathrm{C}$ the mortar surpassed the hollow temperature until the mortar 
reached $100{ }^{\circ} \mathrm{C}$. All parts of the wall had a plateau at $100{ }^{\circ} \mathrm{C}$, as the free water in the block was heated and driven out of the block in the form of steam. The length of the plateau was dependent on the free water available for evaporation. The longest plateau occurred in the mortar, because it had a higher free water content than the block. The two different mortar locations (middle mortar and corner mortar) were found to produce very similar results. The differences were more likely linked to the localized differences in the mortar thicknesses. The second longest plateau occurred in the solid part of the block as it had all the free water from the web section. The shortest plateau occurred in the hollow part because the only free water available was from the faceshells. Because the plateau lasted for such a long time in the mortar, the mortar went from being the hottest part of the wall to the coolest part. After the $100{ }^{\circ} \mathrm{C}$ plateau the temperature at all points increased at a similar rate. This is because the difference in thermal conductivity between the mortar and the block is largely impacted by the free water content, thus suggesting free water content of the materials to be one of the most important factors for the fire resistance of partition walls.

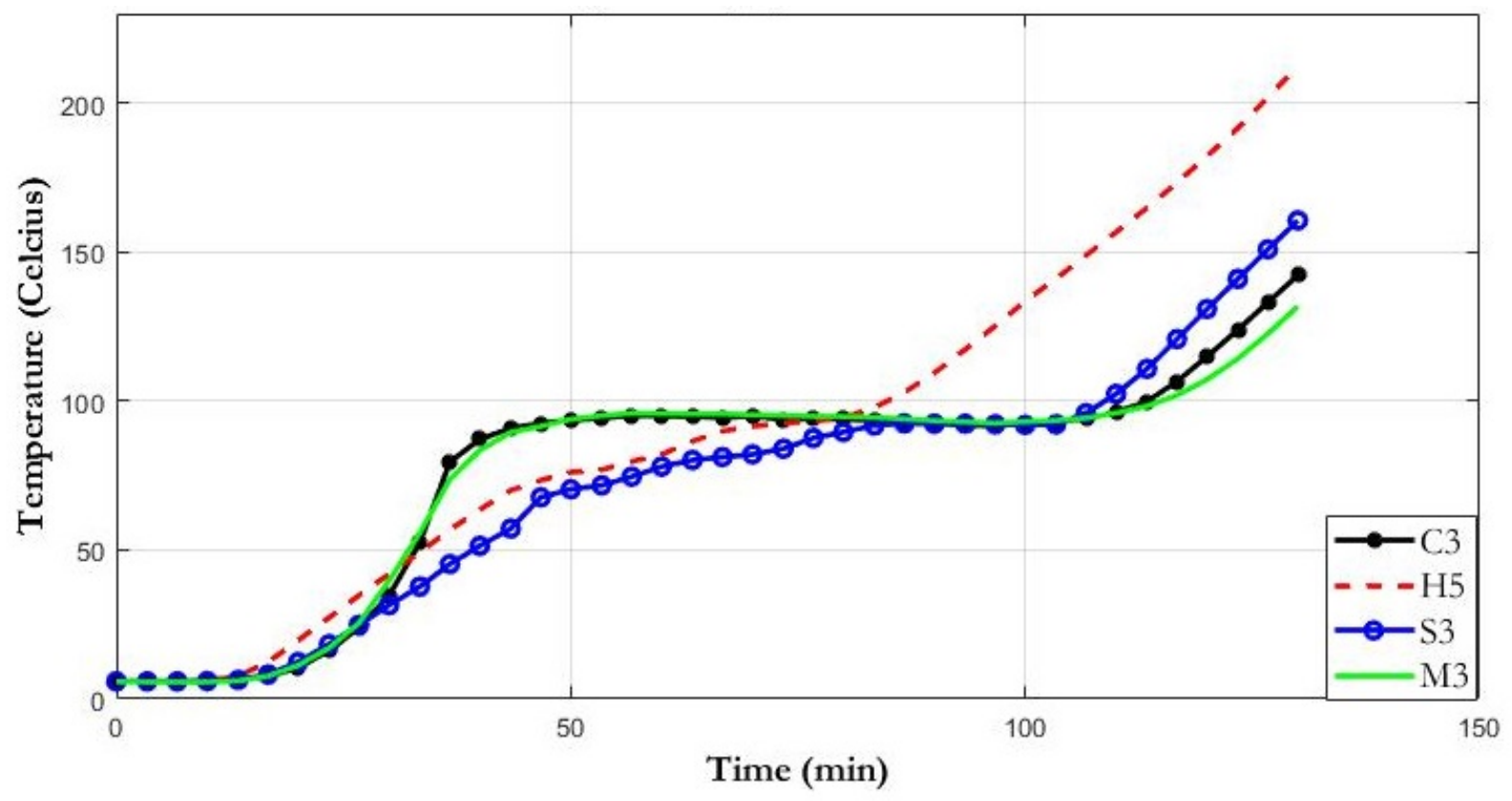

Figure 4.11: The effect of different thermocouple locations 


\subsubsection{Almonte Test2 The Effect of the Hollow Cell}

It can be seen in Figure 4.12 that the temperature drops $200{ }^{\circ} \mathrm{C}$ from one side of the hollow cell to the other (point $\mathrm{H} 2$ to point $\mathrm{H} 4$ ). The heat inside of the hollow is mainly transferred through conduction and radiation. For this reason, even though the thermocouple $\mathrm{H} 3$ is not touching anything but air, it still has a temperature halfway between $\mathrm{H} 2$ and $\mathrm{H} 4$. This means that if the convection and radiation within the cells can be reduced, then the cells would be less critical.

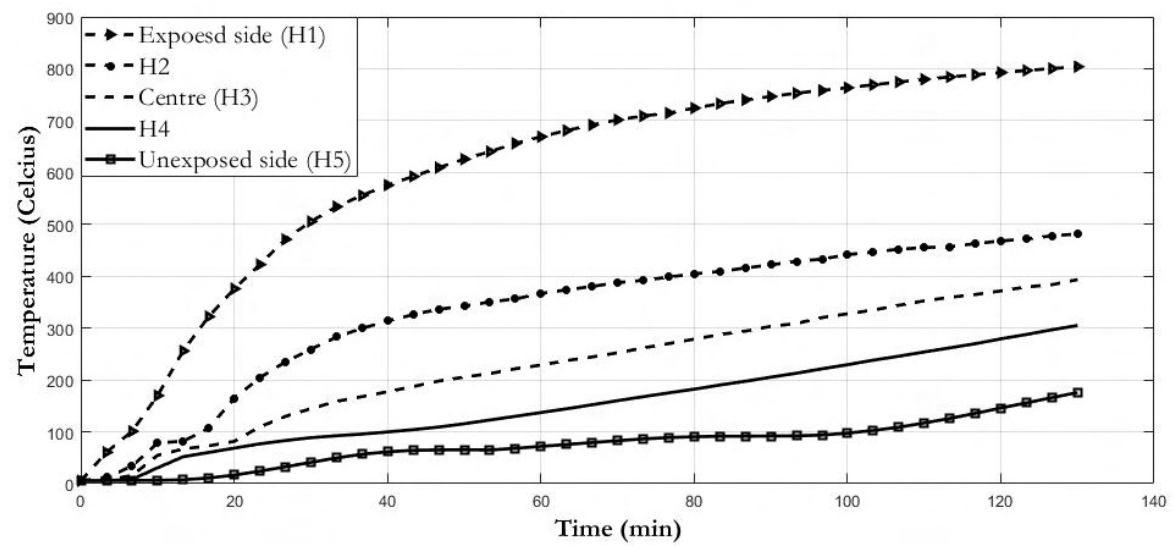

Figure 4.12: Effect of the Hollow Cell

\subsubsection{Almonte Test2 The Effect of the Mortar}

The temperature of the mortar in the raked joint wall was compared to the temperature of the mortar in the control wall (Figure 4.13). Results indicate that at every point throughout the thickness of the mortar, the raked joint temperature was higher than the control joint. This makes sense because the raked joint has less material than the concave control joint. However, as the temperature readings gets closer to the unexposed side of the wall the temperature difference between the two joints decreases. The raked joint has a shorter plateau than the concave joint at $100{ }^{\circ} \mathrm{C}$, which is due to the reduction in joint thickness. At the end of the test the hottest raked joint had just reached a temperature of $147^{\circ} \mathrm{C}$ (which was just above the insulation failure of a $140{ }^{\circ} \mathrm{C}$ increase), while the hottest control joint had not even gone above $100{ }^{\circ} \mathrm{C}$. Though it can be seen that raked joints are not superior to concave joints, 


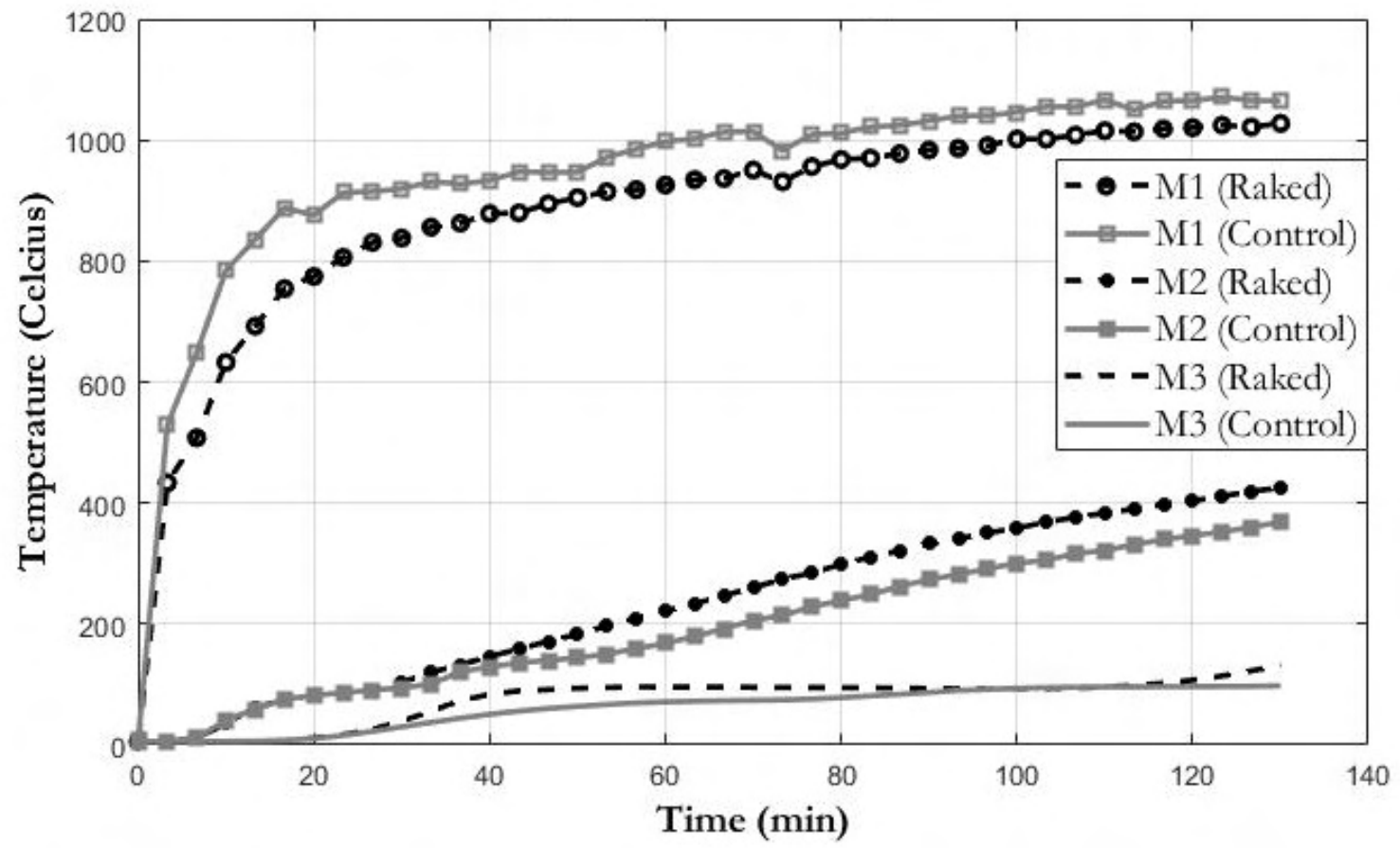

Figure 4.13: Comparing mortar temperatures between the control wall and the raked joint wall

the effect of raked joints on the overall wall temperature was limited as both walls failed due to the hollow cells failing insulation.

The fact that raked joints do not significantly affect the fire resistance of a masonry wall is an important finding because it would suggest that the fire resistance of walls are not dependent on the jointing of the mortar. When tests are conducted for the standards, the walls are always perfectly jointed to ensure the wall receives a high fire resistance rating. Because of this, the only walls that will be able to use that fire rating are walls that have perfectly jointed mortar. If it is found that rake jointed walls also have the same fire rating as perfectly jointed walls, masons will be able to make walls without having to joint them perfectly. This reduces the amount of labour required which would save the masons time and save clients' money.

\subsubsection{Almonte Test2 The Effect of the Bond Beam}

The bond beam had a pronounced effect on the temperature of the wall (Figure 4.14). Two thermocouples (one on the left side of the wall and one on the right) were placed below the bond beam (below the 8th course) and two thermocouples were placed 
above the bond beam (above the 8th course). The thermocouples below the bond beam were consistently hotter than those above. This means that the bond beam was successfully able to reduce the vertical flow of heat through the cells. While some masonry blocks are designed to reduce the convection and radiation that allows heat to travel horizontally through the wall, the bond beam was able to stop the vertical convection inside of the cells. This prevented the hot air from the lower parts of the wall from accumulating at the top of the wall and causing a localized temperature increase. Since all the masonry walls failed when a single point reached $180{ }^{\circ} \mathrm{C}$ increase, having a more uniform temperature inside the wall would improve the fire resistance by shifting the failure time to when the whole wall increased by $140{ }^{\circ} \mathrm{C}$.

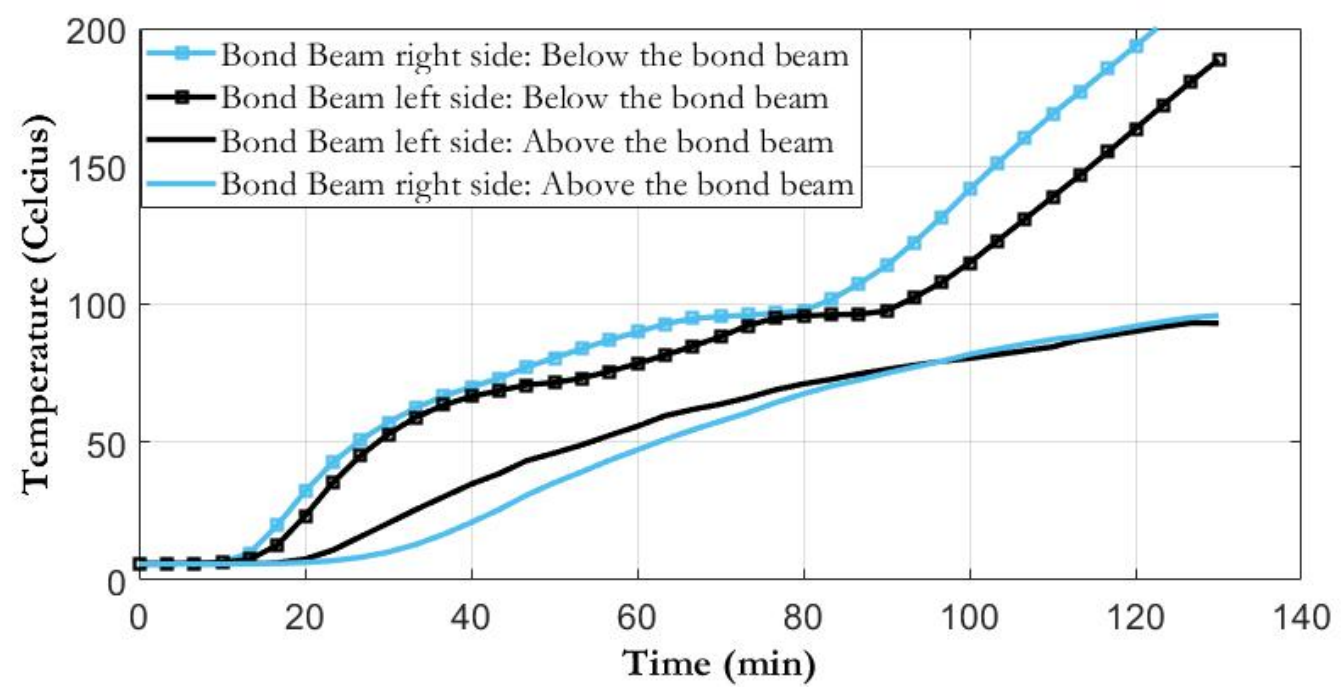

Figure 4.14: The effect of the bond beam

It may have been thought that because the area above the bond beam was cooler than all the other walls, the area below the bond beam would be hotter; however, this is not the case. While the thermocouples just above the bond beam are colder, the thermocouples below the bond beam have similar temperatures as the thermocouples similarly placed in the control wall and reduced web wall (Figure 4.15). The most likely reason why the temperature below the bond beam is cooler than its counterparts is that some of the heat is being absorbed by the solid bottom of the lintel units. As previously mentioned, the lintel units have a higher thermal mass on the bottom of the unit, which means that they can absorb more heat. This would suggest that the 
bond beam is superior to the control wall, even though they have the same equivalent thickness.

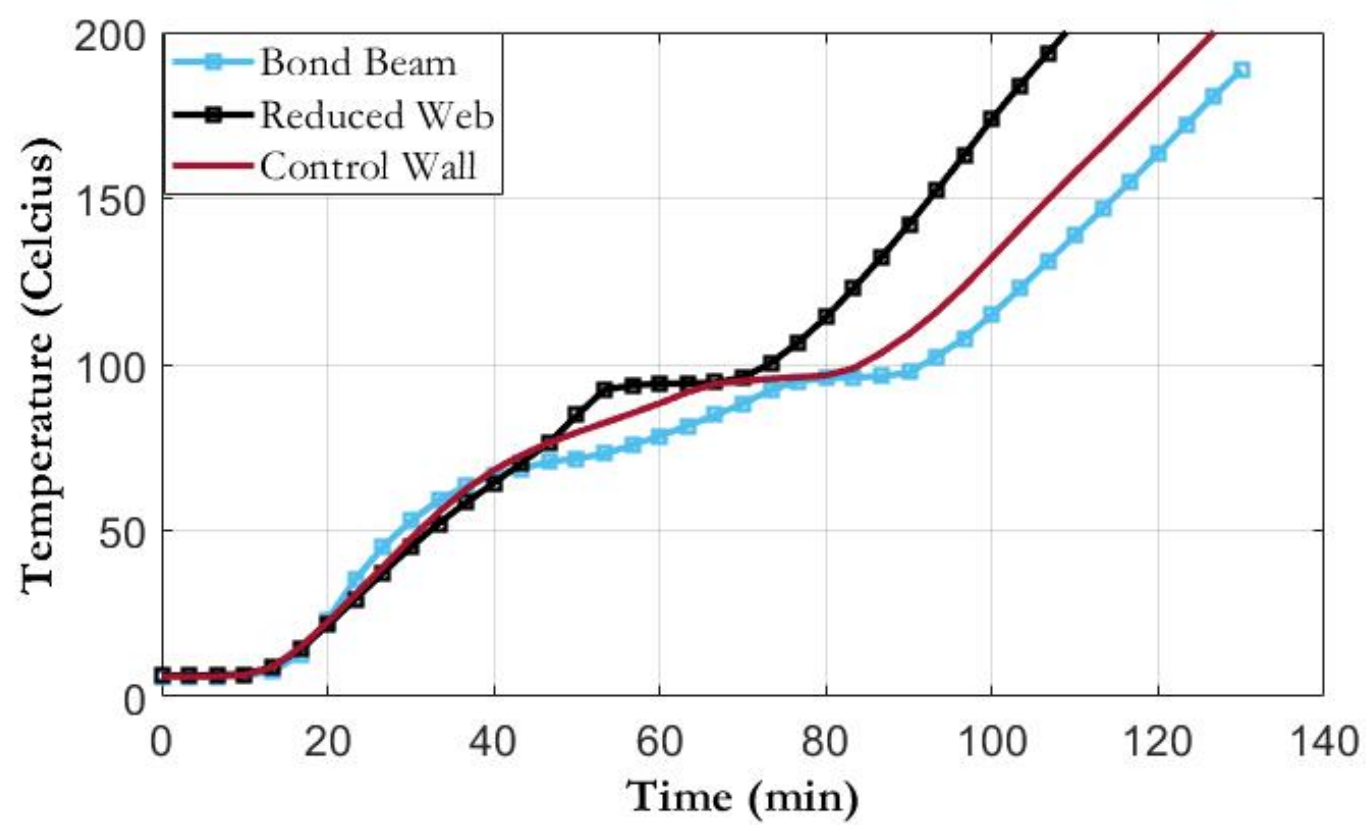

Figure 4.15: The effect of the bond beam

A crack formed at the top of the wall with the bond beam, which greatly increased its temperature and caused it to fail before the control wall. The reason for this crack is most likely due to a defect in one of the masonry blocks used. Future research should retest this type of wall, potentially with more than one bond beam. Since one bond beam was found to have beneficial results due to the compartmentalisation of the wall, determining the ideal number of bond beams would be of great interest.

\subsubsection{Almonte Test2 The Effect of the Reduced Webs}

The equivalent thickness of the reduced web block $(94 \mathrm{~mm})$ was less than the other three walls $(113 \mathrm{~mm})$ because half of the webs were removed (Figure 4.16). For this reason, the reduced web wall had a lower estimated fire resistance rating than the other three walls. The results of the test showed that this estimate was correct, as the reduced web wall failed first. A major reason why the reduced web wall failed first was the lack of material, which meant less thermal mass. As the temperature on the exposed face-shell increases, the block itself absorbs the heat. The more 
material available to absorb the heat, the lower the temperature on the unexposed side. Another reason is based on the geometry of the blocks. As there was no web on the top half of the block, the conduction and radiation within the block increased and the heat was able to travel laterally along the wall. Similar to Alhazmy et al. study, the more partitions inside of the blocks the better the thermal resistance [39]. Because reducing the webs is similar to decreasing the partitions, it would make sense that the wall had a lower thermal resistance.

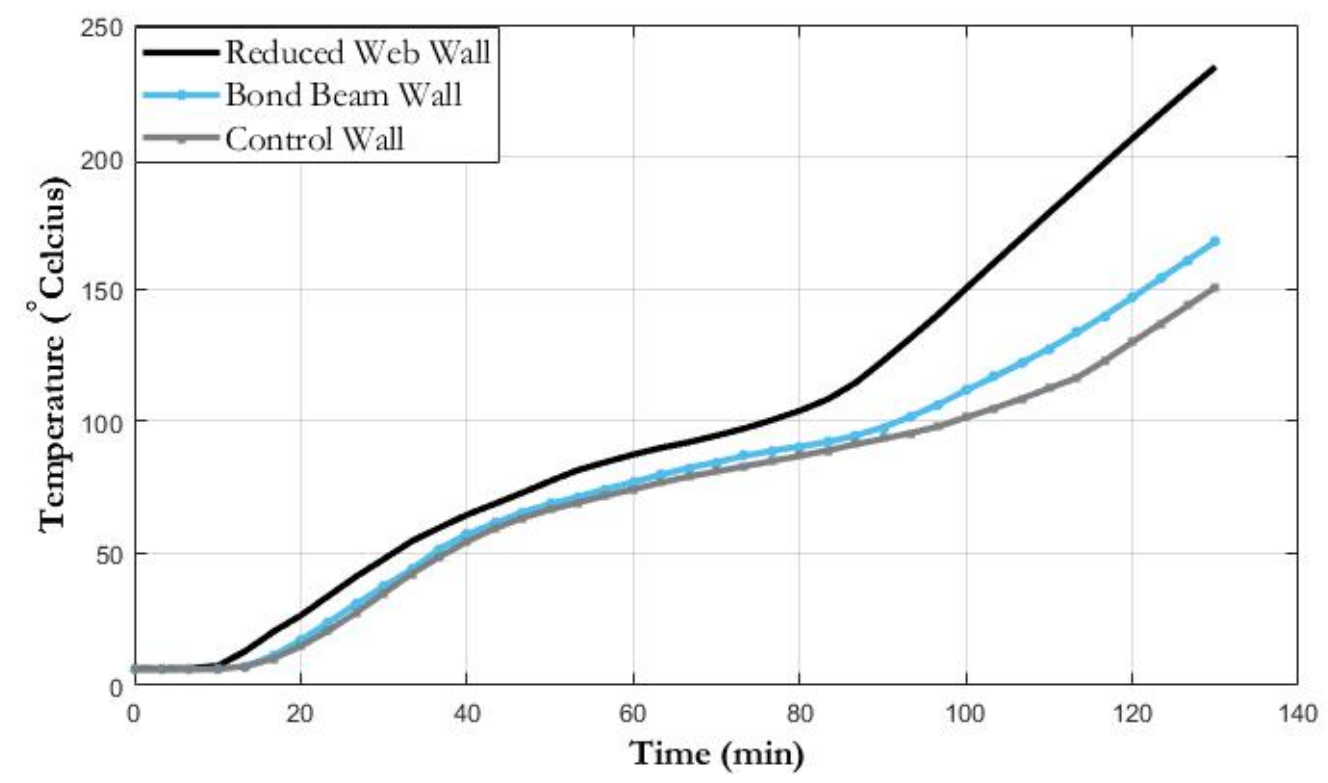

Figure 4.16: The effect of the different wall geometries

While it is true that the reduced web wall failed first, it exceeded the equivalent thickness estimation for its fire resistance. This is because the equivalent thickness method does not take into consideration where the material is located within the block. The material that was removed was taken from the webs instead of the faceshell. As stated previously, the thickness of the faceshell is more important than the thickness of the webs for reducing the heat flow through the block. Therefore having a block with thicker faceshell and reduced webs performed better than a block with full webs but smaller faceshell. 


\subsubsection{Almonte Test2 Thermal Imaging Results}

Thermal imaging shows the temperature distribution of the whole wall. This allows for a visual demonstration of the different temperatures on the wall surfaces. The control wall (Figure 4.17a) had a similar pattern to the raked joint wall (Figure 4.17b) and the bond beam wall (Figure 4.17c), with the columns of heat on the surface of the hollow cells separated by the columns of cooler masonry on the surface of the webs. The top part of the wall is hotter in all areas (cells and webs). However, the surface in line with the cells is much hotter at the top of the wall than at the bottom of the wall. This is due to the hot air rising in the cells due to convection, and keeping the higher cells hotter.

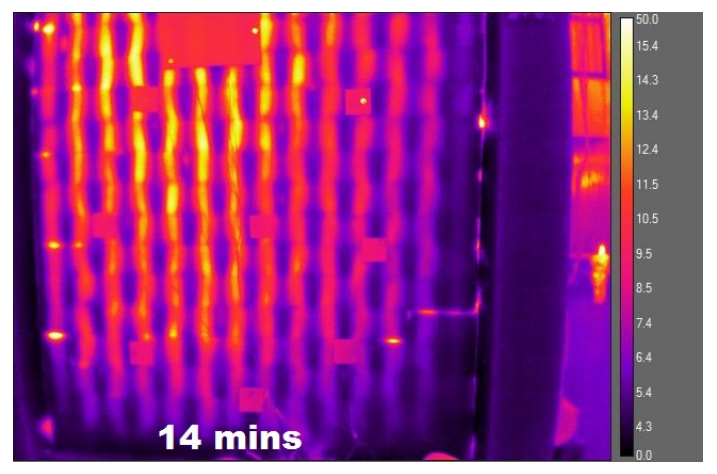

(a)

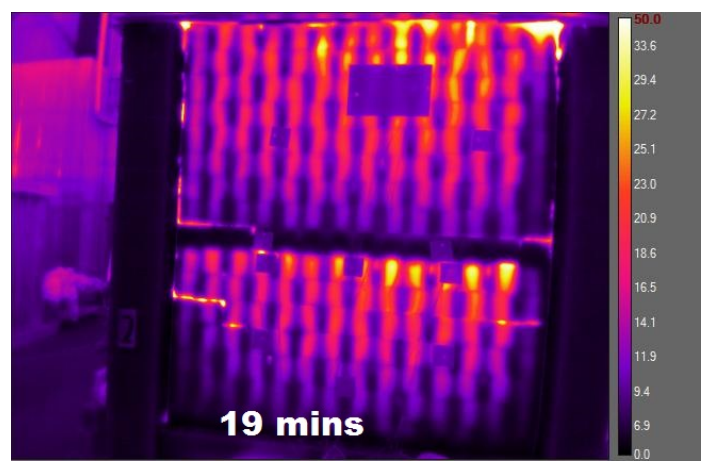

(c)

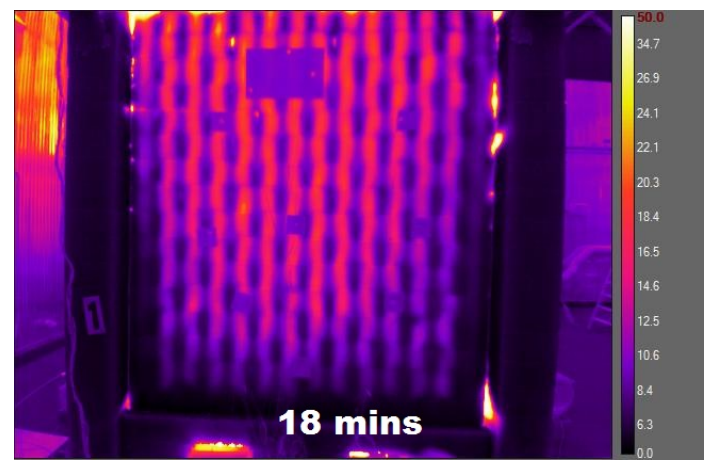

(b)

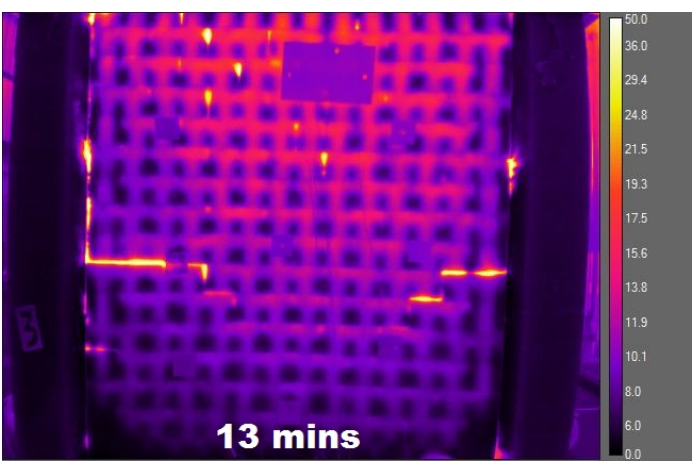

(d)

Figure 4.17: (a) Control Wall (b) Raked Wall (c) Bond Beam Wall and (d) Reduced Web Wall

The thermal imagining of the bond beam wall in Figure $4.17 \mathrm{c}$ demonstrates the effect of the bond beam in the center of the wall. The bond beam was much cooler than the rest of the wall, due to the bond beam having a higher equivalent thickness 
and therefore having a reduced horizontal heat flow. The space below and above the bond beam had very different temperatures. This is because the bond beam was able to stop the convection of hot air through the cells. $4.17 \mathrm{c}$ is from early on in the test, but it can still be seen that the area above the bond beam was around $20{ }^{\circ} \mathrm{C}$ colder than the area below. As the test progressed this difference in temperature increased with time.

The thermal imaging of the reduced web wall in Figure 4.17d demonstrates how the reduction of the webs changed the way the wall heats up. Instead of having only columns of heated concrete, there are also rows of heated concrete. This is because horizontal convection left and right was able to occur due to the gaps formed by the reduced web. Similar to the other walls tested, the top of the wall was hottest in the cells at the top. However due to the ability for the heat to transfer horizontally, the temperature in the cells at the top of the wall was more uniform, rather than having some cells much hotter than others.

The thermal imaging helps to show the non-uniform temperature distributions of masonry, with the hollow cells being the most critical. It also helps to illustrate that while the equivalent thickness method can be used to get a rough estimate of the fire resistance rating, it fails to take into account any of the variations in block geometry.

\subsubsection{Almonte Test2 Results of Thermal Bowing}

Thermal bowing occurs when one side of a wall is exposed to a fire and heated, while the other side is unexposed. The temperature difference causes uneven expansion inside the wall, due to the fire exposed side expanding more than the unexposed side. This causes the wall to bend out towards the fire, with the maximum curvature being at the wall's centre, Figure 4.18. This is still an important phenomenon because it can lead to premature failure due to the curvature of the wall. The curvature happens rapidly at the start of the fire and then recovers during the fire. This rapid change happens due to the increase in the temperature difference between the exposed and unexposed side. The reason the wall recovers is that the unexposed part eventually heats up as well and reduces the temperature difference between the two sides [58]. When non-loadbearing walls are tested, the restraint from the frame causes the wall to curve in a spherical shape with cracks across the four corners, Figure 4.19 b. 


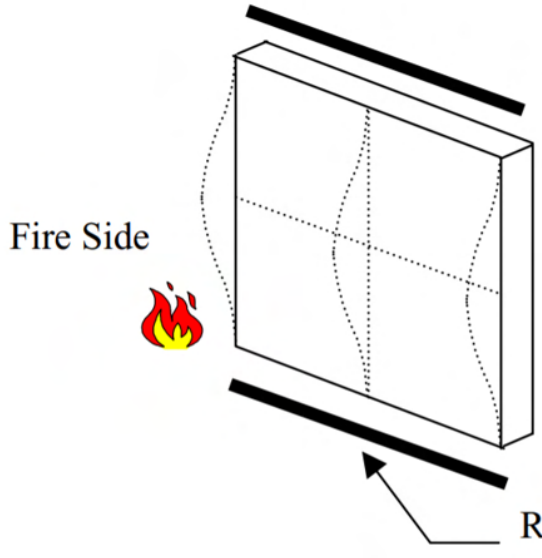

(a)

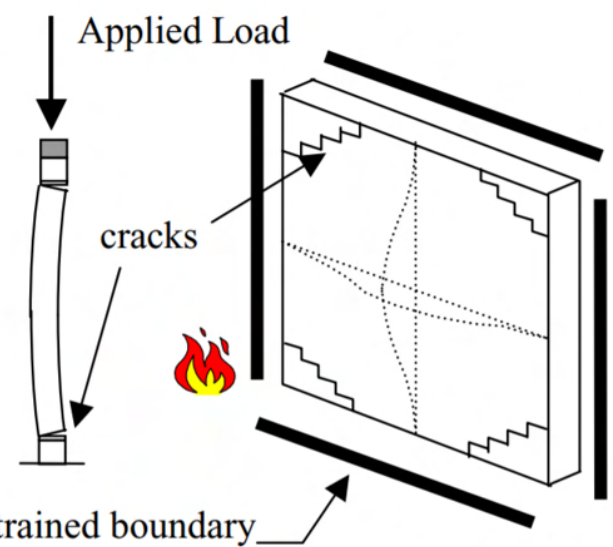

(b)

Figure 4.18: Thermal Bowing a) Loaded b) Unloaded [60]

When comparing the crack formation of the concave wall to the raked joint wall it was found that the raked joint wall had less cracking (Figure 4.19). The cracks are usually caused by thermal expansion or thermal bowing. The reduced amount of mortar may have allowed the wall to undergo thermal bowing without causing as many cracks. When cracks did occur in the raked joint wall, they were at the interface between the block and mortar. Whereas the control wall had cracks along the interface, and through the concrete blocks.

During the test each of the walls underwent some thermal bowing. As each of the walls were constructed of the same material and had the same slenderness ratio, the only major factors were the temperature gradient and the block geometry. The reduced web wall had the most deflection throughout the test, while all of the other walls had only minor deflections. Near the beginning of the test the walls were very hot on the exposed surface, but relatively cool on the unexposed surface. As the test progressed the exposed face-shell of the walls became much hotter than the unexposed faceshell, and this unequal temperature caused the thermal bowing in all of the walls. The reason why the reduced web wall had more deflection than the other walls early on was that the exposed faceshell of the reduced web wall was able to heat up much faster than the other walls. After some time the temperature difference between the exposed and unexposed sides of the walls reduced. Because of this the wall deflections stop increasing. They remain close to constant for the duration of the test. After the test was done and the walls had cooled completely the deflections decreased, but did 


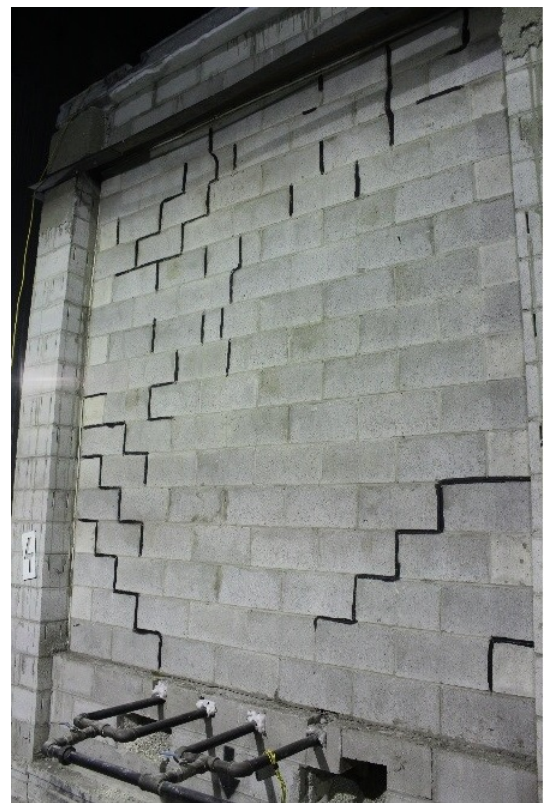

(a)

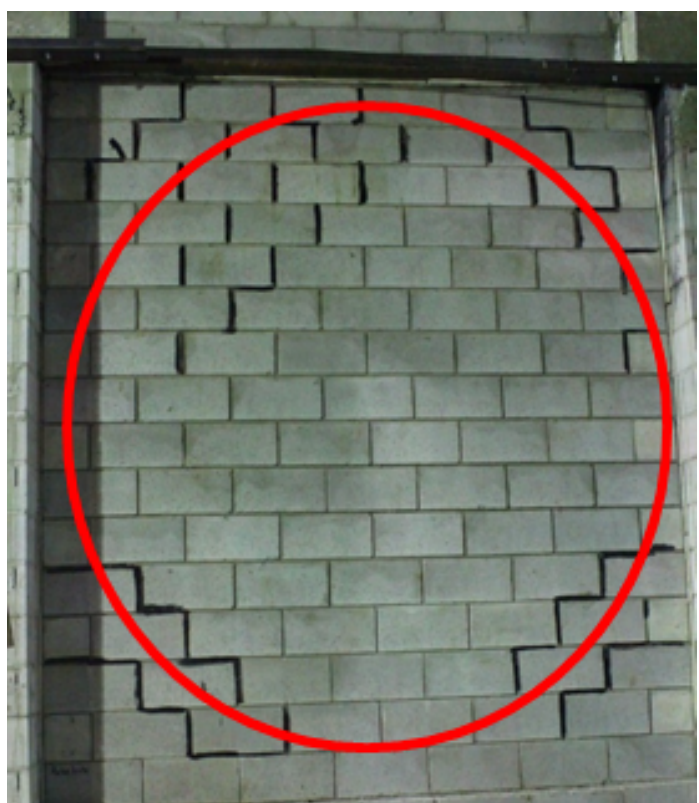

(b)

Figure 4.19: (a) Concave Wall Cracks and (b) Raked Wall Cracks

not vanish completely.

In non-loadbearing tests, the specimens are built to fit tightly into a semi-rigid rectangular frame and the resistance provided by the frame makes it unlikely for any cracks to open up [5]. Also, because the frame restrains the walls "the main body of the wall curves in a spherical shape with cracks across the four corners". This phenomenon is illustrated with Figure 4.19. When comparing the crack formation of the control wall to the raked joint wall it was found that the raked joint wall had less cracking. The cracks are usually caused by thermal expansion or thermal bowing. The reduced amount of mortar may have allowed the wall to undergo thermal bowing without causing as many cracks. When cracks did occur in the raked joint wall, they were at the interface between the block and mortar. Whereas the control wall had cracks along the interface, and through the concrete blocks.

\subsubsection{Almonte Test2 Results of Spalling}

As there were no cameras to watch the exposed side of the walls, it is not possible to precisely determine how much of the spalling happened during the test and how much occurred after the walls cooled down. Due to the fact that most of the rubble was tiny 
pieces found just below the wall, it is safe to assume that a majority of the spalling was not explosive spalling, but instead the slower spalling (sloughing off) that occurs later as cracks form parallel to the fire-affected surfaces [66]. There was a substantial amount of spalling that occurred with all of the walls due to the amount of debris located at the base of the walls. The reduced web wall had the worst spalling, and the faceshells of the blocks on the top of the wall fell apart and left only parts of the web and the exterior faceshells. A pictures of the spalling can be found in Figure 4.20. If any of the faceshell had fallen off during the test, the unexposed temperature would likely have changed. However, as no change was seen in the graphs, it is more likely that it occurred after the test was completed.

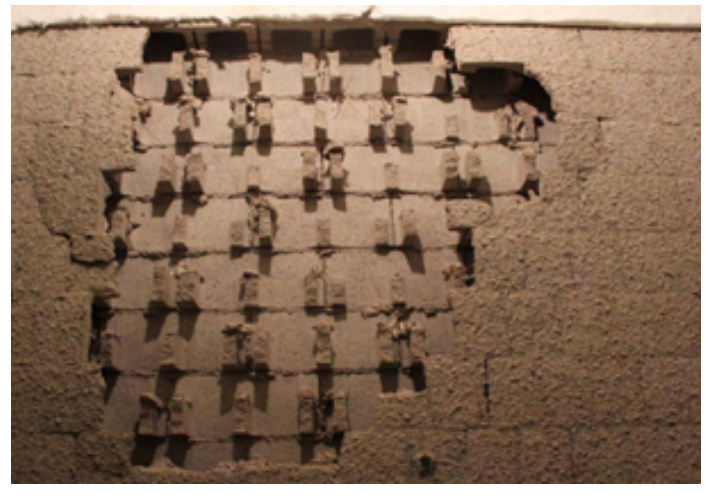

(a)

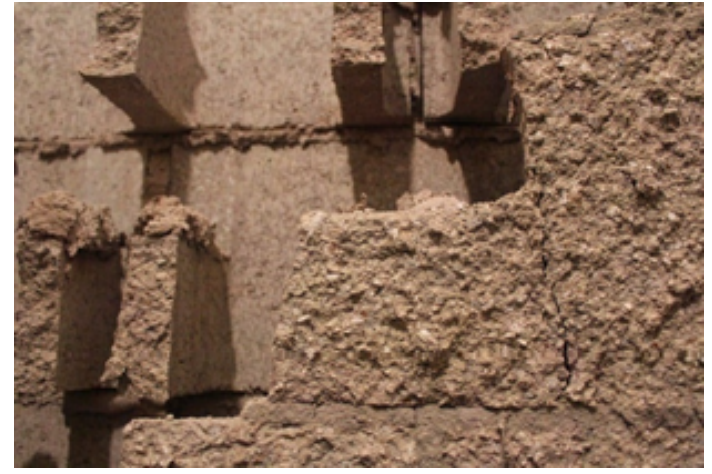

(b)

Figure 4.20: (a) Reduced Web Wall Spalling and (b) Close up of Spalling

\subsubsection{Almonte Test2 Experimental Conclusions}

The fire resistance of masonry blocks is largely affected by its geometry. Blocks with more material and partitions have a better fire resistance, as it reduces the convection and radiation through the blocks. While the equivalent thickness can be a useful tool for giving a rough estimate of the fire resistance of masonry blocks with different amounts of material, it fails to take into account the effects of different block and wall geometries.

As masonry is not homogeneous, the surface temperature of the wall varied. The hollow cells heated much faster than the solid webs and mortar, because the webs and mortar remained at $100{ }^{\circ} \mathrm{C}$ longer while the free water evaporated. Therefore, 
reducing the heat flow through the cells is critical in improving the fire resistance of masonry.

At the beginning of the test, the bond beam wall showed that masonry walls that are more compartmentalized can have an improved fire resistance by reducing vertical heat flow which convects hot gasses to the top of the wall. This reduction in convection reduces hot spots by keeping the wall temperature more uniform, which in turn improves the fireresistance. Due to the formation of a crack within the wall partway through the test, the bond beam wall did not surpass the control wall in terms of fire resistance. Therefore future testing is required in order to confirm the validity of this option for a full length fire resistance test.

The reduced web wall showed that the volume of concrete in the blocks is important. The webs act to compartmentalize the wall and reduce hot spots, as well as act as a heat sink which delays the time to failure. However, since the faceshell remained at full thickness, the reduced web wall had a much higher fire resistance than was estimated using equivalent thickness. This is because the thickness of the faceshell does more to improve the fire resistance than the thickness of the webs.

The type of jointing did not have a large impact on the fire resistance of the masonry walls. While the mortar in the raked joint heated up faster than the mortar in the concave joint, it was still much cooler than the hollow part of the masonry block. This meant that even with less mortar in the joints, the governing location was still the air cells. Another reason for the mortar joints not failing first could be attributed to the higher amount of free water in the mortar, which allowed it to stay cooler than the other parts of the wall. Thermal imaging showed that the two different walls had the same heat flow pattern throughout the wall. Finally, the raked joint was found to have better crack resistance than the control wall, with only minor cracking along the interface of the blocks.

Future research with more lintel units would be beneficial in order to confirm that the vertical heat flow can be reduced by the addition of these blocks. This can be done by using a varying amount of bond beams in order to determine their effectiveness, as well as the optimal number of bond beams. Once their benefit is confirmed, new specialized blocks can be designed to reduce vertical heat flow in a similar manner. 


\subsection{Barnsdale Test $1 \mathrm{~A}$ results}

The purpose of this test was to locate flaws within the test structure and to ensure that the furnace could follow the standard fire curve. During the test there were some issues that may have effect the results, which are outlined in more detail where applicable. In particular, there was some flame impingement on the lower courses of some of the walls, which cause some of the thermocouples at the lower points of the walls to read higher than expected.

After three false starts, the final test ran for six minutes. While the fire was extinguished after that time, the heat transfer within the walls continued for quite some time after heat source was gone. The following results include data from when the fire was running, as well as the subsequent cooling.

\subsubsection{Barnsdale Test 1A Furnace temperature during all heating attempts}

The furnace was turned on a total of four times. The first two times the furnace was turned on it ran for roughly five minutes, then cooled for five minutes. The third time the furnace was turned on only for a brief time. The final time the furnace was turned on it remained on for six minutes before being shut off and allowed to cool. The exact temperature of the furnace over time can be seen from Figure 4.21. The following results with focus mainly on the final time the furnace was turned on, and the subsequent cooling. However, since the furnace was turned on three times before this final heating, many thermocouples were reading temperatures above ambient conditions.

\subsubsection{Barnsdale Test 1A Final test Furnace temperature}

During the final test the ambient conditions within the test structure were an average of $64{ }^{\circ} \mathrm{C}$ (Figure 4.22). When the furance was turned on the gas flow was changed so that the furnace temperature could approximate the standard fire temperature. After six minutes and an average temperature of $662{ }^{\circ} \mathrm{C}$, the test was stopped and the furnace temperature began to drop rapidly. Four minutes after the gas was shut off the the average furnace temperature was $100{ }^{\circ} \mathrm{C}$, but at this point the temperature decrease had begun to slow. Over the next 32 minutes, the temperature continued to 


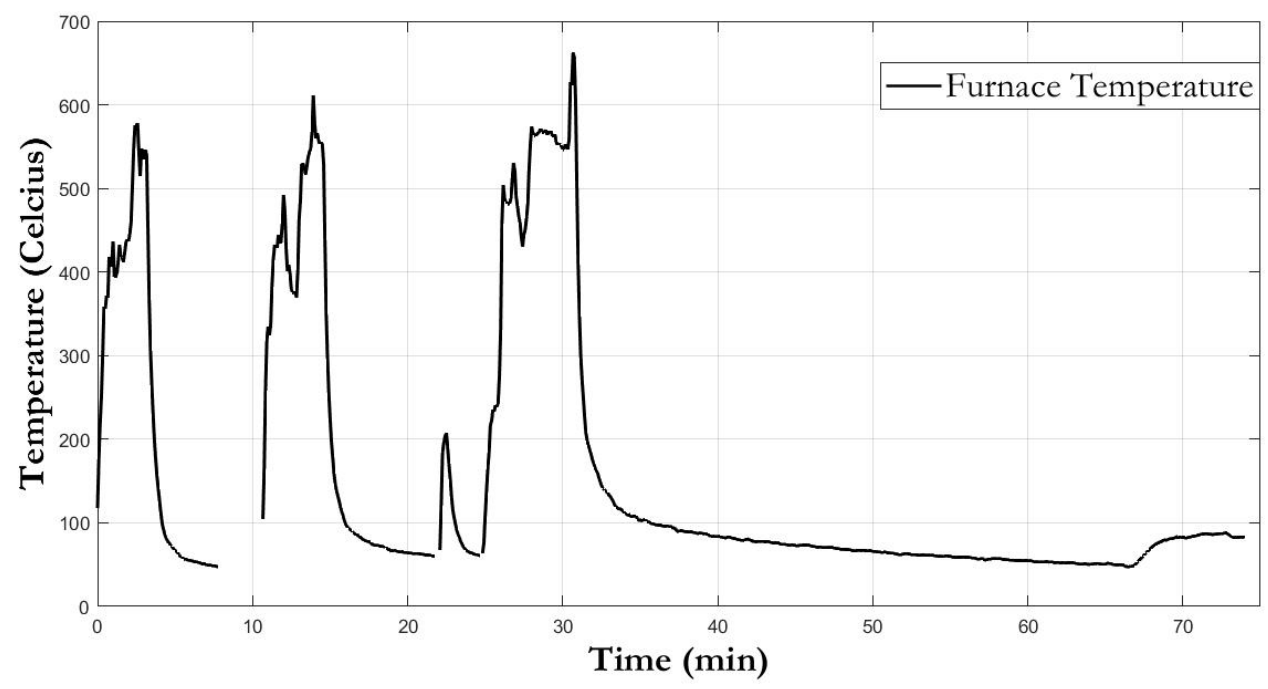

Figure 4.21: Barnsdale Test 1A, The furnace temperature throughout the test.

decrease. After 42 minutes the ceiling vent was closed, and the furnace temperature began to rise back up close to $100{ }^{\circ} \mathrm{C}$, but after six minutes the temperature began to decrease again.

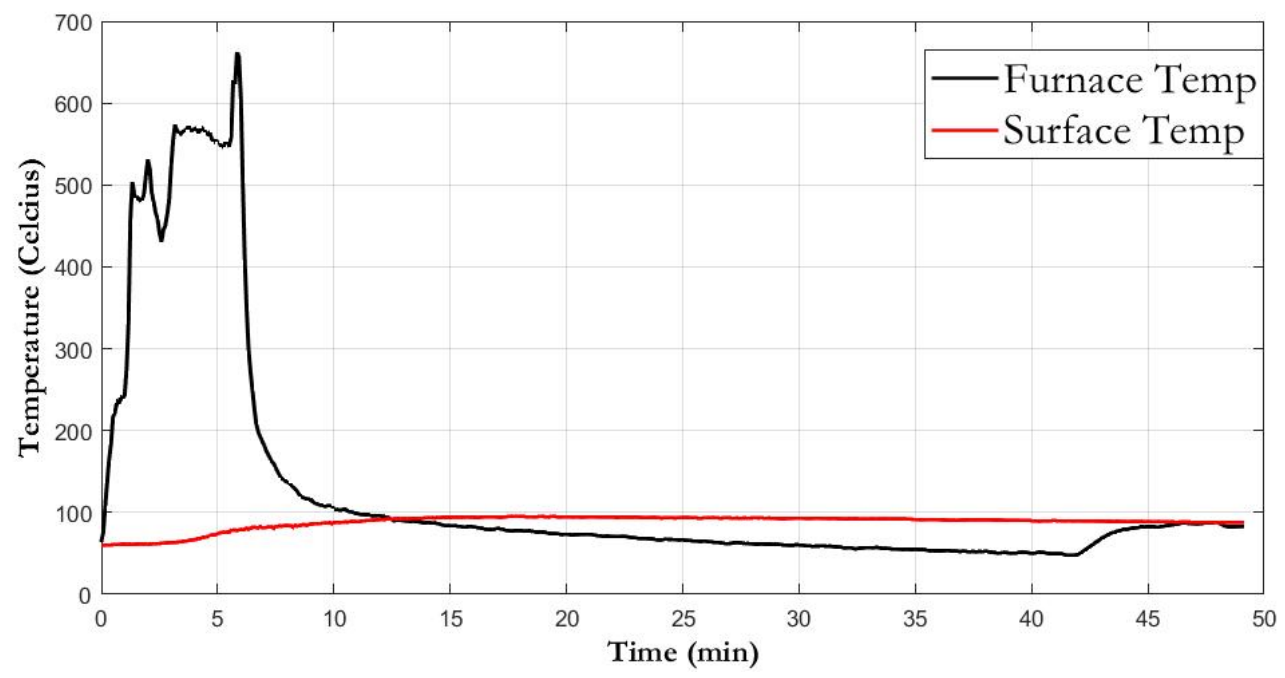

Figure 4.22: Barnsdale Test 1A, The furnace temperature compared to the average exposed wall temperatures.

The reason the temperature increased when the ceiling vent was closed was the the airflow within the test structure decreased. This meant that heat radiating from 
exposed masonry surface could no longer flow up and out of the test structure thereby cooling the furnace thermocouples. Instead, the air remained trapped within the structure. This trapped air was allowed to heat up and radiate that heat back to the furnace thermocouples, as well as the masonry walls themselves.

The exposed masonry surface temperature began to increase when the furnace temperature was high. Even after the furnace was turned off, the surface continued to slowly heat up for another 12 minutes due to the hot air, burner, and internal surfaces. After that point the masonry surface began to cool very slowly. When the ceiling vent was closed, the masonry surface continued to cool, and the heat given off by this surface is what caused the increase in the Furnace Temperature thermocouples.

Concrete has a high thermal inertia. This means that concrete takes time to heat, but also that concrete takes time to dissipate that heat. Even after the fire is extinguished, the heat continues to flow through the concrete, heating up the various parts of the blocks and increasing the unexposed surface temperatues. The exact nature of this heat flow can be found in the following sections.

\subsubsection{Barnsdale Test 1A Average Unexposed temperaures of the four walls}

Since the walls were constructed outdoors, the initial temperature of the walls ranged from $15-30{ }^{\circ} \mathrm{C}$ (Figure 4.23). The reason for the wide temperature difference came mostly due to the effects of the hot sun shining down on the Struck Joint Wall and the Splitter wall, and the Control Wall and Bond Beam wall being more in the shade. During the first few false starts, the initial temperatures ranged from $30{ }^{\circ} \mathrm{C}$ to just over $40{ }^{\circ} \mathrm{C}$.

As the test progressed the temperature of all of the walls began to increase, with the struck joint wall increasing a little more rapidly. As the test was stopped after six minutes, the splitter wall began to undergo some issues with the thermocouples. As the cooling process began, the Splitter Wall appears to be the coolest wall, however this is most likely due to malfunctions in the thermocouples themselves.

During the cooling phase, the walls unexposed surface actually increased in temperature. This is because the concrete was able to absorb heat from the furnace while it was on, and it takes time for that heat to transfer from the exposed side of the wall to the unexposed side. While the exposed side of the wall did begin to cool with the 


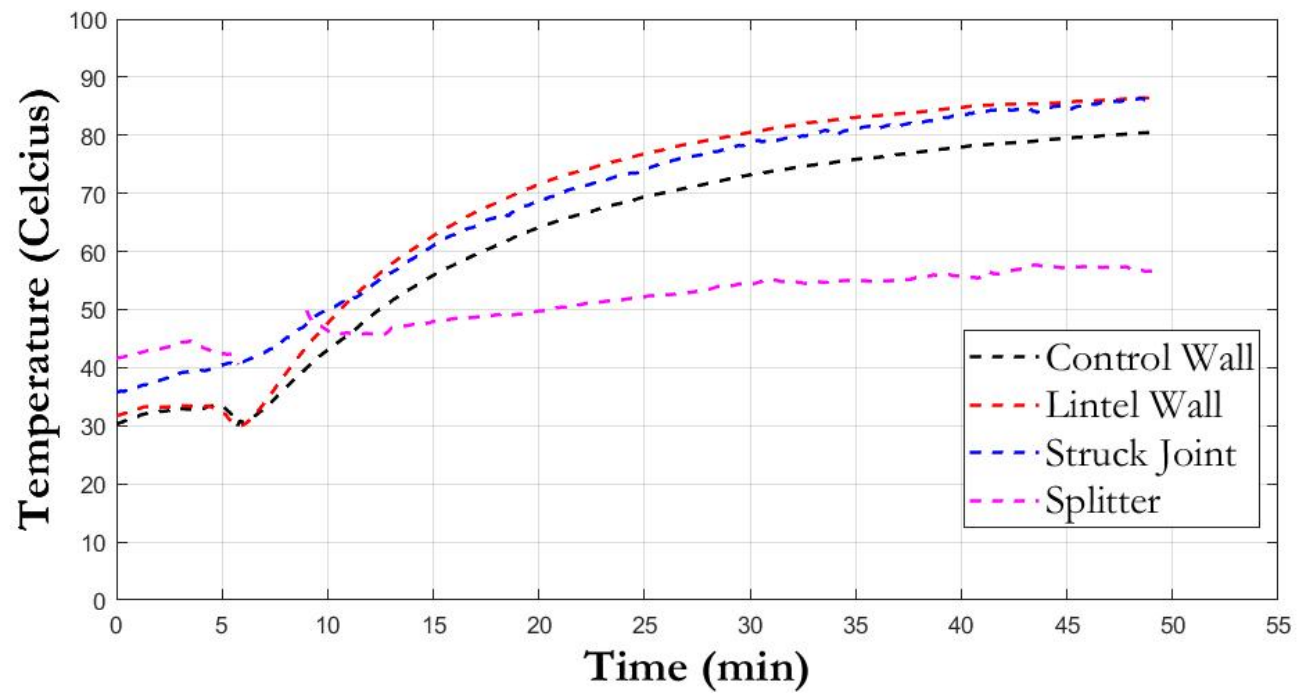

Figure 4.23: Barnsdale Test 1A, Average unexposed wall temperatures

removal of the flames, it was still much hotter than the unexposed side. This meant that heat would continue to flow from the exposed side to the unexposed side.

The graph of the unexposed temperatures shows that the temperature increased rapidly just as the test was stopped and began to increase less as time progressed. The reason for this is that the temperature on the unexposed side of the wall began to approach that of the exposed side of the wall. In fact, the unexposed temperature actually increased past the current furnace temperature. This is due in part because the furnace thermocouples were being cooled by the flowing air, and in part because the thermocouples on the unexposed side were insulated with pads in order to reduce the heat transfer from the unexposed side of the wall to the ambient conditions.

\subsubsection{Barnsdale Test 1A Internal Temperatures Within a Block}

The three distinct parts of the wall were the Mortar, the Hollow Cell, and the Solid Web. The temperatures at the midpoint between the exposed and unexposed side for each of the three locations can be found in Figure 4.24. The three thermouples were placed at the top of the wall in the highly instrument block. As the test starts, the hollow cell is already the hottest part of the wall. This is because the cell was pre-heated from the false starts, and the hot air was able to acumulate at the top of 
the wall. The next hottest part at the start was the web. This is in part due to the heat within the cavity radiating and convecting not only from the exposed side of the wall to the unexposed side, but also from left to right. This heat transfer caused the web to heat more than the mortar. While there is a small cavity in between the two mortar joints, its size does not allow for as much convection or radiation. The smaller mortar joint cavity also does not hold as much hot air, which is another reason why it started the test as coldest part of the wall.

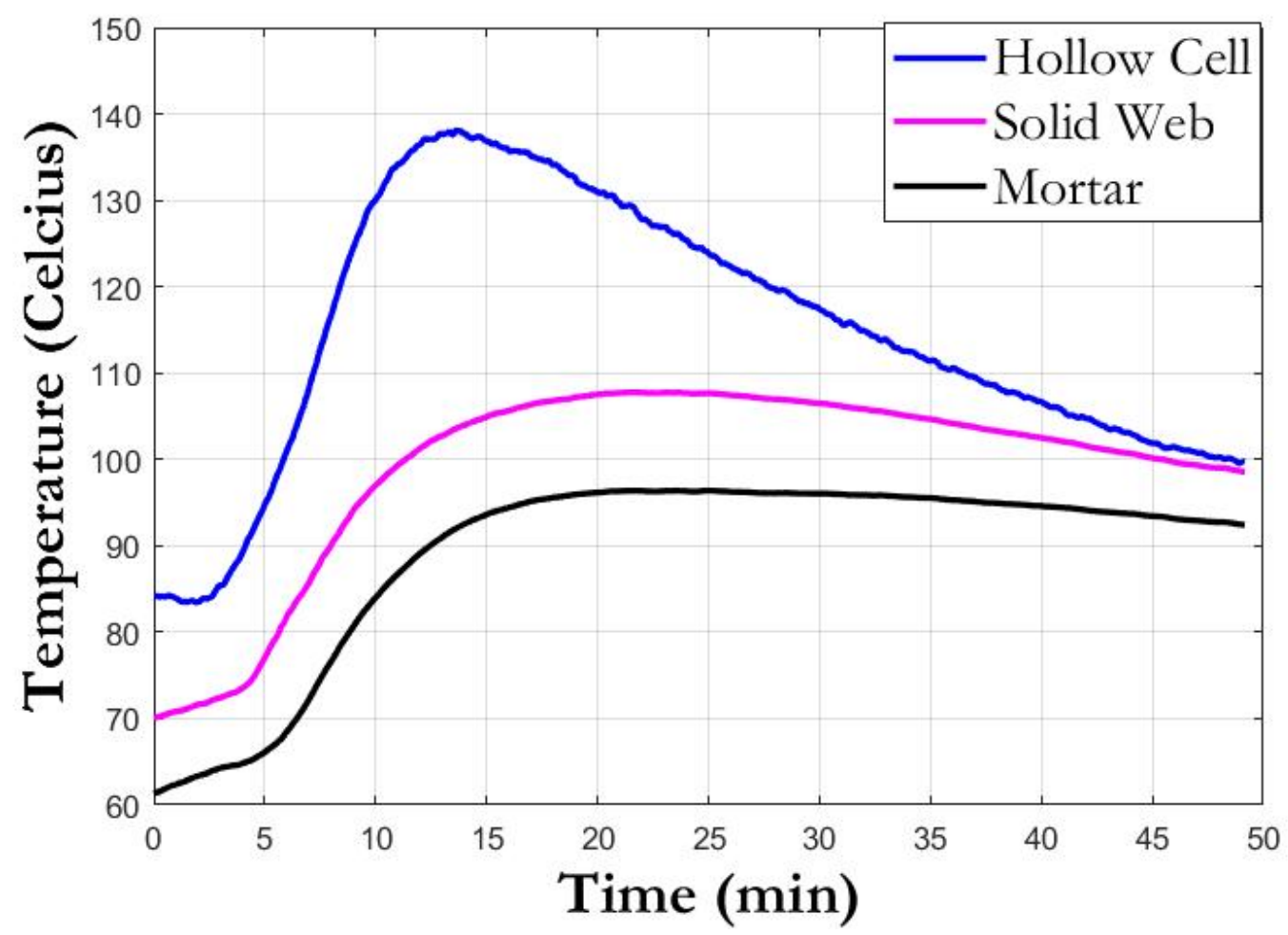

Figure 4.24: Barnsdale Test 1A, The effect of thermocouples locations on the temperatures halfway through the wall

As furnace was turned off all three parts of the wall began to increase in temperature, with the hollow cell increasing the most due to the hot air from the courses below convecting vertically upwards. The solid web and mortar both increased at similar rates, with the solid web increasing slighty more (due to the same reasons that the solid web started out hotter).

After about ten minutes from when the furnace was extingished, the middle parts of the wall began to cool. While the solid parts of the wall cooled slowly, the hollow 
cell cooled at a much faster rate, almost reaching the temperature of the solid web. The solid parts of the wall have a higher thermal inertia, which means they take longer to heat up, but they also take longer to cool down as well.

\subsubsection{Barnsdale Test 1A Unexposed surface cooling rate of the different thermocouple locations}

The unexposed sufrace of the masonry displayed similar results to the internal temperatures, as it was found that the hollow cell was the hottest part of the wall (Figure4.25). The mortar and the solid web were found to have very similar temperatures when the furnace was on. After the furnace was shut off the hollow cell began to heat up rapidly as the hot gasses traveled vertically up the hollow cells. While the solid web had remained close in temperature to the mortar when the furnace was on, the solid web began to heat up faster than the mortar after the furnace was turned off. This is likely because the heat transfer through the mortar cells is limited to convection and radiation, which is limited. The main source of heat transfer through the mortar after the furnace is shut off is likely due to conduction from the surrounding webs. This explains why the mortar heats up at a slower rate than the solid web. All three locations converged at $88^{\circ} \mathrm{C}$ as the wall temperature began to equalize fully.

\subsubsection{Barnsdale Test 1A The difference between exposed, in- ternal, and unexposed temperatures in the hollow cell}

The temperatures at various points within the hollow cell can be found in Figure 4.26. The exposed surface temperature at this point on the hollow cell began at $80{ }^{\circ} \mathrm{C}$. The internal temperatures ranged from $50{ }^{\circ} \mathrm{C}-57^{\circ} \mathrm{C}$. The unexposed surface began at amient conditions. This is because the three false starts heated up the exposed surface, and that heat began to transfer through the concrete, but had not yet reached the unexposed surface.

As the furnace began to heat up the exposed surface slowly began to heat up. The reason for the slow increase at the start of the test is in part due to the thermal lag from the thermocouples. The interior parts of the wall were already heating up due to the heat transfer from the false starts. The unexposed surface temperature 


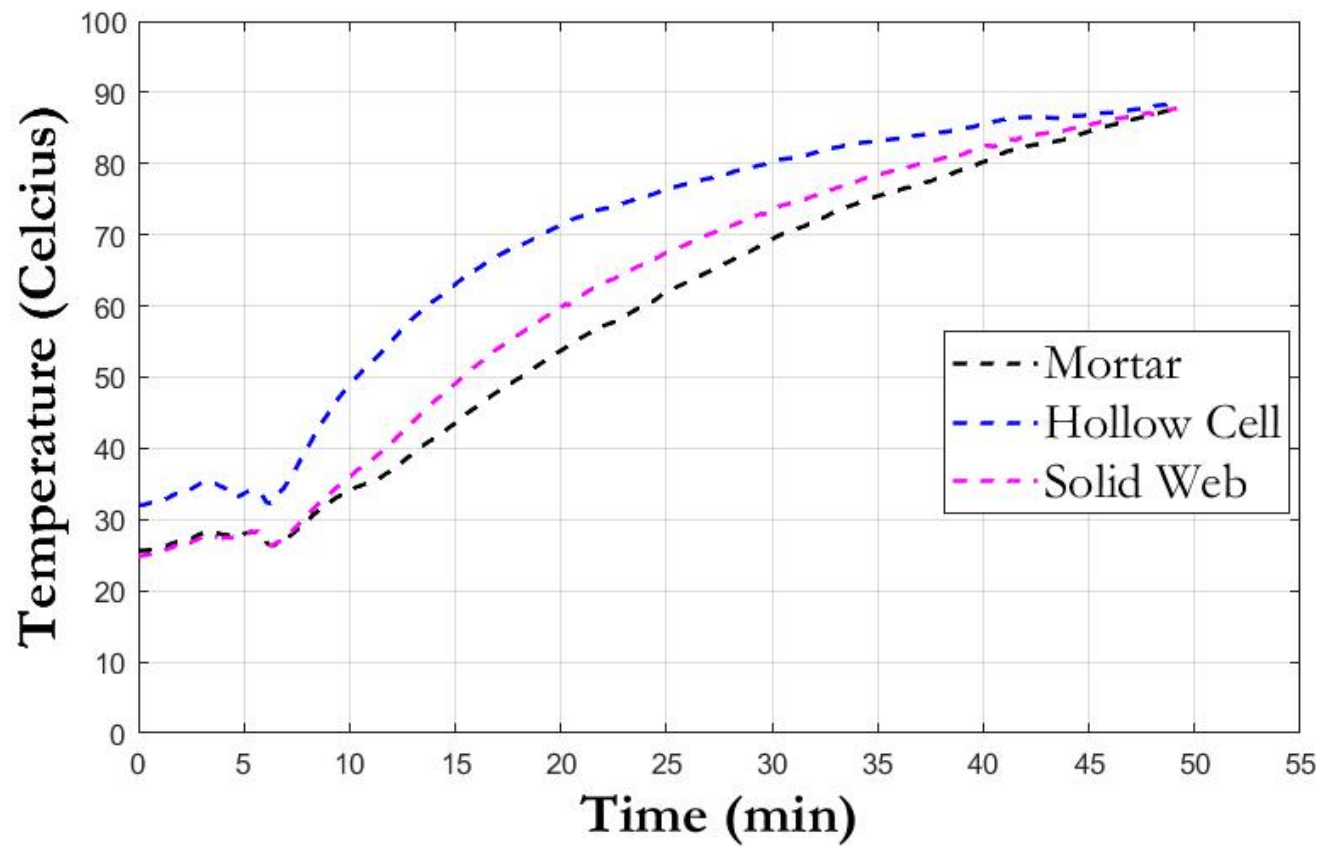

Figure 4.25: Barnsdale Test 1A, The effect of thermocouples locations on the temperatures on the unexposed side of the wall

actually began to decrease at the start of the test. This is because it takes time for heat to transfer through the concrete. Since the most recent false start had been several minutes before, the unexposed surface was transfering more heat to the ambient conditions then it was receiving from the rest of the concerete. However, after six minutes the unexposed side of the wall began to increase as the transferred heat finally reached the unexposed side of the wall.

After the furnace was shut off, the exposed surface continued to increase. The exposed surface reached its maximum temperature after 13.3mins. The three interior points $\mathrm{H} 2, \mathrm{H} 3$, and $\mathrm{H} 4$ reached their maximum temperatures at 14.3 mins, 17mins, and 18.8mins respectively. The closer the point was to the exposed side of the wall, the sooner it reached its peak and began to cool. This is because the masonry wall was beginning to cool, and the internal temperatures were beginig to equalize. The surface temperature was still increasing when the recording was terminated, however once it began to approach the temperature of H4, it would have begun to cool. 


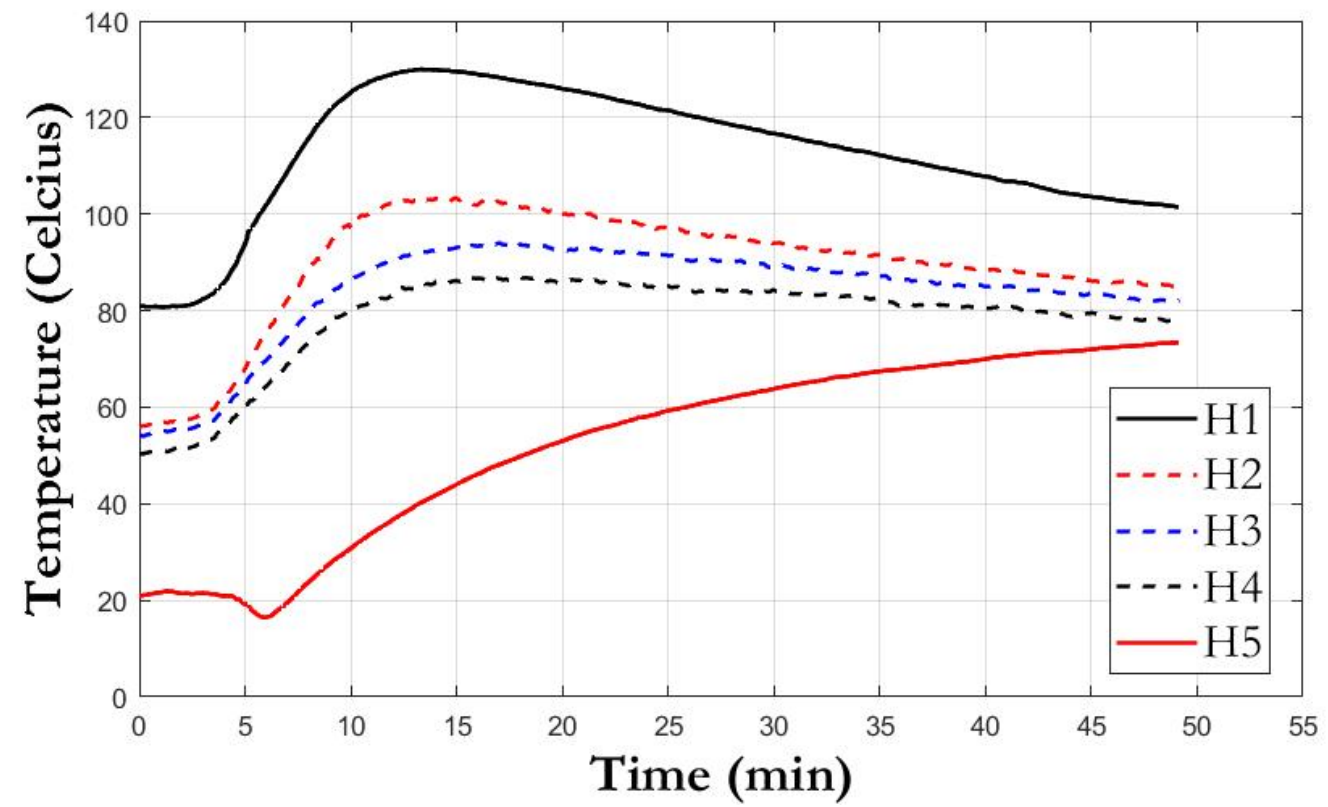

Figure 4.26: Barnsdale Test 1A, Temperatures within the hollow cell. H1 being the exposed side of the wall, and $\mathrm{H} 5$ being the unexposed side. $\mathrm{H} 2-\mathrm{H} 4$ are intermediate points within the hollow cell.

\subsubsection{Barnsdale Test 1A Effect of the bond beam}

For the bond beam the thermocouples were placed at various locations below and above the bond beam (Figure 4.27). Since the previous test had a crack form which heated up a section of the wall, the thermocouples were placed on the surface and inside various different cells to limit the effects of a localized failure. There were also two sets of thermocouples for each bond beam position, to ensure that there would be usable date from the testing even if one side of the wall failed.

The reasoning for using the bond beams was to stop the heat from traveling vertically up the wall. By segmenting the wall into four seperate sections the top parts of the wall would be able to remain cooler than the bottom parts of the wall. At the start of the test the points on the surface above the bond beams were found to be $10{ }^{\circ} \mathrm{C}$ cooler (Figure 4.28). As the test progressed this temperature difference increased to $15{ }^{\circ} \mathrm{C}$. The reason for this is that the heat rises within each section and once it reaches the bottom of the bond beam, it has nowhere else to go. This heat collects under the bond beam, and heats up that part of the wall, while the point 


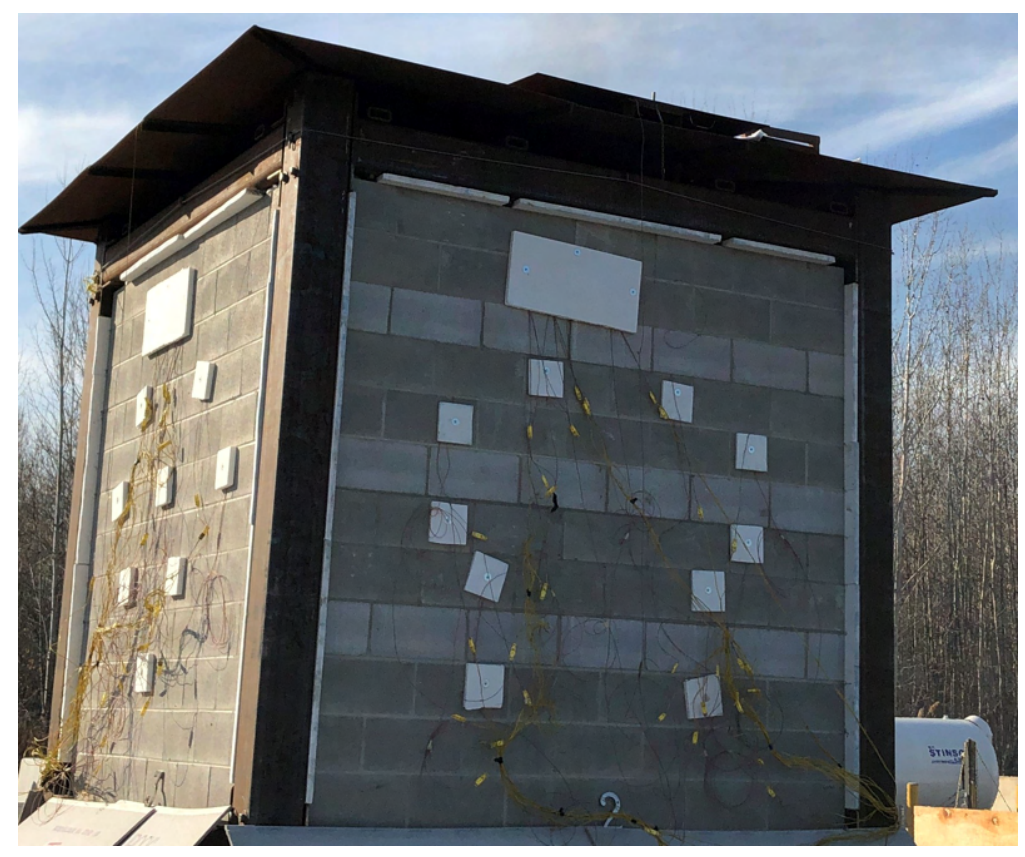

Figure 4.27: Barnsdale Test 1A, The locations of the extra thermocouples on the Lintel Wall

above the bond beam is noticeably cooler.

It is important to note there were some issues with flames impinging from below the test structure, which caused the lower part of the wall's surface to heat up faster than expected. However, the bond beams did prevent that heat from traveling up to the top of the wall.

As the furnace was shut off it was found that all points on surface of the lintel wall continued to increase (similar to other walls). The temperatures on the surface of each of the four sections of the wall began to approach the same temperature. This makes sense, as part of the cooling process involve the masonry wall equalizing the temperature throughout. However, it should be noted that the temperature difference between sections of the wall were about $10{ }^{\circ} \mathrm{C}$ each.

To determine how the cell temperatures compared to the cell temperatures of other walls, thermocouples were placed within the hollow cells of the struck joint wall at points of equivalent height to the three bond beams (Figure 4.29). As mentioned before, part of the reason the temperatures at the base of the bond beam wall were higher was due to flames impinging on the bottom of the bond beam wall. Even with this flame impingement, it is still possible to see how useful the bond beams are at 


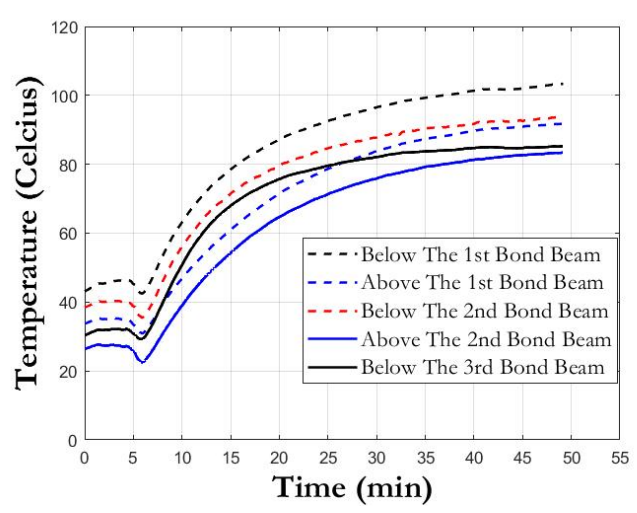

(a)

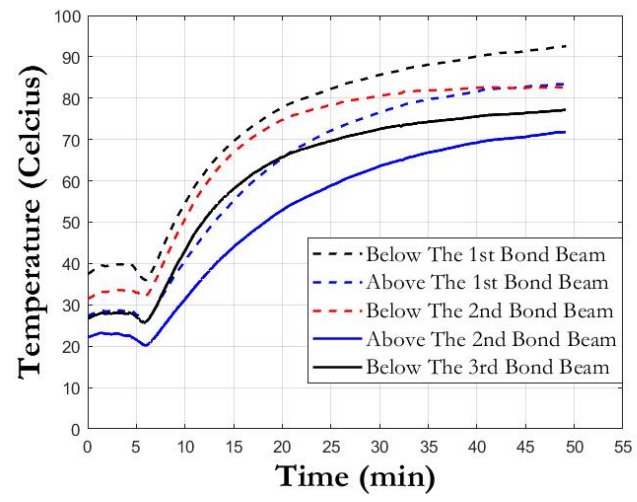

(b)

Figure 4.28: Barnsdale Test 1A, Comparing the unexposed temperatures above and below the bond beam a) left side of the wall b) right side of the wall

preventing the upper parts of the wall from heating up.

The 1st struck joint cell remained the coolest point throughout the test. This is because it was the lowest cell, and there was no flame impingement on the struck joint wall. The cell below the 1st bond beam was the hottest point throughout the test. This is because the flames heated up the lower part of the bond beam wall, and the hot air remained within the cells. Even with the flame impingement, the point above the first bond beam was colder than the other two struck joint cells.

When the furnace was running, every point above the first bond beam on the bond beam wall was cooler than their counterparts on the struck joint wall, even with the effects of the flame impingement. After the furnace was shut off and the wall began to equalize, the temperatures below the bond beams eventually became very close to their counterparts in the struck joint wall. These results seem to indicate that bond beams do help to reduce vertical heat flow, and they do not negatively impact the temperatures at lower parts of the wall. One of the failure criteria is that average wall temperature cannot increase by more than $140{ }^{\circ} \mathrm{C}$, and these results seem to indicate that bond beams do not create additional hot spots that might increase the average temperature of the wall.

The temperatures above the bond beams remained at comparatively lower temperatures even after the furnace was shut off and the wall began to equalize. One of the failure criteria is that the maximum temperature at one point on the wall cannot increase by more than $180{ }^{\circ} \mathrm{C}$. The top of the wall is usually the hottest area, and 


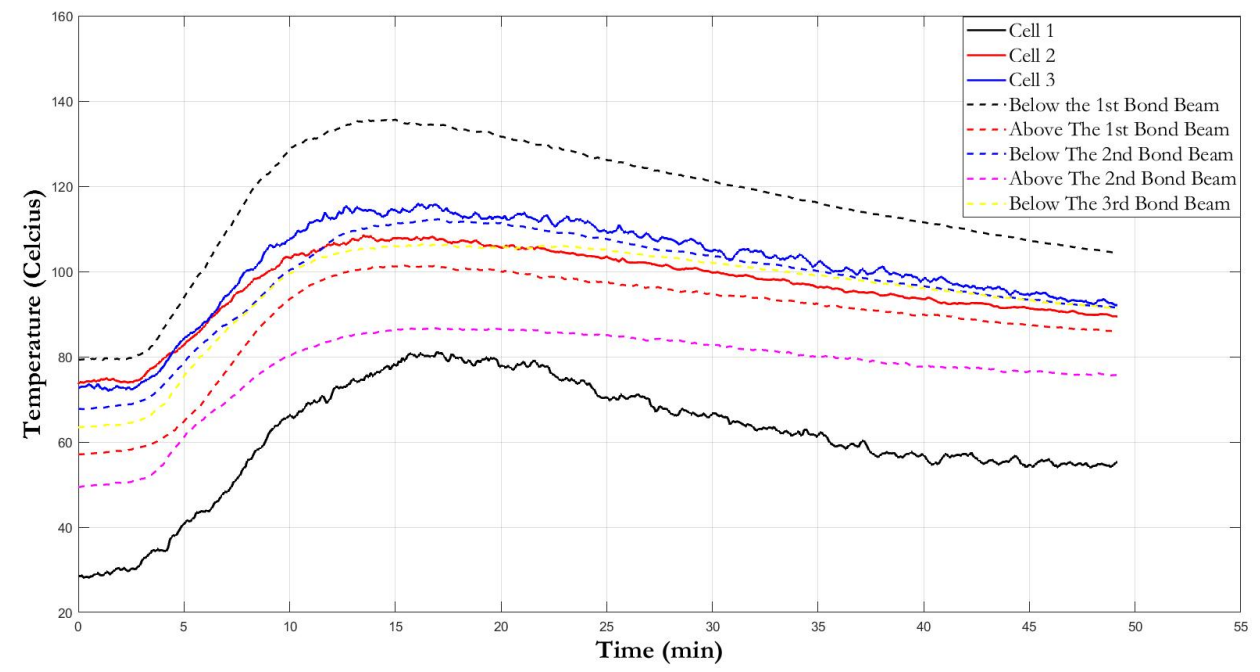

Figure 4.29: Barnsdale Test 1A, Comparing the cell temperatures between the Lintel Wall and the Struck Joint Wall

therefore it is the usually the point of failure. By including the bond beams the upper part of the wall is able to remain cooler, which would increase the time it would take for the top of the wall to reach a $180{ }^{\circ} \mathrm{C}$ temperature increase.

\subsubsection{Barnsdale Test 1A Effect of the mortar}

The struck joint wall was tested to determine if using joints other than a full concave mortar joint had a negative effect of the fire resistance of the masonry wall. Mortar temperatures from the top of each of the four walls can be found in Figure4.30. From these results, it was found that the mortar temperature of the control wall, splitter wall, and struck joint wall all had similar temperature profiles. The mortar on the lintel wall was found to have a lower temperature throughout the test, which is most likely due to the bond beams keeping the top of the wall cooler than the other three walls. From this Figure, it would appear that struck joints do not negatively effect the mortar temperature on the unexposed side of the wall.

These preliminary results do seem to indicate that the mortar joints significantly impact a masonry wall's fire resistance. However, since the duration of the test was short, it is still unknown whether or not the struck joint wall is more prone to integrity failure due to diminished bond strength between blocks and the mortar. In future 


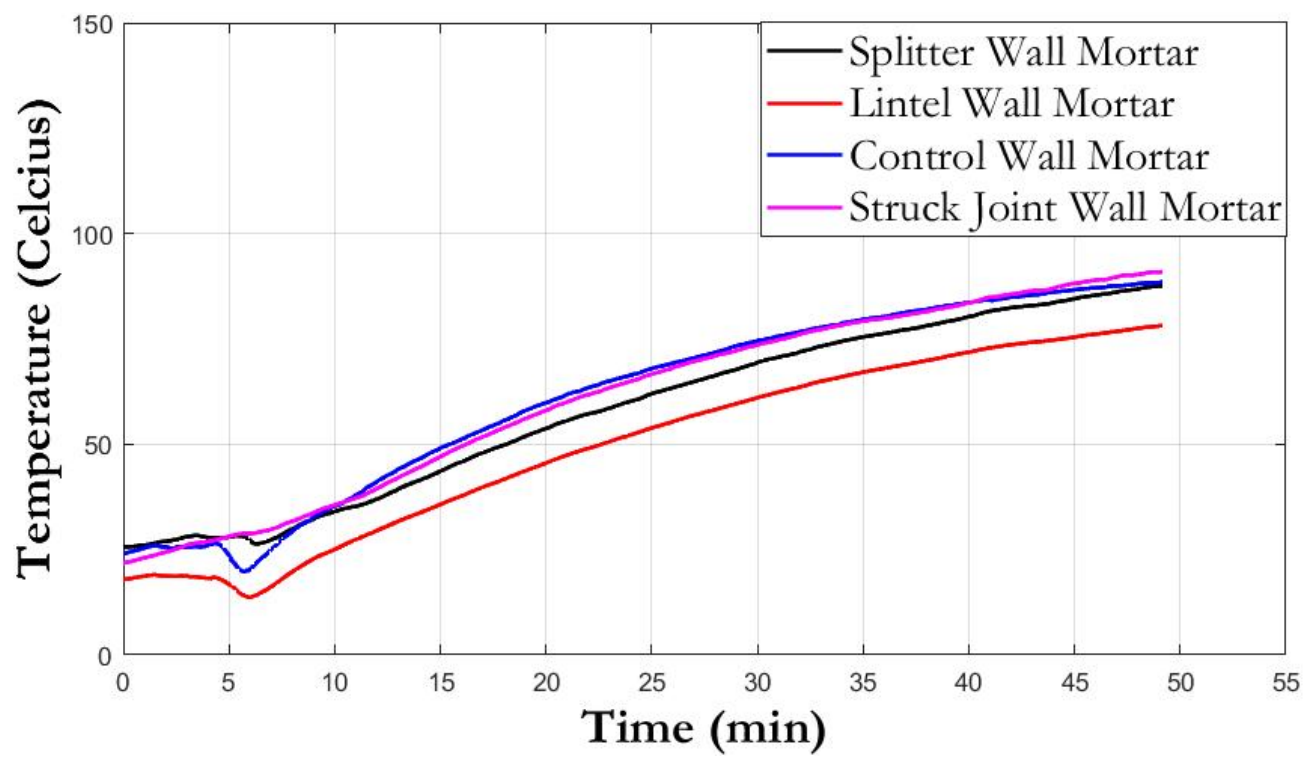

Figure 4.30: Barnsdale Test 1A, Comparison of mortar temperatures for the four different walls.

tests it will be important to watch out for hot spots that might arise due to failure at the block and mortar interface. If integrity failure does not occur, then it is likely that struck joints can be used instead of concave joints, especially in applications where the concrete is being covered up and esthetics are not an issue.

\subsubsection{Barnsdale Test 1A Thermal Imaging}

A thermal imaging picture was taken of each of the four tested walls before the furnace was turned on (Figure 4.31). Even without the effect of the fire, it is still possible to see temperature differences within the masonry walls due to the effects of the sun, and an increase in ambient temperature. The overnight temperature was just below freezing. Throughout the morning, the masonry walls began to heat up as the temperature increased to $15{ }^{\circ} \mathrm{C}$. The test was done early in the afternoon, so the masonry walls had had some time to heat up, but the temperature of the masonry walls were far from uniform. The outer surface of the walls varied depending on which ones were exposed to the sun and wind.

The control wall was the coldest of the walls, as it was facing away from the sun. This also meant that the wall had a more uniform temperature. However, it 


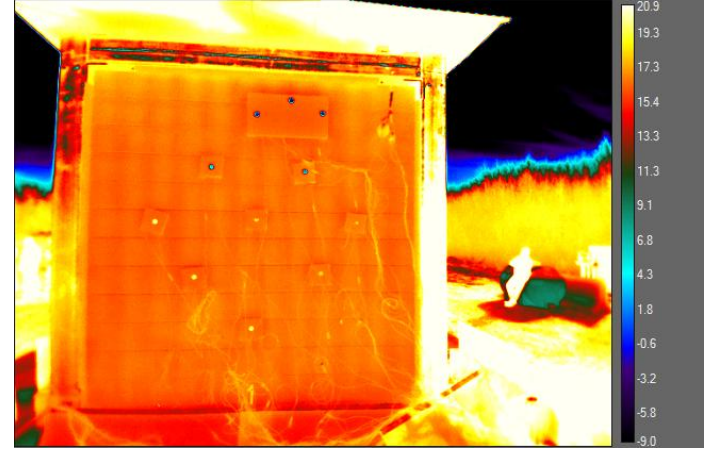

(a)

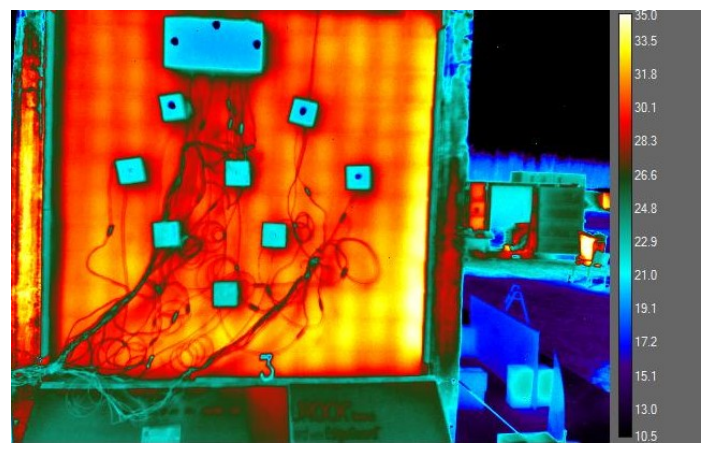

(c)

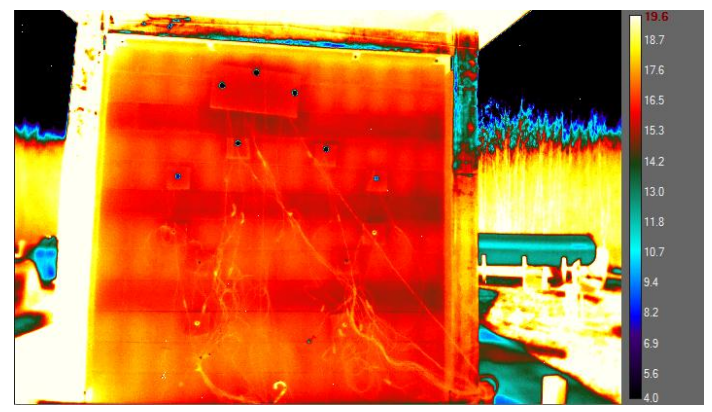

(b)

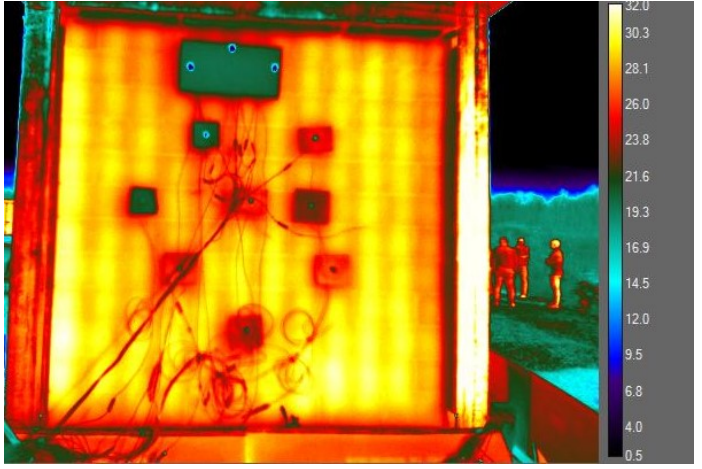

(d)

Figure 4.31: Barnsdale Test 1A, Thermal images before the start of the test. a) Control Wall b) Lintel Wall c) Splitter Wall d) Struck Joint Wall.

is still possible to see the individual hollow cells within the wall, due to the slight temperature variations. For the lintel wall, it is very easy to see the three bond beams, as they are noticeably cooler than the rest of the wall. This is due mainly from the thicker faceshell that the lintel units have compared to the standard $15 \mathrm{~cm}$ units. The splitter wall and the struck joint wall were both warmer, as they had more direct sunlight. It is possible to see the columns of heat emanating from the hollow cells in the walls.

As the test progressed more thermal images were taken. These thermal images help to confirm the results found from the thermocouples and explain some phenomena that occurred during the test. As the flames impinged on the bottom of the wall, and the bottom of the walls were closest to the furnace and the initial flames, the bottom of the walls early on were found to be hotter than the top of the walls. Later in the test, once the furnace was turned off and the hot gasses were given a chance to rise, the temperature profile changed, and the top of the walls began to heat up 
more (Figure 4.32).

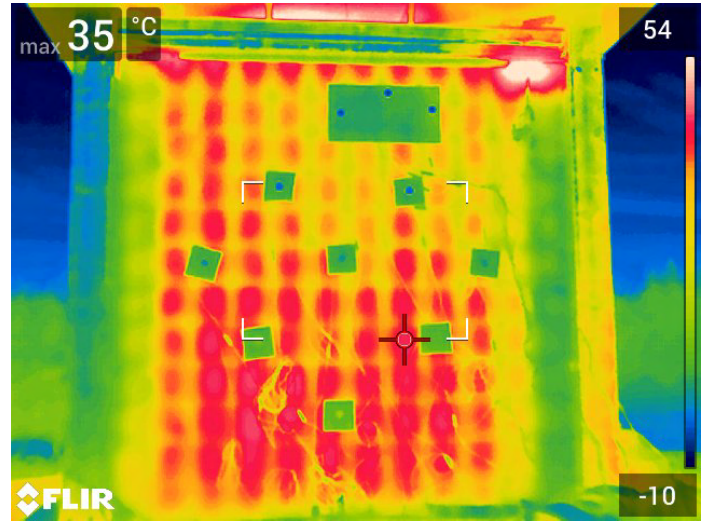

(a)

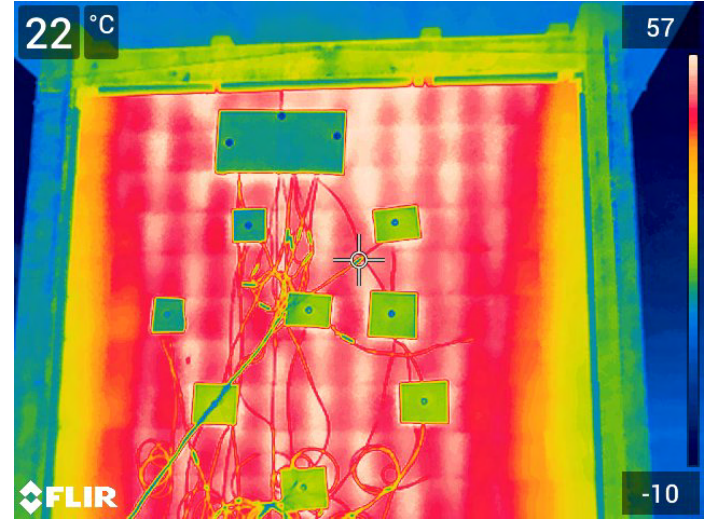

(b)

Figure 4.32: Barnsdale Test 1A, a) Temperature profile early on in the test b) Temperature later in the test

At the top of each of the walls there were insulation boards to protect the steel frame. It was found that in some locations at the top of the walls the insulation had not completely covered the top of a cell. This allowed the hot gasses to escape from the cells, instead of collecting at the top. This caused certain cells to remain colder than others. A good example of this can be found in Figure 4.32a. The rightmost cell of the wall can be seen to be a cooler green throughout, with a much hotter red/white area at the top. This hot area at the top is the area where the hot gasses were allowed to escape, thereby cooling the entire column. In future tests, extra insulation will be placed to ensure that there are no cracks or gaps where heat can escape.

The control wall, splitter wall, and struck joint wall all had similar temperature profiles (Figure 4.33). The hollow cells began to heat up faster than the rest of the wall, which is why the initial thermal images show a checkerboard pattern at the earlier stages of the test (Figure $4.33 \mathrm{a}$ and c). The cooler yellow parts of the image are the web and the mortar, both of which took longer to heat up initially. As the test progressed the mortar joints connecting the hollow cells together began to heat up as well, which is why the vertical columns of hotter concrete are more pronounced (Figure $4.33 \mathrm{~d}$ ).

The lintel wall can be seen to have four distinct sections, separated by the cooler bond beams (Figure $4.33 \mathrm{~b}$ ). The hotter part of the lintel wall are the points just 


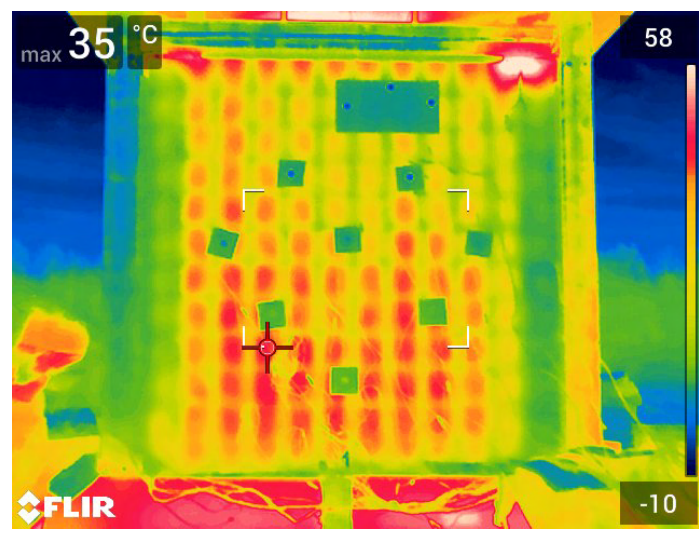

(a)

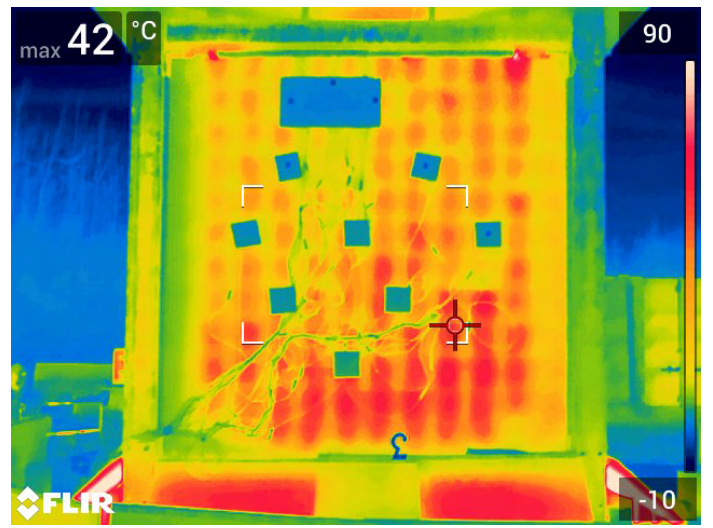

(c)

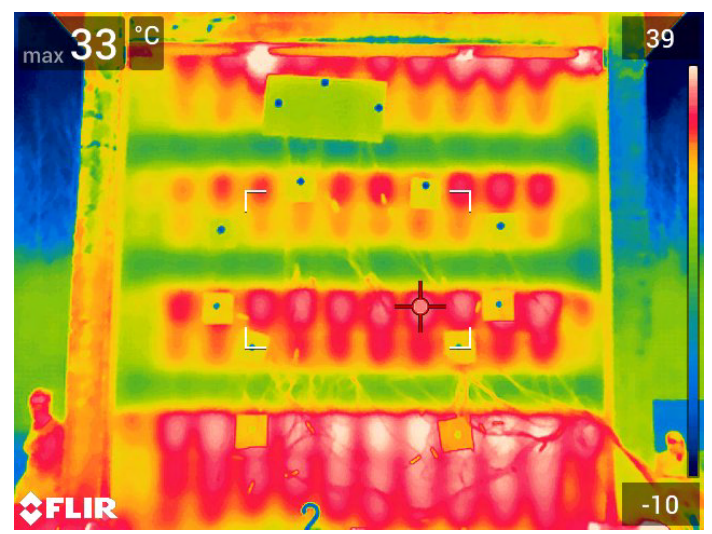

(b)

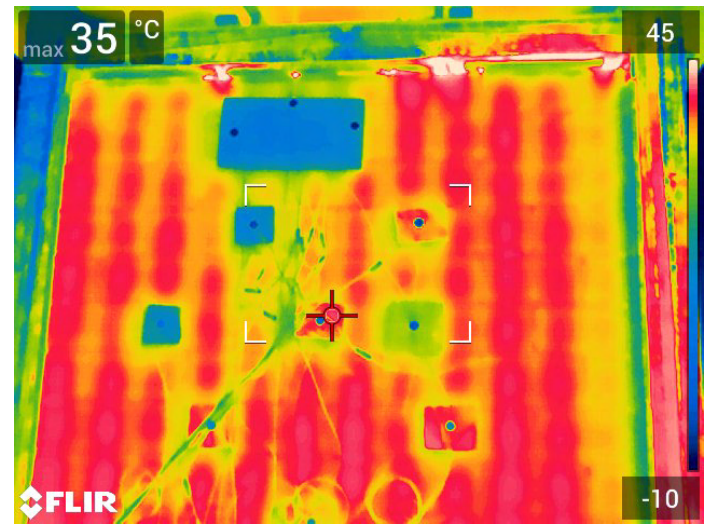

(d)

Figure 4.33: Barnsdale Test 1A, Thermal images of the different walls during the test. a) Control wall b) lintel wall c) Splitter Wall d) struck joint wall

below each of the bond beams, and the top of the wall. This is because the heat inside the wall attempts to rise up, but instead collects around the base of each of the bond beams. It can be seen that even though the bottom of the lintel wall is much hotter due to the flame impingement, the heat is not transferred vertically through the wall. This would indicate that bond beams can be very useful for partitioning the walls and preventing vertical heat flow. This partitioning can help to improve the fire resistance and limit the chances of localized failure causing widespread heat transfer.

It can be seen from Figure 4.34 that the locations below the bond beams on the lintel wall are close in temperature to those in the neighboring control wall. However, the locations on and above the lintel are noticeably colder. This would suggest that 
the lintel wall is able to restrict heat flow without negatively impacting the lower portions of the wall. It can also be seen that the base of the test structure is hot, which again explains why the lower portion of the walls had higher than expected temperatures.

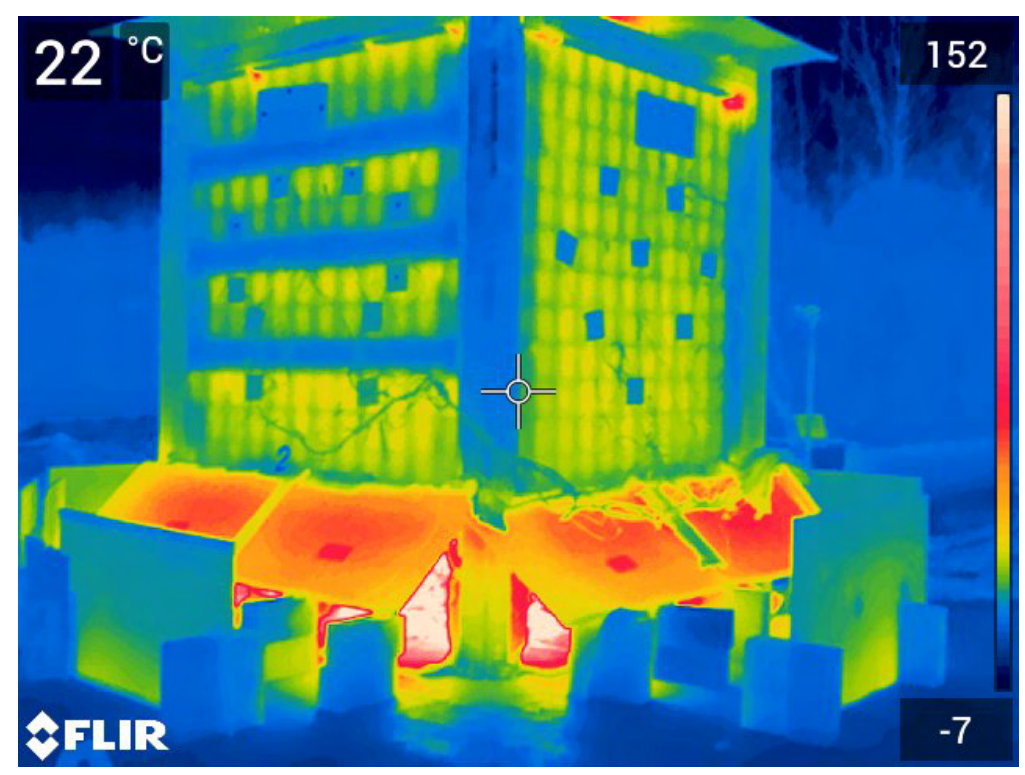

Figure 4.34: Barnsdale Test 1A, Comapring the temperatures on the Lintel Wall to the Control Wall 


\subsection{Barnsdale Test 1B results}

This test was done to determine whether or not the furnace could follow the standard fire curve with the new modifications. The walls had been pre-burned in earlier tests, and part of the free water within the walls had evaporated. It is also important to note that the heating and cooling had caused some microcracking that reduced the integrity of the walls before the test had started.

The test ran for 1 hour, and then the walls were allowed to cool naturally to ambient. The data from both the burning time and cooling time are presented here.

\subsubsection{Barnsdale Test 1B Furnace temperature}

The furnace temperature was able to follow the standard fire curve closely (Figure 4.35). In order to get accurate times for fire resistance, a corrected fire endurance is required. Equation 4.2 can be used to determine the actual fire resistance based on failure times during the test.

$$
C=I+\frac{2 I *(A-A s)}{3(A s+L)}
$$

Where: $\mathrm{C}=$ corrected fire endurance period $(\mathrm{h}) \mathrm{I}=$ fire endurance period obtained before correction (h) $\mathrm{A}=$ area under the curve of indicated average furnace temperature for the first three quarters of the uncorrected fire endurance period obtained from the test, $\left({ }^{\circ} \mathrm{C}^{*} \mathrm{~h}\right) \mathrm{As}=$ area under the standard curve for the same part of the period, $\left({ }^{\circ} \mathrm{C}^{*} \mathrm{~h}\right) \mathrm{L}=$ lag correction (in the same units as $\mathrm{A}$ and $\left.\mathrm{As}\right),\left(30{ }^{\circ} \mathrm{C}^{*} \mathrm{~h}\right)$

The test was stopped after 1 hour, and using Equation 4.2, it was found to have been a 1.02 hour standard fire. Since the furnace temperature was above the standard fire test for most of the test, the corrected fire endurance values were all higher.

\subsubsection{Barnsdale Test 1B Failures}

\section{Barnsdale Test 1B Integrity Failure/Thermal Bowing}

All of the walls failed the integrity criteria within 10-15 minutes of the test due to the formation of cracks around the perimeter. The test was continued even though this failure had happened, and the insulation failure criteria can be found in the next section. The cracks were formed due to thermal bowing induced stress. None of the 


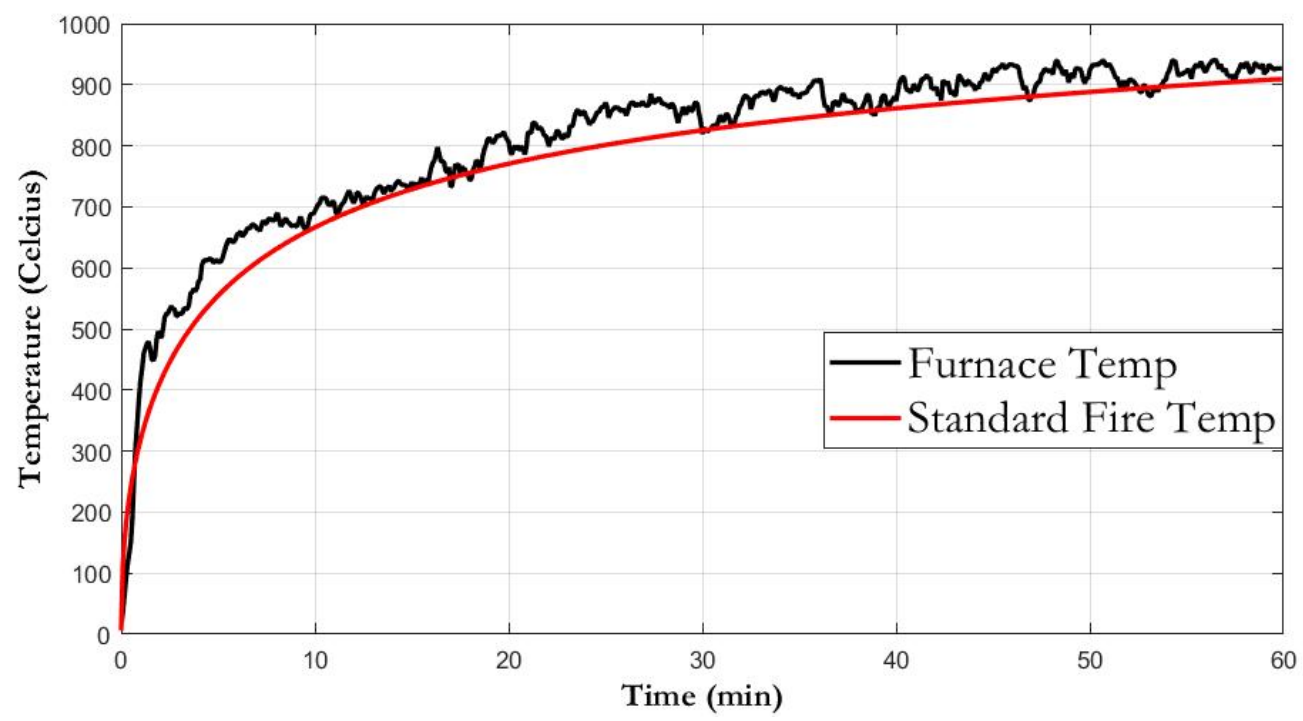

Figure 4.35: Barnsdale Test 1B, Standard Fire Temperature Compared to the Furnace temperature

four walls had mortar on the sides or on the tops of the walls. This lack of restraint meant that the walls bowed much sooner than expected, and by a larger amount. All of the walls bowed with the maximum deflection at the centre of the walls. This circular bowing caused cracks to form at the corners of each of the walls, running mainly along the mortar joints both horizontally and vertically (Figure 4.36). These corner cracks were quite excessive in three of the walls (Control Wall, Lintel Wall, and Struck Joint Wall), with the blocks shifting several centimeters.

It is important to note that the cracking in the struck joint wall was similar to those of the Control Wall and the Splitter Wall. One of the concerns with the Struck Joint wall was that integrity failure might occur sooner, or to a larger extent due to the effect of the jointing. Based on the cracking it would appear that the wall cracking was not negatively affected by the jointing. Unfortunately, due to the thermal bowing, it is not possible to determine whether or not the Struck Joint Wall would have failed integrity before the other three walls.

The one wall that bowed differently was the splitter wall. While it had some cracking at the corners, the corner cracking was less widespread than the other three walls and the thickness of the cracks was not as extreme. Instead, there were several long cracks running vertically down the wall. These cracks followed the mortar joints, 
but also ran halfway between the blocks. The reason for this is that splitter blocks are designed to be split in half directly in the centre of the block. This weakness means that instead of the central web being a strong point, which causes the crack to travel horizontally along the mortar, the central web becomes a weak point which allows cracks to travel down the centre of the block.

After the furnace was turned off the walls slowly began to cool, and effects of thermal bowing diminished as the temperature inside the wall began to equalize. The control wall, lintel wall, and struck joint wall all ended up with a permeant $4 \mathrm{~cm}$ deflection at the centre of the wall. The splitter wall ended up with a $3 \mathrm{~cm}$ deflection. The reason the splitter wall had less of a permanent deflection is most likely due to the fact that the wall was allowed to crack in several places vertically along the wall, which reduced the maximum deflection at the centre. 


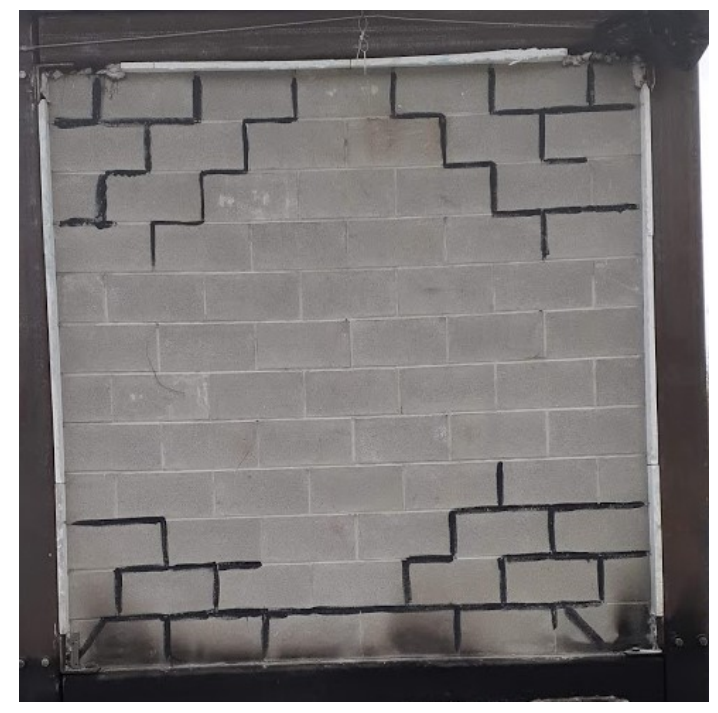

(a)

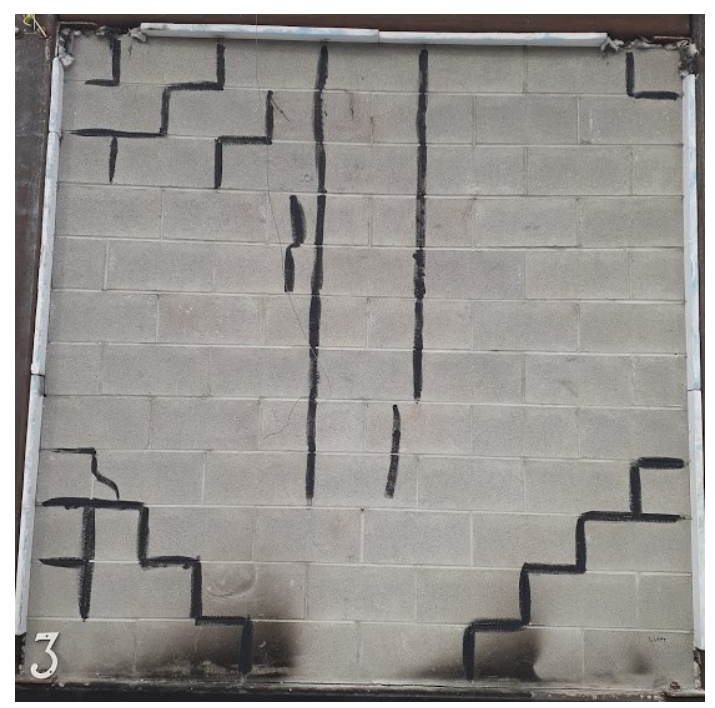

(c)

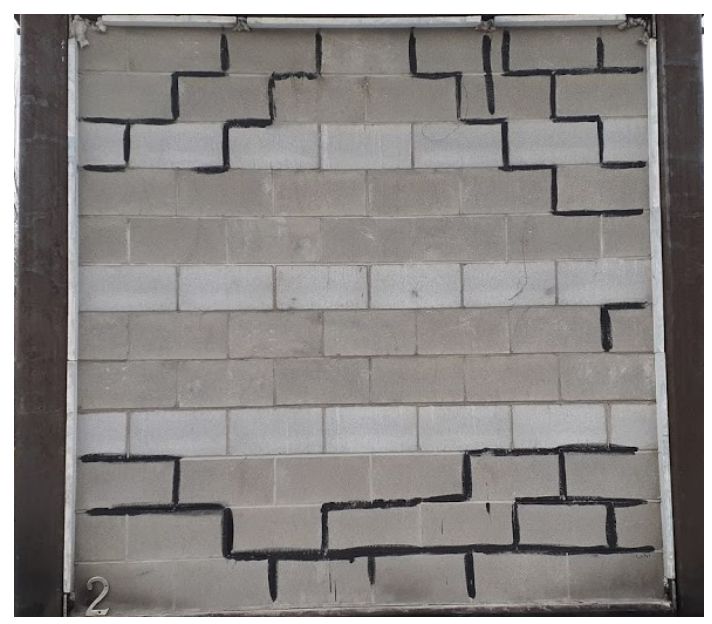

(b)

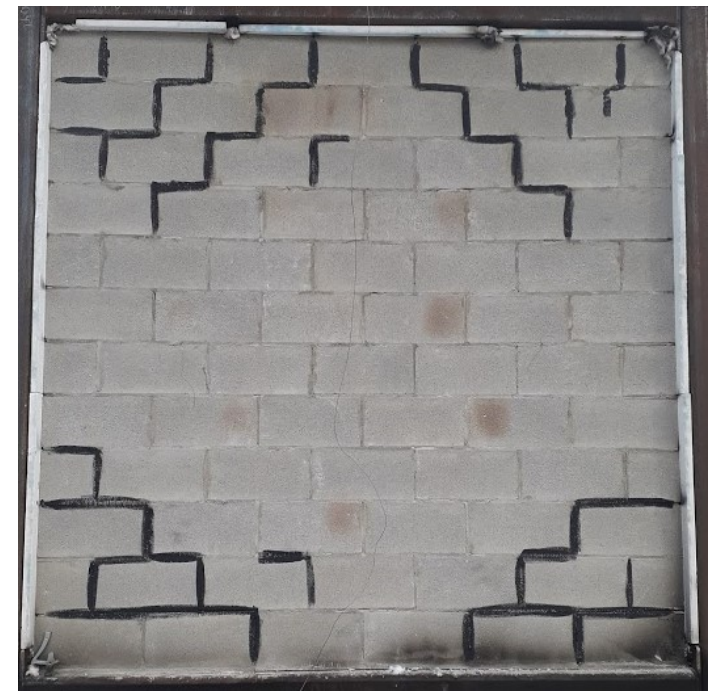

(d)

Figure 4.36: Barnsdale Test 1B, Different crack formation in the four walls a) Control Wall b) Lintel Wall c) Splitter Wall d) Struck Joint Wall 


\section{Barnsdale Test 1B Spalling}

Spalling occurs either when there are high thermal gradients, or more commonly when the free water inside the concrete causes excessive pressure. In the case of this test, the free water remaining in the blocks was limited due to the past heating of the walls. For this reason, there was very little spalling during the test. After the test there was a piece of concrete in one of the walls that spalled off after it had cooled.

Underneath the walls there was a concrete pad that had been insulated with flexible fibrous insulation. During the test the heat from the furnace was such that some of the floor slab reached a critical temperature and began to spall quite violently (Figure 4.37). While the free water in the walls had mostly been evaporated in previous tests, the concrete pad had been rained on since the initial test and would have a higher free water content. This is most likely the reason why the concrete pad spalled and the walls themselves did not.

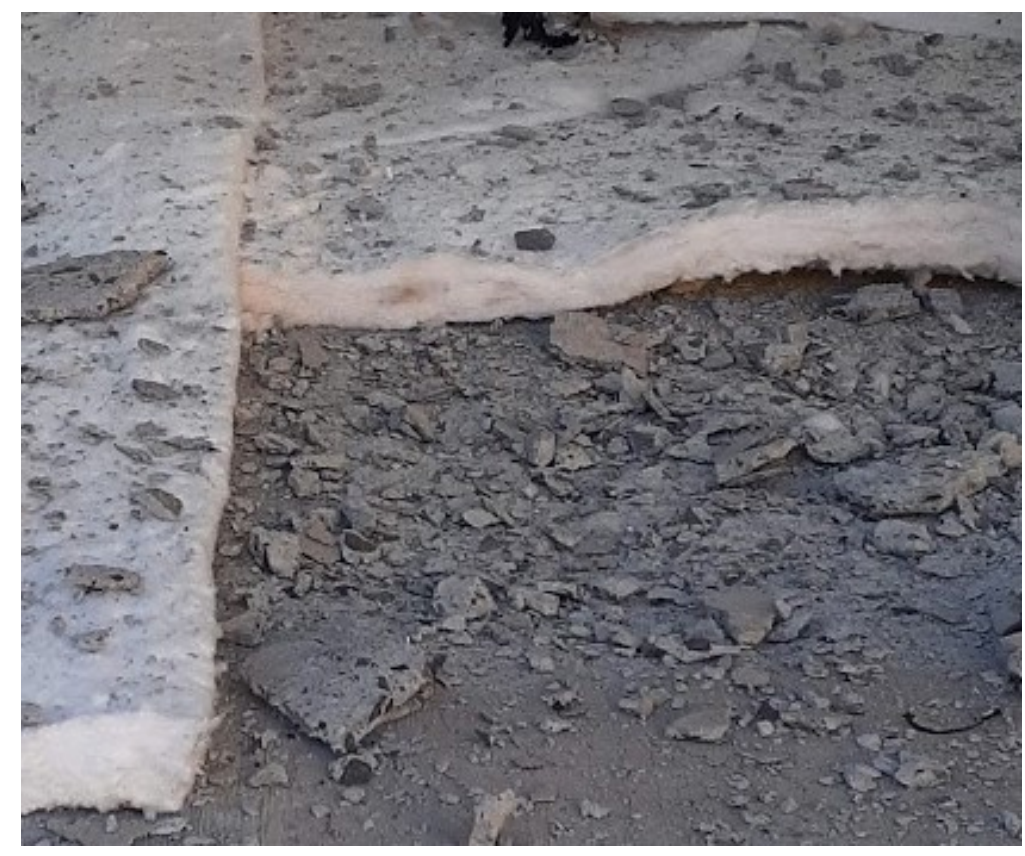

Figure 4.37: Barnsdale Test 1B, Spalling of the concrete pad

\section{Barnsdale Test 1B Insulation Failure times}

Based on the equivalent thickness fire rating, all of the walls should have been able to exceed a $1.1 \mathrm{~h}$ standard fire. It is important to note that the insulation failure 
happened sooner than the expected fire resistance for all of the walls. One reason for this is that the walls had to be tested earlier which had caused a loss of free water and microcrack formation. The other reason is that integrity failure had occurred due to thermal bowing induced cracks, and so hot gasses were allowed to travel through the wall and heat up the exterior of the wall. However, all of the four walls were subjected to the same fires, and so comparing the results between the four walls can still give some qualitative results.

The values in Table 4.2 show the failure times of the four walls based on average wall temperature, and the temperature failure at a single point. The values in Table 4.3have been corrected to account for the slight difference between the furnace temperature and the standard fire temperature. In all four walls the governing insulation failure was through the average wall temperature criteria.

Table 4.2: Barnsdale Test 1B Failure Times

\begin{tabular}{|c|c|c|}
\hline Wall Type & $\begin{array}{c}\text { Average Temp Failure } \\
\text { (Minutes) }\end{array}$ & $\begin{array}{c}\text { Single Point Failure } \\
\text { (Minutes) }\end{array}$ \\
\hline Control & 50.9 & 55.9 \\
\hline Lintel & 53.8 & 60.2 \\
\hline Splitter & 51.8 & 53.3 \\
\hline Struck Joint & 45.1 & 51.0 \\
\hline
\end{tabular}

Table 4.3: Barnsdale Test 1B Failure Times corrected

\begin{tabular}{|c|c|c|}
\hline Wall Type & $\begin{array}{c}\text { Average Temp Failure } \\
\text { (Minutes) }\end{array}$ & $\begin{array}{c}\text { Single Point Failure } \\
\text { (Minutes) }\end{array}$ \\
\hline Control & 52.4 & 57.5 \\
\hline Lintel & 55.2 & 61.7 \\
\hline Splitter & 53.3 & 54.8 \\
\hline Struck Joint & 46.5 & 52.5 \\
\hline
\end{tabular}

The control wall and the splitter wall were found to have similar failure times. The Control Wall failed less than a minute before the Splitter Wall in terms of average 
wall temperature, but the splitter wall failed before the control wall for the maximum temperature at a single point. The similar failure times was expected due to the fact that the blocks have the same equivalent thickness, and similar block shapes.

The Lintel wall was found to have improved fire resistance, failing a few minutes after the Control Wall. The Struck Joint wall failed earliest, which was expected due to bonding issues induced by the jointing method.

\subsubsection{Barnsdale Test 1B Heating Period}

\section{Barnsdale Test 1B Average Wall Temperatures}

Every wall other than the splitter wall had the unexposed side start at an average temperature of around $5{ }^{\circ} \mathrm{C}$ (Figure 4.38). The splitter wall started at $10^{\circ} \mathrm{C}$ because it was facing the sun and had begun to heat up. The failure time was still similar to that of the other walls, since the failure time has to do with an increase in temperature on the unexposed side and not an absolute temperature. It is important to note that this failure time for the splitter wall might not be as conservative as it could have been, because while the surface temperature was higher, the internal wall temperatures varied between the ambient $5{ }^{\circ} \mathrm{C}$ and the heated $10{ }^{\circ} \mathrm{C}$. This means that the splitter wall is likely to have a slightly lower fire resistance, by up to a maximum of two minutes (which is the difference in time between when the wall reached $145^{\circ} \mathrm{C}$ instead of $150{ }^{\circ} \mathrm{C}$ ). Even with this potential change, the Splitter wall still has a failure time that is close to that of the Control wall.

After the test started, all of the walls remained at ambient for just under 10 minutes. At that point the heat had traveled through the walls and begun to heat up the unexposed side. The walls began to heat up at roughly the same rate, except for the Struck Joint wall. This wall began to heat up faster, which accounts for its earlier failure time.

All of the walls undergo a slight plateau at roughly $140{ }^{\circ} \mathrm{C}$. Unlike in past tests there was limited free water in the walls. So, the length of the plateau was very short, which is part of the reason the walls failed earlier than expected.

Since all walls other than the struck joint wall follow each other closely, it does not appear that there is much of a difference between the fire resistance of the three walls. While this was expected for the splitter wall and the control wall, the lintel wall was expected to surpass the other two by a larger margin. Some of the reasons 


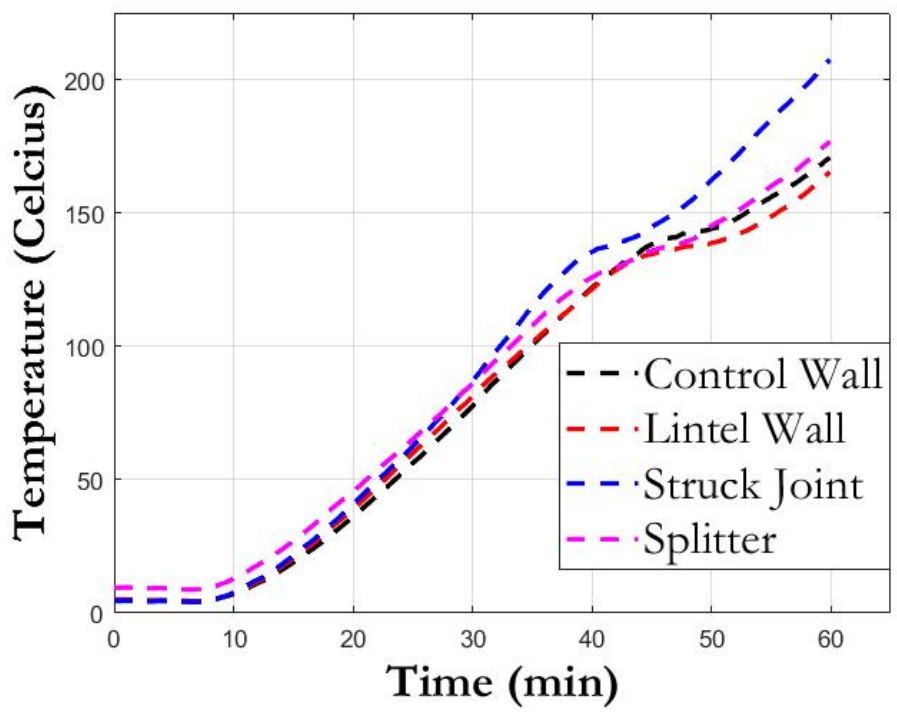

Figure 4.38: Barnsdale Test 1B, Time Temperature Curve of the average temperature of the unexposed side of the four walls.

this did not occur was due to cracking heating up the exterior of all of the walls at a faster rate than expected.

\section{Barnsdale Test 1B Internal Temperatures Within the Block}

The three distinct parts of the wall were the Mortar, the Hollow Cell, and the Solid Web. The temperatures at the midpoint between the exposed and unexposed side for each of the three locations can be found in Figure 4.39. The three thermocouples were placed at the top of the wall in the highly instrument block. It can be seen that all points started out at the same ambient temperature. After about three minutes the temperatures start to rise.

The hollow cell begins to heat up faster, as heat is able to radiate and convect from the inside of the faceshell. As time goes on the hot air is also allowed to rise up through the column of cells and collect at the top of the wall, further heating the hollow cell. The mortar is the next to heat up, having a higher thermal conductivty than the solid web, and also having a small air gap. While the effect of radiation and convection within the mortar joint does exist, it is more limited than in the larger hollow cell. At $100{ }^{\circ} \mathrm{C}$ the mortar temperature begins to plateau as the remaining water is evaporated out of the mortar. As this wall had been tested previously, the 


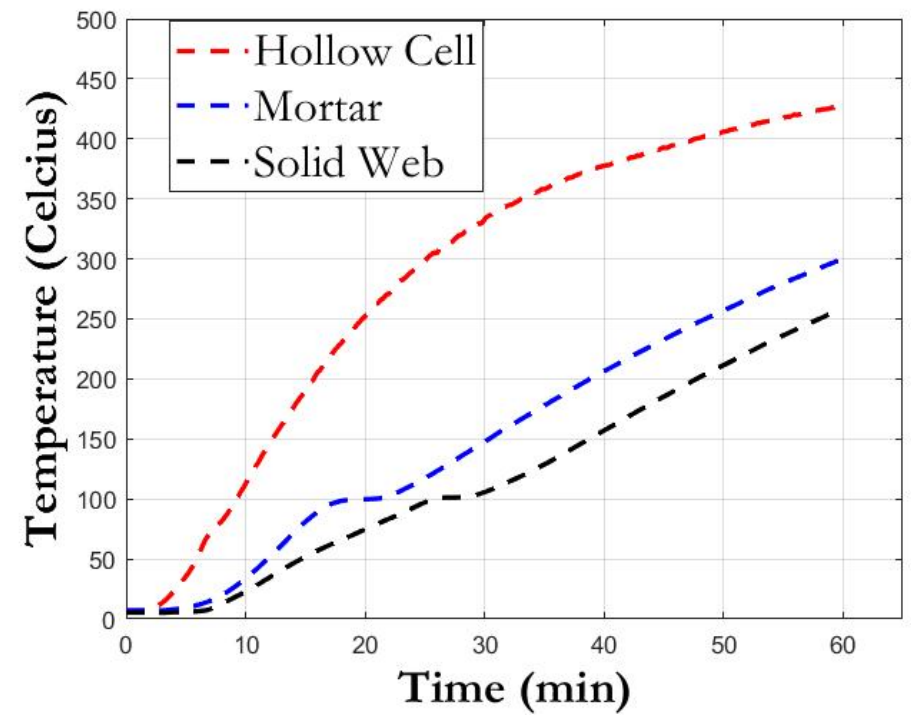

Figure 4.39: Barnsdale Test 1B, Comparing the internal thermocouple temperatures.

length of this pleateau was shortend due to some of the moisutre already having been evaporated. After the free water was removed the mortar continued to increase in temperature. The solid web took the longest time to heat up, as the heat could only travel through conduction. Similar to the mortar, the solid web had a small plateau at $100{ }^{\circ} \mathrm{C}$ as the energy was used to evaporate the free water. The plateau for the web was shorter than for the mortar, and that is because the solid masonry block has less free water than the mortar. After the plateau the solid web began to heat up at a similar rate to the mortar.

\section{Barnsdale Test 1B Effect of the bond beam}

The bond beam was found to have a positive impact on the fire resistance of the masonry wall. The temperature at various points above and below the three bond beams can be found in Figure 4.40. All of the points on the wall start at ambient, after 8 minutes they begin to increase in temperature. It can be seen that the temperatures below each of the bond beams are higher than the temperatures above the bond beams. This is because the hot air rises through the hollow cells and collects under each of the bond beam. Through most of the heating period, the temperature below the 3rd bond beam is the hottest, which is because the temperature inside the furnace is hottest at the top of the walls. The area under the 2 nd bond beam was found to be 
very close to the $3 \mathrm{rd}$ bond beam, whereas the area under the 1st bond beam remained cooler. Around the 38 minutes mark the area below the 1st bond beam began to heat up more than the other two, which is most likely due to the large cracks that formed at the bottom of the wall, allowing hot gasses to more easily pass through.

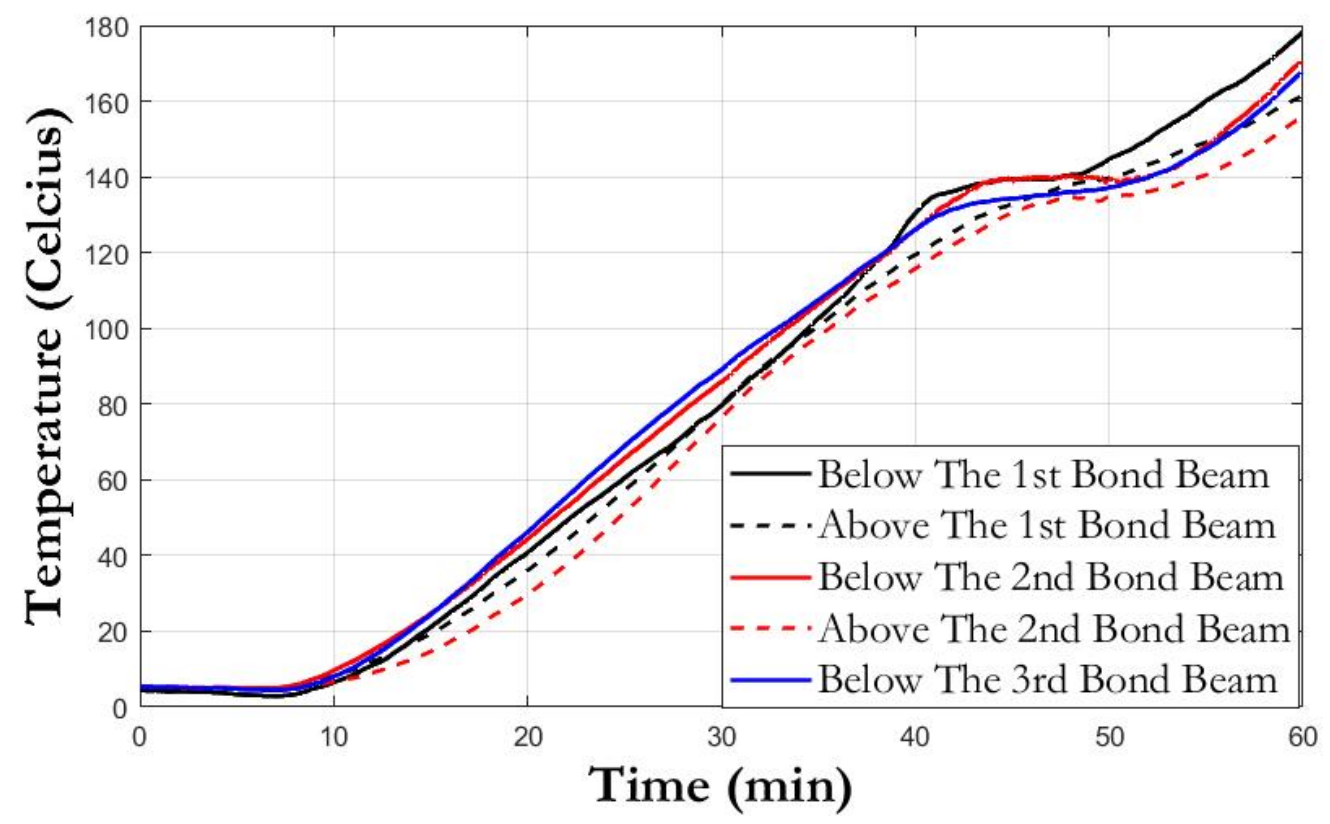

Figure 4.40: Barnsdale Test 1B, The unexposed temperature difference above and below the bond beam. The 1st bond beam is the lowest, and the 3rd bond beam is the highest.

The areas above the bond beams remained between $5-10{ }^{\circ} \mathrm{C}$ cooler throughout the test because the hot gasses were trapped below the bond beam, allowing the cells above the bond beam to remain cooler. This also stopped the hot gasses that began penetrating the lower sections of the wall through the thermal bowing induced cracks from reaching the top parts of the wall.

While it is important to see how the bond beams work within the lintel wall itself, it is also important to determine whether or not it had a beneficial or detrimental impact when compared to another wall. For this reason, thermocouples were placed in the hollow cells of the Struck Joint wall to determine the temperatures at locations with equivalent height in the struck joint wall to the first, second, and third bond beam on the lintel wall (Figure 4.41). 


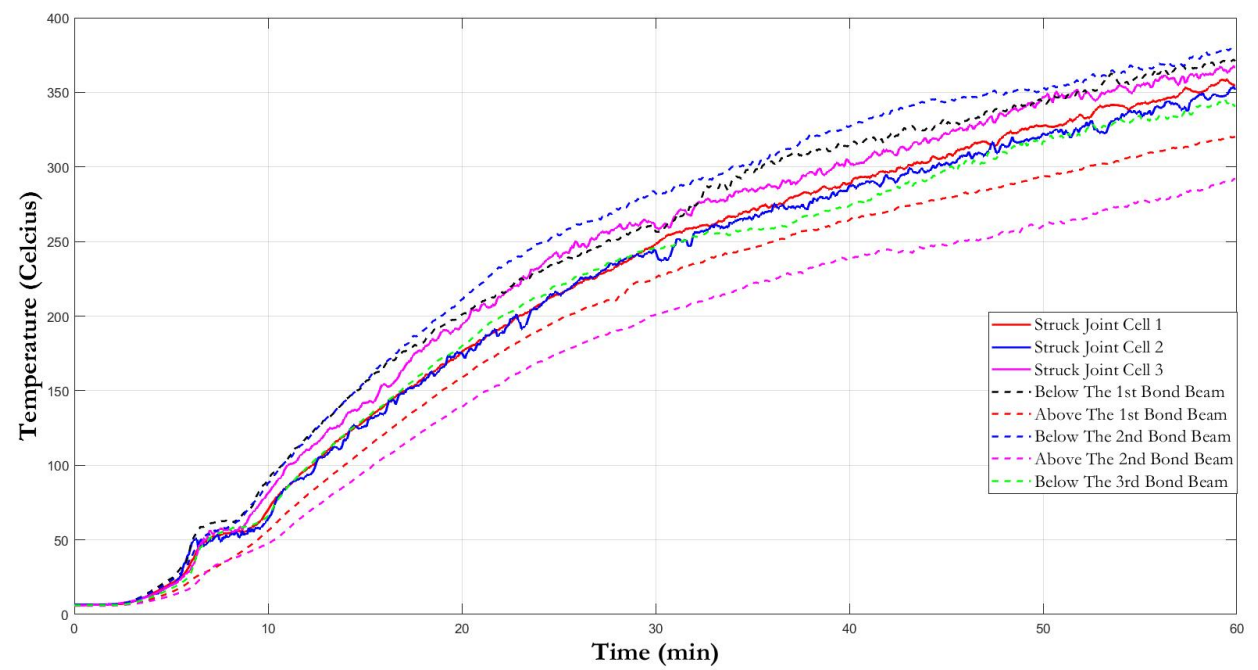

Figure 4.41: Barnsdale Test 1B, Comparing the cell temperatures within the Lintel Wall to the cell temperatures within the Struck Joint wall.

The first two cells in the struck joint, Cell 1 and Cell 2, remained relatively close in temperature throughout the test. Cell 2 started out a little warmer, but then became a littler cooler as the cracks at the base of the wall caused Cell 1 to heat up a bit more. Cell 3 at the top of the wall remained hotter throughout the test, by roughly $15-20{ }^{\circ} \mathrm{C}$.

When compared to the lintel wall it can be seen that the areas below the first two bond beams are hotter than their counterparts on the struck joint wall. Whereas the areas above the bond beams are much cooler, by almost $40{ }^{\circ} \mathrm{C}$. The reason the first two areas below the bond beams were much hotter is most likely due to the concentration of hot gasses from the cracks in the base of the wall. These hot gasses caused the bottom of the wall to be much hotter than anticipated. The area below the third bond beam remained cooler than its counterpart on the struck joint wall, which does indicate that the bond beam was working to stop hot gasses from rising through the cells. The purpose of the lintel wall was to reduce the temperature at the top of the wall without decreasing the fire resistance in another part of the wall. If all points in the wall had remained below or close to those of the other walls, then it would indicate that the lintel units had improved the fire resistance. This is because the 180 ${ }^{\circ} \mathrm{C}$ increase usually happened at the top of the wall, so having a more uniform wall temperature would stop this from happening. However, since the two points below 
the bond beams were hotter than their counterparts by roughly the same amount that the points above the bond beam were cooler, they would not increase the time to failure through the $140{ }^{\circ} \mathrm{C}$ average criteria, and they actually caused the wall to fail the $180{ }^{\circ} \mathrm{C}$ at a single point criteria.

The results indicate that the lintel wall could improve the fire resistance of masonry walls by compartmentalizing the hot gasses, however, due to the cracks in the lower portion of the wall causing the lower cells to heat up much faster, it is not possible to conclusively state that the bond beams will have a significant impact on the fire resistance of masonry walls.

\section{Barnsdale Test 1B Effect of the mortar}

Since the struck joint wall had a different joint type, the mortar temperature of all of the walls is important. As can be seen from Figure 4.42, the mortar temperature taken from the top of each of the walls are compared to each other. The struck joint wall was not hotter than all the other walls and was in fact cooler than the Control Wall and Splitter Wall for much of the test. The lintel wall had cooler mortar throughout, which makes sense since the bond beams did manage to keep the top of the Lintel wall cooler than the other three. Since the mortar temperature was not adversely affected by the jointing, it would appear that it did not have an effect on the insulation criteria. However, there is still the chance that the struck joint wall could crack more easily under fire conditions which would cause it to fail integrity and/or insulation. 


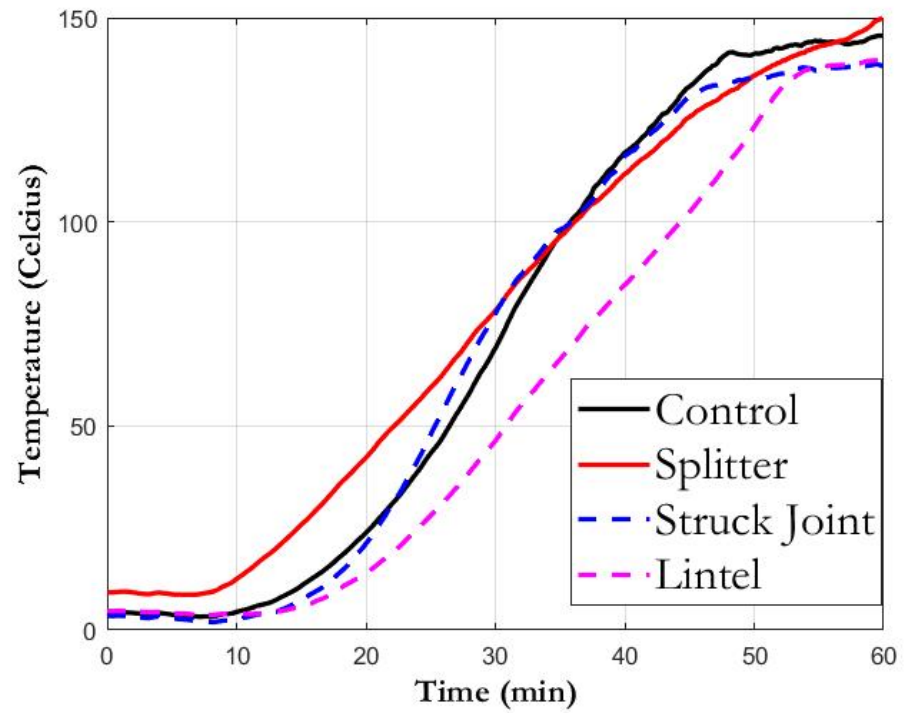

Figure 4.42: Barnsdale Test 1B, Effect of the wall type on the unexposed mortar temperature. 


\subsubsection{Barnsdale Test 1B Cooling Phase}

\section{Barnsdale Test 1B Average unexposed temperature of the four walls}

Even though the furnace was turned off after 60 minutes, the unexposed side of the walls continued to heat up for another 40-60 minutes (Figure 4.43). The maximum temperature reached was with the struck joint wall, which reached an average unexposed temperature of $350{ }^{\circ} \mathrm{C}$. The walls reached an average temperature increase of $160-205{ }^{\circ} \mathrm{C}$ within the first hour, and they all nearly doubled that temperature increase within the next hour, even without any external heat.

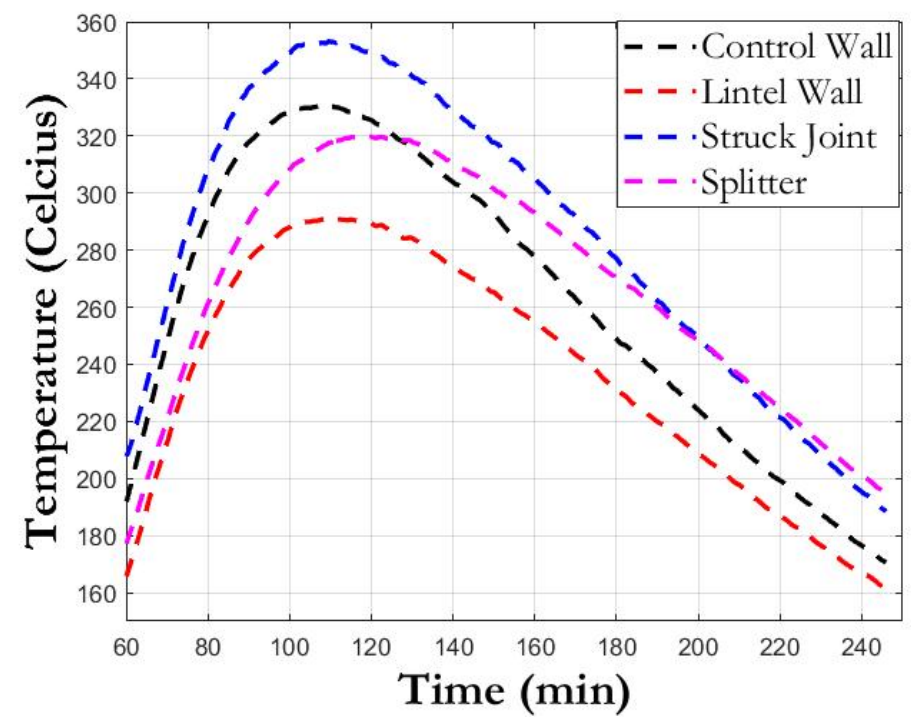

Figure 4.43: Barnsdale Test 1B, Average unexposed temperature of the four walls during the cooling period

This temperature increase could mean that fire spread from one room to another may still occur after a fire has been put out. If a masonry partition wall is heated hot enough and for long enough, it is possible that the unexposed side may later reach a critical temperature that causes the ignition on items in adjacent rooms. The pads on the thermocouples stop the thermocouples on unexposed side of the wall from reading the effects of cooling to ambient through convection and radiation. This is to simulate a solid object on the other side of the wall touching the masonry wall. The temperatures reached within the second hour of the test are hot enough to ignite some materials. 
The temperature increase throughout the second hour also means that parts of the concrete that might still have been able to retain most of their mechanical strength might be weakened. When concrete reaches temperatures above $400{ }^{\circ} \mathrm{C}$ it begins to lose strength. This heating after the fire has been put out means that more concrete is heated past this point, thereby reducing the overall strength of the member.

\section{Barnsdale Test 1B Temperature at different points on the unexposed side of the wall}

To determine how the different parts of the wall cooled, thermocouples were placed midway through the Hollow Cell, the solid web, and the mortar in the highly instrumented block at the top of the wall. When the test shut off all different parts of the wall continued to increase in temperature (Figure 4.44). The mortar and the solid web continued to increase in temperature for $75 \mathrm{mins}$ and $80 \mathrm{mins}$ respectively. The hollow cell however only increased slightly before decreasing. Part of the reason the cell began to decrease earlier was due to the hot air escaping through the cracks in the concrete, thereby cooling the cells. There was also the convection within the cells causing the temperatures within the cells to become more uniform, which mean a decrease in Hollow cell temperature at the top of the wall.

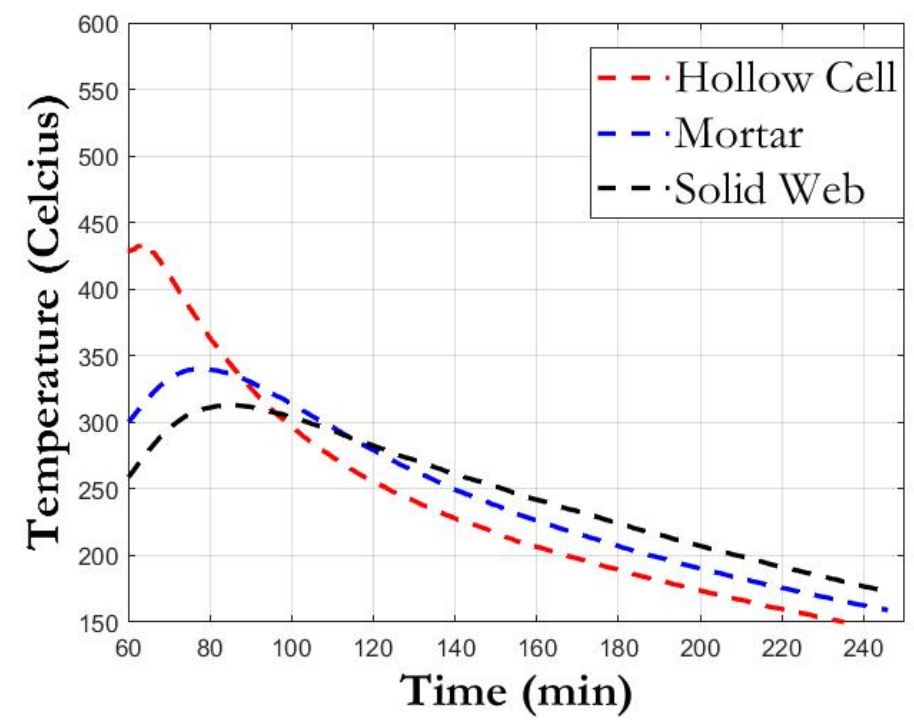

Figure 4.44: Barnsdale Test 1B, The effect of cooling on different parts of the masonry. 
The mortar went from being hotter than the solid web to cooler. The reason for this is that the solid web run through the whole thickness of the block, whereas the mortar is only $10 \mathrm{~mm}$ thick. This means that the solid web has more mass, which in turn means higher thermal inertia. This means that it takes longer to heat up, but also longer to cool down.

\section{Barnsdale Test 1B Effect of the hollow cell}

During the heating period the hollow cell followed the expected pattern (Figure 4.45). The temperature on the exposed side was the hottest, and the temperature cooled as you moved through the block. With the cooling, the graph is a bit more interesting. The exposed side of the hollow cell began to cool first, shortly after the fire was extinguished. The three internal thermocouple locations followed suit shortly after. The unexposed surface of the hollow cell however began to increase for another hour. The reason for this is due to the pads that were placed on the unexposed side of the wall. So while the unexposed side of the wall should have started cooling shortly after the internal points, the inability to convect or radiate heat to the ambient air meant that the temperature continued to rise.

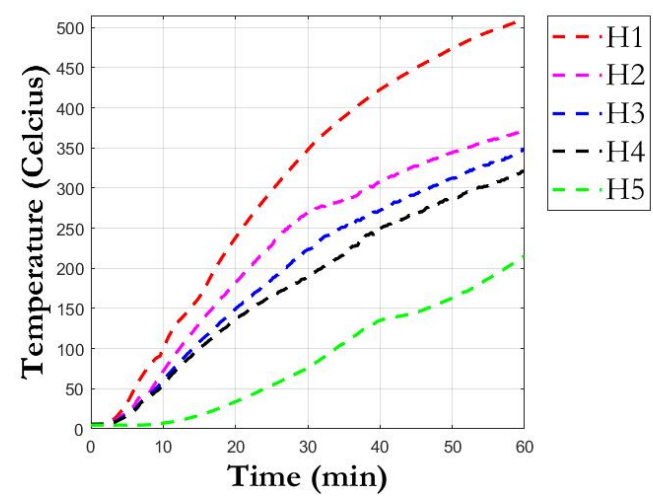

(a)

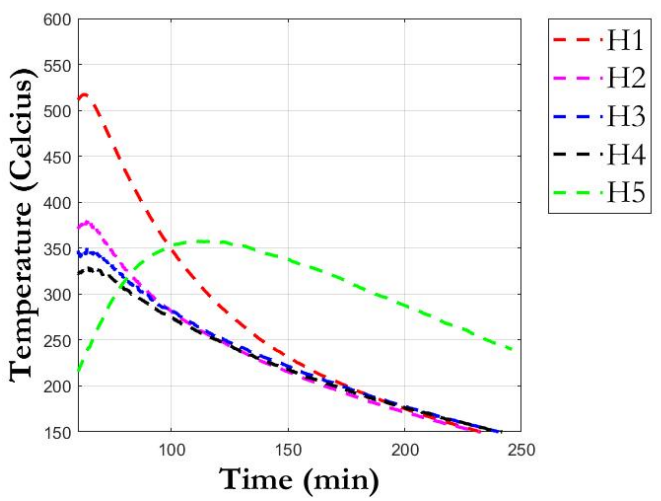

(b)

Figure 4.45: Barnsdale Test 1B, Temperatures within the hollow cell. H1 being the exposed side of the wall, and H5 being the unexposed side. H2-H4 are intermediate points within the hollow cell. a) Heating period b) cooling period. 


\subsubsection{Barnsdale Test 1B Thermal Imaging}

The thermocouples on the surface of the walls were covered with insulating pads in order to reduce the effects of radiation and convection from the wall to the ambient air. It is important to note that the thermal imaging pictures measure the temperature on the surface of the masonry walls which are not covered by the insulation pads. Therefore, the thermal imaging temperatures are expected to be slightly lower than the thermocouple temperatures during the heating of the walls, and significantly lower during the cooling phase. The reason there is such a discrepancy in the cooling phase is that the cooling of the walls surface is mainly done through radiation and convection to the ambient air, which is blocked by the pads. For this reason, the cooling is mainly done through conduction to the surrounding concrete, which then radiates and convects that heat to the ambient air.

Therefore, especially for the cooling phase of the test data, the thermal imaging camera is better for displaying the rate of cooling for a wall with nothing on the unexposed surface. The thermocouples are better at displaying the effects of cooling on a wall with something remaining in contact with the unexposed side of the wall (like a piece of furniture). Both of these cooling rates are important as they demonstrate the cooling under two different conditions.

\section{Barnsdale Test 1B Initial Temperature}

While all of the other walls had uniform surface temperatures of roughly $5{ }^{\circ} \mathrm{C}$, the splitter wall was facing the sun, and so the surface had begun to heat up. The impact of the sun was significant, as parts of the wall ranged from $10-20{ }^{\circ} \mathrm{C}$ (Figure $4.46 \mathrm{e}$ ). The thermocouples showed that the average splitter wall temperature at the start of the test was $10{ }^{\circ} \mathrm{C}$, which is lower than what can be seen from the thermal imaging. This is because the insulation pads insulated the surface thermocouples from the sun, which reduced their rate of heating compared to the insulated parts of the unexposed side. As was mentioned earlier, the heating was mainly on the surface, as the interior sections of the wall were between $5-10{ }^{\circ} \mathrm{C}$. This means that the exact failure time could be off by a minute or two, since the failure is tied to a temperature increase and not an absolute temperature. 


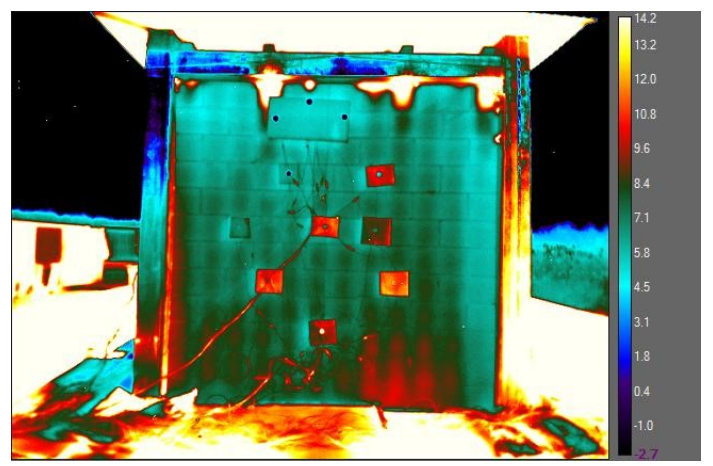

(a)

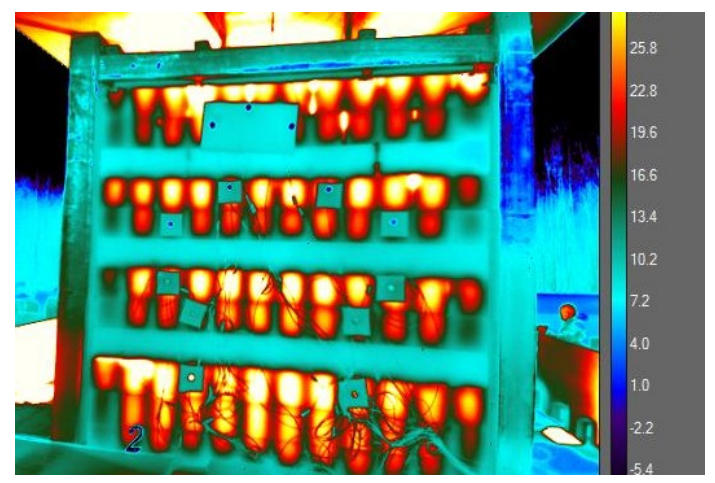

(c)

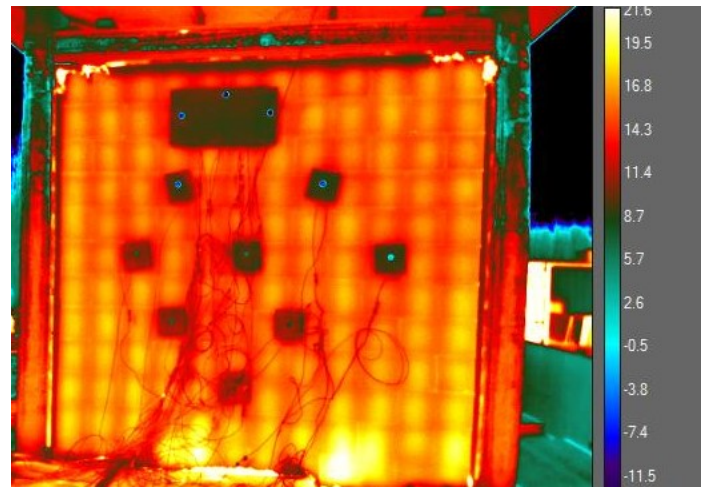

(e)

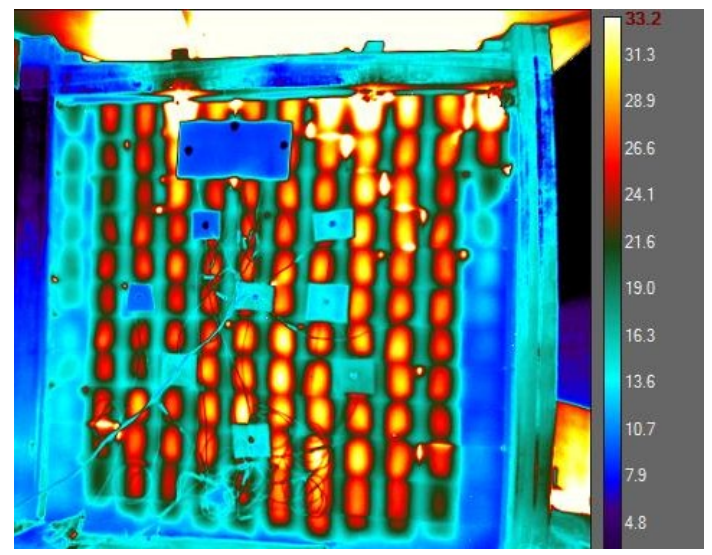

(b)

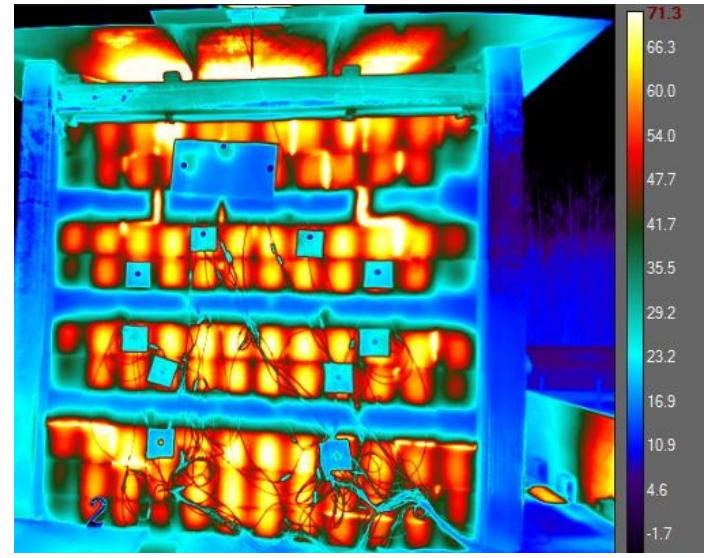

(d)

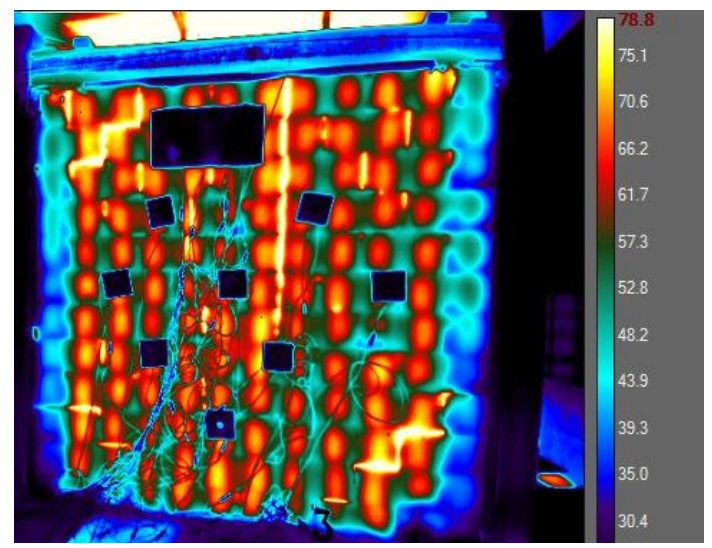

(f)

Figure 4.46: Barnsdale Test 1B, Thermal imaging during the heating period. a) $\mathrm{T}=5$ mins, The thermal profile of the struck joint wall a few minutes after the test started b) $\mathrm{T}=15 \mathrm{mins}$, The thermal profile of the struck joint wall in the middle of the heating period c) $\mathrm{T}=17 \mathrm{mins}$, Thermal profile of the Lintel Wall at the early heating period d) $\mathrm{T}=30 \mathrm{mins}$, Thermal profile of the Lintel Wall in the middle of the heating period e) $\mathrm{T}=0 \mathrm{mins}$, Initial temperature profile of the splitter wall before the test $\mathrm{f}$ ) $\mathrm{T}=28 \mathrm{mins}$, Thermal profile of the splitter wall partway through the heating period. 


\section{Barnsdale Test 1B Burning Phase}

When the test started, it took a few minutes for the unexposed surface of the walls to begin to heat up. After several minutes the uniform temperature profile that was present in the walls began to change. Since the burner was at the bottom of the test structure, the heating started at the bottom of the walls. It can be seen in Figure 4.46 a) that the bottom few cells of the struck joint wall began to heat up, while the rest of the wall remained close to ambient.

After some time, the heating became more uniform as the air within the furnace heated and the surface of the walls began radiating heat back to each other (Figure $4.46 \mathrm{~b})$. The columns of hot air within the cell are clearly visible in the thermal images. The cooler blue/green sections are the webs and mortar, and the red/yellow sections are the hollow cells. The hotter yellow section is at the centre of the hollow cells. This is due in part because the effects of radiation are highest at the entre of the cell, and in part because the outer sections of the cells conduct some of the heat to the webs and mortar. At the top of the wall where the hot gasses collect, the webs and mortar are hotter because the heat begins to spread horizontally along the top of the wall.

The lintel wall also had the lower section of the wall that started several degrees warmer than the rest of the wall, but the bond beam reduced the vertical heat flow (Figure $4.46 \mathrm{c}$ ). The thermal image displays the hot areas below the bond beams where the hot gasses have collected, with the area above the bond beams remaining cooler. The lintel units themselves are very cool because they have thicker faceshells which means that it takes longer for the hot air within the cells to heat the unexposed surface of the lintel units. As the test progressed, the whole wall increased in temperature, but the top section of the wall remained cooler than the lower sections (Figure $4.46 \mathrm{~d}$ ). This would indicate that the bond beams were effective in reducing vertical heat flow.

The thermal images also show the locations of cracks as the form in the wall. Cracks show up as hot lines. Early in the test cracks began to form around the perimeter of all four of the walls. Large cracks zig zagging along the mortar joint can be seen on the top right corner of the struck joint wall, as well as three courses up from the bottom of the wall on the left and right sides (Figure $4.46 \mathrm{~b}$ ). The top left and right corner of the lintel wall also had large cracks going through the 3rd bond beam, as well as cracks just below the first bond beam (Figure $4.46 \mathrm{~d}$ ). The splitter 
wall was the only wall to have a different crack pattern. While it can be seen clearly that the top left corner and bottom right corner of the wall had the same zig zag crack pattern along the mortar, there are also two distinct vertical cracks running through the centre of the wall (Figure $4.46 \mathrm{f}$ ). These cells around these vertical cracks are warmer than those in other parts of the splitter wall, which indicates that these large central cracks had a detrimental effect on the fire resistance of the splitter wall. The crack locations found through thermal imaging match those found after the test from visual inspection.

The cells on either end of the walls have been partially protected with insulation in order to reduce the effect of the fire on the structure itself. That is why there are colder cell columns on either end of the struck joint wall. However, as the hot gasses collect at the top of the wall they do move horizontally, which is why the top right corner of the struck joint wall is hot (Figure $4.46 \mathrm{~b}$ ). It is possible to see the colder areas on either side of the lintel wall, but they are not as distinct as the other walls. This is because when the hot air collects under the bond beams, it begins to move horizontally, which heats up the sides of the wall (Figure $4.46 \mathrm{~d}$ ).

The furnace was shut off after 1 hour. Figure 4.47 shows the temperature profile of all the walls at this point. While the thermocouples showed that the walls had already failed before an hour, the areas of the wall without pads were still around an average of $110{ }^{\circ} \mathrm{C}$. This means that the pads kept the thermocouples warmer by roughly $35^{\circ} \mathrm{C}$ at this point. 


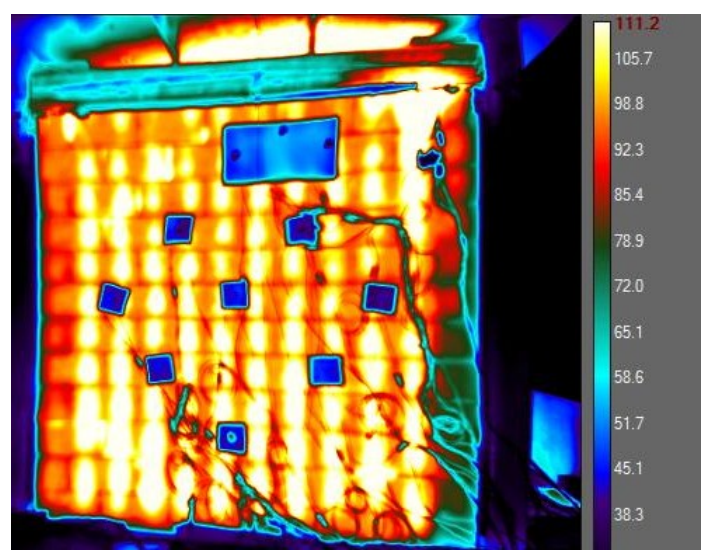

(a)

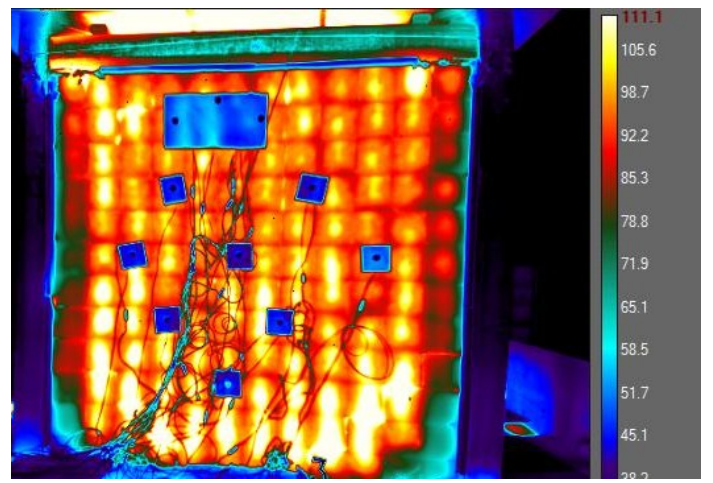

(c)

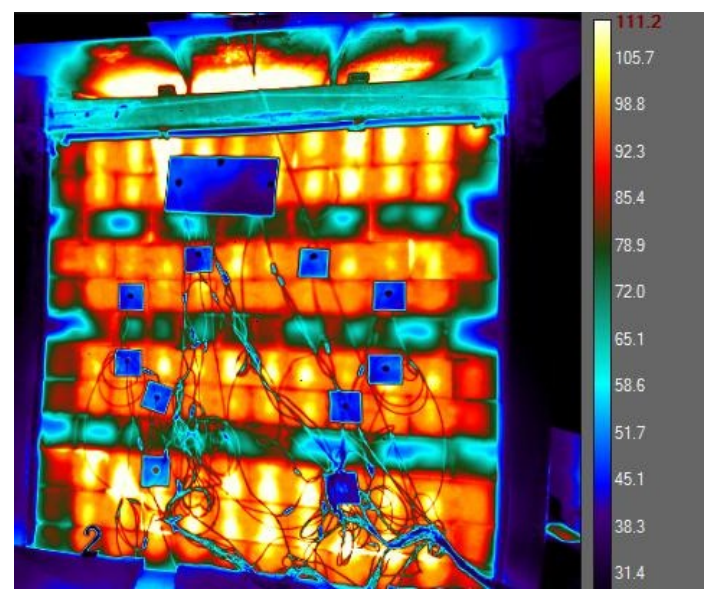

(b)

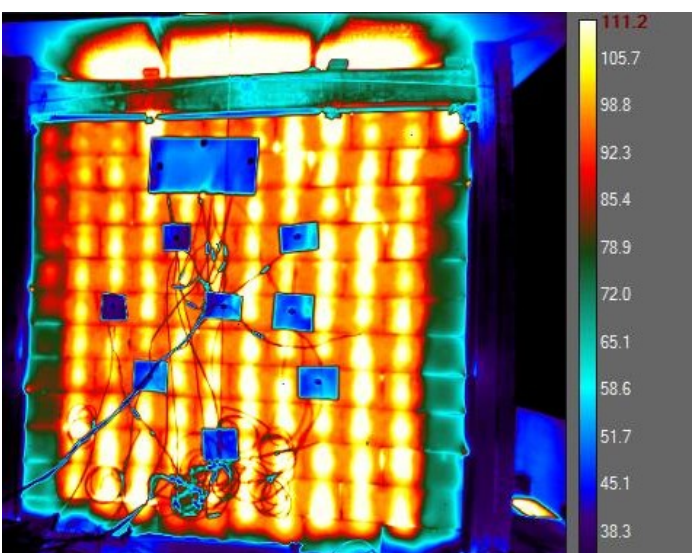

(d)

Figure 4.47: Barnsdale Test 1B, Thermal profile of the four walls after 1 hour (the point when the furnace was turned off). a) Control wall b) Lintel Wall c) Splitter Wall d) Struck Joint Wall 
Unlike in the past thermal images, the mortar connecting the bond beam together is visible due to it heating up faster than the lintel units. While the bottom section of the wall is still the hottest section, the fact that the mortar joints have begun to heat up on the bond beam suggest that those are weak points. The bond beam mortar joints have comparable temperature profiles to those of the other mortar joints on the lintel wall, so they themselves are not hotter than average. However, they might reduce the effectiveness of the bond beam in terms of compartmentalisation as the hot gasses are able to travel through the small cells within the mortar joints.

For the other three walls they all had similar temperature profiles. The Control Wall and Struck Joint Wall had similar wall temperatures. The splitter wall was slightly cooler than the other two walls, which is different from what the thermocouples showed. This could be because cracks in the wall caused certain thermocouples to heat up a bit more on the splitter wall, which would account for the slight temperature discrepancy.

\section{Barnsdale Test 1B Heating after the furnace was shut off}

The furnace was shut off after 1 hour, however the unexposed side of the walls continued to heat up for a full hour afterwards (Figure 4.48). This is because concrete has high thermal inertia, which means it takes longer to heat up, but it also takes longer to cool. So, while part of the heat from the hotter side of the masonry wall was being cooled into the furnace air, the rest of the heat energy traveled through the wall to the unexposed side. As the heat flowed through the masonry, it began to equalize along the masonry surface. Instead of having very hot cells and colder webs, the masonry surface became more uniform. 


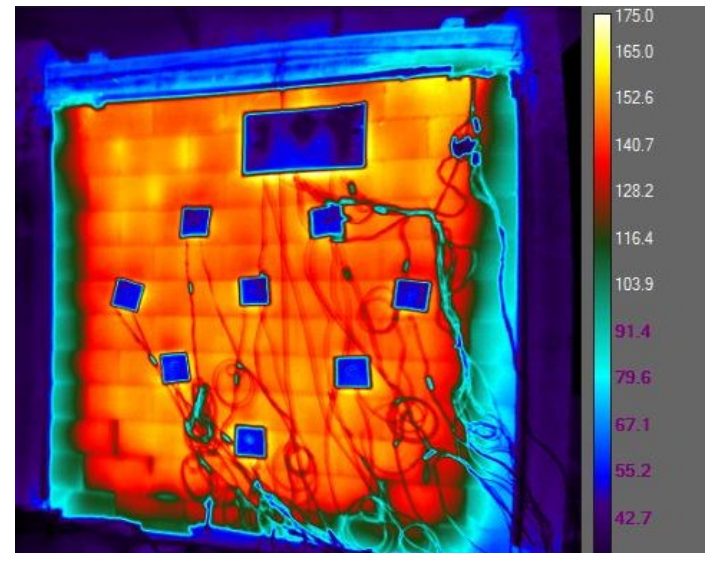

(a)

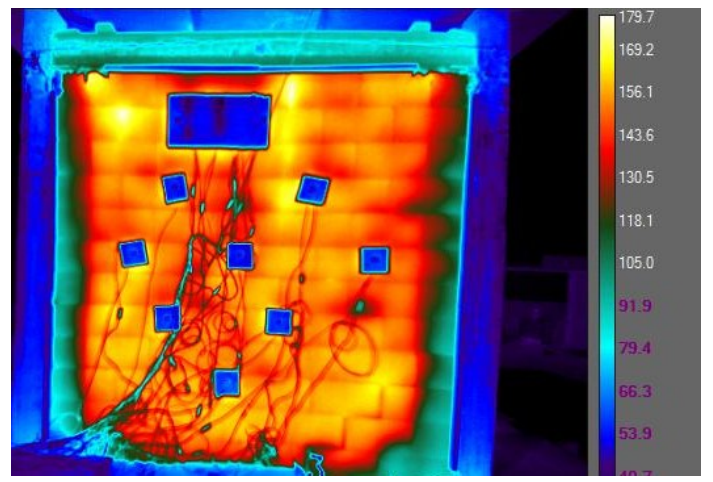

(c)

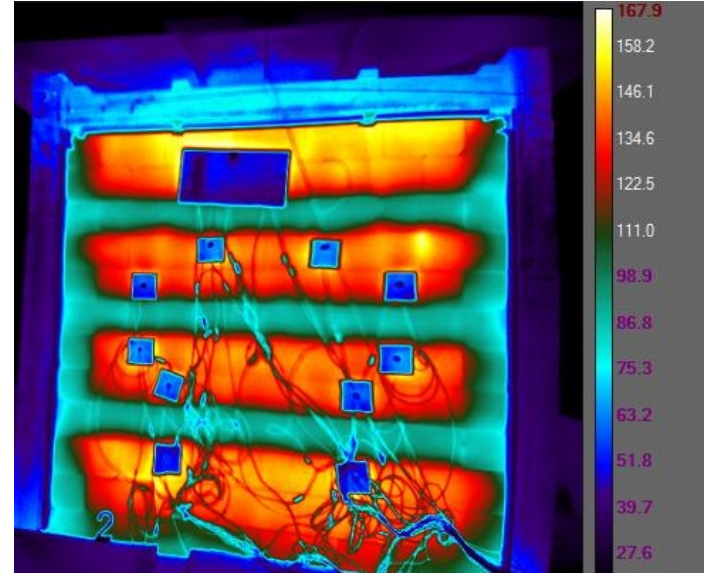

(b)

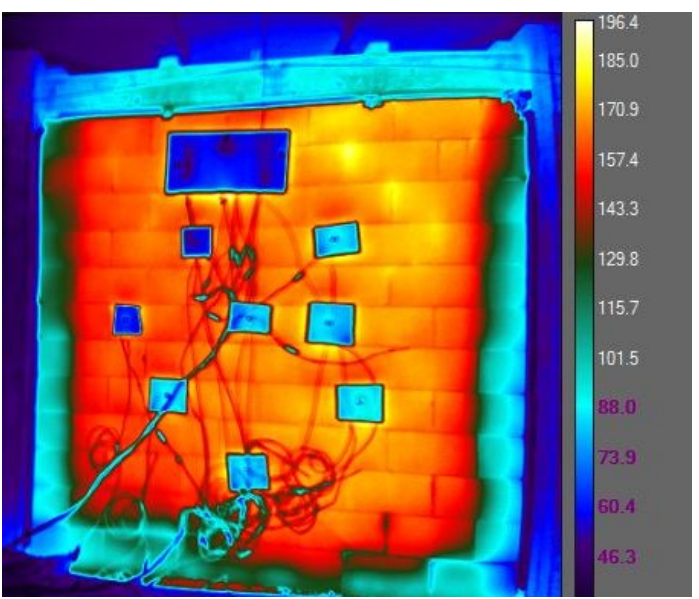

(d)

Figure 4.48: Barnsdale Test 1B, Thermal profile of the four walls after 2 hours (When the unexposed surface temperatures were the maximum) a) Control wall b) Lintel Wall c) Splitter Wall d) Struck Joint Wall 
At this point the bottom of the lintel wall is cooler than the top of the lintel wall. This is because the cool air was entrained from below the walls, and the air was heated as it rose towards the top of the wall. This meant that on the exposed side, the bottom of the lintel wall was able to cool more efficiently than the top of the lintel wall. This in turn meant that the top of the lintel wall on the unexposed side began to heat up more than the bottom.

The Lintel wall reached an average temperature of around $140{ }^{\circ} \mathrm{C}$. The Control wall and the Splitter wall reached an average of $155^{\circ} \mathrm{C}$, while the Struck Joint wall reached an average of $170{ }^{\circ} \mathrm{C}$. These maximum temperatures make sense, as the Struck Joint wall was consistently hotter than the other three, and the Lintel Wall was consistently cooler. The reason the lintel wall was cooler could be attributed to the fact that the bond beams created a barrier that trapped the hot gasses in the lower section of the wall. The lower section of all of the walls had large cracks that allowed hot gasses to enter the hollow cells and heat up the wall. The bond beam meant that less hot gas was allowed to enter the wall, so the wall as a whole remained cooler.

Similarly, the struck joint wall was expected to have some issues with bonding and was more likely to have integrity failure. This means it is likely that more cracks formed on the interior of the struck joint wall, which allowed more hot gasses into the cells. The hot gas was able to travel up the whole wall, and so the whole wall temperature increased.

\section{Barnsdale Test 1B Cooling Phase}

Without the heat from the furnace and with the temperatures within the wall beginning to even out, the walls eventually began to cool. This cooling started at the lower portions of the wall, as that is where the cool air was being entrained (Figure 4.49). The bottom corners of each of the walls began to cool the most. As time went on the area of colder masonry on the bottom portion of the walls grew until the whole wall had reached the ambient temperature. During the cooling phase the lintel wall remained the coldest, the control and splitter walls remained close, and the struck joint wall remained the hottest. 


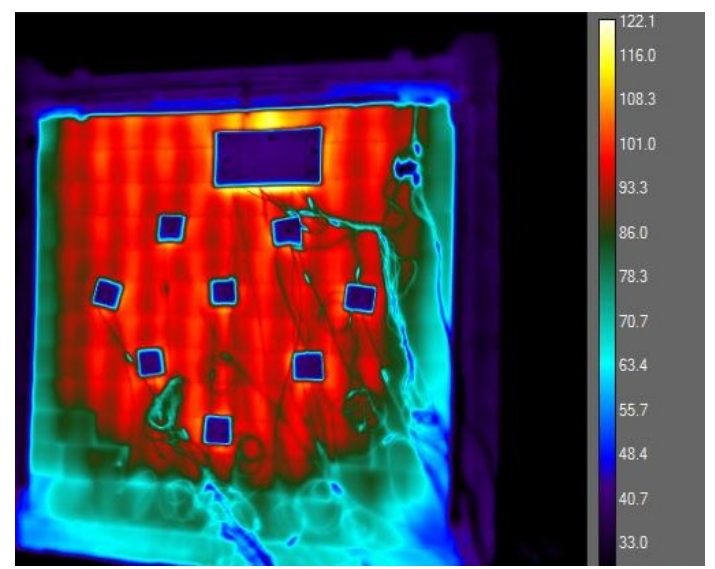

(a)

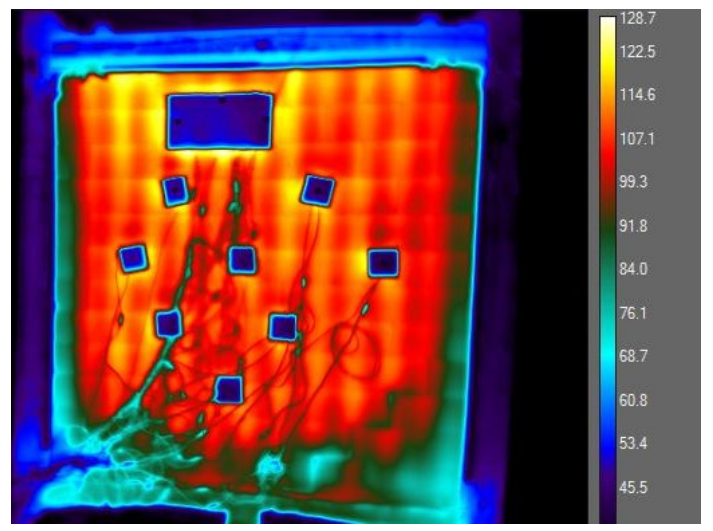

(c)

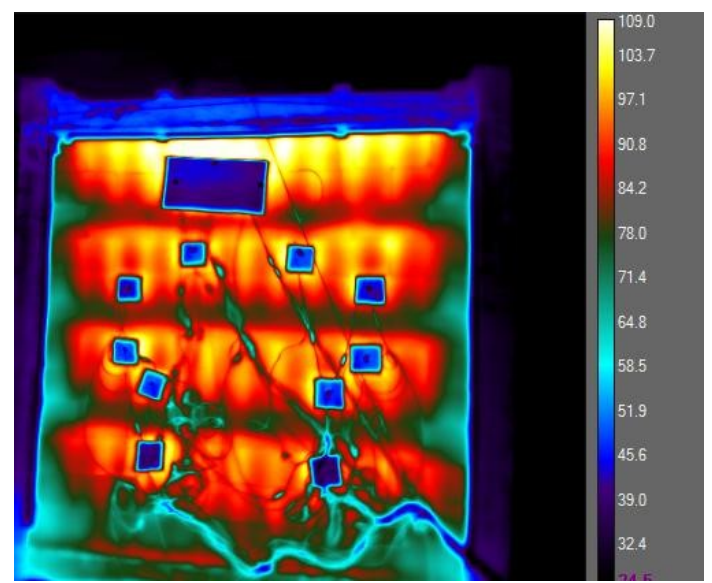

(b)

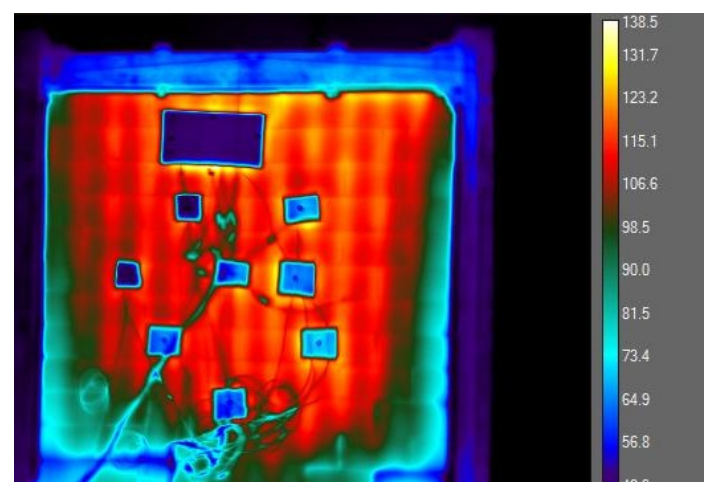

(d)

Figure 4.49: Barnsdale Test 1B, Thermal profile of the four walls during the cooling phase (3 hours after the test) a) Control wall b) Lintel Wall c) Splitter Wall d) Struck Joint Wall

\section{Barnsdale Test 1B Comparing Thermal Imaging Temperature Data}

The insualtion pads meant that the thermocouple temperature readings were different from the thermal imaging temperatures. A graph comparing both temperature sources can be seen in Figure 4.50. It can be seen that the thermcouple data reaches a much higher maximum temperature. This is because there is minimal heat loss to ambient due to the pads. Both the thermocouple and thermal data show that the hollow cells reach the highest temperature, and in both cases the hollow cells begin to cool first. Similar to what can be seen from the thermal imaging figures, the hollow cells and the solid webs begin to cool at so that the temperature difference between 
them decreased.

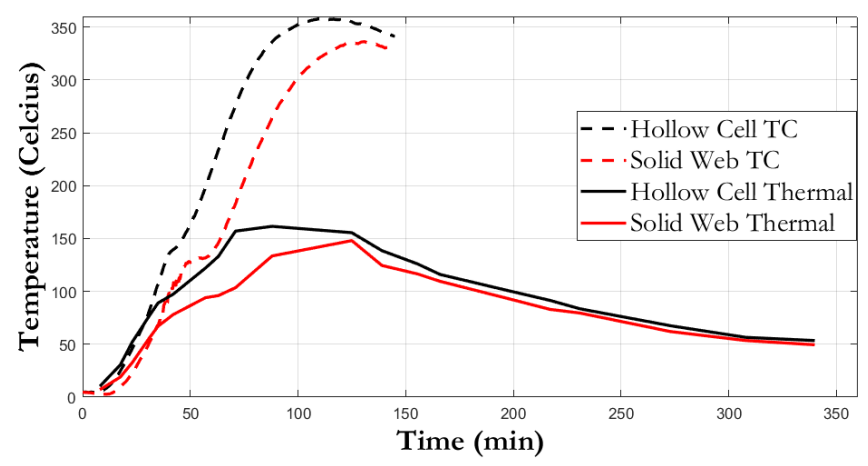

Figure 4.50: Barnsdale Test 1B, Cooling of the mortar on different walls

The thermal data for both the hollow cell and the solid web of each wall can be found in Figure 4.51. The Struck Joint Wall remained hottest throughout most of the time. The Control Wall and the Splitter Wall reached roughly the same maximum temperature, but the Control Wall began to cool faster. The Lintel Wall and the Control wall had similar cooling profiles, however the Lintel wall's peak temperature was colder for both the solid web or the hollow cell locations.

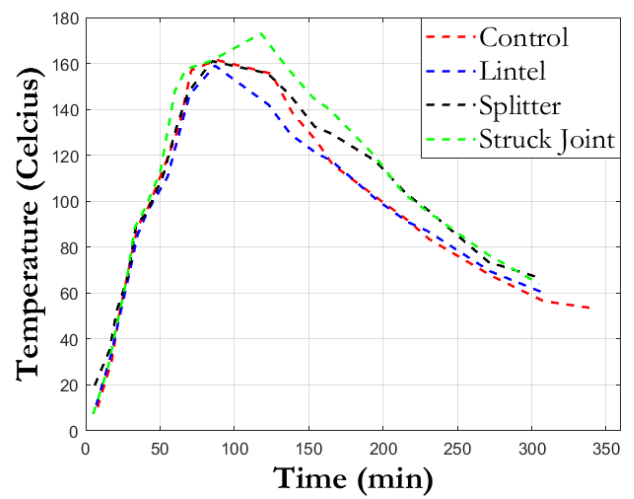

(a)

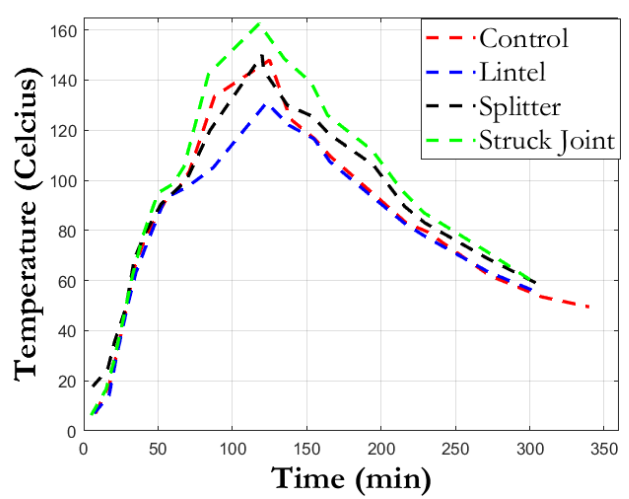

(b)

Figure 4.51: Barnsdale Test 1B Thermal Data a) Hollow Cell b) Soild Web 


\subsection{Comparing Almonte Tests and Barnsdale Tests $1 \mathrm{~A}$ and $1 \mathrm{~B}$}

\subsubsection{Comparing Barnsdale Tests 1A and 1B}

\section{Furnace Temperature}

The furnace temperature in the first test was close to where it needed to be, however the wind was causing fluctuations, and the furnace safeties were being tripped. The second test had the furnace temperature exceed the standard fire curve, which means that the modifications were sufficient.

\section{Average Unexposed Wall Temperatures}

In both tests the control wall and the lintel wall were similar in terms of temperature and in both cases the Struck joint wall was the hottest wall. The splitter wall always started off hotter because it was in the sun and had been heated, but due to the broken thermocouples during the first test, this wall can't be compared between the two tests.

\section{Comparing inner thermocouple locations}

In both tests the hollow cell was the hottest part of the wall. In the initial test where the wall still had all of its free water, the mortar was the coolest point because the mortar has more free water to be evaporated. In the second test the web was the coolest point because most of the free water was already gone, and so the mortars higher thermal conductivity and thinner thickness caused it to be hotter.

\section{Effect of the bond beam}

In both tests the bond beam did not preform as expected, but for different reasons. In the first test incomplete combustion and flame impingement caused the thermocouples on the bottom of the wall to heat up faster than expected. In the second test large cracks formed at the base of the wall that caused the lower section to heat up faster. Both of these events caused the bottom of the wall to be hotter than the top of the wall. When compared to the struck joint wall, both tests showed that the maximum struck joint wall cell temperatures were lower than the maximum lintel cell 
temperatures, which means that the lintel wall did not accomplish its goal. However, from comparing the temperatures above and below the bond beams, it can be seen that it did compartmentalize the wall successfully in both cases. The hot gasses were not allowed to travel from the lower section of the wall to the top. Further tests need to be done to conclusively prove the benefit of the lintel units, and to quantify what that benefit is.

\section{Temperatures after the furnace is shut off}

In both cases the temperatures continued to increase for about an hour after the furnace was shut off. This seems to indicate that this is the amount of time it takes for the wall to equalize the heating throughout its thickness.

\section{Thermal imaging}

On both days the walls facing the sun had a noticeable increase in temperature. This can account for some error in the final fire resistance of the wall. It should also be noted that the thermocouples will have different temperatures than the thermal imaging due to the fact that the thermocouples are insulated, and therefore are not as affected by change in ambient conditions.

In all cases the hollow cells heated up faster than the solid web and mortar. The centre of the cells heated up the most. The walls began with a checkerboard pattern, which eventually turned to columns of heat as the horizontal mortar along the hollow cells began to heat up.

The lintel wall can be seen to compartmentalize the wall and stop the hot gases from rising to the top of the wall.

As the walls began to cool the temperatures within the wall began to equalize, becoming more uniform. Then the bottom of the wall began to cool, and the cool area spread to the top of the wall.

\section{Cracking}

While there was minor cracking during the first test, the cracks did not start to form until 10-15 minutes into the second test. The reason the first test did not have cracking was due in part to the lower furnace temperatures, better time for the wall to transfer heat through its thickness, and the fact that it started intact. The second 
test had a much hotter fire with no false starts, and it began with a wall that had some cracks in it.

\section{Thermal Bowing}

The first test had less of a thermal gradient because of all of the false starts. The temperature at points throughout the wall were higher, so the thermal gradient was lessened. The short duration of the burns meant that no critical temperature difference was created which mean thermal bowing was not induced. During the second test the hotter furnace temperatures couple with the lack of fixed supports on the walls meant that thermal bowing was more likely.

\section{Spalling}

Similar to the reason why the first test had minimal cracking, the temperature was not hot enough and did not last long enough to spall the walls in the first test. In the second test the walls had a lot less free water, which made them less prone to spalling.

\subsubsection{Comparing Almonte to Barnsdale Tests}

\section{Furnace Temperature}

In both locations there was an issue with ventilation that resulted in soot covering the inner part of the furnace. With the Almonte test this was solved by adding more blowing and ensuring symmetrical airflow and heating. With the Barnsdale tests this was done by increasing the cement board baffle angle and setting up barriers to reduce the effects of the wind. In each case the first test was aborted early due to the errors in the test structure, but the later test was able to proceed properly.

\section{Average Unexposed Wall Temperatures}

The unexposed wall temperatures in each of the individual tests had the correct failure order based on fire resistance rating. Some cracking and other defects caused a few of the walls to fail sooner than expected. 


\section{Comparing inner thermocouple locations}

The unexposed wall temperatures in each of the individual tests had the correct failure order based on fire resistance rating. Some cracking and other defects caused a few of the walls to fail sooner than expected.

\section{Effect of the bond beam}

In both tests the bond beam appeared to have beneficial effects both from the thermocouples and from the thermal imaging. Unfortunately for both of the tests cracks and flame impingement meant that a conclusive answer cannot be given. Future work needs to be done to confirm its use.

\section{Temperatures after the furnace is shut off}

In all the tests the unexposed temperature of the walls continued to rise after the furnace was shut off. This is because the heat needs to dissipate through the wall. The amount of heating after the furnace was turned off was quite significant, and could potentially cause a fire to spread from one extinguished room to another adjacent room.

\section{Thermal imaging}

In all cases with standard block geometry the hollow cells heated up first creating a checkerboard patter. As the wall continued to heat up the became columns of heat as the air inside the cells began to heat up the horizontal mortar. As the walls cooled the temperature became close to uniform, and then the lower parts of the wall began to cool.

\section{Thermal Bowing}

All of the walls bowed. In the first Almonte test the thermal bowing was part of the reason the test had to be stopped. The $10 \mathrm{~cm}$ walls were too slender, and the amount of deflection was excessive. The $15 \mathrm{~cm}$ walls also deflected, which is why there was cracking. With the $20 \mathrm{~cm}$ walls there was less deflection due to thermal bowing, as the walls were not as slender. Finally, in the Barnsdale test, the deflection due to thermal bowing was quite high, as the walls were not fixed on all ends as in the Almonte tests. This allowed for high deflections early on in the test. 


\section{Cracking}

All of the walls cracked. Most of the cracking was done on around the corners of the walls due to the thermal bowing. The lightweight walls had less cracking than the normal weight walls, likely due to their lower coefficient of thermal expansion. The splitter wall had a unique cracking pattern, with several long cracks down the centre of the wall, most likely due to fact that they are designed to be easily split into two along the centre web.

\section{Spalling}

Spalling occurred in all of the tests. In the first Almonte test it occurred with the roof slab that was unprotected. The walls themselves did not undergo much spalling. In the second test there was a lot of surface spalling, and the reduced web wall had some large sections spall off after cooling. In the Barnsdale test the walls did not spall very much, but the concrete pad on the edges of the test structure did spall where the insulation ended. 


\subsection{Barnsdale Test 2 results}

\subsubsection{Furnace temperature}

The furnace was able to follow the standard fire relatively closely for most of the test, with a loss of heat at the 25-minute mark (Figure 4.52). The furnace was turned onto the maximum output for the remainder of the test, and it remained just below the standard fire. This means that the actual fire resistance rating time of the walls will be lower than the actual time of failure. As the furnace was on the maximum output, it could mean that future fire resistance tests that are meant to be longer than 2 hours may require additional time to ensure that failure occurs.

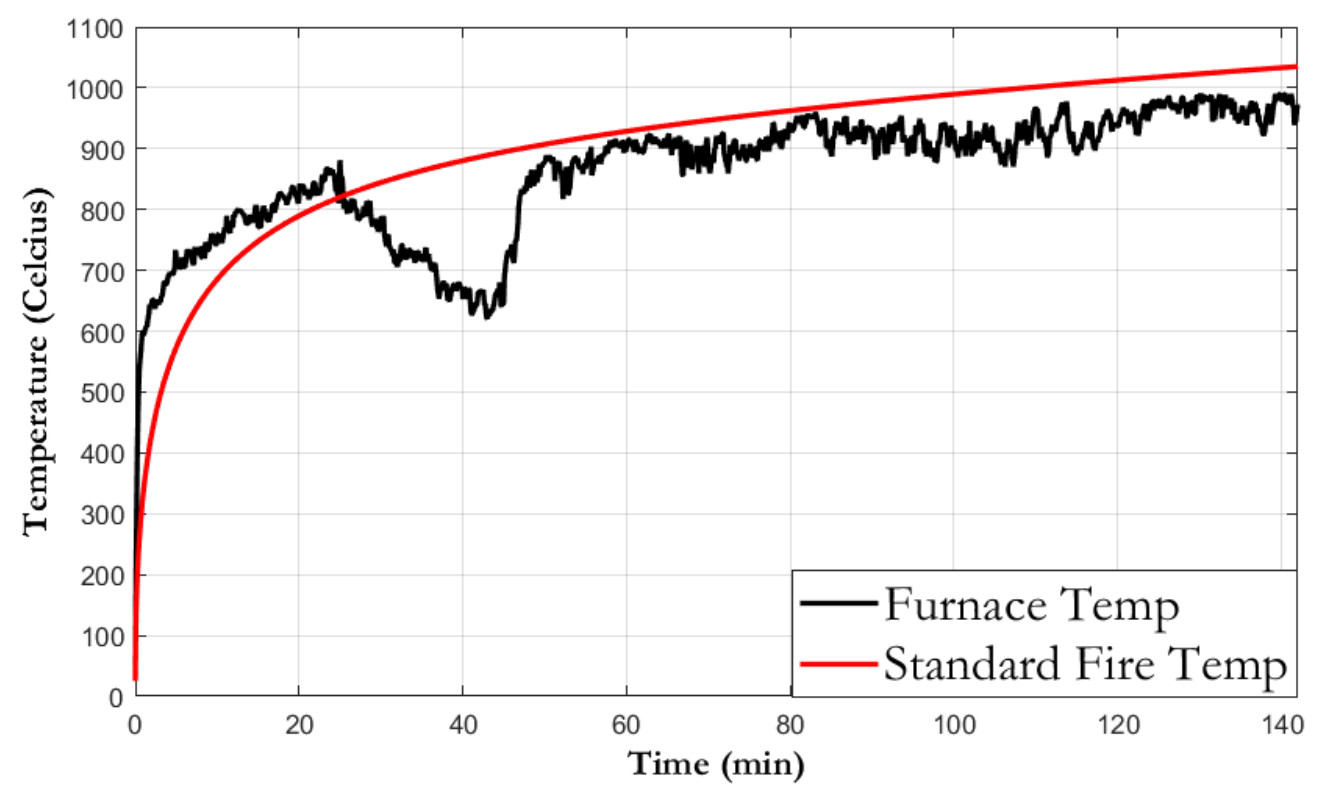

Figure 4.52: Barnsdale Test 2, Furnace Temperature during the heating period

Again, Equation 4.1 was used to determine the corrected fire resistance of all the walls. The test was stopped after 142 minutes, and this amounted to an equivalent fire severity of 135.8 minutes.

\subsubsection{Integrity failure, thermal bowing, spalling}

While the previous Barnsdale test underwent significant thermal bowing that led to early integrity failure, this test saw only minor thermal bowing at the beginning of 
the test, which mostly recovered during the test and after cooling. For the $20 \mathrm{~cm}$ walls the decrease in thermal bowing was partly because the walls were less slender than the $15 \mathrm{~cm}$ walls. However, the most likely reason for the reduction in thermal bowing was the removal of the insulation boards and the use of full mortar joints along the perimeter of the walls. The mortar joints around the perimeter provided more restraint, which reduced the amount of thermal bowing. This would indicate that the improvements made from the previous test were successful and will be used in future testing.

While cracks still formed at the corners of the walls due to the thermal bowing, the cracks were smaller than the previous test for all four walls (Figure 4.53). There was also cracking all along the perimeter of the walls where the mortar met the steel frame. These small cracks did not lead to integrity failure during the test, and so the insulation failure criteria were the governing failure mechanisms for determining fire resistance. The $\mathrm{LW} 15 \mathrm{~cm}$ wall had very minimal cracking, the Carbon Cured wall had average cracking, whereas the Semisolid and the Split-Face walls both had high levels of cracking (compared to the other two walls). It is important to note that even the highest level of cracking in this test was still much less than the cracking in the first Barnsdale test (as cracks are formed mainly due to thermal bowing). 


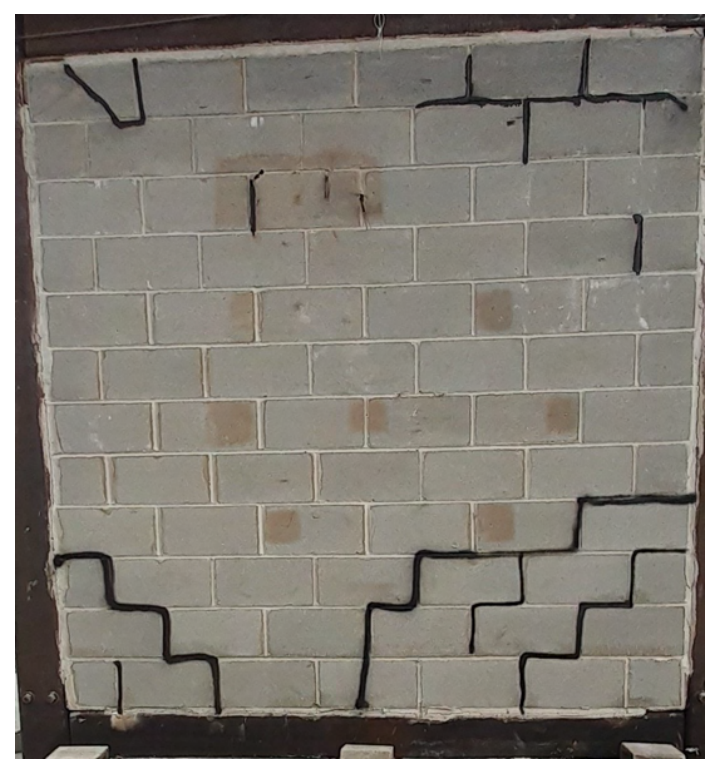

(a)

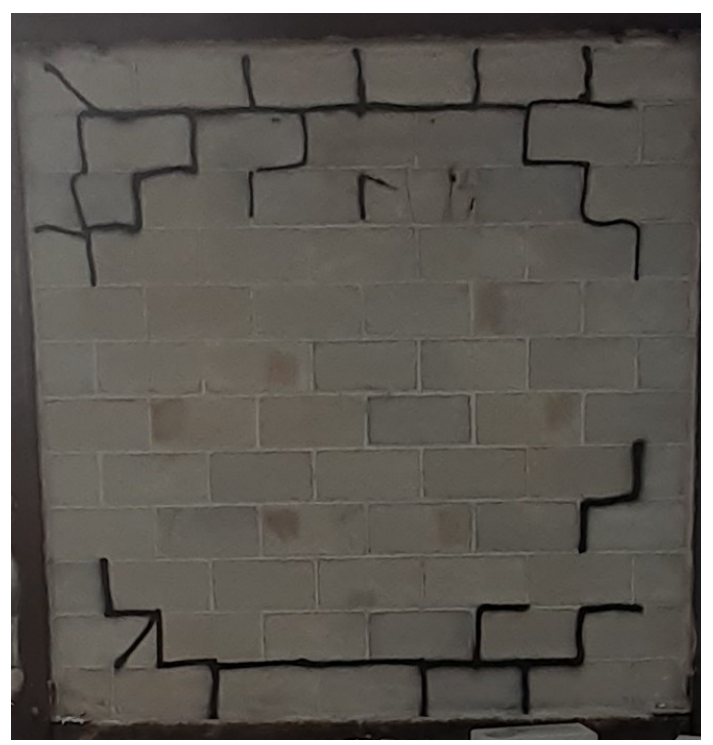

(c)

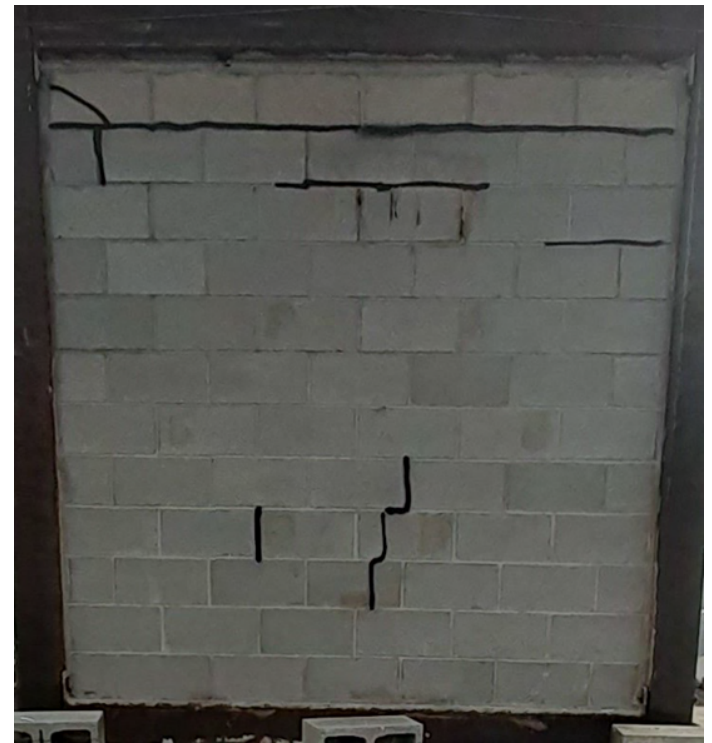

(b)

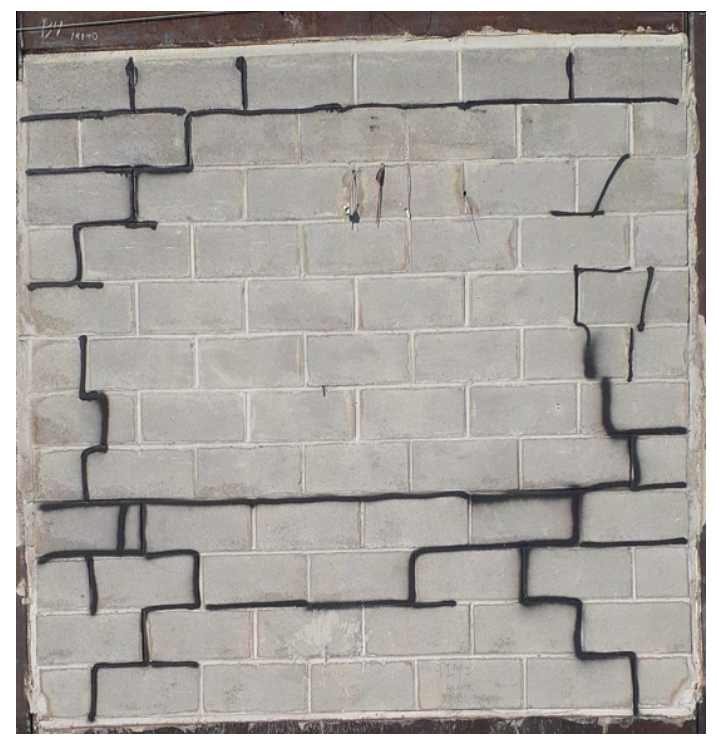

(d)

Figure 4.53: Barnsdale Test 2, Crack Patterns a) Carbon Cured Wall b) LW15cm Wall c) Semi Solid Wall d) Split-Face Wall 
During the test there was only minor spalling of the surface of the walls. Even 24 hours after the test there was still only minor spalling. The Carbon Cured wall had some larger scale spalling on the surface of the first course, but the rest of the wall was unaffected (Figure 4.54). However, after one week each of the walls showed significant amounts of spalling (Figure 4.55). The spalling on the Carbon Cured wall had increased from the first course to the whole wall, and it is possible to see the color change of some of the aggregates (Figure 4.56). The lightweight wall did not show much spalling on any part of the blocks themselves, however on the upper half of the wall the mortar showed some loss of material due to spalling. This is consistent with the literature, as lightweight concrete is more resistant to the effects of spalling due to the porosity of the aggregates. It is also possible to see the difference between the lightweight blocks and the normal weight lintel units on the top course of the LW15cm wall. The Semi Solid wall seemed to have the most spalling damage when compared to the other walls, with a larger amount of material collected underneath the wall. The amount of spalling on the Split-Face was more difficult to see visually, as the block itself starts off with a rough surface. After one week the surface of the Split-Face wall no longer had the same rough surface due to the splitting of the block, but instead had the same brittle surface as the other normal weight walls due to the loose concrete. Running a hand over the surface of any of the three normal weight walls resulted in more concrete crumbling from the walls. Figure 4.57 demonstrates the fine concrete residue that piled up below the walls due to the spalling of the concrete. 


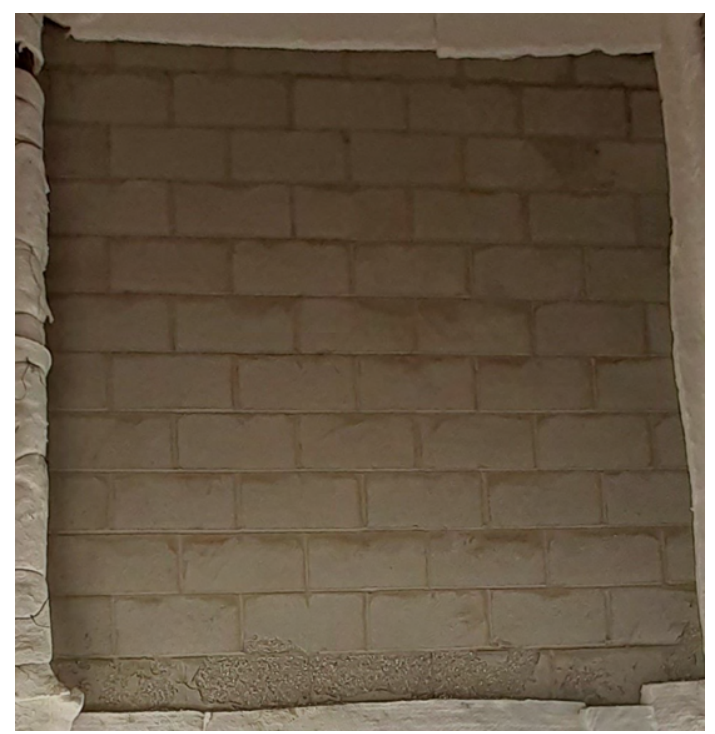

(a)

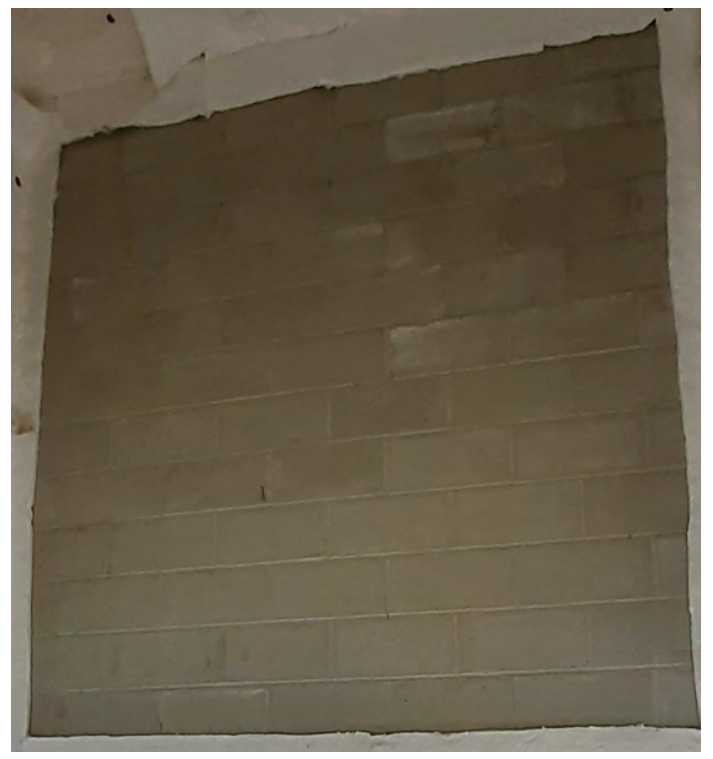

(c)

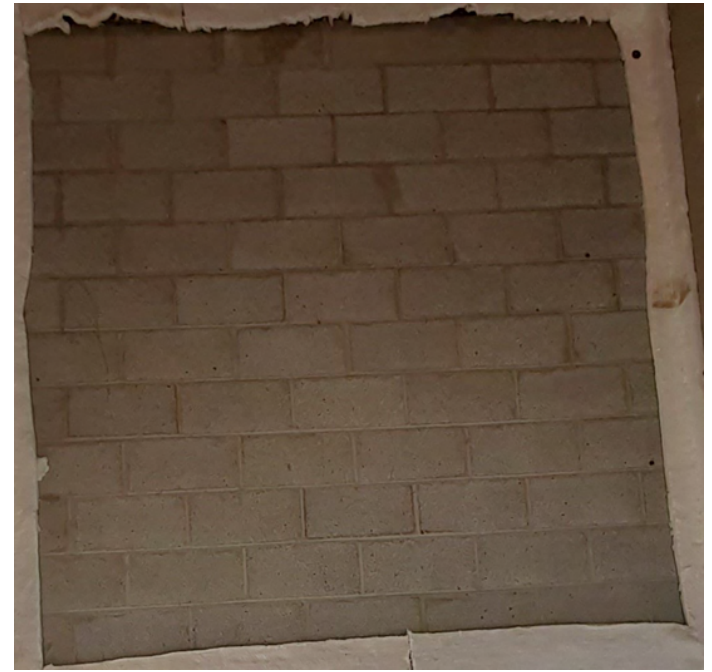

(b)

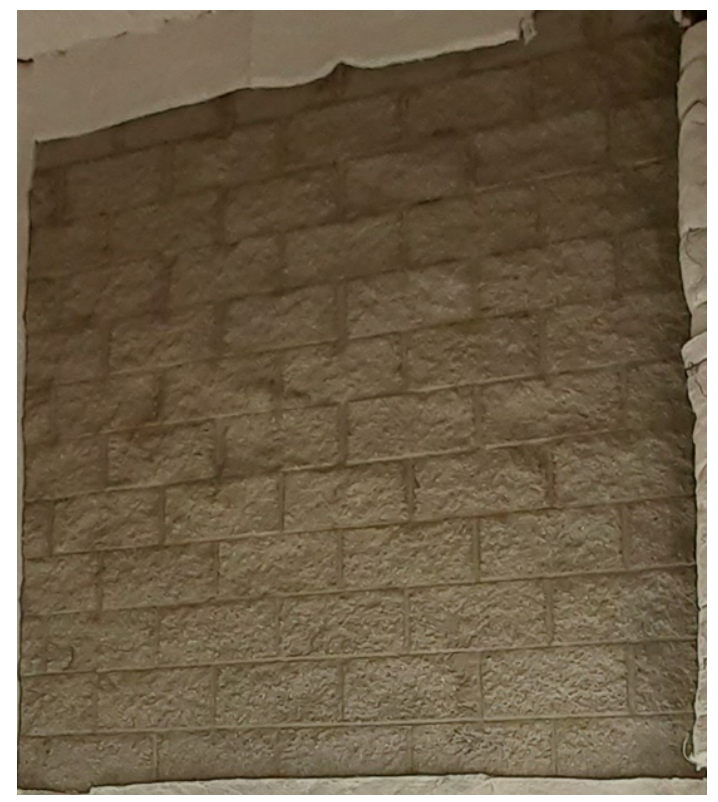

(d)

Figure 4.54: Barnsdale Test 2, Fire exposed side of the walls 24 hours after the test a) Carbon Cured Wall b) LW15cm Wall c) Semi Solid Wall d) Split-Face Wall 


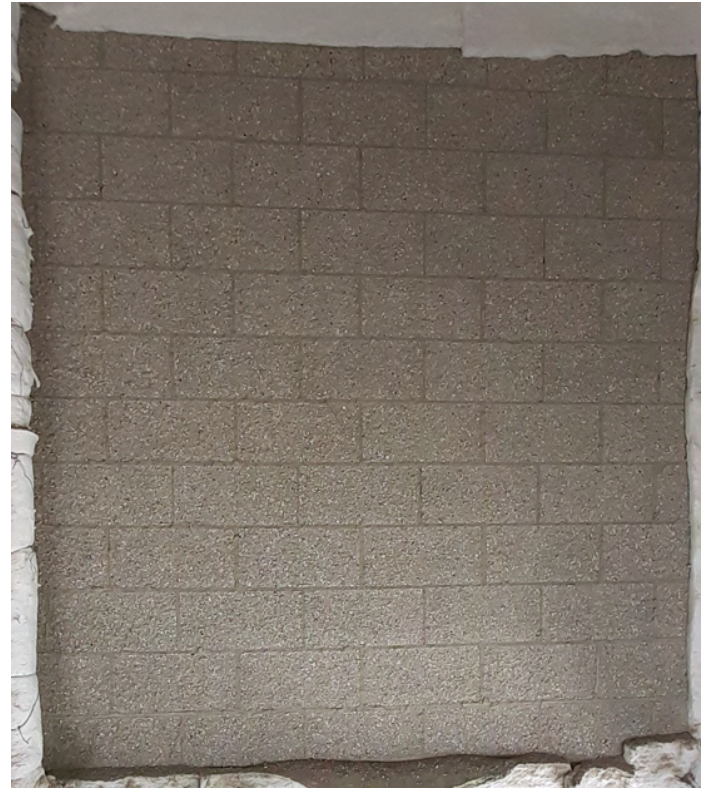

(a)

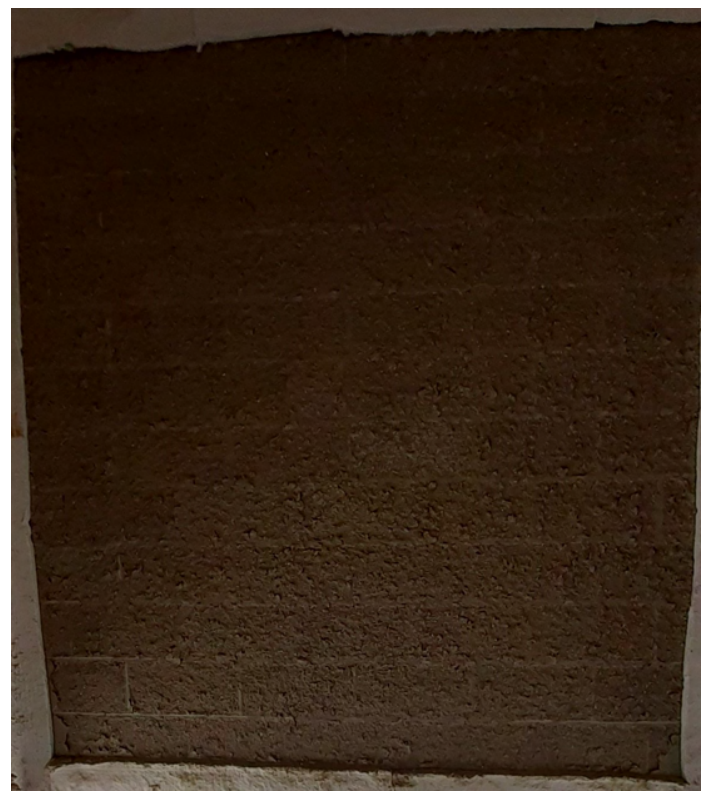

(c)

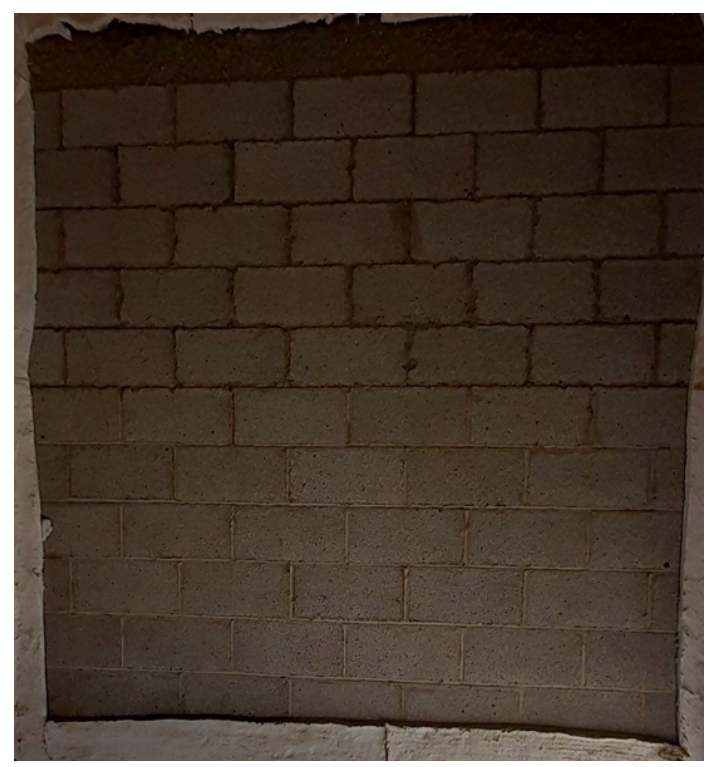

(b)

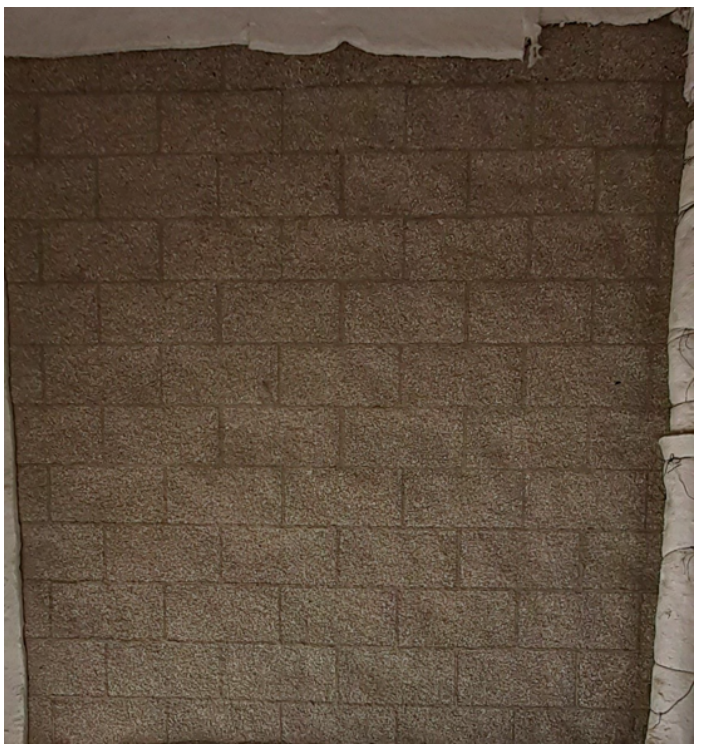

(d)

Figure 4.55: Barnsdale Test 2, Fire exposed side of the walls one week after the test a) Carbon Cured Wall b) LW15cm Wall c) Semi Solid Wall d) Split-Face Wall 


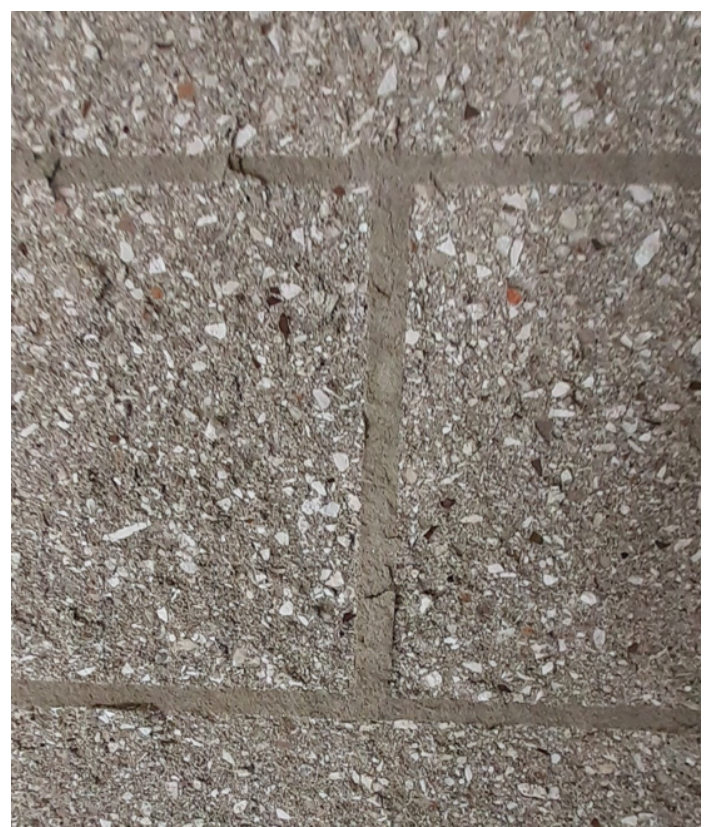

(a)

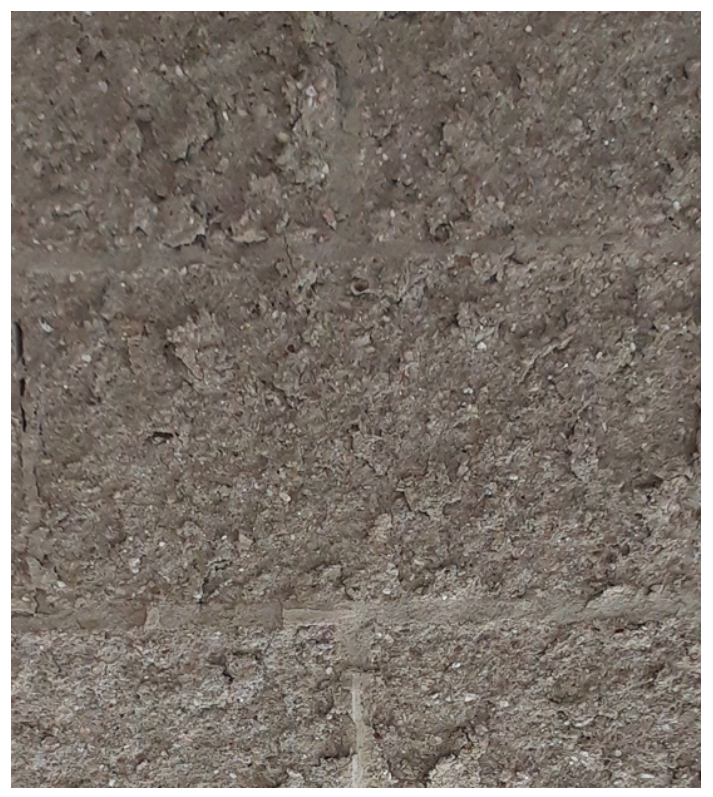

(c)

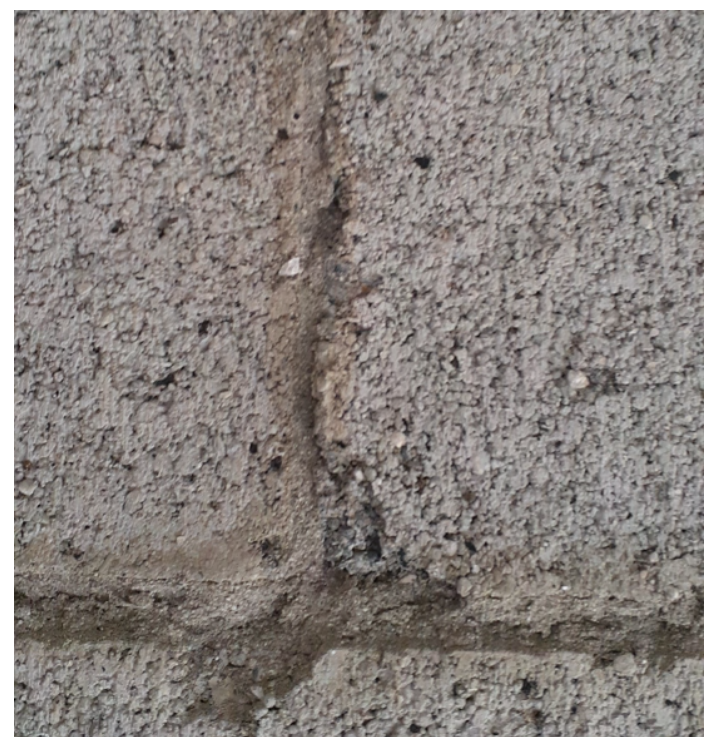

(b)

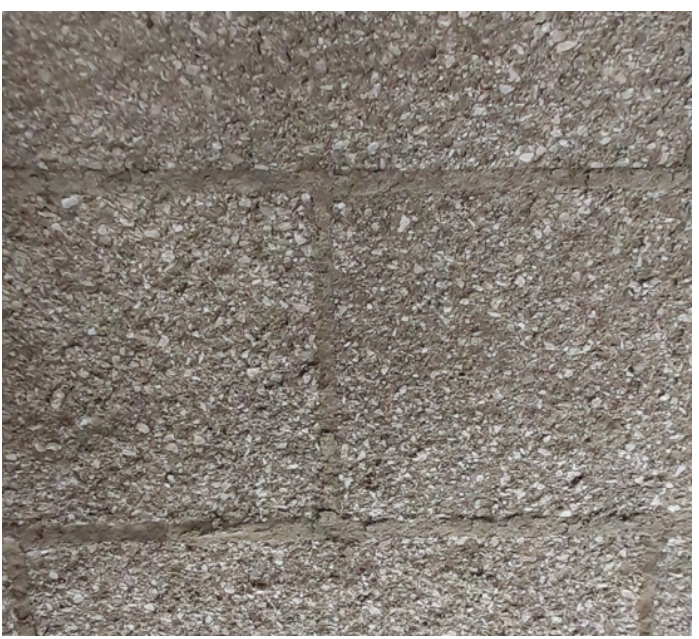

(d)

Figure 4.56: Barnsdale Test 2, Fire exposed side of the walls one week after the test (closeup) a) Carbon Cured Wall b) LW15cm Wall c) Semi Solid Wall d) Split-Face Wall 


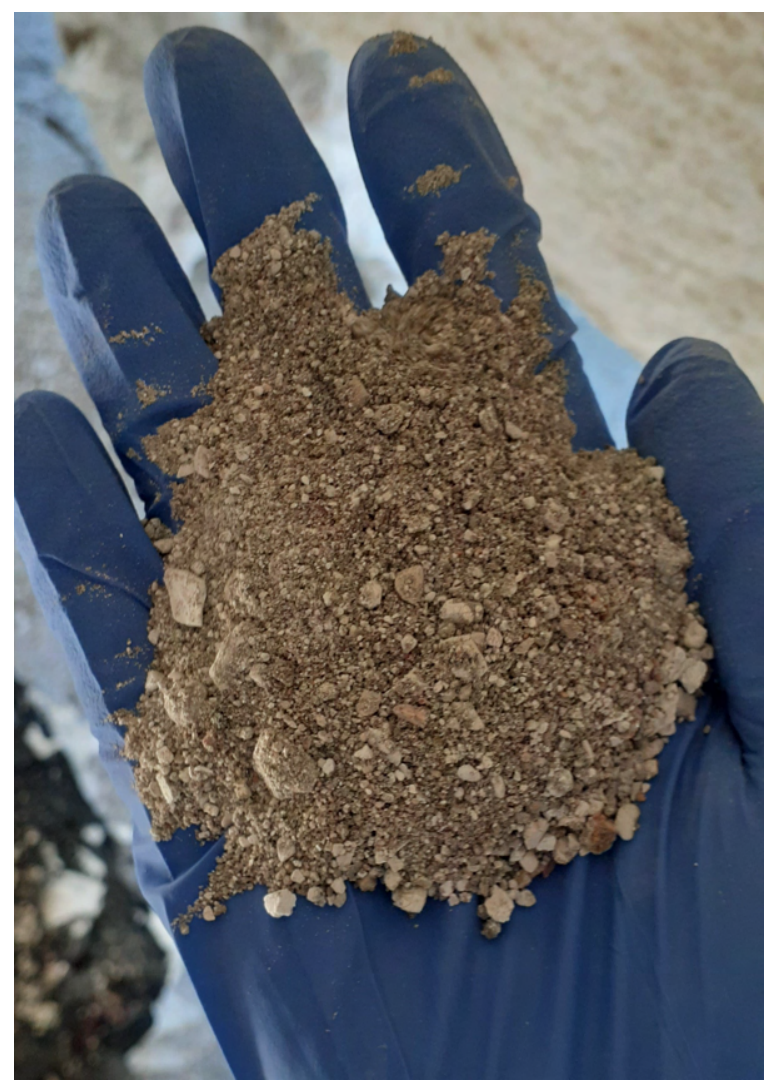

Figure 4.57: Barnsdale Test 2, Spalling Residue 
When the walls were taken down it was possible to measure the amount of spalling in the blocks. The three NW concrete blocks all had some level of spalling (Figure 4.58). It was found that the amount of spalling on the exposed side was roughly 0.5 $\mathrm{cm}$ for the three NW blocks. This spalling was relatively even over the entire exposed faceshell for the Carbon Cured and Semi Solid blocks. The Split Face wall however had more severe spalling on the exposed side of the hollow cells. While the entire faceshell on the Split Face blocks had spalled by at least $0.5 \mathrm{~cm}$, the exposed side of the hollow cells had spalled an addition amount, up to $2 \mathrm{~cm}$ (for a total of $2.5 \mathrm{~cm}$ ). This is likely due to a weakening of the block face as a result of the cutting process. Split Face blocks are made in pairs and roughly cut into two separate blocks, which gives them the desired rough surface. This process apparently makes the surface more susceptible to cracking and loss of material during a fire.

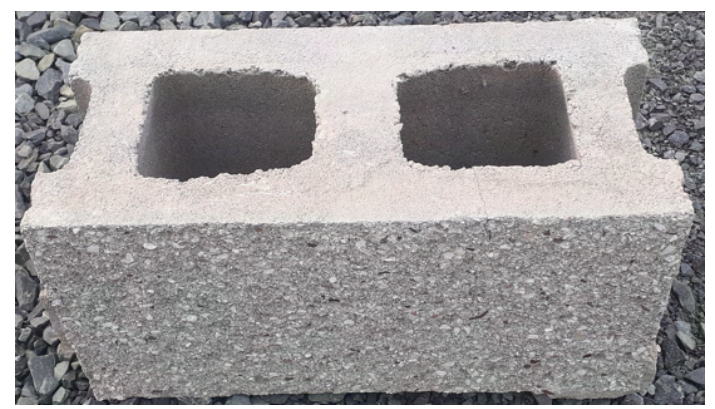

(a)

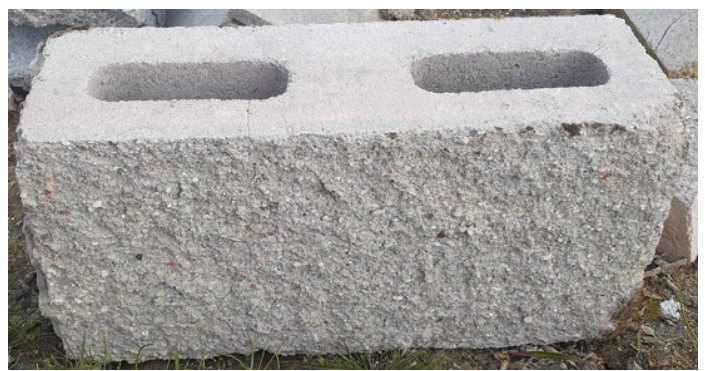

(b)

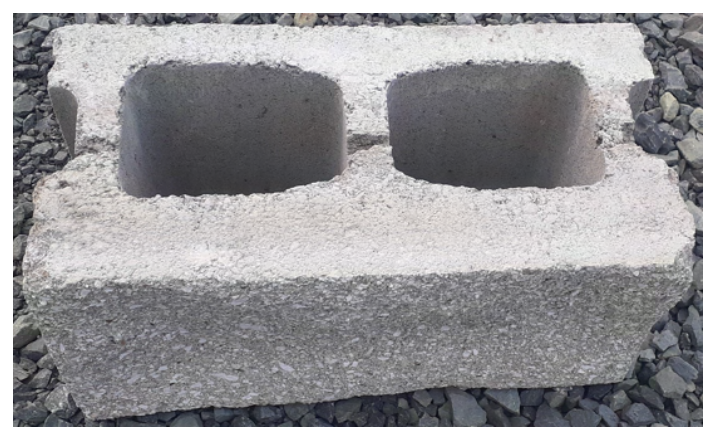

(c)

Figure 4.58: Barnsdale Test 2, Single block spalling after removal from the wall a) Carbon Cured Wall b) Semi Solid Wall c) Split-Face Wall 
When the walls were being demolished by the masons, it was found that the Semi Solid $15 \mathrm{~cm}$ wall was difficult to take down. This makes sense, as it has a thicker faceshell which would be more difficult for them to smash through. While the Carbon Cured $20 \mathrm{~cm}$ and $L W 15 \mathrm{~cm}$ walls were as expected, the Split Face wall was easier to demolish then expected. This is due to the spalling that had occurred on the fire side of the hollow cells. While all of the other walls had roughly $0.5 \mathrm{~cm}$ of spalling, the Split Face blocks had additional spalling on the hollow cells, sometimes up to $2 \mathrm{~cm}$. This would explain why the blocks were easier to tear down than expected.

\subsubsection{Insulation Failure Times}

The four walls all had different predicted failure times based on equivalent thickness, ranging from 90 minutes to 126 minutes (Table 4.4). The values in Table 4.5 show the failure times of the four walls based on average wall temperature, and the temperature failure at a single point. The values in Table 4.6 have been corrected to account for the difference between the furnace temperature and the standard fire temperature. All four of the walls failed due to the single point failure.

Table 4.4: Barnsdale Test2 Predicted Failure Times

\begin{tabular}{|l|c|}
\hline Wall Type & $\begin{array}{c}\text { Predicted Failure Time } \\
\text { (Minutes) }\end{array}$ \\
\hline Carbon Cured $20 \mathrm{~cm}$ & 108 \\
\hline LW15cm & 90 \\
\hline Semi Solid $15 \mathrm{~cm}$ & 120 \\
\hline Split Face $20 \mathrm{~cm}$ & 126 \\
\hline
\end{tabular}

The LW15cm failed first, and only slightly surpassed the predicted failure time by 1.7 minutes. The second wall to fail was the Semi Solid wall, which failed 15.8 minutes earlier than its posted fire resistance. The third wall to fail was the Carbon Cured wall, surpassing the predicted failure time by 3.3 minutes. The final wall to fail was the Split Face wall, which exceeded its failure time by 17.8 minutes. This 
Table 4.5: Barnsdale Test2 Failure Times

\begin{tabular}{|l|l|c|}
\hline Wall Type & $\begin{array}{l}\text { Average Failure } \\
\text { (Minutes) }\end{array}$ & $\begin{array}{c}\text { Single Point Failure } \\
\text { (Minutes) }\end{array}$ \\
\hline Carbon Cured $20 \mathrm{~cm}$ & 125.0 & 116.0 \\
\hline LW15cm & 107.0 & 94.8 \\
\hline Semi Solid $15 \mathrm{~cm}$ & 111.2 & 108.4 \\
\hline Split Face $20 \mathrm{~cm}$ & 150.0 & 149.3 \\
\hline
\end{tabular}

Table 4.6: Barnsdale Test2 Corrected Failure Times

\begin{tabular}{|l|c|c|}
\hline Wall Type & $\begin{array}{c}\text { Average Failure } \\
\text { (Minutes) }\end{array}$ & $\begin{array}{c}\text { Single Point Failure } \\
\text { (Minutes) }\end{array}$ \\
\hline Carbon Cured $20 \mathrm{~cm}$ & 119.7 & 111.3 \\
\hline LW15cm & 102.8 & 91.7 \\
\hline Semi Solid $15 \mathrm{~cm}$ & 106.8 & 104.2 \\
\hline Split Face $20 \mathrm{~cm}$ & 144 & 143.8 \\
\hline
\end{tabular}

would seem to indicate that the equivalent thickness method is relative accurate for prescribing the fire resistance of standard block shapes, but is less accurate with more unique shapes such as the split face wall. The Semi Solid wall failing more than 15 minutes before the posted fire resistance would seem to indcate that some sort of unexpected cracking occured within the wall to cause this premature failure.

\subsubsection{Barnsdale Test2 Heating Period}

\section{Average Wall Temperatures}

All of the walls had average unexposed temperatures ranging from $26-30{ }^{\circ} \mathrm{C}$ (the variations were due mainly to the sun as the test structure is outdoors). As the failure times are based on an increase in temperature, these temperature differences did not affect the failures times. As the test started the unexposed side of the walls remained at ambient for just over 10 minutes, which is when the $15 \mathrm{~cm}$ walls began 
to heat up, followed shortly by the Carbon Cured wall, and finally the Split-Face wall (Figure 4.59). Each of the four walls underwent a plateau between $100-120{ }^{\circ} \mathrm{C}$ due to the evaporation of free water. In the previous test the walls had undergone several pre-burns to test the furnace which had removed most of the free water. In this test however, the plateau remained and has a large impact on the fire resistance. The Split face wall had the longest plateau, with the $\mathrm{LW} 15 \mathrm{~cm}$ and Semi Solid walls having similar plateau lengths. The Carbon Cured wall had a shorter plateau, but its rate of temperature increase was more gradual than the $15 \mathrm{~cm}$ walls.

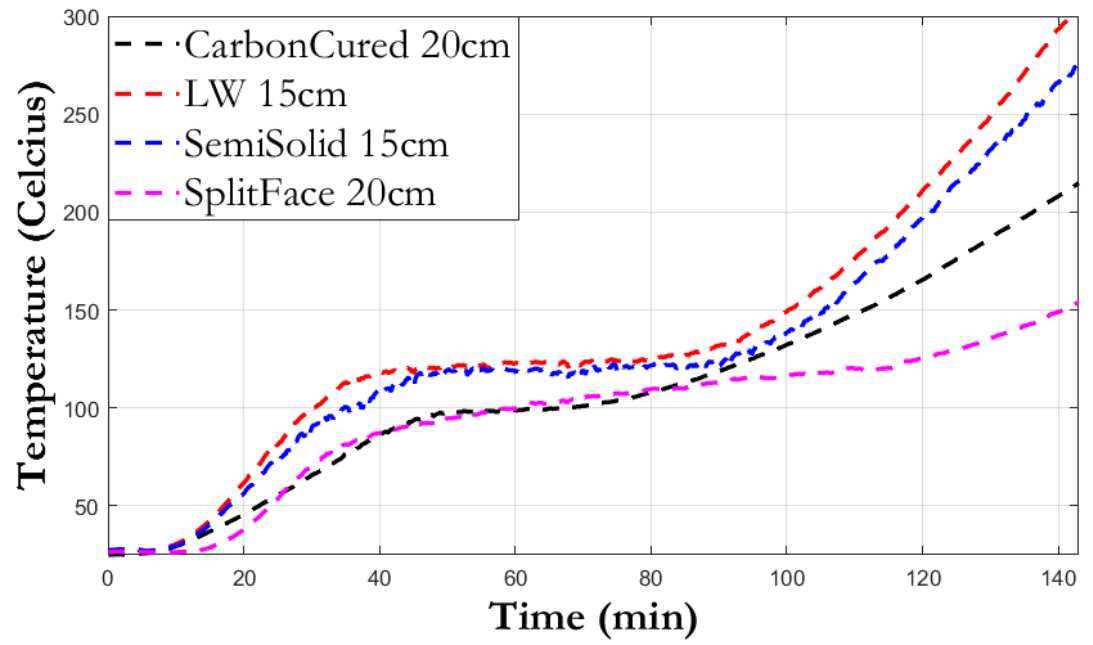

Figure 4.59: Barnsdale Test 2, Average Wall Temperatures during the heating period

\section{Barnsdale Test2, Free Water}

The free water within the walls created the plateaus in Figure 4.59. The free water could be seen to begin evaporating from the top of the walls, as that is where the heat within the cells collected (Figure 4.60). The free water started to evaporate from the mortar joints first, but as time went on the free water began to evaporate from every part of the wall (Figure 4.61). 


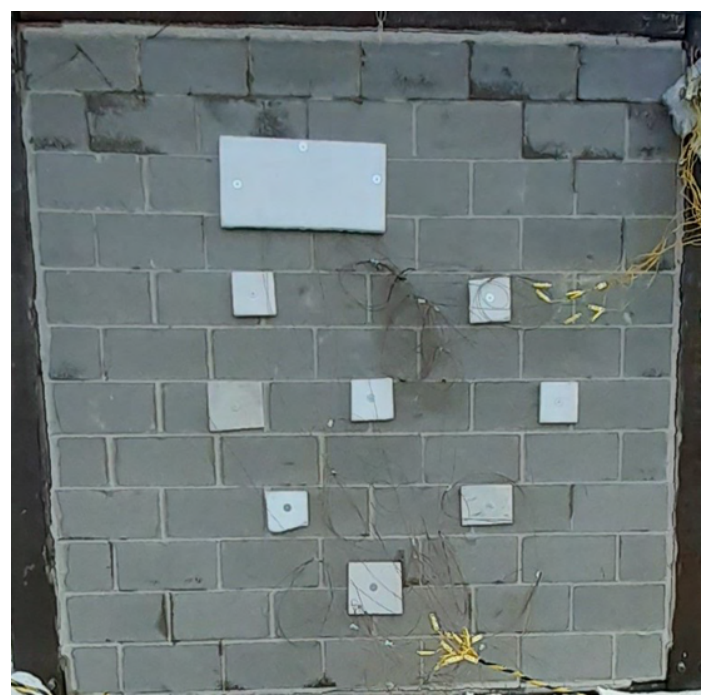

(a)

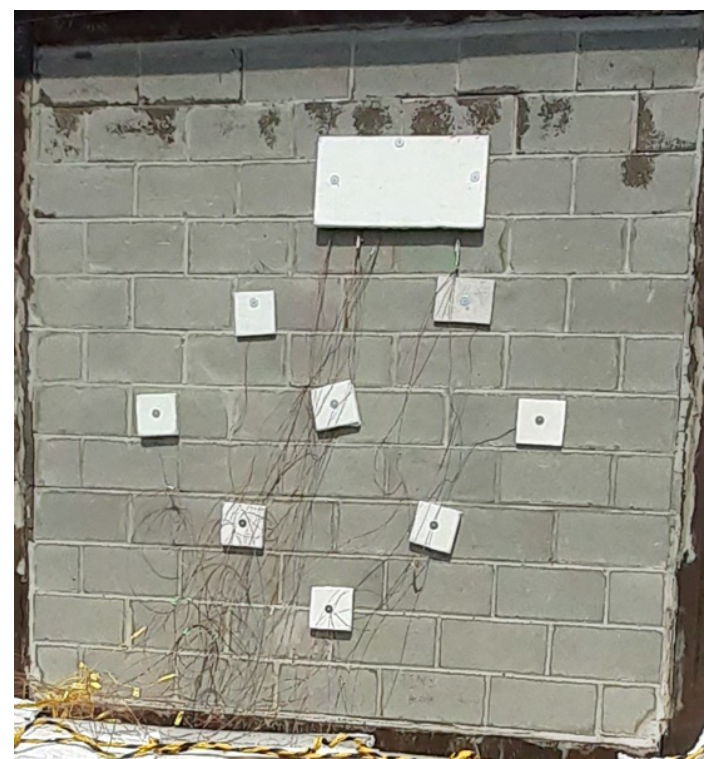

(b)

Figure 4.60: Barnsdale Test 2, Free water evaporating at the start of the test a) Carbon Cured Wall b) Split-Face Wall

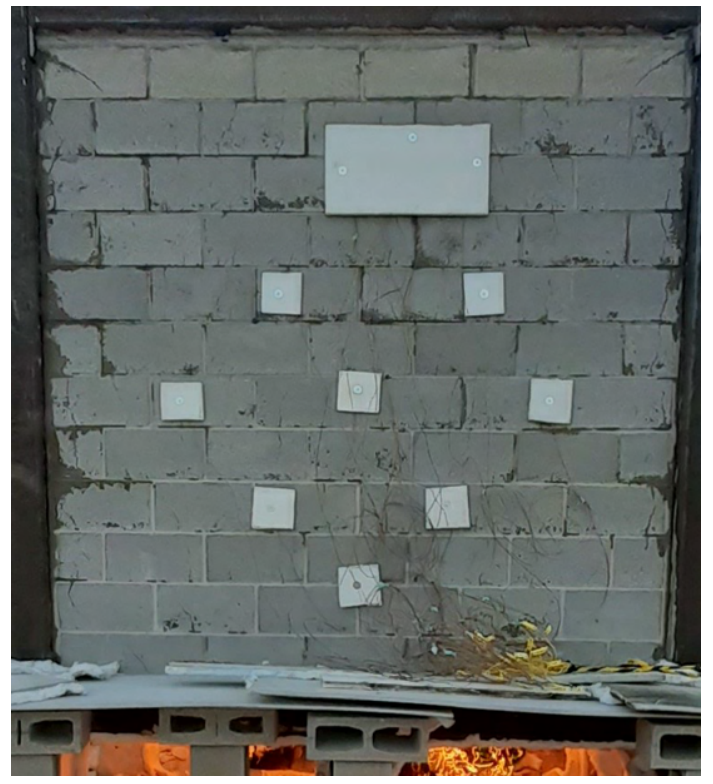

(a)

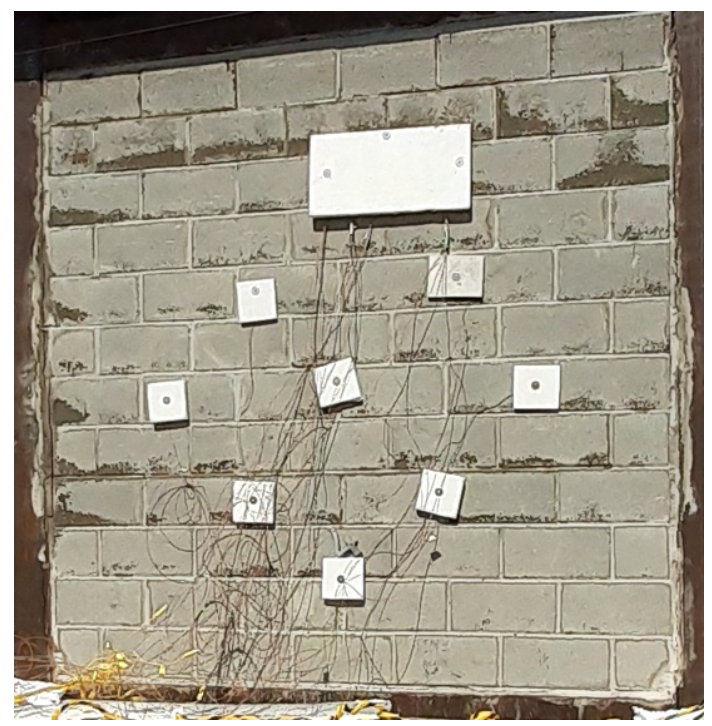

(b)

Figure 4.61: Barnsdale Test 2, Free water evaporating at the start of the test a) LW15cm Wall b) Split-Face Wall 


\section{Comparing Block Surface Locations}

Similar to the past tests, the mortar underwent a much longer plateau than the block, which caused it to remain the coolest part of the wall (Figure 4.62). The solid web had the second longest plateau, which accounts for it being the second coolest part of the wall. The hollow cell had the shortest plateau, and subsequently remained the hottest part of the wall during the test. As the mortar far surpassed the block, it would indicate that a wall could be constructed with novel blocks and the same mortar to achieve a superior fire resistance. However, if the block surpasses the previous fire resistance by more than half an hour, the mortar may become the hottest part of the wall and the source of the insulation failure.

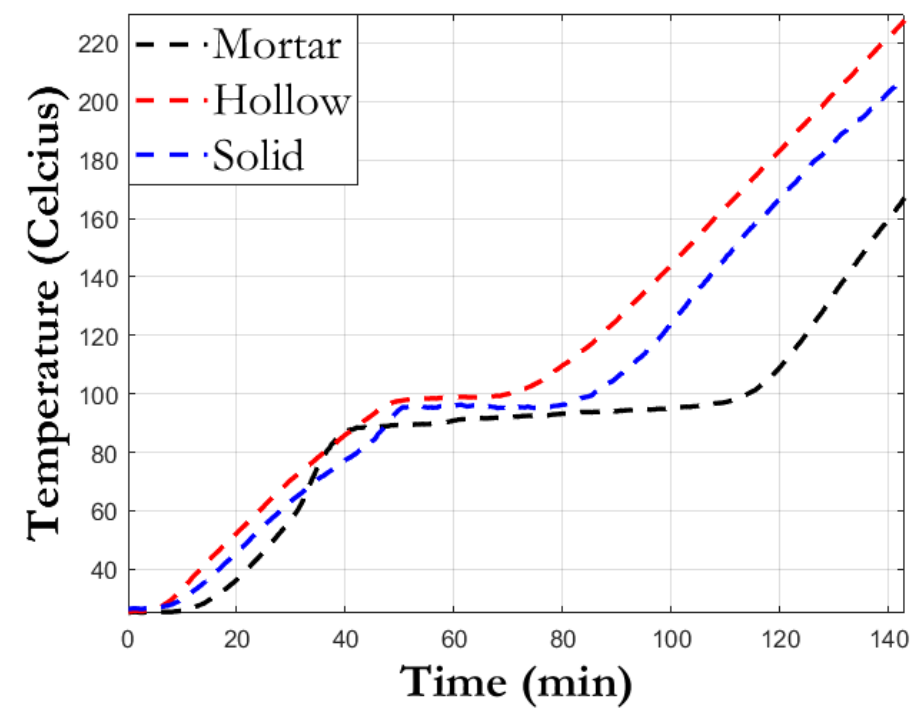

Figure 4.62: Barnsdale Test 2, Unexposed Surface Temperature of the Carbon Cured Wall at various locations during the heating period

\section{Comparing Temperature at $\mathrm{H} 2$}

The four walls all had different face shell thicknesses (and the LW15cm wall had a different aggregate type). The temperature of each wall at the $\mathrm{H} 2$ thermocouple location (the fire side of the interior hollow cell) can be found in Figure 4.63. There is a short time at the start of the test where the temperatures remain at ambient, but after a few minutes the temperatures begin to rise. At $100{ }^{\circ} \mathrm{C}$ there is a small plateau 
due to the evaporation of free water from the facesehell. Then the walls undergo a roughly linear temperature increase, as the exposed surface temperature no longer increases at such a high rate. The Semi Solid and $L W 15 \mathrm{~cm}$ walls both had similar temperature profiles, with the Semi Solid wall remaining cooler than the $L W 15 \mathrm{~cm}$ wall. The Carbon Cured wall remained cooler than the $15 \mathrm{~cm}$ walls, and the Split face wall remained very cool, due to the much thicker faceshell.

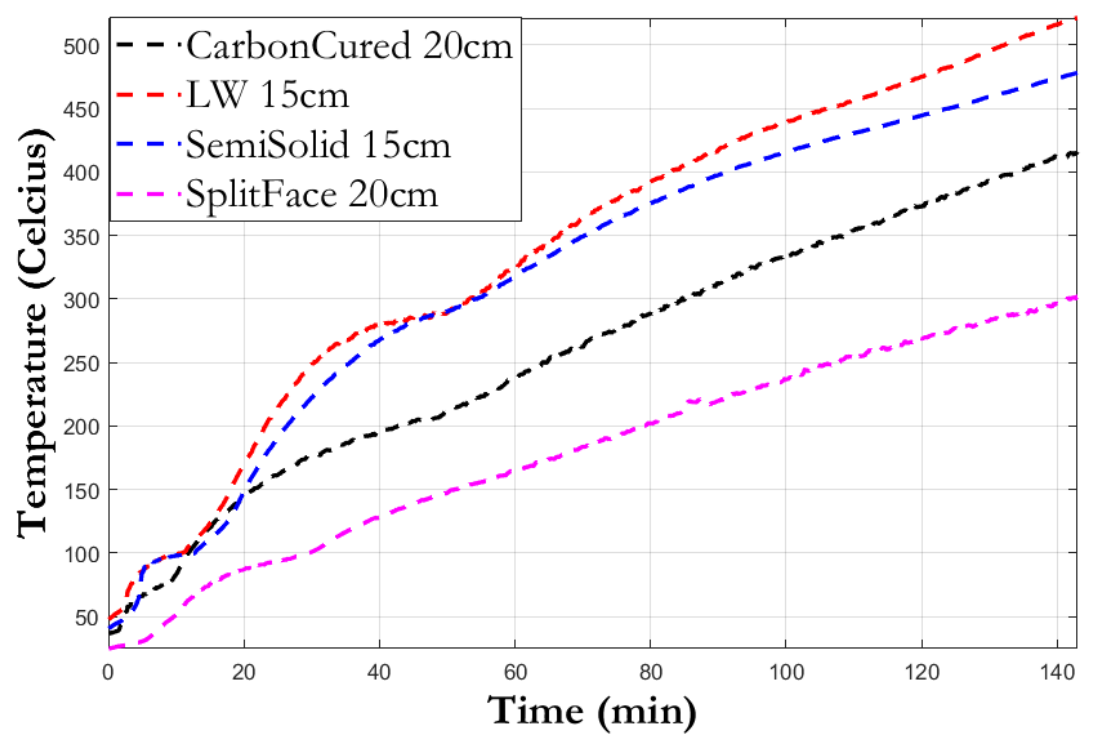

Figure 4.63: Barnsdale Test 2, The temperature profile at $\mathrm{H} 2$ for each of the four walls during the heating period

\section{Comparing the Average Cell Temperatures}

The cell temperature for each of each of the walls followed a similar patter to the $\mathrm{H} 2$ values. One of the main changes was that the temperature difference between the Split Face and the Carbon Cured walls was increased, which is likely due to the cooler cell surface of the Split-Face wall radiated and convected less heat than the hotter Carbon Cured wall as the heat flow through radiation and convection increases with an increase in surface temperature (Figure 4.64). 


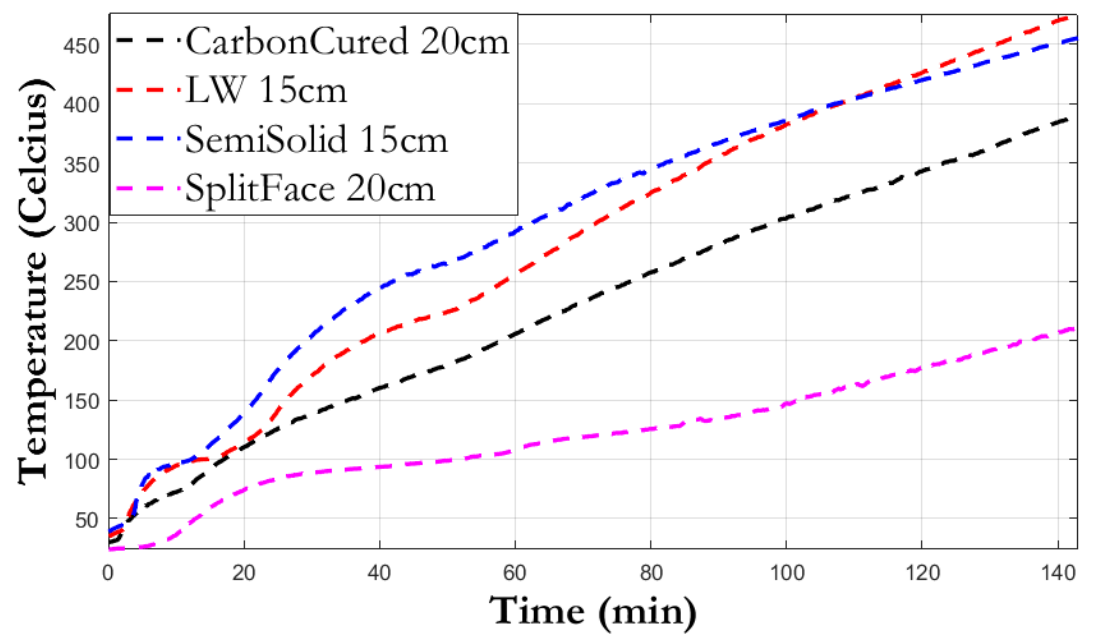

Figure 4.64: Barnsdale Test 2, The temperature profile of the cells for each of the four walls during the heating period 


\subsubsection{Cooling Period}

\section{Furnace Temperature}

After 142 minutes the furnace was shut off, and the cool air flowing through the test structure quickly cooled the furnace (Figure 4.65). The cooling rate slowed as the furnace temperature was less dependent on the air within the furnace, and more dependent on the heat radiating from the exposed sides of the walls themselves. Even though the furnace cooled quite rapidly, the walls retained a lot of heat, which would take quite some time to dissipate.

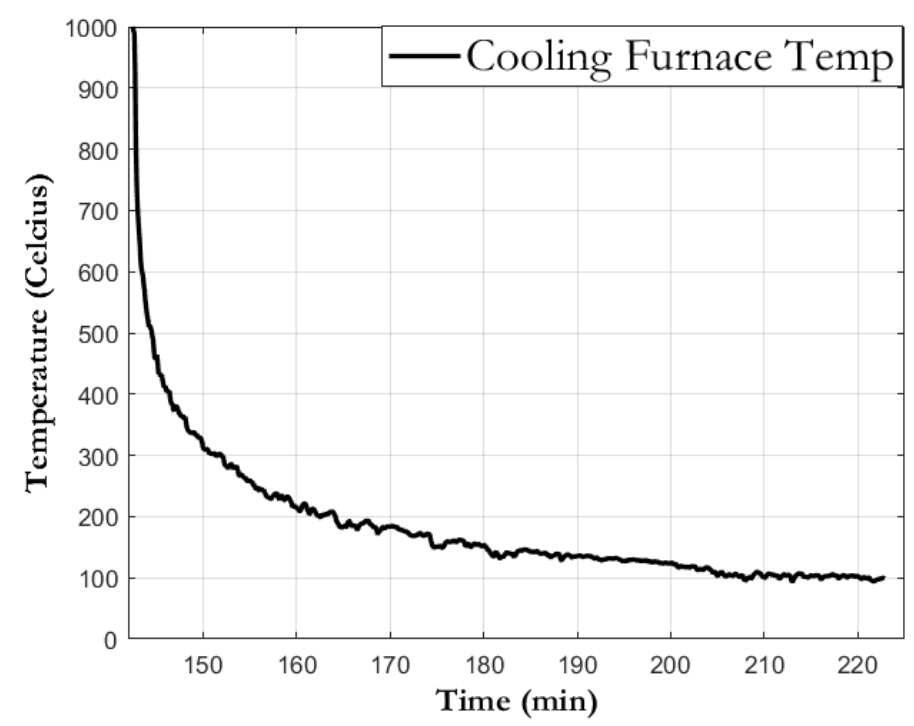

Figure 4.65: Barnsdale Test 2, The temperature profile of the furnace after the burner was turned off

\section{Average Wall Temperatures}

Even after the furnace was turned off, the walls continued to heat up (Figure 4.66). This is because the exposed side of the walls remained at over $500{ }^{\circ} \mathrm{C}$, and so the temperature within the block needed to equalize. This temperature increase ranged from $60{ }^{\circ} \mathrm{C}$ to almost $140{ }^{\circ} \mathrm{C}$. The Carbon Cured wall saw the smallest increase in temperature, whereas the other three walls saw a much larger temperature increase. This temperature increase after the test could affect the concretes structural integrity, as more of the concrete undergoes physical and chemical changes. The temperature 
change could also cause ignition of materials on the unexposed side of the wall an hour after the fire in the initial room is extinguished.

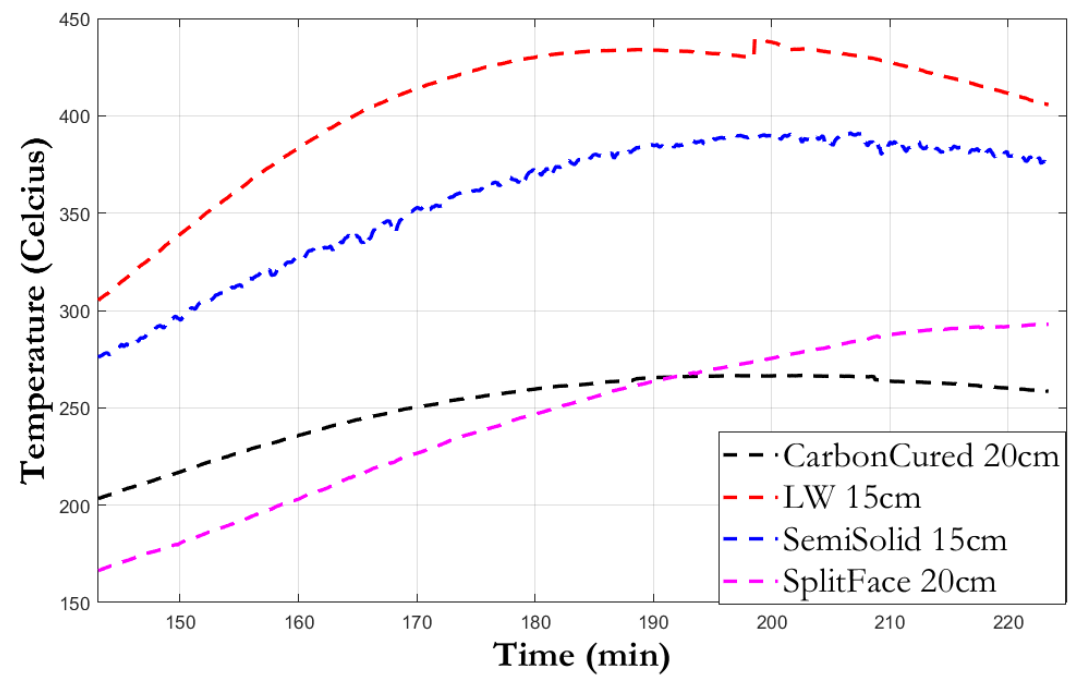

Figure 4.66: Barnsdale Test 2, Average Wall Temperatures during the cooling period

\section{Comparing Temperature at $\mathrm{H} 2$}

The temperature decrease on the fire side of the interior faceshell happened much faster than for the unexposed side of the wall (Figure 4.67). The temperatures started to decrease in the reverse order to the walls failure times, with $L W 15 \mathrm{~cm}$ beginning to cool first, followed closely by the Semi Solid, then the Carbon Cured, and finally the Split-Face began to cool much later. This is because thicker materials with higher thermal mass also take longer to dissipate heat. That explains why the $L W 15 \mathrm{~cm}$ wall cools faster than the other three walls.

\subsubsection{Thermal Imaging}

\section{Initial Phase}

The initial thermal profile of the walls are relative similar (Figure 4.69). Each of the walls are mostly uniform at their ambient temperature of between $26-30{ }^{\circ} \mathrm{C}$. It can be seen that the hollow cells are slightly hotter than the webs, and the mortar is slightly 


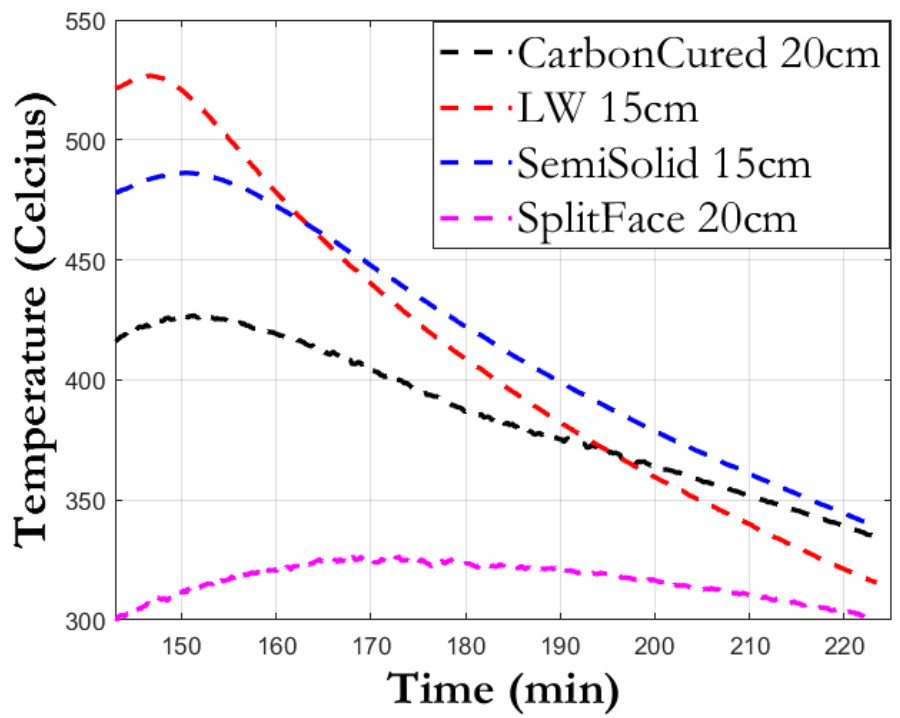

Figure 4.67: Barnsdale Test 2, Temperature at $\mathrm{H} 2$ for each of the walls during the cooling period

cooler than the blocks. For the Semi Solid wall, the bottom half of the wall is slightly warmer than the top half, as the top half is partially shaded from the sun. Similarly, the right side of the Split-Face wall and the left side of the LW15cm wall are slightly warmer as they are the sides facing the sun. 


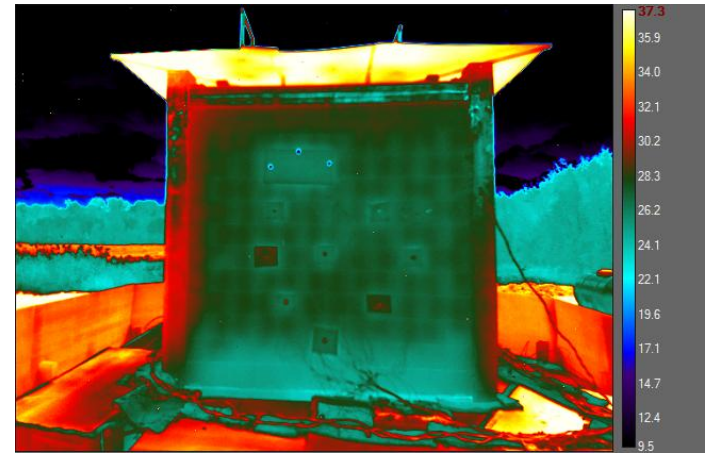

(a)

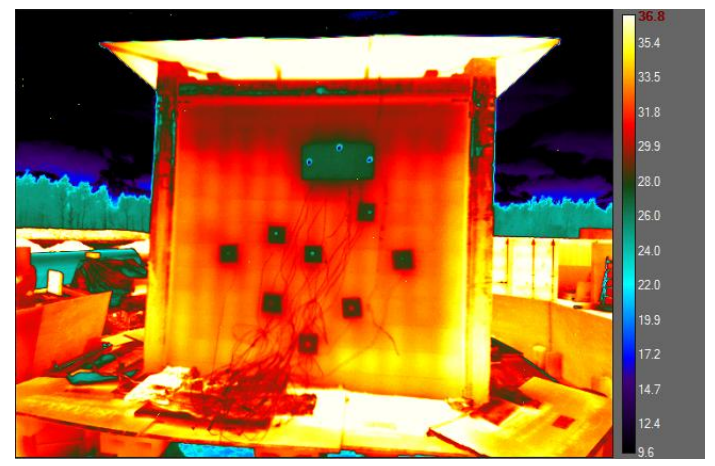

(c)

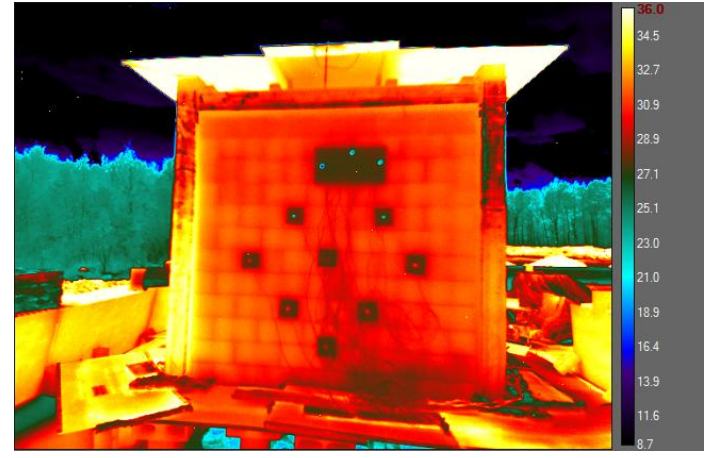

(b)

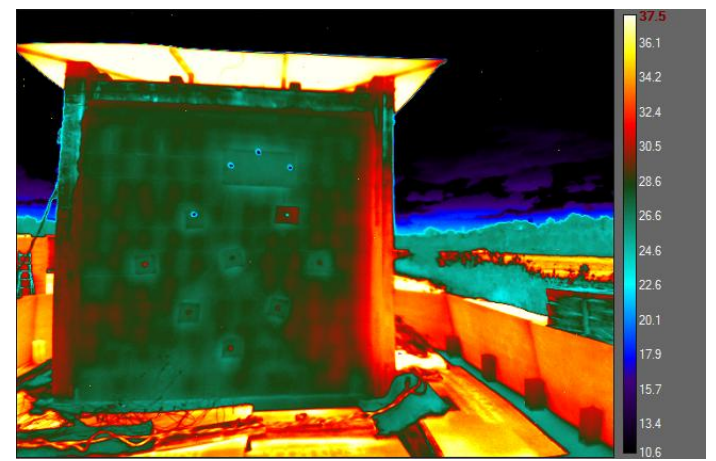

(d)

Figure 4.68: Barnsdale Test 2, Initial Thermal Images a) Carbon Cured Wall b) LW15cm Wall c) Semi Solid Wall d) Split-Face Wall 


\section{Burning Phase}

It took each of the walls some time for the surface to begin to heat up, but after roughly 15 minutes the familiar temperature profile with the columns of heat was visible for all four walls (Figure 4.69). The Split Face wall took longer to heat up, so at 15 minutes the columns of heat were less pronounced. The cooler columns are the webs, and slightly cooler lines can also be seen where the mortar is cooler than the blocks.

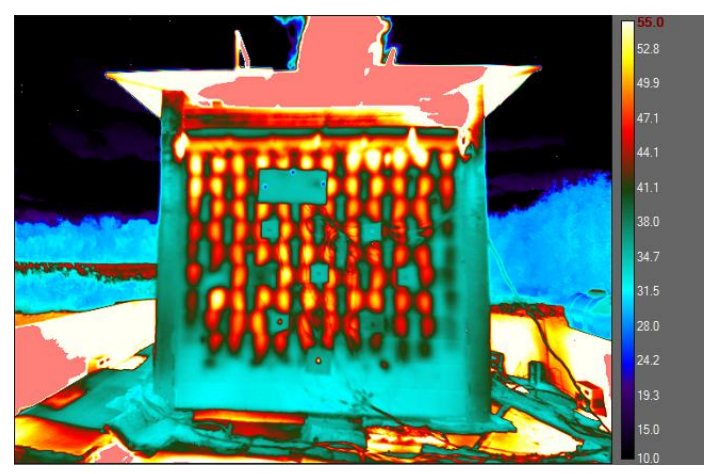

(a)

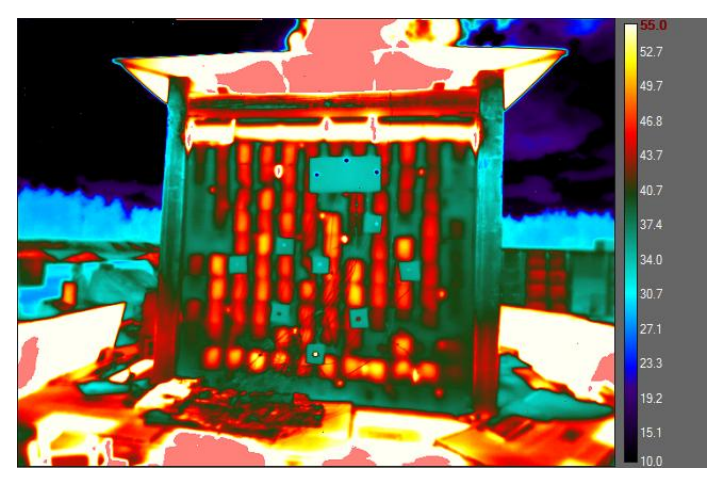

(c)

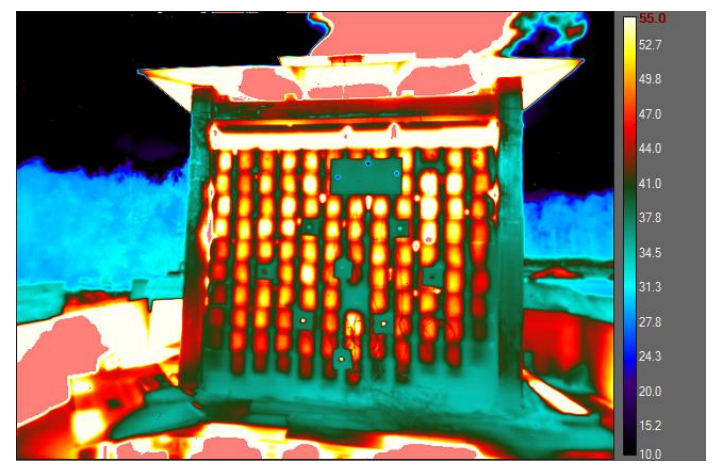

(b)

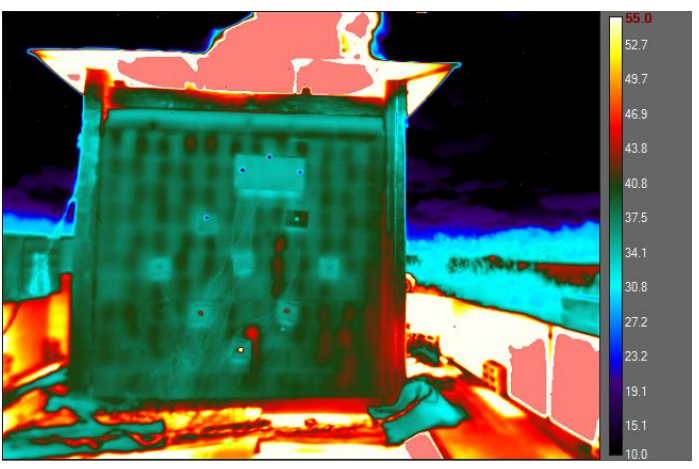

(d)

Figure 4.69: Barnsdale Test 2, Thermal Images at 15 minutes a) Carbon Cured Wall b) LW15cm Wall c) Semi Solid Wall d) Split-Face Wall

The walls each had a course of lintel units placed upside down as the top course so that the hot air would not come into contact with the steel, and so that a solid mortar joint could be placed on the surface to further protect the test structure. This is why the top course of each wall is a uniformly hot mass.

After 1 hour the columns of heat were less distinct, and some cracks began to be visible (Figure 4.70). As was mentioned previously, this test had much less thermal 
bowing, and so the amount of cracking was reduced. This is evident in the thermal images, as there are only small hot spots on the walls (mainly on the top course of the walls).

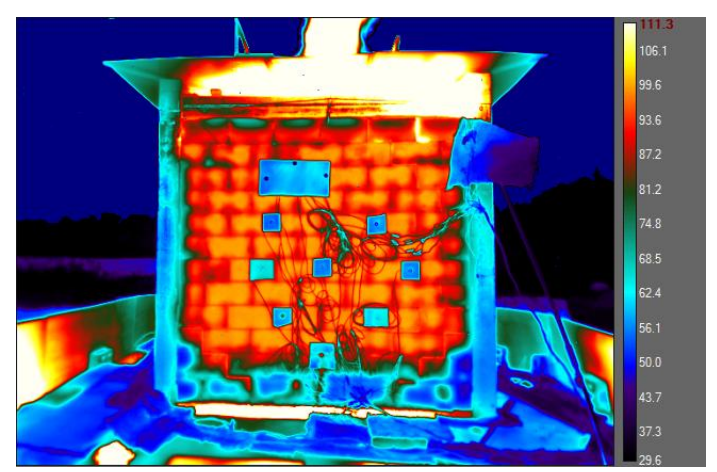

(a)

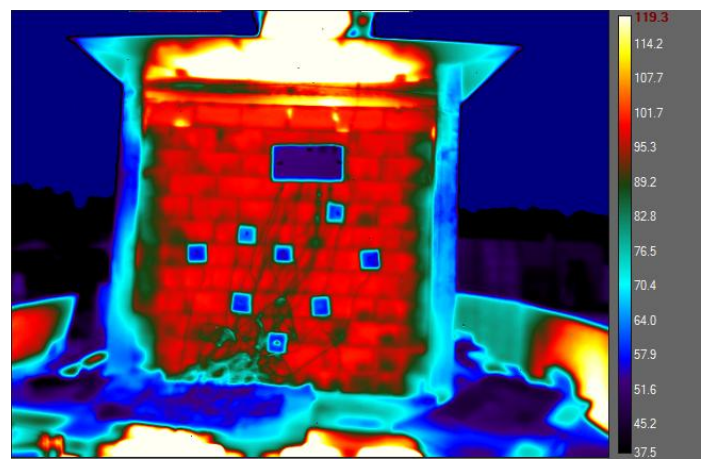

(c)

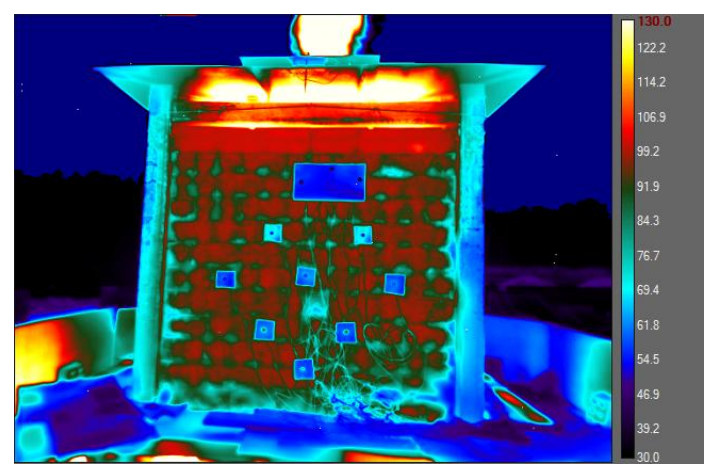

(b)

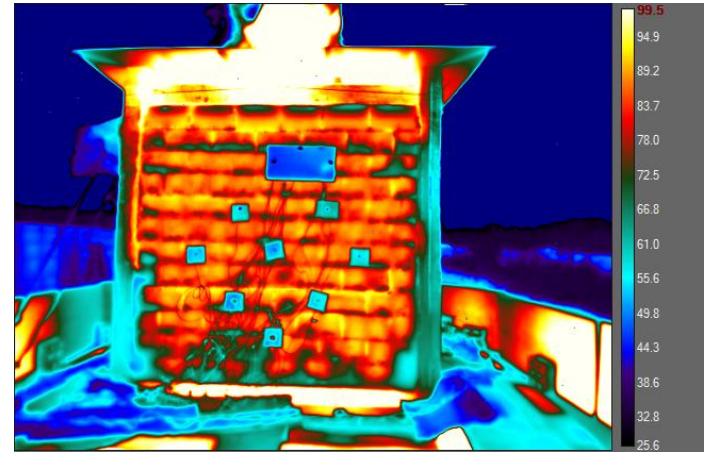

(d)

Figure 4.70: Barnsdale Test 2, Thermal Images at 1 hour a) Carbon Cured Wall b) LW15cm Wall c) Semi Solid Wall d) Split-Face Wall 
As the test ended the Carbon Cured, LW15cm, and Semi Solid walls all showed very hot average temperatures within the cells (around $160{ }^{\circ} \mathrm{C}$ ) (Figure 4.71). At this point the Split-Face wall looked still be around $110{ }^{\circ} \mathrm{C}$, with hot spots of 125 ${ }^{\circ} \mathrm{C}$ appearing in various cells. All of the temperatures measured by the thermal imaging camera are cooler than those measured by the thermocouples due to the heat convecting and radiating to ambient. Part of the reason why the Split-Face wall had a cooler surface temperature could be due to the wind, which lightly was blowing from the direction of that wall.

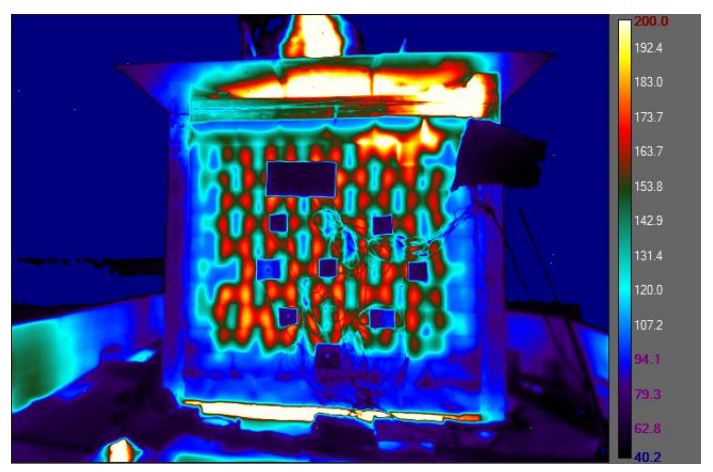

(a)

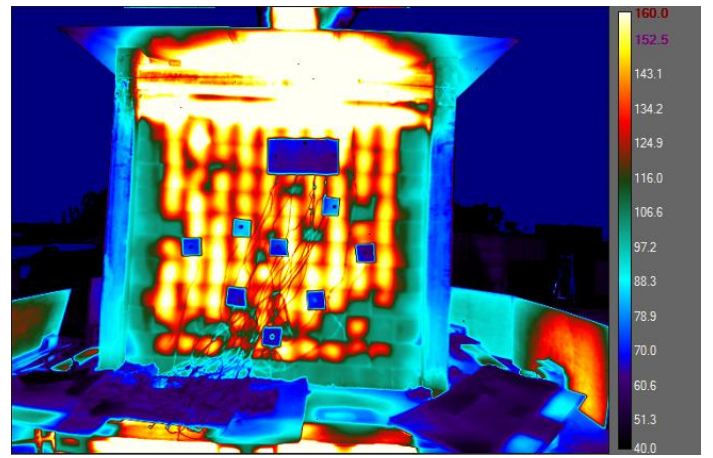

(c)

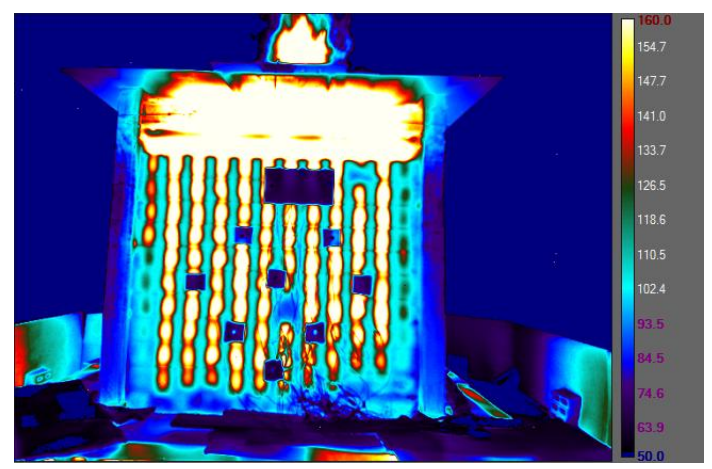

(b)

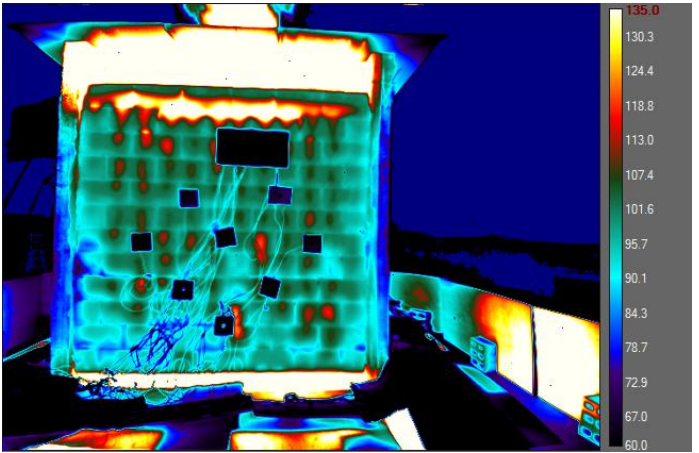

(d)

Figure 4.71: Barnsdale Test 2, Thermal Images the end of the test (140 minutes) a) Carbon Cured Wall b) LW15cm Wall c) Semi Solid Wall d) Split-Face Wall 


\section{Cooling Phase}

After 3.5h the walls stopped heating up and had began to cool down (Figure 4.72). This cooling started from the frame and worked inwards. The perimeter of the walls can be seen to be cooler, particularly the bottom. The top course of the walls still remains slightly hotter, as the warmer air still collects at the top of the walls. For the Semi Solid and Splitter walls, some irregularly cool pockets arose around where cracks had formed, which allowed some of the warm air within the cells to escape.

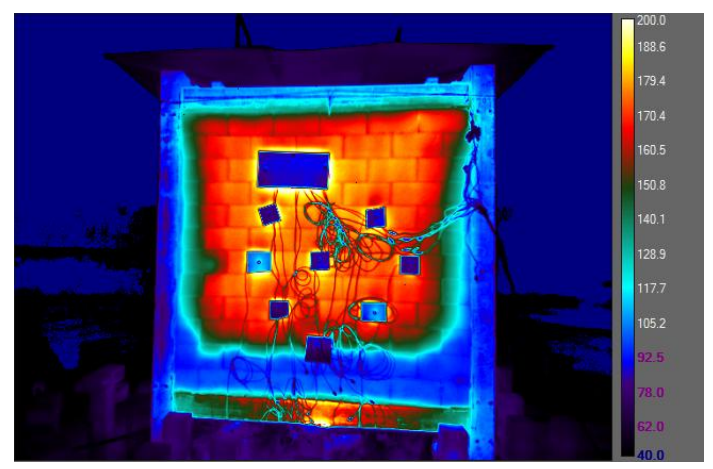

(a)

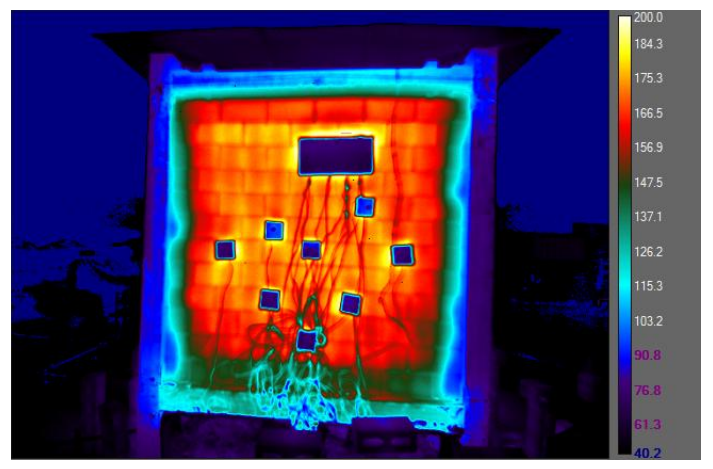

(c)

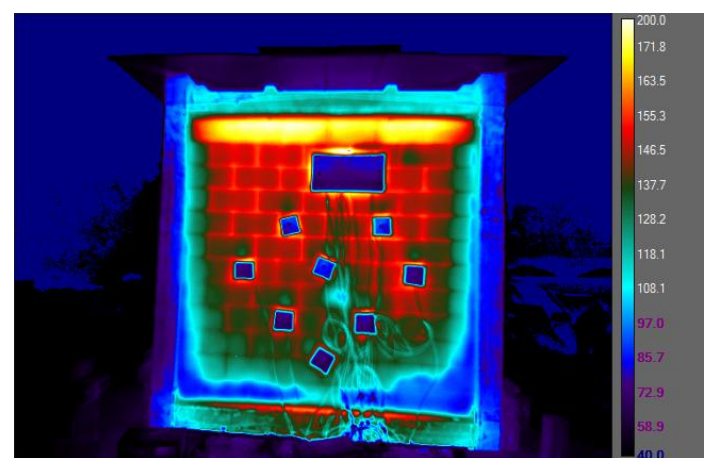

(b)

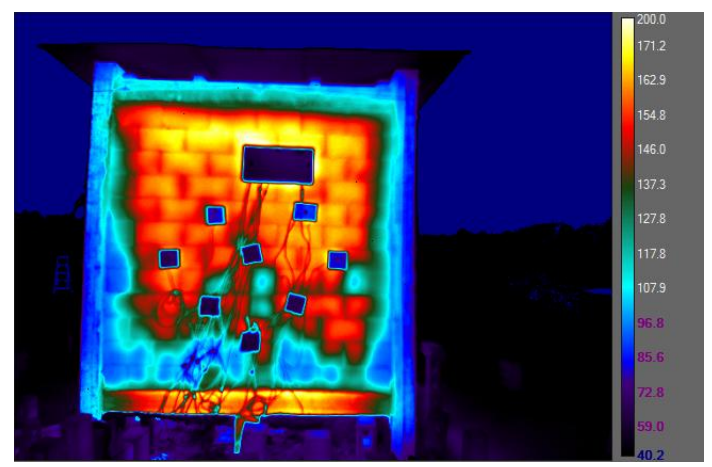

(d)

Figure 4.72: Barnsdale Test 2, Thermal Images after 3.5 hours a) Carbon Cured Wall b) LW15cm Wall c) Semi Solid Wall d) Split-Face Wall 


\subsubsection{Comments on the different blocks}

\section{Comments on the Carbon Cured}

The Carbon Cured blocks behaved similarly to the $20 \mathrm{NW}$ concrete blocks tested in Almonte. Both of them exceeded the $1.8 \mathrm{~h}$ fire resistance by several minutes, both had minimal thermal bowing and spalling. The Carbon cured block was slightly superior in terms of fire resistance, but without more testing it is not possible to definitively say it is significantly better. However, as Carbon Cured blocks are more environmentally friendly due to their ability to trap $\mathrm{CO}_{2}$, they would be a good choice to replace the standard NW concrete blocks.

\section{Comments on the $\mathrm{LW} 15 \mathrm{~cm}$}

One note for the lightweight wall was that a crack formed under one of the thermocouple pads. The failure time was due to the $180{ }^{\circ} \mathrm{C}$ failure and was 91.7 minutes. If the crack had not formed the $180^{\circ} \mathrm{C}$ failure would not occur until 107 minutes, which is would have been after the average failure at 106 minutes (this 106 minutes is the corrected average failure time without the thermocouple on the crack). This means that a single crack decreased the fire resistance of the wall by 11.1minutes. In the case of a fire resistance test the lower failure time stands. However, it is important to know that lightweight wall could have surpassed its prescribe fire resistance by even more, but it would still be well short of a 2 hour fire resistance rating.

\section{Comments on the Semi Solid}

The Semi Solid blocks were easier to lay than the $20 \mathrm{~cm}$ blocks, and they were supposed to have a higher fire resistance. While the actual fire resistance during the test was lower than expected and lower than the $20 \mathrm{~cm}$ block, this is likely due to integrity failure on the fire side of the wall which heated up the blocks faster than expected. Even with earlier failure time, the fire resistance of the Semi Solid blocks was close to the $20 \mathrm{~cm}$ blocks, which means that they could be used as an alternative if thinner walls are required.

\section{Comments on the Split-Face}

The split face wall was the only wall to have a noticeably higher fire resistance rating than prescribed equivalent thickness fire resistance rating. This is mainly because the 
equivalent thickness method does not take into account the effects of unique geometry, such as having a thicker faceshell on the fire side. One potential future test would be to see the effect of placing the thicker faceshell on the unexposed side to determine the decrease in fire resistance. 


\subsection{Barnsdale Test 3 results}

\subsubsection{Furnace temperature}

The furnace was able to closely follow the standard fire for the duration of the test (Figure 4.73). The furnace temperature slightly exceeded the standard fire at the beginning of the test and was slightly less than the standard fire temperature near the end of the test. The thermocouple readings stopped after 124 minutes and using Equation 4.1 the corrected duration of the test was 123 minutes. This would indicate that the furnace was able to closely follow the standard fire curve.

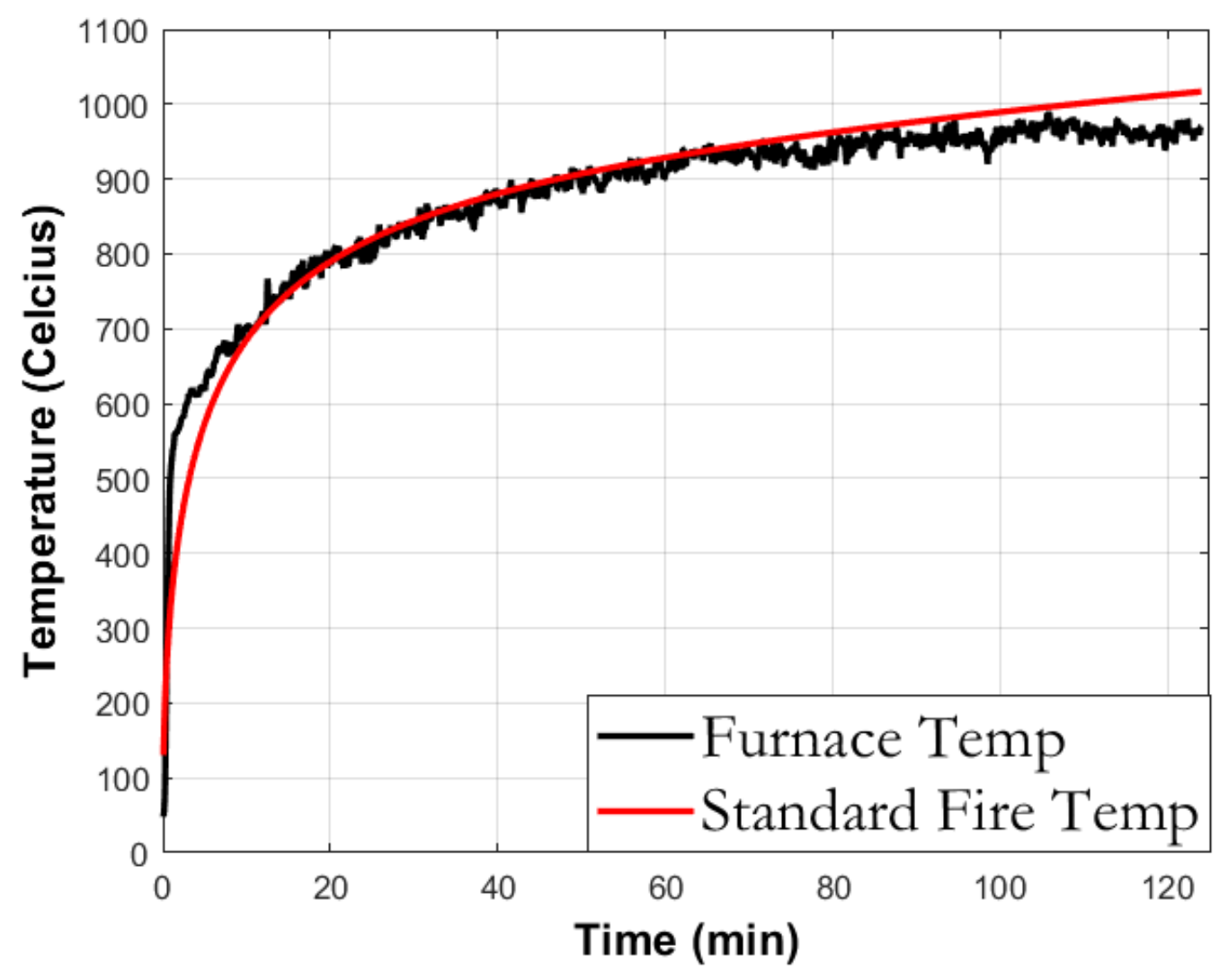

Figure 4.73: Barnsdale Test 3, Furnace Temperature during the test 


\subsubsection{Integrity failure, thermal bowing, spalling}

All of the walls underwent some thermal bowing which caused cracks to form around the perimeter of the walls. However, as with the test immediately preceding this test, the full mortar joints around the perimeter fixed the walls into place and reduced the amount of bowing that occurred.

While cracking occurred, there was no passage of hot gas or smoke, and so the integrity failure criteria did not govern the tests. As with past tests there was cracking around the corners of the walls. Unlike the past tests there were some interesting crack patterns that formed on the insulated walls. Rather than following the mortar, there were more cracks through the block itself (Figure 4.74). 


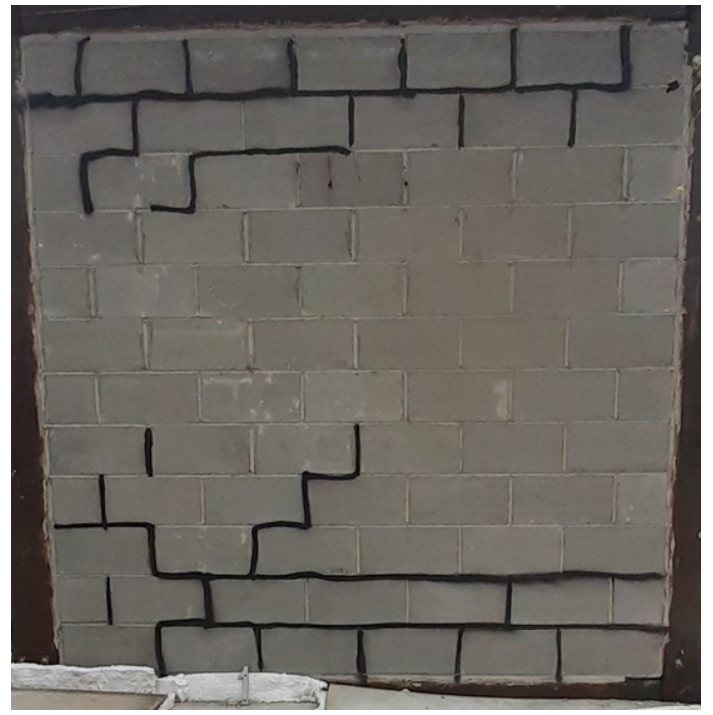

(a)

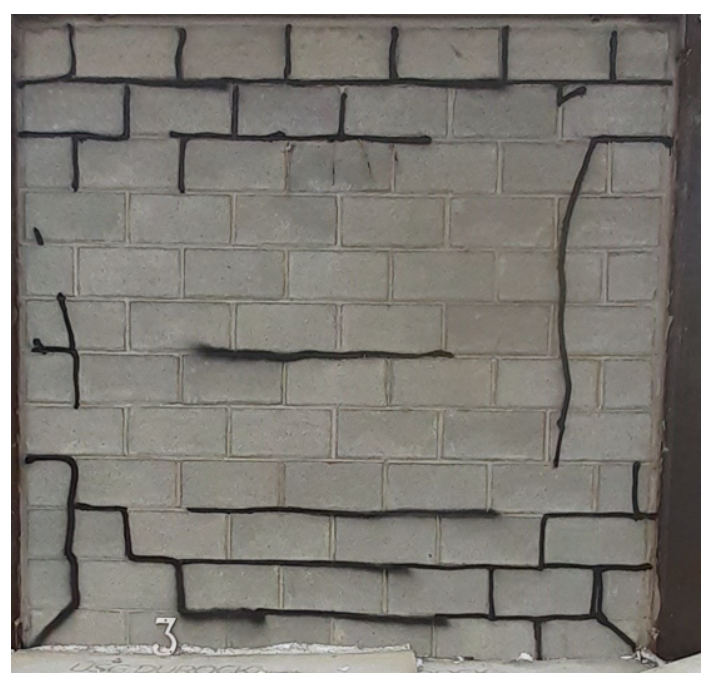

(c)

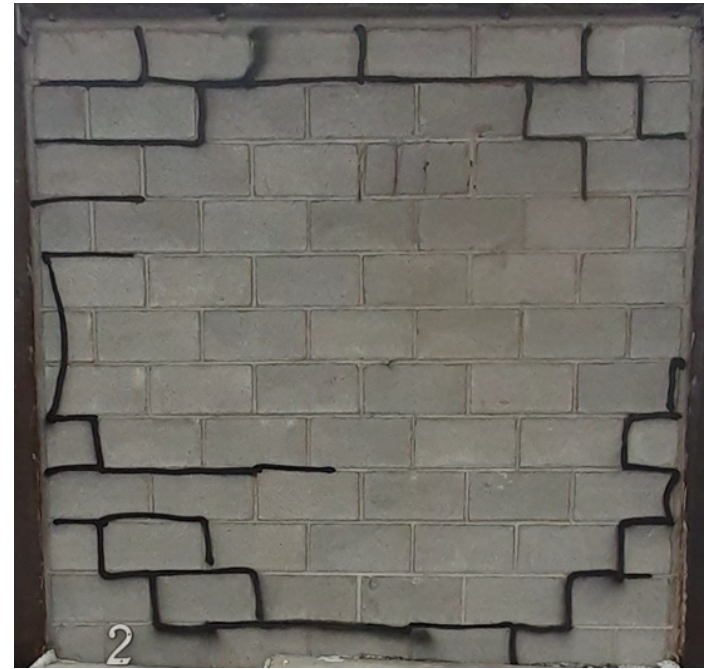

(b)

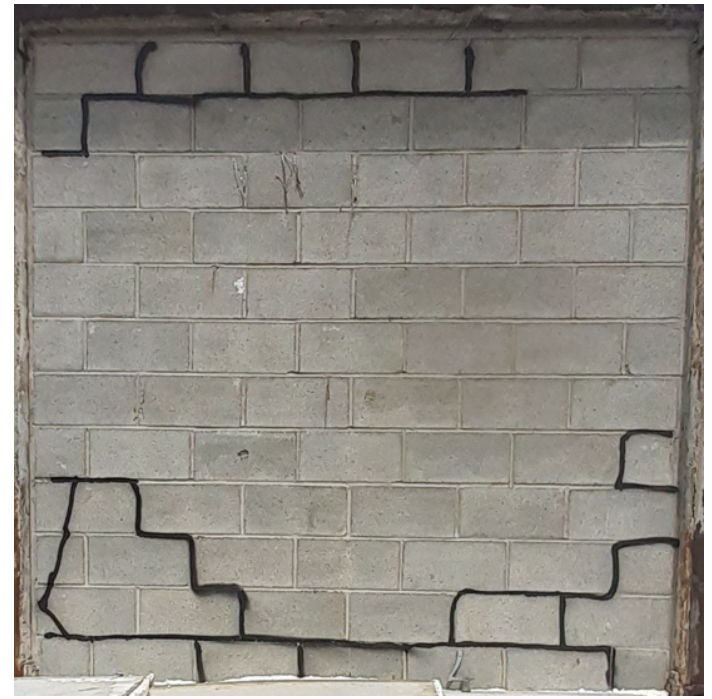

(d)

Figure 4.74: Barnsdale Test 3, Crack Patterns a) Two Hour Fire Wall b) Rockwool 1inch Wall c) Vermiculite Wall d) Rockwool Full Wall 
During the test there was no major spalling that occurred. When looking 4 days after the test it can be seen that each of the walls had significant amount of spalling (Figure 4.75). The three NW15cm walls all had identical spalling patters, with the concrete and mortar spalling off to leave a uniform rough surface. This is contrasted with the Two Hour Fire wall which had more spalling on the block face than the mortar, which is why the individually blocks are clearly visible. With the Vermiculite wall the single lightweight block that was used can be seen to be the only part of the wall that did not undergo spalling, due to the increased thermal stability of the lightweight concrete. In addition to the surface spalling, the Two-hour fire wall also underwent cracking within the wall which caused the interior faceshells to bow inward towards the furnace while the unexposed side of the wall remain relatively flat (Figure 4.76). This caused additional cracks to form at the centre of the wall's surface (Figure 4.76). 


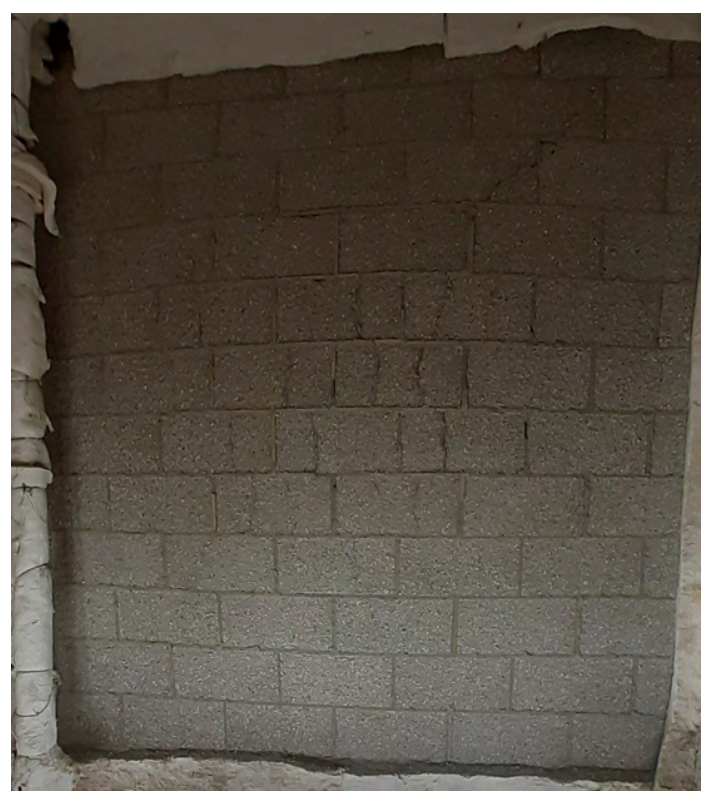

(a)

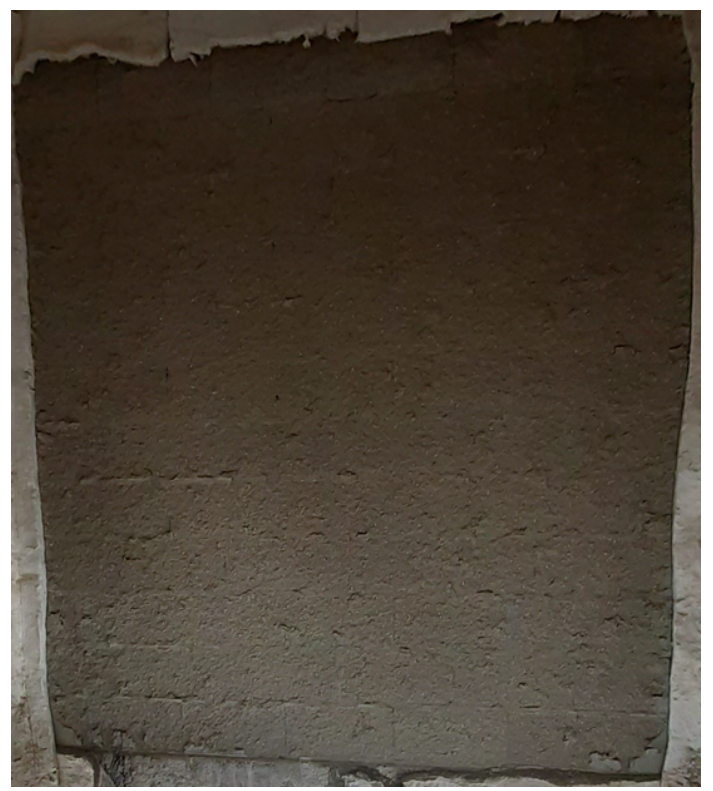

(c)

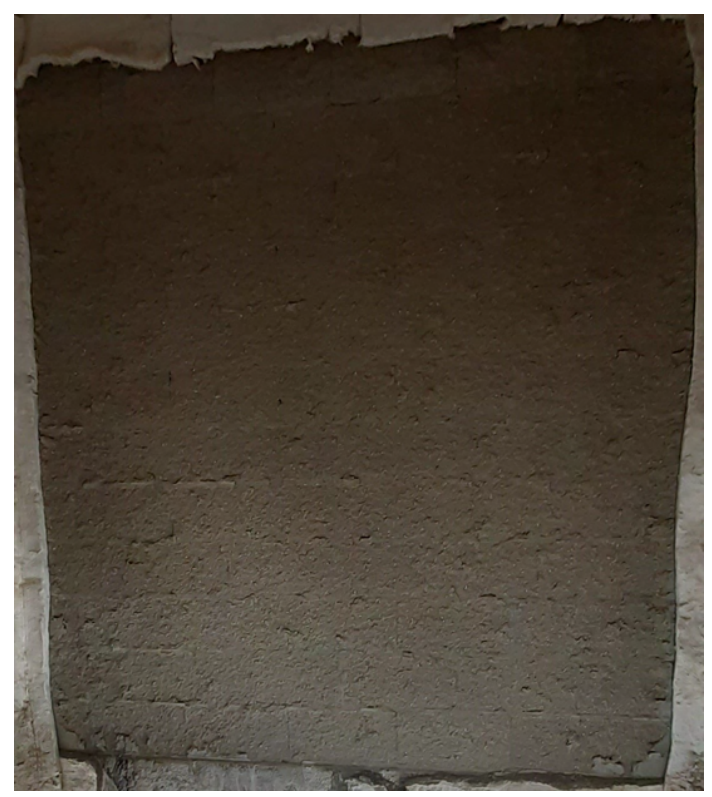

(b)

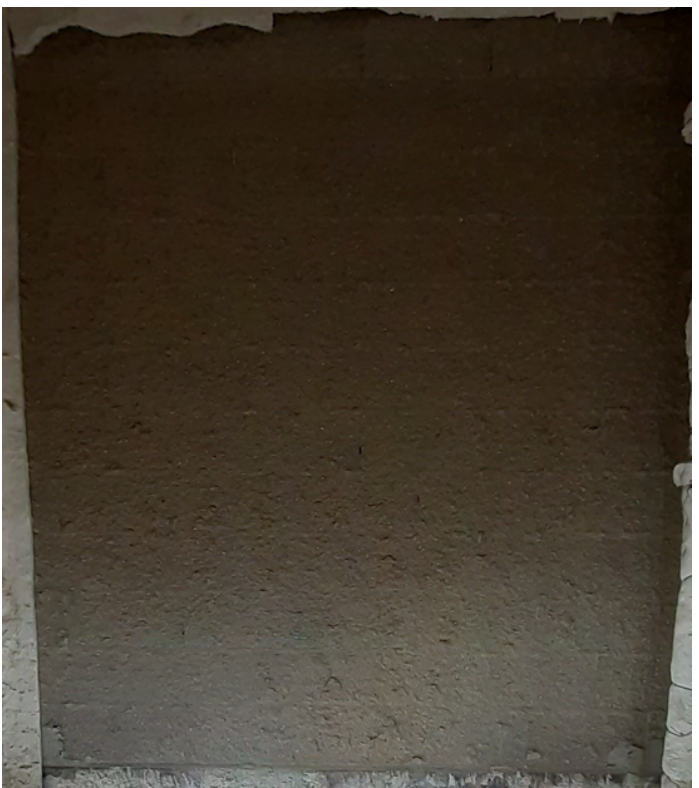

(d)

Figure 4.75: Barnsdale Test 3, Fire exposed side of the walls 4 days after the test a) Two Hour Fire Wall b) Rockwool 1inch Wall c) Vermiculite Wall d) Rockwool Full Wall 


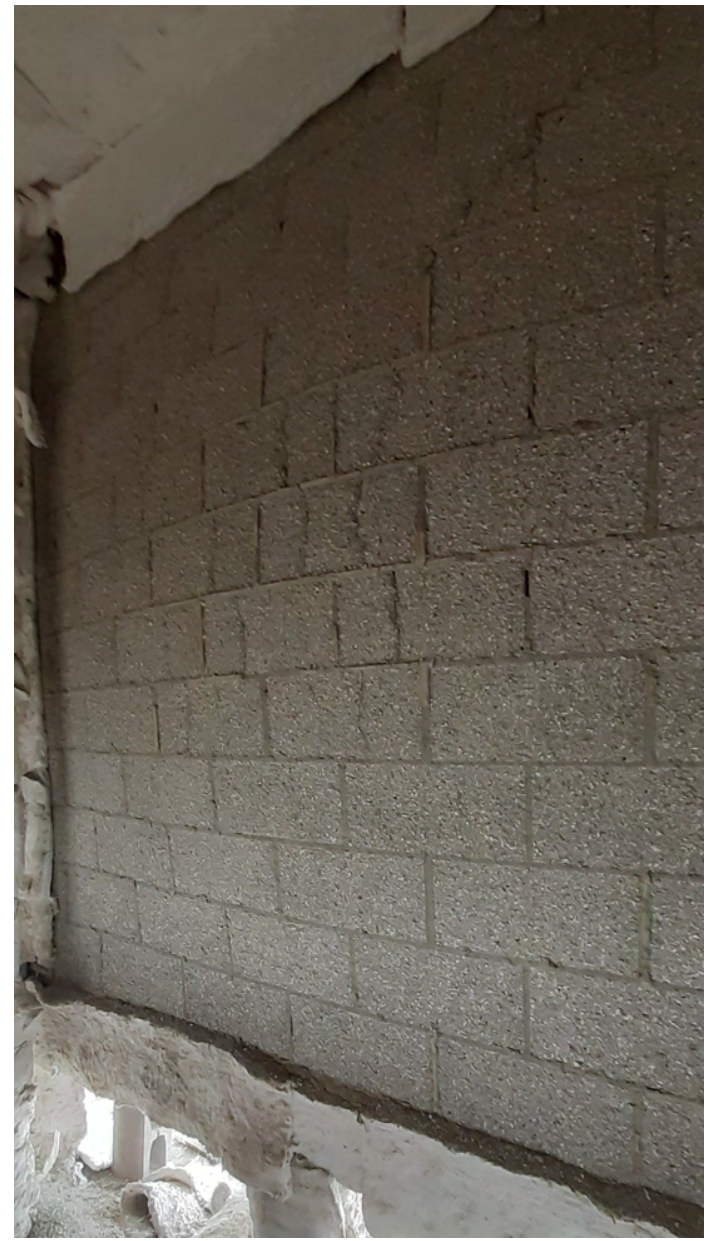

(a)

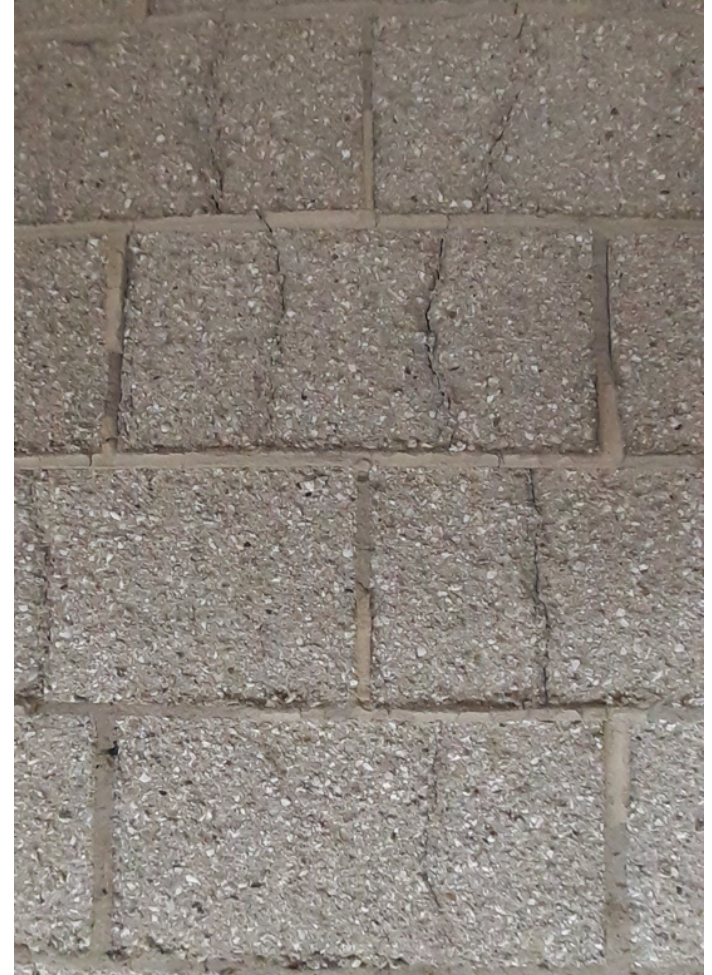

(b)

Figure 4.76: Barnsdale Test 3 Spalling of the Two Hour Fire wall a) Faceshell bowing b) Close up of the cracks at the centre of the wall 


\subsubsection{Insulation Failure Times}

Unlike with past tests, only the Two Hour Fire wall had a prescribed fire resistance (of 2 hours). While a NW15cm block is prescribed to have a fire resistance of $1.1 \mathrm{~h}$, it was expected that all three insulated blocks would exceed the 2 hour fire resistance rating.

Due to the event of rain, the test was stopped after 124 minutes, which was before all four walls could reach failure. The Two Hour Fire and the Rockwool 1inch walls were the only two to undergo insulation failure due to a maximum temperature increase of $180{ }^{\circ} \mathrm{C}$ at one point. The failure times for the Two Hour Fire and the Rockwool 1inch walls were $122.8 \mathrm{~min}$ and $124 \mathrm{~min}$ respectively. When corrected using Equation 4.1 the failure times are $121.8 \mathrm{~min}$ and $123 \mathrm{~min}$ respectively.

As only two of the walls underwent insulation failure, and as that failure was due to only a single point it is also useful to compare the average wall temperatures and maximum wall temperatures at the end of the test (Table 4.7). It can be seen that while the maximum temperature of the Two Hour Fire wall was slightly higher than the Rockwool 1inch wall, the average temperature was $11{ }^{\circ} \mathrm{C}$ lower. This would indicate that that the Two Hour Fire wall is likely better than the Rockwool 1inch wall, even though it failed slightly earlier. This would mean that to meet the $2 \mathrm{~h}$ fire resistance rating, a slightly thicker insert may be required.

Table 4.7: Barnsdale Test3 Temperatures at the end of the test

\begin{tabular}{|c|c|c|}
\hline Wall & $\begin{array}{c}\text { Average Temp } \\
\text { Increase } \\
\left({ }^{\circ} \mathbf{C}\right)\end{array}$ & $\begin{array}{c}\text { Max Temp } \\
\text { Increase } \\
\left({ }^{\circ} \mathbf{C}\right)\end{array}$ \\
\hline Two Hour Fire & 127.9 & 183.0 \\
\hline Rockwool 1inch & 138.9 & 180.0 \\
\hline Vermiculite & 103.3 & 154.8 \\
\hline Rockwool Full & 95.2 & 157.0 \\
\hline
\end{tabular}

The full insulation blocks (Vermiculite and Rockwool Full) both had similar maximum temperature increases, and Rockwool Full had an average temperature that was $8.1^{\circ} \mathrm{C}$ cooler than the Vermiculite wall. This would indicate that the rockwool wall was superior to the vermiculite. When comparing the wall temperatures to the 
Two-Hour Fire wall, both fully insulated walls were far cooler. This would indicate that fully insulating a NW15cm block can allow it to exceed the $2 \mathrm{~h}$ fire resistance rating.

\subsubsection{Average Wall Temperatures}

The average wall temperatures ranged from $25{ }^{\circ} \mathrm{C}-33{ }^{\circ} \mathrm{C}$ (Figure 4.77 ). This difference in temperature was due to the effects of the sun, which heated the Rockwool 1inch and Vermiculite walls more than the other two walls. After 10 minutes from the start of the test the unexposed side of the walls began to heat up. The three insulated walls began to heat up faster than the Two Hour Fire wall. This is likely due to the increase thermal mass of the larger block used in the Two Hour Fire wall. However, as the test continued the Two Hour Fire wall began to heat up faster than the fully insulated walls. This is due in part to the hot gasses in the cells increasing the amount of radiation and convection transferred through the Two Hour Fire block. Each of the walls underwent a plateau due to the evaporation of free water. The longest plateau was with the Rockwool Full wall, and the shortest plateau was in the Rockwool 1inch wall. At the end of the test the hottest wall was the Rockwool 1inch wall, followed by the Two Hour Fire wall, then the Vermiculite wall, and finally the Rockwool Full wall. 


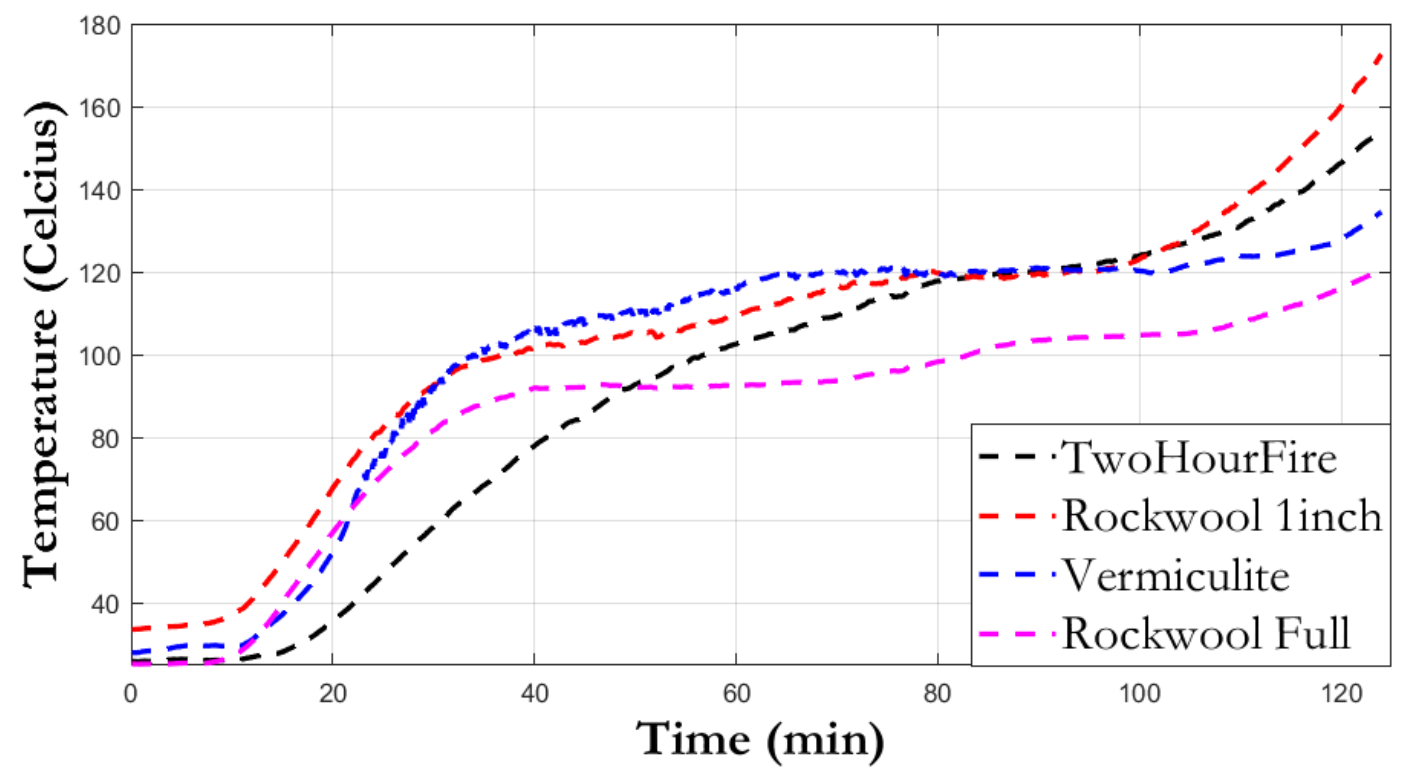

Figure 4.77: Barnsdale Test 3, Average Wall Temperatures

\subsubsection{Comparing Block Surface Locations}

\section{Unexposed Hollow Cell Comparison}

The temperatures on the surface of the hollow cell for the four walls can be found in Figure 4.78. The Two Hour Fire and Rockwool 1in both had very similar temperature profiles for the latter half of the test. The Two Hour Fire block has more thermal mass which is why it took longer to heat up at the start. The similarity in their temperature profile would seem to indicate that adding the 1inch of Rockwool did manage to reduce the heat flow through the cells so that it became comparable to the Two Hour Fire block. While the Rockwool 1inch block does not have the same thermal mass as the Two Hour Fire block, the 1inch of insulation appears to be enough to reduce the cell temperature on the fire side. As lower cell temperatures lead to less radiation and convection, it explains the why the Rockwool 1inch wall had improved fire resistance.

The unexposed hollow cell on the Vermiculite wall heated up faster than the other three walls. However, it underwent a plateau that kept it cooler than the Rockwool 1inch and Two Hour Fire wall. The Rockwool Full wall had a plateau at a much lower temperature and remained the coolest for the majority of the test (excluding 


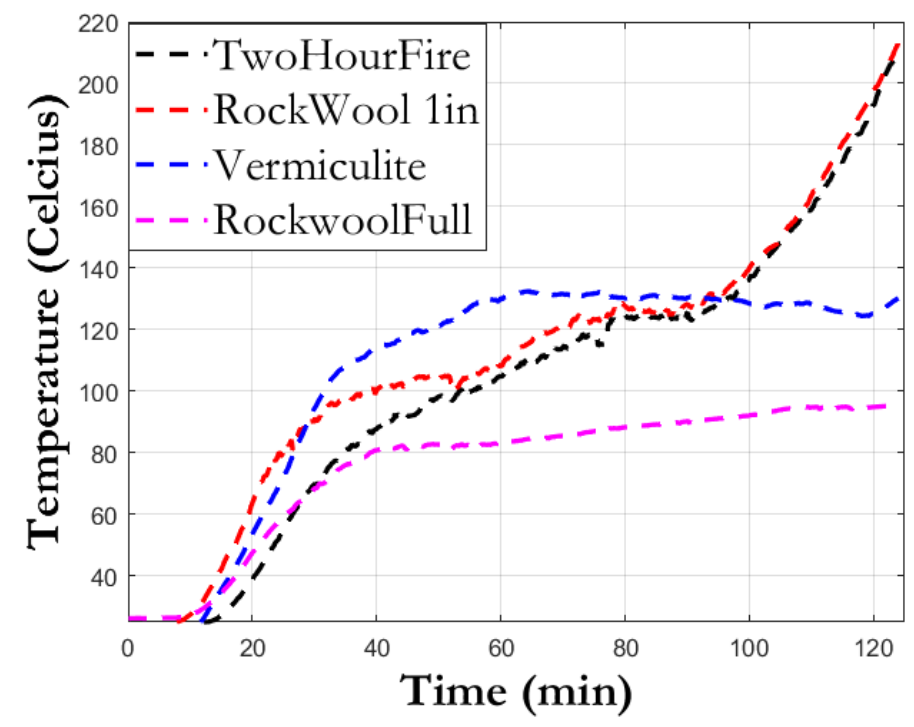

Figure 4.78: Barnsdale Test 3, Unexposed Surface Temperature of the hollow cell for each wall

the start due to the Two Hour Fire blocks higher thermal mass). As the hollow cells are normally the locations for the $180{ }^{\circ} \mathrm{C}$ increase insulation failure, the fully insulated walls reduce the likelihood of that failure occurring within the hollow cells. The fully insulated blocks also reduced the vertical heat flow through the cells, which contributed to the lower temperatures on the unexposed side of the cells at the top of the wall.

\section{Unexposed side of the solid webs comparison}

The temperatures on the unexposed side of the webs can be found in Figure 4.79. Similar to the hollow cell, the Two Hour Fire block took longer to heat up at the start. However, after a short plateau it continued to heat up. While there were no changes to the webs themselves for the insulated blocks, the reason the webs remained cooler is due in part to the reduced radiation within the cells. While a lot of the focus is on reducing the radiation and convection through the cells from the unexposed side to the exposed side, there is also heat being transferred laterally to the webs. By adding insulation material within the cells, the webs remain cooler for the same reason that the unexposed side of the hollow cell remained cooler. 


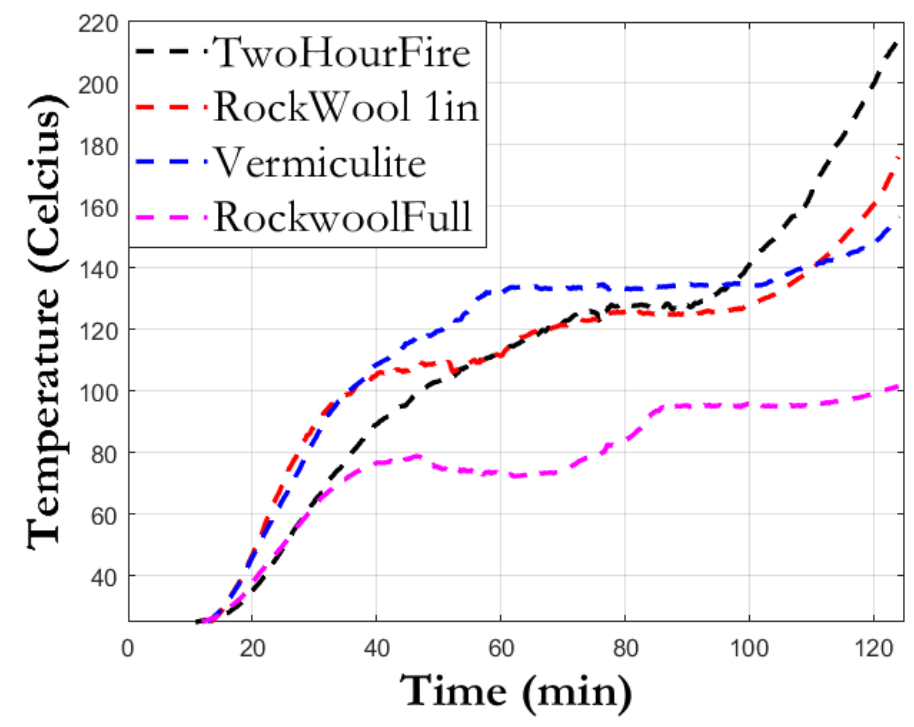

Figure 4.79: Barnsdale Test 3, Unexposed Surface Temperature of the solid webs for each wall

\section{Unexposed side of the mortar comparison}

The temperature on the unexposed side of the mortar can be found in Figure 4.80. The Vermiculite wall increased in temperature quickly, but underwent a long plateau, the other three walls increased in temperature at a slower pace, and the Two Hour Fire and Rockwool 1inch became very close to the Vermiculite mortar temperature. The reduced heat transfer in the cells also reduce temperatures in the webs, which in turn reduces the mortar temperatures. However, the effect of the temperature reduction is less prominent within the mortar. As was seen in previous tests, the mortar temperature is generally lower than the web and hollow cell temperatures, which means it does not usually contribute to the $180{ }^{\circ} \mathrm{C}$ failure. However, it is possible that with longer fire tests integrity failure at the block and mortar interface might become more likely, which could cause cracks to form which in turn will heat up the mortar. 


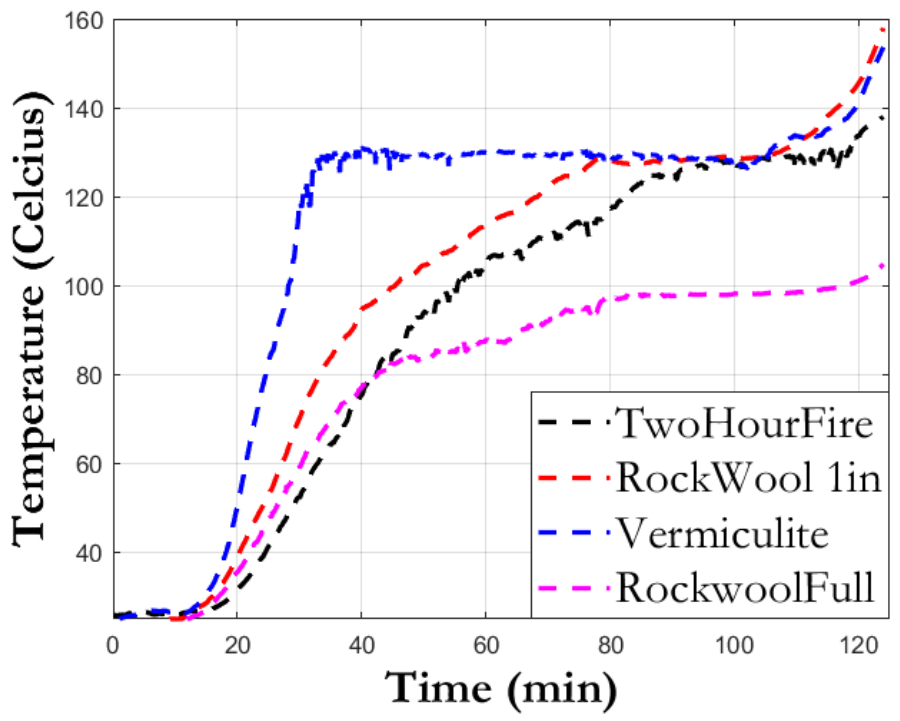

Figure 4.80: Barnsdale Test 3, Unexposed Surface Temperature of the mortar for each wall

\subsubsection{Comparing the Rockwool Insulated Walls Unexposed surface locations within the Rockwool Walls}

The temperature profiles of the different unexposed surface locations for the Rockwool 1inch and Rockwool Full can be found in Figure 4.81. For the Rockwool 1inch the temperature profiles are similar to regular blocks, with the hollow cell being the hottest, the webs being the cooler, and the mortar being the coolest part of the wall. However, unlike regular blocks, the temperature differences between the three locations are much closer due to the reduced cavity radiation.

With the Rockwool Full wall, the pattern is different than usual. The hollow cells and solid webs are both very close in temperature throughout the test. In this case the mortar is actually slightly hotter than the other two parts of the wall. This is due to the insulation reducing the heat transfer through the hollow cells and causing a more uniform surface temperature. Reducing the heat flow improves the fire resistance and having a uniform surface temperature reduces the likelihood that the $180{ }^{\circ} \mathrm{C}$ insulation failure will occur much sooner than the average $140{ }^{\circ} \mathrm{C}$ wall failure temperature. 


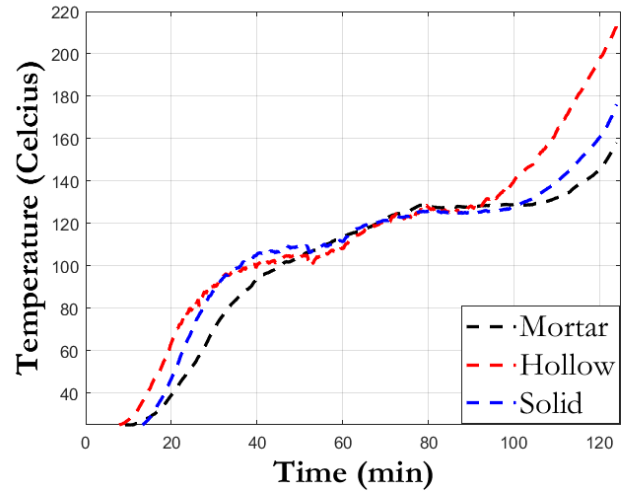

(a)

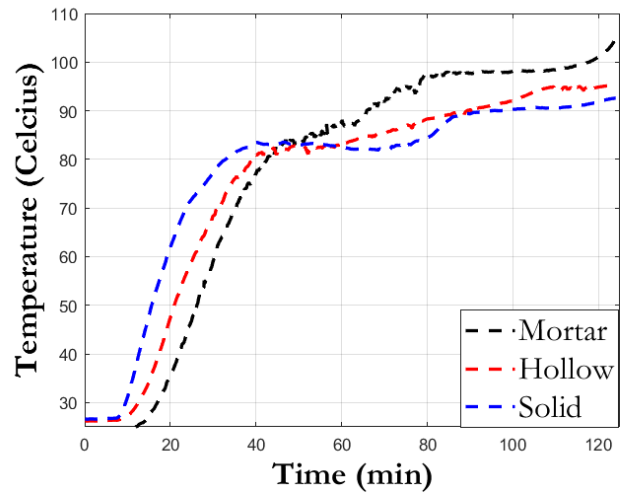

(b)

Figure 4.81: Barnsdale Test 3, Surface Temperatures at different block locations for the a) Rockwool 1inch Wall b) Rockwool Full Wall

\section{Unexposed surface locations within the Rockwool Walls}

The temperature profile of the hollow cells of the Rockwool walls can be found in Figure 4.82. For almost all of the locations through the hollow cell the Rockwool Full was found to be better as expected. In each of the locations within the cells a plateau at $100{ }^{\circ} \mathrm{C}$ can be seen due to the evaporation of water. The Rockwool Full wall had a larger plateau in all cases. This is due in part to the extra material within the cells, but it is also partially due to the full rockwool insulation limiting the vertical heat flow within the cells. The steam within the cells was unable to travel vertically through the hollow cells, and therefore was forced out through the block.

\subsubsection{Thermal imaging}

At the start of the test the Rockwool 1inch and Vermiculite walls were hotter than the Rockwool Full and Two Hour Fire walls due to the sun. After 15 minutes the Rockwool Full and Two Hour Fire walls were still close to ambient and quite uniform, whereas the Vermiculite and Rockwool 1inch walls had begun to heat up from the bottom of the walls first (Figure 4.83). 


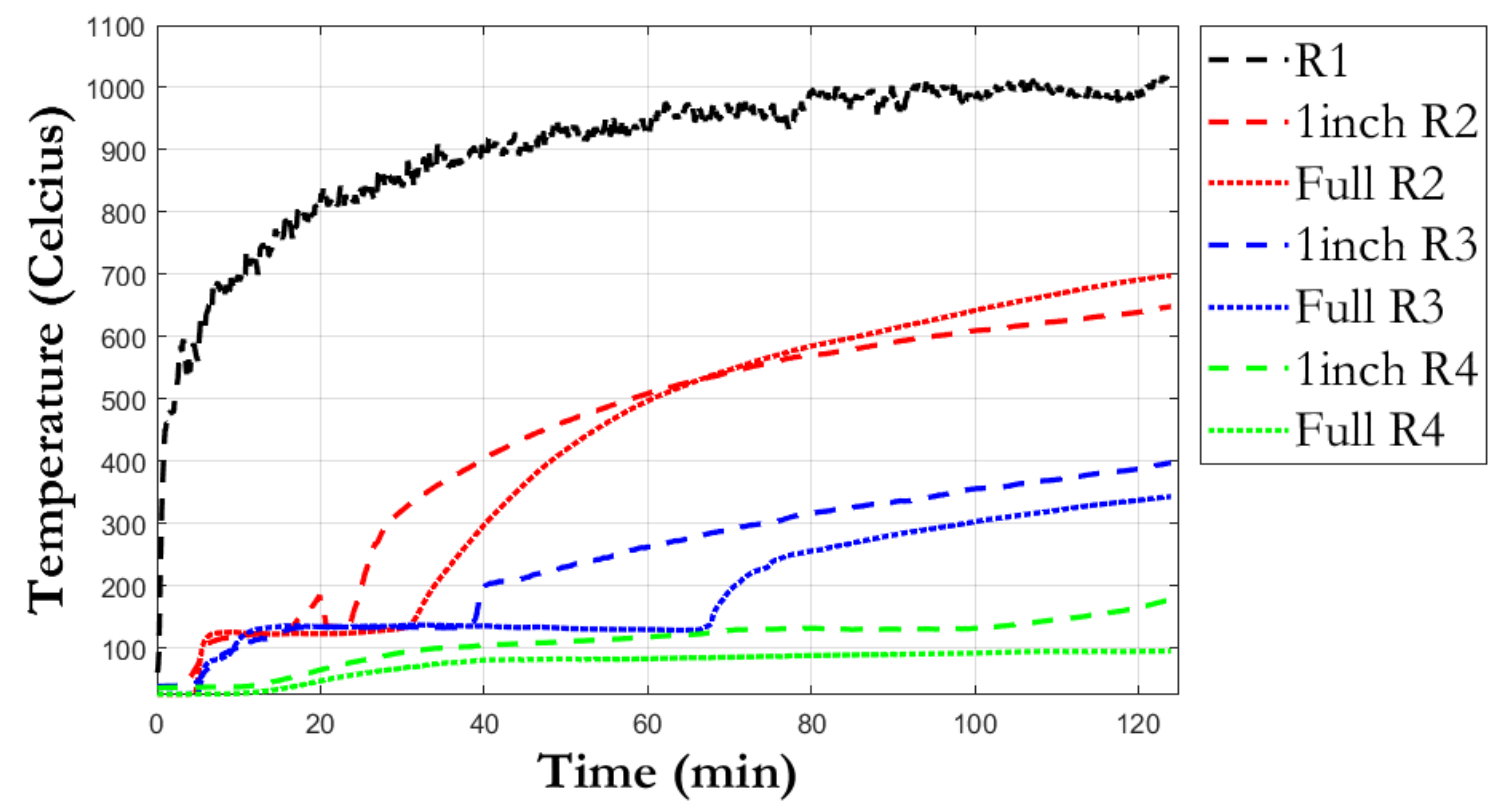

Figure 4.82: Barnsdale Test 3, Temperatures through the hollow cell on the Rockwool walls 


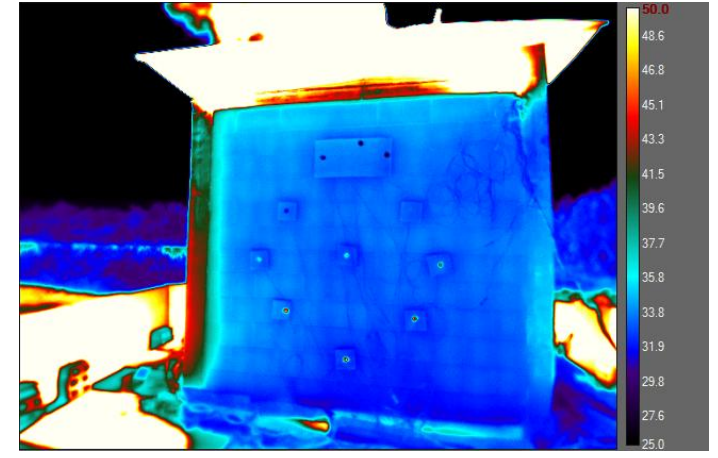

(a)

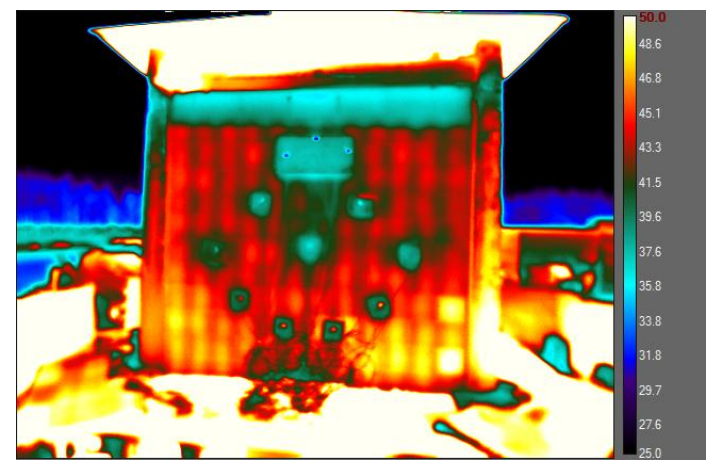

(c)

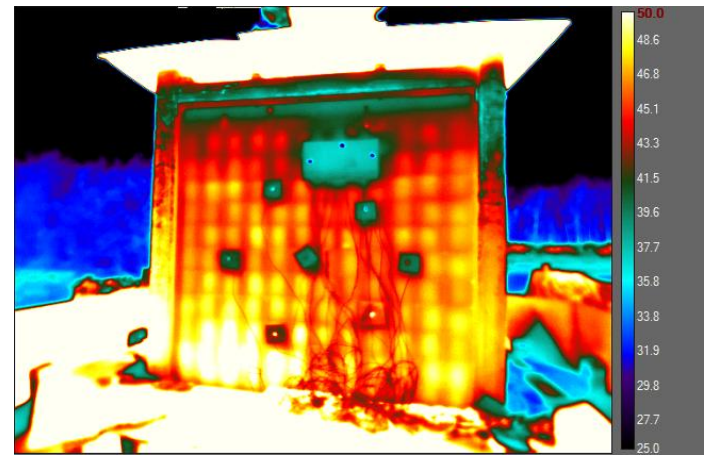

(b)

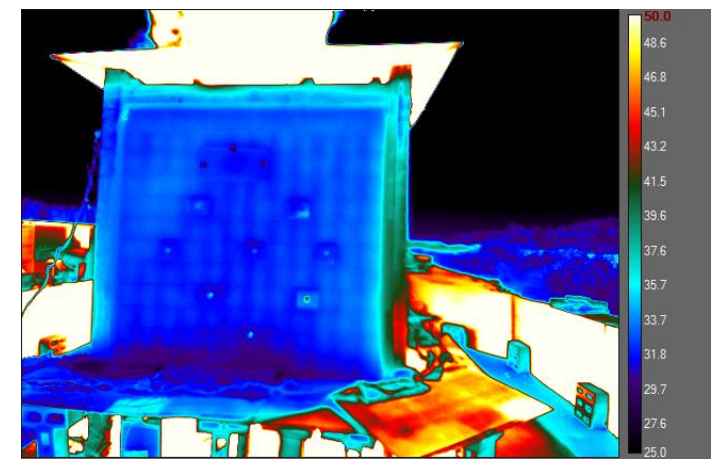

(d)

Figure 4.83: Barnsdale Test 3, Thermal Images at 15 minutes a) Two Hour Fire Wall b) Rockwool 1inch Wall c) Vermiculite Wall d) Rockwool Full Wall 
After 25 minutes cracks have begun to form in the head joints of the top course of wall, likely due to the effect of the steel beam (Figure 4.84). The cells within the Two Hour Fire and Rockwool full walls can be seen to start heating up. The vermiculite and Rockwool 1inch walls have cells that are much hotter.

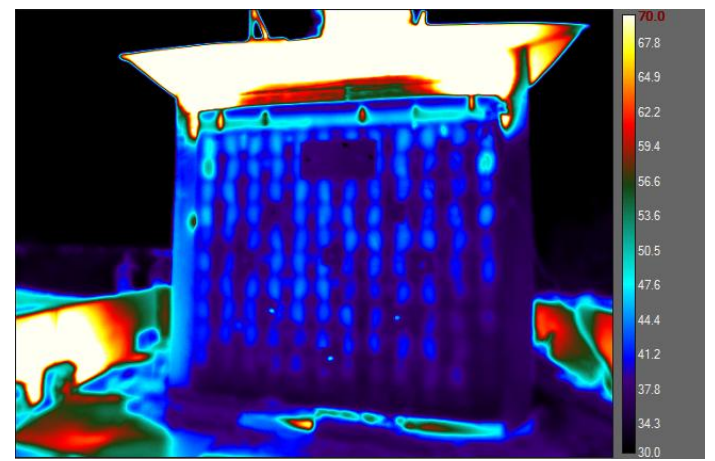

(a)

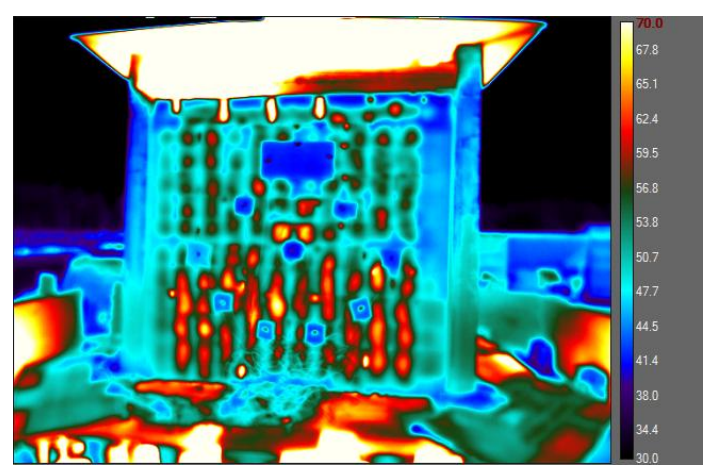

(c)

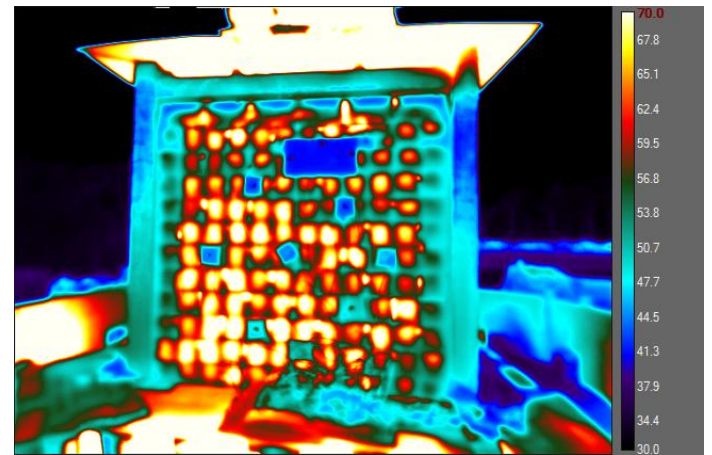

(b)

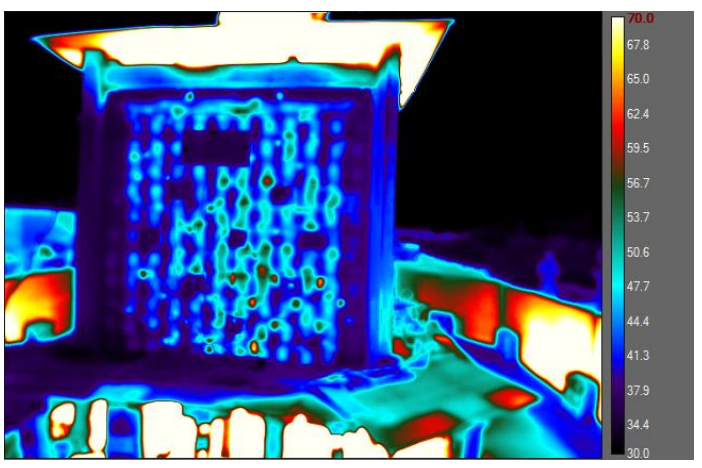

(d)

Figure 4.84: Barnsdale Test 3, Thermal Images at 25 minutes a) Two Hour Fire Wall b) Rockwool 1inch Wall c) Vermiculite Wall d) Rockwool Full Wall 
After 1 hour the cells in the Two Hour Fire wall and the Rockwool Full wall continued to heat up faster than the webs and the mortar (Figure 4.85). The Rockwool 1inch and Vermiculite walls both have more uniform temperature profiles within the blocks, with the mortar remaining cooler than the blocks. At the centre of the Vermiculite wall three cells began to heat up faster than the rest of the wall. This is likely due to a crack forming on the exposed surface, which in turn heated up the affected cells.

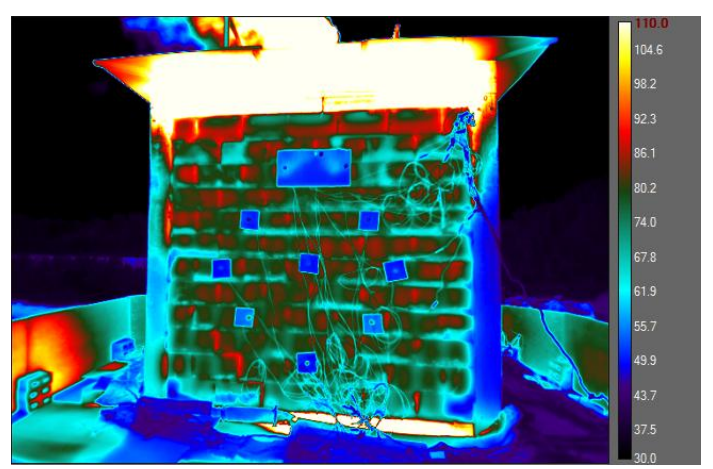

(a)

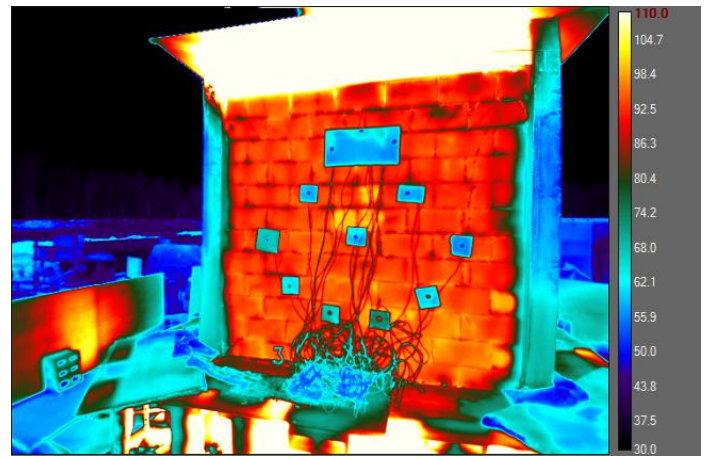

(c)

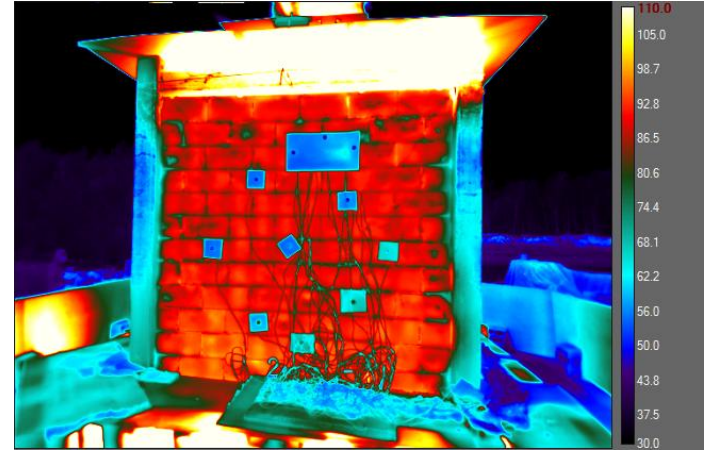

(b)

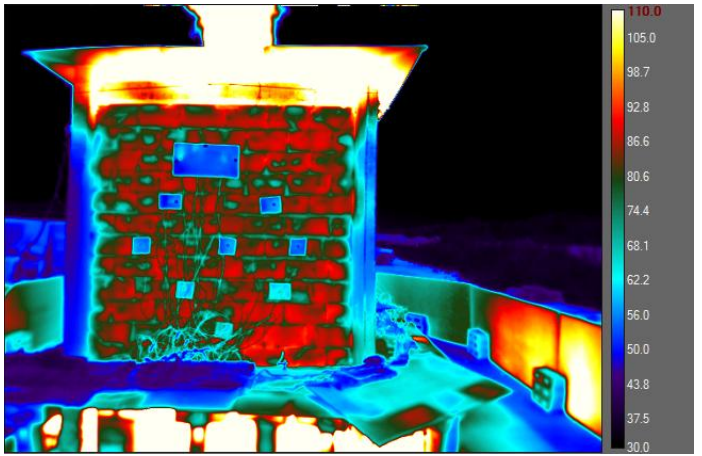

(d)

Figure 4.85: Barnsdale Test 3, Thermal Images at 1 hour a) Two Hour Fire Wall b) Rockwool 1inch Wall c) Vermiculite Wall d) Rockwool Full Wall 
After 90 minutes the Two Hour Fire wall can be seen to have the hollow cells as the hottest points, with the mortar the coldest, as is consistent with the past hollow walls (Figure 4.86). The Rockwool 1inch wall had a different temperature profile, with some areas having the cells as the hottest part of the block, and other having the webs as the hottest part of the block. This would seem to indicate that the 1inch rockwool insulation improves the hollow cells so that they are on par with the webs. The Vermiculite wall had the hollow cells remain the coolest parts of the block, and the webs were the hottest part of the block. This would indicate that the vermiculite insulation improves the hollow cells beyond the solid webs. The Rockwool full wall had the hollow cells as the coolest part of the wall, including the mortar which is normally the coldest part of the wall. The hot spots on the Rockwool full wall are found around the webs and the mortar joints.

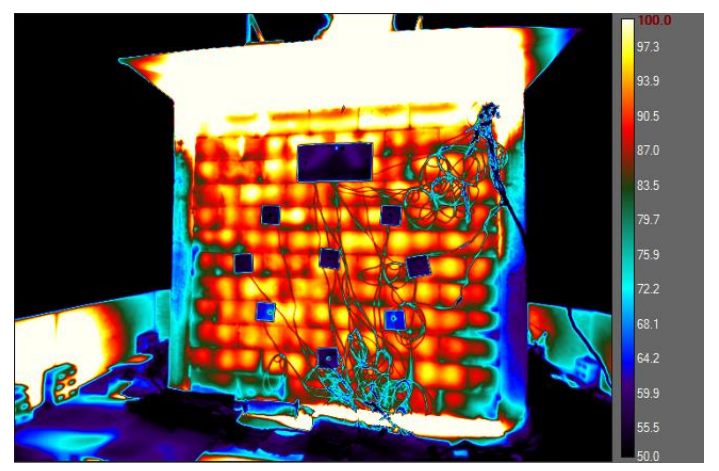

(a)

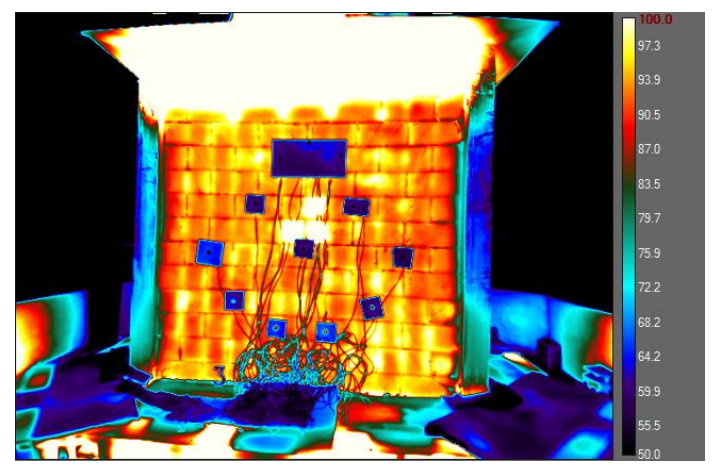

(c)

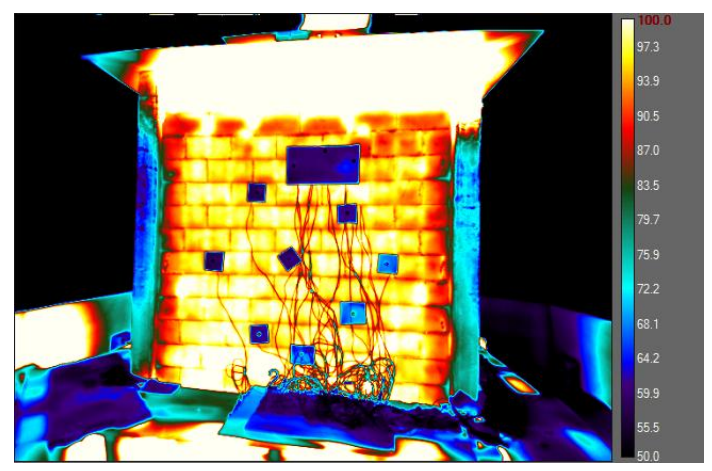

(b)

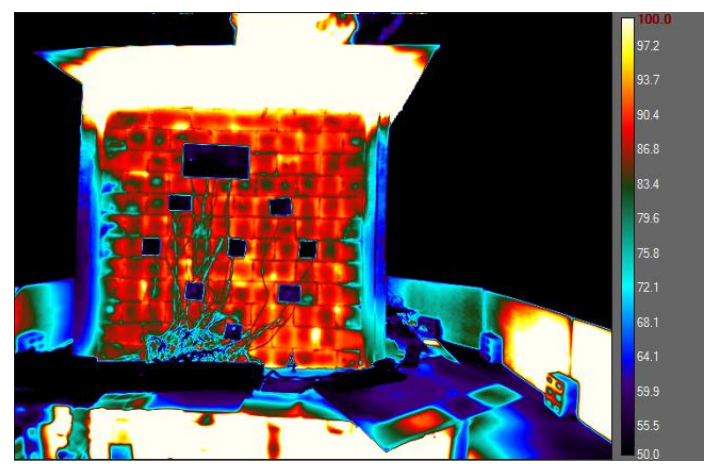

(d)

Figure 4.86: Barnsdale Test 3, Thermal Images at 90 minutes a) Two Hour Fire Wall b) Rockwool 1inch Wall c) Vermiculite Wall d) Rockwool Full Wall 
One hour after the end of the test (3h from the start of the test) the wall temperature profiles were different for the insulated and uninsulated walls (Figure 4.87). The Two Hour Fire wall had the cells at the top of the wall as the hottest part, since the hot air was allowed to rise up and collect at the top of the wall. The insulated walls all had cooler cells, with the hot areas being the webs in between the cells.

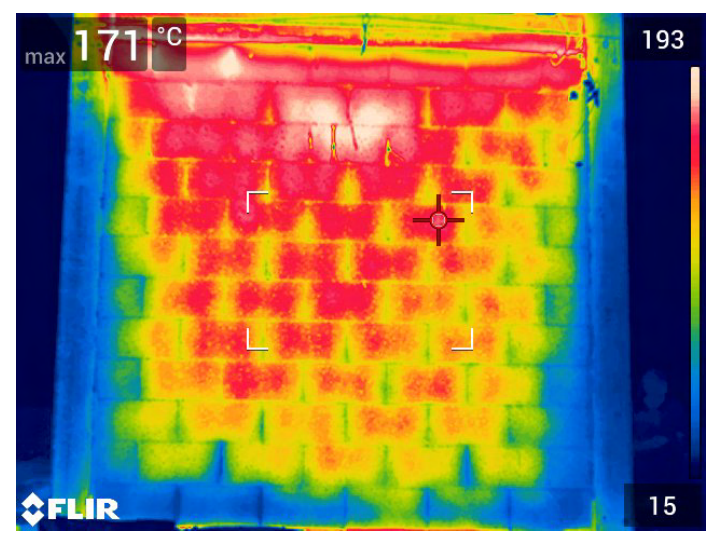

(a)

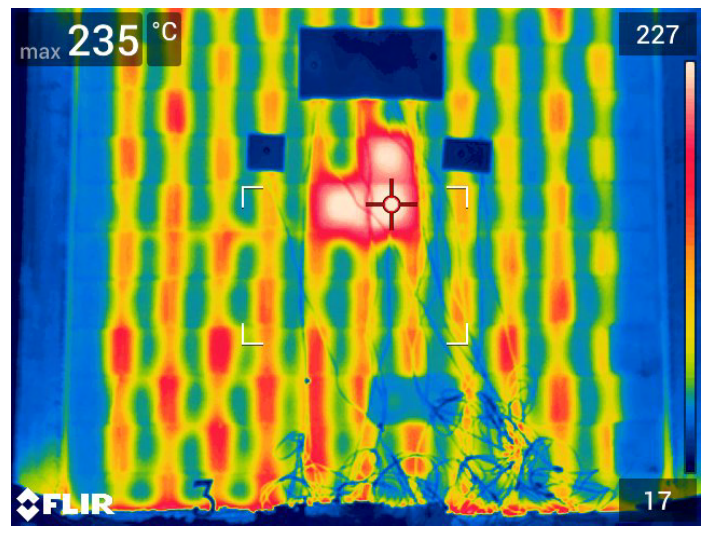

(c)

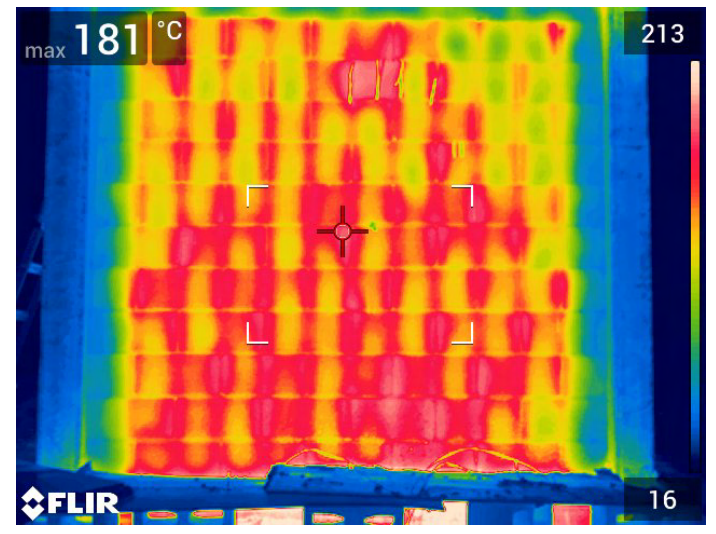

(b)

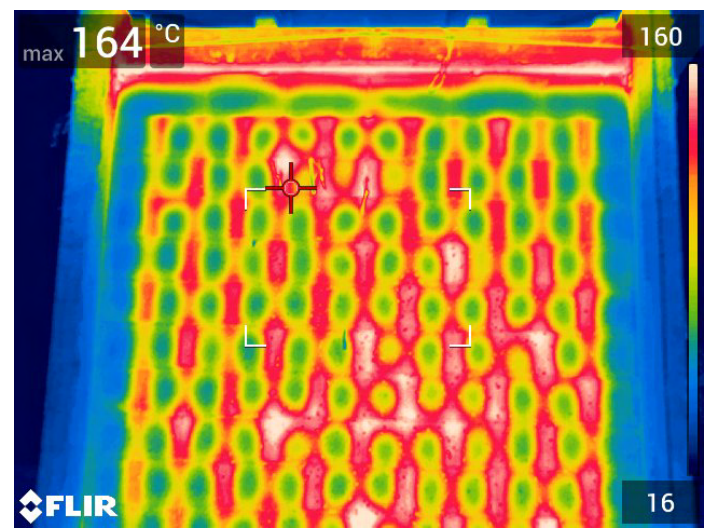

(d)

Figure 4.87: Barnsdale Test 3, Thermal Images at 3h a) Two Hour Fire Wall b) Rockwool 1inch Wall c) Vermiculite Wall d) Rockwool Full Wall 


\subsubsection{Barnsdale Test 3 comments on the different types of blocks}

\section{Two hour Fire}

The two hour Fire wall did surpass the 2 hour fire rating before failure, but this was also done by the standard $20 \mathrm{~cm}$ blocks. The major difference between this block and the standard $20 \mathrm{~cm}$ blocks was that the average temperature of the wall was much lower. In most of the past tests the $180{ }^{\circ} \mathrm{C}$ single point temperature increase failure occurred close to the $140{ }^{\circ} \mathrm{C}$ average temperature increase failure. In the case of this test the average temperature was still $15{ }^{\circ} \mathrm{C}$ below the failure temperature when the single point failure occurred. This would seem to indicate that this wall has improved fire resistance when compared to the standard $20 \mathrm{~cm}$ units.

\section{Rockwool 1inch}

While the Rockwool 1inch wall did fail after the Two Hour Fire wall, the average temperature of the Rockwool 1inch wall was higher than the average temperature of the Two Hour Fire wall. This would seem to indicate that a slightly thicker amount of rockwool may be required to truly meet the $2 \mathrm{~h}$ fire resistance. Having the insulation on the fire side produces the better fire resistance than if it is placed on the unexposed side of the cell, and so it is possible that a fire from the opposite direction could have failed the wall sooner. Having a thicker insert (either 1.5inch or 2 inches) should improve the fire resistance enough to confidently reach a 2 hour fire resistance.

\section{Rockwool Full}

The full rockwool insulation far surpassed the Two Hour Fire wall. This would clearly indicate that it can improve a NW15cm block to exceed a $2 \mathrm{~h}$ fire resistance. The difference in workability between the full insulation and 1inch insulation was minor, and so the only reason not to opt for the full cavity insulation would be related to cost. Also, as the block itself was found to be cooler than the mortar, using a more fire-resistant mortar would be beneficial since the mortar will likely be the cause of the $180{ }^{\circ} \mathrm{C}$ insulation failure. With both of the rockwool walls the next step would be developing a way of inserting the rockwool into the cells during manufacturing, as inserting the rockwool by hand is time consuming. 


\section{Vermiculite}

While vermiculite was not as good as the full rockwool insulation, the vermiculite still surpassed the Two Hour Fire wall. This shows that vermiculite is capable of improving a NW15cm block to reach a fire resistance of $2 \mathrm{~h}$. One of the issues with vermiculite is the installation process takes time, and it is possible that mortar could block the cells and stop the vermiculite from fully filling the wall. Also, if any holes or other damage are done to the walls it is possible that the vermiculite could pour out of the walls and leave an air gap, therefore reducing the fire resistance of the wall. 


\section{Chapter 5}

\section{Model Creation}

\section{$5.1 \quad$ Introduction}

One of the best ways to answer a scientific question is to do a physical test. However, these tests can be expensive and time consuming. Modelling is another option that can be used. When creating a new model is helpful to have physical data in order to validate the results. Once the model matches the physical test, changes can be made in order to make predictions for other tests. The more physical data available during the model creating, the more accurate the model can be.

Once a working model is created, new models can be created to determine what physical tests should be done in the future. In the case of the testing of masonry walls, new wall mix designs and geometries could be modelled, and only those with promising results would actually be built and tested under a standard fire. The physical tests would then help to further validate and refine the model and to confirm the accuracy of the results.

The first step was to model the full-scale tests from both the Almonte and Barnsdale tests. The second Almonte test was used to create the initial models, but the other test were used to help validate the model. Future tests will be used to further refine the model.

The finite element method can be used through the Abaqus software to simulate the experimental fire resistance tests. As the experiments were on non-loadbearing members, the models are a pure thermal analysis which focuses only on evaluating the temperature profile within masonry materials. The fire the member is exposed to is an input, which is selected to be the CAN/ULC S-101 standard fire to align with

the fire used in the physical testing. The heat transfer model able to calculate the fire 
resistance of the member using the insulation criterion, as this is the most common failure mechanism for partition walls. This model required the exact geometry of the elements, the thermal properties of the various materials and the heat transfer coefficients at the boundaries of the members.

\subsection{Numerical Simulation Technique}

In a pure thermal analysis, the main factors of the finite element model are the thermal properties of the material, Interaction Properties, meshing, and load/boundary conditions. The place of these factors within the ABAQUS software are described in the following sections.

\subsubsection{Material thermal properties}

To create a model, it is important to have the correct values for the thermal properties, as they impact how the model behaves under fire conditions. These thermal properties can be incorporated into Abaqus as temperature-dependent data items. The first step was to find all of the properties of concrete at different temperatures. The main properties that were required were the thermal conductivity, specific heat, and density. These values were taken from Fabian Ayala's doctoral thesis and can be found in Tables 5.1 and 5.2 [72]. These values change as the concrete heats up and so each of these variables are temperature dependent. There are also different values for the concrete blocks and the mortar.

Table 5.1: Thermal Properties of Normal Weight Concrete

\begin{tabular}{|l|l|l|l|}
\hline Temperature & Density & Specific Heat & Thermal Conductivity \\
\hline$(\mathrm{K})$ & $(\mathrm{Kg} / \mathrm{m} 3)$ & $(\mathrm{J} / \mathrm{kgK})$ & $(\mathrm{W} / \mathrm{mK})$ \\
\hline 293 & 2300 & 900 & 1.60 \\
\hline 473 & 2200 & 1050 & 1.35 \\
\hline 673 & 2200 & 1150 & 1.15 \\
\hline 873 & 2200 & 1220 & 1.00 \\
\hline 973 & 2200 & 1260 & 0.90 \\
\hline 1073 & 2200 & 1300 & 0.85 \\
\hline
\end{tabular}


Table 5.2: Thermal Properties of Mortar

\begin{tabular}{|l|l|l|l|}
\hline Temperature & Density & Specific Heat & Thermal Conductivity \\
\hline$(\mathrm{K})$ & $(\mathrm{Kg} / \mathrm{m} 3)$ & $(\mathrm{J} / \mathrm{kgK})$ & $(\mathrm{W} / \mathrm{mK})$ \\
\hline 293 & 1900 & 750 & 1.2 \\
\hline 473 & 1800 & 850 & 2.9 \\
\hline 673 & 1800 & 1050 & 1.4 \\
\hline 873 & 1800 & 1150 & 1.4 \\
\hline 973 & 1800 & 1050 & 1.4 \\
\hline 1073 & 1800 & 900 & 1.4 \\
\hline
\end{tabular}

In order to ensure that the thermal properties were correct and to better understand their effect on solid concrete, a solid block of concrete $190 \mathrm{~mm}^{3}$ was created (Figure 5.1). This would roughly simulate the web in a masonry block. The values from Table 5.1 were used at the start, but the results were not exactly in line with the expected results for a $20 \mathrm{~cm}$ block. This was in part due to the fact that the solid block did not have the same geometry as a masonry block or wall. But the other reason had to do to with the thermal properties. In order to create a more accurate model, it was important to determine the effects of changing these thermal properties.

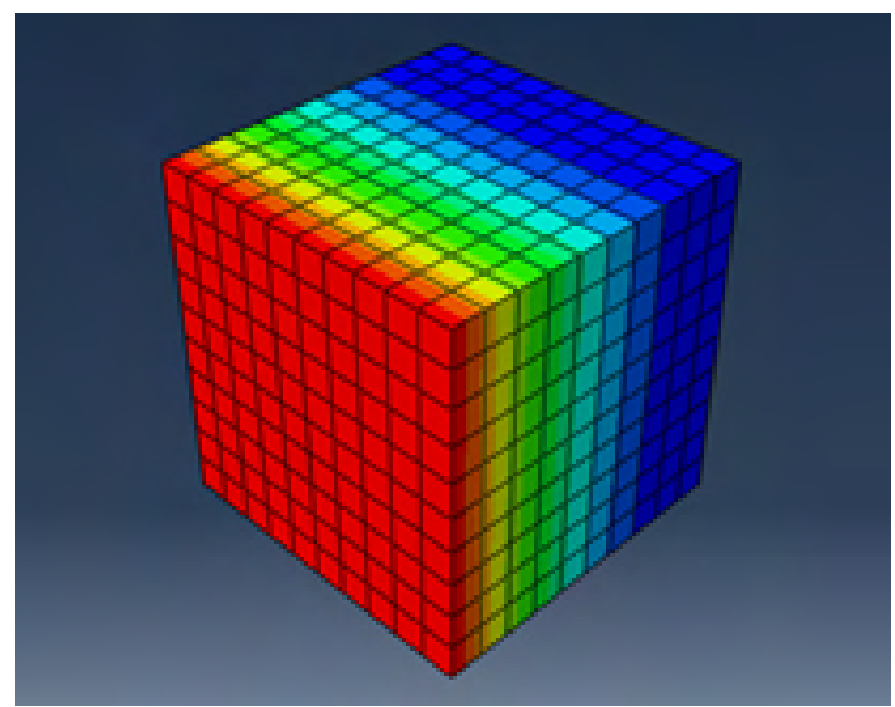

Figure 5.1: Solid Concrete Block Model

A series of $20 \mathrm{~cm}$ masonry blocks were modelled in order to determine how changing 
one thermal property while leaving the other two the same would affect the failure time. The thermal conductivity was varied from $0.4-3.2 \mathrm{~W} / \mathrm{mK}$, the specific heat was varied from $500-2400 \mathrm{~J} / \mathrm{kgK}$, and the density was varied from $1800-2500 \mathrm{~kg} / \mathrm{m}^{3}$. The failure times for each point was found and plots were created to compare the effects of the different thermal property ranges.

Figure 5.2a demonstrates the change in thermal conductivity. It be seen that the lower the thermal conductivity the higher the fire resistance (longer failure time). The effect of thermal conductivity is not linear, and so the increase in fire resistance between 3.0-2.5 W/mK is much lower than the increase in fire resistance between $1.5-1.0 \mathrm{~W} / \mathrm{mk}$. Figure 5.2b demonstrates the change in specific heat. It can be seen that the higher the specific heat the higher the fire resistance. For this test the effect of free water was kept constant throughout. It can be seen that the effect of specific heat is linear, so any increase in specific heat will yield roughly the same increase in fire resistance. Figure 5.2c demonstrates the change in density. The higher the density the lower the fire resistance. This result makes sense, as particles are closer in denser materials, which improves heat transfer.

\section{Material thermal properties-Free water}

One of the main issues with the initial modeled time temperature curves at was the lack of plateau at the $100^{\circ} \mathrm{C}$ mark. This lack of a plateau would cause the models to be consistently hotter than the physical test data. The reason for this is that the free water within the walls is what causes the plateau, and so the effect of the free water needs to be taken into consideration. Heating up water takes energy and causing water to vaporise takes even more energy. Since this energy requirement is directly related to the specific heat, the specific heat values around $100^{\circ} \mathrm{C}$ were increased in order to take into account the effects of the free water.

This increase was done by calcualting the free water content of the concrete (around 2.5\%) and adding that percentage of water's specific heat value $(4.2 \mathrm{KJ} / \mathrm{KgK})$ to the concrete. Since vaporising water takes more energy, the heat of vaporisation of water was found $(2458.3 \mathrm{KJ} / \mathrm{Kg})$, and that value was divided by the temperature range it would be spread over $(20 \mathrm{~K})$ in order to get a specific heat value $(\mathrm{KJ} / \mathrm{KgK})$. This value was also added to the specifc heat at temperatures around $100^{\circ} \mathrm{C}$. 


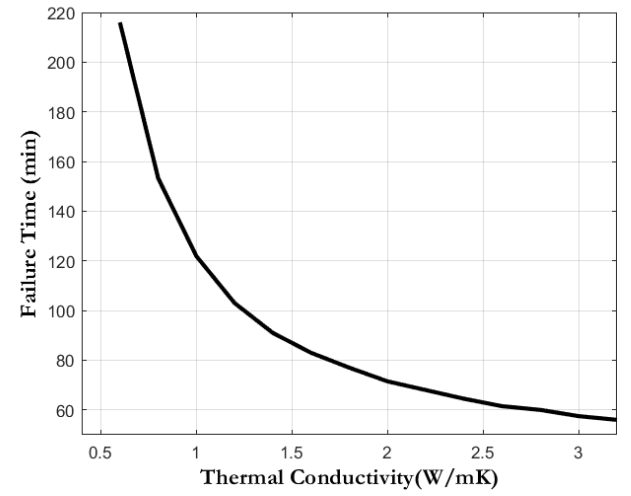

(a)

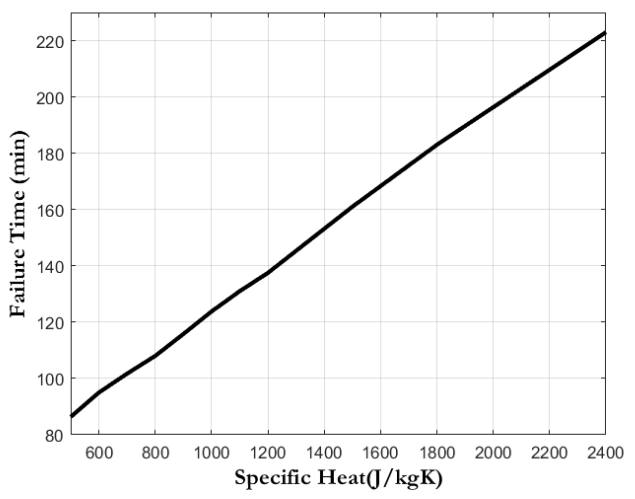

(b)

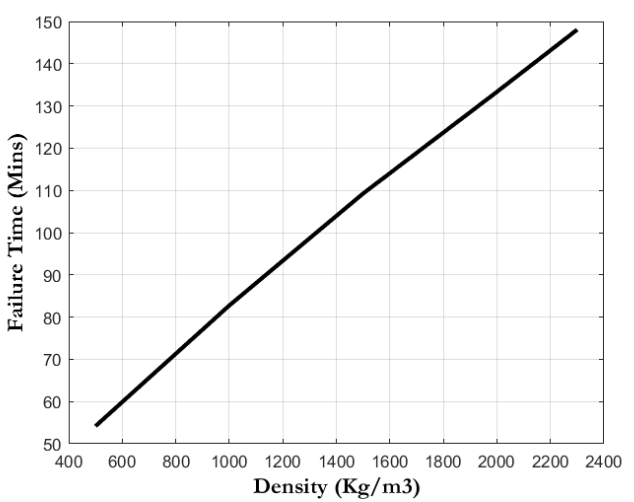

(c)

Figure 5.2: Effect of concrete properties on failure time a) Thermal conductivity b) Specific Heat c) Density

$$
\begin{aligned}
& \mathrm{Cp}_{\text {water }}+\Delta \mathrm{Hvap}_{\text {water }}+\mathrm{Cp}_{\text {concrete }}=\mathrm{Cp}_{\text {total }} \\
& (0.025) *(4.2)+(0.025) *(2458.3) /(20)+0.822=4.0 \mathrm{KJ} / \mathrm{Kg} / \mathrm{K}
\end{aligned}
$$

By increasing the specific heat, the graphs began to include a reduced slope at the $100^{\circ} \mathrm{C}$ mark. Unlike the physical tests, the model does not show a horizontal plateau, but instead a more gradual temperature increase at this part of the graphs. The reason the physical tests have that plateau is because the thermocouples are reading the temperature of vaporised water, which remains constant at $100^{\circ} \mathrm{C}$ until all the water is gone. Since the model does not directly incorporate the water, and instead indirectly approximates the increase in specific heat due to the water, the graph at that point slightly diverges from the physical test data.

While Almonte Test 2 had walls with plenty of free water inside, the Barnsdale 
Test1B did not. As the Barnsdale Test1B walls had been previously burned, most of the free water had already been evaporated. When modeling those walls, including the free water meant that the model was much colder than the experimental data. In Figure 5.3 the effects of the free water were removed from the specific heat values, and it was found that the results were much closer after this change was made, Figure 5.3 .

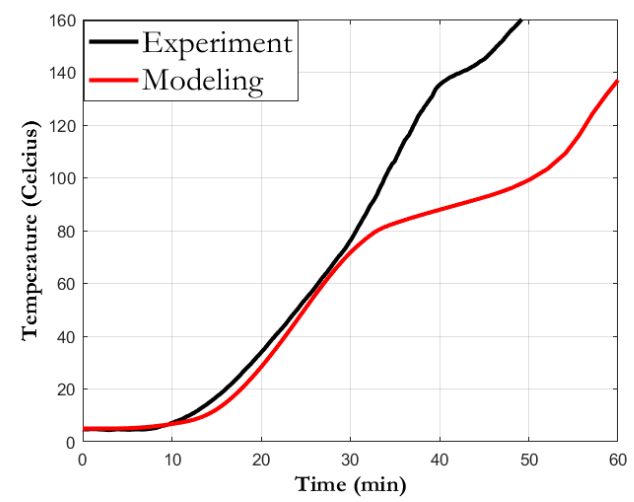

(a)

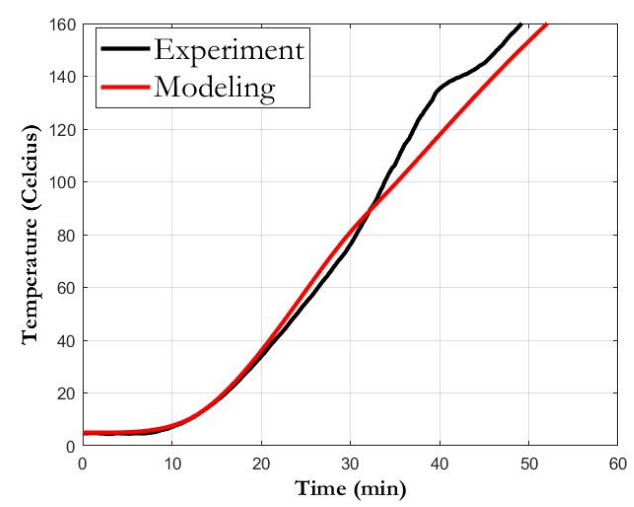

(c)

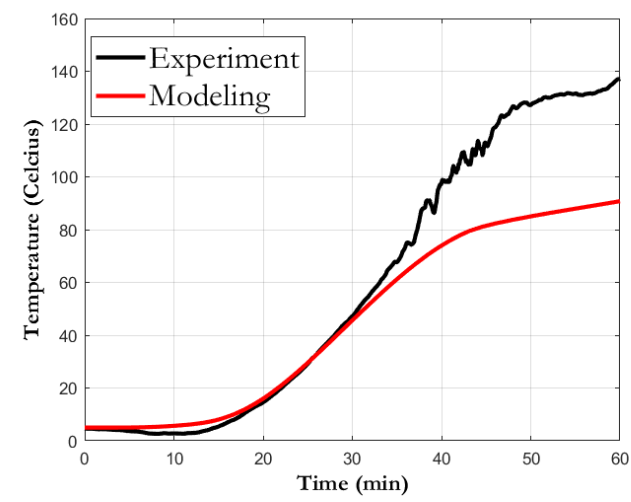

(b)

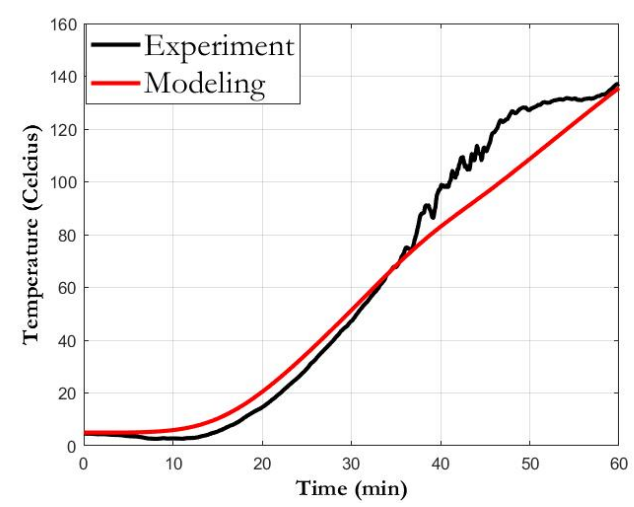

(d)

Figure 5.3: Comparing the NW15cm block experiment data with the model, with free water in the model a) Hollow Cell b) Solid Web and without free water in the model c) Hollow Cell d) Solid Web 


\subsubsection{Meshing}

Finite elements software is widely used for modeling thermal and mechanical problems. One of the most important parts of the model is creating the appropriate mesh in order to accurately and efficiently determine the values at different locations. A finer mesh means more detailed and accurate the results. However, a finer mesh also takes longer to model. It is important to balance precision with time constraints. The mesh created does not need to always be uniform. Areas of concern or interest can be meshed finely, while areas of least interest can have a coarser mesh.

The approximate element size is used in Abaqus to create the mesh, with a smaller element size leading to a finer mesh. In order to determine which mesh size was optimal, a mesh refinement analysis was done. A very fine mesh was created on a single block, and then coarser meshes were created to see how the error changed. The fine mesh took six hours to run, and the coarse mesh took around 10 minutes. Images depicting the mesh sizes can be found in Figure 5.4. The results from each test can be seen in Figure 5.5a and b, and where taken from the centre of the web and the centre of the hollow cell. The fine mesh (approximate element size of 5) was the most accurate, and as the mesh got coarser the graphs started to change slightly. The changes in the graphs was concentrated mostly around the areas where the free water came into effect. A closer look at the graphs can be seen in Figure 5.5c and d.

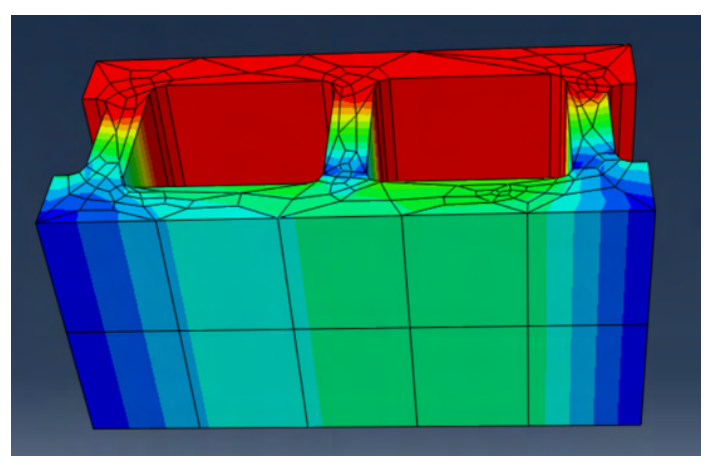

(a)

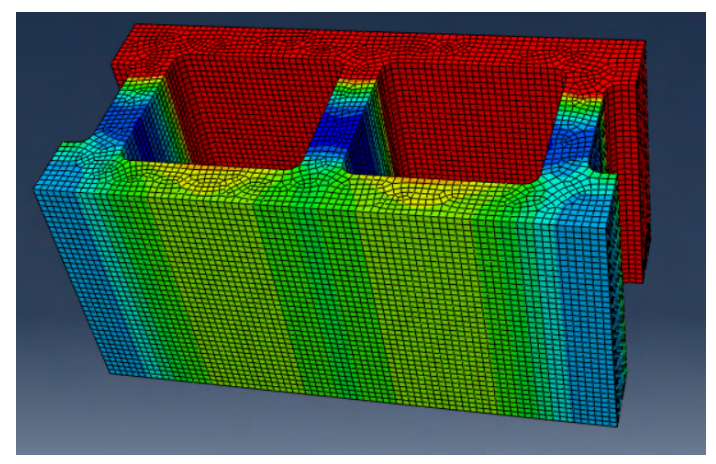

(b)

Figure 5.4: Difference between mesh sizes a)Very Coarse Mesh40 b)Very Fine Mesh5 


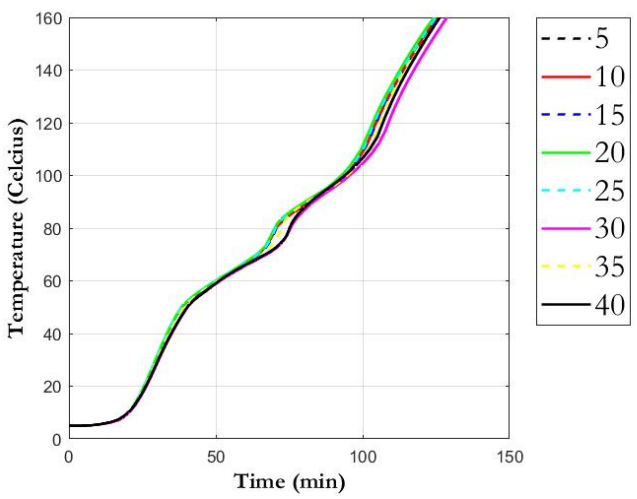

(a)

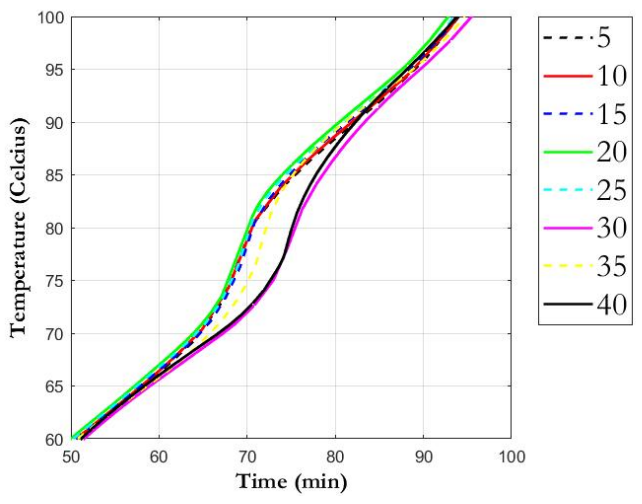

(c)

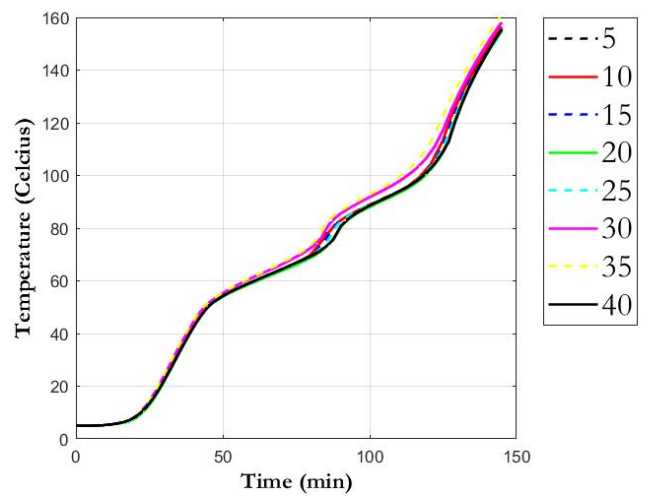

(b)

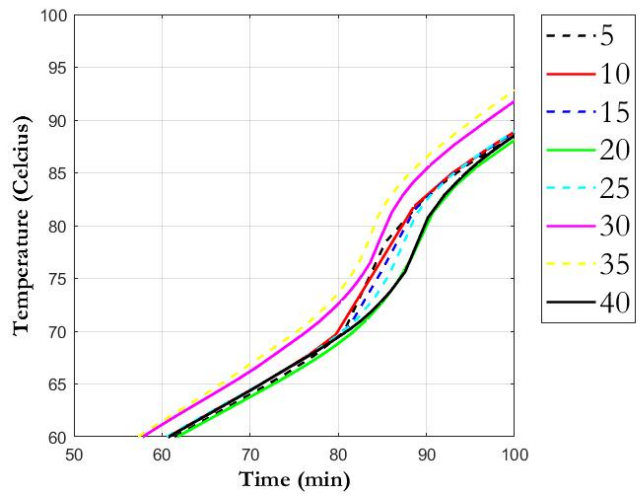

(d)

Figure 5.5: Difference between mesh sizes a) and c)Hollow Cell b) and d)Solid Web 
In order to determine the error between the graphs, the area under the graphs was calculated and compared to the finest mesh (approximate element size 5). The results can be found in Table 5.3. It can be seen that for the meshes with approximate element sizes up to 30 had very little error (under 2.4\%). After 30 the error was still under $5 \%$, but would not be recommended for final modelling. One of the reasons the coarser meshes had issues was in part because the nodes did not align exactly with the center of the webs and the center of hollow. Having less nodes means it is less likely that the nodes are exactly in the right positions, which leads to discrepancies. This is why even though the Mesh40 was coarser, the fact that the node was in centre of the hollow cell meant that it had a more accurate hollow cell temperature than the Mesh35. While finer meshes are more accurate, it is also important to ensure that the nodal points align closely to the locations where temperature measurements are needed.

Table 5.3: Mesh Refinement Error

\begin{tabular}{|l|l|l|l|}
\hline $\begin{array}{l}\text { Approximate } \\
\text { Element Size }\end{array}$ & $\begin{array}{l}\text { Number of } \\
\text { Elements }\end{array}$ & $\begin{array}{l}\text { Hollow Cell } \\
\text { Error (\%) }\end{array}$ & $\begin{array}{l}\text { Solid Web } \\
\text { Error (\%) }\end{array}$ \\
\hline 5 & 67,830 & 0 & 0 \\
\hline 10 & 9,405 & 0.0848 & 0.2027 \\
\hline 15 & 3,744 & 0.2416 & 0.4923 \\
\hline 20 & 2,150 & 0.6784 & 2.129 \\
\hline 25 & 1,456 & 2.378 & 1.8965 \\
\hline 30 & 924 & 0.1505 & 1.10333 \\
\hline 35 & 700 & 4.209 & 2.362 \\
\hline 40 & 655 & 1.631 & 4.337 \\
\hline
\end{tabular}

\subsubsection{Interaction Properties}

The ABAQUS model, though assembled needs to be further connected in the interaction module. These connections include the conduction from the blocks in physical contact with the mortar, as well as the convection and radiation through the hollow 
cells. As the materials in physical contact were solid bodies transmitting heat energy, thermal conductance property was selected for the entire assembly [71]. "The thermal conductance property defines a conductance between the surfaces in contact" [71] [73]. The surfaces in contact (known as contact pairs) can be generated automatically or manually. Once the surfaces in contact have been generated, master and slave surfaces need to be defined for all surfaces in contact. "The contact interaction formulation in ABAQUS requires that the specific slave surfaces are more finely meshed of the surfaces" [71] [73]. Therefore, the concrete masonry blocks were chosen as the master surface while the mortar joints were chosen as the slave surface.

A second form of interaction involving surface radiation and convection was used in the heat transfer step in the interaction module. For this form, a surface emissivity and film coefficients were both defined as interaction properties and then applied to the hollow sections of the assembly [71]. In order to determine their effects on heat transfer, $20 \mathrm{~cm}$ and $15 \mathrm{~cm}$ hollow masonry blocks were created (Figure 5.6).

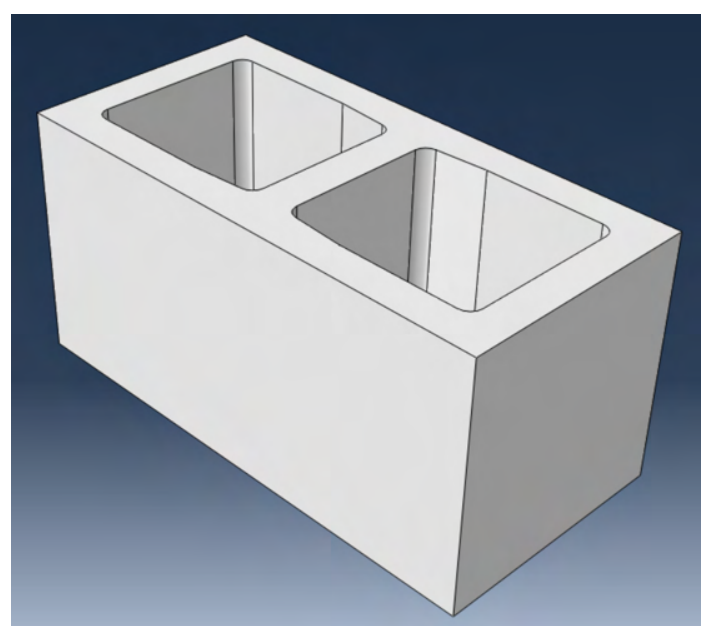

(a)

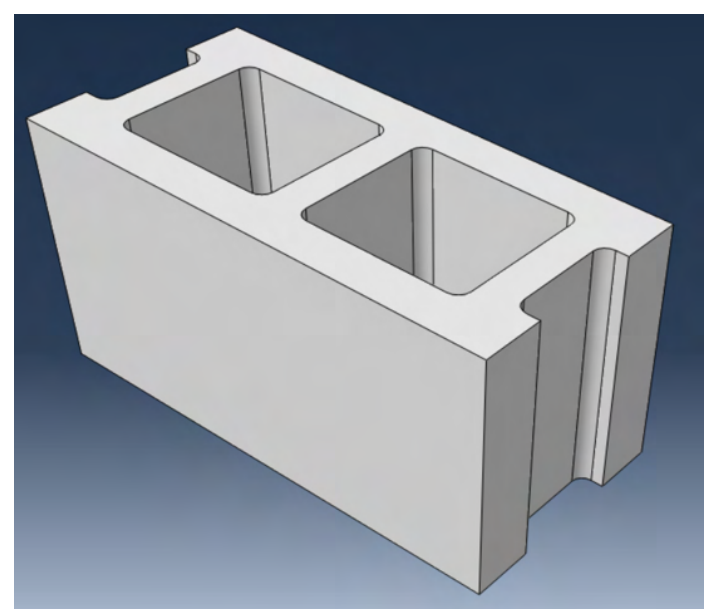

(b)

Figure 5.6: Modelled Masonry Blocks a) $15 \mathrm{~cm}$ block b) $20 \mathrm{~cm}$ block

The emissivity of concrete is ranges from 0.8-0.95 [12]. Several models were created to test the effects of different emissivity's, and their time temperature curves can be found in 5.7. As the emmisivity increased, so did the average temperature on the unexposed side. This is becasue the emmisivity changes the heat transfered from the fire to the unexposed side, as well as from the hot side of the hollow cells to the colder sider of the cells. After analysing the data, a value of 0.94 was found to be the most 
optimal.

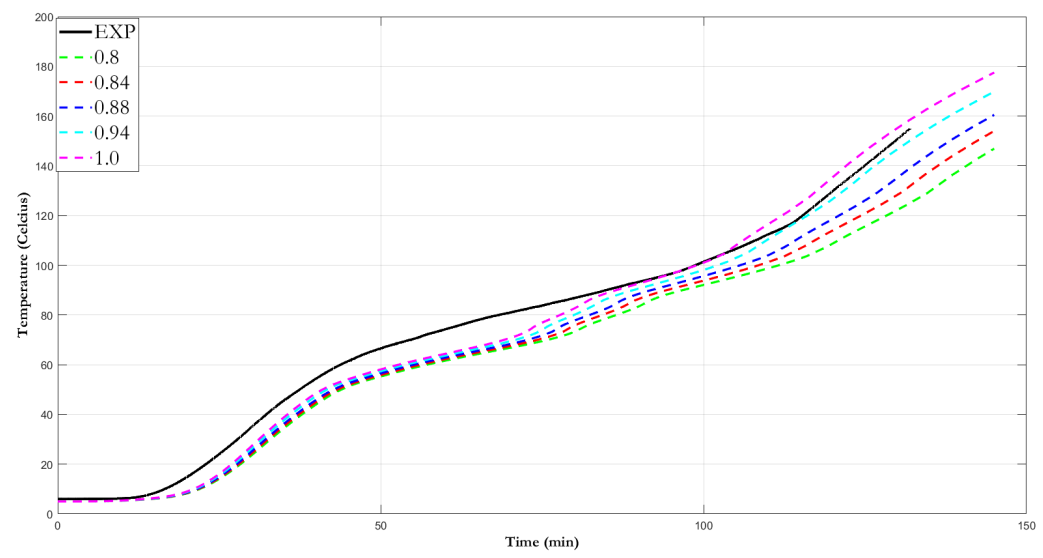

Figure 5.7: Effects of different Emmisivity values

The convective heat transfer coefficient depends on the temperature and properties of the air that is undergoing convection. One option was to use a single value for the convective heat transfer, and so models were created with varying values of $h$ (Figure 5.8). It was found that lower values of $\mathrm{h}$ lead to the unexposed side heating up much to fast, and higher values left the unexposed side too cool. A value of around $0.21 \mathrm{~W} / \mathrm{mK}$ was found to be optimal, but still not exact.

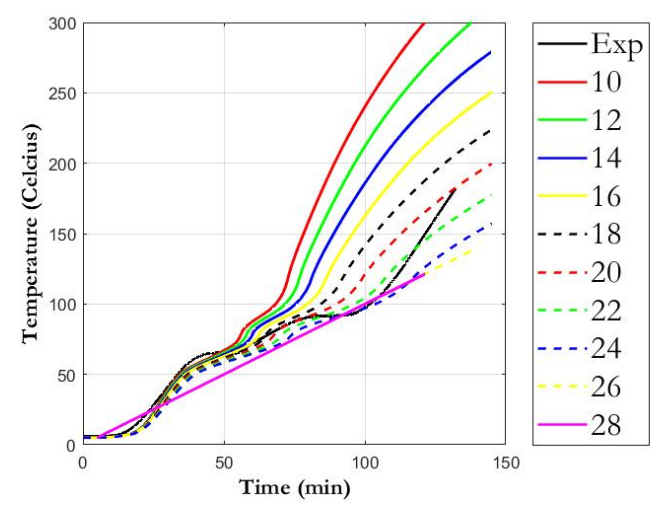

(a)

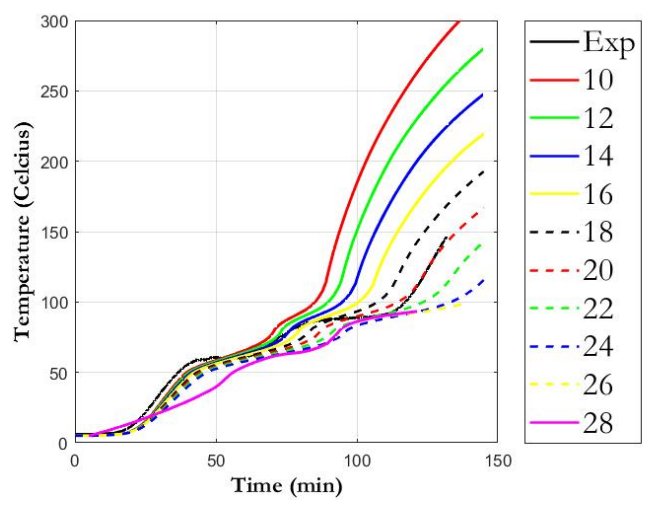

(b)

Figure 5.8: Difference between Heat Transfer coeficient (units $\mathrm{W} / \mathrm{m}^{2} \mathrm{k}$ ) a) Hollow Cell b)Solid Web

The properties of air at different temperatures can be found in (Figure 5.9) and 
an equation for calculating the convective heat transfer coefficient based on this data (Equation 5.1,5.2, and 5.3). These values were used to calculate the heat transfer coefficient with respect to temperature, and the results can be found in Table 5.4.

\begin{tabular}{|c|c|c|c|c|c|c|c|}
\hline$T K$ & $\rho \mathrm{kg} / \mathrm{m}^{3}$ & $c_{p} \mathrm{~kJ} / \mathrm{kg} \cdot \mathrm{K}$ & $\mu 10^{7} \mathrm{~N} \mathrm{~s} / \mathrm{m}^{2}$ & $v \cdot 10^{6} \mathrm{~m}^{2} / \mathrm{s}$ & $\mathrm{k} \cdot 10^{3} \mathrm{~W} / \mathrm{m} \mathrm{K}$ & $\alpha \cdot 106 \mathrm{~m}^{2} / \mathrm{s}$ & $\operatorname{Pr}$ \\
\hline 100 & 3.5562 & 1.032 & 71.1 & 2.00 & 9.34 & 2.54 & 0.786 \\
\hline 150 & 2.3364 & 1.012 & 103.4 & 4.426 & 13.8 & 5.84 & 0.758 \\
\hline 200 & 1.7458 & 1.007 & 132.5 & 7.590 & 18.1 & 10.3 & 0.737 \\
\hline 250 & 1.3947 & 1.006 & 159.6 & 11.44 & 22.3 & 15.9 & 0.720 \\
\hline 300 & 1.1614 & 1.007 & 184.6 & 15.89 & 26.3 & 22.5 & 0.707 \\
\hline 350 & 0.9950 & 1.009 & 208.2 & 20.92 & 30.0 & 29.9 & 0.700 \\
\hline 400 & 0.8711 & 1.014 & 230.1 & 26.41 & 33.8 & 38.3 & 0.690 \\
\hline 450 & 0.7740 & 1.021 & 250.7 & 32.39 & 37.3 & 47.2 & 0.686 \\
\hline 500 & 0.6964 & 1.030 & 270.1 & 38.79 & 40.7 & 56.7 & 0.684 \\
\hline 550 & 0.6329 & 1.040 & 288.4 & 45.57 & 43.9 & 66.7 & 0.683 \\
\hline 600 & 0.5804 & 1.051 & 305.8 & 52.69 & 46.9 & 76.9 & 0.685 \\
\hline 650 & 0.5356 & 1.063 & 322.5 & 60.21 & 49.7 & 87.3 & 0.690 \\
\hline 700 & 0.4975 & 1.075 & 338.8 & 68.10 & 52.4 & 98.0 & 0.695 \\
\hline 750 & 0.4643 & 1.087 & 354.6 & 76.37 & 54.9 & 109 & 0.702 \\
\hline 800 & 0.4354 & 1.099 & 369.8 & 84.93 & 57.3 & 120 & 0.709 \\
\hline 850 & 0.4097 & 1.110 & 384.3 & 93.80 & 59.6 & 131 & 0.716 \\
\hline 900 & 0.3868 & 1.121 & 398.1 & 102.9 & 62.0 & 143 & 0.720 \\
\hline 950 & 0.3666 & 1.131 & 411.3 & 112.2 & 64.3 & 155 & 0.723 \\
\hline 1000 & 0.3482 & 1.141 & 424.4 & 121.9 & 66.7 & 168 & 0.726 \\
\hline 1100 & 0.3166 & 1.159 & 449.0 & 141.8 & 71.5 & 195 & 0.728 \\
\hline 1200 & 0.2902 & 1.175 & 473.0 & 162.9 & 76.3 & 224 & 0.728 \\
\hline 1300 & 0.2679 & 1.189 & 496.0 & 185.1 & 82 & 238 & 0.719 \\
\hline 1400 & 0.2488 & 1.207 & 530 & 213 & 91 & 303 & 0.703 \\
\hline 1500 & 0.2322 & 1.230 & 557 & 240 & 100 & 350 & 0.685 \\
\hline 1600 & 0.2177 & 1.248 & 584 & 268 & 106 & 390 & 0.688 \\
\hline 1700 & 0.2049 & 1.267 & 611 & 298 & 113 & 435 & 0.685 \\
\hline 1800 & 0.1935 & 1.286 & 637 & 329 & 120 & 482 & 0.683 \\
\hline
\end{tabular}

Figure 5.9: Properties of air at different temperatures [12]

$$
R_{e}=\frac{\rho u L}{\mu}
$$

Where $R_{e}$ is the Reynolds number, $\rho$ is density, $u$ is flow speed, $L$ is characteristic linear dimension, and $\mu$ is viscocity of the fluid.

$$
N u=0.664 R_{e}^{(1 / 2)} \operatorname{Pr}^{(1 / 3)}
$$

Where $N u$ is the Nusselt number, $R_{e}$ is the Reynolds number, and $\operatorname{Pr}$ is the Prandtl number.

$$
h=\frac{N u k}{L}
$$


Table 5.4: Heat Transfer Coefficient Values

\begin{tabular}{|l|l|}
\hline $\begin{array}{l}\text { Temperature } \\
(\text { Celcius })\end{array}$ & $\begin{array}{l}\mathbf{h} \\
\left(\mathbf{W} / \mathbf{m}^{2} \mathbf{K}\right)\end{array}$ \\
\hline 0 & 11.50 \\
\hline 27 & 12.10 \\
\hline 77 & 13.75 \\
\hline 127 & 15.42 \\
\hline 177 & 16.99 \\
\hline 227 & 18.52 \\
\hline 277 & 19.96 \\
\hline 327 & 21.35 \\
\hline 377 & 22.68 \\
\hline 427 & 23.97 \\
\hline 477 & 25.19 \\
\hline
\end{tabular}




\subsubsection{Loads and boundary conditions}

The experimental members were exposed on one side to the CAN-ULC S-101 standard fire. This was simulated by exposing one side of the assembly to a uniform heat flux, $\dot{q}^{\prime \prime}(\mathrm{W} / \mathrm{m} 2)$, defined in Equation 5.4 [71].

$$
\dot{q}^{\prime \prime}=h_{c}\left(T_{f}-T_{s}\right)+\phi \varepsilon_{e f f} \sigma\left(T_{f}^{4}-T_{s}^{4}\right)
$$

Where; $h_{c}=$ coefficient of convection, $T_{f}=$ furnace temperature $(\mathrm{K}), T_{s}=$ surface temperature of assembly $(\mathrm{K}), \phi=$ configuration factor, $\varepsilon_{e f f}=$ surface emissivity, $\sigma$ $=$ Stefan-Boltzmann constant, $\left(5.67 \times 108 \mathrm{~W} / \mathrm{m}^{2} K^{4}\right)$.

In the ABAQUS model, this heat flux equation was incorporated as a boundary condition using an edited user Distributed Flux (DFLUX) subroutine developed by [74]. "The DFLUX subroutine is a set of computer programming instructions, which is incorporated in an ABAQUS simulation for applying thermal loads on a modelled assembly" [71]. Using this DFLUX subroutine, the heat flux can be applied as a distributed flux to the exposed surface of the member being modeled.

"The transient conduction of heat within the entire assembly is governed by the three-dimensional heat transfer equation", Equation 5.5 [71].

$$
\rho c \frac{\partial T}{\partial t}=\frac{\partial}{\partial x}\left(k \frac{\partial T}{\partial x}\right)+\frac{\partial}{\partial y}\left(k \frac{\partial T}{\partial y}\right)+\frac{\partial}{\partial z}\left(k \frac{\partial T}{\partial z}\right)+S
$$

Where; $\rho=$ density $\left(\mathrm{kg} / \mathrm{m}^{3}\right), x, y, z=$ distances in the respective axes from heat source, $c=$ specific heat capacity $(\mathrm{J} / \mathrm{kgK}), k=$ thermal conductivity $(\mathrm{W} / \mathrm{mK}), t=$ time (s), $S=$ Source of heat $\left(\mathrm{W} / m^{3}\right)$

\subsection{Created Models}

\subsubsection{Model For 20CM standard unit}

After all of model properties were determined and optimized, the next step was to validate the model. When the model was compared to the experimental data of the control wall from the second Almonte test, it was found that there was good correlation (Figure 5.10). There is a small discrepancy between the numerical model and the experimental data at temperature below $100^{\circ} \mathrm{C}$. This is due to the increase in specific heat used to incorporate the evaporation of the free water. The higher 
specific heat values used in the numerical model cause the time temperature curve to heat up slower than the experimental results. However, once the free water has evaporated from the experimental test, the curves are very close to each other. The next in the validation of the would be to use the same properties with a different block geometry.

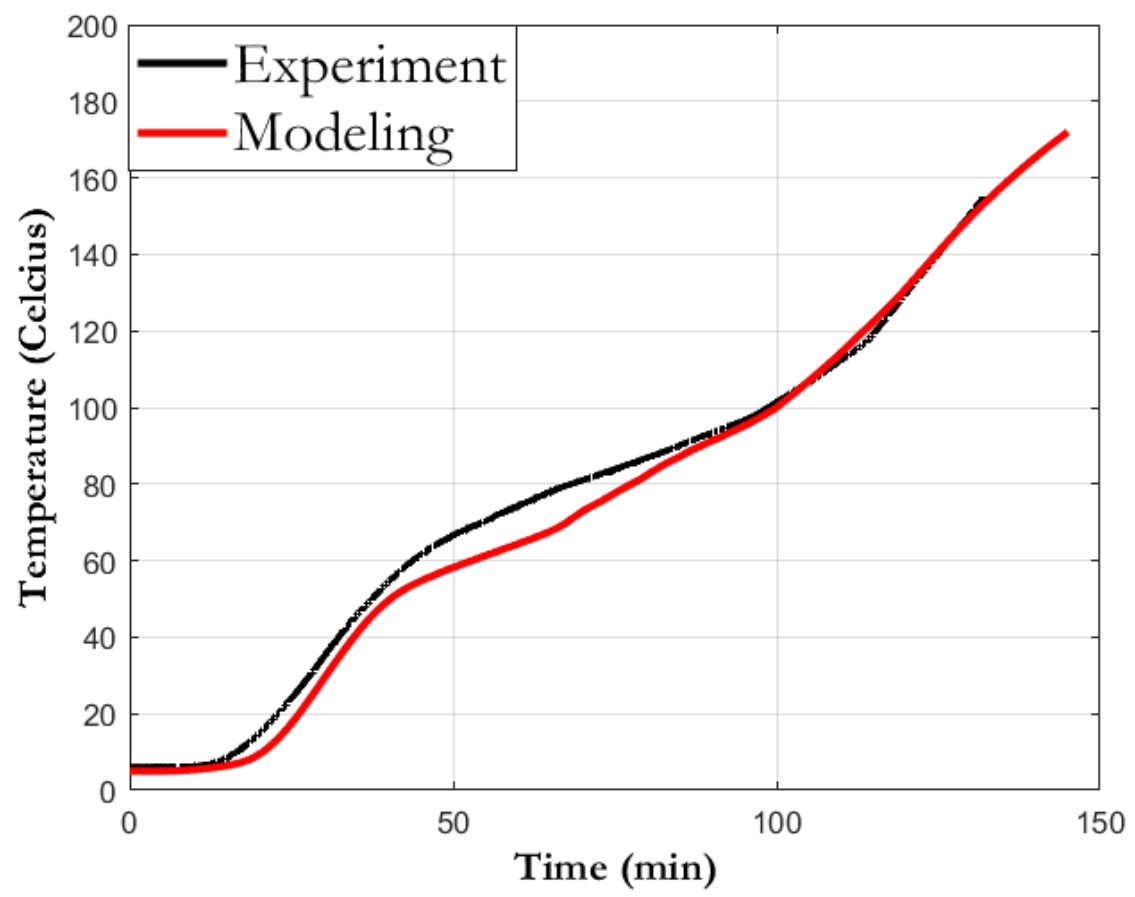

Figure 5.10: $20 \mathrm{~cm}$ standard unit experimental and numerical average unexposed time temperature curve comparison

\subsubsection{Modeling the other tested wall geometries}

In order to further validate the model it is important that other block geometries are modeled and compared to the experimental data. While it is possible to create a model that works for a specific scenario, a true model should be able to work for each of the different tested walls. The following sections demonstrate the modeling results compared to the experimental results for the different block geometries. 


\section{Reduced Web}

The reduced web was created and modeled (Figure 5.14). It was found that without changing any part of the model other than the geometry, the model time temperature curve was closely related to the test data. The failure times for both the experimental and modeling data were almost identical. This again shows that even though the reduced web wall did not perform as well as the other walls, it still has a superior fire resistance when compared to the estimation from the equivalent thickness method.

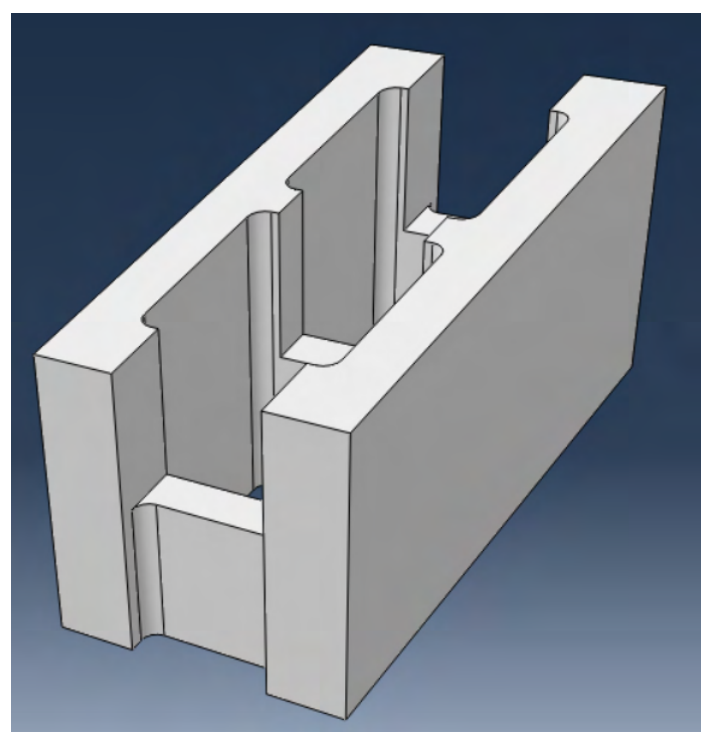

(a)

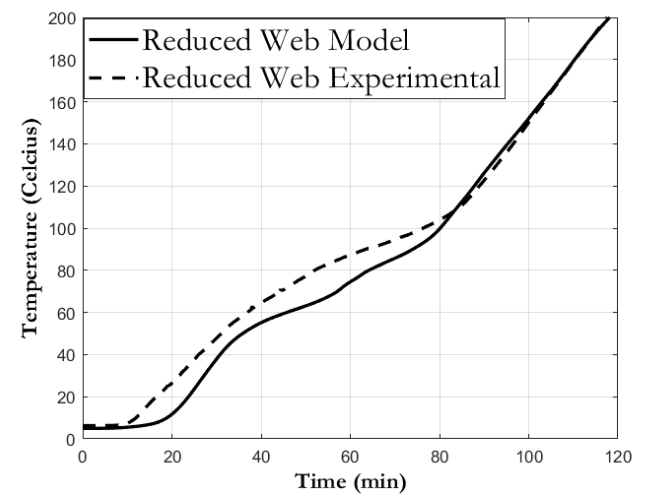

(b)

Figure 5.11: a) Reduced Web Block Model b) Comparing the Reduced Web Block experimental and modeling data

\section{Bond Beam}

The lintel unit from the bond beam wall was modeled. However, the thermocouple readings on the bond beam wall were taken from the standard $20 \mathrm{~cm}$ units. This means that in order to get temperature data the thermal imaging data was required. The bond beam modeling data was compared to the time temperature curve taken from the thermal imaging data (Figure 5.12). Because thermal images were not taken continually, the number of data points was limited. Since the bond beam had a thicker faceshell and no webs, the fire resistance of the block was far superior to standard $20 \mathrm{~cm}$ block. Both the thermal imaging and numerical data showed that the lintel 
units themselves reamined at around $100^{\circ} \mathrm{C}$ at the end of the test, which is much cooler than the rest of the wall, which was an average of $145^{\circ} \mathrm{C}$ at the end of the test.

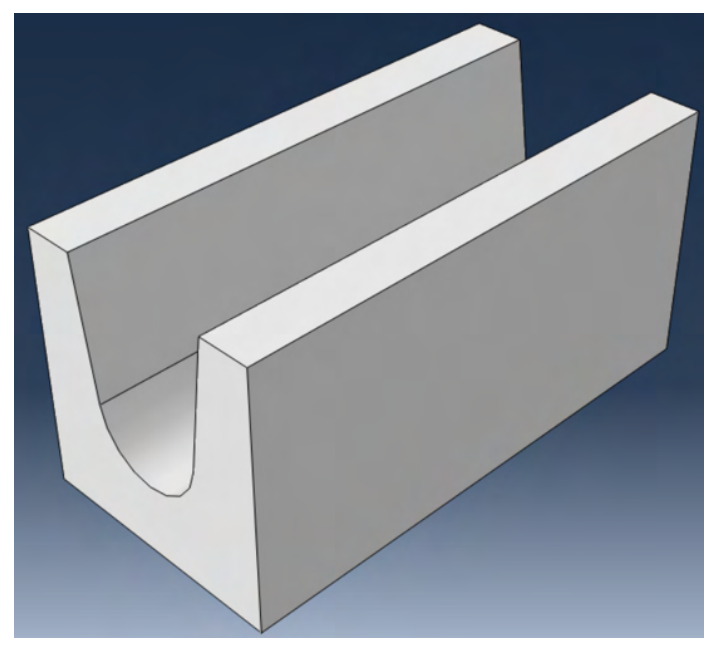

(a)

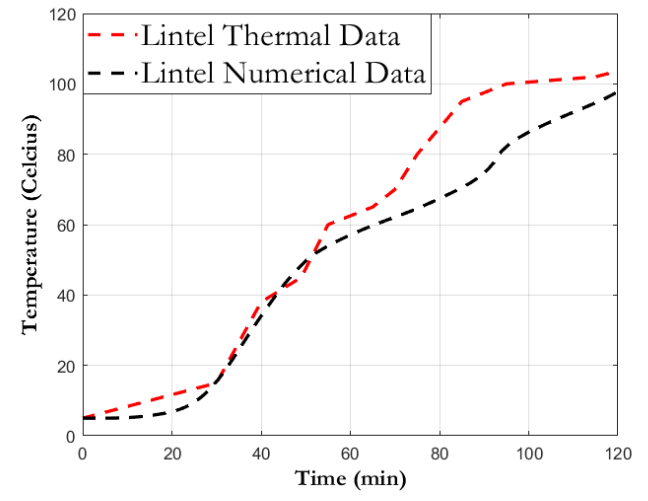

(b)

Figure 5.12: a) Lintel Block Model b) Comparing Lintel Block experimental and modeling data

\section{Raked Joint}

The raked joint wall modeled and the results were a good match to the experimental data (Figure 5.13). The average wall temperatures were quite similar to the experimental data. As with the experimental data, the mortar temperature of the raked joint was higher than the concave joints, but its effect on the average wall temperature was not enough to govern the failure criteria (Figure 5.13). This would indicate that as long as the hollow cells fail the $180^{\circ} \mathrm{C}$ temperature increase at a single point before the average temperature criterion comes into play, then the jointing does not negatively impact the insulation criteria.

\section{$15 \mathrm{~cm}$ Normal Weight}

The $15 \mathrm{~cm}$ normal weight block required a slight change to the specific heat, due to fact that the free free water had already been evaporated from the blocks in a previous test. Without the large spike in speicifc heat, the results showed good correlation (Figure 5.14). The experimenatal data is a bit warmer than the numerical data, but 


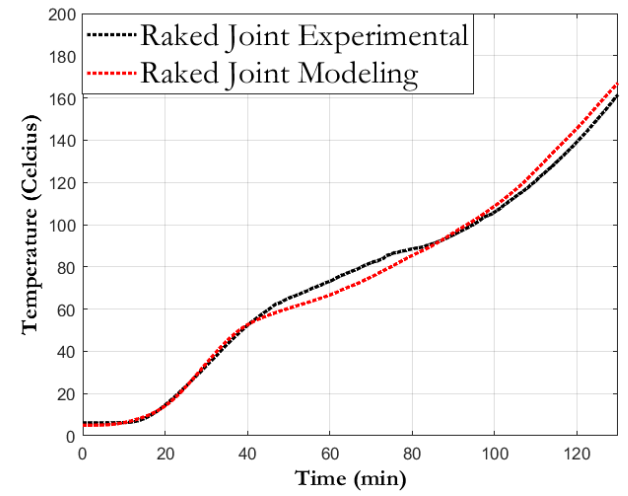

(a)

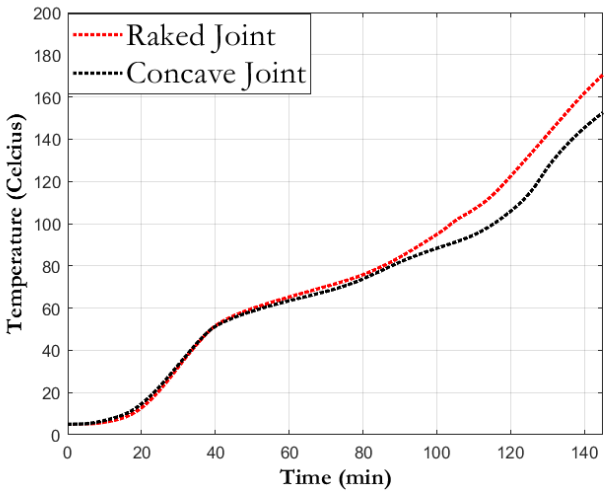

(b)

Figure 5.13: a) Comparing Raked Joint Wall experimental and modeling data b) Comparing Numerical Raked Joints to Numerical Concave Joints

his is expected as the test also had some insualtion issues which caused the walls to heat up faster than expected.

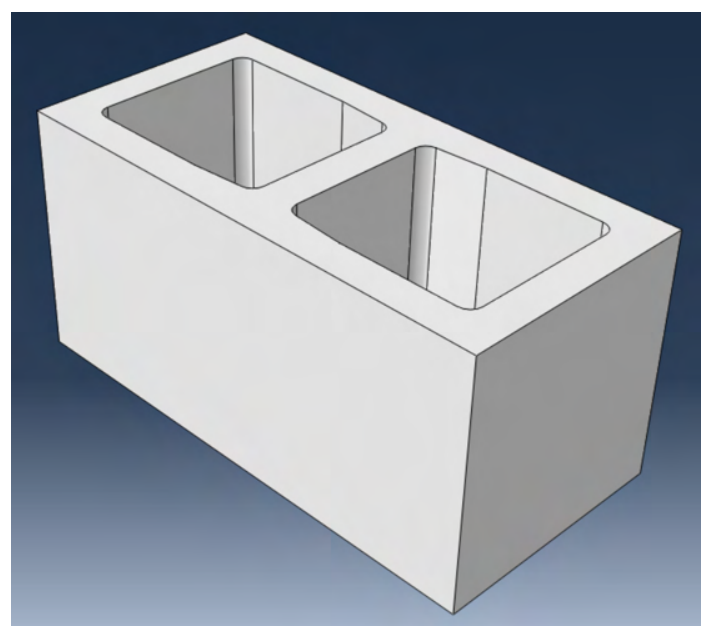

(a)

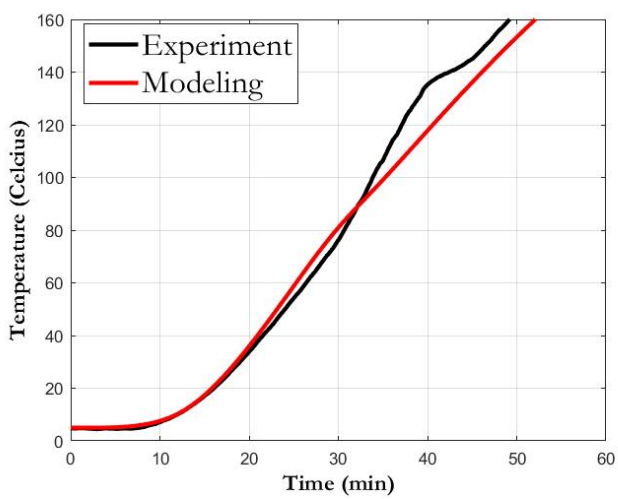

(b)

Figure 5.14: a) $15 \mathrm{~cm}$ Normal Weight Model b) Comparing the experimental and modeling data of the $15 \mathrm{~cm}$ normal weight block

\section{Carbon Cured 20cm}

The carbon cured block was modeled using the same thermal properties as the previous NW20cm block (Figure 5.15). The failure time was again predicted to be just 
shy of the 2-hour mark. This would seem to indicate that the carbon cured block is similar to the standard NW20cm blocks.

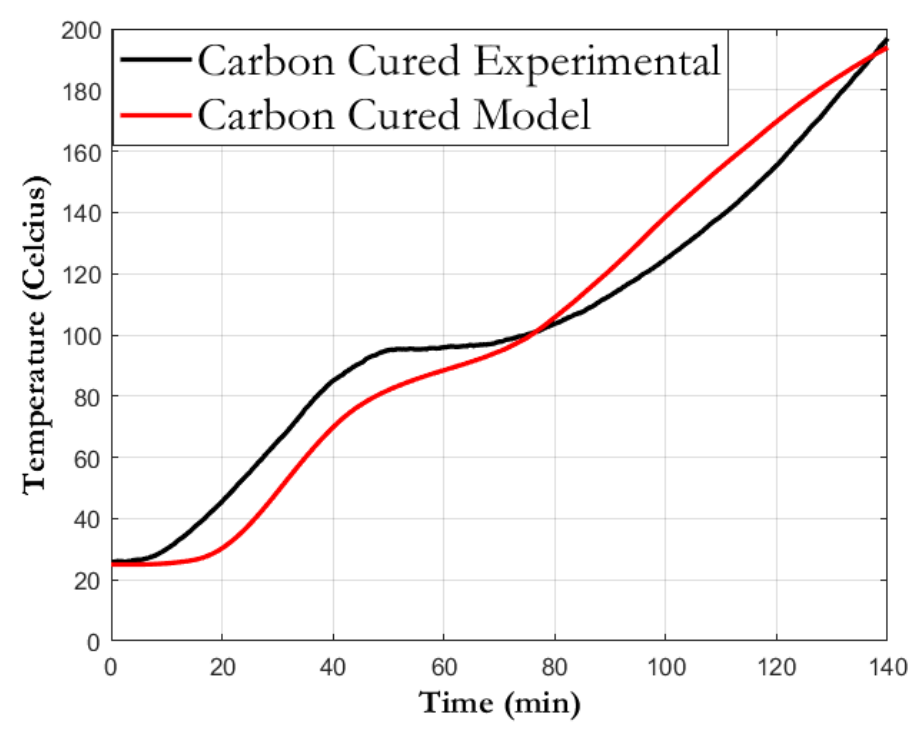

Figure 5.15: Carbon Cured 20cm standard unit experimental and numerical average unexposed time temperature curve comparison

\section{LW15cm}

Modeling the LW15cm block meant determining new values for the thermal conductivity, specific heat, and density. The values were taken from the thesis of Hannah Keelson, and can be found in Table 5.5 ( [71]). After chaining the thermal properties from normal weight concrete to the lightweight concrete the model was able to accurately predict the failure time of the wall (Figure 5.16). As the LW15cm block had one very hot thermocouple (likely due to a crack) that increased the average temperature, the accuracy when comparing the model to the experimental data was improved when this thermocouple was not included. The initial error was $1.9 \%$, but when the hot thermocouple was removed the error dropped to $0.95 \%$. 


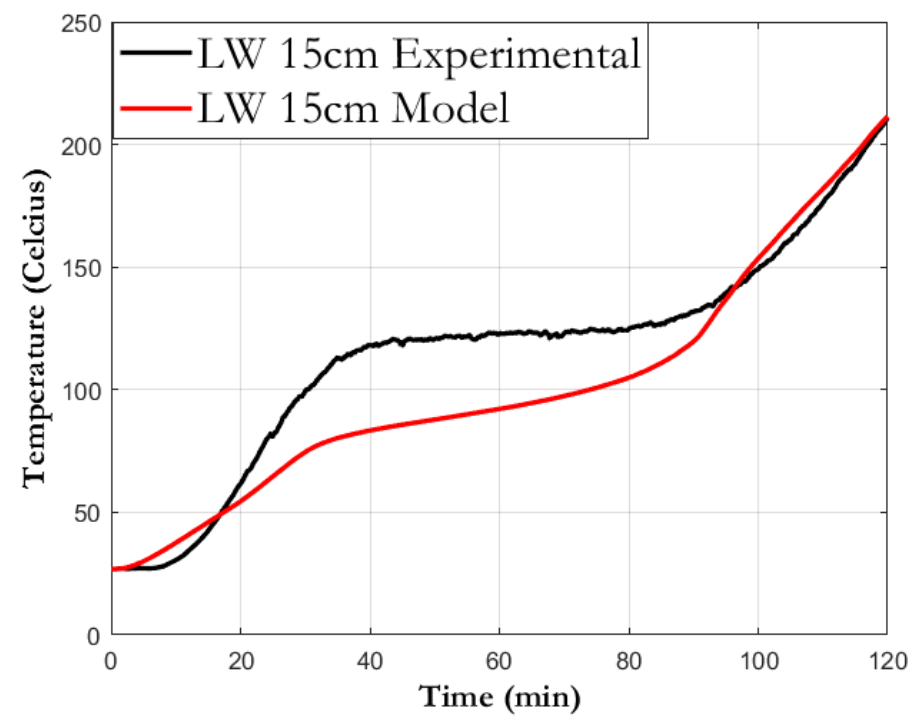

Figure 5.16: LW15cm unit experimental and numerical average unexposed time temperature curve comparison

\section{Semi Solid $15 \mathrm{~cm}$}

The experimental data from the semi solid $15 \mathrm{~cm}$ block differed from the posted fire resistance rating of the block. This would indicate that the block suffered some sort of integrity failure that caused the wall to fail earlier. For this reason, the experimental and modeling results are not closely in line (Figure 5.17). The modeling data was able to predict a failure time of 122.5 minutes, which is just over the 2-hour fire resistance that the block is rated to. As the average experimental wall temperature caused failure after 106.8 minutes, the results are obviously different from the model.

\section{Split Face $20 \mathrm{~cm}$}

The split face block exceeded the fire resistance prescribed by the equivalent thickness method. This was expected as more material was placed on the faceshell on the fire side of the block. While the block was supposed to fail after 126 minutes, it lasted for 150 minutes (144 minutes after being corrected). The modeling results did show that the block should have had a slightly higher fire resistance, but part of the error could be attributed to the approximations done with correcting the furnace fire severity (5.18). As the walls continue to heat up even after the furnace has been turned off, having a slightly cooler furnace temperature near the end of the test may not have 
Table 5.5: Thermal Properties for Lightweight Concrete [71]

\begin{tabular}{|c|c|c|c|}
\hline $\begin{array}{l}\text { Temperature } \\
\text { (C) }\end{array}$ & $\begin{array}{l}\text { Density } \\
(\mathrm{Kg} / \mathrm{m} 3)\end{array}$ & $\begin{array}{l}\text { Specific heat } \\
(\mathrm{J} / \mathrm{kgK})\end{array}$ & $\begin{array}{l}\text { Thermal Conductivity } \\
\qquad(\mathrm{W} / \mathrm{mK})\end{array}$ \\
\hline 20 & 1800 & 840 & 1 \\
\hline 50 & 1800 & 840 & 0.98 \\
\hline 100 & 1700 & 840 & 0.97 \\
\hline 150 & 1700 & 840 & 0.95 \\
\hline 200 & 1700 & 840 & 0.92 \\
\hline 250 & 1700 & 840 & 0.9 \\
\hline 300 & 1700 & 840 & 0.87 \\
\hline 350 & 1700 & 840 & 0.84 \\
\hline 400 & 1700 & 840 & 0.81 \\
\hline 450 & 1700 & 840 & 0.78 \\
\hline 500 & 1700 & 840 & 0.73 \\
\hline 550 & 1700 & 840 & 0.7 \\
\hline 600 & 1700 & 840 & 0.63 \\
\hline 650 & 1700 & 840 & 0.61 \\
\hline 700 & 1700 & 840 & 0.59 \\
\hline 750 & 1700 & 840 & 0.52 \\
\hline 800 & 1700 & 840 & 0.51 \\
\hline
\end{tabular}

as much of an effect on reducing the equivalent fire severity.

\section{Two Hour Fire Block}

The experimental and modeling results of the Two Hour Fire block were in line with each other (Figure 5.19). The Two Hour Fire block was meant to have a fire resistance of $2 \mathrm{~h}$. At the end of the experimental test the average wall temperature was still below the failure temperature, and this results also occurred with the modeling. This result makes sense, as the standard $20 \mathrm{~cm}$ blocks previously tested met a $2 \mathrm{~h}$ fire resistance, 


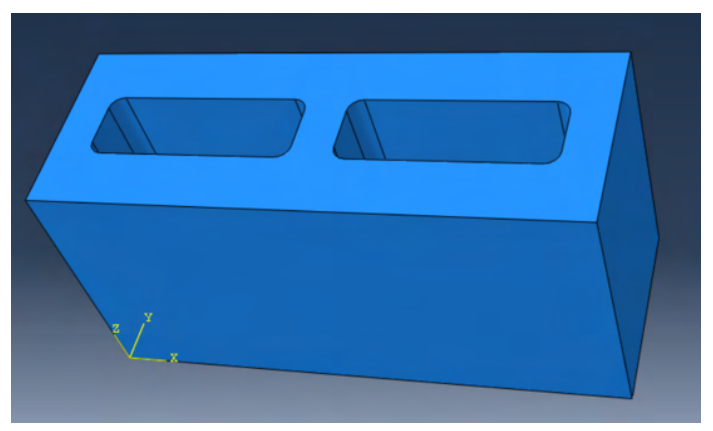

(a)

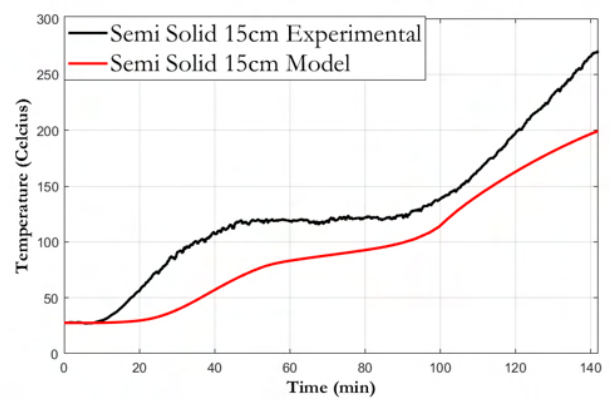

(b)

Figure 5.17: a) $15 \mathrm{~cm}$ Normal Weight Model b) Comparing the experimental and modeling data of the $15 \mathrm{~cm}$ normal weight block

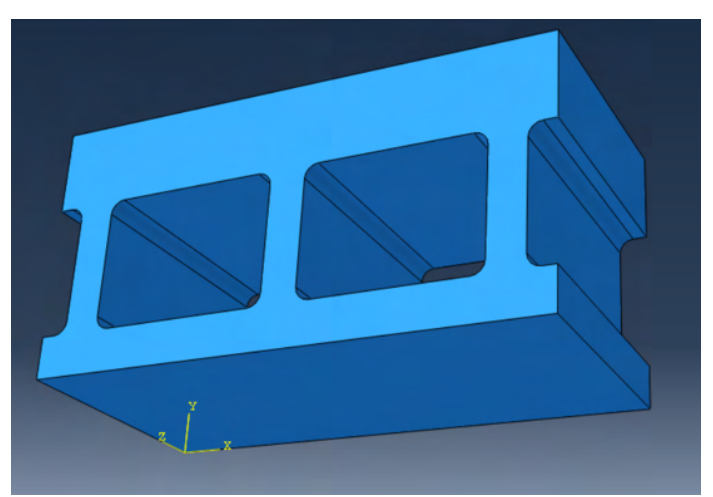

(a)

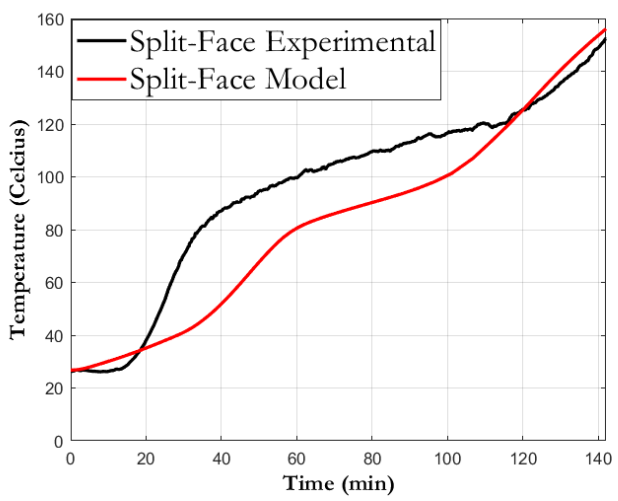

(b)

Figure 5.18: a) $15 \mathrm{~cm}$ Normal Weight Model b) Comparing the experimental and modeling data of the $15 \mathrm{~cm}$ normal weight block

and the Two Hour Fire block has additional material.

\section{Rockwool Full}

The experimental and modeling results of the Two Hour Fire block were in line with each other (Figure 5.20). The Two Hour Fire block was meant to have a fire resistance of $2 \mathrm{~h}$. At the end of the experimental test the average wall temperature was still below the failure temperature, and this results also occurred with the modeling. This result makes sense, as the standard $20 \mathrm{~cm}$ blocks previously tested met a $2 \mathrm{~h}$ fire resistance, and the Two Hour Fire block has additional material. 


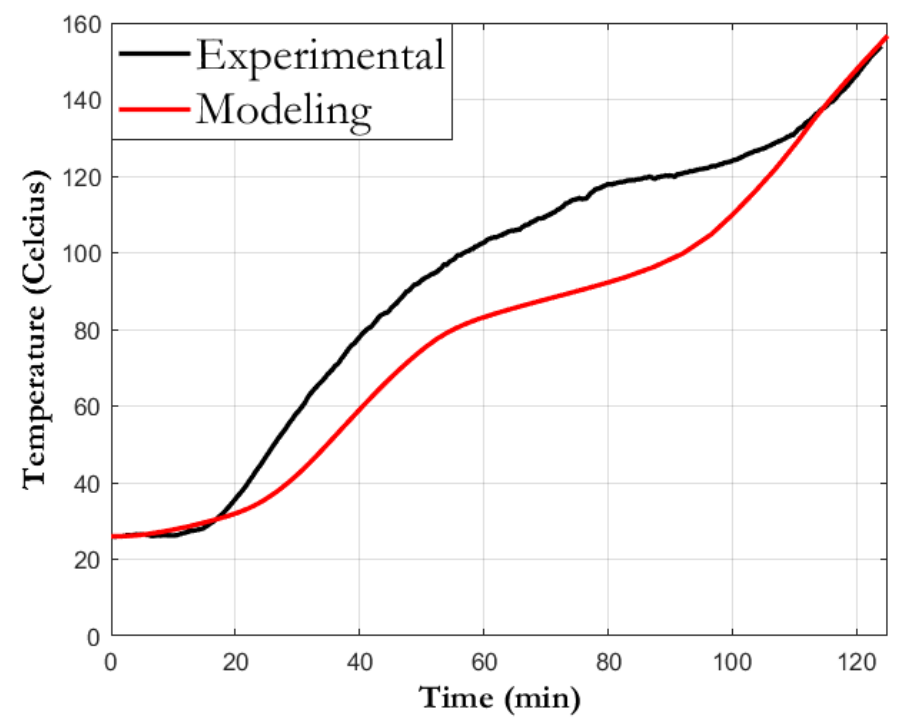

Figure 5.19: Two Hour Fire Block experimental and numerical average unexposed time temperature curve comparison

\section{Rockwool 1inch}

The experimental and modeling results of the Two Hour Fire block were in line with each other (Figure 5.21). The Two Hour Fire block was meant to have a fire resistance of $2 \mathrm{~h}$. At the end of the experimental test the average wall temperature was still below the failure temperature, and this results also occurred with the modeling. This result makes sense, as the standard $20 \mathrm{~cm}$ blocks previously tested met a $2 \mathrm{~h}$ fire resistance, and the Two Hour Fire block has additional material.

\subsubsection{Model Accuracy}

The failure times between the model and the experimental data were compared to determine the accuracy of the model. With all the different walls that were modeled, the results were close to the experimental results, as can be seen in Table 5.6. This means that the model can now be used to predict the effect of different concrete mixes and/or block geometries. Those optimal concrete mixes and block geometries can then be built and undergo physical testing to validate the models. 


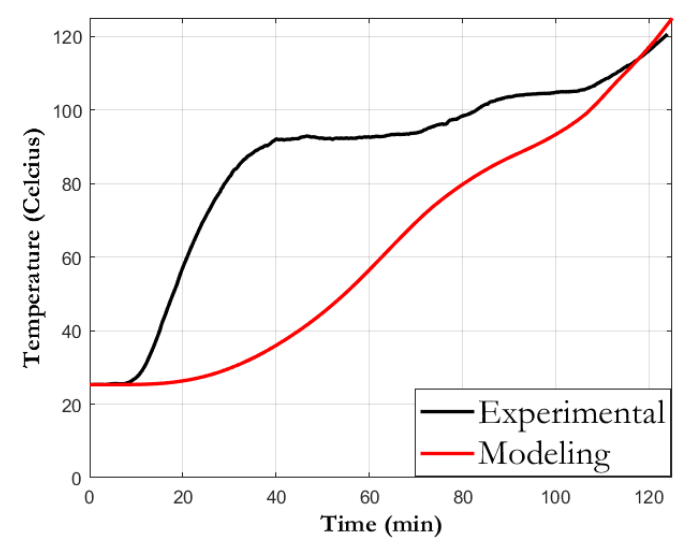

Figure 5.20: Rockwool Full unit experimental and numerical average unexposed time temperature curve comparison

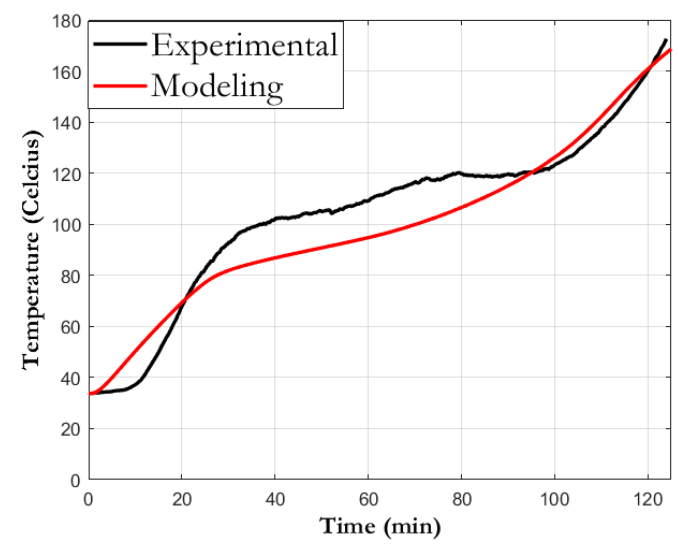

Figure 5.21: Rockwool 1inch unit experimental and numerical average unexposed time temperature curve comparison

\subsubsection{Summary of Creating a model}

The first step to creating a model for masonry was to create the proper shape of the block. Block and mortar dimension for each of the block and mortar types were used to create accurate models. The next step was to input the thermal properties of the different materials. These properties were taken from 5.1, with the specific heat corrected for the free water content. Once that is done the different materials are assembled (the blocks and mortar are put together) and set to be in contact with each other to allow for conduction between materials. The ambient conditions are put into place, and the appropriate standard fire temperature is set. The effects of convection and radiation within the cells are included, using values from Table 5.4 
Table 5.6: Error Between Experimental and Numerical Fire Resistance

\begin{tabular}{|l|l|}
\hline Block & Error \\
\hline 20cm Standard & $0.71 \%$ \\
\hline Reduced Web & $0.79 \%$ \\
\hline Raked Joint & $0.83 \%$ \\
\hline $15 \mathrm{~cm}$ Standard & $1.56 \%$ \\
\hline Carbon Cured $20 \mathrm{~cm}$ & $0.95 \%$ \\
\hline LW15cm & $13.20 \%$ \\
\hline Semi Solid $15 \mathrm{~cm}$ & $1.30 \%$ \\
\hline Split Face $20 \mathrm{~cm}$ & $1.60 \%$ \\
\hline Two Hour Fire & $0.48 \%$ \\
\hline Rockwool 1inch & $0.57 \%$ \\
\hline Rockwool Full & $0.62 \%$ \\
\hline
\end{tabular}

for specific heat and 0.94 as the emissivity. The appropriate mesh size is determined, and the model is validated using experimental data from multiple tests. 


\subsection{Modeling Results}

\subsubsection{The Effect of Aggregate types}

A thermal model of a hollow concrete masonry block was created using ABAQUS to test the effects of concrete aggregate types in order to demonstrate their effect on the time to failure of masonry materials (Figure 5.22).

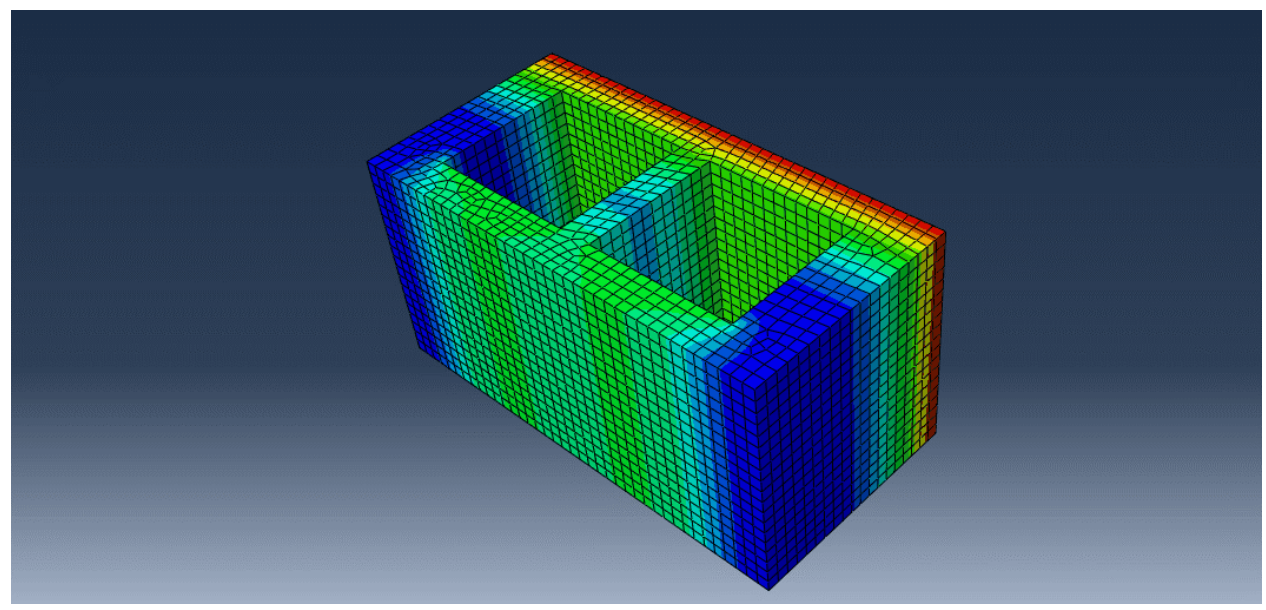

Figure 5.22: Finite Element Model of a Masonry Block

A $20 \mathrm{~cm}$ masonry block was used for all of the models. The values that were changed between different thermal models were the thermal conductivity and the density. The thermal conductivity were higher for temperatures below $100^{\circ} \mathrm{C}$, in order to account for free water's effect on the thermal conductivity. This was done by using the free water corrected values for temperatures under $100^{\circ} \mathrm{C}$, and then using the values without free water from for temperatures over $100^{\circ} \mathrm{C}$. Since no specific heat values were given in the table, the same specific heat was used for all mixes. The value chosen was that of a lightweight concrete since the densities from the table are mainly lightweight, and it was also the more conservative value. The effect of free water evaporation was incorporated by increasing the specific heat around the $100^{\circ} \mathrm{C}$ point to simulate the spike in specific heat. The purpose of the model was to qualitatively determine the effects different aggregates have on the fire resistance of the hollow cells and the solid webs. Because of this, the effect of cement and other mix designs aspects were not incorporated into the model.

Each of the different aggregate blocks were exposed to the standard fire, and their 
insulation failure times were found. The two failure temperatures of importance are the $140^{\circ} \mathrm{C}$ increase average temperature, and the $180^{\circ} \mathrm{C}$ increase at a critical point. Since the hollow cells are the critical location (being the hottest part of the block), the value for the $180^{\circ} \mathrm{C}$ was chosen to denote the failure of the cells. Since the solid web is less critical the $140^{\circ} \mathrm{C}$ temperature was chosen for its failure.

Figure 5.23 demonstrates the results for all different aggregate types. The most fire resistant aggregate was the expanded slag, and the least fire resistant was the pure cement. This makes sense, because the thermal conductivity of cement was consistently higher than all others, while the thermal conductivity of the expanded slag was consistently lower. Most of the mixes showed a decrease in fire resistance as the density increased. This would suggest that the negative effect of the increased thermal conductivity outweighed the benefit of the greater density. Some of the aggregates showed an increase in fire resistance with an increase in density at the lower density values. This means that the benefit caused by the increase in density outweighed the negative of the increase in thermal conductivity. This is most likely due to the fact that the change in density was more significant than the change in thermal conductivity at the lower density values. However, as the density continued to increase, these materials also began to show a reduction in fire resistance, similar to all of the other aggregates.

Figure 5.24 shows that the no-fines pumice has an increase in fire resistance at the lower density values, but the improvement lessens as the density increases, until it starts to decline. The change in density at the lower values is comparable to the change in thermal conductivity. However after the first three data points the thermal conductivity begins to increase more than the density, and so the fire resistance stops improving as drastically.

Figure 5.25 shows the difference in temperature between the hollow cell and the solid web. There is minimal temperature change in both locations before 25 minutes. This is due to the thermal inertia of the block, which means that it takes time for the heat on the exposed side to reach the unexposed side. Afterwards there is a slow increase in temperature, with the cell increasing slightly faster than the web. This slow temperature increase is due to the effect of the free water evaporating and increasing the specific heat until all of the free water is gone at $100^{\circ} \mathrm{C}(373 \mathrm{~K})$. Since there is more material (and therefore more free water) in the solid webs, it takes 


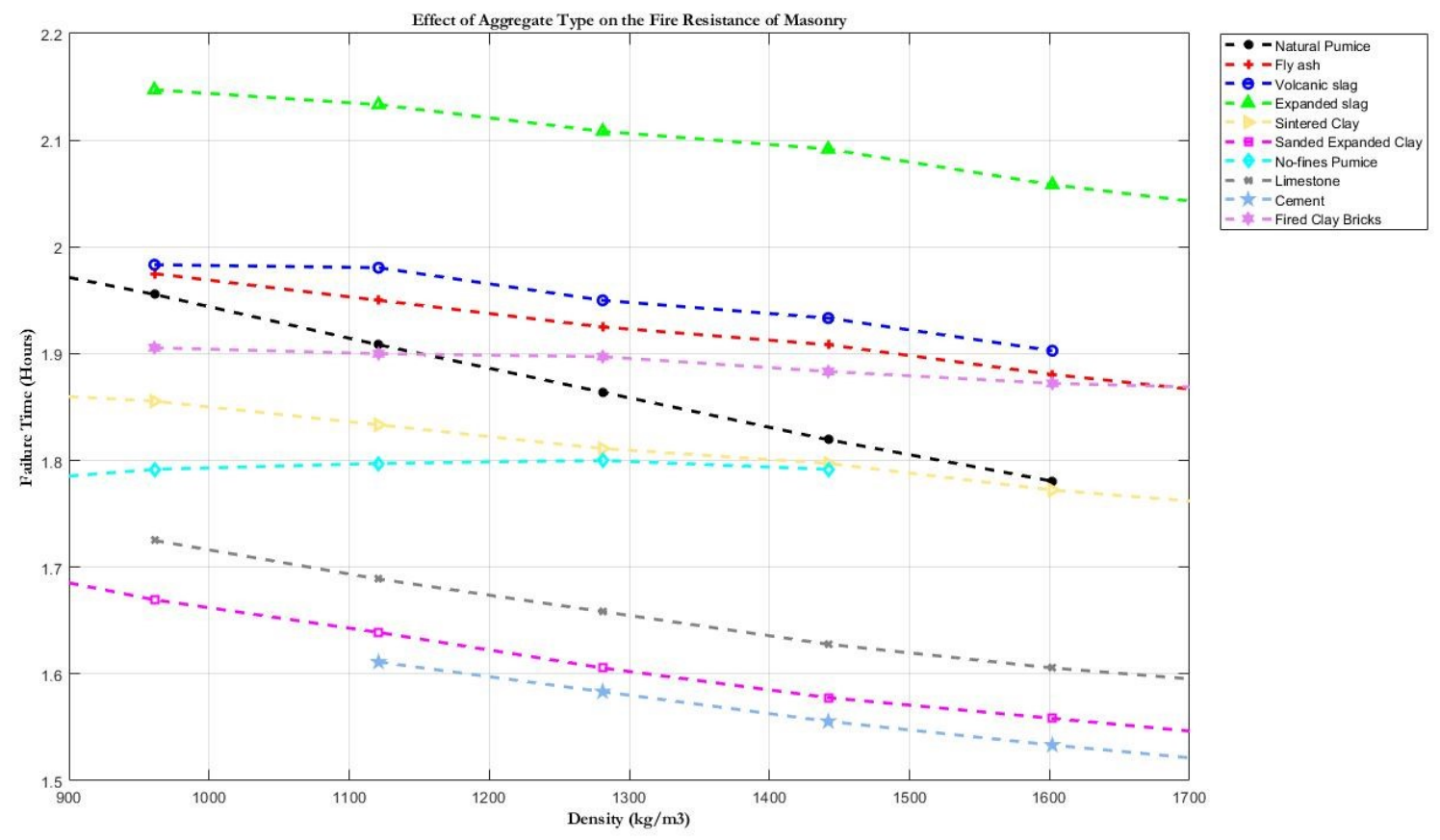

Figure 5.23: The change in failure times based on material

longer for the all of the free water to evaporate. This is why the solid web has a much longer period of slow temperature increase. The next stage is the rapid temperature increase after the free water has been evaporated.

Figure 5.25 shows the different failure times of the web section vs the hollow section. It can be seen that even with the $140^{\circ} \mathrm{C}$ failure temperature, the solid webs consistently fails after the hollow cell. The difference in failure between the two locations remains somewhat constant for different densities.

\section{Aggregate type Conclusions}

The aggregate type has a large impact on the fire resistance of concrete masonry. The lightweight aggregates are better for thermal insulation than normal weight aggregates due to their improved thermal properties.

The insulation capacity of most of the aggregates declined with an increase in density due to the increase in thermal conductivity. The expanded slag aggregate was found to be the best, with pure cement being the worst. This is another reason why low cement content of concrete can help the fire resistance as well as the sustainability 


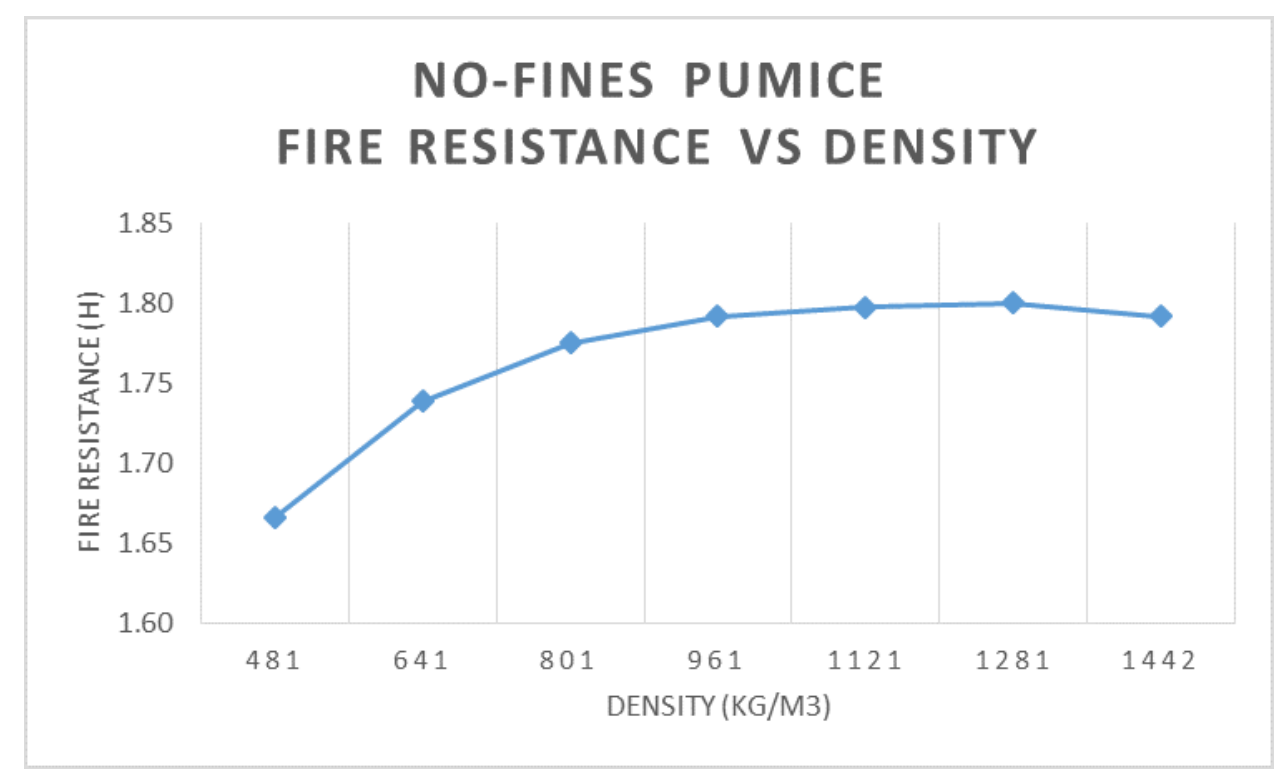

Figure 5.24: No-fines pumice fire resistance vs density

of concrete.

While all parts of the block decreased in fire resistance with an increase in thermal conductivity, it was found that the solid web took longer to reach a failure temperature than the hollow cell in all cases. This shows that the hollow cells are a point of failure for the blocks.

\subsubsection{The Effect of faceshell Thickness}

While the equivalent thickness method is a simple way to estimate the fire resistance of hollow concrete masonry, it is only based on the total amount of material. Since it does not take into account the different geometries that can be created with that same amount of material, it is not a good method to use to determine the fire resistance of non-standardized geometries. The first hypothesis that was tested was to determine the effect of faceshell thickness. In order to increase the thickness of the faceshell without increasing the amount of material, the web sizes needed to be altered. Since the outer two webs were larger than the middle web, the material was taken from these locations first. Once the three webs were reduced to the same size, the material was taken from all three webs equally. The minimum web thickness of $9 \mathrm{~mm}$ was chosen in order to ensure integrity of the webs if the theoretical block was actually 


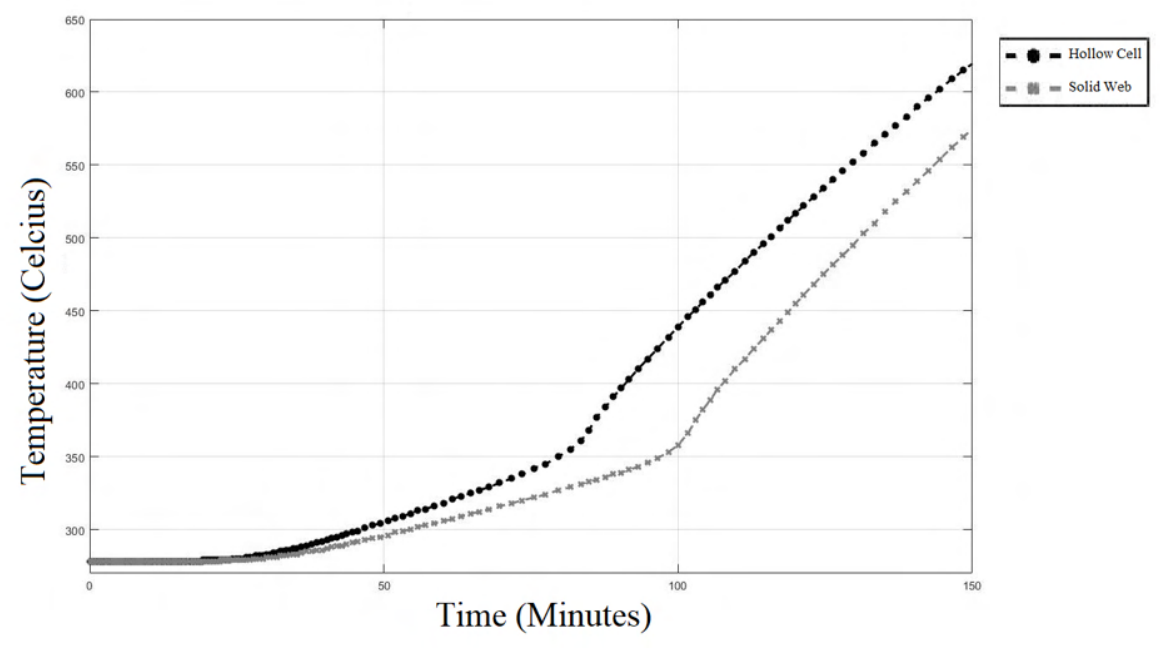

Figure 5.25: The difference between the web and the cell

constructed. The results of the test are shown in Figures 5.26a,5.26b, 5.27.

It was found that the faceshell thickness had a large impact on the fire resistance of the block. As the faceshell thickness increased the failure time also increased linearly for the hollow cells. This makes sense because there is now more material in that section which means larger thermal mass. This thermal mass is able to absorb more energy and lowers the temperature more before it reaches the cells, which means that the temperature radiating from the hot of the cells to the cold side is less. As radiation is based on temperature to the fourth power, a reduction in temperature radiating has a large impact on the amount of energy transmitted. As the effect of the radiation was minimized, the fire resistance of the hollow cells and the webs started to converge. The reason for the slope change of the web at $41 \mathrm{~mm}$ in Figure $5.26 \mathrm{a}$ was because that is when all the webs were the same size and so the middle web began to be reduced after that point. This reduction meant that the web heated up faster due to the reduction in thermal mass, however it was still improved because of the thicker faceshell. Therefore increasing the faceshell thickness by taking material from the webs improves the fire resistance of the block (both the cells and the webs). Since the webs do not have a large impact on the strength of the walls, this is a valid option for improving the fire resistance without increasing the equivalent thickness (and therefore without increasing the dead weight of the wall).

The reason the temperatures start to converge with the thicker faceshells in Figure $5.26 \mathrm{~b}$ is due to the fact that at the 2 hour mark some of the blocks are above $100^{\circ} \mathrm{C}$ and 


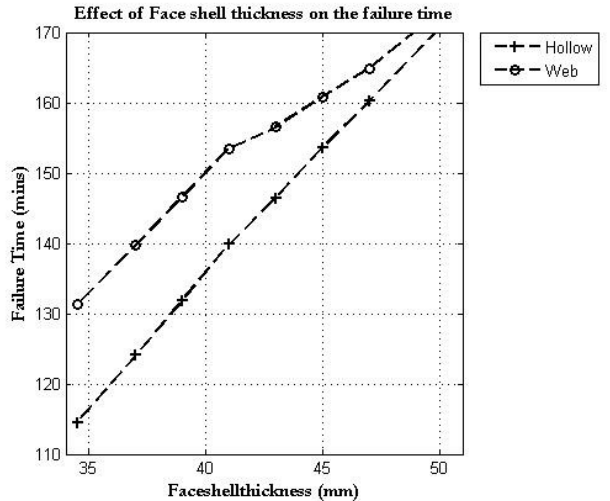

(a)

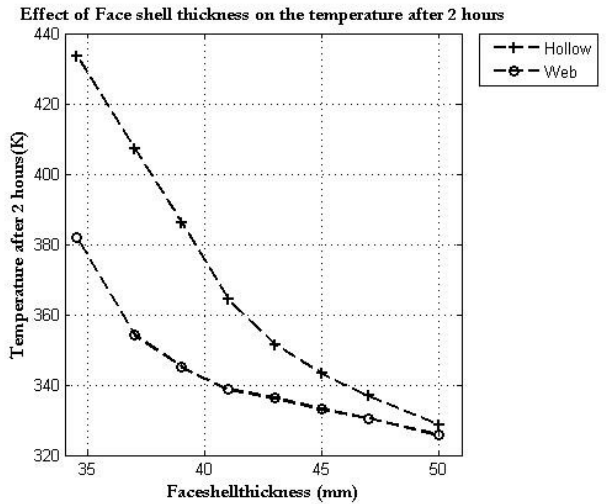

(b)

Figure 5.26: The effect of the faceshell thickness on the a) Failure Time b) Temperature after 2 hours)

some are below. The reason this affects the graph is because of the increased specific heat values inputed from $80^{\circ} \mathrm{C}-100^{\circ} \mathrm{C}$. The time temperature graphs all undergo a similar shape (Figure 5.27). There is a lag time at the start of the test where the temperature remains close to ambient. This lag is due to the fact that it takes time for the exposed side of the block to heat up and transfer that heat throughout the thickness of the block. Once the unexposed side starts to heat up there is a gentle increase in temperature, caused by the increased specific heat accounting for the free water. This ends at $100^{\circ} \mathrm{C}$ and the then the graph has a sharper increase in temperature. Since Figure 5.26b was taken at the 2 hour mark for each block, the thinner faceshells were at the 3rd stage, whereas the thicker faceshells were at the 2nd stage. This caused the convergence and non-linearity of the graph. It is important to note that while Figure 5.26a may cause it to appear that increasing the faceshell becomes less and less effective, Figure 5.26a and Figure 5.27show that there is a continued and linear increase in effectiveness. The shape for all of the graphs in Figure 5.27 are so similar that they are almost a transposition of each other.

\subsubsection{The Different Block Sizes}

Masonry blocks generally come in sizes starting from $10 \mathrm{~cm}$ and increasing by $5 \mathrm{~cm}$. They can be hollow, semi-solid, or solid (Figure 5.28). The hollow blocks have the least amount of material, with larger hollow cells. The semi-solid blocks have thicker faceshells and webs. Finally, the solid blocks are pure rectangles of concrete. As the 


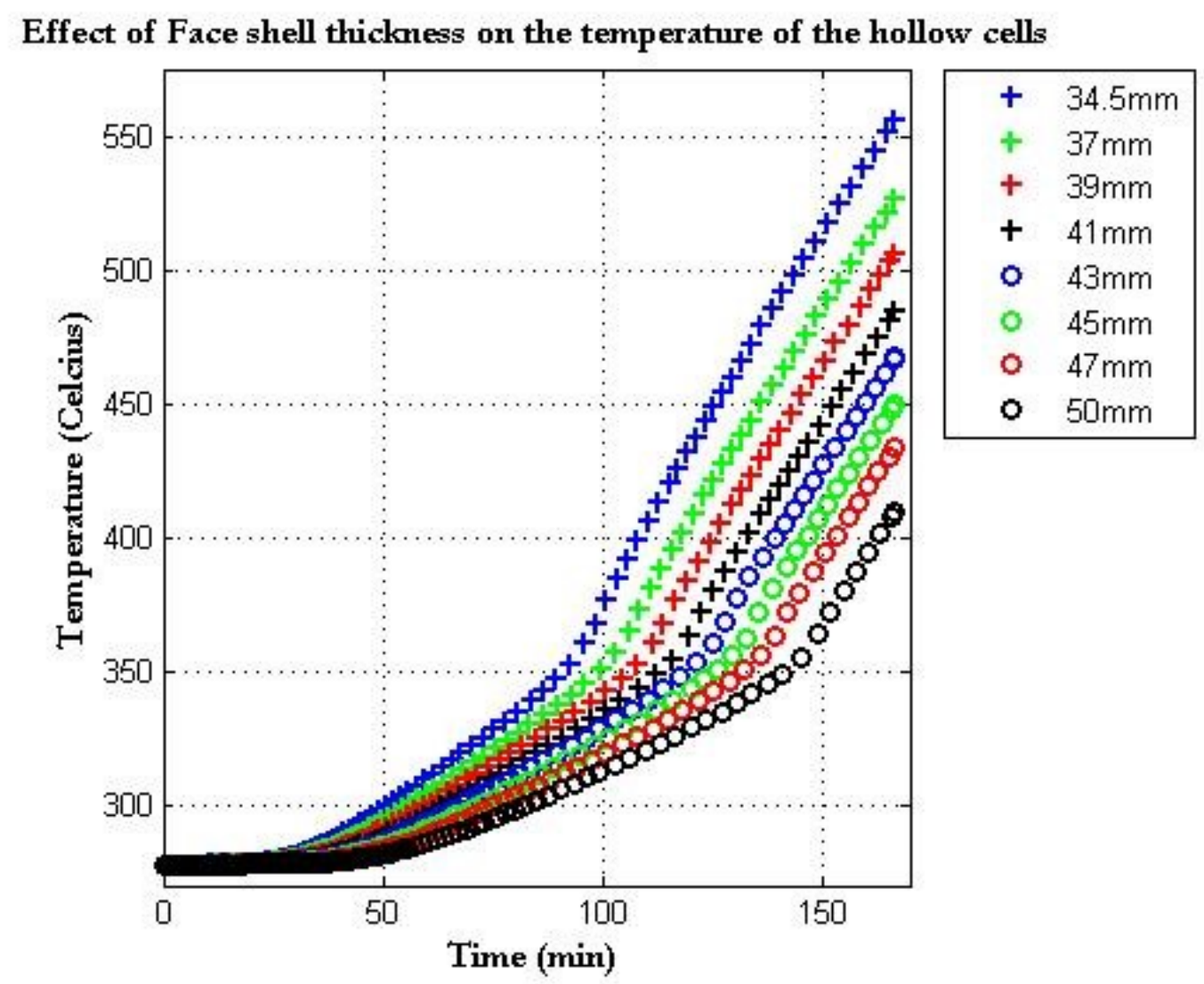

Figure 5.27: faceshell Model

equivalent thickness increases the fire resistance increases, so the hollow blocks are the least fire resistant, and the solid blocks are the most fire resistant.

The time temperature curves of four hollow blocks $10 \mathrm{~cm}-25 \mathrm{~cm}$ thick can be found in Figure 5.29. As the thickness of the blocks increases so does the fire resistance. The time temperature curve from the four $75 \%$ semi-solid blocks can be found in Figure 5.30. While increasing the thickness of the block improves the fire resistance, making the block itself more solid might be more beneficial in terms of saving space within the building. The improvement of the fire resistance of the semi solid blocks is more noticable with the larger blocks, as the faceshell thickness increases substantially for the larger blocks. The faceshell thicknesses for hollow blocks are $26 \mathrm{~mm}, 26 \mathrm{~mm}$, $32 \mathrm{~mm}$, and $35 \mathrm{~mm}$ for the $10 \mathrm{~cm}, 15 \mathrm{~cm}, 20 \mathrm{~cm}$, and $25 \mathrm{~cm}$ blocks respectively. For the semi-solid blocks, the faceshell thicknesses become $30 \mathrm{~mm}, 44 \mathrm{~mm}, 60 \mathrm{~mm}, 75 \mathrm{~mm}$ for the $10 \mathrm{~cm}, 15 \mathrm{~cm}, 20 \mathrm{~cm}$, and $25 \mathrm{~cm}$ blocks respectively. So while the difference in 


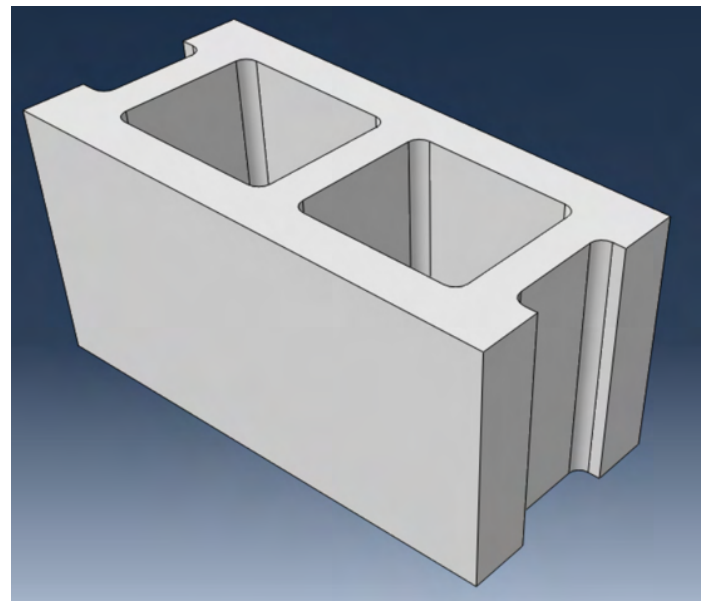

(a)

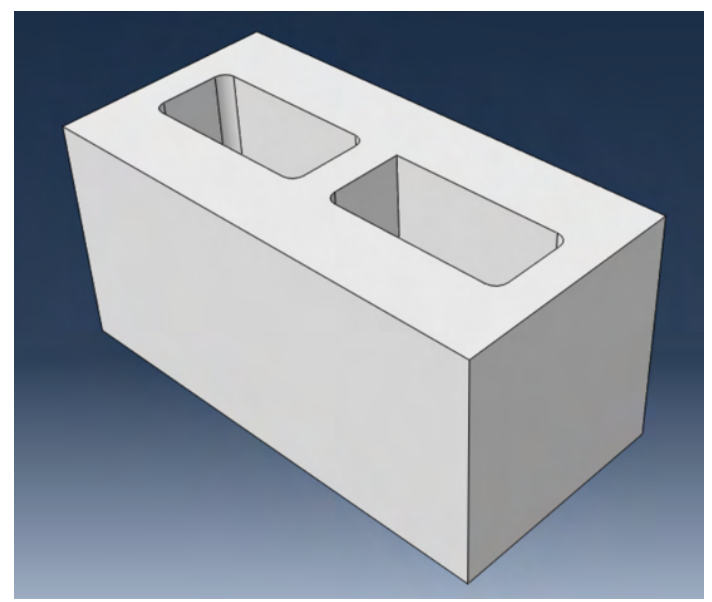

(b)

Figure 5.28: a) 25cm Hollow Block b) $25 \mathrm{~cm}$ Semi-Solid Block

hollow blocks faceshell thicknesses for all four blocks is under $10 \mathrm{~mm}$, the semi-solid blocks increase the faceshell thickness by up to $45 \mathrm{~mm}$. The $10 \mathrm{~cm}$ block has only minor changes to the geometry between the hollow and semisolid blocks, and so the difference between the two time temperature curves are minor. However, the thicker blocks show a larger improvement between the hollow blocks and semi-solid blocks due to the large increase in faceshell thickness.

\subsubsection{The Effect of an Asymetrical Block}

Harmathy's rules for fire resistance state that the fire resistance in one direction is not the same as the fire resistance in the other direction if the member is not homogeneous and symmetrical [44]. When comparing the fire resistance of two combined materials, having the material with the higher fire resistance on the fire side leads to improved fire resistance. In order to prove this rule an asymmetric block was created by removing $15 \mathrm{~mm}$ from one faceshell and putting it on the other. This created an asymmetric block with the same equivalent thickness but having one thick faceshell and one thin faceshell (Figure 5.31a). The rule would suggest that having the thicker faceshell on the fire side would lead to improved fire resistance, and from Figure 5.31 it can be seen that the rule is correct. The test with the thicker side exposed to the fire took longer to heat up. In the temperature range where the free water was being 


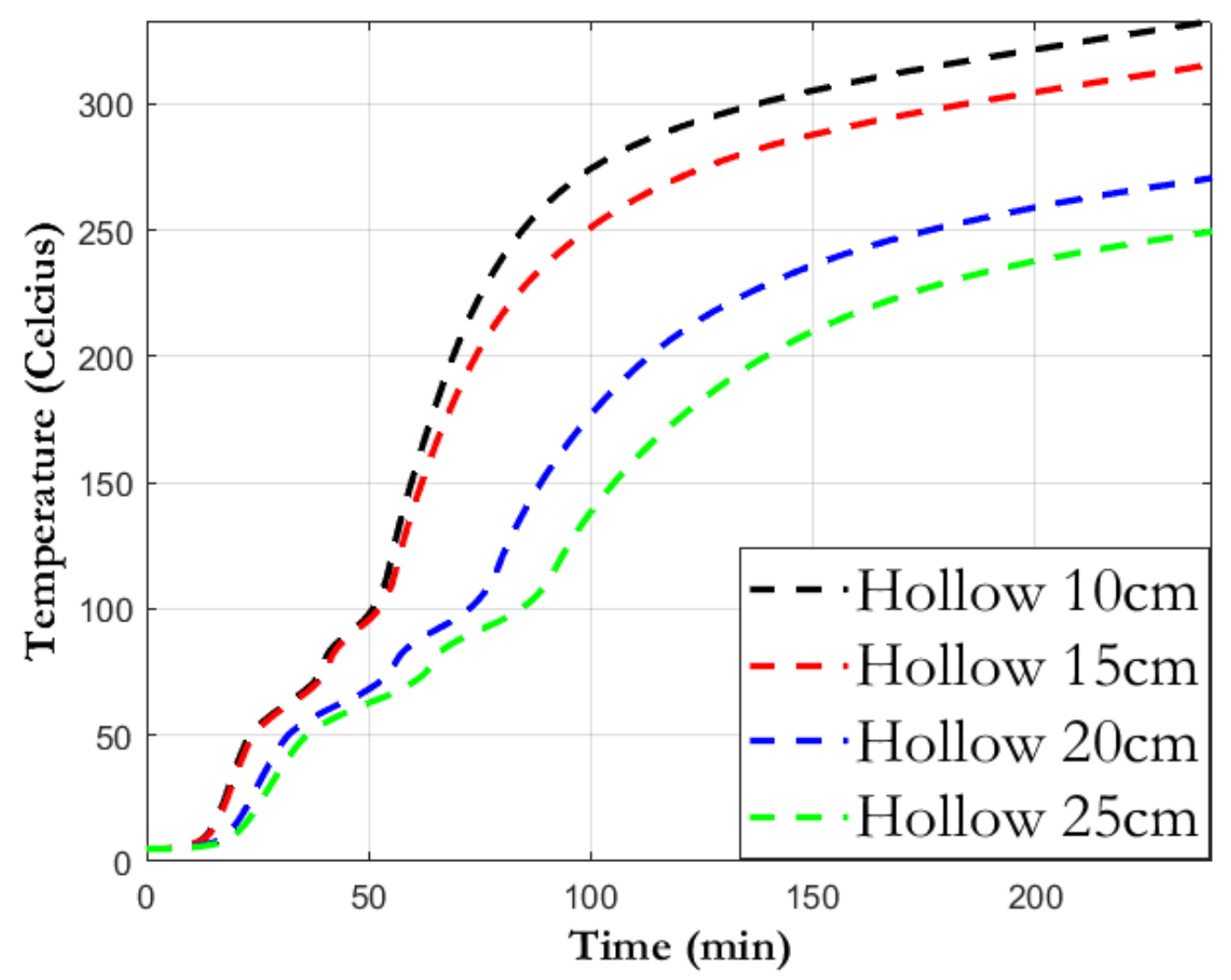

Figure 5.29: Effect of Different Hollow Block Sizes

evaporated both fire exposures were very close, but after the free water evaporated the block with thicker side exposed again remained cooler than its counterpart. This means that for partition walls where the fire is more likely to come from one specific side, an asymmetrical block might be beneficial.

\subsubsection{The Effect of an extra faceshell}

Having a thicker faceshell was shown to improve the fire resistance of concrete masonry blocks. This is the main reason why the lintel units have such good fire resistance, as they have thicker faceshells then standard units. Another option to improve the fire resistance would be to further divide the block into sections by adding an additional faceshell. A model was created in which the central web was removed, and the material from this web was used to create an extra faceshell within the block, Figure 5.32 EFS1. The original faceshells and the two other webs remained unchanged. It 


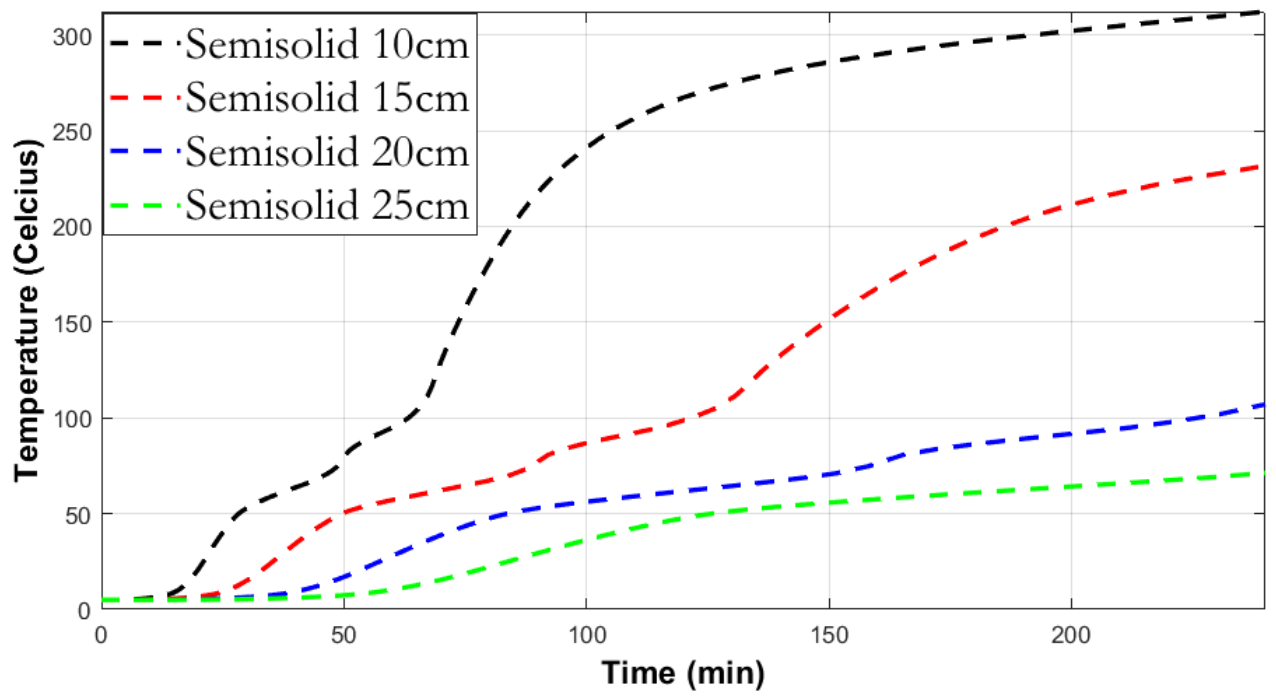

Figure 5.30: Effect of Different Semi-Solid Block Sizes

was found that the extra faceshell improved the fire resistance of the block (Figure 5.33). Three other models were created with different block geometries to determine their effect on the fire resistance. EFS2 was created by using half of the two remaining webs and creating another additional faceshell. EFS3 was created similarly to EFS2, but instead of two internal faceshells, one thick internal faceshell was created. Finally, EFS4 was created by taking part of the original faceshells in order to create two thicker internal faceshells. Relevant block dimensions can be found in Table 5.7.

Table 5.7: Extra Faceshell Block Dimensions

\begin{tabular}{|c|c|c|c|c|}
\hline Model & Faceshells & $\begin{array}{c}\text { Faceshell } \\
(\mathbf{m m})\end{array}$ & $\begin{array}{c}\text { Web } \\
\mathbf{( m m})\end{array}$ & $\begin{array}{c}\text { Extra Faceshell(s) } \\
\mathbf{( m m})\end{array}$ \\
\hline EFS1 & 1 & 34.5 & 28 & 12 \\
\hline EFS2 & 2 & 34.5 & 14 & 12 \\
\hline EFS3 & 1 & 34.5 & 14 & 24 \\
\hline EFS4 & 2 & 23 & 14 & 23 \\
\hline
\end{tabular}

All tests models other than EFS4 improved the fire resistance. The reason EFS4 did not improve the fire resistance is most likely due to the fact that material from 


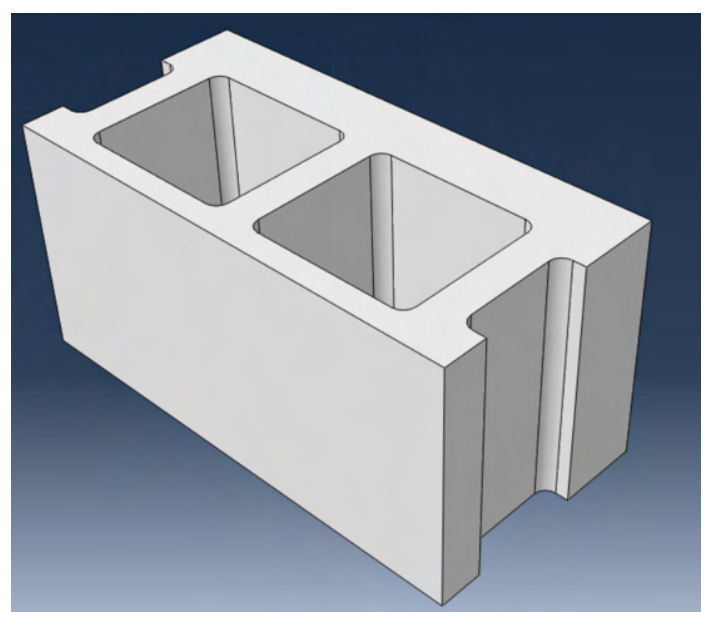

(a)

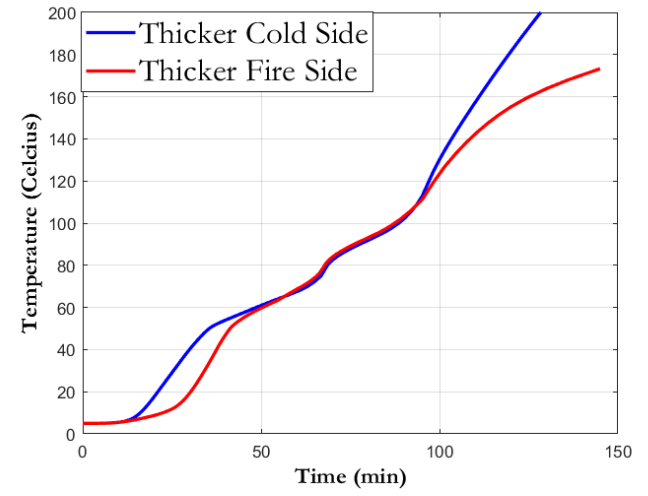

(b)

Figure 5.31: a) b)

the original faceshells was taken, making the faceshell on the fire side thinner. EFS1 and EFS3 were found to have similar temperature profiles, even though the extra faceshell in EFS3 was twice the thickness of EFS1. EFS2 was found to have the best fire resistance, because of the two interior faceshells and no reduction in the original faceshell thickness. When compared to the lintel beam only EFS2 was superior. EFS2 heated up faster than the lintel unit at the lower temperatures, but slower at elevated temperatures. This is likely due to the fact that at higher temperatures differences the effects of radiation are higher, and the EFS2 block does a better job at segregating the block so that the temperature differences are minimized. Therefore thicker faceshells improve the fire resistance of concrete masonry, but as long as the faceshell is not effected, adding more separation within the block also improves the fire resistance.

\subsubsection{Effect of Block Facing and Ribs}

Some masonry blocks are architectural facing units that have one side made different than the other. These can be split-face, which is when a few extra millimetres of concrete is placed on the surface of one side in order to give it texture. Another option is to add ribs to the concrete facings. In this case extra concrete is added on to one side of the masonry block, but there are slight indents within this extra concrete so that the surface is split up into multiple "ribs". Figure 5.34. shows the model of a split-face block, as well as a block with two and three ribs. The effect of the extra concrete improves the fire resistance of the blocks when compared to 


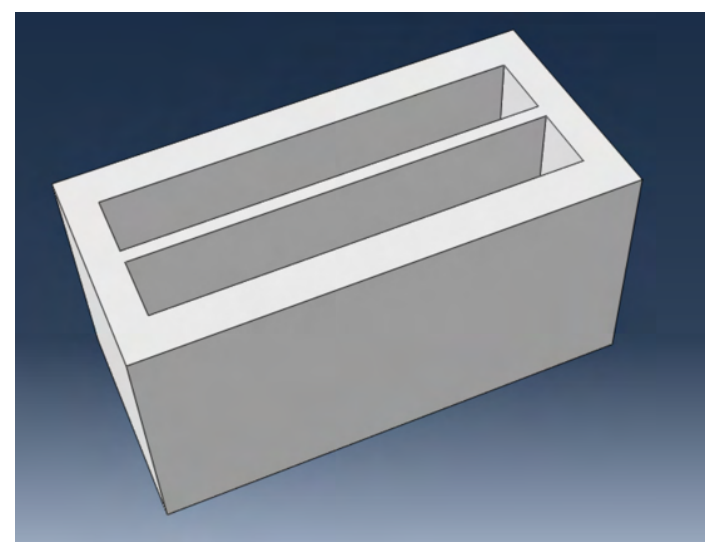

(a)

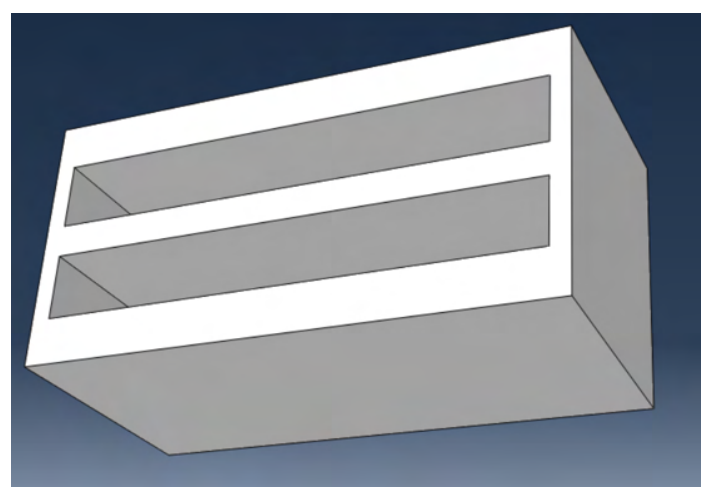

(c)

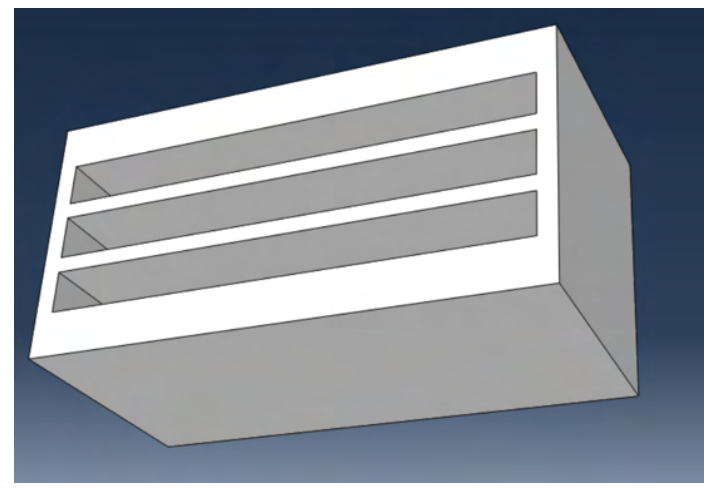

(b)

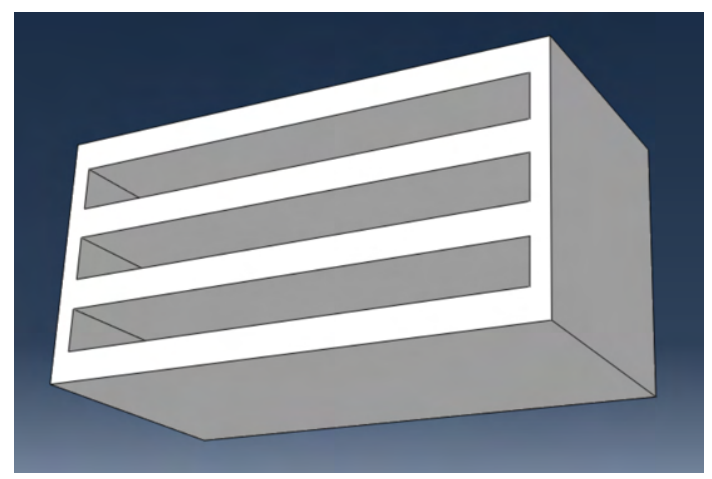

(d)

Figure 5.32: a) EFS1 b) EFS2 c) EFS3 d) EFS4

standard blocks. With the two ribs concrete is removed from just above the central web, and with three ribs the concrete is removed from above the hollow cells. Models were created for all three block types, with blocks ranging from $15 \mathrm{~cm}-25 \mathrm{~cm}$. The results are found in Figure 5.35 and Figure 5.36.

It was found that as the number of ribs increased, the fire resistance decreased. This makes sense, as the ribs allowed the fire to penetrate deeper into the block, thereby lessening the beneficial effects of the extra concrete. For the data taken in line with the hollow cell it was intuitive to understand that having a slight reduction in material over the web would lead to a reduction fire resistance, and a larger reduction in material over the hollow cells would cause a larger reduction in fire resistance. However, for the webs it was interesting to note that even though the block with 


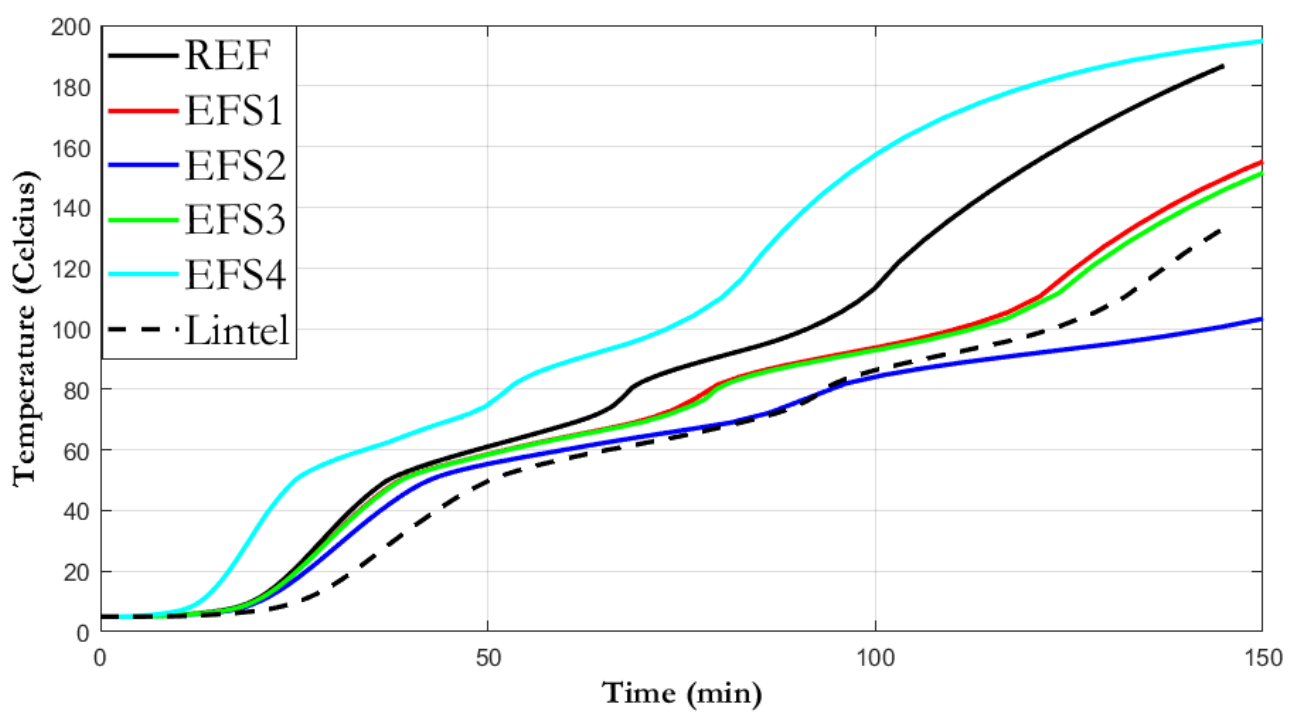

Figure 5.33: Effect of the different faceshell tests

three ribs did not have material removed above the web, the unexposed side of the web was still hotter than the block with two ribs. This seems to indicate that the number of defects within the block is more important than their location.

\subsubsection{The Effect of Insulation Material}

Modeling a full block with insulation is the next step to determine the effect of conduction through the block (Figure 5.37). There are several different block fillers such as gypsum, mineral wool, grout, etc. A $15 \mathrm{~cm}$ block was created with hollow cells, and the insulation material was created and placed inside of the hollows. Since there is no open air, the only method of heat transfer modeled was conduction. The values for the material properties can be found in Table 5.8.

Figure 5.38 show the time temperature curves of all materials tested. It was found that all insulation materials had a benificial effect on the fire resistance, increasing the time to failure by several hours. This seems to indicate that factors such as the cost, ease of installation, additional dead load, and high temperature stability will need to be factored in before deciding the most effective solution.

While materials like rockwool may not insulate as well as other materials like 


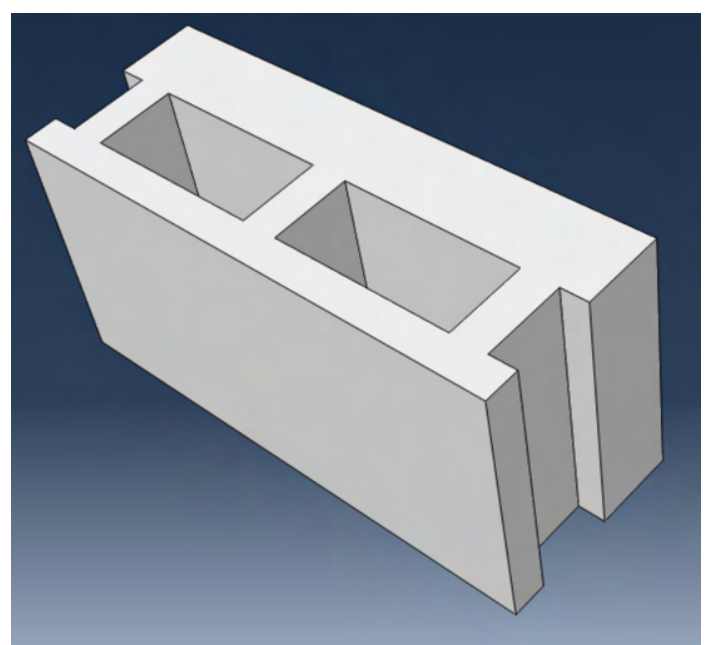

(a)

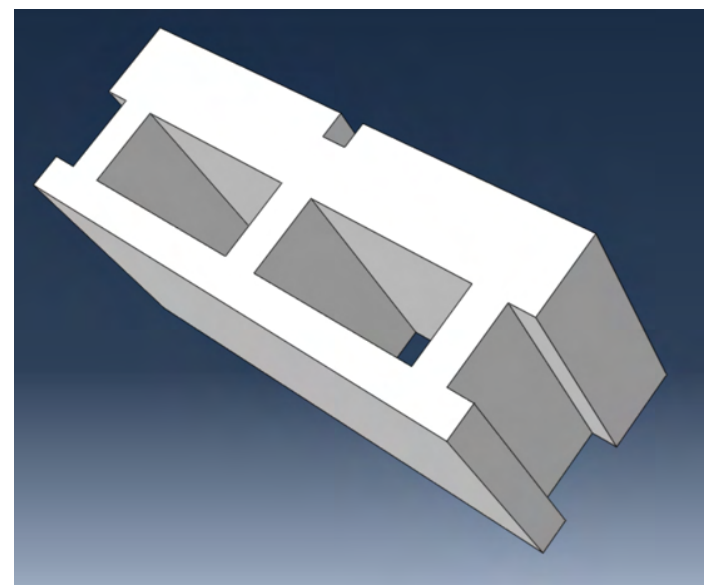

(b)

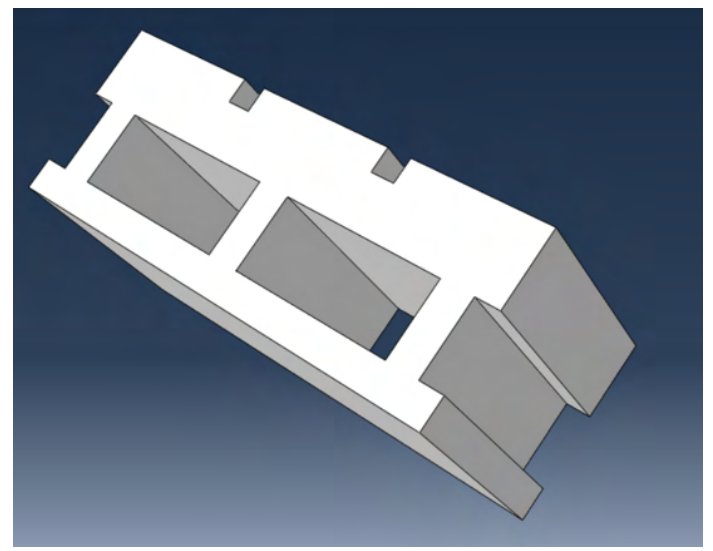

(c)

Figure 5.34: a) $15 \mathrm{~cm}$ Split Face Block b) $15 \mathrm{~cm}$ Split Face with two ribs c) $15 \mathrm{~cm}$ Split Facae with three ribs

gypsum and XPS, it has a higher resistance to elevated temperatures which might make it more useful. Also, some of the materials like XPS are combustible, which may have a negative effect on the fire resistance if damage to the member leaves them exposed. 


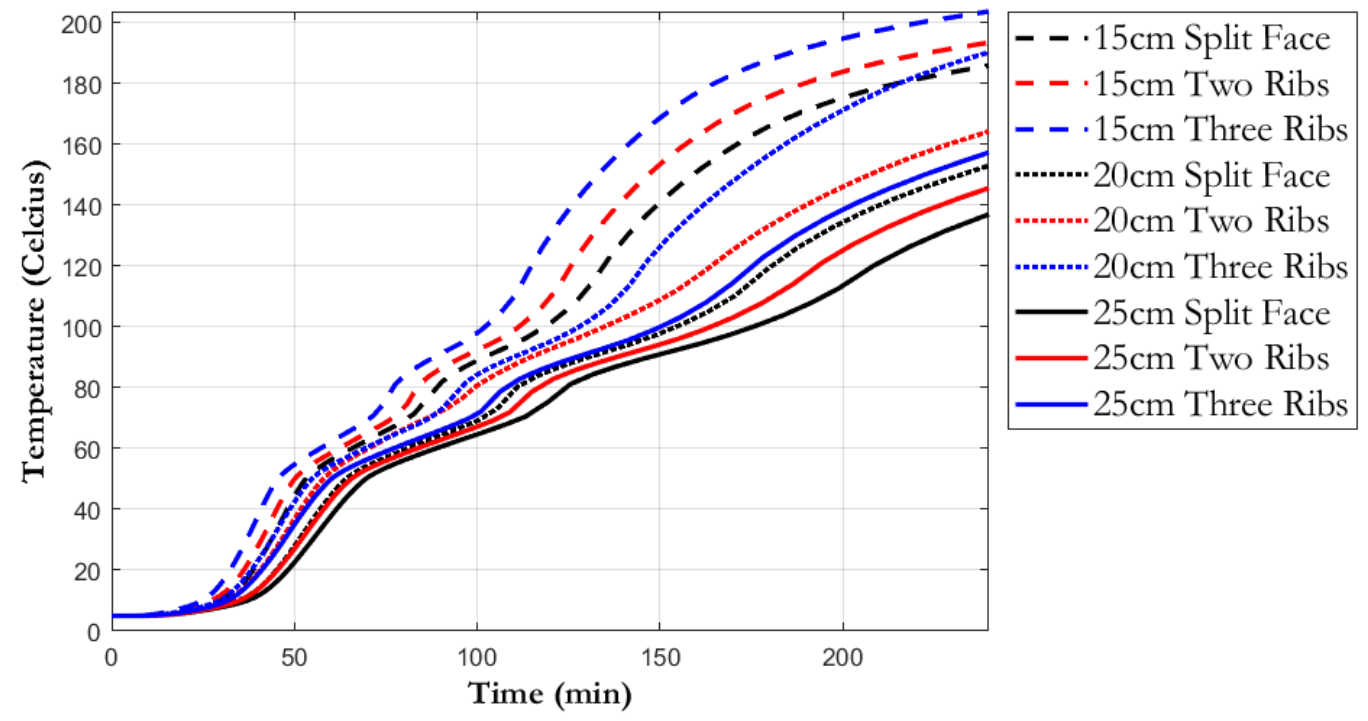

Figure 5.35: The effect of Ribs on the time temperature curves of the Hollow Cells with various block sizes.

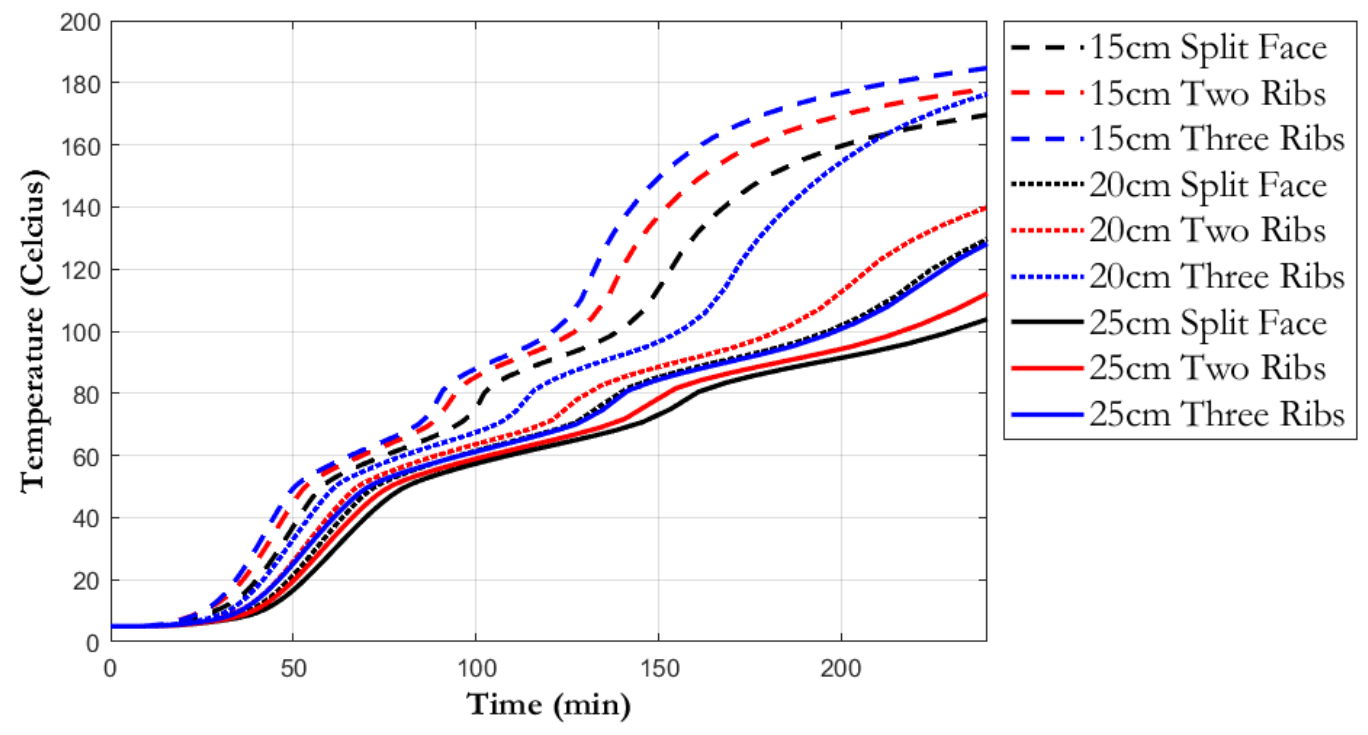

Figure 5.36: The effect of Ribs on the time temperature curves of the Solid Web with various block sizes 


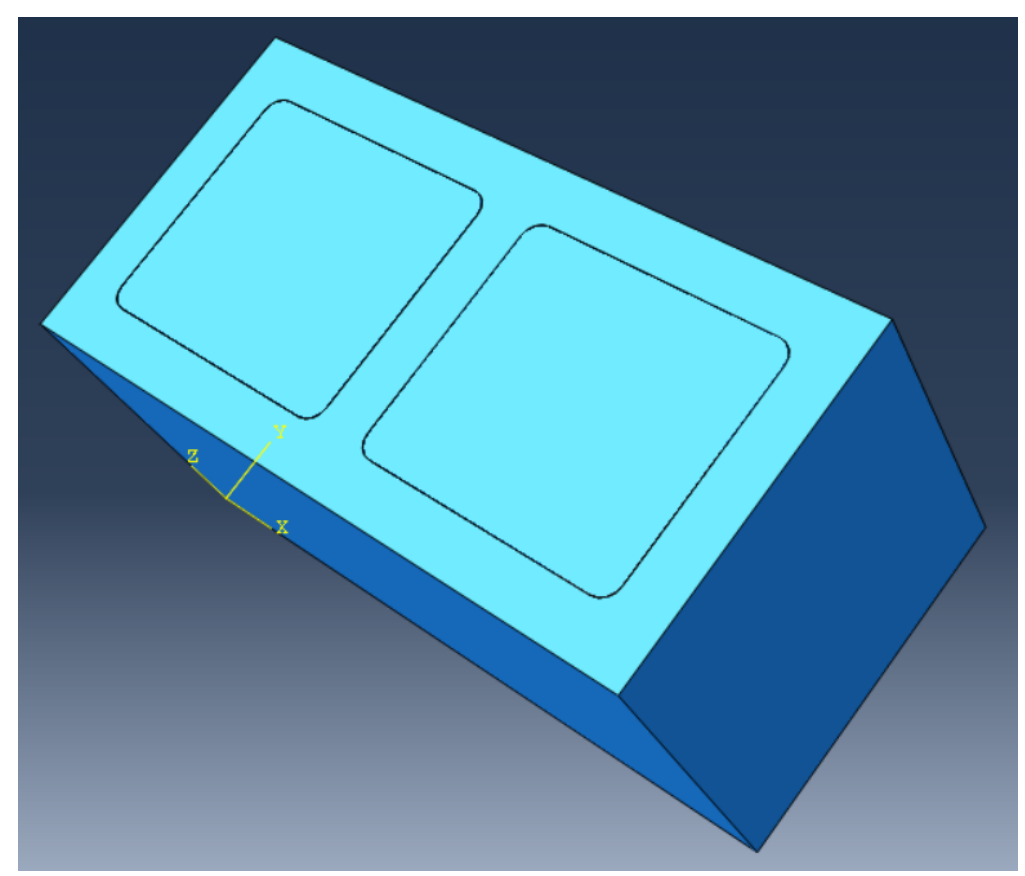

Figure 5.37: Block With Insulation Model

Table 5.8: Insulation Thermal Properties

\begin{tabular}{|c|c|c|c|}
\hline Material & $\begin{array}{c}\mathrm{k} \\
(\mathrm{W} / \mathrm{mK})\end{array}$ & $\begin{array}{c}\text { cp } \\
(\mathrm{J} / \mathrm{kg}-\mathrm{K})\end{array}$ & $\begin{array}{l}\text { Density } \\
(\mathrm{kg} / \mathrm{m} 3)\end{array}$ \\
\hline Cellulose & 0.046 & 1500 & 48 \\
\hline CorkSlab & 0.049 & 1500 & 150 \\
\hline Denim & 0.038 & 1340 & 40 \\
\hline EPS & 0.037 & 1500 & 20 \\
\hline PUR & 0.025 & 1300 & 35 \\
\hline Rockwool & 0.04 & 1000 & 60 \\
\hline Woodwool & 0.07 & 1500 & 180 \\
\hline XPS & 0.022 & 1500 & 21 \\
\hline Gypsum & 0.3 & 950 & 800 \\
\hline
\end{tabular}




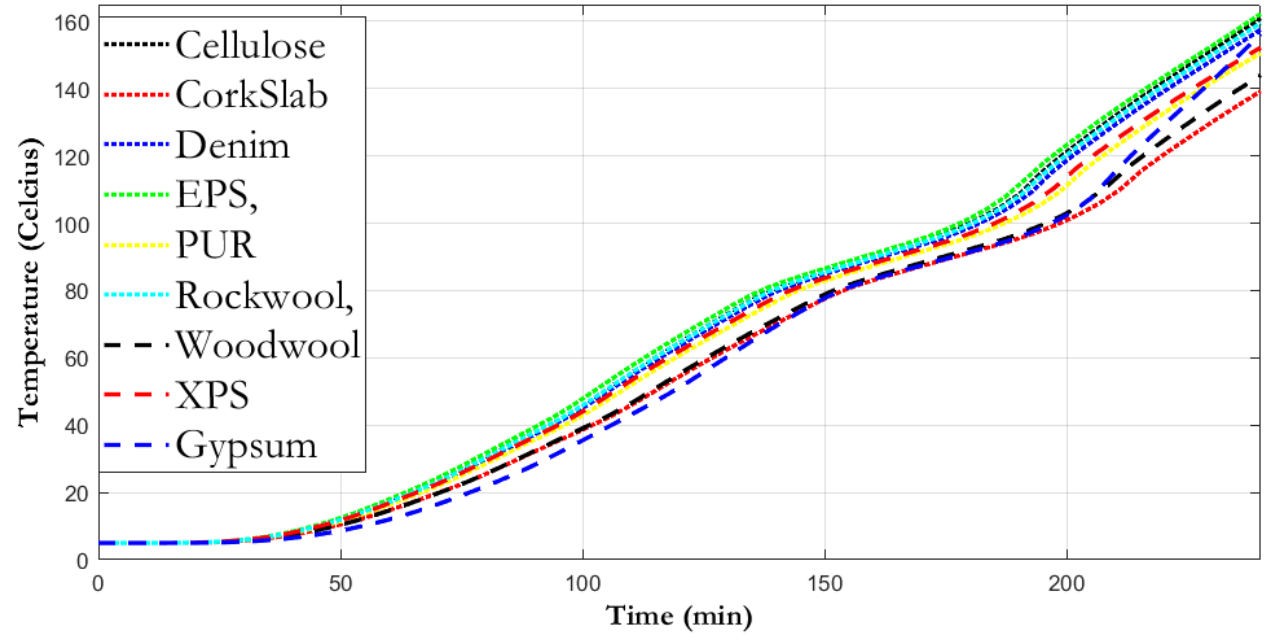

Figure 5.38: Block With Insulation Model 


\section{Chapter 6}

\section{Modeling Different Mix Designs}

\subsection{Methodology}

\subsubsection{Thermal properties collation}

A literature review of various journal papers was undergone in order to collate thermal properties of concrete mixes with NA, RCA, and LWA. While a large portion of the papers had complete data on the three thermal properties at various temperatures or temperature ranges, several had missing data from one of the three thermal properties. In cases when the thermal conductivity, specific heat, or density were missing from the journal results, appropriate values for the type of concrete being tested were used. These assumed values were left constant for all mixes from the same source to allow for more accurate comparison of results. Some of the specific heat results already accounted for the spike in specific heat due to the free water within the concrete, others did not. In order to ensure that the results could be better compared, the effects of free water were included in all of the models. Due to the variability of the thermal properties, comparing between different researchers should only be done qualitatively.

\subsubsection{Model creation}

A thermal model of a $20 \mathrm{~cm}$ normal weight concrete masonry wall was created using finite element software and validated with physical testing results from Pope2020 (Figure 6.1) [42]. The model was created to compare the results of a standard fire test on masonry walls, and so the model was subjected to the CAN-ULC-S101 standard fire [38]. The model included all three heat transfer methods through the masonry 
block. Conduction through the solid concrete, as well as radiation and convection between the hollow cells and frogs. The values of emissivity and convective heat transfer at different temperature ranges had been previously determined through iterations of model refinement. The thermal properties of the concrete in the model were altered in order to match the thermal properties of each new test mix. This means that the results can be compared to each other and the estimated fire resistance of different mix designed can be determined. The results allow for the comparison of different thermal properties that arise from the different aggregate types tested.

Temperature data was taken from the hottest point on the unexposed side of the unit. The hottest point was found to be the surface of the hollow cell due to the increase in convection and radiation through the air at elevated temperatures.

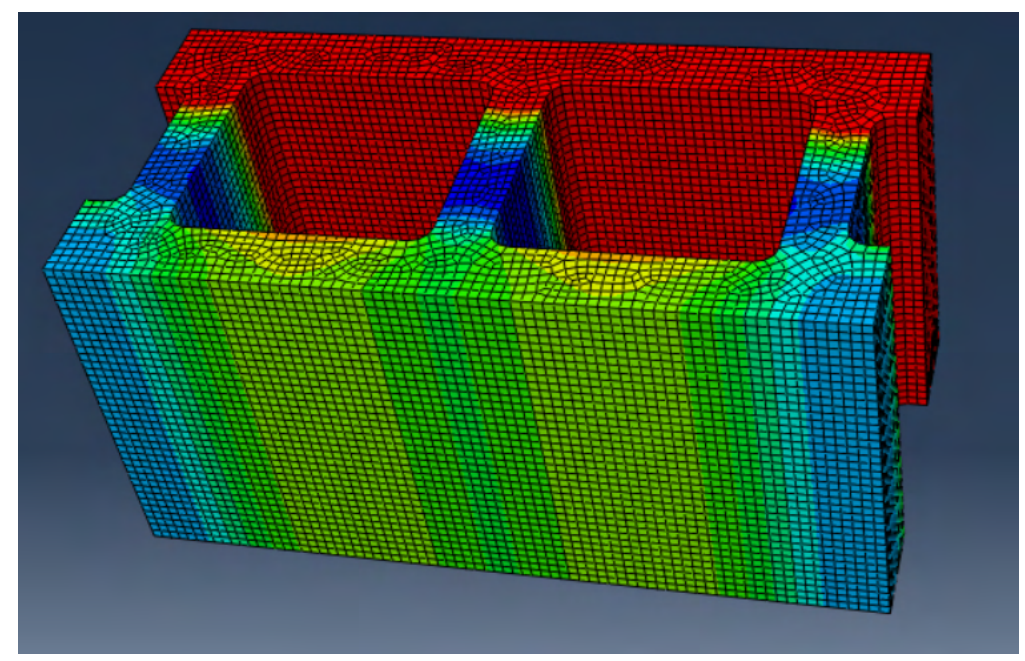

Figure 6.1: Thermal Modeling Block

\subsection{Aggregate Type Results}

\subsubsection{Effect of changing different thermal properties}

The three thermal properties of concrete can vary between mix designs, but it is important to know just how much the variation in thermal conductivity, specific heat, or density effects the fire resistance of a concrete masonry unit. A series of blocks were modelled in order to determine how changing one thermal property while leaving the other two the same would affect the failure time. The thermal conductivity was 
varied from $0.4-3.2 \mathrm{~W} / \mathrm{mK}$, the specific heat was varied from $500-2400 \mathrm{~J} / \mathrm{kgK}$, and the density was varied from $1800-2500 \mathrm{~kg} / \mathrm{m} 3$. The failure times for each point was found and plots were created to compare the effects of the different thermal property ranges.

Figure 6.2a demonstrates the change in thermal conductivity. It be seen that the lower the thermal conductivity the higher the fire resistance (longer failure time). The effect of thermal conductivity is not linear, and so the increase in fire resistance between 3.0-2.5 W/mK is much lower than the increase in fire resistance between 1.5$1.0 \mathrm{~W} / \mathrm{mk}$. Figure $6.2 \mathrm{~b}$ demonstrates the change in specific heat. It can be seen that the higher the specific heat the higher the fire resistance. For this test the effect of free water was kept constant throughout. It can be seen that the effect of specific heat is linear, so any increase in specific heat will yield roughly the same increase in fire resistance. Figure 6.2c demonstrates the change in density. The higher the density the higher the fire resistance. While denser materials normally have worse thermal properties, density itself improves the thermal performance due to there being more material to absorb heat.

Changing the mix design will result in different thermal properties. If all the thermal properties of the new mix are better than the reference mix, then the new mix will have an improved fire resistance. However, when the change involves many different changes to the thermal properties at different temperatures, it can be difficult to determine the fire resistance without modeling or physical tests.

\subsubsection{Normal weight concrete}

There are many different concrete mixes that are defined as normal weight concrete (NWC) or normal strength concrete [3] [4] [42] [5] [75]. However, the thermal properties of these mixes can vary significantly depending on the exact mix design used. In most NWC the aggregates used are either Calcareous (such as limestone) or Siliceous (such as granite). The two aggregates have different thermal performances, with siliceous aggregates usually having higher thermal conductivity as well as higher specific heats when compared to calcareous aggregates [3] [76]. Calcareous aggregates usually provide better fire resistance; however, as can be seen from Figure 6.3, this was not the case for Naser 2019 [3]. This variability in mix designs and time temperature curves in Figure 6.3 is one of the reasons quantitative comparisons between 


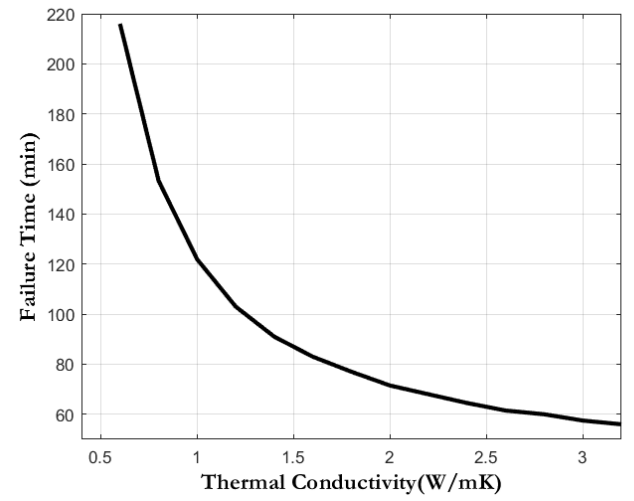

(a)

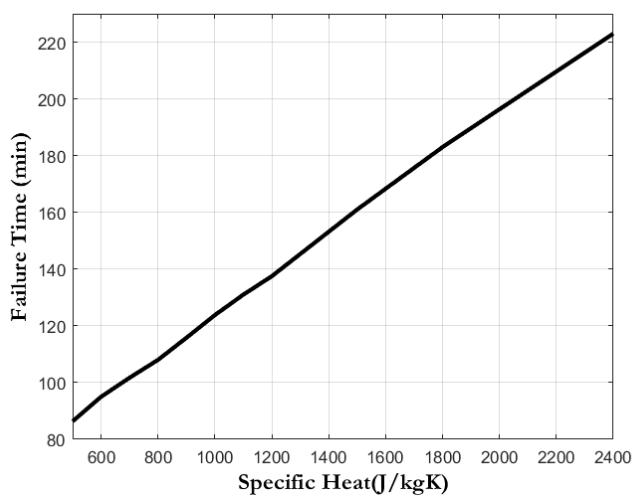

(b)

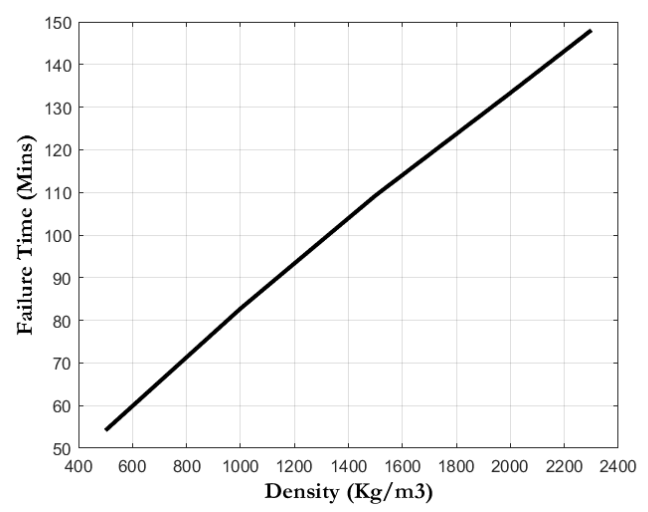

(c)

Figure 6.2: The effect of changing different thermal properties (a) Thermal Conductivity (b) Specific Heat (c) Density

researchers is difficult. If the reference concretes are too different, then even a qualitative comparison is difficult to achieve. Keeping the different mix designs in mind while comparing results is imperative.

\subsubsection{RCA}

RCA has a higher degree of variability when compared to natural aggregates. This is because the source of the RCA and its aggregate size can have a large impact on its performance [78]. Regular concrete's properties vary based on aggregate type, w/c ratio, and additives. RCA concrete has this variability not only in the mix design, but within the aggregate itself [78]. Because of this, many researchers have varied or 


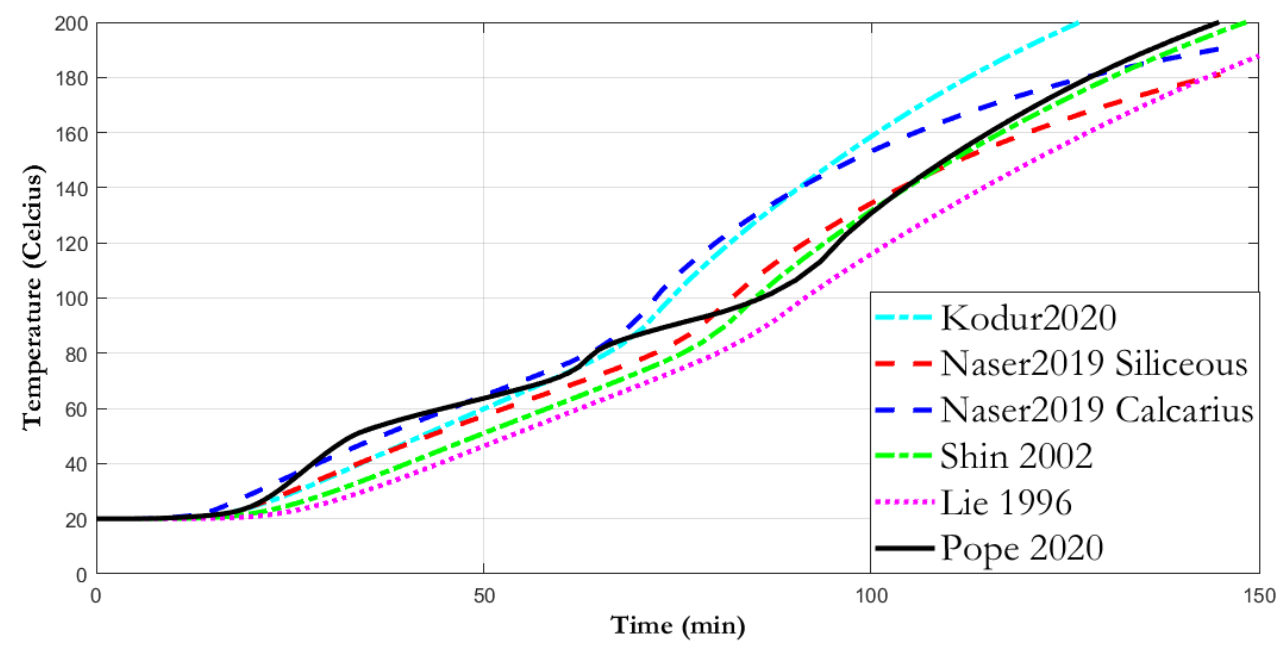

Figure 6.3: Modeling time temperature curves of normal weight concrete mixes. [77]

contradicting results when it comes to its performance. Other aspects that impact its performance is the method in which the RCA concrete is prepared. RCA may need to be wetted before mixing in order to improve the workability of the concrete, or special additives could be used to achieve the same effect [78]. All of the research presented here is on RCA from demolished buildings.

In general, RCA has lower density and lower thermal conductivity when compared to NA [78]. The reason for these reductions is because RCA concrete is more porous due to the mortar attached to the aggregates [78]. As can be expected, the higher the RCA replacement, the greater the effects. As the temperature increased both the thermal conductivity and density decreased, partly due to the loss of free water [78]. The specific heat is usually similar for the NA and RCA mixes, and they followed the same changes with temperature [78]. The mechanical properties of RCA are again variable. The decrease in density usually results in a decrease in compressive strength. Depending on the RCA, this decrease in strength can be minimal, but in some cases a significant drop in compressive strength can occur when RCA is added.

Zhao 2018, Tosic et al 2015, and Guo et al 2020 all researched the effect of different RCA replacement percentages. The results between the tests showed the same trend, with RCA having improved fire resistance as the percentage of RCA increased from 0-100\%. However, the magnitude of the improvement was different between the tests.

For Zhao 2018, since the density and thermal conductivity were reduced without large changes to the specific heat, the fire resistance of the concrete improved with 
the addition of RCA (Figure 6.4a). The mix with 50\% RCA replacement had a 6.6\% higher fire resistance, and the mix with RCA 100\% replacement had a $26.6 \%$ higher fire resistance.

Guo et al 2020 looked into the thermal insulation properties of recycled aggregate thermal insulation concrete (RATIC) [79]. This is thermal insulation concrete (TIC) that includes both RCA as well as glazed hollow beads (GHB) [79]. The compressive strength decreased as the amount of RCA increased, for a maximum strength loss of $25 \%$ [79]. The thermal performance improved by up to $50 \%$ with a $100 \%$ RCA replacement (Figure 6.4b).

Tosic et al 2015 research NA with both natural river aggregate and crushed stone aggregate, as well as 50\% and $100 \%$ RCA replacement of the coarse aggregate [80]. It was found that the compressive strength between the mixes were all very similar, along with the density and thermal conductivity [80]. The modeling results demonstrated mix failure times all within 5 minutes of each other (Figure 6.4c).

As RCA can be quite different from one researcher to the next, it is likely that the RCA used in Zhao 2018 and Guo et al 2020 was quite different from the NA, whereas in Tosic et al 2015 the RCA likely had similar properties to the coarse aggregate used. This would explain why in some tests the improvement was more significant.

Marinkovic et al 2010 and Damdelen et al 2014 studied the effect of w/c ratio on NA and mixes in order to determine their effects. Marinkovic et al 2010 studied the effect of NA and 65\% RCA mixes with different w/c ratios $(0.6,0.52$, and 0.47$)$ [81]. Damdelen et al 2014 researched the effect of NA and $30 \%$ RCA with different w/c ratios of 0.57 and 0.35 [82].

For both researchers, as w/c ratios decreased, the compressive strength increased due to an increase in concrete density. However, it was found that concrete with lower w/c ratios had worse thermal properties than those with higher $\mathrm{w} / \mathrm{c}$ ratios. The reason for this is most likely related to the density of the concrete, as lower w/c ratio usually means higher density concrete. The major benefit of the lower w/c ratio was the increase in compressive strength, so it would be up to a designer whether or not an increase in compressive strength is worth a decrease in fire resistance. Damdelen et al 2014 found that the w/c ratio improved the fire resistance by roughly 20 minutes, whereas Marinkovic found that the improvement was only within a few minutes, with the RCA having the largest variance in thermal performance likely due to the variability of the aggregate. 


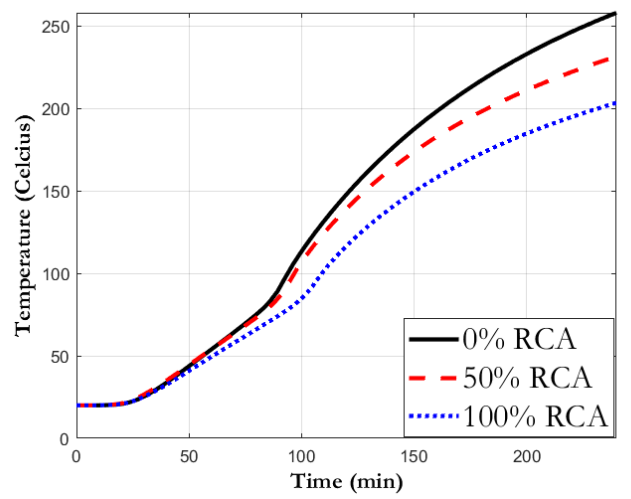

(a)

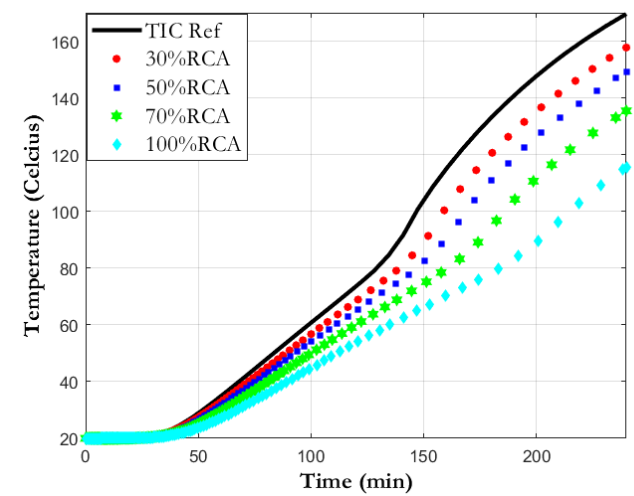

(b)

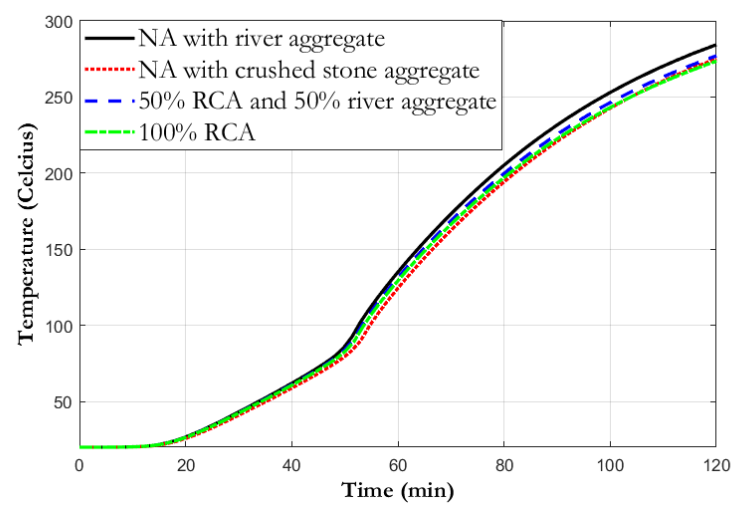

(c)

Figure 6.4: The effect of RCA replacement (a) Zhao 2018 (b) Guo et al 2020 (c) Tosic et al 2015

For Damdelen et al 2014 it was found that the RCA had improved fire resistance for all w/c ratios, with the RCA concrete failing roughly 50 minutes after the NA concrete (Figure 6.5a). This is the expected result and matches results from Zhao 2018, Tosic et al 2015, and Guo et al 2020. Marinkovic et al 2020 however found that the RCA had reduced fire resistance when compared to the NA.

Marinkovic et al 2020 found that the RCA mixes showed improved thermal conductivity but significantly lower density [81]. The densities of the RCA mixes were roughly half of the NA mixes [81]. Because of the large drop in density, the RCA mixes demonstrated a decrease in thermal performance by 35 minutes when compared to the NA concrete (Figure 6.5b). While the compressive strengths are comparable, this RCA mix is not optimal for fire resistance due to the much lower density and 
only a small decrease in thermal conductivity. These results seem to indicate that either a much lighter aggregate was being used as the RCA or the RCA was causing a major increase in porosity in Marinkovic et al 2020's research. These scenarios would account for the extreme change in density and thermal performance.

As RCA can be quite different from one researcher to the next, it is important to know how close the NA aggregate properties are the RCA being used. In general RCA improves the thermal performance with a decrease in mechanical properties, but the extent of these changes relies on how different the RCA is to the NA. RCA could be used as an environmental substitute without major changes in the mechanical and thermal properties if appropriate testing is done on the specific RCA being used.

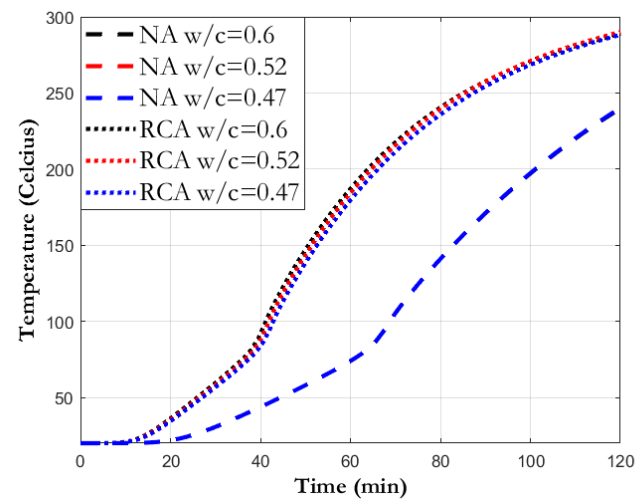

(a)

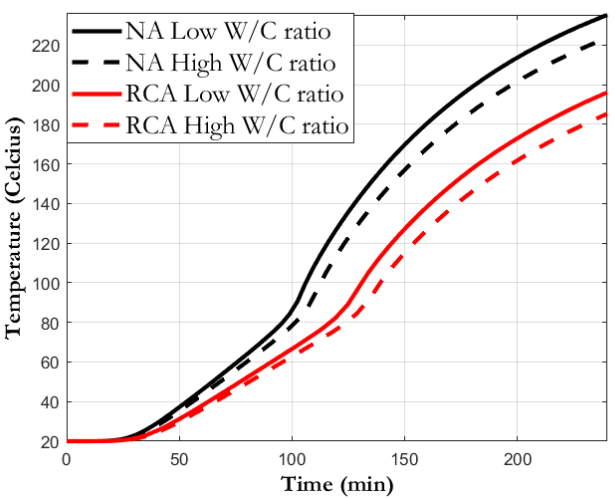

(b)

Figure 6.5: RCA concrete with different w/c ratios (a) Marinkovic et al 2020 and (b) Damdelen et al 2014

\subsubsection{Common LWA Mixes}

Pumice is a porous aggregate made from volcanic rock. Due its porosity, it has lower thermal conductivity and density [83] [84]. However, when pumice is added, the ambient compressive strength of the concrete reduces to $35 \%$ or more with $100 \%$ PA replacement [83]. It was found that the unit weights, thermal conductivity, and compressive strength of concrete all decrease with an increase in PA ratio and temperature [83] [84]. PA was found to improve the fire resistance of concrete, and the more aggregate replaced the longer it would take to fail. For the biggest improvement in fire resistance, a larger percentage of aggregate will need to be replaced. As 
concrete with PA aggregate is not as strong, it would work better in non-loadbearing partitions.

Turkman et al. 2017 and Uysal et al 2004 researched the effect of pumice aggregate (PA) replacement [83] of the fine aggregate, up to $100 \%$ replacement. The results of the modeling can be seen in Figure 6.6. From Turkman et al 2017 the failure time increased steadily with an increase in PA. For Uysal et al the improvement in fire resistance was less for the mixes up to $75 \%$, and much higher for the $100 \%$ PA mix. The main reason for the difference in thermal performance was that Uysal et al 2004 had a density reduction of $41 \%$ compared to the density reduction of $13 \%$ in Turkman et al 2017. Lower density leads to lower thermal conductivity, but sometimes the decrease in density causes the concrete to heat up faster earlier in the test. Both results show that using $100 \%$ pumice improves the fire resistance, but the magnitude of that improvement is related to the exact aggregate and mix design.

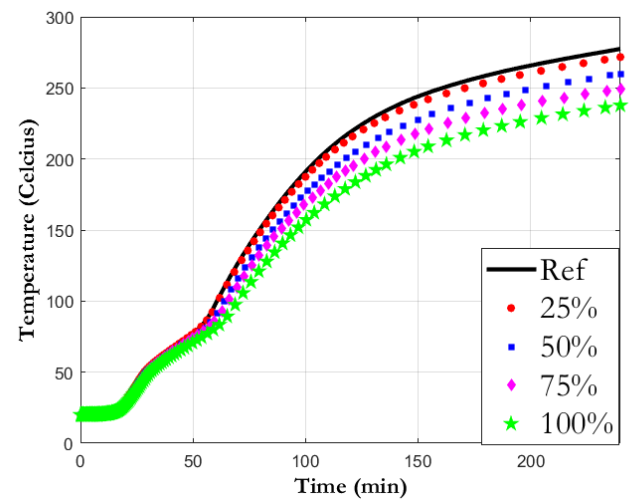

(a)

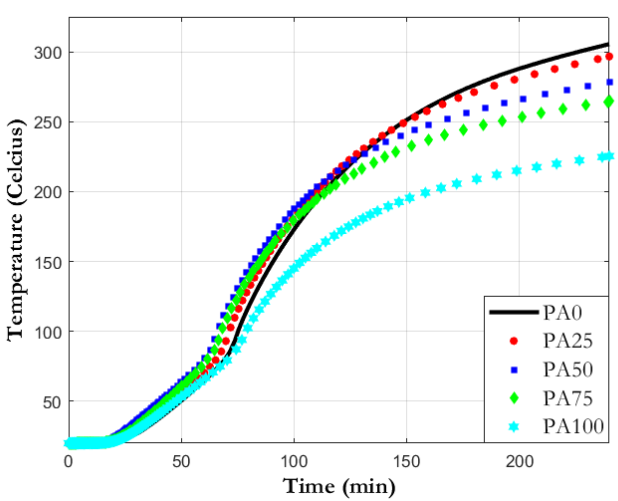

(b)

Figure 6.6: The effect of pumice replacemnt on fire resistance (a) Turkman et al 2017 (b) Uysal et al 2004

Nguyen 2014 et al researched the effects of different coarse LWA, different fine LWA replacement, as well as different coarse aggregate sizes [85]. The different aggregate types used were clay, pumice, and shale [85]. The coarse LWA replaced the NWA completely while the fine NWA was partially replaced by either 0,50 , or $100 \%$ LWA [85]. Two different clay coarse aggregate mixes were tested $(4 / 8 \mathrm{~mm}$ vs $4 / 10 \mathrm{~mm})$ in order to determine the effect of the aggregate sizes [85].

It was found that as the amount of fine NWA was replaced by LWA the fire resistance improved for all mixes [85] (Figure 6.7). In terms of the different coarse 
aggregate sizes, having the larger aggregate size difference (4/10) demonstrated improved thermal performance. When comparing the different aggregates, shale had the lowest fire resistance, followed by the $4 / 8$ clay, then the $4 / 10$ clay and pumice had very similar fire resistances.

In terms of mechanical performance, the addition of LWA reduced the compressive strength [85]. The aggregates with the best thermal properties had the lower mechanical properties [85]. While the pumice aggregate showed similar fire resistance to the $4 / 8$ clay mixture, the compressive strength of the pumice concrete was far superior (by between 5-10MPa) [85]. The coarse aggregates had a larger impact than the fine aggregates in terms of compressive strength reduction [85]. This would indicate that it may be possible to improve the fire resistance of concrete by replacing the fine aggregate with LWA while keeping a stronger coarse aggregate [85].

Real et al 2016 researched the effect of several different lightweight aggregates (LWA) [9]. The aggregates tested (from most to least dense) were Stalite (expanded slate), Lytag (sintered fly ash), Leca (expanded clay), and Argex (expanded clay with different mix classes) [9]. The aggregates were all found to improve the fire resistance of the concrete (by between 35 minutes to 1 hour), while also having a negative effect on the compressive strength (by between 14\%-55\%) (Figure 6.8) [9]. As Argex was the lowest density LWA, it had the best fire resistance but the worse mechanical performance [9]. If thermal performance is the major concern Argex is a good option; however, if strength is also important then Stalite (the densest aggregate) should be used due to its high compressive strength [9].

\subsubsection{Comparing NWC, RCA, LWC, and novel LWC}

Stephan et al 2020 studied the effects of several different mix designs on the thermal prosperities of concrete [86]. The different mix design groups included NWC, expanded clay aggregate LWC, RCA, LWC with open pore structure, LWC with crushed textile and foam plastic, and LWC with mineral wool insulation shreds [86]. The first three mix design groups also included some specimens with either $16 \mathrm{~mm}$ PP fibers $16 \mathrm{~mm}$ or a $55 \mathrm{~mm} \mathrm{PE} / \mathrm{PP}$ fiber mix in order to determine the effects of fibers on the thermal and mechanical properties [86]. Concrete cubes with thicknesses of $3 \mathrm{~cm}, 6 \mathrm{~cm}$, and $12 \mathrm{~cm}$ were created for each different mix design, and thermocouples 


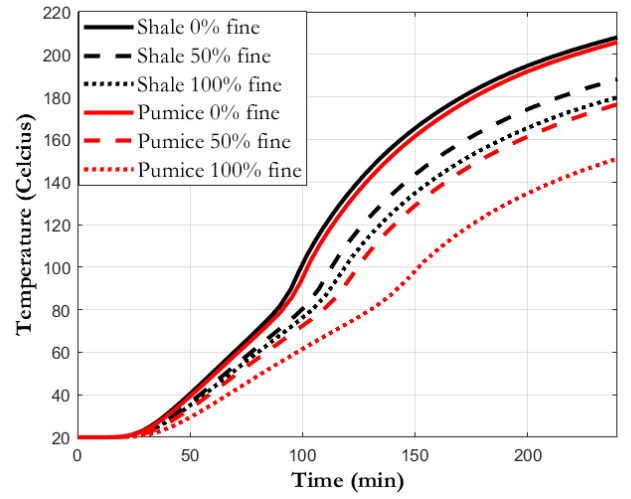

(a)

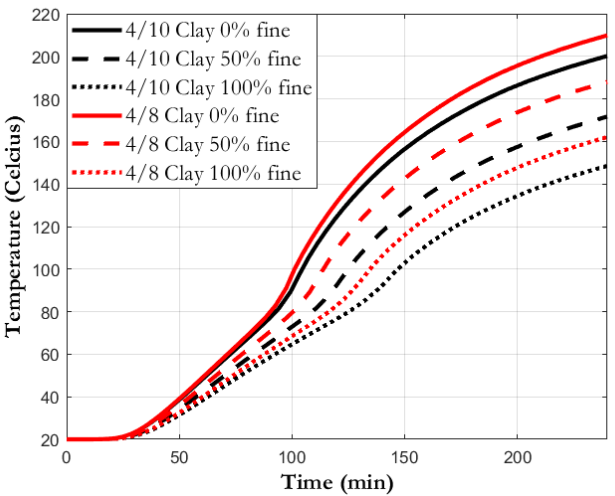

(b)

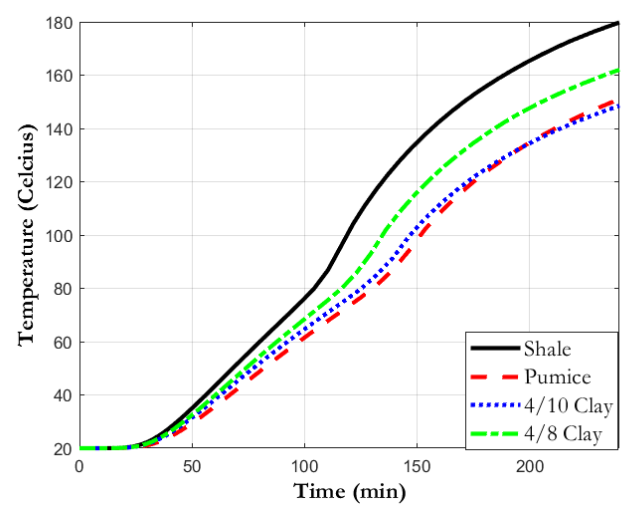

(c)

Figure 6.7: Different LWA replacement (a) Shale and Pumice (b) 4/10 Clay and 4/8 Clay (c) All four aggregates with $100 \%$ fine aggregate replacement

were placed at various points on the surface and within the specimens for temperature readings [86].

The density, specific heat, and thermal conductivity of each specimen were measured at ambient conditions, as well as after fire exposure to the ISO 834 fire curve [86]. The thermal properties change as the concrete is heated, so it is important to have values at different temperatures. Stephan et al 2020 used equations from the Eurocode in order to determine the values of each property at different temperatures for their own numerical model (Equations 6.1-6.4) [86].

For the density it remains constant up until $115^{\circ} \mathrm{C}$, which is when the heat begins to evaporate the water within the concrete [86]. After $115{ }^{\circ} \mathrm{C}$ the density begins to decrease using three different linear equations for different temperature ranges. This 


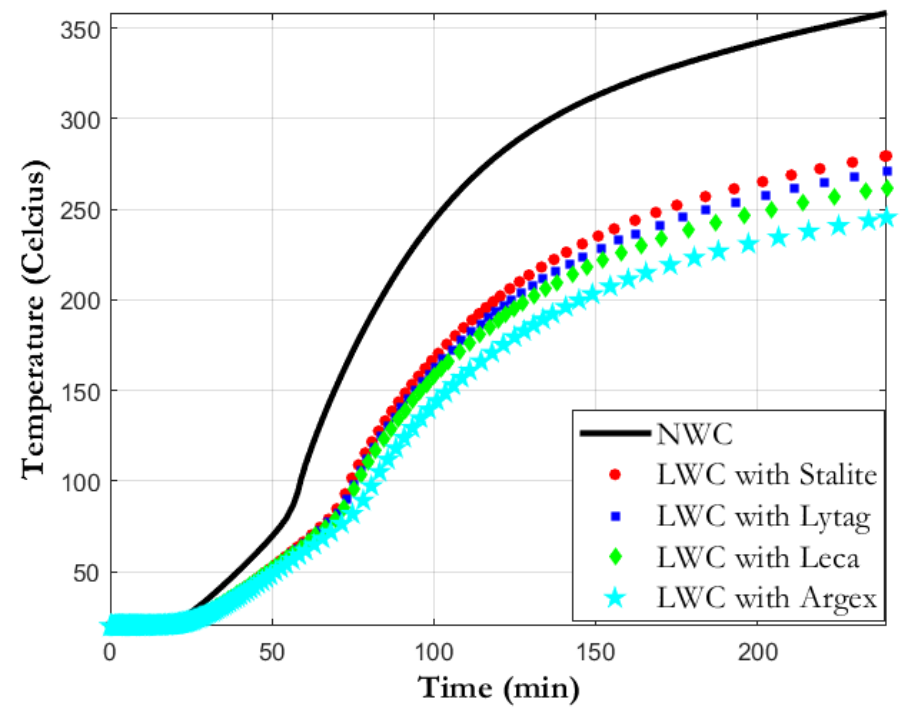

Figure 6.8: The effect of different aggregate types Real et al 2016

decrease accounts for the mass lost due to the evaporation of water. For the specific heat the equation is a bit more complex. The equation incorporates the original $\mathrm{C}_{p}$ value, and a $\mathrm{C}_{p, u}$ value which accounts for the free water content of the concrete specimen. The $\mathrm{C}_{p, u}$ values are $0,570,1120$, and $4700 \mathrm{~J} / \mathrm{kgK}$ for a free water content of $0 \%, 1.5 \%, 3 \%$, and $10 \%$ respectively [86]. Interpolation and extrapolation can be used to determine the values of $\mathrm{C}_{p, u}$ for different free water contents. Between 0-100 ${ }^{\circ} \mathrm{C}$ the specific heat is constant, but as the temperature reaches between $100{ }^{\circ} \mathrm{C}-115$ ${ }^{\circ} \mathrm{C}$ the specific heat increase by the $\mathrm{C}_{p, u}$ value [86]. As the temperature increases the effect of the $\mathrm{C}_{p, u}$ value decreases, but the specific heat is still higher than ambient, as specific increases with temperature even without a high free water content. The finial specific heat value is $200 \mathrm{~J} / \mathrm{kgK}$ higher than the ambient specific heat [86].

There are two different thermal conductivity equations; one for NWC and one for lightweight concrete. The normal weight values are the same for all types of NWC, which means it does not take into account different mix designs that may have an ambient thermal conductivity other than $2 \mathrm{~W} / \mathrm{mK}$ [86]. The thermal conductivity equation has the values decrease quadratically as the temperature increases. For the lightweight concrete the thermal conductivity is related to the initial value, which is a more accurate way of calculating the thermal conductivity. The values decrease linearly as the temperature increases, to a maximum decrease of $50 \%$ at $800{ }^{\circ} \mathrm{C}$ [86]. 


$$
\begin{gathered}
\rho=\rho_{0} \times \begin{cases}1 & \text { for } \theta \leq 115^{\circ} \mathrm{C}, \\
\left(1-0.02 \frac{\theta-115}{85}\right) & \text { for } 115^{\circ}<\theta \leq 200^{\circ} \mathrm{C}, \\
\left(0.98-0.03 \frac{\theta-200}{200}\right) & \text { for } 200^{\circ}<\theta \leq 400^{\circ} \mathrm{C}, \\
\left(0.95-0.07 \frac{\theta-400}{800}\right) & \text { for } 400^{\circ}<\theta \leq 1200^{\circ} \mathrm{C},\end{cases} \\
C_{p}=C_{p, 0}+ \begin{cases}0 & \text { for } \theta \leq 100^{\circ} \mathrm{C}, \\
C_{p, u} & \text { for } 100^{\circ}<\theta \leq 115^{\circ} \mathrm{C}, \\
C_{p, u}-\left(C_{p, u}-100\right) \frac{\theta-115}{85} & \text { for } 115^{\circ}<\theta \leq 200^{\circ} \mathrm{C}, \\
100+\frac{\theta-200}{2} & \text { for } 200^{\circ}<\theta \leq 400^{\circ} \mathrm{C}, \\
200 & \text { for } 400^{\circ}<\theta \leq 1200^{\circ} \mathrm{C},\end{cases} \\
\lambda=2-0.2451 \frac{\theta}{100}+0.0107\left(\frac{\theta}{100}\right)^{2}
\end{gathered}
$$

Where $\rho=$ density $\left(\mathrm{kg} / \mathrm{m}^{3}\right), \rho_{0}=$ original density $\left(\mathrm{kg} / \mathrm{m}^{3}\right), \theta=$ temperature ( $\left.{ }^{\circ} \mathrm{C}\right), C_{p}=$ specific heat $(\mathrm{J} / \mathrm{kgK}), C_{p, 0}=$ original specific heat $(\mathrm{J} / \mathrm{kgK}), C_{p, u}=$ free water content factor $(\mathrm{J} / \mathrm{kgK}), \lambda=$ thermal conductivity $(\mathrm{W} / \mathrm{mK}), \lambda_{0}$ original thermal conductivity $(\mathrm{W} / \mathrm{mK})$.

Stephan et al 2020 used the thermal properties to model the physical tests, and there was good correlation between the experimental and physical data [86]. The results of the test found that the NWC had the highest residual compressive strength, which makes sense as the NWC had the highest ambient strength [86]. The LWCs had the higher relative residual compressive strength, as LWA is better at resisting the effects of elevated temperatures [86].

The fibers were found to have very little effect on the thermal properties of the concrete, and so the effects on insulation were limited [86]. The results showed that the time temperature curves were closely aligned for mixes with and without fibers. The fibers did help to reduce the effects of spalling, which stopped degradation in the thermal and mechanical performance. The one exception to this was when the fibers were longer than the thickness on the specimen, as it caused the specimen to explode completely [86]. 
The LWC with crushed textile and foam plastic, did not preform well structurally, as there were numerous cracks and drastic reduction in mechanical properties [86]. The LWC with mineral wool insulation shreds was found to perform well in terms of the mechanical properties both at ambient conditions and after being exposed to fire [86]. The LWC with mineral wool also had improved thermal properties, which suggests it would be a good choice for a both loadbearing and non-loadbearing members [86].

The masonry modeling results can be found in Figure 6.9. As was expected, the NWC had was the hottest. The RCA was found to be an improvement on the NWC, which is similar to results from other tests [78] [86]. The LWC with crushed textile and foam was found to have a similar temperature profile to the RCA. Since the LWC also had a decrease in mechanical strength, it is inferior to the RCA. The LWA and the LWC with open pore structure were found to have similar temperature profiles. The LWC with open pore structure had lower density, but lower ambient and residual compressive strength, which would indicate that it is not an improvement unless there is no strength requirement and dead weight is of particular concern. The LWC with mineral wool insulation shreds was found to be much cooler than all of the other mixes. During the $4 \mathrm{~h}$ simulation the block did not fail the insulation criteria. This fact, coupled with the good compressive strength and high residual compressive strength, makes it a good choice for future study.

\subsection{Aggregate Type Conclusion}

The thermal properties of concrete have a large impact on its insulation fire resistance. Reducing the thermal conductivity improves the fire resistance, while increasing the specific heat and density improves the fire resistance.

Normal weight concrete can have a varied fire resistance depending on the exact mix design and aggregate type. Two concretes that are being used as references for different tests may in fact have large differences in their failure times.

RCA concrete has a higher cement content due to the cement within the RCA. As cement has better thermal properties than most NWA, it means that the thermal performance of the concrete is improved with the addition of RCA. However, as RCA is highly variable, the exact thermal performance changes from one mix to another. For the thermal performance, some mixes showed that the RCA behaved similar to 


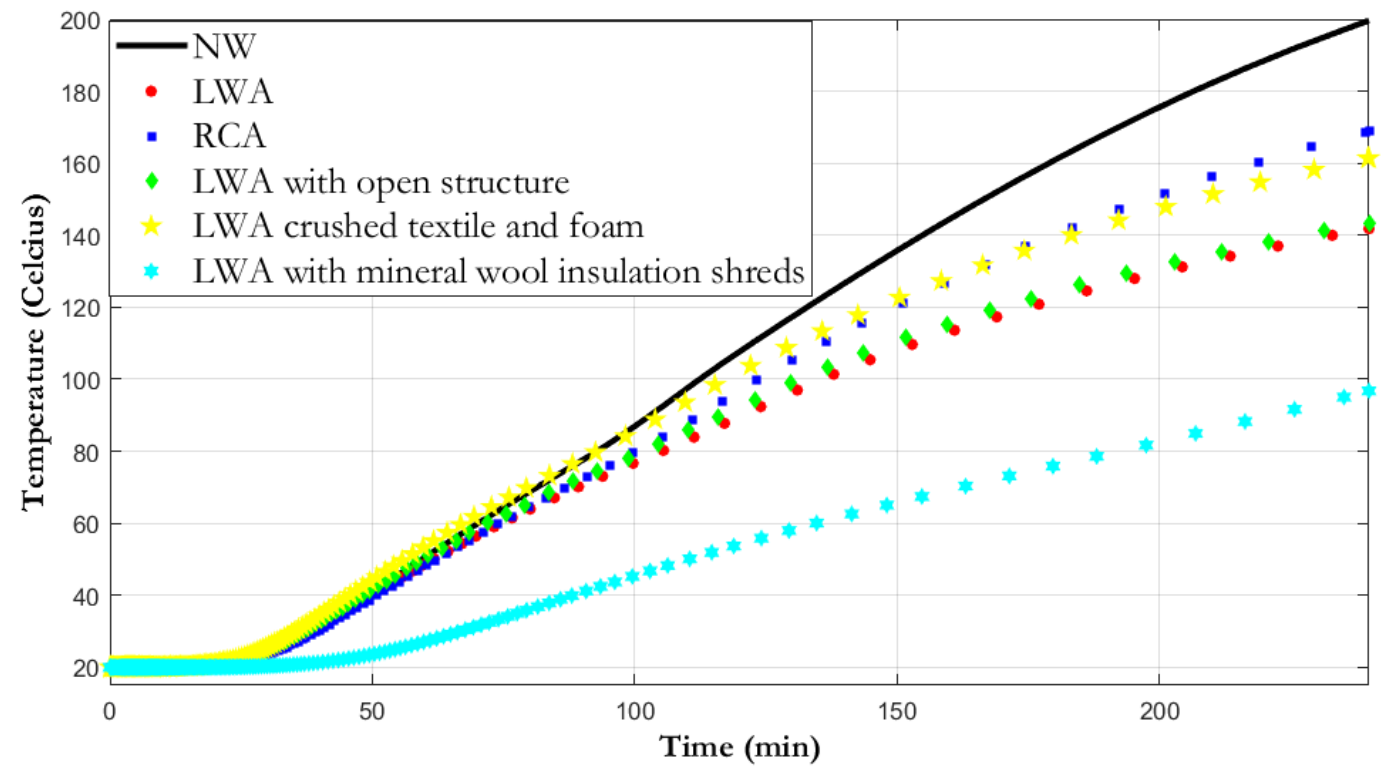

Figure 6.9: Comparing the effect of the different aggregate types Stephan et al 2020

the reference concrete, most found that it had improved thermal properties, and a small number found that the RCA reduced the thermal performance. The mechanical performance of RCA concrete is generally close to the reference concrete in terms of strength; however, it is usually at least slightly lower. If the proper RCA can be found, then it is a viable option as it improves the thermal performance without a major decline in the mechanical properties, and it helps the environment.

There are many common LWA such as expanded clay, shale and pumice. As with most aggregates, those with lower densities provide lower compressive strength but higher fire resistance. It was found for coarse aggregate replacement that the strength reduction normally makes the concrete more suitable for non-loadbearing members. With fine aggregate replacement the strength reduction was lower, so that may be a better option for improving the fire resistance of concrete. 


\subsection{Novel Aggregate Results}

\subsubsection{Vermiculite and Expanded Polystyrene coarse aggre- gate}

Schachow et al 2014 investigate the effects of vermiculite and expanded polystyrene (EPS) as coarse aggregate replacement within concrete [87]. The research tested the effects of $55 \%$ and $65 \%$ lightweight aggregate replacement by either vermiculite or EPS [87]. Vermiculite can be purchased for use in creating lightweight concrete, but EPS is a recycled material that could potentially meet the same requirements at a fraction of the cost [87]. This study also used air entraining agents in order to improve the workability and focused on the values of $0.5 \%$ and $1 \%$ replacement by weight [87].

The results showed that larger percentages of air entraining agent led to a decrease in compressive strength for both materials [87]. EPS had better compressive strength for $0.5 \%$ air entraining agents, whereas vermiculite had better compressive strength with $1 \%$ air entraining agents [87]. The change between $55 \%$ and $65 \%$ replacement led to a decrease in compressive strength for both vermiculite and EPS [87]. In terms of thermal conductivity, vermiculite had lower values than EPS for both aggregate replacement percentages [87]. As more aggregate was replaced the thermal conductivity dropped for both vermiculite and EPS [87].

The modeling showed that vermiculite had better fire resistance than EPS for all replacement percentages (Figure 6.10). The vermiculite mix with $65 \%$ replacement showed the best fire resistance, as it did not reach failure within the four hours. Both mixes improved with higher replacement percentages, but the vermiculite showed a large improvement, whereas EPS showed only a minor improvement. Since the strength decreases with increased replacement, higher replacement on EPS may not be as beneficial if compressive strength is important.

The research was supposed to determine if EPS would be a good replacement for vermiculite and the results show that for lower air entraining and lower aggregate replacement EPS has higher compressive strength and comparable fire resistance. For higher replacement and larger air entraining, vermiculite is both stronger and more fire resistant. If a medium fire resistance is all that is required, then EPS is a viable replacement that would be better for both environmental and cost saving concerns. 


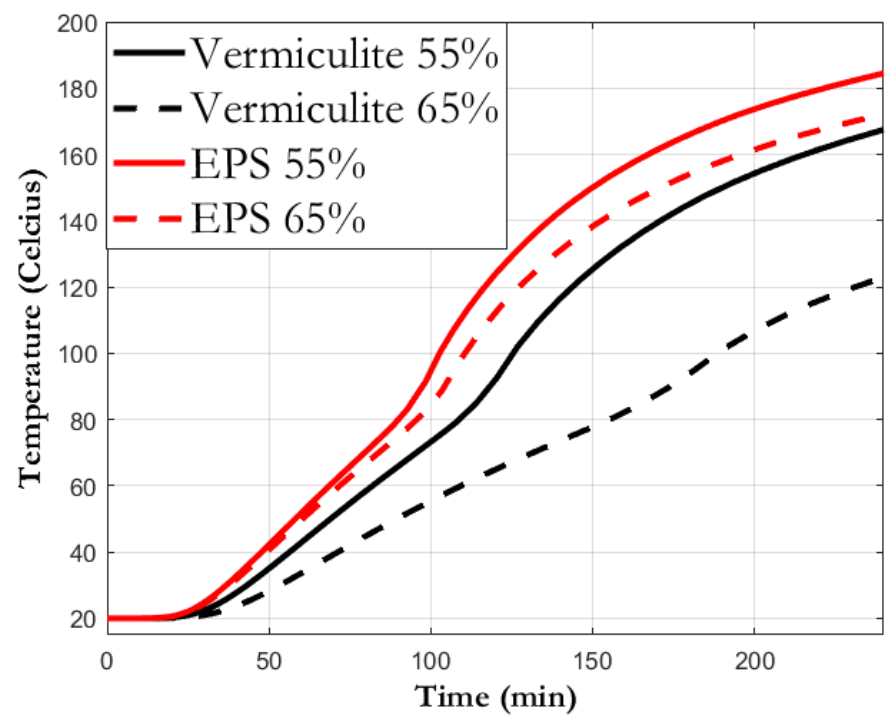

Figure 6.10: Time temperature curves of EPS and Vermiculite concrete

\subsubsection{Polyurethane}

Mounanga et al 2008 researched the effect of Polyurethane (PUR) added to concrete [88]. Series1 looked into the effects of the PUR amount, w/c ratio, S/C ratio, and cement content [88]. Series 2 tested the effect of different PUR amounts with better packing [88]. The differences between the mix can be found in Table 6.1. It was found that PUR improved the thermal properties but reduced the strength as the amount of PUR was increased [88].

For Series 1, the results of the thermal modeling showed that the reference mix had the worse thermal performance, and the addition of PUR improved the fire resistance (Figure 6.11). The figure shows that MixI-1 and MixI-2 had similar temperature profiles, and MixI-3 and MixI-4 also had similar temperature profiles. MixI-1 had a slightly higher w/c ratio than MixI-2, but everything else in the mix designed was the same. This explains why they both had similar temperature profiles, with MixI1 being slightly better due to the higher w/c ratio creating a less dense concrete. Both MixI-3 and MixI-4 were made without sand, instead using PUR as the fine aggregate, with MixI-4 having more PUR and cement. The lack of sand explains the improvement in thermal properties, and the increase in cement caused a slight reduction in thermal performance.

For Series 2 the results are quite straightforward. As the amount of sand went 
Table 6.1: Mounanga et al 2008 Mix designs

\begin{tabular}{|l|l|l|l|l|l|}
\hline Series & Mix & w/c ratio & S/C & \% PUR & Cement $(\mathrm{kg} / \mathrm{m} 3)$ \\
\hline \multirow{4}{*}{ Series1 } & Mix I-Ref & 0.7 & 4.28 & 0 & 362 \\
\cline { 2 - 6 } & Mix I-1 & 0.7 & 0.75 & 17.3 & 631 \\
\cline { 2 - 6 } & Mix I-2 & 0.6 & 0.75 & 17 & 685 \\
\cline { 2 - 6 } & Mix I-3 & 0.7 & 0 & 21.8 & 761 \\
\cline { 2 - 6 } & Mix I-4 & 0.7 & 0 & 28.2 & 699 \\
\hline \multirow{4}{*}{ Series 2 } & Mix II-Ref & 0.47 & 3.75 & 0 & 382 \\
\cline { 2 - 6 } & Mix II-1 & 0.81 & 2.00 & 13.1 & 357 \\
\cline { 2 - 6 } & Mix II-2 & 0.81 & 1.20 & 21.2 & 370 \\
\cline { 2 - 6 } & Mix II-3 & 0.81 & 0 & 33.7 & 395 \\
\hline
\end{tabular}

down and the amount of PUR increased, the thermal performance increased. When comparing Series 2 to series 1, it can be seen that the amount of PUR was the main factor effecting the thermal performance. The increase in packing did not seem to have much of an effect on the thermal performance, however none of the mixes between Series 1 and Series 2 were close enough to accurately compare. MixI-3 and MixII-2 had similar PUR content and similar temperature profiles, but MixII-2 had sand and slightly less PUR. So while Mix1-3 was slightly better, it is not clear whether or not this is due to the packing having a negative effect on MixII-2, or if the sand or reduction in PUR is the reason for the slightly hotter time temperature curve. The mixes in Series 2 all had lower compressive strengths, which would indicate that it is not a beneficial mix choice.

\subsubsection{Perilte aggregate}

Tandiroglu 2010 research the effect of perlite aggregate and w/c ratio [89]. Different mixes with different densities and $\mathrm{w} / \mathrm{c}$ ratios were researched. It was found that the perlite mixes had improved mechanical properties at ambient and elevated temperatures [89]. The thermal properties were found to be more dependent on the density than the $\mathrm{w} / \mathrm{c}$ ratio [89]. As the $\mathrm{w} / \mathrm{c}$ ratio decreased, the thermal conductivities only 


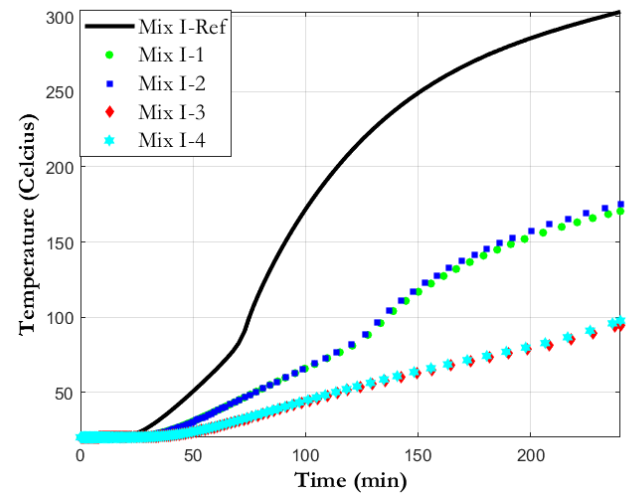

(a)

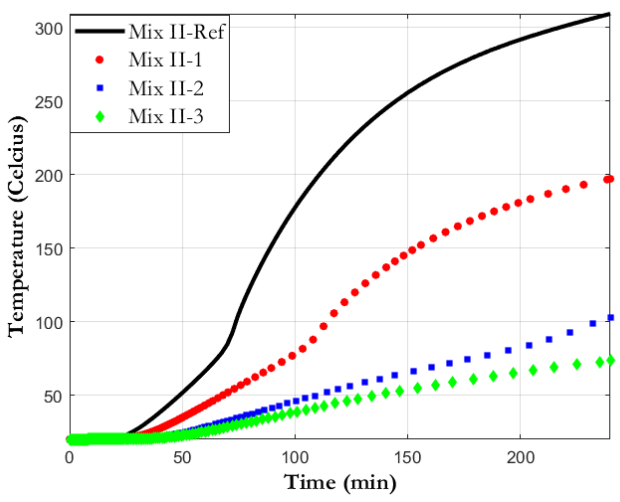

(b)

Figure 6.11: Effect of concrete mixes with different amounts of PUR (a) Mix1 (b) Mix2

increased slightly [89]. The results of the thermal model show that as the density increased the thermal performance decreased (Figure 6.12). It also demonstrates that the perlite concrete fails sooner than most conventional normal weight concrete, failing well under the $1.8 \mathrm{~h}$ fire resistance of most normal weight $20 \mathrm{~cm}$ masonry blocks. So while perlite might improve the mechanical properties at elevated temperatures, it decreases the thermal performance of the concrete.

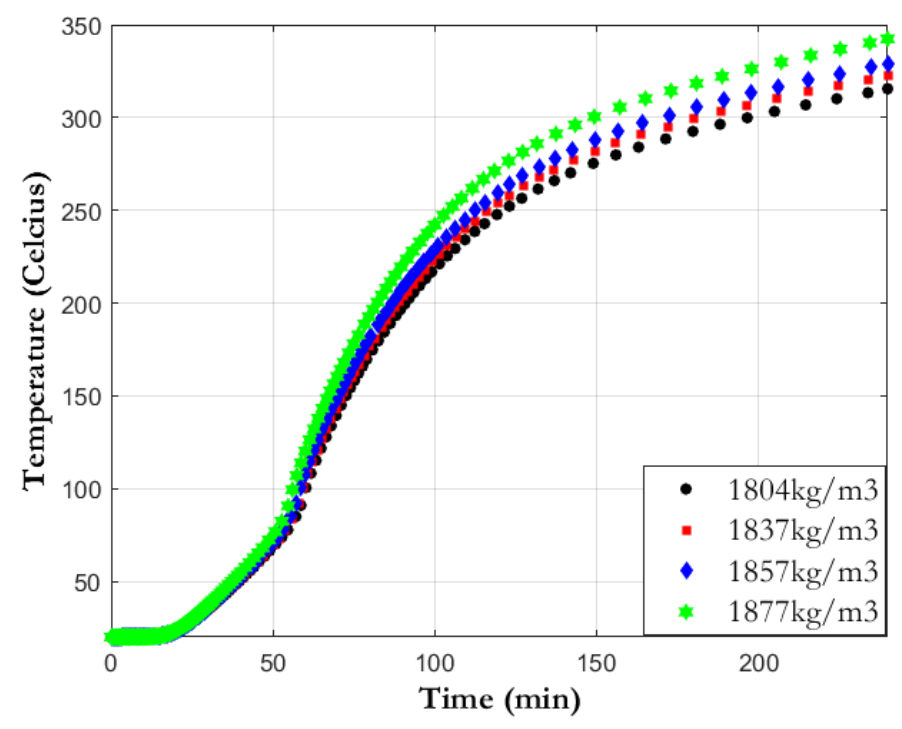

Figure 6.12: The effect of diffrent perlite aggregate mixes with different densities 


\subsubsection{Expanded Perlite}

Sengul et al 2011 researched the effect of using expanded perlite (EP) as partial replacement of the fine aggregates [90]. As the EP percentage was increased the thermal conductivity and density decreased [90]. With the 20\%EP and $40 \% \mathrm{EP}$ the reduction in thermal conductivity was small ( $5 \%$ and $12 \%$ respectively), but at the $60 \% \mathrm{EP}$ replacement the thermal conductivity decreased by a larger margin $(42 \%)$ [90]. Comparatively, the compressive strength of the concrete decreased by $40 \%$ with only the addition of $20 \% \mathrm{EP}$ and decreased by $84 \%$ with the addition of $60 \% \mathrm{EP}$ [90]. This would seem to indicate that EP should only be used in members that are not structural, as the thermal conductivity is only significantly improved when the strength is very low [90].

When comparing the thermal performance, the reference concrete, the $20 \% \mathrm{EP}$, and $40 \% \mathrm{EP}$ all had similar failure times (Figure 6.13). This is because the thermal conductivities were similar for those three mixes, and the improvement from the thermal conductivity was mitigated by the reduction in density. The $60 \% \mathrm{EP}$ mix showed noticeable improvement on the fire resistance, and the $80 \% \mathrm{EP}$ and $100 \% \mathrm{EP}$ mixes showed excellent fire resistance. Due to the strength reduction, the higher EP mixes are not suitable for structural members, and as the $80 \% \mathrm{EP}$ and $100 \% \mathrm{EP}$ mixes had compressive strengths of $1.1 \mathrm{MPa}$ and $0.1 \mathrm{MPa}$ respectively, they may not even be suitable for partition members. . 


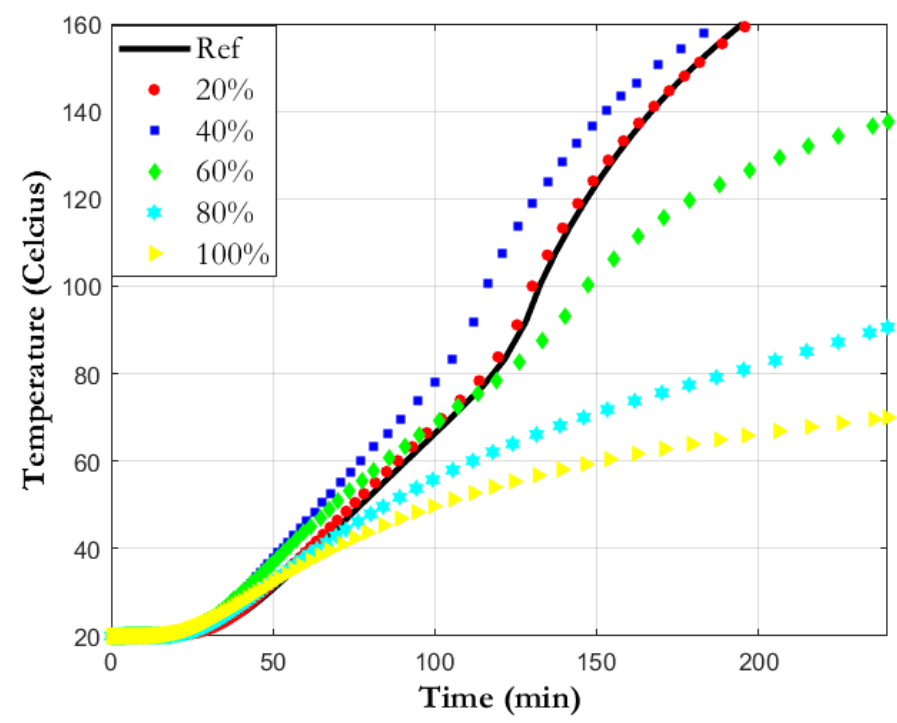

Figure 6.13: Comparing the effect of different EP replacement

\subsubsection{High impact polystyrene}

Wang and Meyer 2012 researched the effect of concrete mortar made with high impact polystyrene (HIPS) as a replacement for the fine aggregate [91]. HIPS is used in electronics, and with the increase in electronic waste it is important to find another use for HIPS [91]. The addition of HIPS reduced the compressive strength, density, and thermal conductivity of the mortar [91].

The thermal performance of the mortar improved with the addition of the HIPS, with the greatest fire resistance being at the maximum replacement of the fine aggregates (Figure 6.14). The $10 \%$ and 20\% HIPS replacement only had a roughly $10 \%$ and $20 \%$ reduction in compressive strength respectively [91]. This would indicate that this level of replacement could be used to improve the fire resistance of loadbearing concrete. However, the test only focused on concrete mortar, so there is no data on the effect HIPS with coarse aggregates within the concrete. As coarse aggregate can have a significant effect on the thermal and mechanical performance, it would be important to determine whether the same increase in thermal performance and decrease in mechanical performance occur with regular concrete. 


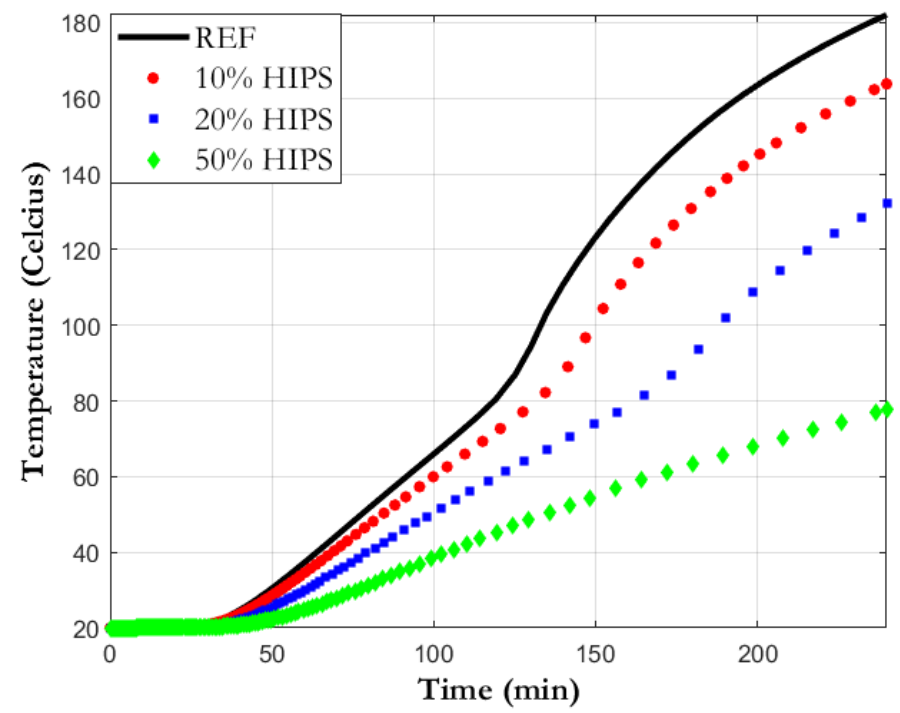

Figure 6.14: Comparing the effect of the different HIPS replacement

\subsubsection{Cement-based lightweight composites}

Yu et al 2013 researched the effect of cement-based lightweight composites (CLC) on concrete's thermal and mechanical properties [92]. The two types of CLC researched were self-compacting cement-based lightweight composites (SCLC) and vibrated cement-based lightweight composite (VCLC) [92]. The four mixes included a reference concrete (REF), a SCLC mix with a small amount of limestone powder (SCLC1), a SCLC mix with a larger amount of limestone powder (SCLC2), and a VCLC mix [92].

It was found that the normal weight reference concrete had the worse fire resistance (Figure 6.15). This is expected as the other three mixes had LWA included in the mix. All three of the lightweight mixes had failure times well over 2hours. The SCLC mixes both had better fire resistance than the VCLC, with the SCLC mix containing less limestone powder having the best fire resistance. The compressive strength of the three mixes varied from 23.3MPa, 30.2MPa, and 27.5MPa for SCLC1, SCLC2, and VCLC respectively [92]. From this, SCLC2 would be the best option for structural members where a 3 hour fire resistance is required. For members where a longer fire resistance is required and mechanical strength is less of a concern, the SCLC1 mix did not fail after 4 hours and would be a good fit. The VCLC mix had lower compressive strength and fire resistance than the SCLC2 mix, and so it is not optimal. 


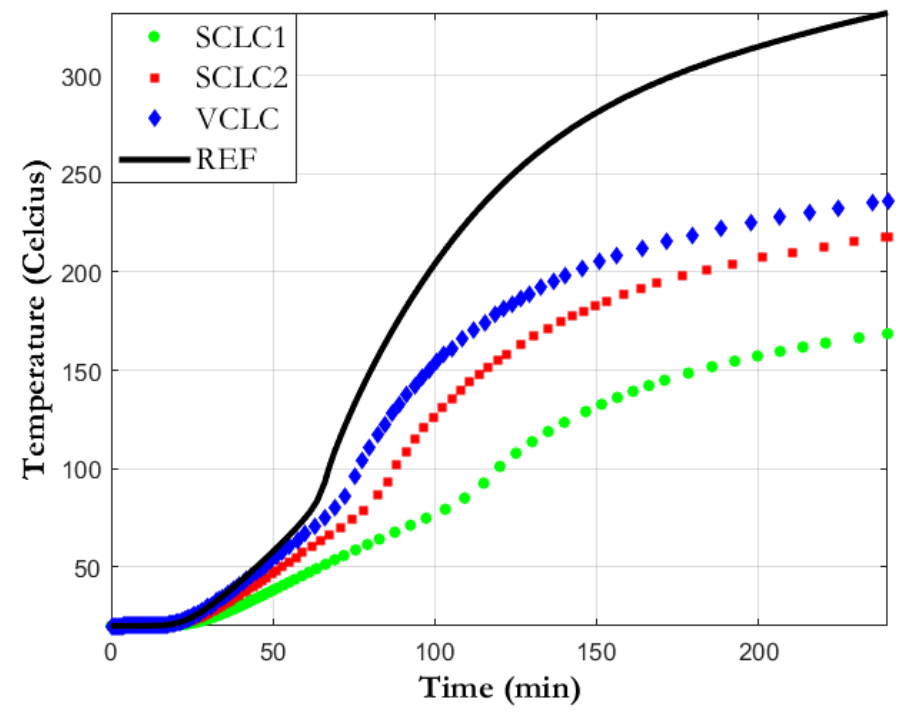

Figure 6.15: Comparing the effect of the different CLC mixes

\subsubsection{Lightweight Concrete with Furnace bottom ash re- placement}

Zhang and Poon 2015 researched the effect of Furnace Bottom Ash (FBA) as a fine aggregate replacement [93]. FBA is a lightweight aggregate produced as a by-product from coal manufacturing [93]. As a lightweight aggregate, it has higher porosity and lower density and usually these properties lead to improved fire resistance at the cost of mechanical strength [93]. However, the results from Zhand and Poon 2015 demonstrated that even with 100\% FBA replacement of fine aggregates, the workability and mechanical strength were similar to the reference concrete [93]. This means that FBA could be used to create lower density concrete for structural members. Zhang and Poon 2015 tested a NA mix for comparison, then tested LWA mixes with various FBA replacement of the fine aggregate $(0 \%, 25 \%, 50 \%, 75 \%$, and $100 \%$ replacement) [93]. One issue with the NA mix for comparison is that it had a high w/c ratio of 0.6 , while every other mix had a lower w/c ratio of 0.39 [93]. The amount of cement and aggregate were also different, which makes using it as a comparison difficult [93].

The results showed that as the amount of FBA was increased, the density, thermal conductivity, and strength decreased [93]. When compared to the NA, the addition of LWA increased the time to failure by 10 minutes (Figure 6.16). The addition of $100 \%$ FBA increased the time to failure by an additional 10 minutes. The replacement 


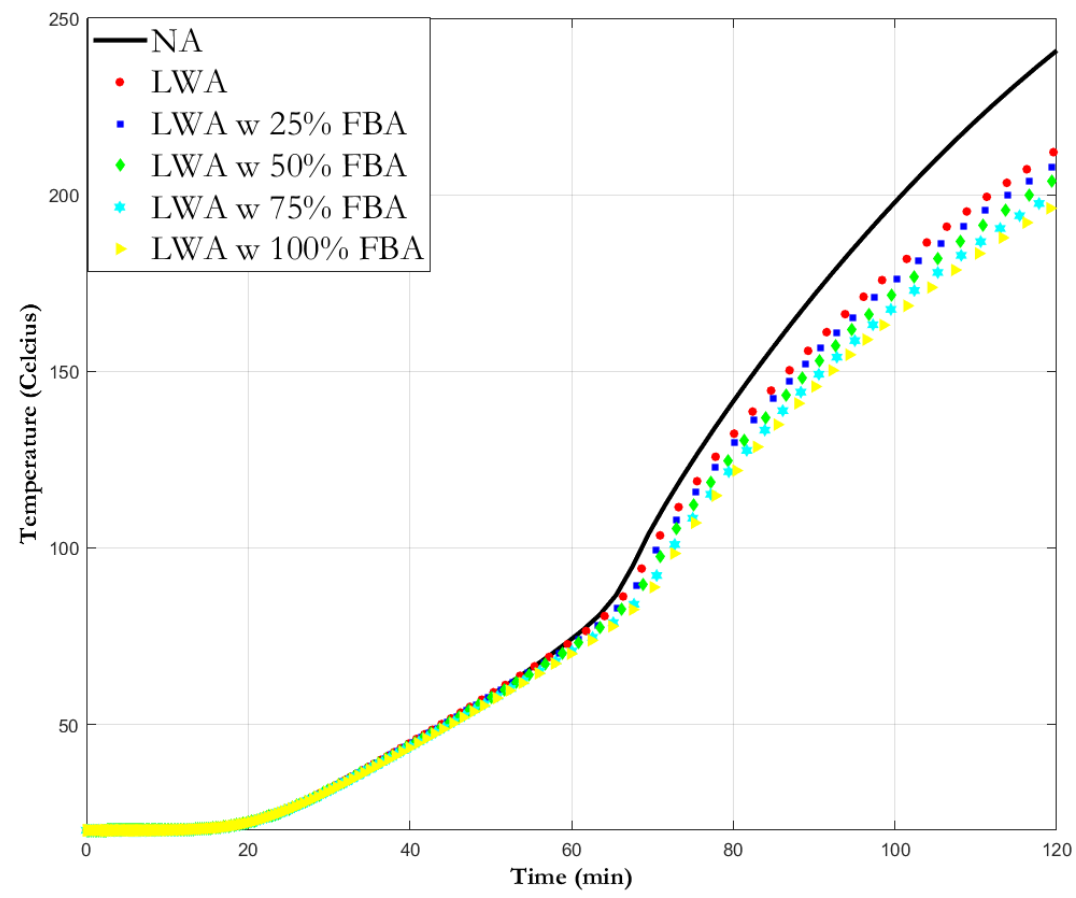

Figure 6.16: Comparing the effect of the different aggregate FBA replacement

percentages in between 0-100\% replacement gave failure times between 10 and 20 minutes.

For the strengths, the NA mix had a higher water cement ratio, and so it was weaker than the LWA mix [93]. Therefore, comparing the strength loss to the NA mix would not be appropriate. By instead comparing the strength to the LWA mixture without BFA, it was found that adding BFA improved the thermal properties, but it decreased the strength by up to $33 \%$ at the $100 \%$ replacement [93]. This strength reduction is significant, and so when using BFA in a structural member, it may be beneficial to find the optimal replacement percentage in order to balance the thermal and mechanical performance of the concrete.

\subsubsection{NSC and HSC with LWA replacement}

Zhou et al 2019 investigated the thermal and mechanical properties of normal strength (NS) and high strength concrete (HSC) including aggregates such as silica sand, 
Table 6.2: Zhou et al 2019 Mix designs

\begin{tabular}{|c|c|c|c|c|c|}
\hline Mix ID & $\begin{array}{l}\text { Fly ash } \\
\text { cenospheres } \\
\text { (fine) }(\%)\end{array}$ & $\begin{array}{l}\text { Silica Sand } \\
(\text { fine })(\%)\end{array}$ & $\begin{array}{l}\text { Gravel } \\
\text { (coarse) } \\
(\%)\end{array}$ & $\begin{array}{l}\text { RiverLite } \\
\text { (fine) }(\%)\end{array}$ & $\begin{array}{l}\text { RiverLite } \\
\text { (coarse) } \\
(\%)\end{array}$ \\
\hline NS-SS-G & - & 100 & 100 & - & - \\
\hline NS-FAC/SS-G & 50 & 50 & 100 & - & - \\
\hline NS-FAC/RLF-G & 50 & - & 100 & 50 & - \\
\hline NS-SS-RLC & - & 100 & - & - & 100 \\
\hline NS-FAC/SS-RLC & 50 & 50 & - & - & 100 \\
\hline NS-FAC/RLF-RLC & 50 & - & - & 50 & 100 \\
\hline HS-SS-G & - & 100 & 100 & - & - \\
\hline HS-FAC/SS-G & 50 & 50 & 100 & - & - \\
\hline HS-SS-RLC & - & 100 & - & - & 100 \\
\hline HS-FAC/SS-RLC & 50 & 50 & - & - & 100 \\
\hline
\end{tabular}

limestone gravel, RiverLite lightweight aggregates (fine and coarse), and fly ash cenospheres (FAC) [94]. The NWC used 100\% cement, the HSC replaced $15 \%$ of the cement with silica fume [94]. In order to increase the strength of the HSC, quartz flour and a lower w/b ratio was used. Table 6.2 outlines the aggregates used in each sample [94].

The test found the thermal and mechanical properties at ambient conditions for the various mixes. It was found that LWA reduced the mechanical properties of the concrete, and this decrease in strength was more prominent in the HSC [94]. There was a larger decrease in mechanical properties when the coarse aggregate was replaced with LWA rather than when the fine aggregate was replaced [94]. For the HSC in particular, the fine LWA replacement decreased the compressive strength by $21.5 \%$, while the coarse LWA replacement decreased the compressive strength by $52.9 \%$ [94]. Including the LWA did improve the thermal properties of the concrete by lowering the thermal conductivity, and so would definitely be beneficial for non-loadbearing deigns [94].

When comparing the modeling results of the different NS mixes it can be seen that 
the mix without any lightweight aggregate had the hottest time temperature curve (Figure 6.17). Replacing some of the coarse aggregate with RiverLite aggregate, or half of the fine aggregate with FAC improved the fire resistance by roughly the same amount. Replacing half the fine aggregate with FLC and either all of the coarse or the other half of the fine aggregate with RiverLite aggregate improved the fire resistance even more. The best fire resistance for NS concrete was achieved when FLC and fine RiverLite aggregate replaced the fine aggregate completely, and RiverLite coarse aggregate replaced the coarse aggregate completely.

Both the NS and the HS mixes had similar time temperature graphs (Figure 6.17). The HS mixes had higher thermal conductivity, specific heat, and density when compared to the NS mixes. The increase in specific heat is the reason why the HS mixes had better fire resistance than the NS mixes. Normally the density of HS concrete mixes is much higher than NS concrete mixes, but in the case of these mixes designs the different in density was minor, which also accounts for the similar thermal conductivities between mixes.

Based on the results, these LWA can be used to improve the insulation fire resistance of concrete, at the expense of the mechanical properties. The more LWA replaced the larger the increase in fire resistance, with the greatest fire resistance being when $100 \%$ of the aggregate has been replaced (NS-FAC/RLF-RLC). The HSC with LWA had compressive strengths that were comparable to those of the NWC. This means that for loadbearing members the HSC with LWA could help extend the time for both insulation and stability failure. With LWA having better residual compressive strength, this mix might perform quite well even after a long fire exposure. Further research should be done to determine the thermal and mechanical properties of samples after fire exposure.

\subsubsection{Novel Aggregate Conclusion}

The thermal properties of concrete have a large impact on its insulation fire resistance. Reducing the thermal conductivity improves the fire resistance, while increasing the specific heat and density improves the fire resistance. Specific heat and density effect the fire resistance linearly, whereas thermal conductivity effects the fire resistance non-linearly, with much greater improvements at lower values of thermal conductivity. 


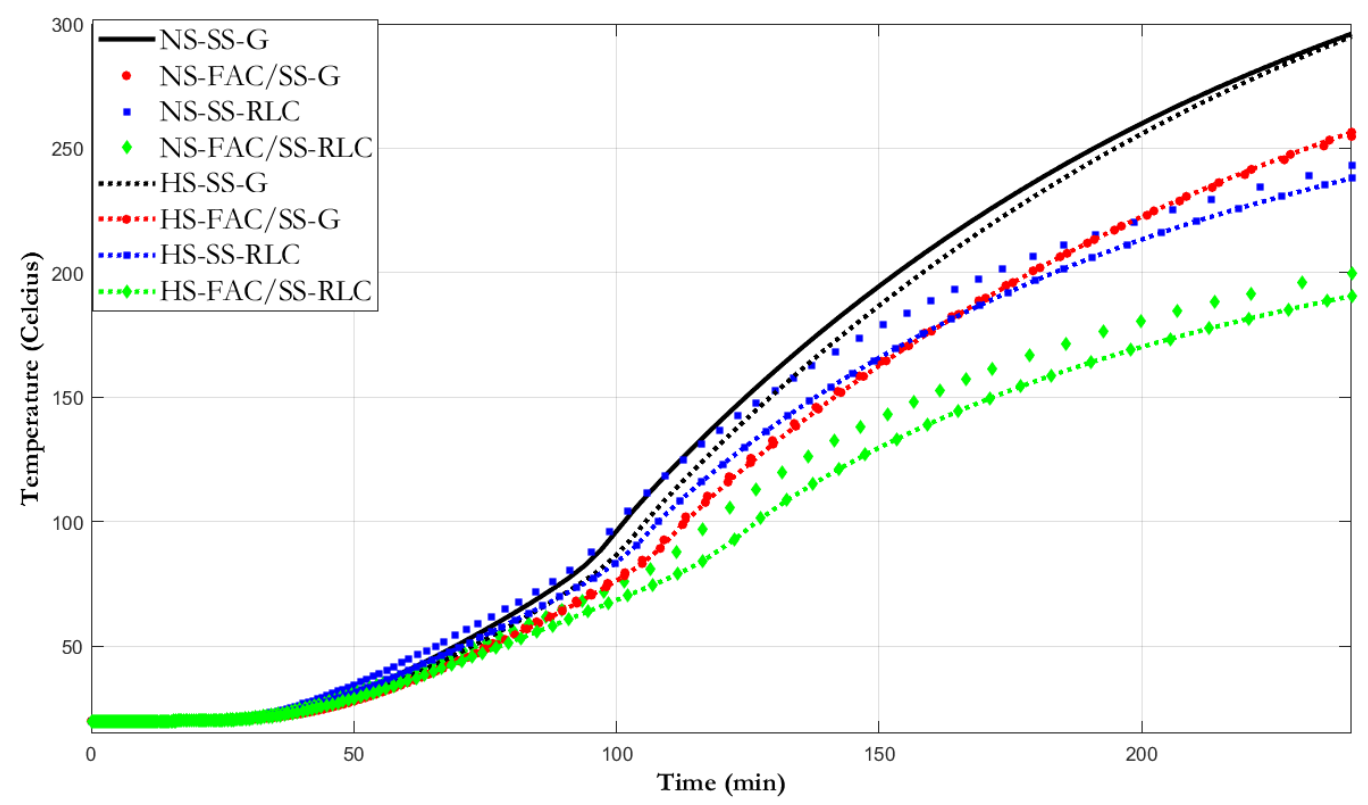

Figure 6.17: Comparing the effect of the different NSC and HSC mixes

There are many novel LWA types. Vermiculite and EPS can be used, with vermiculite having the better mechanical and thermal properties, but higher cost and environmental impact. PUR can be used to dramatically increase the fire resistance of lightweight concrete, at the cost of mechanical strength. The amount of PUR replaced, and the mix design have a large impact on the effectiveness of the PUR aggregate concrete. EP can be used; however, large percentage of aggregate replacement is required to see an increase in thermal performance. HIPS was found to increase the fire resistance of mortar significantly, but its effect on an actual concrete mix is not known. Cement-based lightweight composites can be included to improve the fire resistance, with SCLC having the superior mechanical and thermal properties. FBA replacement of sand was found to improve the fire resistance by 10 minutes, at the cost of $33 \%$ strength reduction, which most likely means that the benefit is not enough to warrant the strength loss. LWA improves the thermal performance of concrete at the cost of the mechanical properties. Fine aggregates provide a good balance between the increase in thermal performance and decrease in mechanical properties. 


\subsection{Cement, Pozzolans, and Addatives Results}

\subsubsection{Cement}

Wu et al 2015 tested regular concrete, as well as two different cement paste mixes with different w/c ratios [95]. It was found that the concrete mix had much higher density and thermal conductivity, which led to worse thermal properties than the two cement paste mixes [95]. The two mixes had very similar thermal performance, with the main differences being their mechanical properties (Figure 6.18). The thermal performance of the cement paste was much higher than the regular concrete mix, and the mechanical performance of the low $\mathrm{w} / \mathrm{c}$ ratio cement paste mix was close to the regular concrete. While this would suggest that creating concrete without aggregates would be beneficial for improved thermal performance, the cost and environmental concerns would make this unfeasible. The results are useful however, as they demonstrate that cement paste has good fire resistance, and that NA reduces that fire resistance.

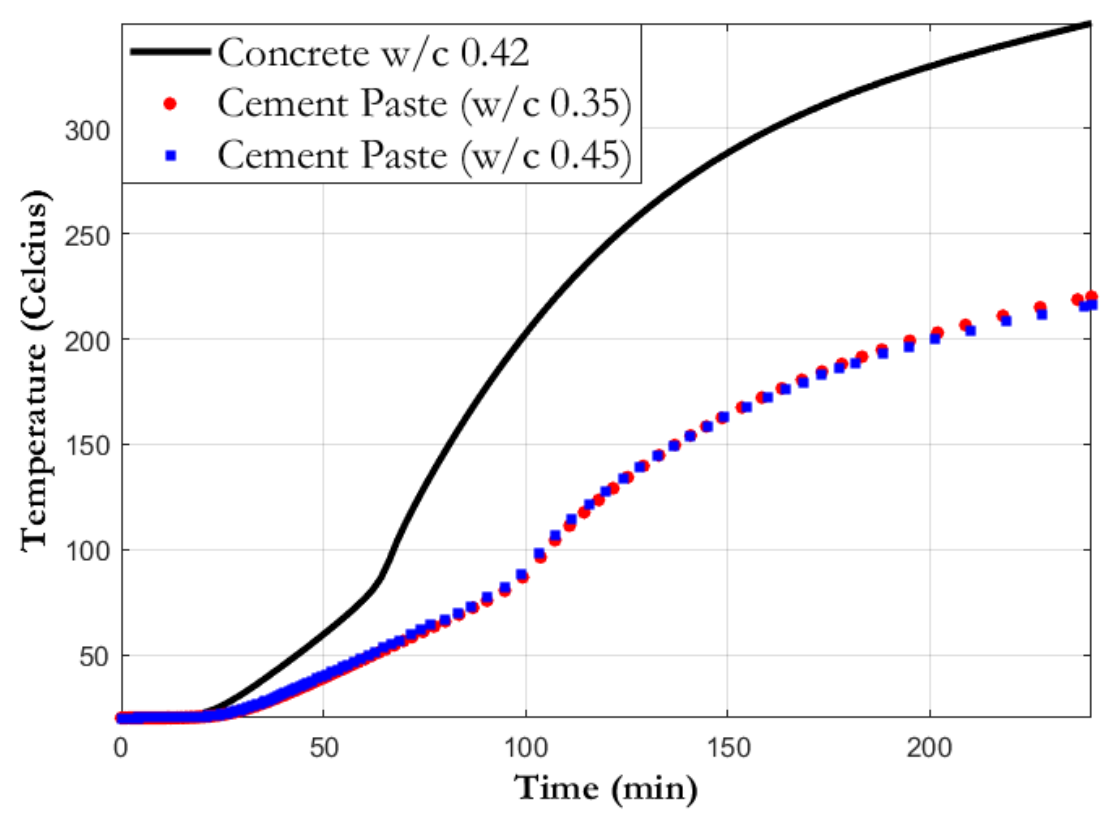

Figure 6.18: Time temperature curves of Concrete and Cement

Uysal et al 2004 researched the effect of different cement contents [84]. The effect of the cement content was tested by using $25 \%$ pumice aggregate replacement, and 
varying the cement content between $200,250,350,400$, and $500 \mathrm{~kg} / \mathrm{m} 3$ [84]. It was found that as the cement content increased the density and thermal conductivity also increased [84]. Through modeling the fire resistances were as expected, with the lower cement content mixes having improved thermal performance (Figure 6.19). The mix with the highest cement content $(500 \mathrm{~kg} / \mathrm{m} 3)$ failed first at roughly $105 \mathrm{mins}$, and then all of the other mixes failed $10-20$ mins afterwards. The $500 \mathrm{~kg} / \mathrm{m} 3 \mathrm{mix}$ had a large jump in thermal conductivity when compared to the other mixes, which is why the failure time is much earlier than the other mixes. While cement paste has better thermal properties than mortar or concrete, having a higher cement content increases the density and thermal conductivity and reduces the fire resistance of the concrete.

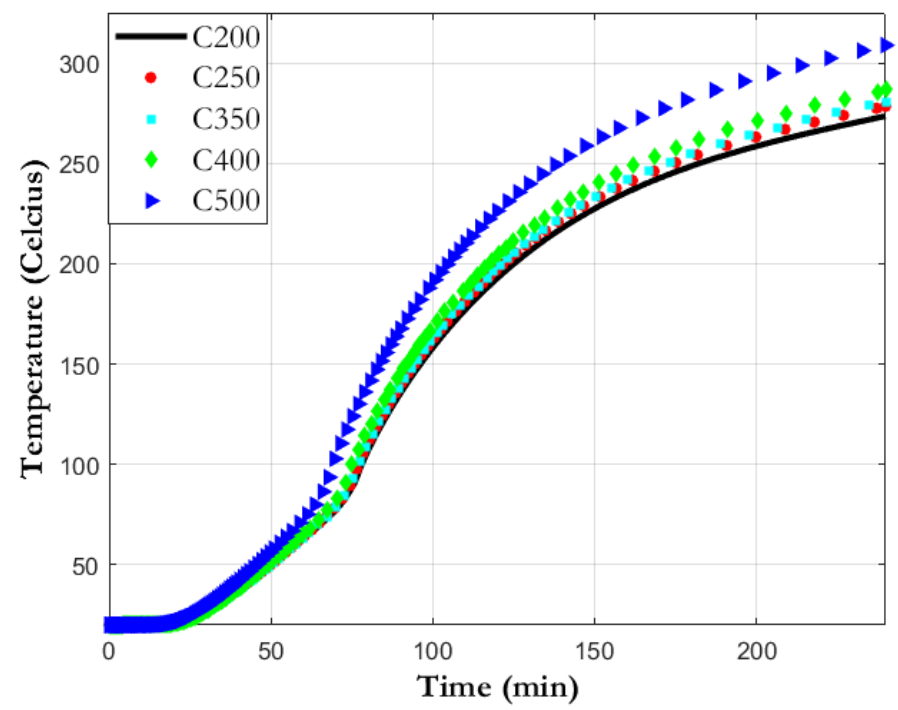

Figure 6.19: Time temperature curves of concrete mixes with various amounts of cement $(\mathrm{Kg} / \mathrm{m} 3)$

\subsubsection{POZZOLANS}

Damdelen et al 2014 researched the effect of RCA and pozzolanic materials on concretes with different w/c ratios [82]. The three pozzolans tested were $45 \%$ ground granulated blast furnace slag (GGBFS), 20\% pulverized fly ash (PFA), and $20 \%$ silica fume (SF) [82]. Higher w/c ratio mixes were created with the reference aggregate (either NA or RCA) then one of the three pozzolans individually [82]. The tests were 


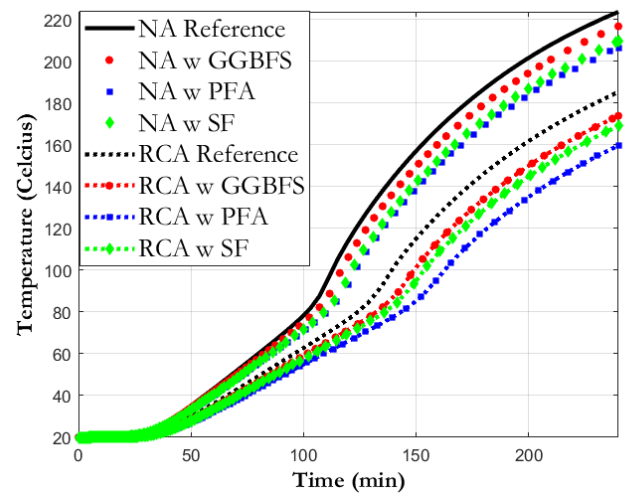

(a)

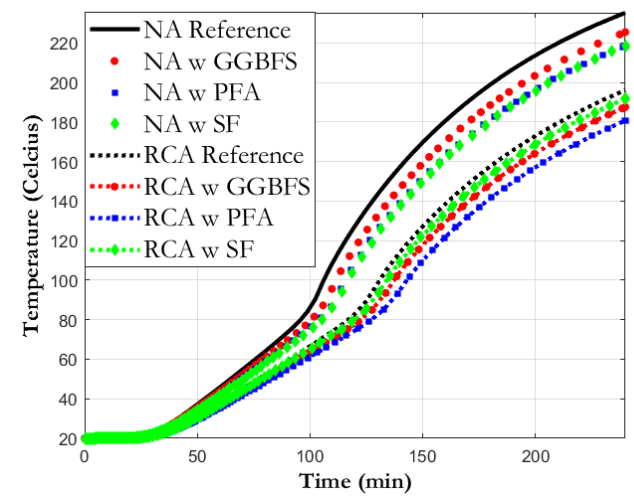

(b)

Figure 6.20: Effect of NA and RCA concrete mixes with different Pozzolans (a) Higher $\mathrm{w} / \mathrm{c}$ ratio (b) Lower $\mathrm{w} / \mathrm{c}$ ratio

then repeated for lower $\mathrm{w} / \mathrm{c}$ ratio mixes [82].

The NA remained hotter than the RCA aggregate in all cases, which matches the literature (Figure 6.20) [82]. It can be seen that the reference concrete was the worse for both the NA and RCA mixes. The GGBFS mixes were found to be the least effect means of improving the fire resistance, as they failed second except for the case of the low w/c RCA. It is important to note that the GGBFS replacement was much higher than that of the PFA and SF, which also would indicate that the other two options are better for replacement. The PFA and SF were both the superior options, with PFA having the best thermal properties. All of the mixes had similar compressive strengths (with the RCA mixes having slightly lower values), which would indicate that PFA is superior in all respects.

O'Moore and O'Brien 2009 researched the effects of GGBFS and FA replacement at various percentages with $32 \mathrm{MPa}$ concrete [96]. As was found in similar research, partial replacement of either FA or GGBFS had some improvement on the thermal performance of the concrete (Figure 6.21) [96]. One of the samples in the research had 200\% FA replacement, and this created a concrete sample with increased density and thermal conductivity [96]. This sample had the worse thermal performance of all of the mixes. So, while partial replacement of the cement is beneficial, adding in FA at high volumes can be detrimental to the thermal performance of the concrete.

Bernt 2015 researched the effect of partial Portland cement replacement with pozzolans, specifically FA and BFS [97]. There was also some research done into the use 


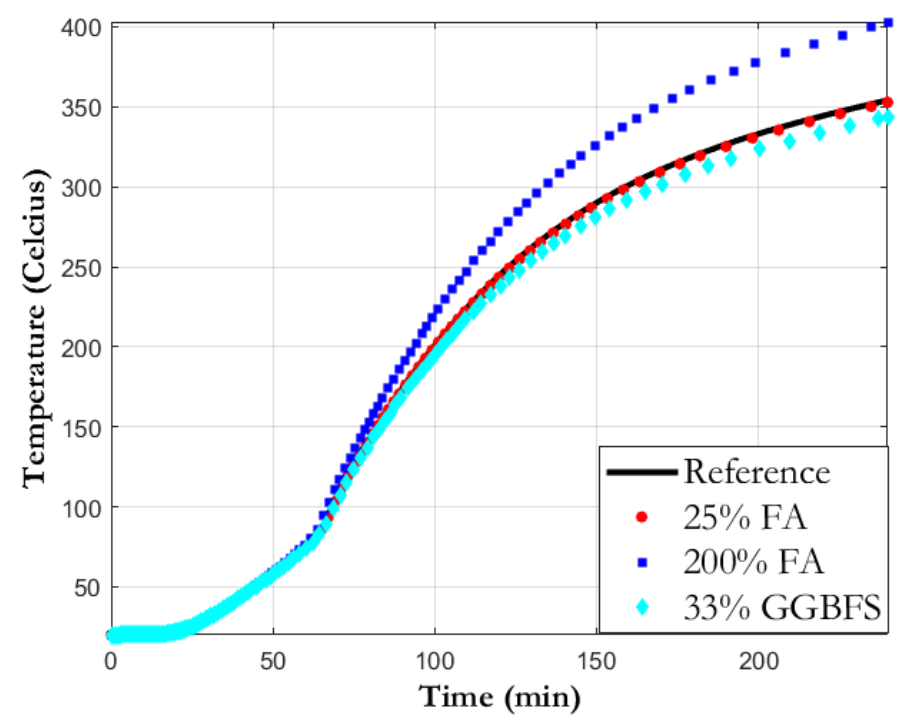

Figure 6.21: Time temperature curves of concrete with FA and GGBFS replacement

of RCA [97]. The focus of the research was on CO2 emissions for environmental concerns. It was found that the use of pozzolans and RCA reduced the $\mathrm{CO} \neg 2$ emissions and would be beneficial for the environment [97].

The thermal properties for all 17 mixes were very similar. The densities were all within $2.5 \%$ of each other, and the thermal conductivity values were all within $5.1 \%$ of each other [97]. This led to failure times that were almost identical for all 17 mixes (Figure 6.22). This thermal property trend is different from results found in other research, as usually pozzolanic materials and RCA reduce the thermal conductivity of concrete. If the replacement percentages had been low the thermal property results would have made more sense, however the maximum RCA, BFS, and FA replacements were $100 \%, 65 \%$, and $25 \%$ respectively. If the thermal properties are accurate, they would indicate that the addition of these materials does not negatively impact the fire resistance of concrete.

While pozzolanic materials generally improve the thermal and mechanciel performance of concrete, the results of specific replacement percentages and pozzolans used varied from researcher to researcher. Bernt 2015, O'Moore and O'Brien 2009, and Damdelen et al 2014 all had slightly different results when pozzolanic materials were added. Demdelen et al 2014 found that FA was the best option for replacement, whereas O'Moore and O'Brien 2009 found that the GGBFS was the superior 


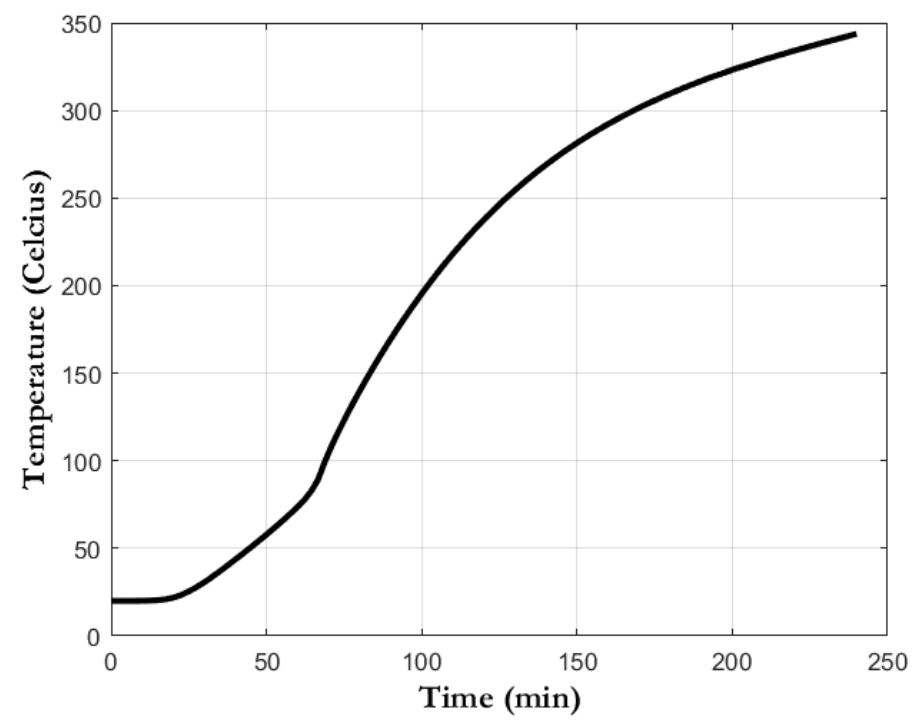

Figure 6.22: Time temperature curve of concrete with pozzolans

option, and Bernt found that all mixes had near identical thermal performance. Part of the reason for the differences in results is due to the variability of the materials themselves. As these materials are generally recycled waste, they can have impurities which effect their properties. In addition, the exact percentage of replaced material was different for all researchers, which makes comparing the results between pozzolans less accurate. The main result is that pozzolans are a good addition to concrete for both mechanical and thermal performance.

\subsubsection{RELATIVE HUMIDITY}

Wang et al. 2017 tested the effects of relative humidity on thermal conductivity using both normal concrete concrete (NC) and concrete with 30\% fly ash replacement [98]. The relative humidifies tested were $25 \%, 45 \%, 75 \%$ and $100 \%$ [98]. It is important to note that this humidity research was done after the concrete was removed from a furnace. So, its usefulness in determine the effects at elevated temperatures less exact, since there are no free water effects after the free water has been evaporated. The addition of fly ash increased the compressive strength of the concrete at all temperatures (including ambient) and the increase in pore size reduced the thermal conductivity of the concrete [98]. This means that fly ash is beneficial both for loadbearing and non-loadbearing members. 
It was found that as the temperature increased thermal conductivity decreased for both mixes [98]. This is partly due to the increase in pore size that occurs when concrete is heated. The larger the pores the more air is inside, which lessens the thermal conductivity. In terms of relative humidity, higher relative humidity led to higher thermal conductivity values [98].

From the thermal modeling it can be seen that in every case the fly ash performed better than the reference concrete (Figure 6.23). As the relative humidity of the testing room increased the fire resistance of the modelled concrete decreased. During a fire, the relative humidity of the room would not play as large a role on the thermal properties, as the free water is evaporated out at the beginning of the test. However, relative humidity can have a large impact on the recorded values of conductivity, which in turn may skew modeling results. This is part of the reason why thermal properties vary between different tests, and results from the same testing method but measured in different atmospheric conditions can yield different results.

From the results of the modelling, fly ash is a beneficial addition to concrete, as it is an improvement to both the ambient mechanical and thermal properties, but also both properties at elevated temperatures.

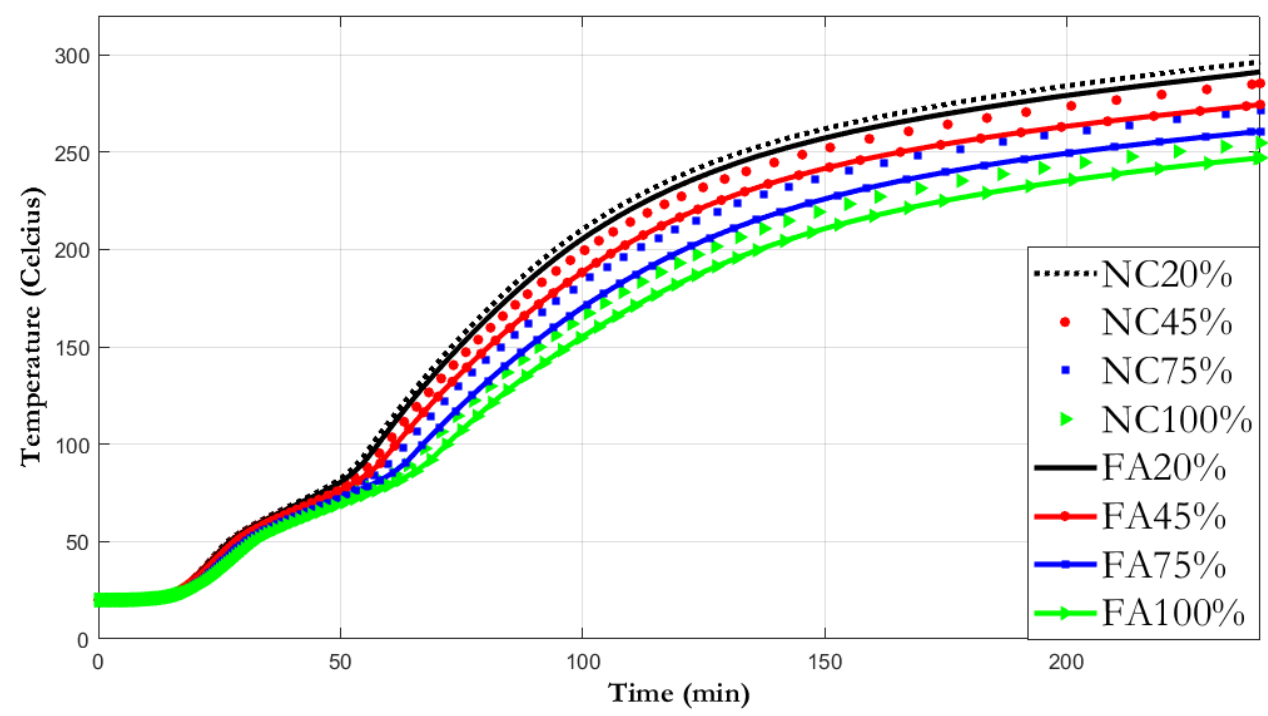

Figure 6.23: The effect of hummidity (from 20-100\%) on the fire resistance of NC and FA concrete 


\subsubsection{SILANE AND SF}

$\mathrm{Xu}$ and Chung 2000 researched the addition of SF and Silane to the cement paste [99]. The mixes all had 15\% SF replacement of cement and varying percentages of silane added (ranging from 0-2\%) [99]. SF is used in high strength concrete to increase the density of the concrete, and so it normally reduces the thermal resistance of the mix by increasing the density and thermal conductivity [99]. Silane is usually added when additives such as SF or fibers need improved wetting [99]. Silane helps to increase the density of the concrete, which also increase the thermal conductivity [99].

From the modeling results, even $0.2 \%$ Silane had a large effect on the thermal performance (Figure 6.24). Without Silane the SF does not bond to the concrete as well, which makes it more porous and improves the thermal conductivity. Once Silane is added the density and thermal conductivity increased. This led to a significant decrease in the fire resistance, that continued to decrease as more silane was added. While the thermal performance was reduced, the mechanical performance increased by 20-30\% [99]. This means that silane can be added if higher compressive strength is required, however it comes at the cost of the thermal performance.

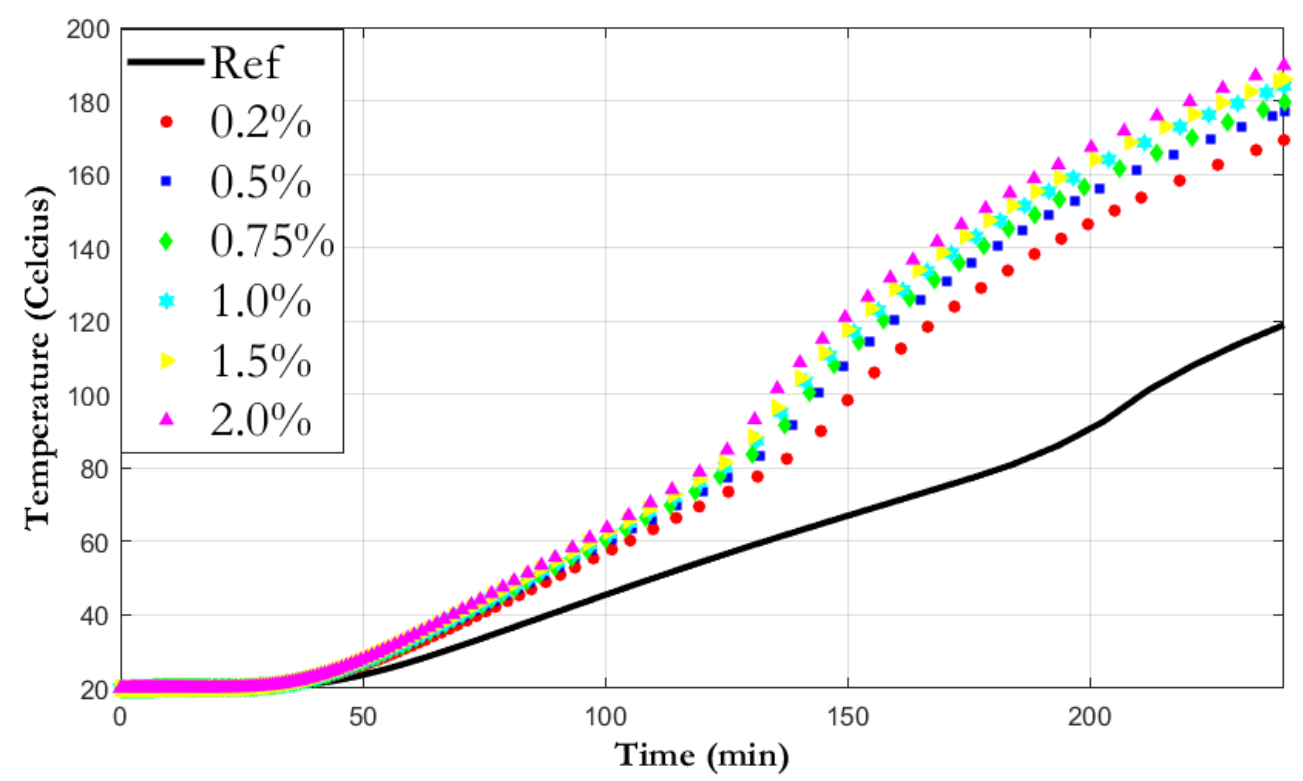

Figure 6.24: Comparing the effect of different amounts of silane

$\mathrm{Xu}$ and Chung 2000 tested the effect of SF added to cement paste and mortar samples [100]. The difference between the cement paste and mortar samples were 
that the mortar samples had sand added to them [100]. The results of the modeling showed that the mortar had worse fire resistance than the cement, and this is because the sand has worse thermal properties than the cement [100]. The addition of SF increased the fire resistance of both mixtures, but the increase was more significant for the cement paste mixture rather than the mortar mixture (Figure 6.25). The reason the difference in fire resistance relates to the interfacing of the SF with the cement verses the interfacing of the sand with the cement [100]. One reason why this test is important is that it helps to highlight the fact that results taken from cement paste mixtures are different from mortar mixtures, which are in turn different from mixtures with coarse aggregate. While something that improves the cement paste generally improves the final concrete mix, the magnitude of that improvement may be overestimated.

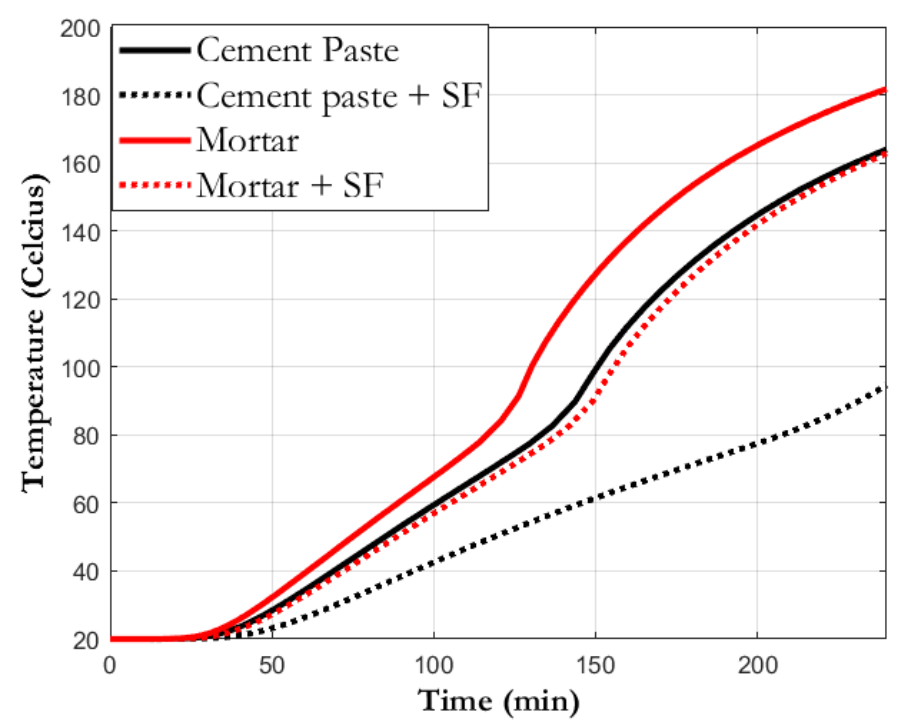

Figure 6.25: Comparing the effect of SF within cement paste and mortar

\subsubsection{ADDATIVES}

\section{SRA}

When comparing the effects of SRA, it was found that SRA reduced the thermal performance of the concrete (Figure 6.26) [95]. The addition of SRA did increase the mechanical properties of the concrete [95]. This makes sense, as SRA reduces the 
entrapped air, which increases the density and thermal conductivity of the concrete. This leads to reduced thermal properties but increased mechanical properties. As the difference in both thermal and mechanical properties were minor, SRA could be used if mechanical strength is required to be slightly higher but should be avoided if thermal performance the main concern.

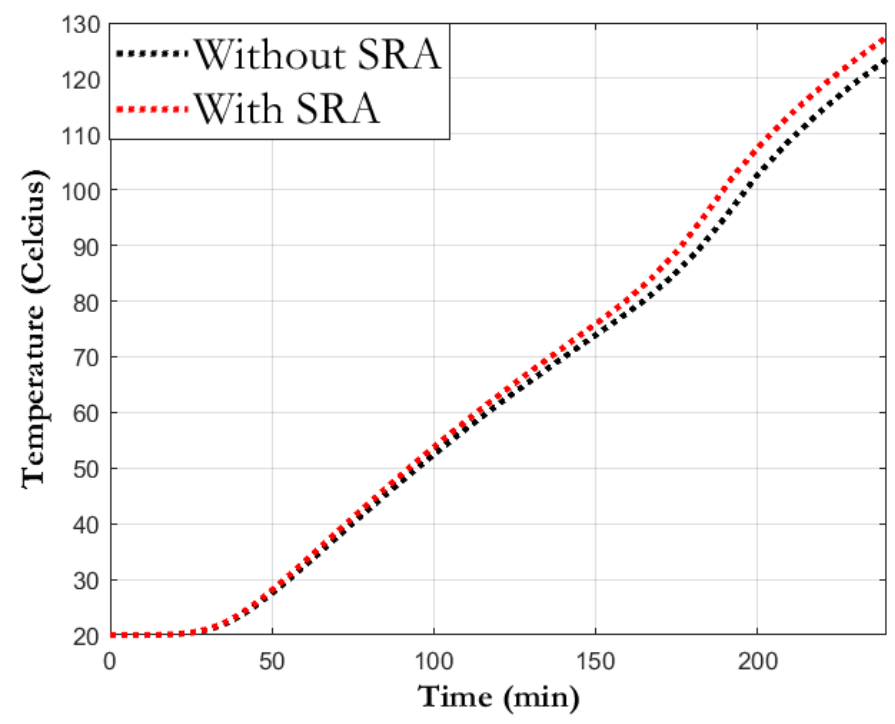

Figure 6.26: Comparing the effect of SRA

\section{VMA}

It was found that VMA increased the thermal performance but reduced the mechanical performance of the concrete (Figure 6.27) [95]. The reason for the change in properties is likely linked to the amount of entrapped air. The VMA mix had a higher amount of entrapped air, which reduced the density, thermal conductivity, and mechanical performance. The difference in entrapped air was higher for the VMA mixes than the SRA mixes, so the difference in thermal and mechanical performance was also higher for VMA. As neither mix failed in the four-hour time, either mix would be suitable for thermal insulation. While mixes with VMA might have improved mechanical properties, the improved workability and thermal performance provided by the addition of VMA may outweigh the mechanical degradation. 


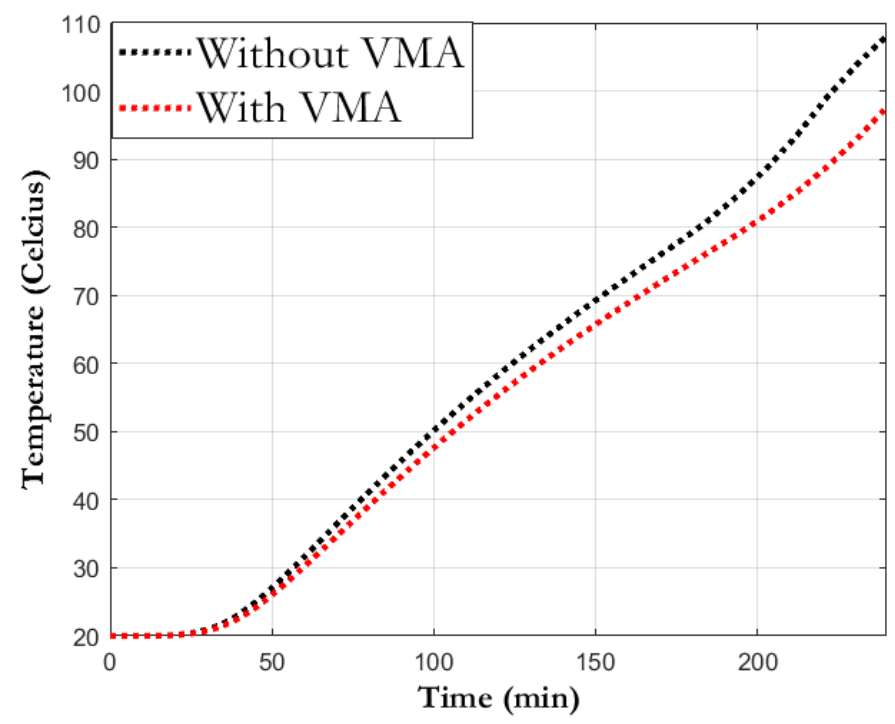

Figure 6.27: Comparing the effect of VMA

\begin{abstract}
$\mathrm{AE}$
Kim et al 2012 research the effect of LWC concrete with different percentages of air entraining (AE) additives [101]. Air bubbles within the concrete decrease the density and the thermal conductivity, thereby improving the thermal performance of the concrete at the cost of its mechanical properties [101]. The compressive strength of the concrete dropped to almost half with the addition of AE [101]. The thermal conductivity and density decreased as the amount of AE increased, except in the case of the $1.0 \%$ AE. This mix had higher thermal conductivity than the AE $0.5 \%$ mix [101]. The researchers only used one sample for each of the different mix designs, which explains the variability in the results. As concrete mixes and thermal property measurements can vary from one specimen to another, having multiple specimens would have allowed for more accurate results.

From the thermal modeling the addition of AE improved the fire resistance of the concrete (Figure 6.28). The AE0.5\% and $1.5 \%$ mixes had very similar thermal performance, and the AE $1.0 \%$ mix had a thermal performance only slightly improved from the reference concrete. As had been previously mentioned, the thermal conductivity of the AE 1.0\% was higher than expected and did not follow the trend of the other mixes, and this would explain the variation in thermal performance. Due to the decrease in compressive strength, concrete with AE should be used in non-loadbearing
\end{abstract}


members rather than loadbearing members.

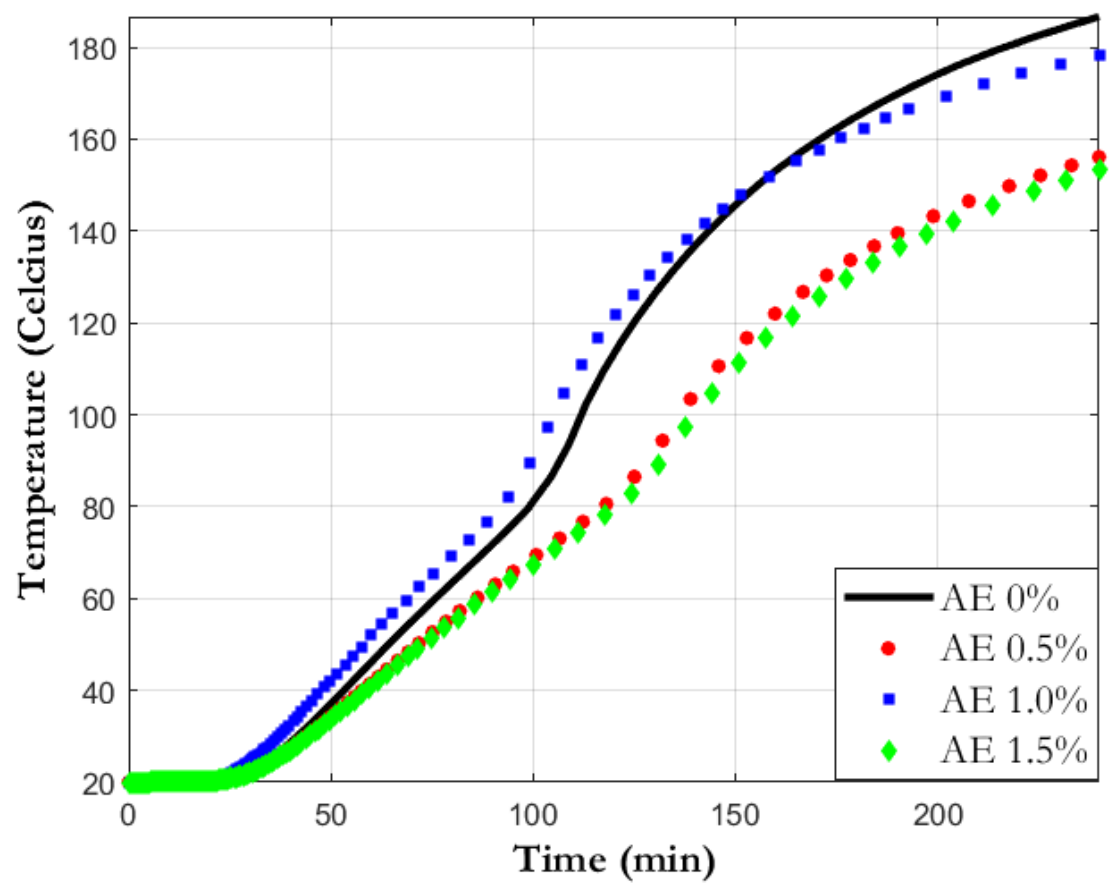

Figure 6.28: Comparing the effect of different amounts of AE

\subsubsection{FOAMED/AERATED CONCRETE}

Othuman and Wang 2011 researched the properties of lightweight foamed concrete (LFC) [102]. This material has been used as a filler material due to its low density and poor mechanical properties, however it may be useful for non-loadbearing members [102]. Foamed concrete is a cement paste with air bubbles which are the source of the decrease in density and mechanical properties [102]. The air bubbles create a pore structure that gives the material good thermal and acoustic properties [102]. Similar to regular concrete, foamed concrete releases water as it is heated, which improves its fire resistance.

The study focused on three different foamed concrete densities. Lowest density $(650 \mathrm{~kg} / \mathrm{m} 3)$, medium density $(1000 \mathrm{~kg} / \mathrm{m} 3)$, and highest density $(1850 \mathrm{~kg} / \mathrm{m} 3)$ [102]. As the density increased the thermal conductivity also increased, as is expected. The specific heat, thermal conductivity, and density were all measured at different 
temperature points in order to get detailed thermal properties for modelling purposes. The thermal properties were validated using their model, and it was found that the air pore size was an important factor for determining the thermal properties.

The masonry modeling showed that all three mixes had very good fire resistance (Figure 6.29). None of the mixes failed the insulation criteria after four hours. At the early stages of the time temperature graph the effects of the specific heat are very important, which is why the medium and high-density concretes took longer to heat up. However, as the test progresses the thermal conductivity becomes more of a factor, which is why the highest density becomes the hottest line. Unlike most materials, the lowest density was not found to be the most fire resistant. This means that the reduction in thermal conductivity and density were not enough to offset the reduction in specific heat. For this reason, the medium density was found to have the best fire resistance.

The study did not focus on the mechanical properties of the materials. As all three mixes remained well under the insulation failure temperatures, the mechanical properties are likely to be the deciding factors. If there are no mechanical requirements, then the lowest density is most likely to be used, as it will have the lowest deadweight.

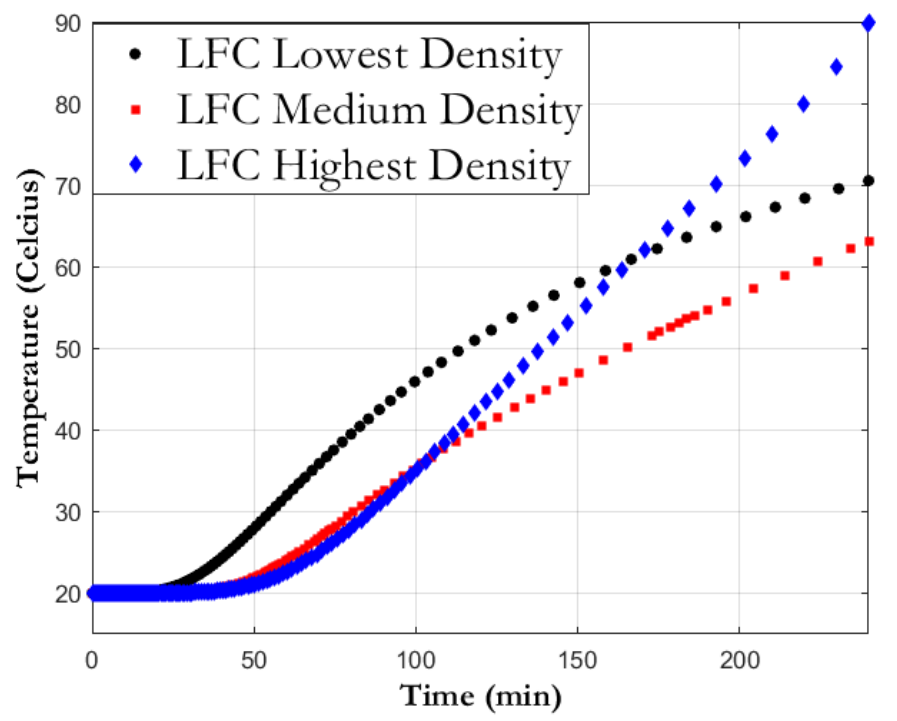

Figure 6.29: Comparing the effect of the different foamed concrete densities

Awoyera et al 2019 research replacing the fine aggregates with ceramics in foamed 
concrete [103]. It was found that ceramics had higher thermal conductivity, but improved residual compressive strength [103]. The authors claimed that there was no significant different in fire resistance when ceramics are added [103]. Through modeling, it was found that the ceramic mixes did have worse fire resistance than the reference mix, however the fire resistances were relatively close to each other (Figure 6.30). As the difference in residual compressive strength between the reference and $100 \%$ ceramic replacement were quite substantial, it would seem that ceramics should be added if compressive strength or residual compressive strength are of particular concern.

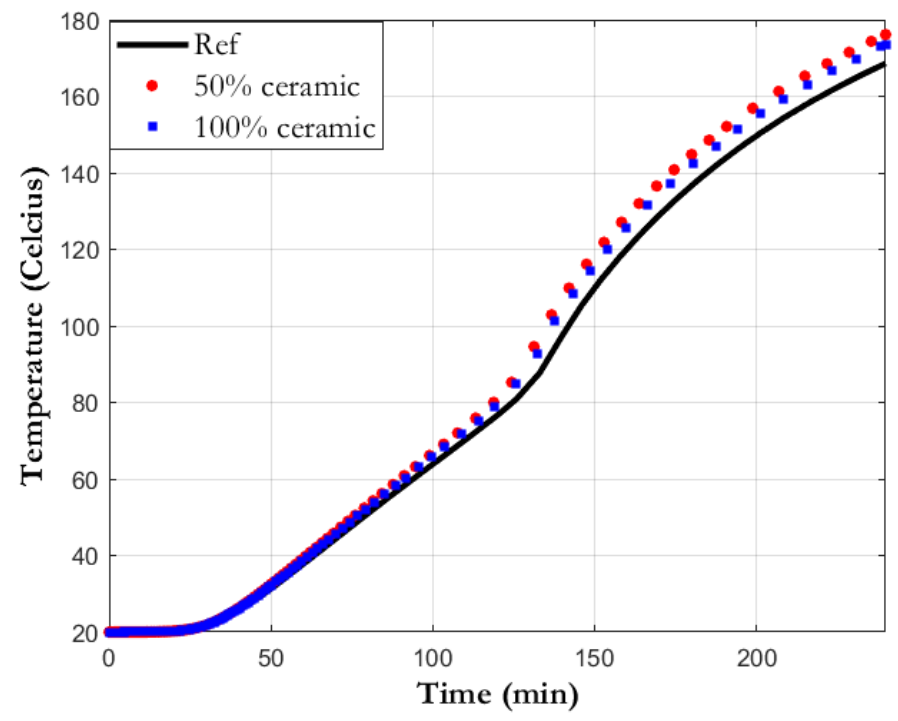

Figure 6.30: Comparing the effect of foamed concrete with different amounts of ceramic fine aggregate

Narayanan and Ramamurthy 2000 researched the properties of aerated concrete [104]. They determined the thermal properties of different mixes with densities ranging from $400-700 \mathrm{~kg} / \mathrm{m} 3$ [104]. The results had a range of thermal conductivity values and the maximum and minimum thermal conductivity values were modeled and compared for each density. As was expected, as the density increased the thermal conductivity increased, thereby reducing the fire resistance [104]. All of the mixes had excellent fire resistance, as none of the mixes failed in the four hours simulated (Figure 6.31). The difference between the mixes with the minimum thermal conductivity values and the maximum values was quite significant, as the time to reach even 
a $20^{\circ} \mathrm{C}$ increase varied by as much as 75 minutes. While the thermal performance of aerated concrete is excellent, it is only suitable for non-loadbearing members due to its low compressive strength.

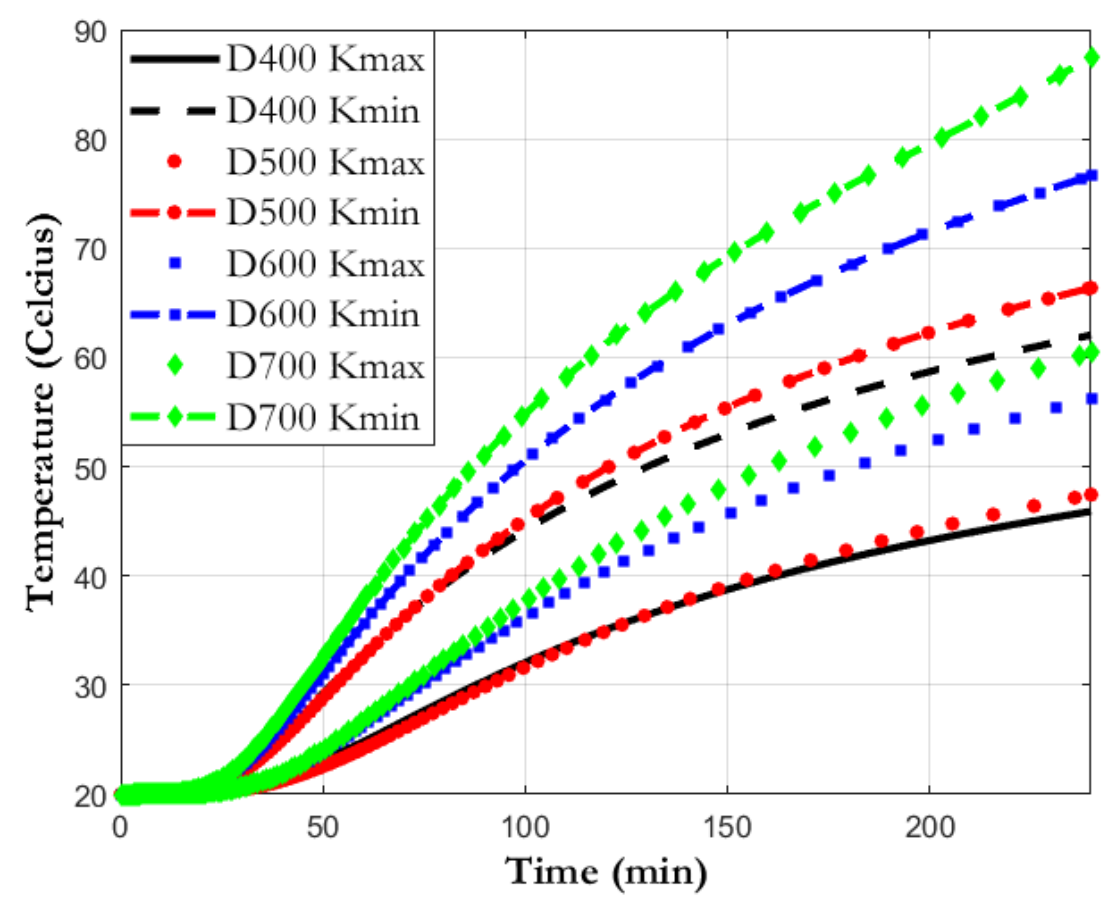

Figure 6.31: Comparing the effect of the different aerated concrete densities and thermal conductivities

\subsection{Cement, Pozzolans, and Addatives Conclusion}

Concretes with a higher cement content usually have higher densities as well as higher thermal conductivities. Lower water cement ratios also produce the same effect of denser concrete with higher thermal conductivity. This means that more cement usually reduces the fire resistance, however it does improve the mechanical performance of the concrete. There are several materials that can replace part of the cement to change the thermal and mechanical properties of the concrete.

If $\mathrm{SF}$ is added to the concrete on its own, it generally increases the porosity and reduces density, thermal conductivity, and mechanical properties. This is because on its own SF does not bond to the concrete very well which accounts for the porosity. 
If additives such as silane are used in addition to the SF, then the density actually increases and produces concrete with a higher thermal conductivity and better mechanical properties. As SF is generally used in HSC, it can lead to excessive spalling if the porosity is too low.

Higher relative humidity leads to a higher free water content within the concrete. This in turn leads to a higher thermal conductivity at ambient conditions; however, after the free water is evaporated the thermal conductivity values will lower. Therefore, the ambient thermal conductivity values are dependent on the relative humidity and may skew modeling results. The free water also leads to higher specific heat values which might actually improve the fire resistance if they are taken into account.

Similar to Silane, SRA increases the density of concrete, which has the same positive effect on the mechanical properties at the expense of the fire resistance. AE and VMA can be added to reduce the density of concrete, and this in turn improves the fire resistance at the cost of the mechanical performance.

Pozzolanic materials such as FA, GGBFS and MK can be used to replace part of the cement. All three have a positive effect on the thermal performance of concrete, with either similar or improved mechanical performance. FA was found to be the superior option, as it not only had the greatest improvement in fire resistance, but it also had the best mechanical properties. Foamed concrete is a type of concrete that is very porous, and so has a very low density (as low as $400 \mathrm{~kg} / \mathrm{m} 3$ ). This concrete has low thermal conductivity to match the low density, but its mechanical properties are such that it usually cannot be used for loadbearing members. In general, the lower density foamed concrete has the better fire performance. In the cases where the fire resistance is not lower for lower densities is usually attributed to the pore structure of the concrete.

\subsection{Cenosphere Results}

\subsubsection{Glazed Hollow Beads}

Guo et al 2020 looked into the thermal insulation properties of recycled aggregate thermal insulation concrete (RATIC) [79]. This is thermal insulation concrete (TIC) that includes both RCA as well as glazed hollow beads (GHB) [79]. The size of the GHB is between the fine and coarse aggregate size [79]. The addition of GHB decreases the thermal conductivity of concrete, while improving the compressive strength [79]. 
Many materials added to reduce the thermal conductivity have a negative impact on the compressive strength which can make them unsuitable to loadbearing applications. Since GHB actually improves the concrete strength, it can be used in both partition and loadbearing applications [79]. Since RCA and GHB both reduce the thermal conductivity of the concrete, they improve the fire resistance when added. Guo et al 2020 researched the effect of different 30\% RCA with different GHB combinations on the thermal resistance at ambient conditions [79].

It was found that as the amount of GHB increased, the thermal insulation improved (Figure 6.32). Having 30\%RCA and high GHB had the best results. The GHB actually increased the strength, with the maximum strength increase at medium replacement [79]. It would also be beneficial to determine the maximum possible GHB percentage that could be incorporated into the concrete mix before mechanical or workability issues arose. Based on the results RATIC is a material that can be used in both loadbearing and non-loadbearing applications. However, as there has been limited research done at elevated temperatures, more research is needed to confirm the stability of GHB under fire temperatures.

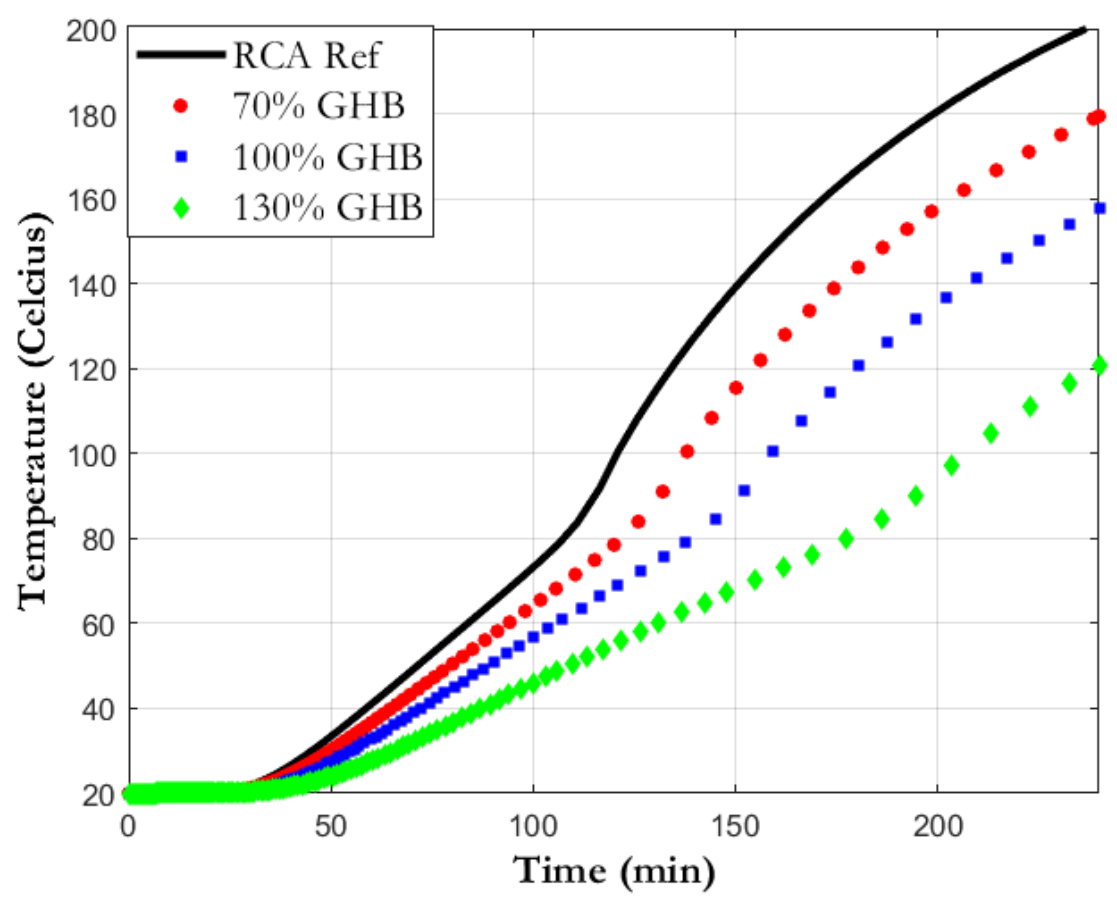

Figure 6.32: TIC mix with $30 \% \mathrm{RCA}$ and varying amounts of GHB 


\subsubsection{Glass bubble}

Yun et al 2013 researched the effect of NA and LWA mixes with glass bubbles added [8]. Instead of using just one LWA, three different aggregates were used, Asanolite (S), Argex (R), and Stalite (T) [8]. The glass bubbles were 65 micrometers [8]. It was found that use of LWA improved the fire resistance of the concrete, and the different LWA types did not have a large impact on the fire resistance [8]. The addition of the glass bubbles reduced the density by up to $28 \%$ and thermal conductivity by up to $25 \%$ [8]. This is because the hollow glass bubbles are lightweight, have low thermal conductivity, and are full of air. As more glass was added the compressive strength was reduced by up to $43 \%$ [8]. This would indicate that the glass bubbles can be used, however the significant drop in compressive strength may limit their usefulness in loadbearing members.

The thermal modeling showed some interesting results. Even though the glass bubbles reduced the thermal conductivity, their addition still led to a decrease in thermal performance (Figure 6.46) [8]. The reason for this is related to the loss in density. As the glass content increases, the thermal conductivity undergoes a small decrease which would improve the fire resistance; however, the density decreases at a more significant rate, which decreases the fire resistance. With most materials the decrease in thermal conductivity governs and improves the thermal performance, but in the case of these glass bubbles the improvement in the LWC thermal conductivity is not enough. Testing the effects of the glass bubbles on materials with higher thermal conductivity may yield better results.

\subsubsection{Fly Ash Cenospheres sizes and hole filling}

Blanco et al 2000 researched the effects of fly ash cenospheres on the thermal and mechanical properties of lightweight concrete [105]. The first part of the researched looked into the effect of leaving a part of the holes created by the cenospheres unfilled (ranging from 0\% unfilled to 50\% unfilled) [105]. Leaving the holes unfilled was expected to create a less dense concrete, which would have a negative impact on the strength, but a positive impact on the thermal performance [105]. The second aspect was to determine the properties if only one size of cenospheres were used. Cenospheres were sorted by diameter into six different size $(4.50 \mathrm{~mm}, 3.60 \mathrm{~mm}, 2.60 \mathrm{~mm}, 1.75 \mathrm{~mm}$, $1.25 \mathrm{~mm}$, and $0.60 \mathrm{~mm}$ ) [105]. The finial part of the research was to determine the 


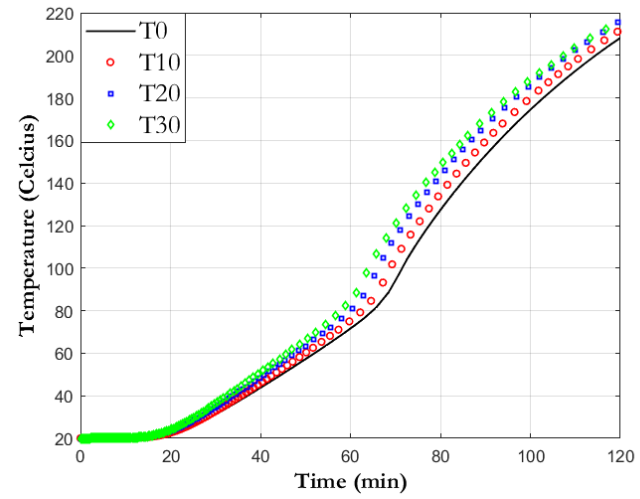

(a)

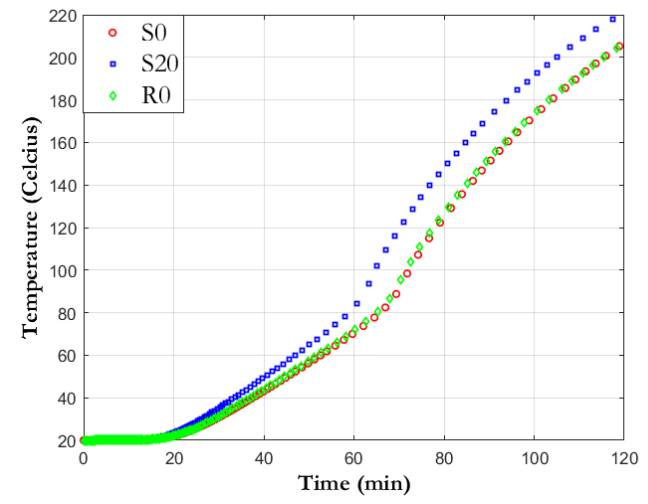

(b)

Figure 6.33: Effect of glass bubbles with different aggregates a) Stalite (t) (b) Asanolite (S) and Argex (R)

effect of using two different cenosphere sizes (called a bimodal mixtures) [105].

It was found that as the percentage of holes left unfilled increased, the density and compressive strength decreased with a maximum decreased of $23 \%$ and $83 \%$ respectively when $50 \%$ of the holes were left unfilled [105]. With only 10-20\% of the holes left unfilled, the density and compressive strength were closer to the reference values [105]. The thermal conductivity also decreased as more holes were left unfilled, which meant an improvement in the thermal properties. When comparing the fire resistance of the different mixes, it was found that the reference mix was the worse as expected (Figure 6.34). However, the mixes from 10\%-40\% were relatively close in their fire resistance, having fire resistances ranging from 10-15minutes better than the reference mixture. The mix with $50 \%$ of the holes unfilled did have a more significant improvement in the fire resistance, with a fire resistance around 1hour better than the reference concrete. This would indicate that leaving $10-20 \%$ of holes unfilled would be beneficial for providing a minor improvement to the fire resistance at the cost of a slight decrease in mechanical properties. If mechanical properties are of no concern, then $50 \%$ of the holes could be left unfilled to reach the best thermal performance; however, the decrease in mechanical properties is so severe that integrity issues may arise during a fire.

When only one cenosphere size was used, it was found that the larger cenosphere diameter provided a small increase in density and a minor improvement in the mechanical properties. As with any increase in density, the thermal properties were 


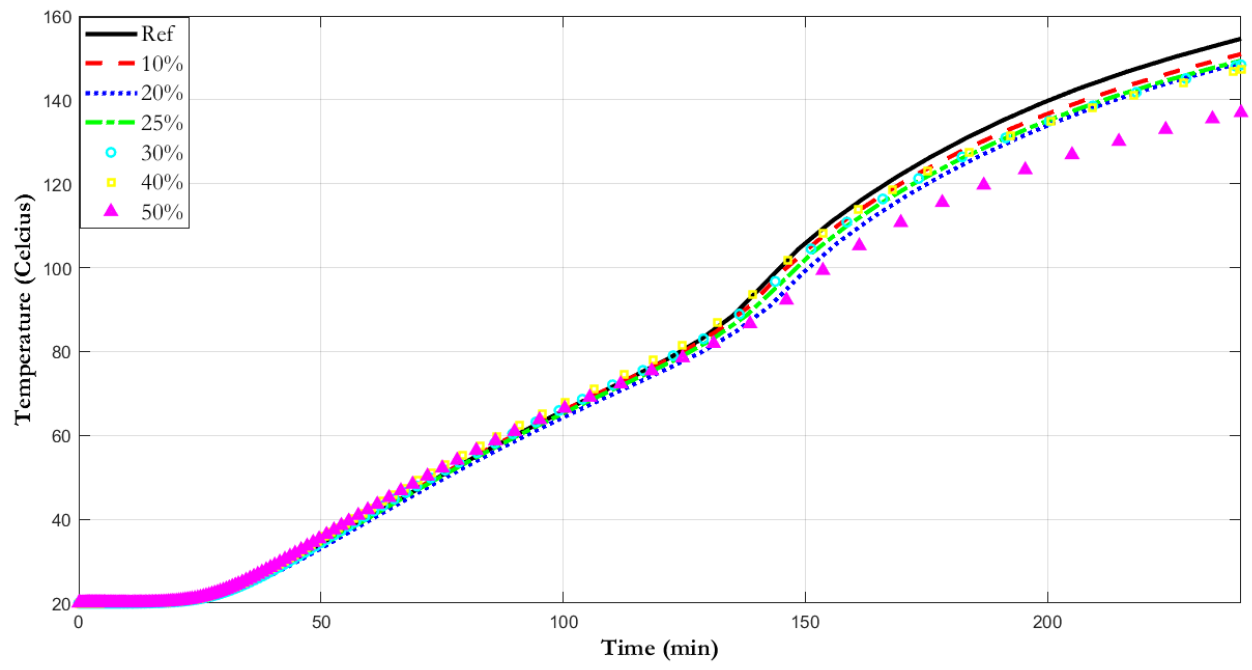

Figure 6.34: FAC with percentage of the holes that were not filled

worse for the mixes with larger cenospheres. Through modeling, it can be seen that while the $4.50 \mathrm{~mm}$ diameter had the worse fire resistance, the next three diameters $(3.60 \mathrm{~mm}, 2.60 \mathrm{~mm}$, and $1.75 \mathrm{~mm})$ all had almost identical fire resistance (Figure 6.35). The smaller diameter mixes were found to have the best fire resistance. The authors suggested that one issue with cenosphere diameters above $4 \mathrm{~mm}$ is that there is a greater variability in the concrete mix, and so sizes about $4 \mathrm{~mm}$ are not recommended. Using smaller cenosphere diameters usually results in more uniform mixing, which could account for the smaller cenospheres having the improved thermal performance (about 30-40 minutes better than the $4.50 \mathrm{~mm}$ mix). Since the compressive strength only has a minor decrease when smaller cenospheres are used, it would be recommended to use them instead of the larger ones in order to gain the improved thermal properties.

When using the bimodal mixtures, it was found that all mixes had similar density and compressive strength, but they were all had slightly lower compressive strengths when compared to the mixes with only one cenosphere size. In terms of thermal properties, the mixes with large and small cenospheres were found to have improved thermal performance (with the two $0.60 \mathrm{~mm}$ cenosphere mixes having the best results) (Figure 6.36). Part of the reason the more diverse mixes had improved thermal properties could be due to the improved mixing of the concrete. Another reason could be that most of the larger cenospheres provide similar fire resistance, and the $0.60 \mathrm{~mm}$ 


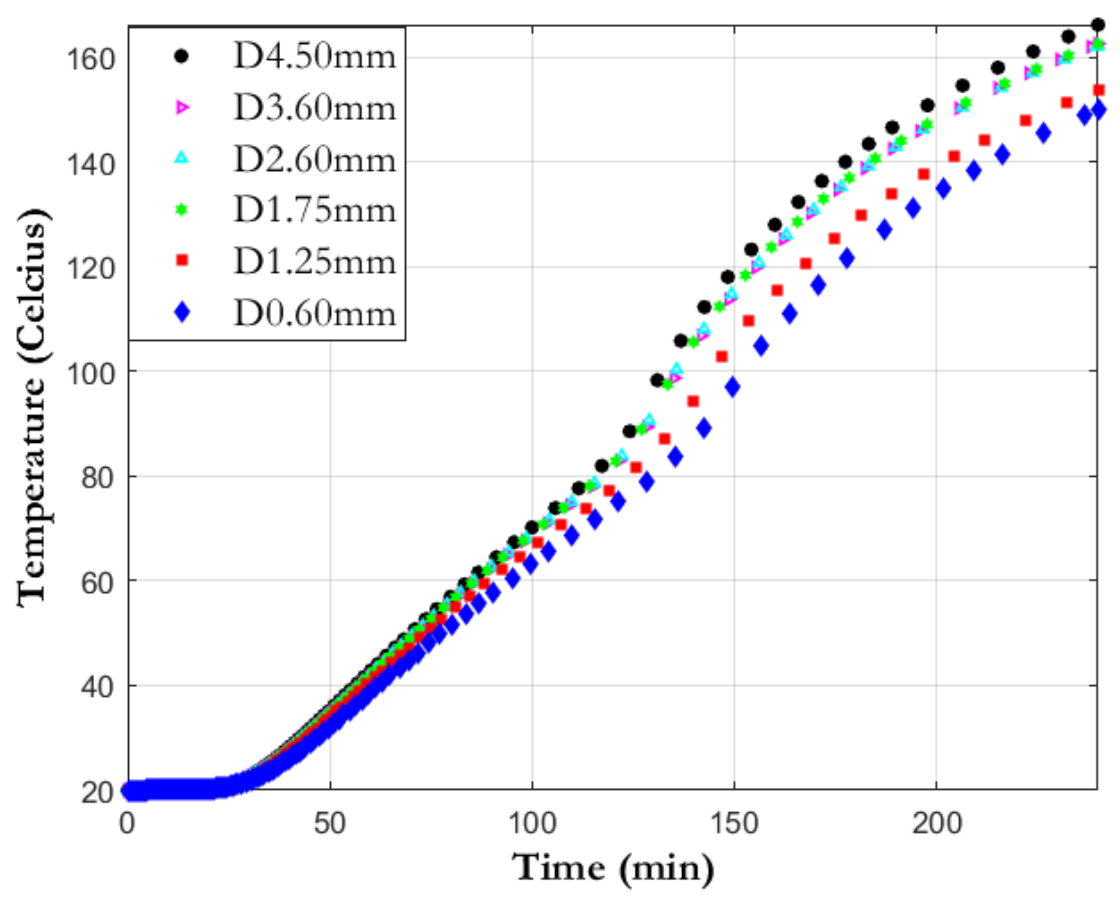

Figure 6.35: Performance of FAC with only a dingle diameter

cenospheres provide improved thermal resistance; therefore, mixes any mix with the $0.60 \mathrm{~mm}$ would have the improved thermal performance. When compared to the mixes with only one cenosphere size, the thermal performances of the bimodal mixes were slightly better. Since the mixtures with all cenosphere sizes, one cenosphere size, and two cenosphere sizes mostly had similar results, the cost of sorting cenospheres may outweigh the benefits of the improved compressive strength or thermal properties. The authors recommended screening out the cenospheres larger than $4 \mathrm{~mm}$. If having an even longer fire resistance is important, than screening out cenospheres larger than $1.25 \mathrm{~mm}$ is recommended.

\subsubsection{Fly Ash Ccenospoheres replaced by Iron Ore Tailings}

Huang et al 2013 researched the effect of green lightweight engineered cementitious composites (GLECC) on concrete [106]. The concrete mixes all had different percentages of Portland cement (C), fly ash (FA), iron ore tailings (IOTs), fly ash cenospheres (FAC), polyvinyl alcohol (PVA) fibers, and high range water reducing admixture (HRWRA) [106]. The exact mixes can be found in Table 6.3. All mixes had the same 


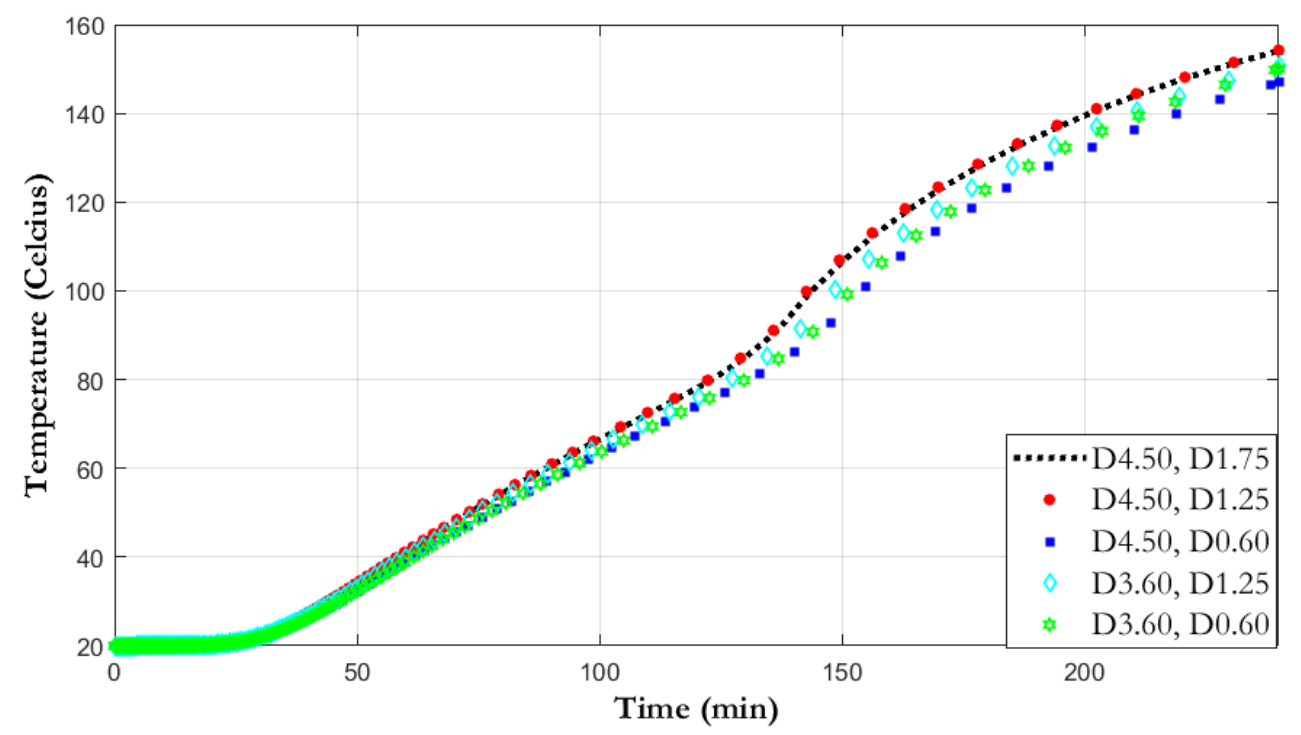

Figure 6.36: Performance of FAC with bimodal mixes

w/c ratio, however C1-C3 had a lower FA/C ratio [106]. For C1-C3 and C4-C6 the IOTs and HRWRA amount decreased as the FAC amount increased [106]. For all mixes the fiber quantity remained constant [106].

Table 6.3: Huang et al 2013 Mix Designs

\begin{tabular}{|l|l|l|l|l|l|l|l|}
\hline Mix ID & $\begin{array}{l}\text { Cement } \\
(\mathbf{k g} / \mathbf{m} 3)\end{array}$ & $\begin{array}{l}\text { FA } \\
(\mathbf{k g} / \mathbf{m} 3)\end{array}$ & $\begin{array}{l}\text { IOTs } \\
(\mathbf{k g} / \mathbf{m} 3)\end{array}$ & $\begin{array}{l}\text { FAC } \\
(\mathbf{k g} / \mathbf{m} 3)\end{array}$ & $\begin{array}{l}\text { Water } \\
(\mathbf{k g} / \mathbf{m} 3)\end{array}$ & $\begin{array}{l}\text { Fibers } \\
(\mathbf{k g} / \mathbf{m} 3)\end{array}$ & HRWRA \\
\hline C1 & 389.5 & 856.8 & 448.7 & 0 & 324.0 & 26 & 0.46 \\
\hline C2 & 389.5 & 856.8 & 179.5 & 84.1 & 324.0 & 26 & 0.38 \\
\hline C3 & 389.5 & 856.8 & 0 & 140.2 & 324.0 & 26 & 0.33 \\
\hline C4 & 227.2 & 999.7 & 441.7 & 0 & 319.0 & 26 & 0.42 \\
\hline C5 & 227.2 & 999.7 & 176.7 & 82.8 & 319.0 & 26 & 0.32 \\
\hline C6 & 227.2 & 999.7 & 0 & 138.0 & 319.0 & 26 & 0.26 \\
\hline
\end{tabular}

It was found that as the IOTs and HRWRA amounts decreased and FAC amount increased, the fire resistance improved by up to 25 minutes (Figure 6.37). When comparing the two $\mathrm{FA} / \mathrm{C}$ ratios, it was found that the higher $\mathrm{FA} / \mathrm{C}$ ratio provided the better fire resistance by between 5-10 minutes. For the mechanical properties, 
the mixes were comparable to normal concrete in terms of tensile and compressive strength. The mechanical properties improved as the percentage of FAC was increased, which would indicate that FAC is good for improving both mechanical and thermal properties. From theses results, these mixes can be used for both loadbearing and nonloadbearing members.

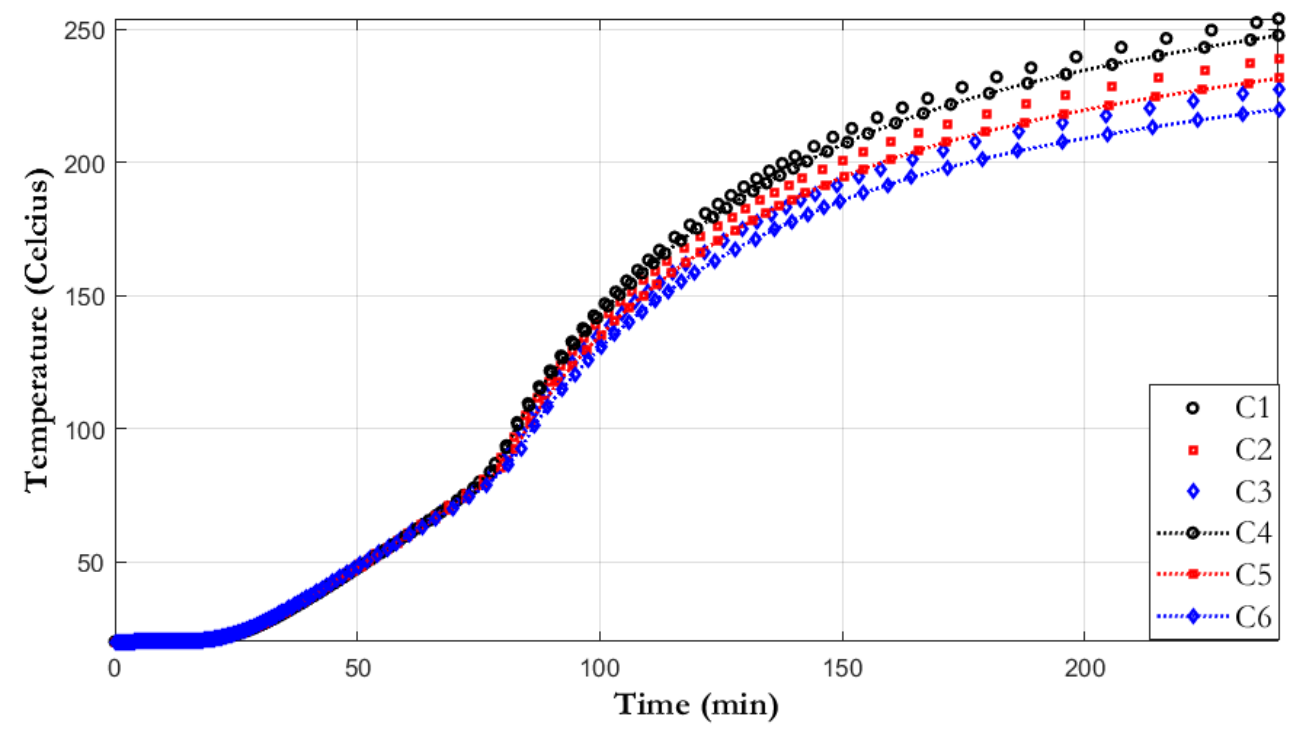

Figure 6.37: Comparing the effect of different mix designs

\subsubsection{Effect of Exlite and QK300}

Wu et al 2015 researched the effect of different lightweight concrete mixes with the inclusion of cenospheres [95]. The two types of cenospheres used were QK300 and Exlite [95]. The difference between them is that QK300 has a higher density than Exlite $(908 \mathrm{~kg} / \mathrm{m} 3$ and $615 \mathrm{~kg} / \mathrm{m} 3$ respectively), and Exlite has smaller particles sizes [95]. The mix designs can be found in Table 6.4.

The benefits of cenospoheres are that they allow for lightweight concrete with good mechanical properties [95]. The cenospheres create pores which account for the lower density and thermal conductivity [95]. However, unlike many other lightweight aggregates, the compressive strength of the material remains similar to normal weight aggregate concrete [95]. The reasons for the strength of the material are due to the 
Table 6.4: Wu et al 2015 Mix Designs

\begin{tabular}{|l|l|l|l|l|}
\hline Mix ID & $\begin{array}{l}\text { Cenosphere } \\
\text { type }\end{array}$ & w/b & $\begin{array}{l}\text { Cenosphere } \\
(\mathrm{kg} / \mathrm{m} 3)\end{array}$ & $\begin{array}{l}\text { Cenospohere } \\
\text { (Vol \%) })\end{array}$ \\
\hline Wu1 & QK300 & 0.35 & 348 & 38.3 \\
\hline Wu2 & QK300 & 0.37 & 402 & 44.3 \\
\hline Wu3 & Exlite & 0.37 & 268 & 43.6 \\
\hline Wu4 & QK300 & 0.45 & 442 & 48.7 \\
\hline Wu5 & Exlite & 0.56 & 317 & 51.6 \\
\hline
\end{tabular}

stiff shell in the cenospheres, the relatively uniform void sizes in the cenospheres, and the formation of a strong bond between the cement paste and the cenospheres [95].

The first few mix designs altered the $\mathrm{w} / \mathrm{c}$ ratio and cenosphere types. The mixes with lower w/c ratios had better mechanical properties, but also higher thermal conductivity and density [95]. This led to a reduction in the thermal performance as the $\mathrm{w} / \mathrm{c}$ ratio increased. It is important to note that none of the mix deigns failed during the 4 hours of the model, which would indicate that these mixes are well suited for thermal insulation (Figure 6.38). As the mixes all had good ambient mechanical properties, it would indicate that these mixes could be used in both loadbearing and non-loadbearing members.

Mix 3 and 4 had similar mix design and w/c ratio, with the major difference being that Mix 3 used QK300 and Mix 4 used Exlite. In terms of cenosphere type it can be seen that Exlite had better thermal performance than QK300, and they both had similar mechanical performance [95]. As the mechanical and thermal performances were very similar, it appears that the cenosphere type does not have a large effect on the properties of the concrete.

\subsubsection{Use of lightweight fillers}

Brookes et al 2018 tested a variety of lightweight fillers (LWF) as fine aggregate replacement of the silica sand [107]. The different LWF used were "expanded polystyrene (EPS) beads, expanded thermoplastic microspheres (ETM), hollow glass microspheres (HGM), and fly ash cenospheres (FAC)" [107]. The sample naming 


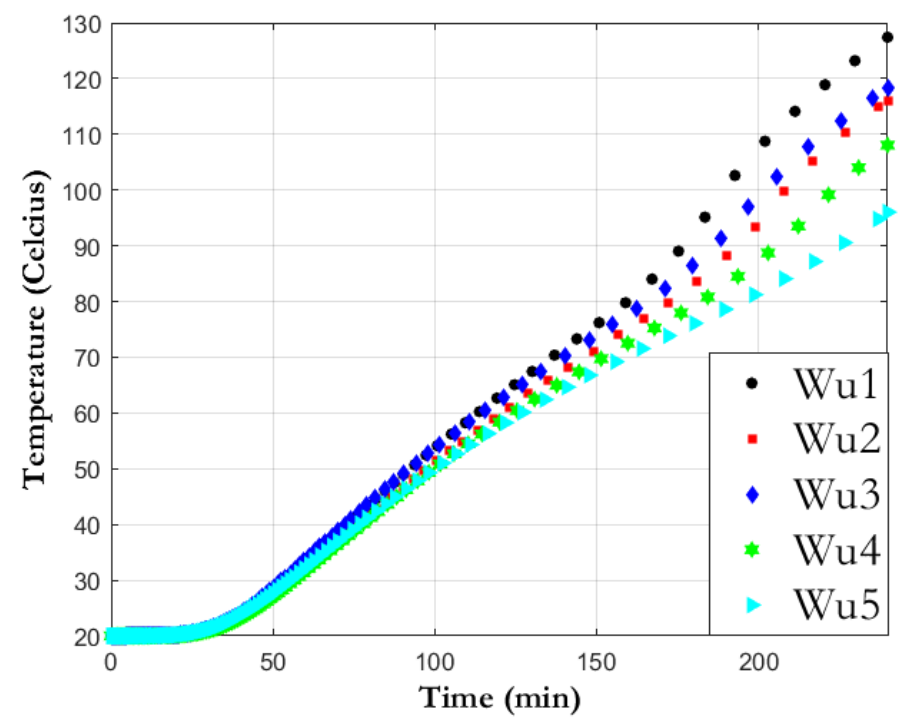

Figure 6.38: Comparing the effect cenosphere type and w/b ratio

convention includes the suffix $-0,1,2,3$, and 4 for $0 \%, 7 \%, 14 \%, 21 \%$, or $28 \%$ silica sand replacement by LWF [107]. The name of each of the 11 LWF can be found in Table 6.5.

EPS beads are low density artificial aggregate than can be added to the concrete mix to reduce density and thermal conductivity [107]. The benefits include better workability and volume stability, and they can be used in both loadbearing and nonloadbearing members. They can be mixed on site, however due to the low density there is the risk of segregation [107]. The use of TPMS behave similarly to EPS, but there are improvements with the tensile strength. The issue with these materials is that the create concrete with lower mechanical properties due to the low crushing strength and reduced thermal stability. Also, EPS releases toxic gasses when it is ignited, and so may have life safety concerns [107].

HGM can also be added to concrete to reduce the density and thermal conductivity [107]. Unlike EPS, HGM has improved crushing strength and thermal stability (up to $650^{\circ} \mathrm{C}$ ) [107]. Since glass has a smooth surface, there are issues with it bonding to the binder which in turn leads to a reduction in strength and brittle failure of the material [107].

FAC are hollow spheres formed as a product of coal combustion. Their low density and thermal conductivity make FAC an excellent addition to LWC [107]. Unlike 
Table 6.5: Brookes et al 2018 Mix Designs

\begin{tabular}{|l|l|l|l|l|}
\hline Mix ID & Material Type & $\begin{array}{l}\text { Particle } \\
\text { size } \\
(\mu \mathbf{m})\end{array}$ & $\begin{array}{l}\text { Density } \\
\left(\mathrm{g} / \mathbf{c m}^{\wedge} 3\right)\end{array}$ & $\begin{array}{l}\text { Wall } \\
\text { Thickness } \\
(\mu \mathbf{m})\end{array}$ \\
\hline EPS-M & EPS beads (2.5mm) & 250 & 0.013 & - \\
\hline EPS-S & EPS beads (1mm) & 100 & 0.031 & - \\
\hline TPMS & Thermoplastic microsphere & $35-55$ & 0.025 & - \\
\hline K25 & Hollow Glass microsphere (3M) K25 & 55 & 0.25 & 0.85 \\
\hline S32 & Hollow Glass microsphere (3M) S32 & 40 & 0.32 & 0.88 \\
\hline S38HS & Hollow Glass microsphere (3M) S38H5 & 44 & 0.28 & 1.20 \\
\hline H50 & Hollow Glass microsphere (3M) H50 & 35 & 0.50 & 1.70 \\
\hline S60 & Hollow Glass microsphere (3M) S60 & 29 & 0.60 & 1.49 \\
\hline E106 & Fly-ash cenosphere E106 & 81.3 & 0.91 & 4.8 \\
\hline E160 & Fly -ash cenosphere E160 & 90.6 & 0.76 & 6.0 \\
\hline E200/600 & Fly -ash cenosphere E200/600 & 349.1 & 0.82 & 16.5 \\
\hline
\end{tabular}

the EPS, TPMS, and HGM, the FAC reacts well with cement binders due to the pozzolanic reactivity. It also has a rougher surface, which improves the bonding to the binder [107].

The results of the physical testing showed that as the amount of LWF increased, the thermal conductivity decreased [107]. While the type of LWF did impact the thermal conductivity, the amount of LWF was the main factor. It was found that the LWF with larger particle sizes had slightly higher thermal conductivity due to the increase in convection within the hollow particles [107].

For compressive strength it was found that the LWF type had a large effect [107]. Concrete mixes with EPS and TPMS showed a rapid decrease in strength as the amount of LWF increased. This is due to the low crushing strength of these aggregates which allows cracks to form and propagate through the concrete [107]. The size of these particles did not have much effect on the strength reduction [107].

For HGM and FAC the inclusion of under 15\% replacement actually increased the compressive strength. This is due to the spherical shape improving the workability of the concrete which reduced the air content [107]. With more than $15 \%$ replacement 
the particle size and thickness had a larger effect on the compressive strength [107]. It was found that smaller and thicker particles showed better compressive strength. With 28\% replacement of H50, S60, E106, and E160 the compressive strength was similar to the reference compressive strength [107]. This would suggest that these mixes could be used to provide a concrete that has good mechanical and thermal properties.

Each LWF material had a slightly different control mixture. The modeling results demonstrated that most of the control mixtures had similar time temperature curves, failing within 20minutes of each other (Figure 6.39). However, the TPMS mixture had a much hotter time temperature curve. The reason for this is due to a very low specific heat for this mixture (almost half of the expected value). The reason for this low specific heat is not mentioned in the research, but it is likely due to a measurement error while determining the specific heat through the Transient Plane Source (TPS) method. The rest of the control mixtures varied mainly due to differences in air content which effected the density, thermal conductivity, and specific heat capacity.

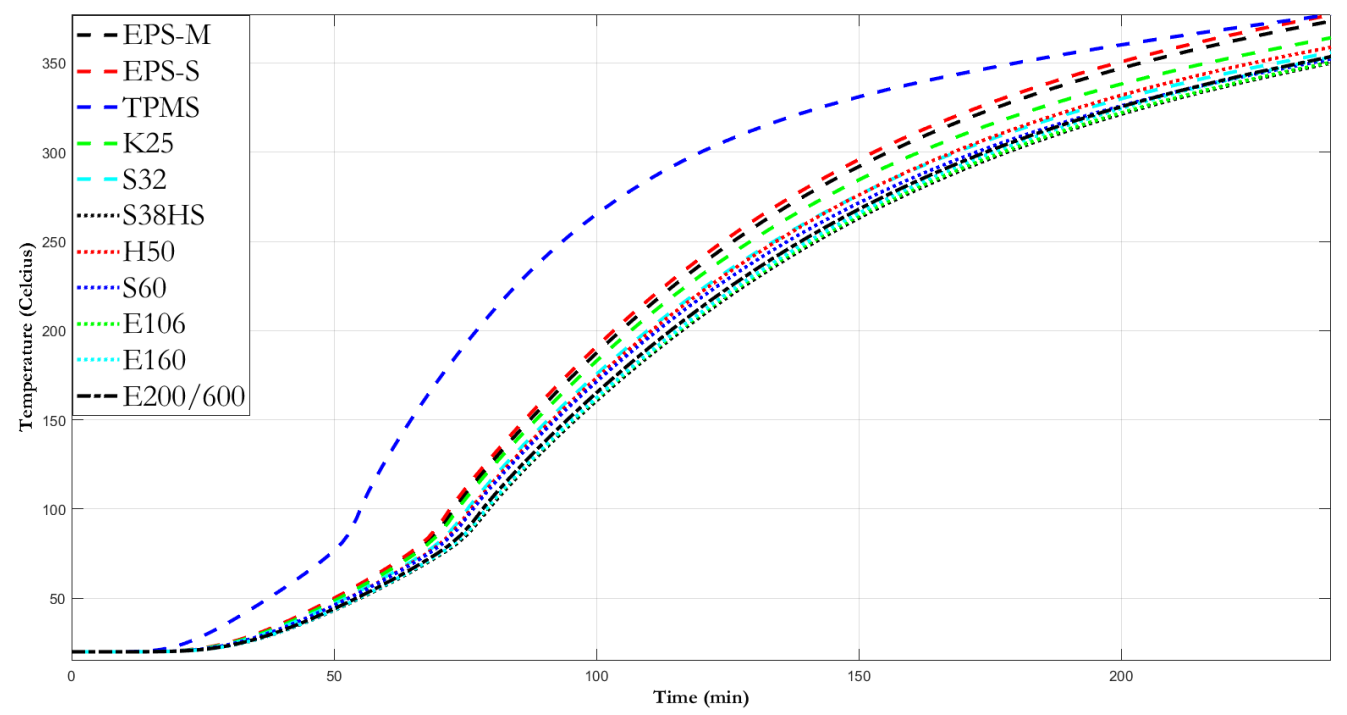

Figure 6.39: Brooks et al 2018 Control specimen time temperature curve comparison

The results of the EPS beads showed that as the amount of LWF was increased the fire resistance also increased. This makes sense as the thermal properties continue to improve as the amount of LWF increases. Between the two EPS bead types, the one with the larger bead size was found to have worse fire resistance than the smaller 
bead size. It was mentioned within the research that the larger beads allowed for more convection, which would decrease the fire resistance. As the percentage of LWF replacement increased, the difference between the two bead sizes grew more apparent. Therefore, using the smaller bead size is recommended for the best fire resistance.

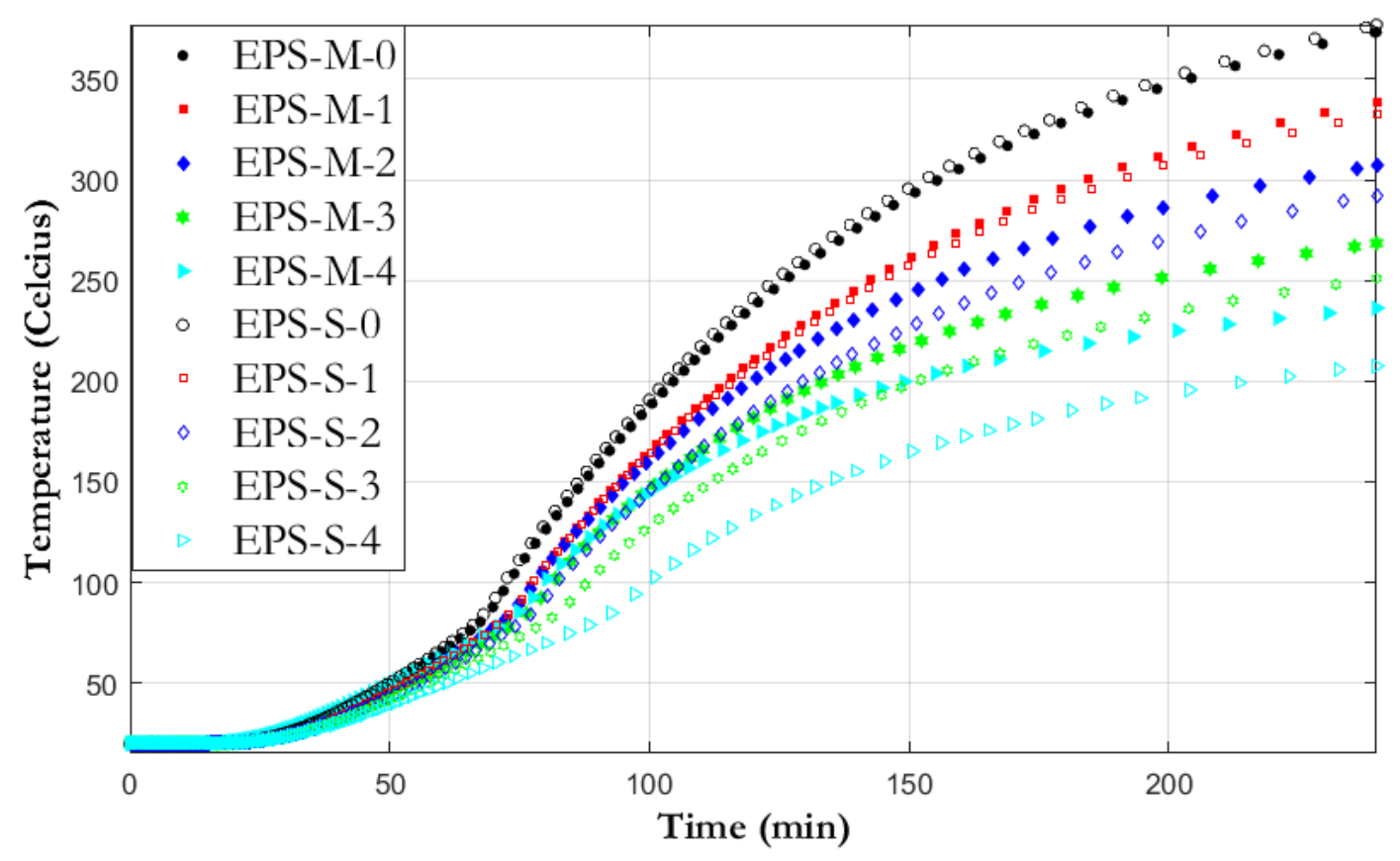

Figure 6.40: Brooks et al 2018 EPS beads time temperature curve comparison

The results of the TPMS show that the as the amount of LWF increases, the fire resistance increases (Figure 6.41). Except in the case of the 28\% replacement. Similar to how the TPMS control mix had a very low specific heat, the specific heat for the $28 \%$ replacement of TPMS was half of what it should be. For this reason, the time temperature curve of the $28 \%$ replacement crosses the other curves. This is likely a measurement error, as it is unlikely that adding an extra $7 \%$ of TPMS would halve the specific heat.

The glass beads were found to have similar time temperature curves (Figure 6.42). The pattern would seem to be that the higher the density of the HGM the worse the fire resistance, except that S60 has a higher density than H50. When looking instead at the particle size there is also no pattern, as the particle sizes continue to decrease. When looking instead at the wall thickness it can be seen that K25 and S32 have very 


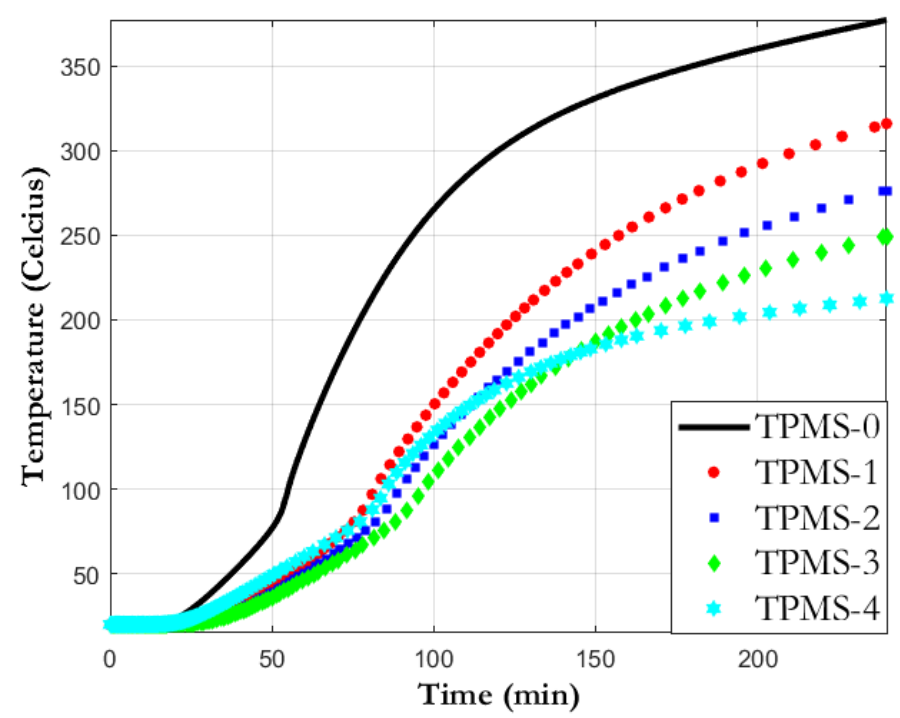

Figure 6.41: Brooks et al 2018 TPMS time temperature curve comparison

similar wall thicknesses, and very similar time temperature curves. Also, unlike all of the other properties, the wall thickness of H50 and S60 do not follow increasing or decreasing pattern, as H50 has the largest wall thickness. This would seem to indicate that the higher wall thickness might not be beneficial to the thermal resistance of the mix. However thicker particles were found to have improved mechanical properties, and so it is important to weigh the two benefits. The H50 28\% mix has a roughly 5\% better compressive strength than the $\mathrm{S} 60 \mathrm{mix}$, and an 9\% decrease in fire resistance. So optimal mix would depend on whether stability or insulation would govern the design.

For the fly ash, the three mixtures were relatively close to each other (Figure 6.43). The E200/600 mixture had larger particles, but also larger wall thickness and medium density, and it was found to have the best fire resistance. The E106 and E160 had very similar fire resistance values. Similar to the glass, the mix with the best fire resistance was not the mix with the best compressive strength. Therefor it is important to determine which failure mode will govern the design.

When comparing all of the different $28 \% \mathrm{LFW}$ mixes together it can be seen that the EPS and TPMS mixes had the worse fire resistances, although still performing better than the control concrete mixes (Figure 6.44). The material with the best fire resistance was the HGM, with every HGM mix outperforming the three FAC mixes. 


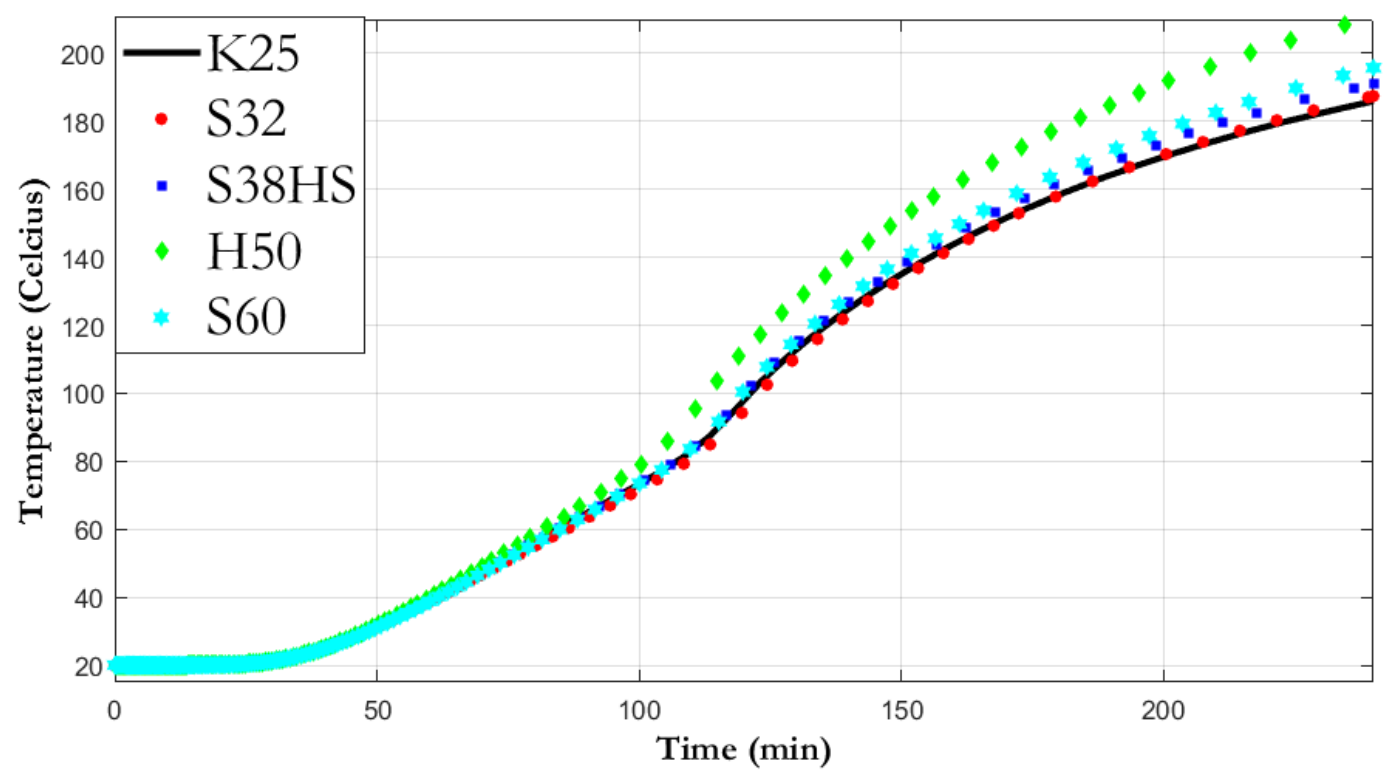

Figure 6.42: Brooks et al 2018 HGM $28 \%$ replacement time temperature curve comparison

Since the HGM mixes also had better compressive strength then the FAC mixes, they seem to be the ideal choice for loadbearing members. However further research would need to be done to determine the actual fire resistance of the materials. Glass is known to increase the likelihood of spalling, whereas fly ash is known to improve the stability of concrete in a fire. Likewise, the residual compressive strengths of glass might be reduced once the material exceed the glass transition temperature of the glass, which could make FAC the preferred choice.

\subsection{Cenospheres Conclusion}

Some novel materials are used to replace the aggregates; however, cenospheres are incorporated into the concrete in a different way due to their very small size (usually within the micrometer size). These spheres are mixed with the concrete and spread around within the void areas between aggregates. Their spherical nature improves the workability of the concrete and helps them mix better, with smaller cenospheres having better mixing. FA cenospheres, hollow glass beads (HGB), Iron ore tailings, EPS beads, and expanded thermoplastic microspheres can all be used. The results 


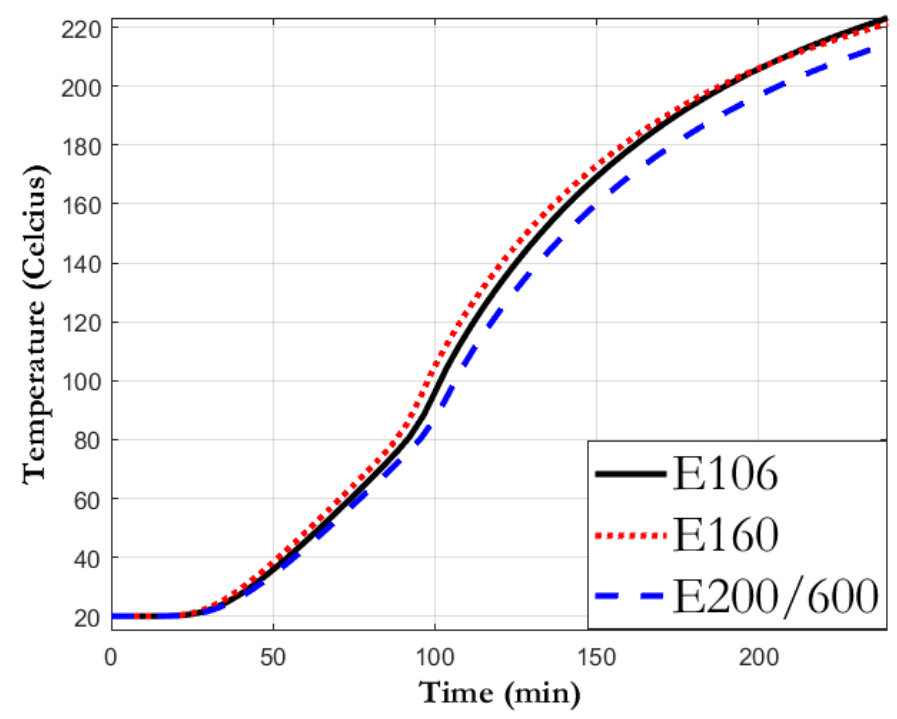

Figure 6.43: Brooks et al 2018 Fly Ash 28\% replacement time temperature curve comparison

show that FA cenopsheres are the superior choice, having the best fire resistance and mechanical properties, but the other cenospheres also improved both the fire resistance and mechanical strength when compared to the reference concrete. This would indicate that cenospheres can be used in loadbearing and nonloadbearing members.

\subsection{Novel Materials Results}

\subsubsection{FIBERS}

\section{Effect of Fibers}

Spalling is a phenomenon that occurs when concrete is heated, and it can result in a significant loss of concrete. One of the main reasons spalling occurs is that the pore pressure within the concrete increase due to the evaporation of free water within the concrete [76]. This increase in pore pressure causes concrete to explode from the members surface and can lead to failure of the member [75]. One method to reduce the effects of spalling is to include fibers within the concrete itself [76] [75]. These fibers can either be steel fibers that expand and cause cracks which allow free water to escape, or polypropylene (PP) fibers which melt at $160-170^{\circ} \mathrm{C}$ and allow avenues for the free water to escape [75]. Both of these types of fibers reduce the effects of 


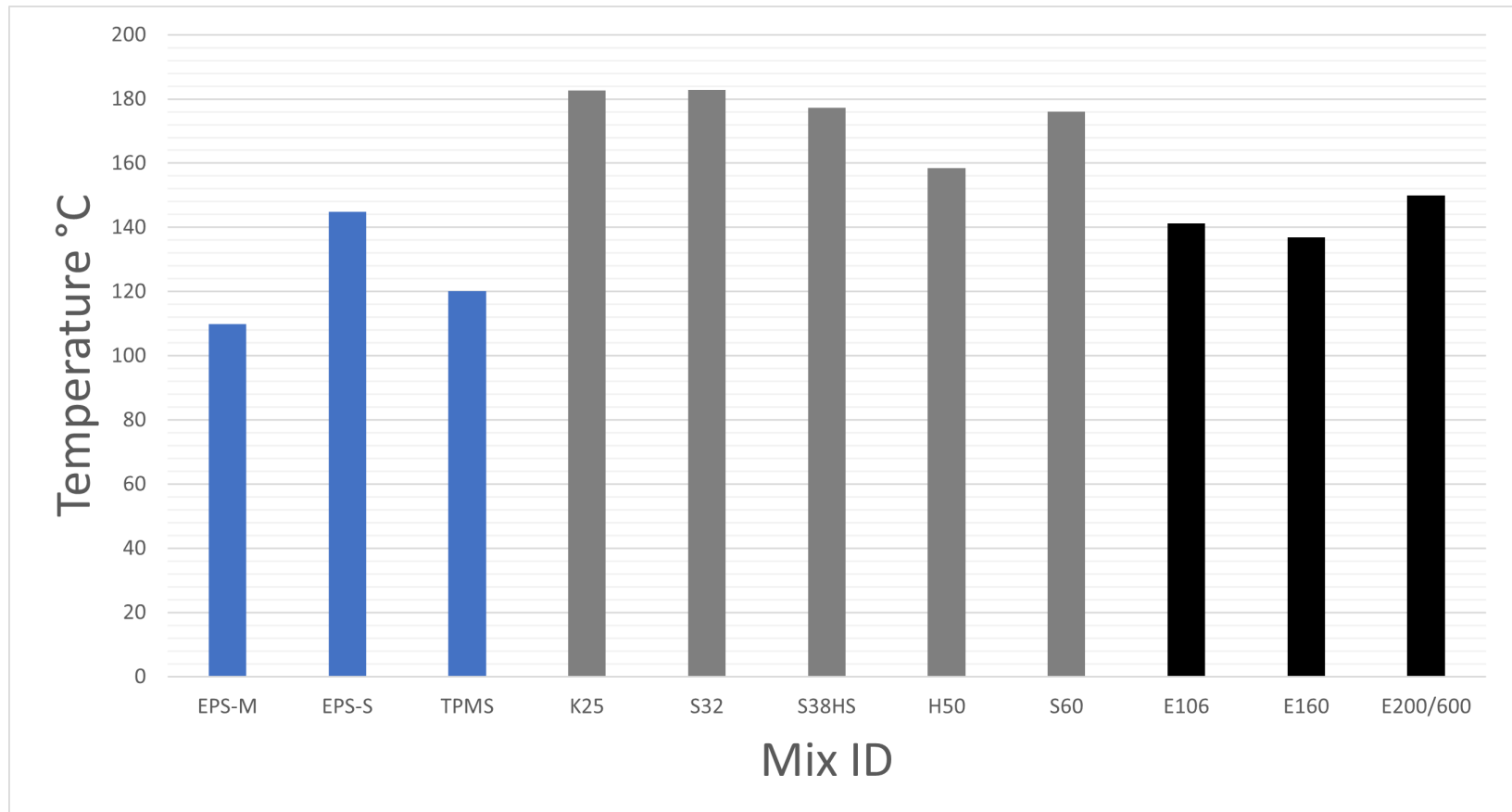

Figure 6.44: Brooks et al 2018 All LWF 28\% replacement failure times comparison

spalling within concrete, however steel actually increases the compressive strength of the concrete, whereas PP fibers can reduce the compressive strength [76] [75].

Lie and Kodur 1996 tested the effects of both steel and PP fibers on calcareous and siliceous concrete [75]. It was found that there were little differences in thermal properties between fiber reinforced concrete and regular concrete [75]. This is most likely because the number of fibers in the concrete is quite small. The thermal conductivity of steel fiber reinforced concrete is slightly higher than regular concrete, which makes sense since steel have a higher thermal conductivity than concrete [75].

From the mechanical side, the thermal expansion of all mixes increased with temperature. The one difference between steel fiber reinforced concrete and regular concrete is that the expansion continues at elevated temperature because the steel continues to expand [75].

Abid et al. 2017 tested reactive powder concrete (RPC) and the effects of adding steel and PP fibers [76]. RPC has improved ambient mechanical properties by using a dense mix design with low water-to-binder ratio along with the use of silica fume and quartz powder [76]. The improved mechanical properties are also partly due to the exclusion of coarse particles which makes the RPC more homogeneous [76]. RPC has higher thermal conductivities and specific heat capacity than normal weight concrete 
at ambient conditions [76].

Similar to the results from Lie and Kodur 1996, Abid et al. 2017 found that the addition of PP fibers does not significantly change the thermal conductivity [76]. However, it was found that the addition of fibers decreased the specific heat capacity of the concrete [76]. The steel fibers were found to increase the strength of the concrete, whereas the PP fibers decrease the concrete strength [76].

The effect of the fibers on the fire resistance were modeled based on the thermal properties provided by Abid et al 2017 for RPC as well as Lie and Kodur for the different aggregate types (Figure 6.45). It was found that normal calcareous aggregate concrete and that with steel added had very similar time temperature curves. Similarly, the curve of RPC and RPC with steel and PP fibers had similar temperature profiles. This seems to indicate that the findings from the two papers that the fibers do not have a large effect on the fire resistance of the concrete. Therefore, fibers can be added to concrete mixes without noticeably decreasing the insulation capacity of the concrete.

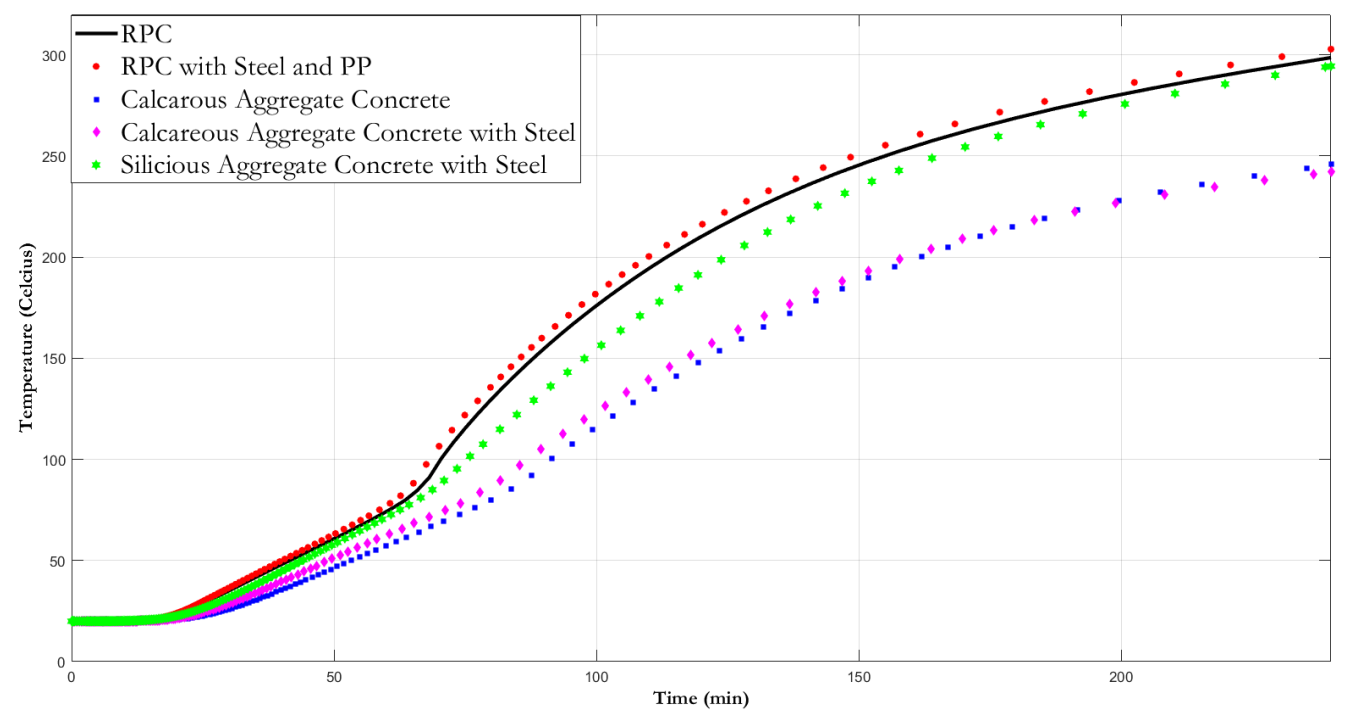

Figure 6.45: Effect of Fibers in concrete 


\section{Different Fiber types}

Gul et al 2007 researched the effect of fibers on perlite concrete [108]. The three different types of fibers were hooked steel fibers, wavey steel fibers, and PP fibers [108]. Each of the three fibers were tested one at a time by replacing $0.25 \%, 0.75 \%, 1.25 \%$, or $1.75 \%$ of the volume of the concrete with fibers [108]. As steel is much denser than PP, the mass of steel included is significantly higher than the mass of the PP included in the mix. It was found that as fibers were added the compressive strength decreased, with the maximum decreasing being $11 \%, 11.5 \%$, and $52 \%$ for the hooked steel, wavey steel, and PP respectively [108]. The steel fibers actually improved the flexural and tensile strength of the concrete, while the PP fibers decrease both. As can be expected, the steel fibers increased the thermal conductivity of the concrete mix. The PP fibers instead decreased the thermal conductivity [108].

From the thermal modeling it can be seen that both of the steel fiber mixes reduced the fire resistance of the concrete (Figure 6.46). The wavey steel fibers were slightly worse than the hooked steel fibers, with the wavey steel fibers failing up to 35minutes before the reference mix at maximum replacement, and the hooked steel fibers failing up to 30 minutes before the reference mix at maximum replacement. Since the hooked steel fibers had better mechanical properties in terms of tensile strength and flexural strength, these steel fibers should be used over the wavey steel fibers. With the use of PP fibers, the fire resistance actually improved, as the PP fibers have lower thermal

conductivity and therefore reduce the thermal conductivity of the concrete when they are added. At the maximum PP fiber replacement, the mix failed 20 minutes after the reference concrete.

In terms of thermal performance, the PP fibers increased the time to failure, whereas the steel decreased the time to failure. If mechanical properties are of particular concern (especially tensile and flexural) then steel fibers could be used to strengthen the concrete and reduce spalling. However, if thermal properties are the main focus, then PP fibers should be used.

\section{Fibers and Silane}

Wu et al 2015 researched the effect of different lightweight concrete mixes with the inclusion of cenospheres [95]. The effects of fibers and Silane addition were also investigated [95]. Similar to previous research, the addition of fibers had a very 


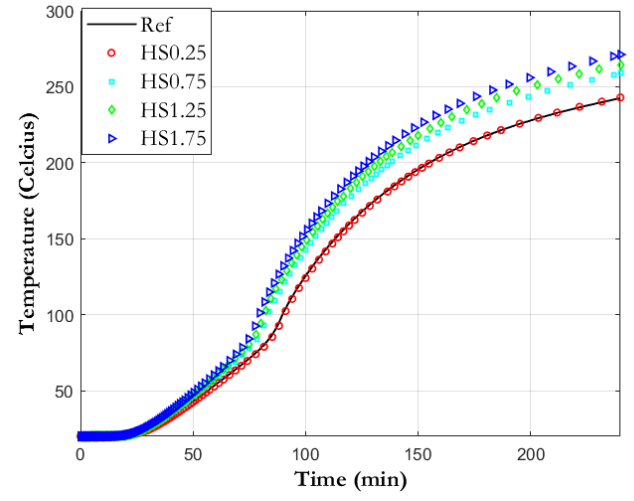

(a)

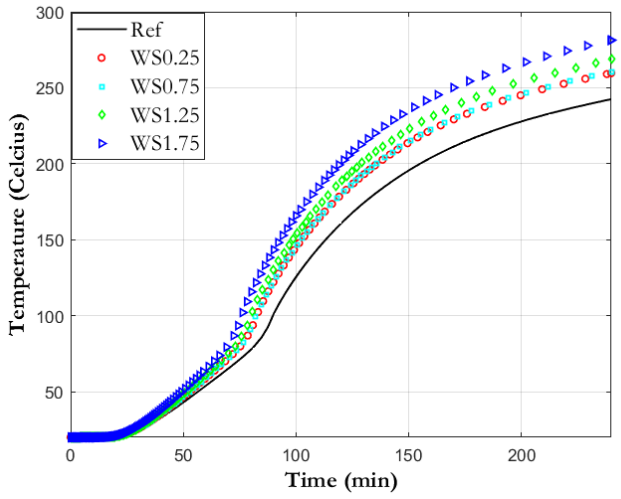

(b)

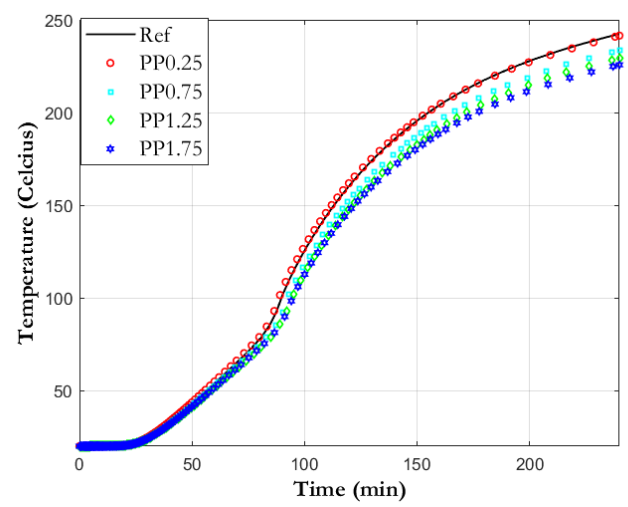

(c)

Figure 6.46: The effect of different fiber types (a) Hooked Steel (b) Wavey Steel (c) $\mathrm{PP}$

minor effect on the thermal or mechanical properties of the concrete mix [95]. The addition of silane did have an impact on the concrete properties 6.47. Silane reduced the thermal conductivity, elastic modulus, and flexural strength, while keeping the density the same and only slightly increasing the compressive strength. Since the density, w/c ratio, and air entrainment was the same for the mixes with and without silane, the reason for the differences in properties is not obvious. One possibility is that the pore structure with silane allows for higher thermal conductivity, however Wu et al had no explanation for the change. 


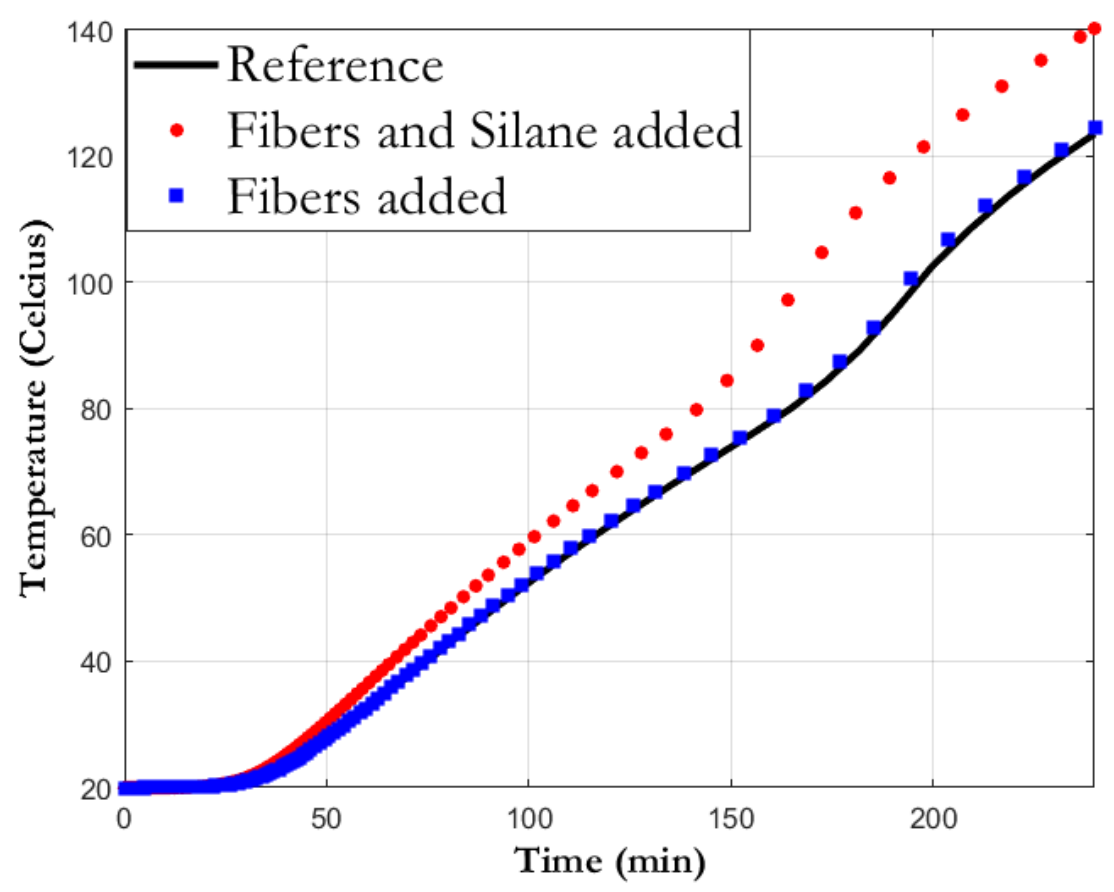

Figure 6.47: Concrete with Fibers and Silane

\section{HSC with LWA and Steel Fibers}

Zhou et al 2019 investigated the thermal and mechanical properties of High Strength Cocnrete (HSC) with and without steel fibers with mixes including aggregates such as silica sand, limestone gravel, RiverLite lightweight aggregates, and fly ash cenospheres (FAC) [94]. the HSC replaced $15 \%$ of the cement with silica fume, and HSC mix with the steel fibers added steel equal to $20 \%$ of the binder weight [94]. In order to increase the strength of the HSC, quartz flour and a lower w/b ratio was used. Table 6.6 outlines the aggregates used in each sample [94].

The test found the thermal and mechanical properties at ambient conditions for the various mixes. It was found that LWA and FAC reduced the mechanical properties of the concrete [94]. Including the LWA and FAC did improve the thermal properties of the concrete by lowering the density and thermal conductivity, and so would definitely be beneficial for non-loadbearing deigns [94].

Unlike many of the other tests including fibers in the mix [76] [75] [86], the steel fibers had an effect on the thermal performance of the concrete (Figure 6.48). The 
Table 6.6: Zhou et al 2019 Mix Designs

\begin{tabular}{|l|l|l|l|l|l|}
\hline Mix ID & $\begin{array}{l}\text { Fly ash } \\
\text { cenosphres } \\
(\mathbf{f i n e}) \mathbf{( \% )}\end{array}$ & Steel fibers & $\begin{array}{l}\text { Silica Sand } \\
(\text { fine } \mathbf{( \% )}\end{array}$ & $\begin{array}{l}\text { Gravel } \\
(\text { coarse }) \\
(\mathbf{\%})\end{array}$ & $\begin{array}{l}\text { RiverLite } \\
(\text { coarse }) \\
(\%)\end{array}$ \\
\hline HS-SS-G & - & - & 100 & 100 & - \\
\hline HS-FAC/SS-G & 50 & - & 50 & 100 & - \\
\hline HS-SS-RLC & - & - & 100 & - & 100 \\
\hline HS-FAC/SS-RLC & 50 & - & 50 & - & 100 \\
\hline HS-SS-G-SF & - & Yes & 100 & 100 & - \\
\hline HS-FAC/SS-G-SF & 50 & Yes & 50 & 100 & - \\
\hline HS-SS-RLC-SF & - & Yes & 100 & - & 100 \\
\hline HS-FAC/SS-RLC-SF & 50 & Yes & 50 & - & 100 \\
\hline
\end{tabular}

addition of the steel to the HS concrete mixes increased the density, thermal conductivity, and specific heat. Without the fibers the order of failure went $100 \%$ gravel, RLC, 50\% FLC and 100\% gravel, then 50\% FLC and 100\% RLC. However, when the fibers were added the failure time of both the $100 \%$ gravel mixes were almost identical, and they were in between the two 50\% FLC mixes. The reason for this change is likely due to the large amount of steel added in this particular test when compared to other research. While small amounts of steel (1-3\% of the volume total) may not have an impact on the properties of the concrete, large amounts (20\% of the binder mass) obviously do.

\section{RCA and PP fibers}

Yan et al 2018 researched concrete made with waste materials. Concrete with $100 \%$ RCA and different amounts of PP fibers were tested [109]. The two different PP fibers mixes were tested with $0.1 \%$ and $0.5 \%$ addition. It was found that in terms of the compressive strength, PP fibers had little effect [109]. For thermal performance, the PP fibers actually had a significant effect on the fire resistance 6.49. This is different from most of the other literature and may be caused by measurement error. Usually, PP fibres have little effect on the density or thermal conductivity, but in the 


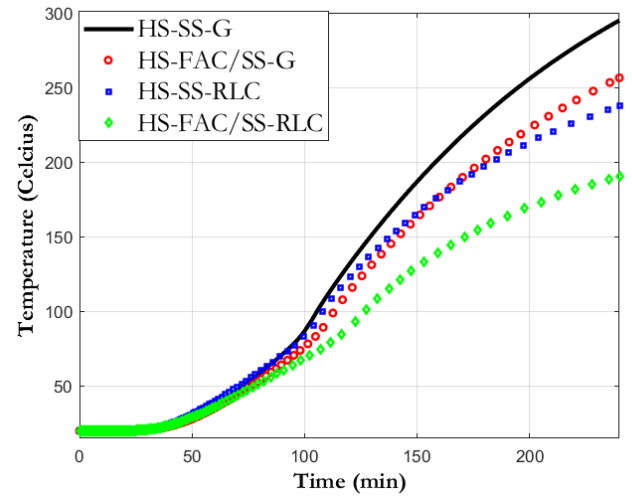

(a)

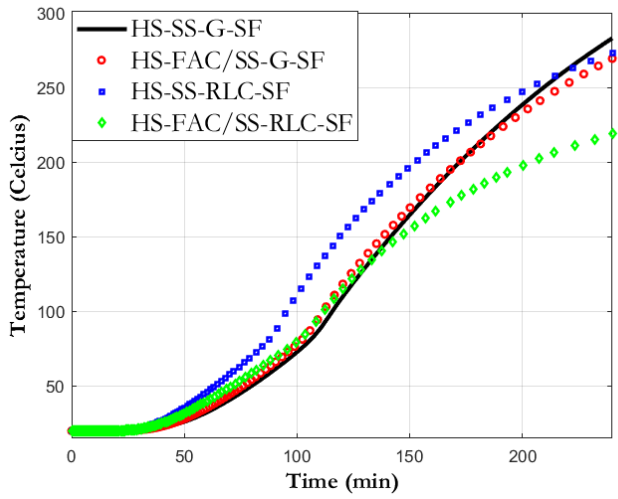

(b)

Figure 6.48: Effect of fibers on HSC (a) HSC without Fibers (b) HSC with Fibers

case of this research the thermal conductivity was higher for the $0.1 \%$ replacement and lower for the $0.5 \%$ replacement. The fact that the effect of the PP fibers is not either an increase or decrease the thermal performance would seem to corroborate the likelihood of a measurement error.

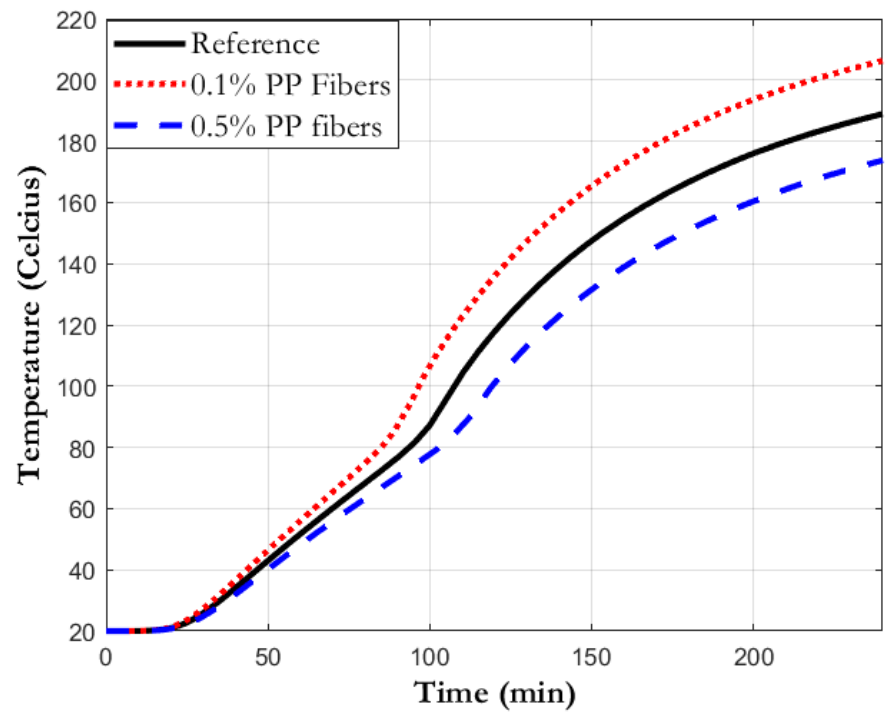

Figure 6.49: RCA with PP fibers 


\subsubsection{GLASS}

\section{Effect of Glass and Metakaolin}

Al-Sibahy 2012 determined the effect of metakaolin and waste glass on the thermal properties of lightweight concrete [110]. Metakaolin (MK) is a pozzolanic material that is used to improve the strength and durability of the concrete by replacing some of the binder [110]. The test compared lightweight concrete without waste materials to lightweight concretes with different amounts of waste glass and metakaolin. The waste glass replaced some of the sand (an equal amount of glass was added in the $0.5-1 \mathrm{~mm}$ range and the 1-2mm range) and the metakaolin replaced some of the cement [110]. The lightweight aggregate used was expanded clay. The percentages replaced were $0 \%$, $5 \%$, and $10 \%$ binder replacement with MK, and $0 \%, 15 \%, 30 \%, 45 \%$ sand replacement with glass [110]. The mix designs and naming can be found in Table 6.7.

Table 6.7: Al-Sibahy 2012 Mix Designs

\begin{tabular}{|l|l|l|l|l|l|l|l|}
\hline & M5G15 & M5G30 & M5G45 & M10G15 & M10G30 & M10G45 & M0G45 \\
\hline MK) & 5 & 5 & 5 & 10 & 10 & 10 & 0 \\
\hline Glass(\%) & 15 & 30 & 45 & 15 & 30 & 45 & 45 \\
\hline
\end{tabular}

It was found that at ambient conditions the new mixes with MK had higher compressive strengths due to the pozzolanic reaction [110]. After 30\% glass replacement the strength decreased, likely due to the reduction in the coating of the concrete parts at higher glass percentages [110]. The MK did increase the strength at both $5 \%$ and $10 \%$ glass replacement [110].

The densities of all the mixes were close to one another. At elevated temperatures the lightweight concrete had a reduction in density due to the loss of free water [110]. At $800^{\circ} \mathrm{C}$ the reduction was about $20 \%$ for the reference and modified mixes [110]. The new mixes had lower thermal conductivities (up to $42 \%$ lower) [110]. However, having more glass did not always decrease the thermal conductivity more, possibly due to a different air void distribution [110]. The reason for the lower thermal conductivity is partly due to the lower thermal conductivity of glass and MK compared to sand and cement. The specific heat values were lower for the new mixes [110]. All mixes had a jump in specific heat at around $100^{\circ} \mathrm{C}$; however, the novel mixtures had higher jumps due to an increase in free water content [110]. 
It was also found that spalling was more likely with a higher glass replacement [110]. Unlike glass, MK reduced the likelihood of spalling when it was added [110]. It was found that the best performance came from $45 \%$ glass and $10 \%$ MK [110]. However higher glass percentages had an increased chance of spalling. So, while the higher values of glass are better thermally, they could cause insulation or stability failure. Using partial glass replacement and 10\% MK would gain the improvements without increase the risk of spalling.

When modeled the effects of glass and MK replacement are clear (Figure 6.50). The higher MK values had better fire resistances. Likewise, the higher the glass percentage the better the fire resistances. However, the fire resistance of $15 \%$ and $30 \%$ glass replacement were very similar for both MK mixes, while the mechanical properties of concrete decrease with higher glass percentages. For the is reason, a $30 \%$ glass replacement should not be used as the reduction in mechanical properties and increase in likelihood of spalling outweigh the slight increase in thermal properties. The $45 \%$ glass replacement option could be used for non-loadbearing walls if fibers were added to reduce the likelihood of spalling.

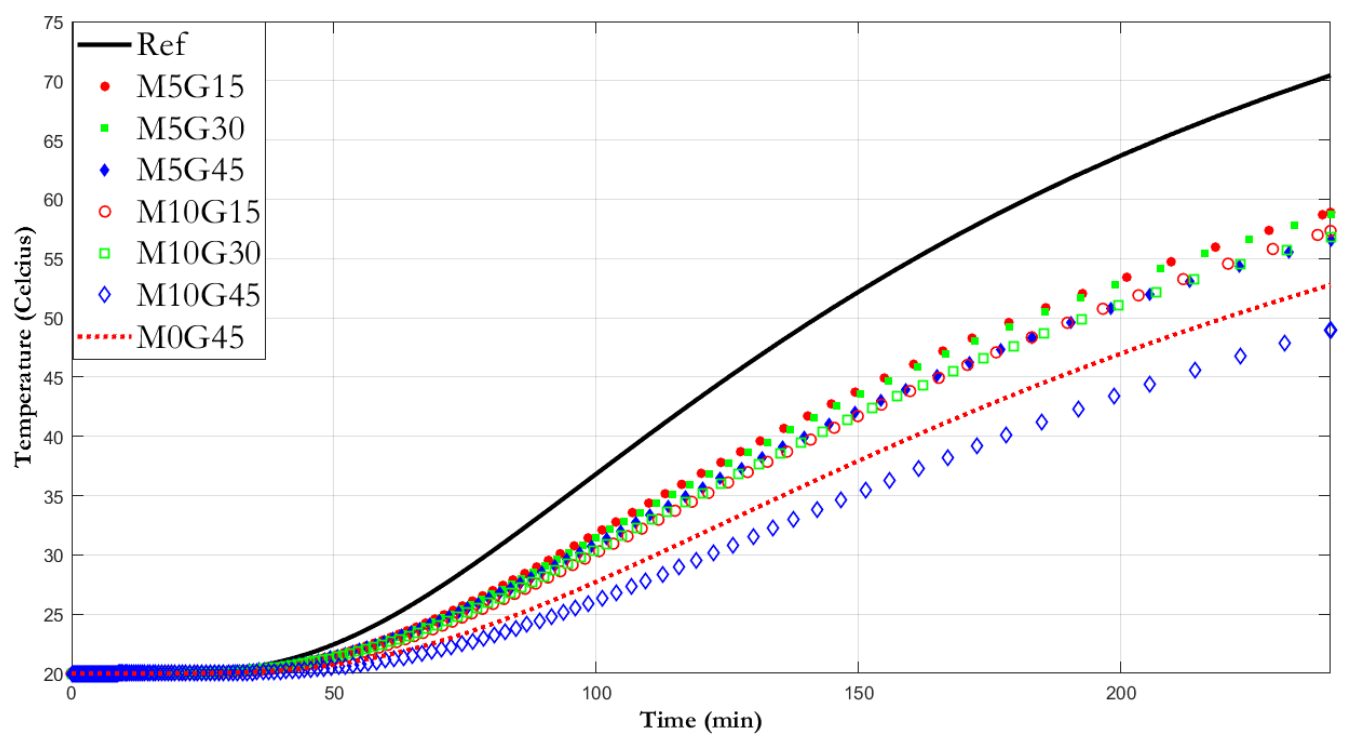

Figure 6.50: Effect of waste glass and MK

None of the glass mixes failed the insulation criteria after 4 hours. As a fire resistance of over 4 hours is not usually required, the optimal mixes were modeled 
with $15 \mathrm{~cm}$ and $10 \mathrm{~cm}$ blocks to determine their fire resistance (Figure 6.51 ). It was found that the differences between the $5 \%$ and $10 \%$ MK replacement were minimal, with the higher MK percentages having slightly better fire resistance. The $45 \%$ glass replacement was the superior option, but as before it should only be used if the chance of spalling is mitigated through the use of fibers. The $15 \mathrm{~cm}$ blocks always had higher fire resistances than the $10 \mathrm{~cm}$ blocks, but the differences were small. Therefore, a $10 \mathrm{~cm}$ block should be used for non-loadbearing partitions as they requires less material, take up less space, and can be built faster.

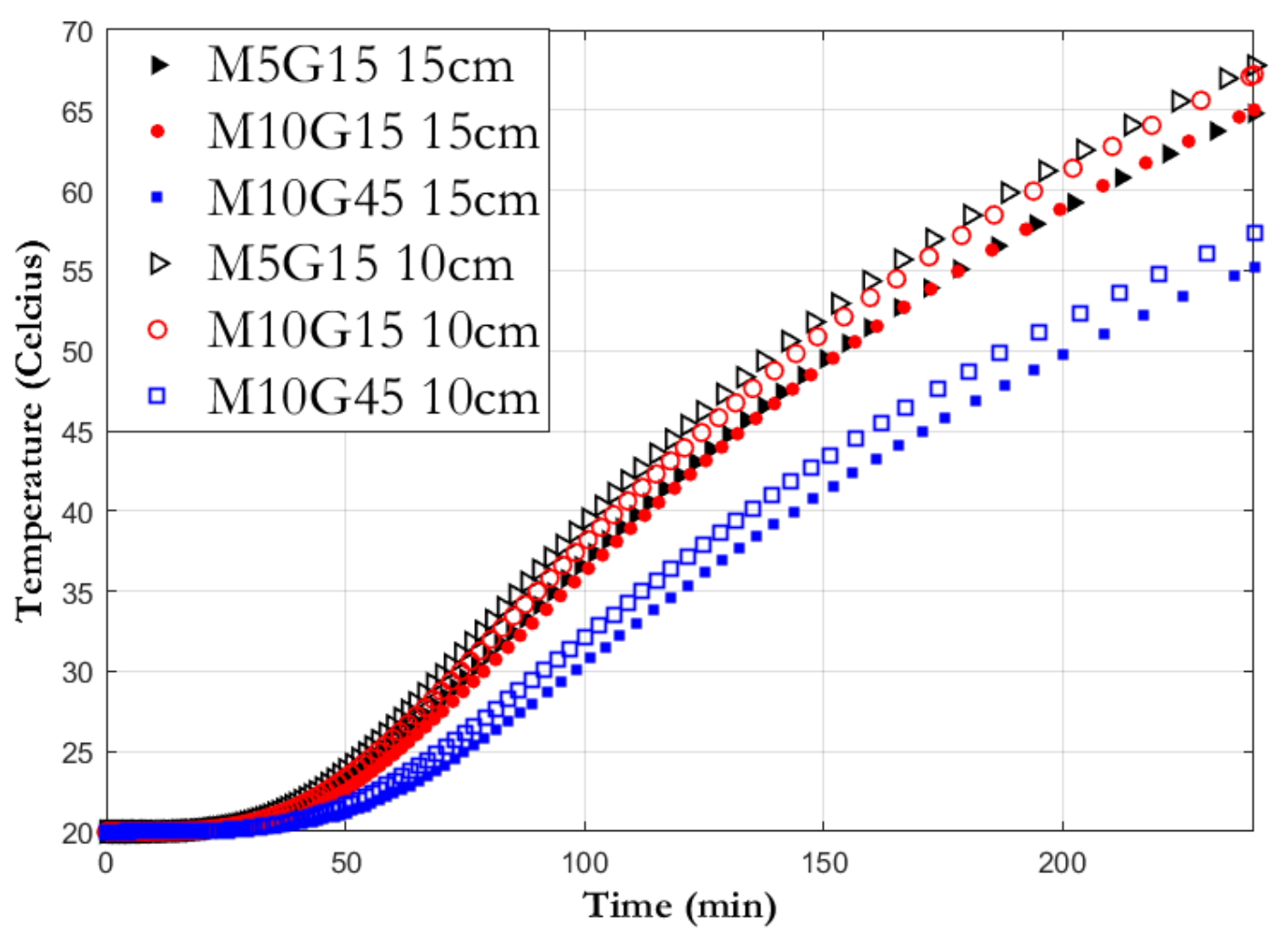

Figure 6.51: Comparing glass mixes between $15 \mathrm{~cm}$ and $10 \mathrm{~cm}$ blocks

\section{RCA, Glass and Polystyrene}

Yan et al 2018 researched concrete made with waste materials. Specifically, concrete with RCA, recycled glass (RG), and recycled polystyrene (RP) were tested [109]. The addition of PP fibers was also investigated [109]. All of the test mixes were made with 
$100 \%$ RCA for the coarse aggregate [109]. Two different PP fibers mixes were tested (with $0.1 \%$ and $0.5 \%$ addition), two different RG replacement mixes were tested (with $35 \%$ and $70 \%$ replacement of fine aggregate), and two different RP mixes were tested (with $5 \%$ and $10 \%$ replacement of fine aggregate) [109].

In terms of compressive strength, the RG with $35 \%$ replacement was actually stronger than the refence concrete at ambient, however it was weaker than the refence concrete at elevated temperatures [109]. The RG with $70 \%$ replacement, and both RP mixes were consistently weaker than the reference concrete at all temperatures, and the RP mixes were the weakest of all [109]. Given the benefit of 35\% RG replacement at ambient conditions, there may be an optimal mix that has mechanical properties that are similar or better than the reference concrete [109].

When comparing the effect of recycled materials, it can be seen that both RG and RP improved the thermal performance of the concrete 6.52. The RP was found to be the most beneficial, and with smaller replacement percentages than the RG. If mechanical properties are of importance, RG may be more beneficial; however, if thermal performance is what is desired, then RP is the superior choice.

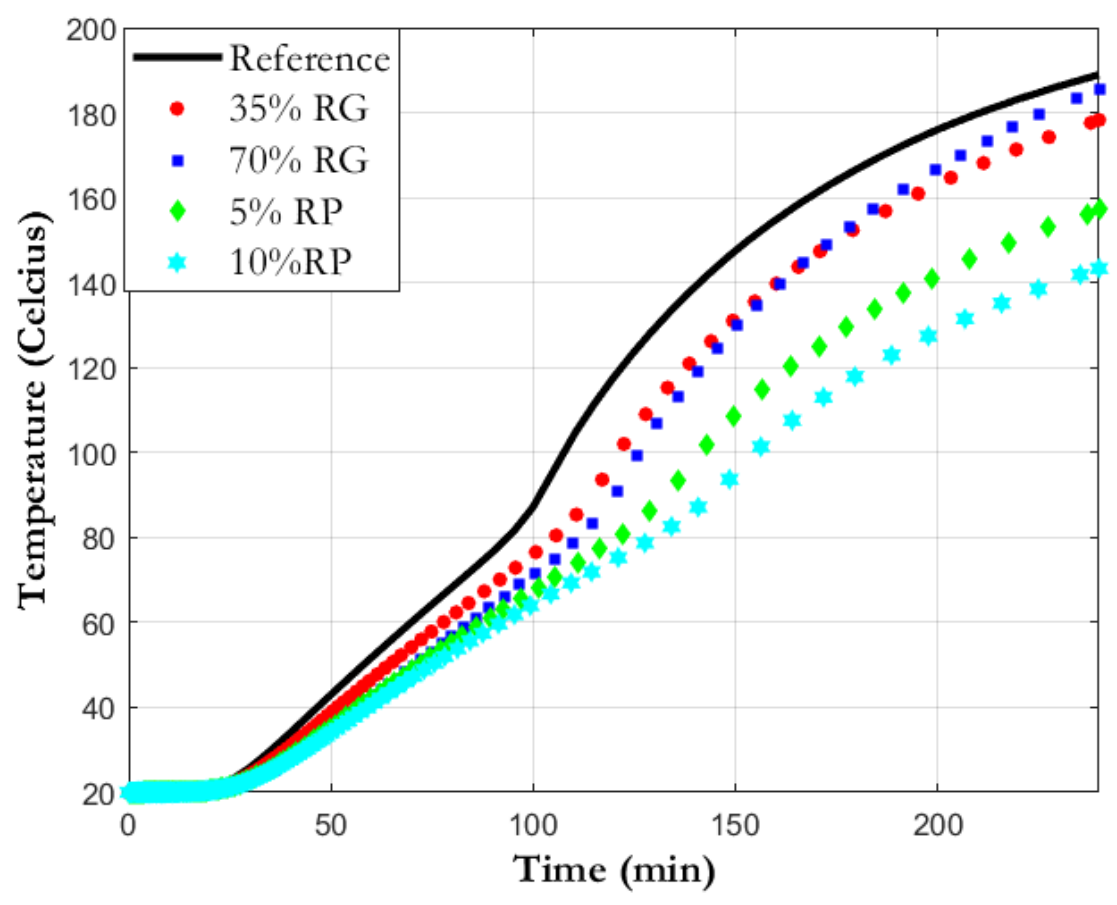

Figure 6.52: Effect of RG and RP 


\subsubsection{Hemp Concrete}

Jami et al 2019 researched the effects of hemp concrete. Hemp concrete is a lightweight, carbon negative material with improved thermal and acoustic properties [111]. The material has good durability, as it is resistant to freeze thaw and salt exposure. The binder used in hemp concrete is hydraulic lime instead of cement, as cement has issues setting with hemp concrete. The density of hemp concrete is generally lower than NWC, but the density is more variable due to the variability of the components. The compressive strength of hemp concrete is also variable, but it is usually around $1 / 20$ th that of NWC [111]. This compressive strength can be increased if some cement is added, or if the material is compacted more. The use in masonry blocks may improve the strength as precast members do not require compacting on site. When compared to NWC, hemp concrete has improved thermal properties due to the low density, low thermal conductivity and increased specific heat [111]. The exact thermal properties vary between tests, however all of them show the improved thermal properties.

Jami et al 2019 outlined information on the advantages and disadvantages of the use of Hemp concrete masonry blocks. The benefits include consistent compaction, easier curing, and faster construction [111]. Depending on the block design, mortar could be eliminated to create a more homogenous wall material. The disadvantages to hemp concrete blocks include increased manufacturing costs, and if mortar joints are required there may be thermal bridging at the joints.

The results of the modeling of different hemp mixes designs can be found in Figure 6.53. Jami et al 2019 compared the thermal properties from several tests, including Arnaud et al 2013 [112], Sassoni et al 2014 [113], Ahlberg et al 2014 [114], and Straube and Walther 2011 [115]. All of the mixes were found to have excellent fire resistance, with the highest temperature reached on the unexposed side of the block being $65^{\circ} \mathrm{C}$ after 4 hours. In all cases the fire resistance improved as the density decreased. This is because even though the lower density concretes had lower specific heats, they also had lower thermal conductivity. When compared to the AAC it was found that the thermal performance of the hemp concrete was sometimes better and sometimes worse, depending on the mix chosen. The best mix was that of lowest density mix from Arnaud et al 2013 [112], however all of the mix designs had excellent fire resistance. Due to the improvement in durability and acoustics, along with the environmental benefits, hemp concrete is worth considering for further fire resistance research where 
loadbearing capacity is not an important factor.

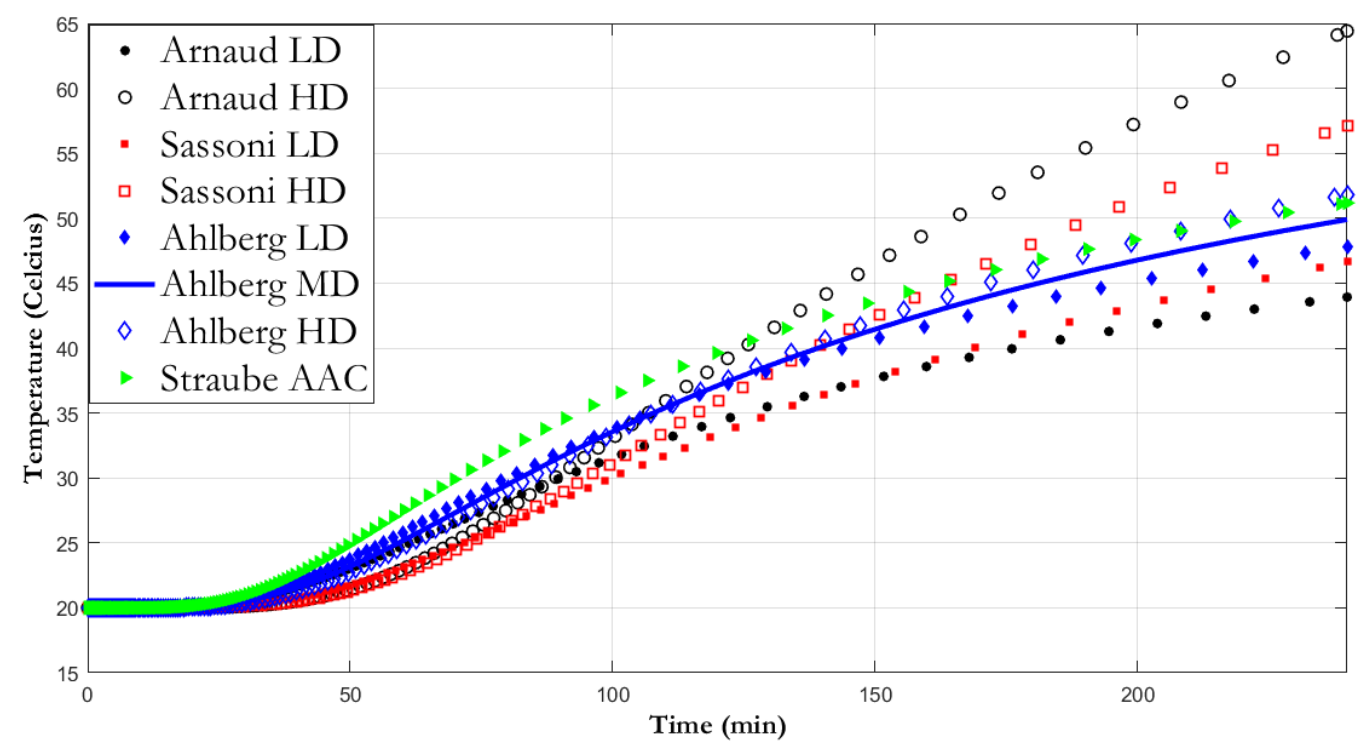

Figure 6.53: Effect of different hemp concrete mixes

Seng et al 2019 researched the thermal properties of hemp concrete [116]. As part of the research, different testing apparatus were used to measure the thermal conductivity. As had been mentioned previously, the equipment used could have an impact on the readings and give different results. In this research both guarded hot plate (GHP) and hot wire measurements were taken [116]. The GHP method requires a sample to be placed in between a hot and cold plate with insulation reducing any heat loss [116]. The hot wire measurement requires a wire to be placed in between two samples of the material and then that wire is heated [116]. Both of the methods used are supposed to have an accuracy of $5 \%$ [116].

The thermal conductivity measurements from both apparatuses were used for the modeling to compare their effects. It can be seen that the hot wire method measured a higher thermal conductivity and resulted in a worse fire resistance (Figure 6.54) [116]. As the hemp concrete has very good fire resistance it is not possible to determine exactly how this would affect the time to failure, as the hemp concrete did not fail during the four-hour test. However, this does help to demonstrate that thermal properties measured from only a few samples are not necessarily the most accurate and could results in modeling results that differ from the experimental results. 


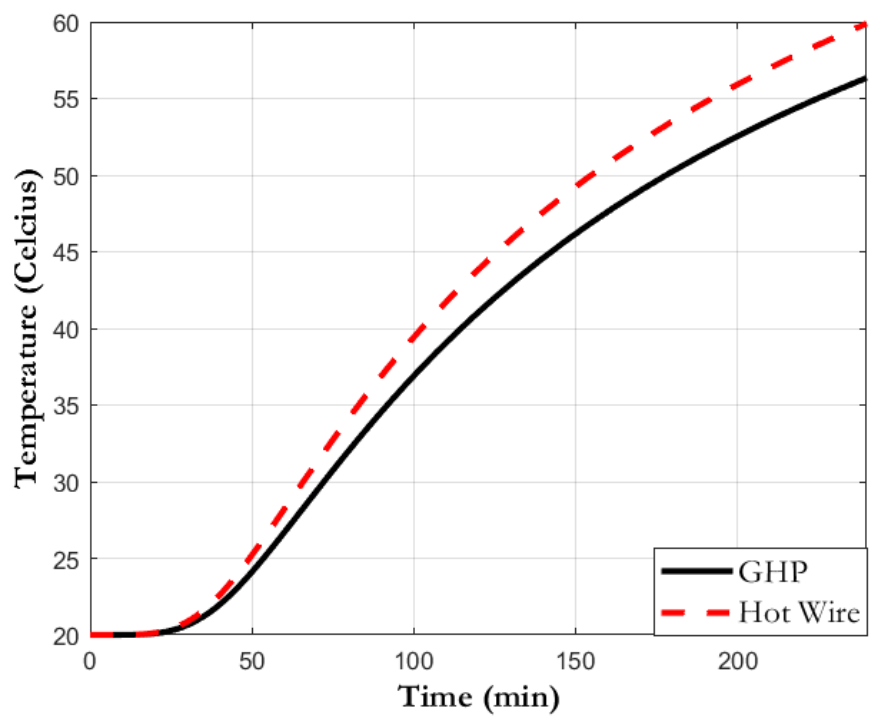

Figure 6.54: Effect of different thermal conductivity measurment techniques

\subsubsection{PHASE CHANGE MATERIALS}

Sukontasukkul et al 2019 researched the effect of phase change materials (PCM) within lightweight concrete aggregate [117]. Special lightweight aggregate was impregnated with PCM, and this new aggregate replaced the existing lightweight aggregate in various percentages $(0 \%, 25 \%, 50 \%, 75 \%$, and 100\%) [117]. The addition of PCM caused an increase in thermal conductivity at ambient conditions due to the aggregate being less porous with the addition of the PCM [117]. However, once the PCM liquified the thermal conductivity decreased [117]. As more PCM was added, the specific heat increased due to the energy absorbed by the PCM (similar to how evaporating water increases the specific heat) [117]. As the PCM was added the density of the concrete increased, as well as the compressive strength (up to a $35 \%$ increase in compressive strength) [117].

From the modeling results, the addition of PCM improves the fire resistance of the concrete (Figure 6.55). This is mainly due to the increase in specific heat that occurs between $40^{\circ} \mathrm{C}$ and $50^{\circ} \mathrm{C}$. As the amount of PCM increased the fire resistance increased by 20 to 30 minutes. As the inclusion of PCM increases the fire resistance and the mechanical properties, it is well suited for loadbearing members. The main reasons for not using 100\% PCM aggregate would be cost. Another reason for not using $100 \%$ PCM aggregate could be related to the increase in deadload, but as the 
concrete is stronger and more fire resistant, it is likely that a smaller member could be made which would reduce the increase in dead load.

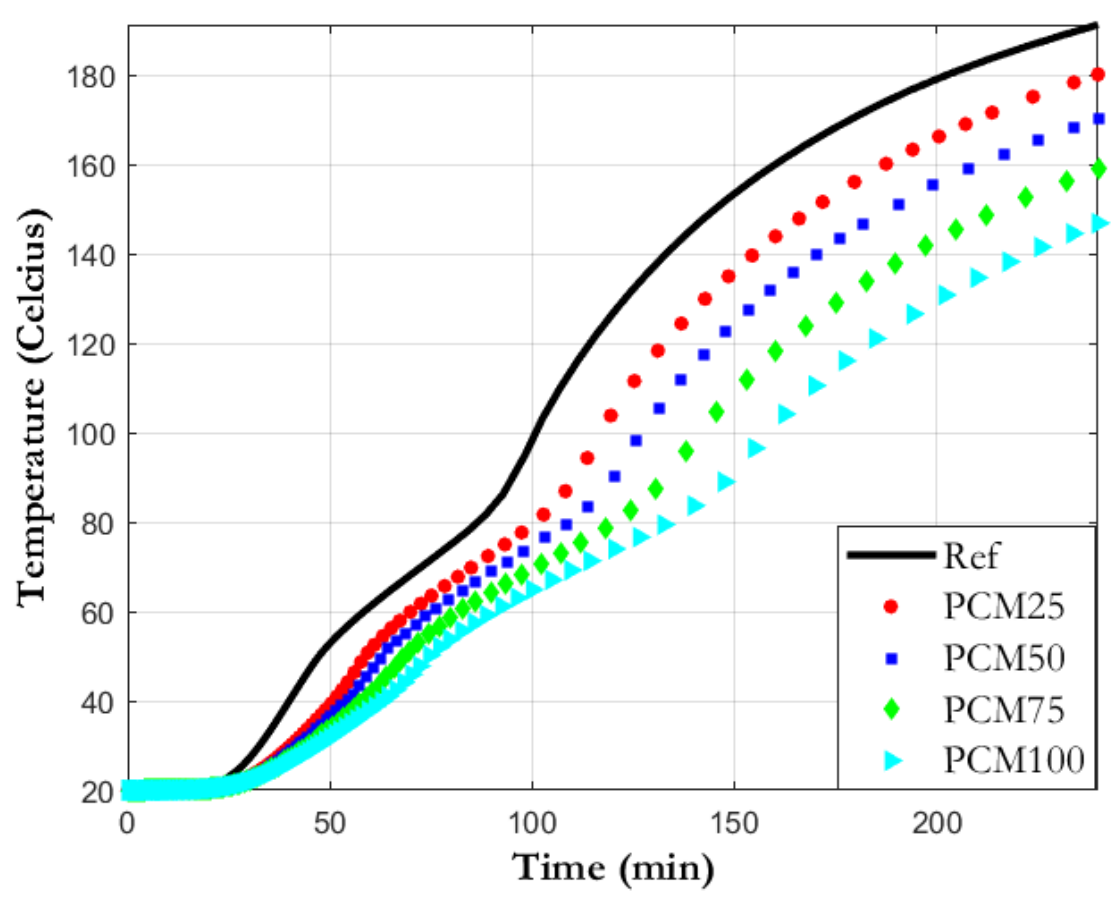

Figure 6.55: The effect of PCM

\section{Microencapsulated phase change materials}

Cao et al 2018 researched the use of thermoregulating materials within the concrete mix [118]. This was done by adding microencapsulated phase change materials (MPCM) to the concrete mix [118]. The two types used were PS-DVB/RT27 (polystyrene cross-linked with divinylbenzene) and MF/PCM24 (melamine-formaldehyde polymer shell) microcapsules [118]. The PS-DVB/RT27 (PS) were $130 \mu \mathrm{m}$ in size, and the MF/PCM24 (MF) were $21 \mu \mathrm{m}$ [118]. The MF was found to have higher latent heat, and higher porosity than the PS [118]. This in turn meant that MF had higher specific heat, and lower thermal conductivity and density than PS [118].

From the thermal modeling it was found that the MF performed better than the PS, as was expected (Figure 6.56). As the percentage of both increased, so did the 
fire resistance. Compared to the reference concrete adding 2.6\% of the MPCM increased the failure time by $20 \mathrm{~min}$ and $35 \mathrm{~min}$ for PS and MF respectively. Adding $5.2 \%$ of the MPCM increased the time to failure by $80 \mathrm{~min}$ and $120 \mathrm{~min}$ for the PS and MF respectively. Cao et al 2018 did not research the mechanical properties of the concrete mixes, however the addition of MPCM was expected to decrease the compressive strength of the concrete [118]. Further research should be done to determine the extent of this strength reduction in order to determine the applicability of MPCM concrete in loadbearing applications, as well as to determine the optimal mix percentage to achieve the best balance between mechanical and thermal performance.

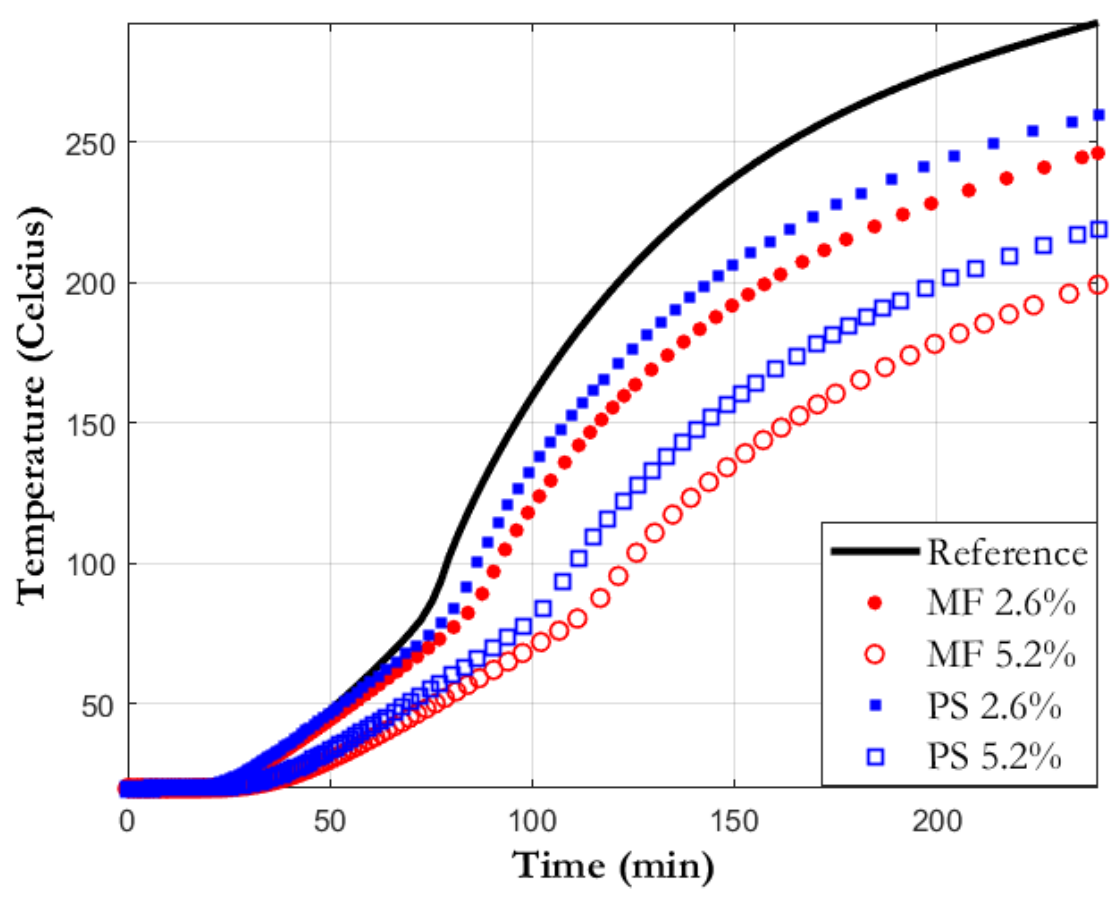

Figure 6.56: The effect of different MPCM

\subsection{Novel Materials Conclusion}

Fibers can be added to concrete to reduce the effects of spalling and/or to improve the mechanical properties. While PP fibers have lower thermal conductivity than concrete, steel and carbon fibers have higher thermal conductivities but improve the mechanical performance of the concrete. In terms of the thermal performance, small 
number of fibers (used to reduce spalling) have only a minor effect. When higher amounts of fibers are added (usually for improved mechanical performance) their effects become more pronounced. If there is a large number of fibers, their impact is more related to the new density of concrete, rather than the thermal conductivity of the fibers themselves. If the fibers are added with silane or other additives that improve their cohesion with the concrete, the density increases which reduces the fire resistance. If there are no such additives, then the density usually decreases which in turn improves the fire resistance.

Glass can be added as either fine aggregate or coarse aggregate replacement. In both cases, as the amount of glass increased the thermal performance improved. Small glass percentages actually improved the mechanical strength, but higher percentages caused the mechanical performance to decrease again. Another issue with higher glass inclusion is that the risk of spalling increases.

Hemp concrete is low density concrete with very good thermal properties. It is also a good option for masonry blocks due to the consistent compaction and ease of curing. The low density leads to strength that is $1 / 20$ th that of NWC, which means it should only be used for partitions. Due to the improvement in durability and acoustics, along with the environmental benefits, hemp concrete is worth considering for further fire resistance research where loadbearing capacity is not an important factor.

Phase change materials are another way to improve the fire resistance as they undergo an endothermic phase change which increases the specific heat at a certain temperature range. The addition of PMC increases the fire resistance, but it also has the potential to increase the density and compressive strength depending on the mix design and the specific PMC used. Other than the latent heat of the PMC, the density of the concrete once mixed also plays a role in the fire resistance of the material. 


\section{Chapter 7}

\section{Summary, Conclusions, Limitations, Recommendations}

\subsection{Research Summary}

This study was undertaken to evaluate the thermal behaviour of full scale masonry walls made with different concrete materials, block geometries, wall geometries, and insulation materials. Common $10 \mathrm{~cm}, 15 \mathrm{~cm}$, and $20 \mathrm{~cm}$ masonry blocks were tested and their fire resistances and thermal profiles were determined. The effects of block geometry, mortar jointing type, wall geometry, and concrete mix design were established. The effects of existing and novel insulations materials within the hollow cells were determined.

A three-dimensional thermal model was developed and accordingly used to simulate the different wall types and configurations in the standard fire condition. A pure heat transfer analysis was used to model the solid body heat conduction with general, temperature dependent conductivity and the combined effect of convection and radiation.

Concrete thermal properties from the literature were collated and the finite element model was used to predict the fire resistance of novel concrete mixes. The results of this modeling were used to determine how applicable the novel concrete mixes are to improving masonry's fire resistance. 


\subsection{Conclusions}

1. Insulation Materials can be placed with the hollow cells to reduce the heat transfer with the hollow cells and greatly improve the overall fire resistance of masonry walls. Adding 1inch of Rockwool insulation improved the fire resistance from $1.1 \mathrm{~h}$ to $2 \mathrm{~h}$ and adding full Rockwool or Vermiculite insulation improved the fire resistance by well over $2 \mathrm{~h}$.

2.There are a variety of novel concrete mixes that improve the thermal performance of concrete. While most improvements in thermal performance lead to a decrease in mechanical performance, these concrete mixes can still be viable in partition walls. There are also environmentally friendly alternatives that have comparable mechanical and thermal properties that can be used instead of more traditional concrete mixes.

3. The type of mortar joint used (concave, raked, or struck) does not impact the insulation failure criteria of the wall, as the mortar is usually the coolest part of the wall. Further research is required to determine if the jointing type might have an increased change of causing integrity failure. Further research also needs to be done to determine the block fire resistance rating which causes the mortar to become the hottest part of the wall.

4. Blocks with thicker faceshells have improved fire resistance. Designing a block with thinner webs and thicker faceshells would improve the fire resistance of the block.

5. Compartmentalising masonry walls improves its fire resistance. This can be done through the addition of lintel units, or through the use of insulation materials within the hollow cells.

6. Finite element modeling can be used to accurately predict the fire resistance of concrete masonry materials. These models can predict the thermal response of full-scale concrete masonry walls which reduces the need to conduct expensive and time consuming physical testing.

7. Lightweight concrete has superior fire resistance when compared to normal 
weight concrete. It also has decreased dead load and is easier for the masons to handle. Lightweight concrete also has better residual mechanical properties and is more resistant to the effects of spalling. All of this makes using lightweight blocks a good choice for improving the fire resistance of concrete masonry.

\subsection{Limitations}

1. As each wall type was only tested once, and the ambient conditions, weather, and furnace temperatures were variable between tests, direct comparison between tests is limited to qualitative comparison.

2. The mechanical properties were not considered in the thermal model, as it was a pure heat transfer analysis.

3. Thermal properties of materials taken from literature can be quite variable depending on the researcher, and so direct comparison of results from one researcher to another should be done qualitatively.

\subsection{Recommendations for Future Studies}

1. As most of the existing block mixes and geometries have already been tested, future tests should focus on novel mix designs and block geometries. Blocks with novel aggregates, pozzolans, additives, cenospheres, filler materials, etc. could be developed and tested. In terms of block geometries, blocks with thicker faceshells, extra faceshells, different mortar joints or other means of compartmentalisation could be developed.

2. Novel concrete materials are continually being developed. Collating the thermal properties of new concrete materials and modeling them can be done to determine new concrete mixes that should be tested. 


\section{List of References}

[1] A. H. Buchanan and A. K. Abu, Structural design for fire safety. John Wiley \& Sons, 2017.

[2] R. G. Drysdale and A. A. Hamid, Masonry Structures Behaviour and Design. Mississauga: Canada Masonry Design Centre, 2005.

[3] M. Naser, "Properties and material models for common construction materials at elevated temperatures," Construction and Building Materials, vol. 215, pp. 192-206, 2019.

[4] K.-Y. Shin, S.-B. Kim, J.-H. Kim, M. Chung, and P.-S. Jung, "Thermo-physical properties and transient heat transfer of concrete at elevated temperatures," Nuclear Engineering and Design, vol. 212, no. 1-3, pp. 233-241, 2002.

[5] V. K. Kodur, S. Banerji, and R. Solhmirzaei, "Test methods for characterizing concrete properties at elevated temperature," Fire and Materials, vol. 44, no. 3, pp. 381-395, 2020.

[6] A. Al-Sibahy and R. Edwards, "Behaviour of masonry wallettes made from a new concrete formulation under combination of axial compression load and heat exposure: Experimental approach," Engineering Structures, vol. 48, pp. 193204, 2013.

[7] O. A. Abdou and K. S. Murali, "The effect of air cells and mortar joints on the thermal resistance of concrete masonry walls," Energy and Buildings, vol. 21, no. 2, pp. 111-119, 1994.

[8] T. S. Yun, Y. J. Jeong, T.-S. Han, and K.-S. Youm, "Evaluation of thermal conductivity for thermally insulated concretes," Energy and Buildings, vol. 61, pp. 125-132, 2013.

[9] S. Real, M. G. Gomes, A. M. Rodrigues, and J. A. Bogas, "Contribution of structural lightweight aggregate concrete to the reduction of thermal bridging effect in buildings," Construction and Building Materials, vol. 121, pp. 460-470, 2016.

[10] W. G. Curtin, G. Shaw, J. Beck, W. Bray, and D. Easterbrook, Structural masonry designers' manual. John Wiley \& Sons, 2008. 
[11] S. Russo and F. Sciarretta, "Masonry exposed to high temperatures: mechanical behaviour and properties an overview," Fire safety journal, vol. 55, pp. 69-86, 2013.

[12] M. J. Hurley, D. T. Gottuk, J. R. Hall Jr, K. Harada, E. D. Kuligowski, M. Puchovsky, J. M. Watts Jr, and C. J. Wieczrek, SFPE handbook of fire protection engineering. Springer, 2015.

[13] J.-C. Mindeguia, P. Pimienta, H. Carré, and C. L. Borderie, "Experimental analysis of concrete spalling due to fire exposure," European Journal of Environmental and Civil Engineering, vol. 17, no. 6, pp. 453-466, 2013.

[14] N. Gnanakrishnan and R. Lawther, "Performance of masonry walls exposed to fire," Fifth North American Masonry Conference, pp. 901-914, 1990.

[15] R. W. B. L. F. Smith, "Fire endurance of wall assemblies constructed with concrete masonry units," in Proceedings, vol. 1, p. 324, Canadian Masonry Symposium, 1986.

[16] K. Cavanaugh, M. McCall, J. F. Speck, T. Musser, S. C. Spinney, K. Ries, A. L. Sukenik, S. S. Szoke, M. S. Bradfield, T. W. Bremmer, et al., "Guide to thermal properties of concrete and masonry systems," American Concrete Institute, ACI, 2002.

[17] D. Drysdale, An introduction to fire dynamics. John Wiley \& Sons, 2011.

[18] S. Handoo, S. Agarwal, and S. Agarwal, "Physicochemical, mineralogical, and morphological characteristics of concrete exposed to elevated temperatures," Cement and Concrete Research, vol. 32, no. 7, pp. 1009-1018, 2002.

[19] H. Pope and E. Zalok, "Impact of fire temperatures on the mechanical performance of concrete masonry materials," 13th North American Masonry Conference, 2019.

[20] I. Netinger, D. Varevac, D. Bjegović, and D. Morić, "Effect of high temperature on properties of steel slag aggregate concrete," Fire safety journal, vol. 59, pp. 1-7, 2013.

[21] Q. Ma, R. Guo, Z. Zhao, Z. Lin, and K. He, "Mechanical properties of concrete at high temperature a review," Construction and Building Materials, vol. 93, pp. 371-383, 2015.

[22] G.-F. Peng and Z.-S. Huang, "Change in microstructure of hardened cement paste subjected to elevated temperatures," Construction and Building Materials, vol. 22, no. 4, pp. 593-599, 2008.

[23] Y. Shao, T. Lefort, S. Moras, and D. Rodriguez, "Studies on concrete containing ground waste glass," Cement and Concrete Research, vol. 30, no. 1, pp. 91-100, 2000 .

[24] B. Demirel and O. Keleştemur, "Effect of elevated temperature on the mechanical properties of concrete produced with finely ground pumice and silica fume," Fire Safety Journal, vol. 45, no. 6-8, pp. 385-391, 2010. 
[25] L. M. Al-Hadhrami and A. Ahmad, "Assessment of thermal performance of different types of masonry bricks used in saudi arabia," Applied Thermal Engineering, vol. 29, no. 5-6, pp. 1123-1130, 2009.

[26] I. Netinger, I. Kesegic, and I. Guljas, "The effect of high temperatures on the mechanical properties of concrete made with different types of aggregates," Fire safety journal, vol. 46, no. 7, pp. 425-430, 2011.

[27] X. Yu, Z. Tao, T.-Y. Song, and Z. Pan, "Performance of concrete made with steel slag and waste glass," Construction and Building Materials, vol. 114, pp. 737-746, 2016.

[28] I. Netinger, M. J. Rukavina, and A. Mladenovič, "Improvement of post-fire properties of concrete with steel slag aggregate," Procedia Engineering, vol. 62, pp. $745-753,2013$.

[29] M. J. Terro, "Properties of concrete made with recycled crushed glass at elevated temperatures," Building and environment, vol. 41, no. 5, pp. 633-639, 2006 .

[30] R. Siddique and A. N. Noumowe, "An overview of the properties of highstrength concrete subjected to elevated temperatures," Indoor and built environment, vol. 19, no. 6, pp. 612-622, 2010.

[31] B. Lothenbach, K. Scrivener, and R. Hooton, "Supplementary cementitious materials," Cement and Concrete Research, vol. 41, no. 12, pp. 1244-1256, 2011.

[32] D. Cree, M. Green, and A. Noumowé, "Residual strength of concrete containing recycled materials after exposure to fire: a review," Construction and Building Materials, vol. 45, pp. 208-223, 2013.

[33] P. Sullivan and R. Sharshar, "The performance of concrete at elevated temperatures (as measured by the reduction in compressive strength)," Fire technology, vol. 28, no. 3, pp. 240-250, 1992.

[34] W. Dias, G. Khoury, and P. Sullivan, "Mechanical properties of hardened cement paste exposed to temperatures up to 700 c (1292 f)," Materials Journal, vol. 87, no. 2, pp. 160-166, 1990.

[35] H. Wang, "The effects of elevated temperature on cement paste containing ggbfs," Cement and Concrete Composites, vol. 30, no. 10, pp. 992-999, 2008.

[36] Y. Xu, Y. Wong, C. Poon, and M. Anson, "Impact of high temperature on pfa concrete," Cement and Concrete Research, vol. 31, no. 7, pp. 1065-1073, 2001.

[37] C.-S. Poon, S. Azhar, M. Anson, and Y.-L. Wong, "Comparison of the strength and durability performance of normal-and high-strength pozzolanic concretes at elevated temperatures," Cement and concrete research, vol. 31, no. 9, pp. 1291$1300,2001$. 
[38] National Standards of Canada, "Standard methods of fire endurance tests of building construction and materials," 2014.

[39] M. M. Alhazmy, "Numerical investigation on using inclined partitions to reduce natural convection inside the cavities of hollow bricks," International Journal of Thermal Sciences, vol. 49, no. 11, pp. 2201-2210, 2010.

[40] A. Noumowe, "Mechanical properties and microstructure of high strength concrete containing polypropylene fibres exposed to temperatures up to 200 c," Cement and Concrete Research, vol. 35, no. 11, pp. 2192-2198, 2005.

[41] H. Andrew, "Concrete structures," Structural Design for Fire Safety, pp. 225$259,2002$.

[42] H. Pope and E. Zalok, "Geometry effects on the fire resistance rating of masonry," The Masonry Society Journal, 2020.

[43] T. Harmathy, "Ten rules of fire endurance rating," Fire Technology, vol. 1, no. 2, pp. 93-102, 1965.

[44] L. W. Allen and T. Harmathy, "Fire endurance of selected concrete masonry walls," ACI Journal, vol. 69, no. 9, pp. 562-568, 1972.

[45] A. Karamanos, S. Hadiarakou, and A. Papadopoulos, "The impact of temperature and moisture on the thermal performance of stone wool," Energy and Buildings, vol. 40, no. 8, pp. 1402-1411, 2008.

[46] I. Antepara, "Moisture dependent thermal properties of hydrophilic mineral wool: application of the effective media theory," Materials Science, vol. 21, no. 3, pp. 449-454, 2015.

[47] M. Krasnovskih, N. Maksimovich, Y. I. Vaisman, and A. Ketov, "Thermal stability of mineral-wool heat-insulating materials," Russian Journal of Applied Chemistry, vol. 87, no. 10, pp. 1430-1434, 2014.

[48] M. M. Smedskjaer, M. Solvang, and Y. Yue, "Crystallisation behaviour and high-temperature stability of stone wool fibres," Journal of the European Ceramic Society, vol. 30, no. 6, pp. 1287-1295, 2010.

[49] M. Jiřičková, Z. Pavlík, L. Fiala, and R. Černỳ, "Thermal conductivity of mineral wool materials partially saturated by water," International journal of thermophysics, vol. 27, no. 4, pp. 1214-1227, 2006.

[50] J. Mehaffey, P. Cuerrier, and G. Carisse, "A model for predicting heat transfer through gypsum-board/wood-stud walls exposed to fire," Fire and materials, vol. 18, no. 5, pp. 297-305, 1994.

[51] W. Grosshandler, W. Grosshandler, A. Maranghides, and T. Mizukami, Analysis of Inter-laboratory Testing of Non-loadbearing Gypsum/Steel-Stud Wall Assemblies. US Department of Commerce, National Institute of Standards and Technology, 2007. 
[52] S. L. Manzello, R. G. Gann, S. R. Kukuck, and D. B. Lenhert, "Influence of gypsum board type (x or c) on real fire performance of partition assemblies," Fire and Materials, vol. 31, no. 7, pp. 425-442, 2007.

[53] R.-J. Jeng, S.-M. Shau, J.-J. Lin, W.-C. Su, and Y.-S. Chiu, "Flame retardant epoxy polymers based on all phosphorus-containing components," European polymer journal, vol. 38, no. 4, pp. 683-693, 2002.

[54] M. Jimenez, S. Duquesne, and S. Bourbigot, "Characterization of the performance of an intumescent fire protective coating," Surface and coatings Technology, vol. 201, no. 3-4, pp. 979-987, 2006.

[55] G.-Q. Li, C. Zhang, G.-B. Lou, Y.-C. Wang, and L.-L. Wang, "Assess the fire resistance of intumescent coatings by equivalent constant thermal resistance," Fire technology, vol. 48, no. 2, pp. 529-546, 2012.

[56] Z. Han, A. Fina, G. Malucelli, and G. Camino, "Testing fire protective properties of intumescent coatings by in-line temperature measurements on a cone calorimeter," Progress in Organic Coatings, vol. 69, no. 4, pp. 475-480, 2010.

[57] H. Pope and E. Zalok, "Issues with masonry and fire: Spalling and thermal bowing," 13th Canadian Masonry Symposium, 2017.

[58] F. Meftah, R. Chammas, A. Mebarki, et al., "The behaviour of masonry walls subjected to fire: Modelling and parametrical studies in the case of hollow burnt-clay bricks," Fire safety journal, vol. 44, no. 4, pp. 629-641, 2009.

[59] G. M. Cooke, "Thermal bowing and how it affects the design of fire separating construction," Fire and Materials, vol. 13, no. 1, pp. 230-236, 1988.

[60] A. Nadjai, M. O'Gara, F. Ali, and R. Jurgen, "Compartment masonry walls in fire situations," Fire technology, vol. 42, no. 3, p. 211, 2006.

[61] S. M. Byrne, "Fire resistance of load-bearing masonry walls," Fire technology, vol. 15, no. 3, pp. 180-188, 1979.

[62] J. P. Ingham, "Application of petrographic examination techniques to the assessment of fire-damaged concrete and masonry structures," Materials characterization, vol. 60, no. 7, pp. 700-709, 2009.

[63] L. T. Phan, "Pore pressure and explosive spalling in concrete," Materials and structures, vol. 41, no. 10, pp. 1623-1632, 2008.

[64] M. B. Dwaikat and V. Kodur, "Hydrothermal model for predicting fire-induced spalling in concrete structural systems," Fire Safety Journal, vol. 44, no. 3, pp. 425-434, 2009.

[65] V. Kodur and L. Phan, "Critical factors governing the fire performance of high strength concrete systems," Fire Safety Journal, vol. 42, no. 6-7, pp. 482-488, 2007. 
[66] J. Zhao, J.-j. Zheng, G.-f. Peng, and K. van Breugel, "A meso-level investigation into the explosive spalling mechanism of high-performance concrete under fire exposure," Cement and Concrete Research, vol. 65, pp. 64-75, 2014.

[67] M. Kanéma, P. Pliya, A. Noumowé, and J. Gallias, "Spalling, thermal, and hydrous behavior of ordinary and high-strength concrete subjected to elevated temperature," Journal of Materials in Civil Engineering, vol. 23, no. 7, pp. 921930, 2011.

[68] T.-D. Nguyen and F. Meftah, "Behavior of clay hollow-brick masonry walls during fire. part 1: Experimental analysis," Fire Safety Journal, vol. 52, pp. 5564, 2012 .

[69] F. Al Nahhas, R. A. Saada, G. Bonnet, and P. Delmotte, "Resistance to fire of walls constituted by hollow blocks: Experiments and thermal modeling," Applied thermal engineering, vol. 27, no. 1, pp. 258-267, 2007.

[70] O. Engineering, "Thermocouple tolerances," 2020.

[71] H. Keelson, Fire Resistance Quantification of Non-Loadbearing Masonry Walls Numerical Study. PhD thesis, Civil Engineering, Carleton University, 2018.

[72] F. R. R. Ayala, Mechanical properties and structural behaviours of masonry at elevated temperatures. PhD thesis, Civil Engineering, University of Manchester, 2010 .

[73] "Abaqus/cae version 6.13 standard manual," Dassault Systemes Simulia Corp, 2013.

[74] L. Peng, Performance of Heavy Timber Connections in Fire. PhD thesis, Civil Engineering, Carleton University, 2010.

[75] T. Lie and V. Kodur, "Thermal and mechanical properties of steel-fibrereinforced concrete at elevated temperatures," Canadian Journal of Civil Engineering, vol. 23, no. 2, pp. 511-517, 1996.

[76] M. Abid, X. Hou, W. Zheng, and R. R. Hussain, "High temperature and residual properties of reactive powder concrete-a review," Construction and Building Materials, vol. 147, pp. 339-351, 2017.

[77] H. Pope and E. Zalok, "Effects of novel concrete mix designs on fire resistance ofconcrete masonry computational analysis," Canadian Masonry symposium, 2021.

[78] H. Zhao, F. Liu, and H. Yang, "Thermal properties of coarse rca concrete at elevated temperatures," Applied Thermal Engineering, vol. 140, pp. 180-189, 2018 .

[79] Y. Guo, Y. Liu, W. Wang, Y. Zhang, Z. Wang, and L. Jiang, "A study on heat transfer performance of recycled aggregate thermal insulation concrete," Journal of Building Engineering, vol. 32, p. 101797, 2020. 
[80] N. Tošić, S. Marinković, T. Dašić, and M. Stanić, "Multicriteria optimization of natural and recycled aggregate concrete for structural use," Journal of cleaner production, vol. 87, pp. 766-776, 2015.

[81] S. Marinković, V. Radonjanin, M. Malešev, and I. Ignjatović, "Comparative environmental assessment of natural and recycled aggregate concrete," Waste management, vol. 30, no. 11, pp. 2255-2264, 2010.

[82] O. Damdelen, C. Georgopoulos, and M. Limbachiya, "Measuring thermal mass of sustainable concrete mixes," in Computing in Civil and Building Engineering (2014), pp. 1554-1561, 2014.

[83] İ. Türkmen, A. F. Bingöl, A. Tortum, R. Demirboğa, and R. Gül, "Properties of pumice aggregate concretes at elevated temperatures and comparison with ann models," Fire and Materials, vol. 41, no. 2, pp. 142-153, 2017.

[84] H. Uysal, R. Demirboğa, R. Şahin, and R. Gül, "The effects of different cement dosages, slumps, and pumice aggregate ratios on the thermal conductivity and density of concrete," Cement and concrete research, vol. 34, no. 5, pp. 845-848, 2004.

[85] L. Nguyen, A.-L. Beaucour, S. Ortola, and A. Noumowé, "Influence of the volume fraction and the nature of fine lightweight aggregates on the thermal and mechanical properties of structural concrete," Construction and building materials, vol. 51, pp. 121-132, 2014.

[86] R. Štefan, M. Foglar, J. Fladr, K. Horníková, and J. Holan, "Thermal, spalling, and mechanical behaviour of various types of cementitious composites exposed to fire: Experimental and numerical analysis," Construction and Building Materials, vol. 262, p. 119676, 2020.

[87] A. Schackow, C. Effting, M. V. Folgueras, S. Güths, and G. A. Mendes, "Mechanical and thermal properties of lightweight concretes with vermiculite and eps using air-entraining agent," Construction and building materials, vol. 57, pp. 190-197, 2014.

[88] P. Mounanga, W. Gbongbon, P. Poullain, and P. Turcry, "Proportioning and characterization of lightweight concrete mixtures made with rigid polyurethane foam wastes," Cement and Concrete Composites, vol. 30, no. 9, pp. 806-814, 2008.

[89] A. Tandiroglu, "Temperature-dependent thermal conductivity of high strength lightweight raw perlite aggregate concrete," International journal of thermophysics, vol. 31, no. 6, pp. 1195-1211, 2010.

[90] O. Sengul, S. Azizi, F. Karaosmanoglu, and M. A. Tasdemir, "Effect of expanded perlite on the mechanical properties and thermal conductivity of lightweight concrete," Energy and Buildings, vol. 43, no. 2-3, pp. 671-676, 2011.

[91] R. Wang and C. Meyer, "Performance of cement mortar made with recycled high impact polystyrene," Cement and Concrete Composites, vol. 34, no. 9, pp. 975-981, 2012. 
[92] Q. Yu, P. Spiesz, and H. Brouwers, "Development of cement-based lightweight composites-part 1: mix design methodology and hardened properties," Cement and concrete composites, vol. 44, pp. 17-29, 2013.

[93] B. Zhang and C. S. Poon, "Use of furnace bottom ash for producing lightweight aggregate concrete with thermal insulation properties," Journal of Cleaner Production, vol. 99, pp. 94-100, 2015.

[94] H. Zhou and A. L. Brooks, "Thermal and mechanical properties of structural lightweight concrete containing lightweight aggregates and fly-ash cenospheres," Construction and Building Materials, vol. 198, pp. 512-526, 2019.

[95] Y. Wu, J.-Y. Wang, P. J. Monteiro, and M.-H. Zhang, "Development of ultralightweight cement composites with low thermal conductivity and high specific strength for energy efficient buildings," Construction and Building Materials, vol. 87, pp. 100-112, 2015.

[96] K. R. O’Brien, J. Ménaché, and L. M. O’Moore, "Impact of fly ash content and fly ash transportation distance on embodied greenhouse gas emissions and water consumption in concrete," The International Journal of Life Cycle Assessment, vol. 14, no. 7, pp. 621-629, 2009.

[97] M. Berndt, "Influence of concrete mix design on co2 emissions for large wind turbine foundations," Renewable Energy, vol. 83, pp. 608-614, 2015.

[98] W. Wang, C. Lu, Y. Li, and Q. Li, "An investigation on thermal conductivity of fly ash concrete after elevated temperature exposure," Construction and Building Materials, vol. 148, pp. 148-154, 2017.

[99] Y. Xu and D. Chung, "Cement of high specific heat and high thermal conductivity, obtained by using silane and silica fume as admixtures," Cement and concrete research, vol. 30, no. 7, pp. 1175-1178, 2000.

[100] Y. Xu and D. Chung, "Effect of sand addition on the specific heat and thermal conductivity of cement," Cement and concrete research, vol. 30, no. 1, pp. 5961,2000 .

[101] H.-K. Kim, J. Jeon, and H.-K. Lee, "Workability, and mechanical, acoustic and thermal properties of lightweight aggregate concrete with a high volume of entrained air," Construction and Building Materials, vol. 29, pp. 193-200, 2012 .

[102] M. A. Othuman and Y. Wang, "Elevated-temperature thermal properties of lightweight foamed concrete," Construction and Building Materials, vol. 25, no. 2, pp. 705-716, 2011.

[103] P. Awoyera, E. Onoja, and A. Adesina, "Fire resistance and thermal insulation properties of foamed concrete incorporating pulverized ceramics and mineral admixtures," Asian Journal of Civil Engineering, vol. 21, no. 1, pp. 147-156, 2020 . 
[104] N. Narayanan and K. Ramamurthy, "Structure and properties of aerated concrete: a review," Cement and Concrete composites, vol. 22, no. 5, pp. 321-329, 2000 .

[105] F. Blanco, P. Garcia, P. Mateos, and J. Ayala, "Characteristics and properties of lightweight concrete manufactured with cenospheres," Cement and Concrete Research, vol. 30, no. 11, pp. 1715-1722, 2000.

[106] X. Huang, R. Ranade, Q. Zhang, W. Ni, and V. C. Li, "Mechanical and thermal properties of green lightweight engineered cementitious composites," Construction and Building Materials, vol. 48, pp. 954-960, 2013.

[107] A. L. Brooks, H. Zhou, and D. Hanna, "Comparative study of the mechanical and thermal properties of lightweight cementitious composites," Construction and Building Materials, vol. 159, pp. 316-328, 2018.

[108] R. Gül, E. Okuyucu, İ. Türkmen, and A. C. Aydin, "Thermo-mechanical properties of fiber reinforced raw perlite concrete," Materials Letters, vol. 61, no. 29, pp. 5145-5149, 2007.

[109] R. Yan, S. Yang, M.-Z. Guo, and C. sun Poon, "Comparative evaluation of fire resistance of partition wall blocks prepared with waste materials," Journal of Cleaner Production, vol. 182, pp. 156-165, 2018.

[110] A. Al-Sibahy and R. Edwards, "Mechanical and thermal properties of novel lightweight concrete mixtures containing recycled glass and metakaolin," Construction and Building Materials, vol. 31, pp. 157-167, 2012.

[111] T. Jami, S. Karade, and L. Singh, "A review of the properties of hemp concrete for green building applications," Journal of Cleaner Production, vol. 239, p. $117852,2019$.

[112] L. Arnaud and E. Gourlay, "Experimental study of parameters influencing mechanical properties of hemp concretes," Construction and building materials, vol. 28 , no. 1 , pp. 50-56, 2012.

[113] E. Sassoni, S. Manzi, A. Motori, M. Montecchi, and M. Canti, "Novel sustainable hemp-based composites for application in the building industry: Physical, thermal and mechanical characterization," Energy and Buildings, vol. 77, pp. 219-226, 2014.

[114] J. Ahlberg, E. Georges, and M. Norlén, "The potential of hemp buildings in different climates: A comparison between a common passive house and the hempcrete building system," 2014.

[115] B. Straube and H. Walther, "Aac with low thermal conductivity," Xella Technologie, Kloster Lehnin, 2011.

[116] B. Seng, C. Magniont, and S. Lorente, "Characterization of a precast hemp concrete. part i: Physical and thermal properties," Journal of Building Engineering, vol. 24, p. 100540, 2019. 
[117] P. Sukontasukkul, P. Uthaichotirat, T. Sangpet, K. Sisomphon, M. Newlands, A. Siripanichgorn, and P. Chindaprasirt, "Thermal properties of lightweight concrete incorporating high contents of phase change materials," Construction and Building Materials, vol. 207, pp. 431-439, 2019.

[118] V. D. Cao, S. Pilehvar, C. Salas-Bringas, A. M. Szczotok, T. Q. Bui, M. Carmona, J. F. Rodriguez, and A.-L. Kjøniksen, "Thermal performance and numerical simulation of geopolymer concrete containing different types of thermoregulating materials for passive building applications," Energy and Buildings, vol. 173, pp. 678-688, 2018. 